

\section{U N I VERS I D A A U T O N O M A DE SAN L UIS POTOSI \\ F A C U L T A D D E C I E N C I A S}

\section{Estudio de las multiplicidades en interacciones hadrónicas}

\section{T E S I S}

Que para obtener el titulo de

L I C E N C I A D O E N F I S I C A presenta

NORA PATRICIA ESTRADA TRISTÁN

San Luis Potosí, S.L.P.

Febrero 2006 
...those were the days of our lives

My Bijou. 


\section{Abstract}

Using data from the SELEX (Fermilab E781) experiment obtained with a minimum-bias trigger, we study multiplicity and angular distributions of secondary particles produced in interactions in the experimental targets.

We observe interactions of $\Sigma^{-}$, proton, $\pi^{-}$, and $\pi^{+}$, at beam momenta between $250 \mathrm{GeV} / c$ and $650 \mathrm{GeV} / c$, in copper, polyethylen, graphit, and berylium targets.

We show that the multiplicity and angular distributions for meson and baryon beams at the same momentum are identical. We also show that the mean multiplicity increases with beam momentum, and presents only small variations with the target material. 


\section{Agradecimientos}

\section{Gracias}

Dr. Jürgen Engelfried: Por el inagotable esfuerzo, esmero y paciencia al dirigir el proceso de elaboración de esta tesis. Por compartirme el tiempo y experiencia y enriquecerme con sus consejos, enseñanzas y correcciones.

IF-UASLP: Por todas las facilidades y el soporte otorgado durante la realización de esta tesis.

Colaboración de SELEX: Por el desarrollo de un experimento exitoso, y las facilidades que me dieron para el uso de sus datos.

Uwe Dersch: Por el esmero que puso en la toma de los datos que fueron la columna vertebral de este trabajo.

Familia: Mamá, Carlos y Miguel, por enseñarme el valor del esfuerzo, por reconocerlo. A papá, quien en donde está ya es capáz de leer y comprender claramente lo que yo confusamente entiendo y escribo.

Mis chachos: Antonio y Daniel, quienes en el proceso sacrificaron más que yo misma.

José Limón C.: Quien forma parte del equipo del centro de computo del IF-UASLP, por la ayuda en el área de computo, los consejos y el tiempo que sin reserva cedió para la realización de este trabajo.

Compañeros: José Luis Sánchez, Jorge Amaro, Ibrahim Torres, Erik Vazquez y Alejandro Blanco. Por su paciencia, por su buena disposición para ayudarme a corregir mis errores y sacarme de mis dudas.

Amigos: Nuche, Erika, Angel, choche, agradezco a este trabajo que fue la vía para conocerlos.

Proyecto realizado con financiamiento de la Secretaría de Educación Pública -Subsecretaría de Educación Superior e Investigación Científica- Dirección General de Educación Superior. Convenio 2003-24-001-026 


\section{Índice general}

Resumen $\quad$ X

$\begin{array}{ll}\text { Introducción } & 1\end{array}$

1. Introducción 1

1.1. El Modelo Standard . . . . . . . . . . . . . . . . . . . . 1

1.2. Rayos cósmicos . . . . . . . . . . . . . . . . . 5

$\begin{array}{ll}\text { Capítulo } 2 & 7\end{array}$

$\begin{array}{lr}\text { 2. Motivación } & 7\end{array}$

$\begin{array}{ll}\text { Capítulo } 3 & 11\end{array}$

3. Experimento SELEX (E781) 11

3.1. Fondo histórico . . . . . . . . . . . . . . . . . 11

3.2. El haz primario . . . . . . . . . . . . . . . . . . 12

3.3. Producción del haz de hiperones . . . . . . . . . . . . . . . . . . 14

3.4. Estructura de los espectrómetros de E781 . . . . . . . . . . . . . . . 17

3.4.1. El espectrómetro del haz . . . . . . . . . . . . . . . . . 17

3.4.2. El espectrómetro del vértice . . . . . . . . . . . . . . . . . 22

3.4.3. El espectrómetro M1 . . . . . . . . . . . . . . . . . . . . 24

3.4.4. El espectrómetro M2 . . . . . . . . . . . . . . . . . . 26

3.4.5. El espectrómetro M3 . . . . . . . . . . . . . . . . 30 
3.5. El disparador E781 . . . . . . . . . . . . . . . . . . . . . . 30

3.5.1. Estructura del disparador E781 . . . . . . . . . . . . . . . . . 31

3.5.2. Disparador de la medición de la sección eficaz total . . . . . . . . . 32

3.6. El software de análisis . . . . . . . . . . . . . . . . . . . . . 34

3.6.1. La toma de los datos (DAQ) en E781 . . . . . . . . . . . . . 34

3.6.2. El procesamiento posterior de los datos . . . . . . . . . . . . 35

$\begin{array}{ll}\text { Capítulo } 4 & 41\end{array}$

4. Toma y análisis de los datos 41

4.1. Toma de datos . . . . . . . . . . . . . . . . . . . . 41

4.1.1. Los blancos . . . . . . . . . . . . . . . . . . . . 41

4.1.2. Saturación del DAQ . . . . . . . . . . . . . . . . . . 42

4.1.3. Ejecución de la toma de datos . . . . . . . . . . . . . . . . . . . 44

4.2. Análisis de los datos . . . . . . . . . . . . . . . . . . 45

$\begin{array}{ll}\text { Capítulo } 5 & 48\end{array}$

$\begin{array}{lr}\text { 5. Resultados } & 48\end{array}$

5.1. Vértice primario (coordenada $z$ ) sin corte en la región del blanco . . . . . . 50

5.2. Haz de polaridad negativa, con momento $650 \mathrm{GeV}$, con blanco de producción para el haz secundario de berilio . . . . . . . . . . . . . . . . . . . 51

5.2.1. Histogramas de control . . . . . . . . . . . . . . . . . . . . 51

5.2.2. Multiplicidad en la región del vértice . . . . . . . . . . . . . 52

5.2.3. Distribuciones de multiplicidad y momento . . . . . . . . . . . 53

5.3. Haz de polaridad negativa, con momento $570 \mathrm{GeV}$, con blanco de producción para el haz secundario de carbón _. . . . . . . . . . . . . 78

5.3.1. Histogramas de control . . . . . . . . . . . . . . . . . . 78

5.3.2. Multiplicidad en la región del vértice . . . . . . . . . . . . . 79

5.3.3. Distribuciones de multiplicidad y momento . . . . . . . . . . . . 80

5.4. Haz de polaridad negativa, con momento $614 \mathrm{GeV}$, con blanco de producción para el haz secundario de carbón _. . . . . . . . . . . . . . . . 105

5.4.1. Histogramas de control . . . . . . . . . . . . . . . . . . . 105

5.4.2. Multiplicidad en la región del vértice . . . . . . . . . . . . . 106 
5.4.3. Distribuciones de multiplicidad y momento . . . . . . . . . . . . 107

5.5. Haz de polaridad negativa, con momento $580 \mathrm{GeV}$, con blanco de producción para el haz secundario de polietileno . . . . . . . . . . . . . . . . . 132

5.5.1. Histogramas de control . . . . . . . . . . . . . . . . . . . . . . 132

5.5.2. Multiplicidad en la región del vértice . . . . . . . . . . . . . . 134

5.5.3. Distribuciones de multiplicidad y momento . . . . . . . . . . . 135

5.6. Haz de polaridad negativa, con momento $614 \mathrm{GeV}$, con blanco de producción para el haz secundario de polietileno . . . . . . . . . . . . . . . 160

5.6.1. Histogramas de control . . . . . . . . . . . . . . . . . . . . 160

5.6.2. Multiplicidad en la región del vértice . . . . . . . . . . . . . . 161

5.6.3. Distribuciones de multiplicidad y momento . . . . . . . . . . . . 162

5.7. Haz de polaridad negativa, con momento $614 \mathrm{GeV}$, con blanco de producción para el haz secundario de cobre . . . . . . . . . . . . . . . . 188

5.7.1. Histogramas de control . . . . . . . . . . . . . . . . . . . . 188

5.7.2. Multiplicidad en la región del vértice . . . . . . . . . . . . . . 189

5.7.3. Distribuciones de multiplicidad y momento . . . . . . . . . . . . 190

5.8. Haz de polaridad positiva, con momento $570 \mathrm{GeV}$, con blanco de producción para el haz secundario de berilio . . . . . . . . . . . . . . . . . 216

5.8.1. Histogramas de control . . . . . . . . . . . . . . . . . . 216

5.8.2. Multiplicidad en la región del vértice . . . . . . . . . . . . . . 217

5.8.3. Distribuciones de multiplicidad y momento . . . . . . . . . . . . 218

5.9. Haz de polaridad positiva, con momento $250 \mathrm{GeV}$, con blanco de producción para el haz secundario de carbón _. . . . . . . . . . . . . . . . . . . 244

5.9.1. Histogramas de control . . . . . . . . . . . . . . . . . . . . . . 244

5.9.2. Multiplicidad en la región del vértice . . . . . . . . . . . . . . 245

5.9.3. Distribuciones de multiplicidad y momento . . . . . . . . . . . 246

5.10. Haz de polaridad positiva, con momento $375 \mathrm{GeV}$, con blanco de producción para el haz secundario de carbón _ . . . . . . . . . . . . . . . . . 272

5.10.1. Histogramas de control . . . . . . . . . . . . . . . . . . . . . 272

5.10.2. Multiplicidad en la region del vértice . . . . . . . . . . . . . 273

5.10.3. Distribuciones de multiplicidad y momento . . . . . . . . . . . 274

5.11. Haz de polaridad positiva, con momento $500 \mathrm{GeV}$, con blanco de producción para el haz secundario de carbón _ . . . . . . . . . . . . . . . . 300

5.11.1. Histogramas de control . . . . . . . . . . . . . . . . . . . . 300

5.11.2. Multiplicidad en la región del vértice . . . . . . . . . . . . . . . 301 
5.11.3. Distribuciones de multiplicidad y momento . . . . . . . . . . . . . 302

5.12. Estudio de aceptancia en ángulo . . . . . . . . . . . . . . . . . . . . . . . . 327

Capítulo 6

329

6. Conclusiones

6.1. Comparación de multiplicidad con haces de energías diferentes . . . . . . . . 329

6.2. Comparación de multiplicidad con composiciones del haz diferentes . . . . . 332

6.3. Comparación de multiplicidad con blancos diferentes . . . . . . . . . . 337

6.4. Resultados del estudio de aceptancia en ángulo . . . . . . . . . . . . . . . 339

La Colaboracion de SELEX 


\section{Resumen}

Se presenta un análisis de las multiplicidades en interacciones hadrónicas usando alta estadística proveniente de datos del experimento E781 (SELEX) realizado en Fermilab, tomados en corridas especiales hechas con el objetivo de medir la sección eficaz total. Se presenta información acerca de las multiplicidades totales en eventos con más de una trayectoria, las multiplicidades como función de la energía, así como un estudio de las distribuciones angulares de los eventos.

Este trabajo se realiza atendiendo a la necesidad de tener información de multiplicidades a energías más altas $(600 \mathrm{GeV} / \mathrm{c})$ que la ya existente a energías de hasta $200 \mathrm{GeV} / \mathrm{c}^{1}$ para su aplicación en la simulación de datos en experimentos de detección de rayos cósmicos y de producción de neutrinos.

Este trabajo esta organizado de la siguiente manera:

En el capítulo 1 se hace un breve resumen de lo que es el Modelo Standard, esencial para comprender el contenido de esta tesis, asi como de Rayos Cósmicos, base de la motivación de este trabajo.

En el capítulo 2 se describe la motivación de este trabajo.

En el capítulo 3 se describen algunos aspectos físicos del experimento E781, así como la estructura del espectrómetro, el disparador y el sistema de adquisición de datos.

En el capítulo 4 se describen las condiciones en que fueron tomados los datos en las corridas especiales para la medición de la sección eficaz, asi como los detalles del software utilizado para este análisis en particular.

\footnotetext{
${ }^{1}$ En experimentos de blanco fijo
} 
En en capítulo 5 se presentan los histogramas con la información de las multiplicidades, mostrando toda la colección de resultados para multiplicidades en la región del vértice y las distribuciones de momento para todas las combinaciones posibles de multiplicidad y multiplicidad con momento medido. Este es, sin duda, el capítulo más largo.

En el capítulo 6 se presentan las conclusiones de este trabajo así como el análisis de las distribuciones mediante algunas comparaciones. Se presenta también el estudio de la aceptancia angular del experimento. 


\section{Capítulo 1}

\section{Introducción}

\subsection{El Modelo Standard}

El Modelo Standard es una teoría que intenta describir toda la materia y todas las fuerzas existentes en el universo (excepto la gravedad). Su elegancia radica en la capacidad de justificar la existencia de cientos de partículas e interacciones complejas, sobre la base de sólo unas pocas partículas e interacciones fundamentales.

Las ideas básicas de esta teoría son las siguientes:

- Partículas materiales: El Modelo Standard establece que la mayoría de las partículas de las cuales tenemos conocimiento están compuestas en realidad de 12 partículas más fundamentales, 6 de estas son llamadas quarks. La tabla completa con la descripción de éstas partículas se encuentra en la figura 1.1. Otra clase de partículas fundamentales llamadas leptones, también 6 , tres de ellos con carga eléctrica negativa y tres neutrales también llamados neutrinos. La Figura 1.2 muestra la tabla completa de leptones.

- Interacciones fundamentales: De acuerdo al Modelo Standard son 4 en orden creciente: gravedad, débil, electromagnética y fuerte, se presentan con más detalle en la tabla de la figura 1.3. 


\begin{tabular}{|l|c|c|}
\hline Sabor & Masa(GeV/c $)$ & Carga elec. \\
\hline u up & .005 & $+2 / 3$ \\
\hline d down & .01 & $-1 / 3$ \\
\hline c charm & 1.5 & $+2 / 3$ \\
\hline s strange & 0.2 & $-1 / 3$ \\
\hline t top & 180 & $+2 / 3$ \\
\hline b bottom & 4.7 & $-1 / 3$ \\
\hline
\end{tabular}

Figura 1.1: Tabla de quarks. La unidad de carga eléctrica utilizada es la carga del protón.

\begin{tabular}{|c|c|c|c|}
\hline & Sabor & $\operatorname{Masa}\left(\mathrm{GeV} / \mathrm{c}^{2}\right)$ & Carga elec. \\
\hline$v_{e}$ & e neutrino & $<7 \times 10^{-9}$ & 0 \\
\hline $\mathrm{e}^{-}$ & electrón & .000511 & -1 \\
\hline$v_{\mu}$ & $\mu$ neutrino & $<.0003$ & 0 \\
\hline$\mu^{-}$ & muón & 0.106 & -1 \\
\hline$v_{\tau}$ & $\tau$ neutrino & $<.03$ & 0 \\
\hline$\tau^{-}$ & tau & 1.7771 & -1 \\
\hline
\end{tabular}

Figura 1.2: Tabla de leptones. La unidad de carga eléctrica utilizada es la carga del protón.

- Partículas portadoras de fuerza: Cada tipo de fuerza fundamental es "transportada"por una partícula portadora de fuerza (Boson).

Los quarks son partículas que además de tener carga eléctrica fraccionaria tienen carga de color (tres tipos diferentes) correspondiente a la interacción fuerte y nunca se observan en estados libres, solo se observan en su estado confinado, junto con otros quarks formando hadrones. La suma de las cargas eléctricas de los quarks, que constituyen un hadrón, es siempre un número entero. En tanto que los quarks individuales llevan carga de color, los 


\begin{tabular}{|c|c|c|c|c|c|}
\hline Interacción & $\begin{array}{c}\text { Gravita- } \\
\text { toria }\end{array}$ & \multicolumn{2}{|c|}{ Electrodébil } & $\begin{array}{l}\text { Fue } \\
\text { Funda- } \\
\text { mental }\end{array}$ & $\begin{array}{l}\text { Itte } \\
\text { Resi- } \\
\text { dual }\end{array}$ \\
\hline Actúa sobre: & Masa-energia & Carga de sabor & $\begin{array}{c}\text { Carga } \\
\text { eléctrica }\end{array}$ & $\begin{array}{c}\text { Carga de } \\
\text { color }\end{array}$ & Ver Info. \\
\hline $\begin{array}{l}\text { Partículas que } \\
\text { la sienten: }\end{array}$ & Todas & $\begin{array}{l}\text { Leptones } \\
\text { Quarks }\end{array}$ & cargadas & \begin{tabular}{|l} 
Quarks \\
Gluones \\
\end{tabular} & Hadrones \\
\hline $\begin{array}{l}\text { Particulas que } \\
\text { la transportan: }\end{array}$ & $\begin{array}{l}\text { Graviton (ann } \\
\text { ne observado) }\end{array}$ & $w^{+} w z^{0}$ & $\gamma$ & Gluones & Hesones \\
\hline $\begin{array}{l}\text { Intensidad para: } \\
2 \text { quarks }\left\{\begin{array}{l}\text { at } 10^{-18} \mathrm{~m} \\
\text { at } 3 \times 10^{-17} \mathrm{~m}\end{array}\right.\end{array}$ & $\begin{array}{l}10^{-41} \\
10^{-41}\end{array}$ & $\begin{array}{l}0.8 \\
10^{-4}\end{array}$ & 1 & 60 & $\begin{array}{l}\text { No apli- } \\
\text { cable a } \\
\text { los } \\
\text { quarks }\end{array}$ \\
\hline 2 protones en el núcleo & $10^{-36}$ & $10^{-7}$ & 1 & $\begin{array}{l}\text { No aplica- } \\
\text { ble a los } \\
\text { hadrones }\end{array}$ & 20 \\
\hline
\end{tabular}

Figura 1.3: Tabla de interacciones

hadrones son de color neutro.

Hay dos clases de hadrones que forman singletes en $\mathrm{SU}(3)$ (neutros en color):

- Bariones: Los bariones son los hadrones constituidos por tres quarks ( $q q q)$. Por ejemplo, los protones son 2 quarks up y 1 quark down (uud) y los neutrones son 1 up y 2 down $(u d d)$.

- Mesones: Los mesones contienen un quark $(q)$ y un antiquark $(\bar{q})$. Por ejemplo, un pión negativo $\left(\pi^{-}\right)$es $(\bar{u} d)$.

Tanto los quarks como los leptones están clasificados en 3 diferentes conjuntos. A cada uno de estos conjuntos se le llama una generación de partículas de materia. Una generación es un grupo formado por un quark y un leptón de cada uno de los tipos de carga. Cada generación es más pesada que la generación previa fig. 1.4

Toda la materia visible en el universo está formada por partículas de materia de la primera generación: quarks up y down, y electrones, debido a que las partículas de la segunda y tercera generaciones son inestables y decaen hacia partículas de la primera generación.

Para toda partícula (materia) existe una correspondiente antipartícula (antimateria). La antipartícula es igual a la partícula correspondiente en todos los aspectos, excepto en la carga que es de signo opuesto. Cuando una partícula y su antipartícula se encuentran, se 


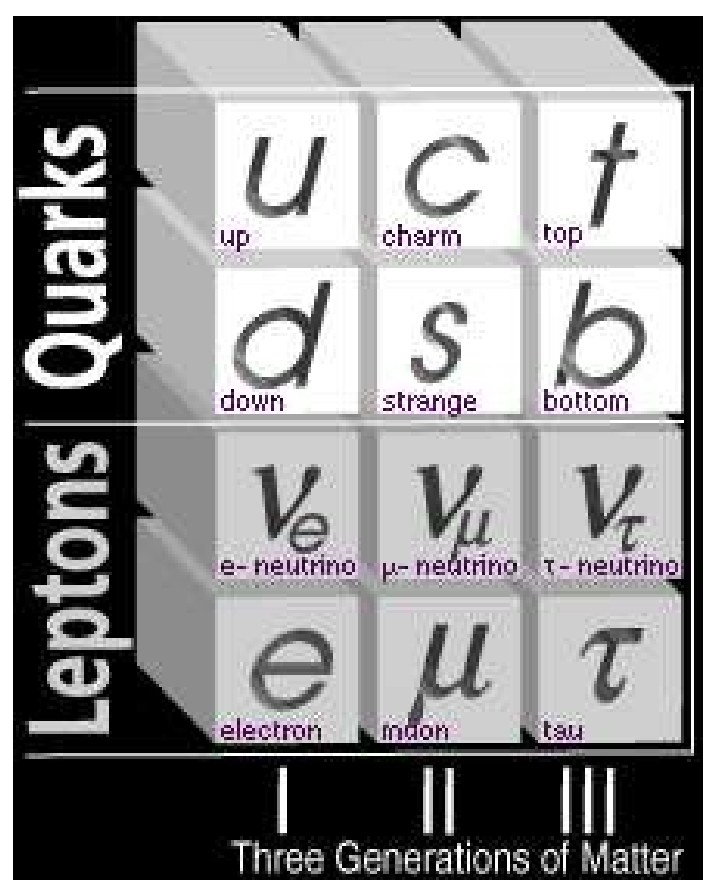

Figura 1.4: Generaciones de la materia

aniquilan entre sí convirtiéndose en energía pura. Esta energía puede entonces dar origen a una partícula neutra portadora de fuerza, como un fotón ó un bosón Z.

El Modelo Standard también incluye la teoría cuántica de las interacciones fuertes (Quantum chromodynamics, o QCD), y la de las interacciones electro-débiles unificadas (débiles y electromagnéticas, QED).

No es una teoría simple y su concepción no fué sencilla ya que se fué formando a partir de los descubrimientos que obligaban a extender o reformar los principios existentes, ejemplo de esto es el caso del quark encanto.

Cuando en noviembre de 1974 fue descubierto el quark encanto [4, 5], el último cuadro tuvo que ser extendido por la estructura del tema. En aquella época solamente los tres quarks u, d y s eran bien conocidos, con lo cual era bien admitida una descripción del espectro de quarks usando simetría aproximada $S U(3)_{\text {Flavor. }}$ El descubrimiento del quark encanto como un nuevo "componente del tema" fue tan espectacular que este instante está llamado desde entonces "revolución de noviembre" en la física. Sin embargo agregar un nuevo quark 
significaba extender el grupo de simetrías de sabor de SU(3) a SU(4), uno espera también la existencia de bariones y mesones adicionales con lo cual por lo menos un quark de valencia es representado por el quark encanto.

\subsection{Rayos cósmicos}

Una parte historicamente importante en el desarrollo del Modelo Standard fué el descubrimiento de los Rayos Cósmicos pues este hecho abrió nuevas cuestiones a responder.

Nuestro planeta recibe constantemente una lluvia de partículas cargadas. Cada segundo 1000 partículas por metro cuadrado golpean las capas más externas de la atmósfera terrestre. Este flujo de partículas (llamado rayos cósmicos), proveniente en su mayoría de nuestra Galaxia, consisten en un $90 \%$ de protones, $9 \%$ partículas $\alpha$ y el resto son núcleos más pesados. Las contribuciones al flujo de rayos cósmicos que llegan a nuestro planeta tiene diversas fuentes. Hasta donde se sabe la fuente más importante de rayos cósmicos son las supernovas en nuestra galaxia. El viento solar también contribuye al flujo de partículas de baja energía que llegan a la Tierra. Cada segundo, el Sol emite un promedio de 300 mil toneladas de materia en forma de gas ionizado que sopla como un viento en una región que cubre todo el sistema solar. En las cercanías de la Tierra el viento solar consiste de un flujo de 100 millones de protones y electrones por centímetro cuadrado cada segundo.

La existencia del viento solar fue predicha en 1958 por las teorías del físico Eugene Parker de la Universidad de Chicago y fue directamente observado en 1961 por los detectores de la sonda espacial Explorer 10. No se sabe que origina o donde son aceleradas las partículas de mayor energía en los rayos cósmicos sin embargo existen varios modelos que predicen que estos Rayos Cósmicos altamente energéticos se originan en otras galaxias y que demás de las supernovas, en una galaxia pueden existir otras fuentes de partículas energéticas, tales como los agujeros negros, las estrellas pulsares y los núcleos galácticos activos (o AGN).

Es en éste rango del energía del flujo de Rayos Cósmicos $\left(10^{20} \mathrm{eV}\right)$ donde actualmente se centra el interés de los experimentos de detección. 
Los rayos cósmicos primarios que golpean las capas más externas de la atmósfera, sufren colisiones con los núcleos que allí se encuentran. De estas colisiones resultan lluvias de nuevas partículas elementales de todo tipo (como electrones, positrones, mesones pi, muones, etc) que eventualmente llegan a la superficie. Estos chubascos de rayos cósmicos secundarios pueden alcanzar una extensión de varios kilómetros cuadrados, con una multiplicidad de partículas, que al parecer depende de la energía del rayo cósmico primario, y donde entendemos por multiplicidad a la cantidad de partículas en que se divide una partícula madre al colisionar o decaer. 


\section{Capítulo 2}

\section{Motivación}

El presente trabajo surge de la necesidad de contar con un estudio detallado de las multiplicidades en interacciones hadrónicas, hasta este momento inexistente mas allá de los $200 \mathrm{GeV} / \mathrm{c}^{1}$.

Recientes experimentos han arrojado resultados a este respecto con cierto detalle utilizando interacciones hadrónicas elásticas en experimentos de blanco fijo en un rango de momento de hasta $160 \mathrm{GeV} / \mathrm{c}[3]$.

En el experimento E781 (SELEX) llevado a cabo en FERMILAB en el periodo 96/97², que es un experimento de blanco fijo, se corrió con un rango de momento de hasta $600 \mathrm{GeV} / \mathrm{c}$, con las condiciones óptimas para hacer este tipo de estudio ya que se hicieron corridas especiales fuera del objetivo original del experimento (estudio de mesones y bariones encantados) en las cuales se utilizaron haces a diferentes energías y de polaridad tanto negativa como positiva sobre diferentes tipos de blancos y con la captura de todos los datos $\operatorname{arrojados}^{3}$, con el fin de utilizarlos en la medición de la sección eficaz total.

Esta medición de la sección eficaz total fue hecha en 1998 por Uwe Dersch para su tesis doctoral y los resultados fueron publicados en el año 2000 [1]. En aquel análisis se utilizó solo una parte de los datos arriba mencionados, aquellos eventos que solo tienen una trayectoria

\footnotetext{
${ }^{1}$ En experimentos de blanco fijo

${ }^{2}$ Capitulo2

${ }^{3}$ Capitulo 3
} 
(más adelante se explicará con mayor detalle), en esta tesis se utiliza la otra parte de los datos, aquellos eventos que tienen más de una trayectoria, por lo que esta tesis, siendo un análisis diferente, tiene como principal fuente de referencia la tesis de Uwe [2].

El estudio de las multiplicidades en interacciones hadrónicas tiene importancia por su utilización en los programas que corren simulación montecarlo aplicada a experimentos de detección de rayos cósmicos, neutrinos atmosféricos y expermientos diseñados para producción de neutrinos, ya que la información que existe es incompleta, lo que produce montecarlos inexactos y predicciones erróneas.

Esto se puede corregir proporcionando un buen estudio de las características generales de las multiplicidades y la reconstrucción completa de los cuadrivectores, aunque esto último no es posible en todos los casos.

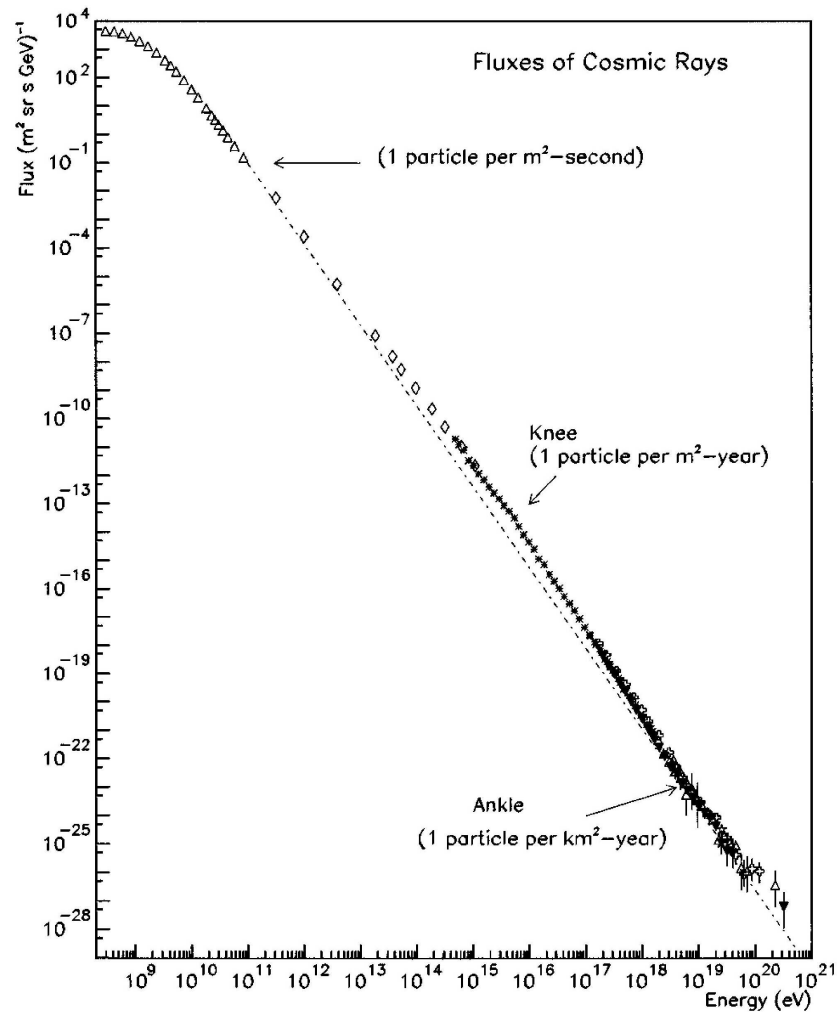

Figura 2.1: Flujo de rayos cósmicos como función de la energía

En la figura 2.1 se aprecia que el flujo de rayos cósmicos se extiende en un rango muy 


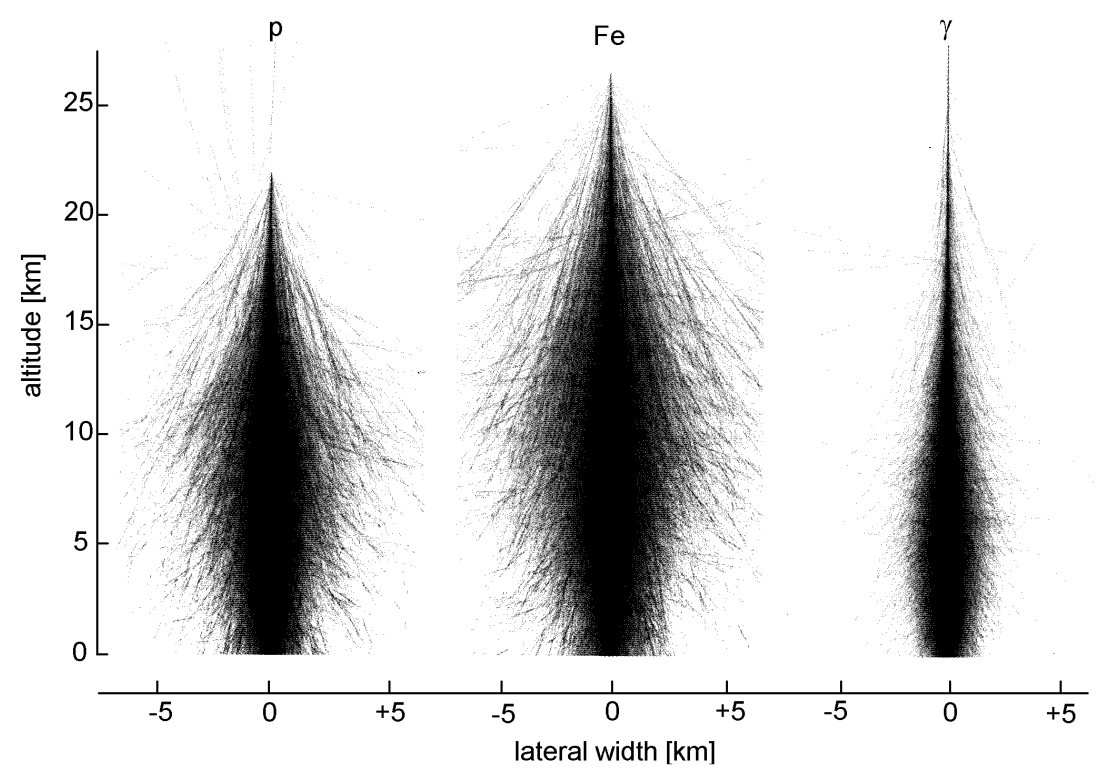

Figura 2.2: Chubascos extensivos, $10^{14} \mathrm{eV}$

amplio de energías, desde energías muy bajas del orden de $10^{9} \mathrm{eV}$, que son, como ya mencione antes, el flujo de Rayos Cósmicos provenientes del interior de nuestra galaxia principalmente del sol, hasta una energía de $10^{20} \mathrm{eV}$, región donde el flujo decae de manera importante, sin embargo también es el rango de energía donde se tiene menor estadística y es en esta región del espectro de energías de los Rayos Cósmicos donde se centra el interés de muchos experimentos de detección, para lo que es necesario desarrollar software de simulación que facilite la tarea de diseñar y probar detectores y software de análisis.

Es cierto, sin embargo, que este nivel de energía de $10^{20} \mathrm{eV}$ queda fuera de la capacidad de cualquier experimento de blanco fijo, incluyendo el experimento SELEX del cual provienen los datos análizados en este trabajo.

Pero, al chocar las partículas primarias de los Rayos Cósmicos con las moléculas que se encuentran en las capas más externas de la atmósfera, ocurre una multiplicación de las partículas produciendose chubascos de incluso varios kilómetros de extensión sobre la superficie de la tierra de modo que las energías medidas en los niveles de detección están dentro del rango del estudio hecho en la presente tesis, lo cual justifica ampliamente éste trabajo. En la figura 2.2 se muestra una gráfica de tres diferentes partículas provenientes de rayos 
cósmicos y la extensión superficial cubierta por la multiplicidad como función de la altura.

Es necesario hablar solo de experimentos de blanco fijo pues es el único tipo de experimentos donde debido a la distribución de los impulsos se pueden reconstruir las trayectorias de todas las partículas que conforman un evento pues éstas tienen una dirección preferentemente hacia adelante, lo cual no sucede con experimentos de colisionadores pues en estos casos, aunque se puede ir a energías más altas, las partículas que son producidas en el choque viajan en cualquier dirección siendo imposible cubrir todo el espacio de detectores por cuestiones de ingenieria.

El grado de multiplicación en las partículas depende de la energía de la partícula, madre donde la forma de ésta dependencia es descrita por varios modelos. La información contenida en este trabajo también será útil para probar dichos modelos. 


\section{Capítulo 3}

\section{Experimento SELEX (E781)}

\subsection{Fondo histórico}

Hasta hoy los mesones encanto se estudian con técnicas que los permite producir y reconstruir cada vez mejor. Aunque ya existían un conjunto de experimentos de blanco fijo (ej. WA62, WA89, E791, FOCUS) que hacían estudios con mesones y bariones encanto, había pocas pruebas de las características físicas de los mesones encantados, tales como tiempos de vida, masas y branching ratios ${ }^{1}$ suficientemente bien medidos. Una razón que justificaba la escasa producción de mesones encanto es la sección transversal tan pequeña de aproximadamente $30 \mu$ barn, por otro lado la masa de éstas partículas es bastante grande por lo que permite decaimientos en varios canales que tienen a su vez branching ratios pequeños, por lo que no hay un modo de decaimiento favorecido sobre el cual se pueda hacer un estudio, además de la dificultad que representa separar la señal del decaimiento de un barion encantado de la señal de fondo.

El experimento E781 en $\mathrm{FNAL}^{2}$, también llamado SELEX, constituye la continuación en experimentos de blanco fijo para espectroscopía de quark encanto. El énfasis de este experimento está en la espectroscopía de bariones con quark encanto y extraño ${ }^{3}$. Para poder

\footnotetext{
${ }^{1}$ Razones de decaimiento

${ }^{2}$ Fermi National Accelerator Laboratory

${ }^{3}$ strange
} 
hacer un estudio de bariones sc en SELEX se requería un haz de hiperones de alta intensidad con un alto contenido de partículas $\Sigma^{-}$. Trayendo estas partículas un quark s de valencia en las condiciones iniciales, hacen posible esperar una producción mayor comparada con un haz de protones. SELEX además fué diseñado para ser un experimento de gran aceptancia en la dirección delantera, además de un filtro de datos en línea, ambas cosas para facilitar la reconstrucción del encanto. El experimento SELEX fue sugerido en el año 1987, tenía en el año 1991 un tiempo breve de haz de prueba para los detectores más importantes y tuvo durante el período 1996/97 su tiempo de haz del TEVATRON, comenzando en 1 julio de 1997 y terminando en septiembre de 1997, tiempo durante el cual se observaron aproximadamente $15 \times 10^{9}$ interacciones. La colaboración de SELEX es una colaboración internacional que cuenta con aproximadamente 120 miembros (ver Apéndice).

\subsection{El haz primario}

La base del experimento E781, como de casi todos los experimentos en el FNAL, es un haz de protones de muy alta energía, el cuál es provísto por el acelerador circular TEVATRON. Para la producción del haz de protones, se ionizan átomos de hidrógeno y después son acelerados en un acelerador tipo Cockroft-Walton a una energía de $750 \mathrm{KeV}$. Más adelante, un acelerador lineal (LINAC) aumenta la energía de los protones hasta $400 \mathrm{MeV}$ y los lanza hacia un booster. el último acelerador es el Sincrotrón, donde ocurre otro aumento de energía hasta $8 \mathrm{GeV}$. Los protones son extraídos desde el Booster hacia en anillo principal, el cuál es un acelerador tipo Sincrotrón y se extiende a lo largo de $6 \mathrm{Km}$. Al llegar ahí las partículas se ajustan a la trayectoria por medio de los aproximadamente 1000 magnetos y se aceleran hasta $150 \mathrm{GeV}$ por medio de resonadores de alta frecuencia $(53 \mathrm{MHz})$. Después de esta etapa de la aceleración los protones llegan a otro Sincrotrón, que se desarrolla directamente por debajo de los imanes del anillo principal, el cual consiste en aproximadamente 1000 imanes superconductores, que se enfrían con helio líquido. Este anillo es el TEVATRON real, porque en él los protones (o los antiprotones) pueden ser acelerados hasta una energía de $1 \mathrm{TeV}$. Hasta la fecha en que se realizó el experimento, el TEVATRON solo podía ser operado ya 


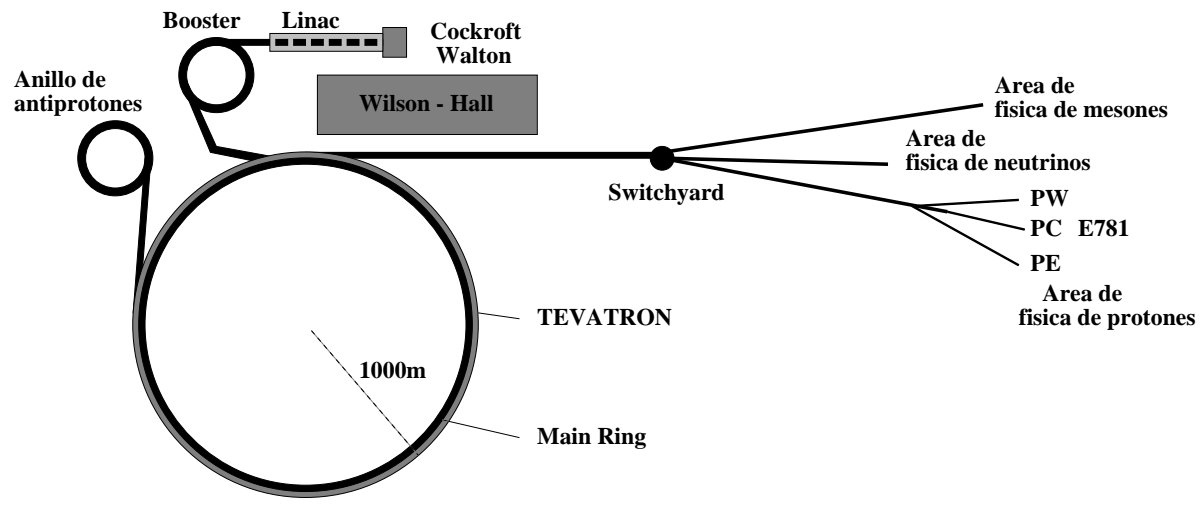

Figura 3.1: Planta de aceleración en FNAL

fuera en modo de colisionador o de blanco fijo, situación que cambió con la adición del tubo del inyector start-up (Main Ring) fuera del anillo.

Durante el periodo de blanco fijo 96/97 el TEVATRON trabajó en ciclos de 60s, 40 de los cuales fué lo que tomó la aceleración en la etapa final de los protones y la etapa de extracción de las partículas dura 20s.

En el modo de blanco fijo el haz primario de protones del TEVATRON alcanza una energía de $800 \mathrm{GeV}$, con una derrama de $2,5 \times 10^{13}$ protones por spill. Después del TEVATRON un distribuidor de haz (en inglés: switchyard) distribuye el haz primario en tres grandes experimentos de blanco fijo para mesones, neutrinos y física de protones fig 3.1.

El experimento E781 se desarrolla en el rango de física de protones $\mathrm{PC}^{4}$ y comparte su sección del haz con dos experimentos más. La intensidad de flujo asignado a SELEX es de aproximadamente $2.0 \times 10^{12}$ protones/spill, sin embargo estos no van directamente al experimento sino que se usan para la producción de un haz secundario, el haz de hiperones. 


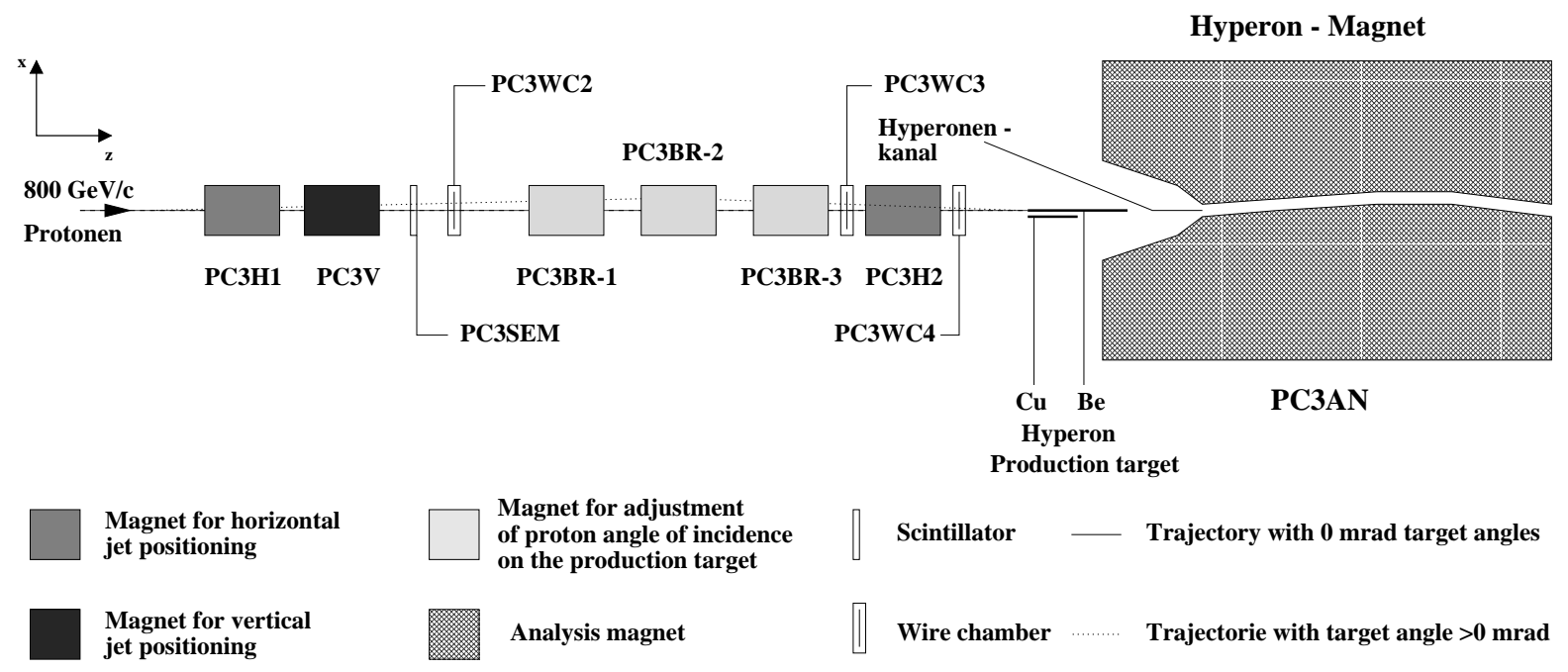

Figura 3.2: Canal del beam alrededor del blanco de producción

\subsection{Producción del haz de hiperones}

Los protones asignados al experimento E781 son orientados continuamente hacia el imán de hyperones utilizando cuadripolos magnéticos como se muestra en la figura 3.2. Con la ayuda de los imanes $\mathrm{PC} 3 \mathrm{H} 1^{5}$, PC3H2 y PC3V1 ${ }^{6}$ el haz de protones procedente del Tevatron es dirigido hacia el blanco de producción de hiperones, el cual tiene un diámetro de cerca de $1 \mathrm{~mm}$ en esta posición. Con la ayuda del imán PC3BR se puede modificar el ángulo de incidencia del haz de protones sobre el blanco de producción. Para el monitoreo se utilizan las cámaras de alambres PC3WC2, PC3WC3 y PC3WC4 que miden la proyección del perfil del haz en cada caso y se utilizan para establecer su posición durante el experimento.

Como blancos de producción se utilizan un blanco de berilio $(1.02 \mathrm{~mm} \times 2.03 \mathrm{~mm} \times$ $406.91 \mathrm{~mm})$ y un blanco de cobre $(1.02 \mathrm{~mm} \times 2.03 \mathrm{~mm} \times 150.55 \mathrm{~mm})$ que son colocados utilizando un sistema mecánico de posicionamiento.

En la interacción de un protón con el blanco de producción se produce todo un espectro de partículas secundarias $\left(\Sigma^{-}, \pi^{-}, K^{-}, \Xi^{-}, \Omega^{-}, \bar{p}, p, \Sigma^{+}, \pi^{+} \ldots\right)$. La producción de hiperones es fa-

\footnotetext{
${ }^{4}$ Proton Center

${ }^{5} \mathrm{PC} 3 \mathrm{H}$ : Photon Center 3 Horizontal

${ }^{6} \mathrm{PC} 3 \mathrm{~V}$ : Photon Center 3 Vertical
} 
vorecida en la dirrección delantera ( $x_{F}$ grandes) en relación a la producción de mesones. Este efecto de partículas principales (Leading Particle Effect) es característico de la producción de hiperones. Como consecuencia favorable de este efecto se pueden encontrar predominantemente partículas $\Sigma^{-}$con alto impulso bajo la producción de partículas negativamente cargadas. El ruido esta principalmente constituido por piones.

La Tabla 3.1 muestra la composición esperada del haz a 10 m del blanco de producción. Los números proceden de un estudio realizado por el experimento E761, experimento de blanco fijo, que utilizó esta zona del haz antes de E781.

La construcción del canal de hiperones es difícil, esto debido a dos factores importantes: El breve tiempo de vida de los hiperones y por otro lado los protones remanentes del haz primario, que constituyen radiación que debe ser interceptada, por lo que es necesario mucho material para el apantallamiento. Este efecto de dependencia de energía de $\Sigma^{-} / \pi^{-}$alta con que se satisfacen ambos criterios, solo es alcanzable en condiciones de altas energías. Con el haz de hiperones de SELEX de $600 \mathrm{GeV}$ se espera una relación $\Sigma^{-} / \pi^{-}$de aproximadamente 1. Se espera también una pequeña porción de otras partículas además de $\Sigma^{-}$and $\pi^{-}$.

El rango de momento (con el énfasis deseado) de las partículas seleccionadas que pasan a través del canal de hiperones a los espectrómetros de E781 está definido por el comportamiento de la corriente y polaridad del magneto de hiperones.

Las partículas filtradas golpean contra las paredes del canal de hiperones donde son absorbidas o permanecen en el núcleo de hierro sólido del imán de hiperones. Durante este último proceso se produce un fondo (background) de mounes ampliamente distribuido que penetra parcialmente en el espectrómetro.

El imán de hiperones es un imán convencional de aproximadamente $400 \mathrm{~T}$ de peso y 7,2 m de largo. El canal de hiperones tiene una sección transversal rectangular con una salida de $4.64 \mathrm{~mm} \times 8.64 \mathrm{~mm}$, alineado con el tungsteno para una mejor absorción de los protones. En corridas estandard las partículas negativamente cargadas son seleccionadas con el imán 


\begin{tabular}{|c|c|c|c|c|c|c|}
\hline Partícula & $\begin{array}{l}\text { Porcentaje } \\
\text { en el beam } \\
\%\end{array}$ & $\begin{array}{l}\text { Masa } \\
\mathrm{MeV} / c^{2}\end{array}$ & $\begin{array}{l}\text { Tiempo de } \\
\text { vida } \\
\tau(\mathrm{s})\end{array}$ & $\begin{array}{l}\text { Principales } \\
\text { canales de } \\
\text { decaimiemto }\end{array}$ & $\gamma$ & $\begin{array}{l}\text { Distancia } \\
\text { de vuelo } \\
\gamma c \tau(\mathrm{m})\end{array}$ \\
\hline \multicolumn{7}{|c|}{ Haz negativo } \\
\hline$\pi^{-}$ & $\approx 53$ & 139.57 & $2,6630 \times 10^{-8}$ & $\mu^{-}+\nu_{\bar{\mu}} 99.99 \%$ & 4300 & 34353 \\
\hline$K^{-}$ & $\approx 1.6$ & 493.77 & $1,2371 \times 10^{-8}$ & $\begin{array}{l}\mu^{-}+\nu_{\bar{\mu}} 63.51 \% \\
\pi^{-}+\pi^{0} 21.16 \%\end{array}$ & 1215 & 1833 \\
\hline$\Sigma^{-}$ & $\approx 43$ & 1197.45 & $1,479 \times 10^{10}$ & $n+\pi^{-} 99.848 \%$ & 501 & 22.2 \\
\hline$\Xi^{-}$ & $\approx 1.6$ & 1321.34 & $1,639 \times 10^{-10}$ & $\Lambda+\pi^{-} 99.887 \%$ & 454 & 22.3 \\
\hline$\Omega^{-}$ & $\approx 0.04$ & 1672.43 & $0,822 \times 10^{-10}$ & $\begin{array}{l}\Lambda+K^{-} 67.8 \% \\
\Xi^{0}+\pi^{-} 23.6 \%\end{array}$ & 359 & 8.85 \\
\hline $\bar{p}$ & $\approx 0.04$ & 938.27 & & & 639 & \\
\hline \multicolumn{7}{|c|}{ Haz positivo } \\
\hline$\pi^{+}$ & $\approx 2.8$ & 139.57 & $2,663 \times 10^{-8}$ & $\mu^{+}+\nu_{\mu} 99.9 \%$ & 4300 & 34353 \\
\hline$K^{+}$ & $\approx 0.8$ & 493.77 & $1,2371 \times 10^{-8}$ & $\begin{array}{l}\mu^{+}+\nu_{\mu} 63.51 \% \\
\pi^{+}+\pi^{0} 21.16 \%\end{array}$ & 1215 & 1833 \\
\hline$\Sigma^{+}$ & $\approx 2.8$ & 1189.37 & $0,799 \times 10^{-10}$ & $\begin{array}{l}p+\pi^{0} 51.57 \% \\
n+\pi^{+} 48.30 \%\end{array}$ & 504 & 12.08 \\
\hline$p$ & $\approx 94$ & 938.27 & $\infty$ & & 639 & $\infty$ \\
\hline
\end{tabular}

Tabla 3.1: Composición esperada del haz a $10 \mathrm{~m}$ del blanco de produccion de hiperones de acuerdo al estudio realizado en el experimento E761 con una energía de haz de 600 Gev para haz positivo y negativo. 
de hiperones dentro de un rango de momento de $600 \pm 30 \mathrm{GeV} / \mathrm{c}$, para lo cual se requiere una corriente en el imán de 3300 A. Después de salir del canal de hiperones el haz tiene un diámetro de $1.2 \mathrm{~cm}$ y una divergencia de $\pm 1.5 \mathrm{mrad}$.

\subsection{Estructura de los espectrómetros de E781}

La colaboración de SELEX tiene un espectrómetro de cuatro niveles con una longitud total de 50 m aproximadamente. Tres de estas etapas cuentan con un imán de análisis. La figura 3.3 muestra un resumen total del espectrómetro de E781. La estructura y función de cada etapa individual se describe en las secciones siguientes.

\subsubsection{El espectrómetro del haz}

Una vez que ha pasado el haz secundario por el canal de hiperones, entonces atraviesa el detector de radiación de transición del haz.

\section{Detector de radiación de transición del haz}

El detector de radiación de transición del haz $\left(\mathrm{BTRD}^{7}\right)$ detecta la radiación electromagnética que se emite por partículas cargadas a medida que estas atraviesan la frontera entre medios con diferentes propiedades dieléctricas. La energía característica de esta radiación es de unos pocos KeV (Rayos-X). El BTRD consiste de 10 módulos idénticos cada uno de los cuales contiene un radiador hecho de 200 láminas de polipropileno de $17 \mu \mathrm{m}$ de ancho, separadas por un espacio de $500 \mu \mathrm{m}$. Enseguida del radiador se encuentran tres cámaras de alambres proporcionales $\left(\mathrm{PWC}^{8}\right)$ que contienen gas en una mezcla de $70 \% \mathrm{Xe}$ y $30 \% \mathrm{CH}_{4}$ para optimizar el tiempo de respuesta de la señal y para optimizar la absorción de fotones de la radiación de transición. Estas cámaras consisten de placas aluminizadas,

\footnotetext{
${ }^{7}$ Beam Transition Radiation Detector

${ }^{8}$ Proportional Wire Chamber
} 


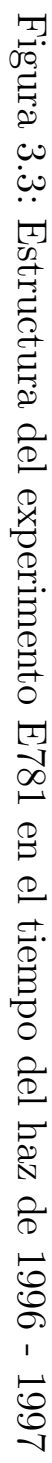

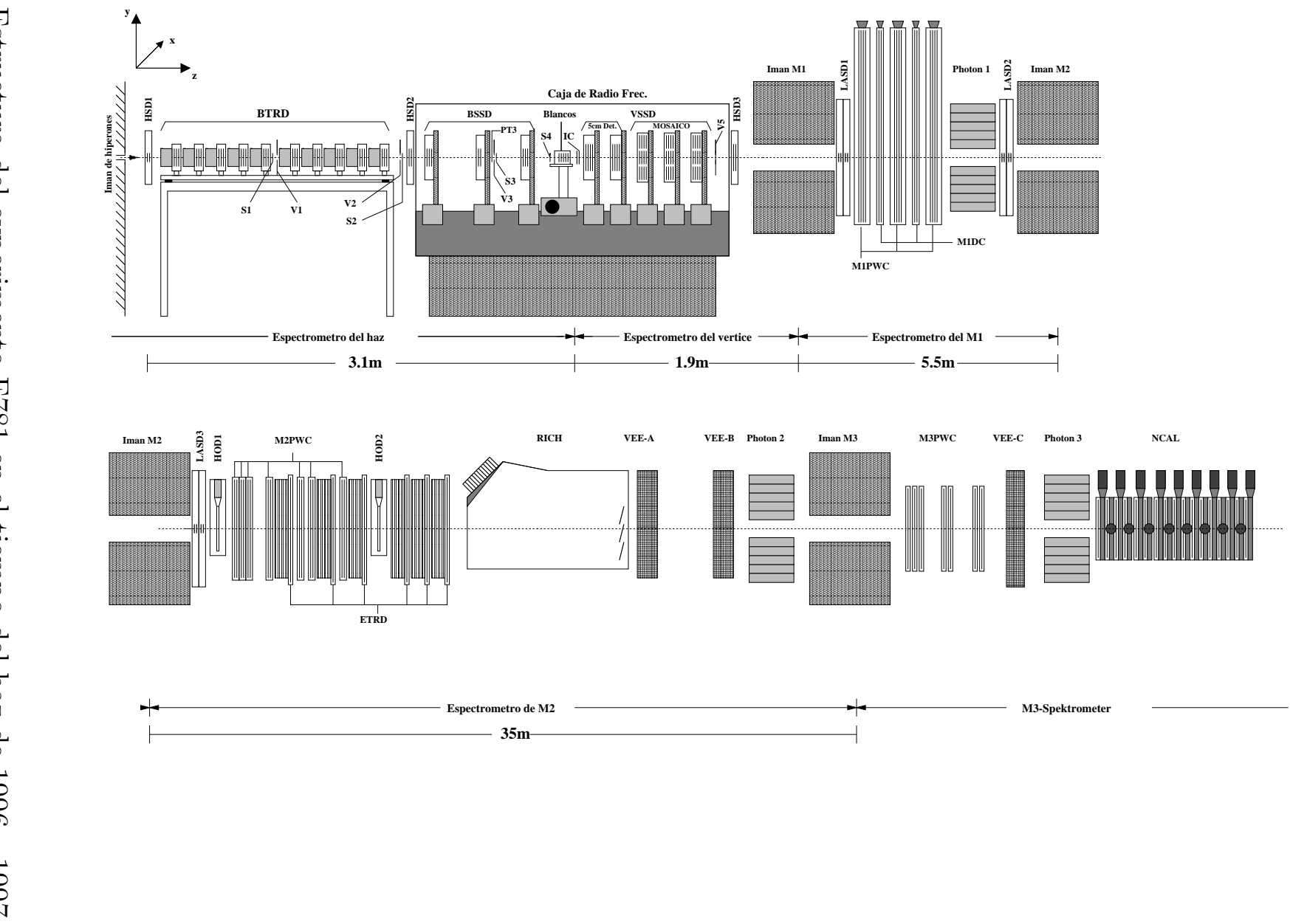


que funcionan como cátodos, con espacios de $2 \mathrm{~mm}$ para arrastre, y mallas con alambres de tungsteno de $15 \mu \mathrm{m}$ de ancho, que están separados por $1 \mathrm{~mm}$, y que funcionan como ánodos. Cada PWC del BTRD da una salida digital cuando se detecta energía sobre un umbral fijo. La suma de todas las PWC que detectan una señal por encima del umbral es igual al número $k$ de planos activados en el BTRD. La probabilidad de que ocurra la emisión de radiación de transición es proporcional al factor de Lorentz $\gamma$. Por lo tanto, un mesón $\pi$ con la mismo momento que un barión, como el $\Sigma^{-}$o un $p$, al pasar por el BTRD activa más planos que el barión. Una distribución de probabilidad típica del número de planos activados por el haz secundario negativo se muestra en la fig 3.4. Se puede observar la componente bariónica y mesónica del haz secundario negativo en pocos y muchos planos activados, respectivamente. Estas componentes pueden ser separadas al ajustar la función:

$$
p_{f i t}(k)=\underbrace{\sum_{i=1}^{2} k_{i}\left(\begin{array}{l}
n \\
k
\end{array}\right) p_{i}^{k}\left(1-p_{i}\right)^{n-k}}_{\text {comp. bariónica }}+\underbrace{\sum_{i=3}^{4} k_{i}\left(\begin{array}{l}
n \\
k
\end{array}\right) p_{i}^{k}\left(1-p_{i}\right)^{n-k}}_{\text {comp. mesónica }}
$$

a la distribución normalizada del número $k$ de planos activados, donde, $n=30$ es el número máximo posible de planos activados en el BTRD, $p_{i}$ y $k_{i}$ son los parámetros de ajuste con las restricciones $K_{1}+k_{2}+k_{3}+k_{4}=1$ y $p_{1}, p_{2}<p_{3}, p_{4}$. El significado de los parámetros $p_{i}$ es la probabilidad de respuesta de una PWC.

De esta manera se obtienen la fracción bariónica $\left(k_{1}+k_{2}\right)$ y la fracción mesónica $\left(k_{3}+k_{4}\right)$ de los haces secundarios tanto negativo como positivo a partir de la ecuación 3.1

Entonces, en la región del blanco de producción, para el haz secundario negativo se tiene que [1]:

- Fracción bariónica $\left(k_{1}+k_{2}\right)=47,5 \pm 1,6 \%$

- Fracción mesónica $\left(k_{3}+k_{4}\right)=52,5 \pm 1,6 \%$ 


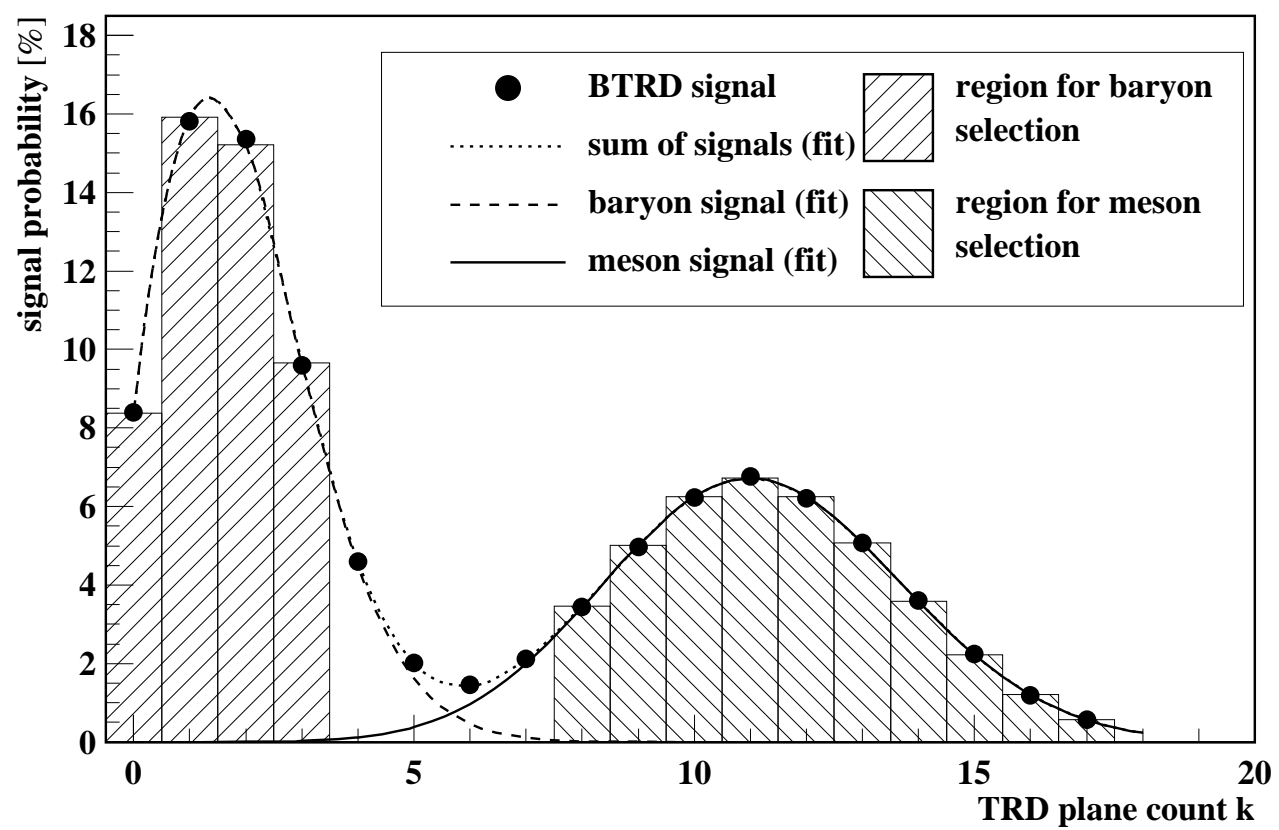

Figura 3.4: Espectro del BTRD con condiciones negativas del haz

Y para el haz positivo se tiene que [1]:

- Fracción bariónica $\left(k_{1}+k_{2}\right)=91,9 \pm 1,4 \%$

- Fracción mesónica $\left(k_{3}+k_{4}\right)=8,1 \pm 1,4 \%$

En la figura 3.4 se muestra como la componente bariónica tiene una fracción contaminante de la componente mesónica y viceversa. Para eliminar esta contaminación en cada componente se utilizaron los siguientes cortes en la distribución: $k \leq 4$ para la componente bariónica, y $k \geq 7$ para la componente mesónica. Luego entonces, la composición de la fracción bariónica del haz secundario negativo es de [1]:

- $\Sigma^{-} 97,52 \pm 4,70 \%$

- $\Xi^{-} 2,48 \pm 0,15 \%$ 

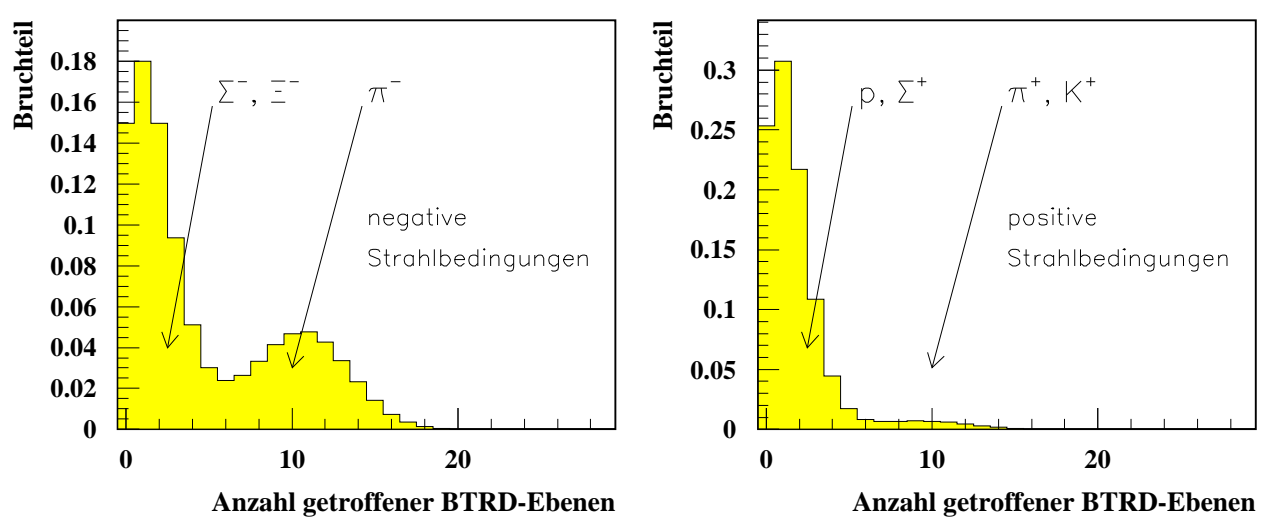

Figura 3.5: Espectro del BTRD con condiciones negativas y positivas del haz

Y la composición de la fracción mesónica del haz secundario negativo es [1]:

- $\pi^{-} 96,95 \pm 4,67 \%$

- $K^{-} 3,05 \pm 1,91 \%$

La composición de la fracción bariónica del haz secundario positivo es de [1]:

- $p 97,06 \pm 2,28 \%$

- $\Sigma^{+} 2,94 \pm 0,76 \%$

Y la composición de la fracción mesónica del haz secundario positivo es de [1]:

- $\pi^{+} 70,00 \pm 17 \%$

- $K^{+} 30,00 \pm 7 \%$

\section{Detector de la trayectoria del haz}

El detector de tiras de silicio del haz $\left(\mathrm{BSSD}^{9}\right)$ consiste en ocho detectores de silicio de un solo lado de $300 \mu m$ de ancho con un pitch de $20 \mu m$. Estos detectores están agrupados en tres estaciones montadas sobre un bloque de granito y colocadas en una caja blindada contra

\footnotetext{
${ }^{9}$ Beam Silicon Strip Detector
} 


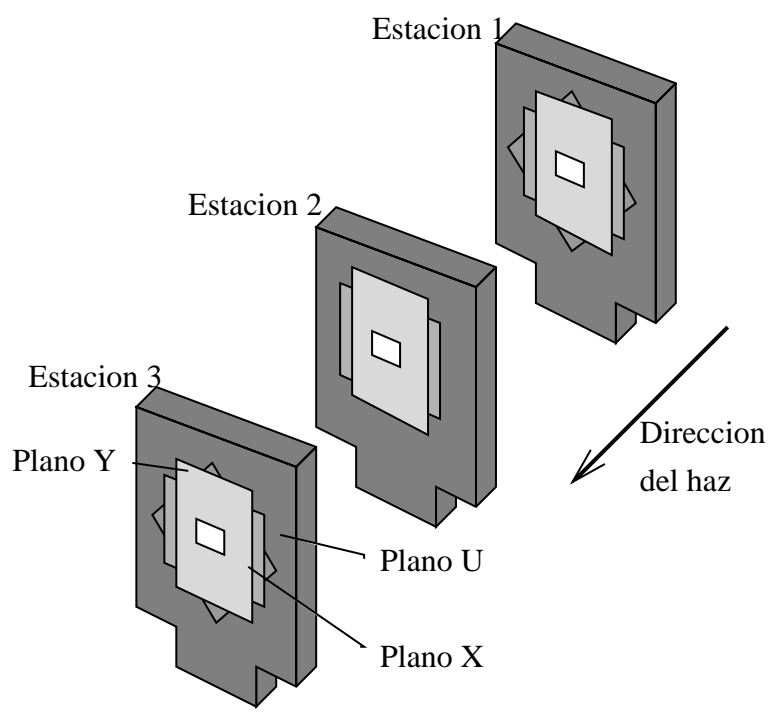

Figura 3.6: Estaciones del detector de la trayectoria del haz

radiofrecuencias. En la Fig 3.6 se muestran estas tres estaciones. En la estación uno y tres se montaron tres detectores y en la estación 2, dos detectores. Estos detectores determinan la posición de la trayectoria del haz en los blancos de producción del quark encanto con una resolución de aproximadamente $4 \mu \mathrm{m}$. Cada detector tiene 1024 tiras de silicio con una región activa de $2 \times 2 \mathrm{~cm}^{2}[6,7]$.

\subsubsection{El espectrómetro del vértice}

Los bariones cs producidos en el blanco decaen en una ruta aérea media de varios milímetros. La separación espacial entre la producción y el vértice del decaimiento es la firma de charm, el decaimiento es requisito necesario de modo que estas posiciones deben ser claramente distinguibles, por lo que se hace una gran demanda al poder de resolución de los espectrómetros de ésta región. Por esta razón, hay en el espectrómetro del vértice 22 detectores de barras de silicio altamente soluble con un número total de 48000 canales. Directamente después del los blancos hay un arreglo de 5 estaciones $\operatorname{VSSD}^{10}$ (fig. 3.7). En las dos primeras

\footnotetext{
${ }^{10}$ Vertex Singlesided Silicon Detectors
} 


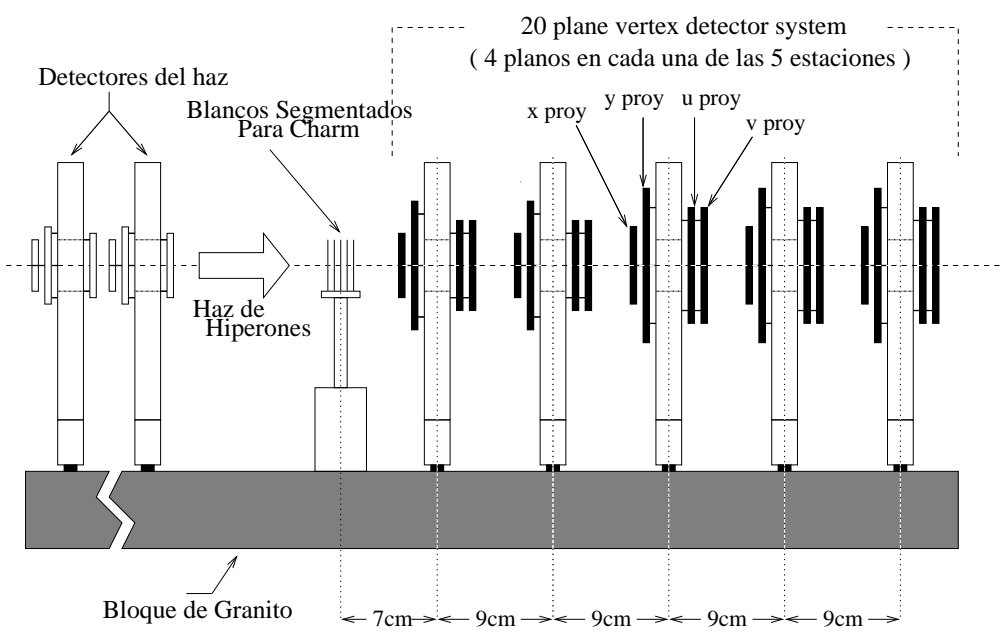

Figura 3.7: Esquema del espectrómetro del vértice

estaciones hay en cada caso cuatro de los llamados detectores de silicio de $5 \mathrm{~cm}$, con $20 \mu \mathrm{m}$ en la dirección delantera y una aceptancia de $5 \times 5 \mathrm{~cm}^{2}$. Las tres siguientes estaciones VSSD, hay en cada caso 4 detectores tipo mosaico, que son detectores de silicio con una superficie activa de $9,6 \times 8,3 \mathrm{~cm}^{2}$. Estas superficies tan largas exceden en 6 pulgadas la medida de fabricación standard en la industria de semiconductores. Aquí tres contadores de barras de silicio fueron ensamblados a un contador ancho, extrayéndose información de cada tira en la región central y cada dos tiras en la región externa. Cada uno de los detectores tiene una eficiencia mayor que el $98 \%$ para detectar una interacción y con una resolución espacial aproximadamente de $6,5 \mu \mathrm{m}$. Con los VSSD se miden las proyecciones $x, y, u$ y $v$ de la trayectoria.

El espectrómetro del vértice está bloqueado con la estación 3 del HSD ${ }^{11}$, esta estación provee la posición de la partícula saliente. Para incrementar la aceptancia, esta estación contiene dos niveles de HSD, que comparados con HSD1 y HSD2 tiene una superficie activa mas grande de $1,9 \times 1,92 \mathrm{~cm}^{2}$ que miden en las direcciones $x$ y y y el readout más rápido.

Para determinar el rastro de la multiplicidad de un evento en el blanco, se colocó un contador de interacción $\mathrm{IC}^{12}$ directamente detrás de la región del blanco. Este contador consiste

\footnotetext{
${ }^{11}$ Hardware Scatter Detector

${ }^{12}$ Interaction Counter
} 
en dos centelladores de $1 \mathrm{~mm}$ de grosor. El espectro de la amplitud del pulso da información acerca de la multiplicidad de la interaccion. Este se convierte en clases de multiplicidad usando un discriminador CAMAC de 8 entradas independientes, lo que permite que la selección de multiplicidad sea un nivel en el disparador.

Detrás del último nivel de MOSAICO está unido el contador de veto V5 que sirve como limpiador para eliminar eventos del detector de silicio cuando ocurren multiplicidades muy altas y se usa también como apoyo para el sistema de disparo de charm.

\subsubsection{El espectrómetro M1}

El espectrómetro M1 consiste del imán M1 y los detectores entre los imanes M1 y M2. El diseño de este espectrómetro se muestra en la figura 3.8. Este aparato fue diseñado para analizar partículas en el rango de momento de $2,5-15 \mathrm{GeV} / \mathrm{c}$.

El imán M1 fue operado a $1.35 \mathrm{~T}$ que corresponde a un $p_{T}$ de $0,74 \mathrm{GeV} / \mathrm{c}$. El espectrómetro M1 tiene tres cámaras de alambre proporcionales y dos cámaras de arrastre para encontrar las trayectorias de las partículas en el rango antes especificado. Las partículas con momento alto son detectadas usando los detectores de slicio de ángulo grande (LASD ${ }^{13}$ ).

\section{Cámaras de alambre proporcionales de M1}

Las tres cámaras de alambre proporcionales $\left(\mathrm{PWC}^{14}\right)$ del espectrómetro $\mathrm{M} 1$ consisten de alambres igualmente espaciados que funcionan como ánodos, centrados entre dos placas (cátodos). El espacio entre alambres es de $3 \mathrm{~mm}$. Estas PWC tienen una región activa de $2 \times 2 \mathrm{~cm}^{2}$ y se llenan con "gas mágico" (75 \% argón, $24.5 \%$ isobutano y $0.5 \%$ freón) que se ioniza cuando pasa una partícula cargada a través de él. El gas ionizado consiste de iones cargados positivamente y de electrones. Los iones positivos son arrastrados por el campo eléctrico hacia el cátodo y los electrones hacia el ánodo. Cuando los electrónes están cerca

\footnotetext{
${ }^{13}$ Large Area Silicon Detector

${ }^{14}$ Proportional Wire Chamber
} 


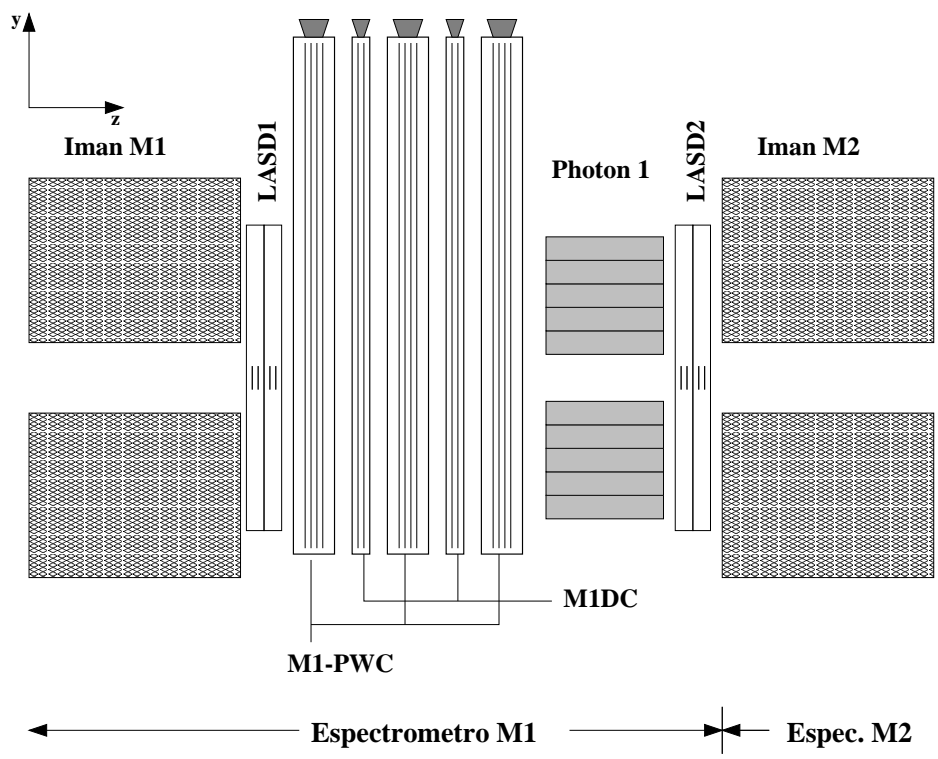

Figura 3.8: Esquema del espectrómetro M1

de un ánodo se genera un proceso de formación tipo avalancha que incrementa la señal que se extrae del ánodo. Cada PWC tiene cuatro mallas (planos) de alambres, cada uno en las proyecciones $x, y, u$ y $v$ a fin de poder determinar la posición de la partícula. El espacio entre cámara y cámara es de $70 \mathrm{~cm}$. Estas PWD tienen una eficiencia mayor de $90 \%$ para detectar una interacción y tienen una resolución espacial de 0,9mm [6].

\section{Cámaras de arrastre de M1}

Las dos cámaras de arrastre $\left(\mathrm{DC}^{15}\right)$ del espectrómetro $\mathrm{M} 1$ se diseñaron para mejorar la resolución angular del rastreo de partículas en el plano horizontal, donde el imán M1 curva las partículas cargadas, lo cual es necesario para obtener una buena medición del momento para partículas de poco momento. Las dos DC se colocaron entre las PWC y cada una de ellas tenía dos planos que detectaban las interacciones en la proyección $x$. Estas DC tiene una región activa de $2,4 \times 1,7 \mathrm{~m}^{2}$, una eficiencia del $80 \%$, y una resolución espacial de

\footnotetext{
${ }^{15}$ Drift Chamber
} 
aproximadamente $0,7 \mathrm{~mm}[23]$.

El funcionamiento de estas camaras está basado en el hecho de que si las velocidades de arrastre de los electrones son constantes y conocidas, y si el tiempo que tarda en atravesar la partícula también se conoce, entonces se puede determinar la posición con una resolución mas fina.

\section{Detectores de silicio de área grande (LASD)}

El propósito de los LASD es cubrir la región del haz de las PWC y DC de la parte final del experimento para mejorar la resolución de las trayectorias, la separación en esta región y lograr una medición precisa del momento menos sensitiva al haz. Los LASD se dividen en tres grupos y están colocados justo detrás del imán M1 y tanto enfrente como detrás del imán M2, por lo que se diseñaron para funcionar correctamente dentro del campo magnético producido por los bordes de los imanes. Cada grupo de LASD consiste de seis planos de detectores: dos detectores (planos) de silicio sencillos (un solo lado) y de dos detectores de silicio dobles (4 planos) para determinar dos puntos en cada una de las tres proyecciones $(x, y, u)$. Los LASD sencillos tienen 2540 tiras de silicio con una área activa de $63.5 \times 63.5$ $\mathrm{mm}^{2}$, y los dobles tienen un área activa de $52.6 \times 66.4 \mathrm{~mm}^{2}$. Los LASD tienen una eficiencia entre 95 - 99 \% para detectar una interacción y una resolución espacial de $15 \mu \mathrm{m}[9,10]$

\subsubsection{El espectrómetro M2}

El espectrómetro M2 se diseño para reconstruir e identificar partículas con momento mayor que $15 \mathrm{GeV} /$ c. El espectrómetro consiste del imán M2 y de todos los detectores entre los imanes M2 y M3. La figura 3.9 muestra el esquema de éste espectrómetro.

El imán M2 fué operado a $1.54 \mathrm{~T}$ que corresponde a un $p_{T}$ de $845 \mathrm{MeV} / \mathrm{c}$. El primer detector en el espectrómetro M2 es el tercer LASD, que está colocado a la salida del imán M2. 


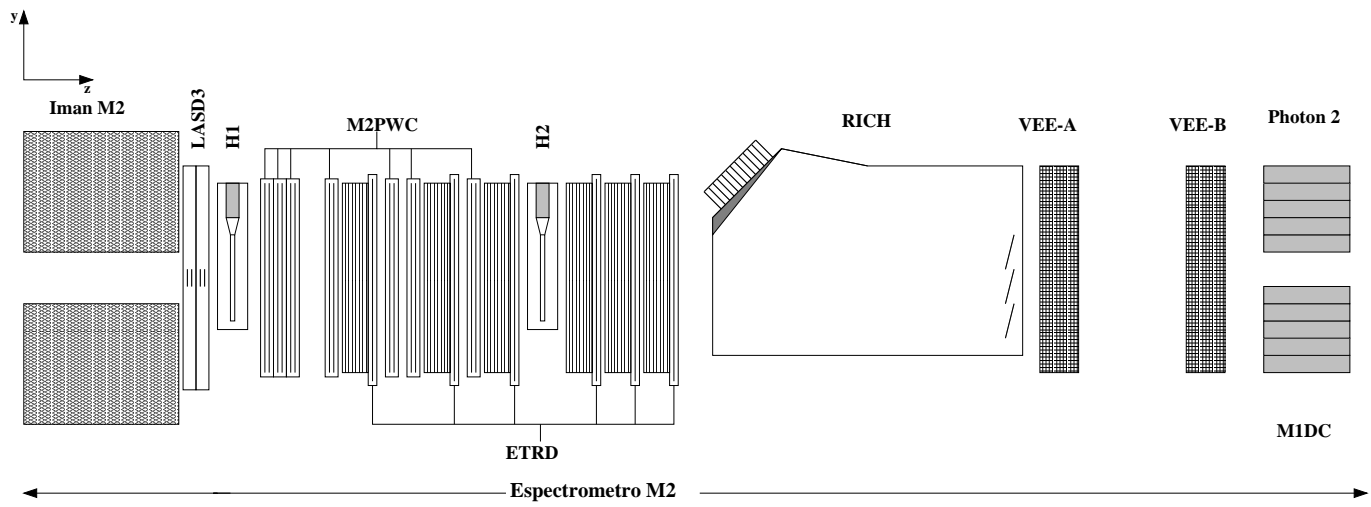

Figura 3.9: Esquema del espectrómetro M2

\section{Los hodoscopios}

Los dos hodoscopios H1 y H2(Fig. 3.9) empleados en el espectrómetro M2 usan contadores de centelleo para dar una respuesta rápida al número de partículas que pasan a través del espectrómetro y para obtener su momento [11]. Esta información la utiliza el mecanismo disparador para decidir si activa o no la adquisición de los datos de un evento.

El hodoscopio consiste de tres regiones: la región de carga negativa, la región central y la región de carga positiva. El signo de la carga se asume basado en la región del detector. Los imanes curvan a las partículas negativas hacia la derecha cuando éstas pasan a través de ellos.

\section{Las cámaras de alambre proporcionales M2}

La reconstrucción de las partículas en el espectrómetro M2 se realiza por medio de las siete PWC que hay en este espectrómetro, que tienen un espacio de $2 \mathrm{~mm}$ entre cada alambre. Las tres primeras cámaras tienen una apertura de $60 \times 60 \mathrm{~cm}^{2}$, y las cuatro últimas tiene una apertura de $60 \times 100 \mathrm{~cm}^{2}$. Cada cámara tiene dos planos sensitivos en dos proyecciones ortogonales y tienen una eficiencia para detectar una interacción mayor que el $95 \%$ con una resolución espacial de $0,6 \mathrm{~mm}[6]$. 


\section{El detector Cherenkov E781}

El detector Cherenkov $\left(\mathrm{RICH}^{16}\right)$ fue diseñado para lograr una buena identificación de las partículas cargadas, lo cual se requiere para buscar los diferentes modos de decaimiento de los bariones y mesones producidos. Este detector provee la separación de piones, kaones y protones. El RICH es un tanque cilíndrico de acero al carbón de 10,2 m de largo con un diámetro de 2,36 m que se llenó con gas neón puro a presión atmosférica. En la parte de atrás del tanque se montaron 16 espejos esféricos en forma hexagonal que tiene un área total de $2,4 \times 1,2 \mathrm{~cm}^{2}$. Los espejos se usan para reflejar la radiación Cherenkov (fotones) hacia una matriz de 2848 tubos fotomultiplicadores que están colocados en la parte delantera del tanque [12].

La radiación Cherenkov se emite cuando una partícula cargada atraviesa un medio con un índice de refracción $n$ a una velocidad $v$ que excede la velocidad de la luz en ese medio $c / n$. La radiación Cherenkov se emite porque la partícula cargada polariza a los átomos a lo largo de su trayectoria de tal manera que se convierten en dipolos eléctricos. La variación en el tiempo del campo eléctrico generado por los dipolos conduce a la emisión de radiación electromagnética. Si $v<c / n$, entonces los dipolos eléctricos se arreglan simétricamente alrededor de la trayectoria de la partícula, de tal manera que el campo eléctrico integrado sobre todos los dipolos se hace cero. Ahora bien, si la partícula que atraviesa el medio se mueve con velocidad $v>c / n$, entonces la simetría se rompe generando un momento dipolar eléctrico, y por consecuencia un campo eléctrico.

Los fotones son radiados a un ángulo respecto a la línea de la trayectoria de la partícula que pasa a través del medio con índice de refracción $n$, que esta dado por

$$
\cos \theta_{c}=\frac{1}{n(\omega) \beta}
$$

\footnotetext{
${ }^{16}$ Ring Imaging Cherenkov Counter
} 
Donde $\omega$ es la frecuencia de la radiación emitida y $\beta$ es la velocidad de la partícula. Este ángulo corresponde al radio del cono de luz visto por los fototubos en el detector. Entonces, los fotomultiplicadores activados son ajustados a círculos y si se conoce el momento de la trayectoria, se puede identificar a la partícula con varios niveles de certidumbre. La eficiencia en la identificación de las partículas es bastante alta $(\approx 98 \%)$ y solamente disminuye a momentos grandes.

\section{Cámaras de arrastre vectoriales}

Después del RICH se colocaron seis de las nueve cámaras de arrastre vectoriales (VDC ${ }^{17}$ ) de SELEX, agrupadas en dos estaciones VeeA y VeeB, con tres cámaras cada una de ellas. Estas cámaras se diseñaron para proveer segmentos cortos de las trayectorias de las partículas cargadas, además de la información usual de la posición. Estos detectores consisten de una región de celdas finas centradas alrededor de la línea del haz y de una región de celdas gruesas lejos del haz. Las VDC fueron diseñadas, también, para reconstruir los productos de los decaimientos que suceden en la parte final del experimento, al proveer segmentos cortos con alta resolución dentro de cada estación. Las trayectorias se midieron en tres proyecciones $(x, y, u / v)$. Cada estación tiene una región activa de $1,16 \times 1,16 \mathrm{~m}^{2} \mathrm{y}$ una eficiencia de aproximadamente el $90 \%$ con una resolución de $100 \mu \mathrm{m}$. Las cámaras con las celdas finas están provistas de ocho alambres sensitivos para cada vista o proyección, y las cámaras con las celdas gruesas estan están provistas de seis alambres sensitivos. De esta manera cada cámara mide una trayectoria con seis o con ocho puntos, y por lo tanto, no solo mide la proyección sino que también el vector de la trayectoria [13]. Después de la segunda estación VDC se encuentra el segundo detector de fotones.

\footnotetext{
${ }^{17}$ Vector Drift Chamber
} 


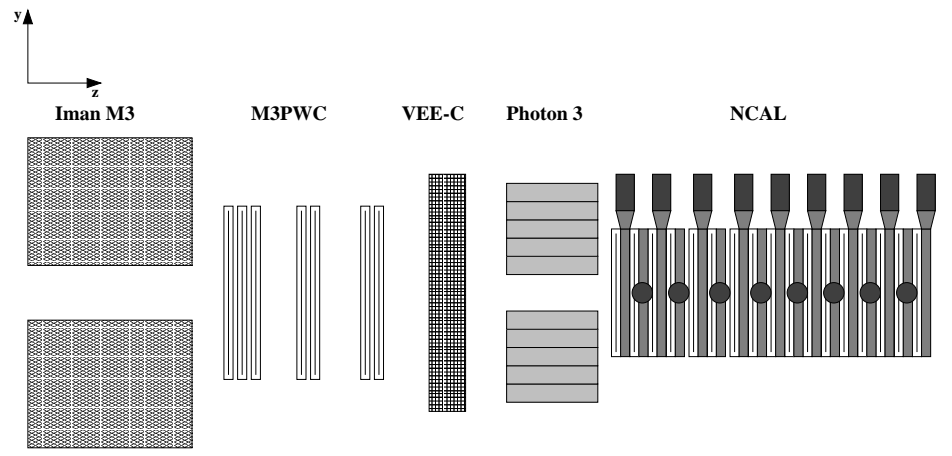

Figura 3.10: Esquema del espectrómetro M3

\subsubsection{El espectrómetro M3}

Para medir el momento de los productos de los decaimientos de las partículas de largo alcance, se emplea un tercer espectrómetro: El espectrómetro M3, cuyo esquema se muestra en la figura 3.10 .

El espectrómetro M3 consiste en el imán M3 que fué operado a $1.3 \mathrm{~T}$ y que corresponde a un $p_{T}$ de $0.72 \mathrm{GeV} / \mathrm{c}$, de dos PWC de $115 \times 89 \mathrm{~cm}^{2}$, seguida de la tercera estación VeeC con tres cámaras VCD. Después se encuentra el tercer detector de fotones y, finalmente, el calorímetro de neutrones que se encuentra en la parte final del detector.

\subsection{El disparador E781}

En el contexto de este trabajo únicamente es necesario un conocimiento básico de la estructura del disparador de E781, que en general es un disparador complicado para la búsqueda de mesones y bariones encanto y del disparador utilizado para la medición de la sección eficaz. Por lo que solo se dará la descripción de las partes de mayor interés. 


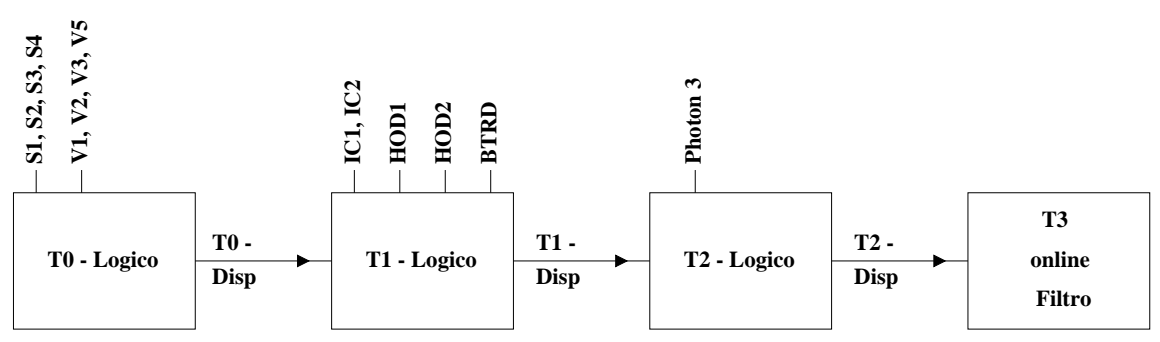

Figura 3.11: Esquema del Disparador y sus detectores asociados

\subsubsection{Estructura del disparador E781}

El disparador de SELEX es un disparador de cuatro niveles. Los niveles se designan de acuerdo a su orden jerárquico como T0, T1, T2 y T3 [14]. Los primeros tres niveles del disparador, T0, T1 y T2, son niveles solo de hardware. El cuarto nivel (T3) es un nivel característico de SELEX. Consta de un disparador de software (programa) que filtra la información en bruto aceptada por las etapas anteriores del disparador según ciertos criterios. Una descripción de la jerarquía de las etapas del disparador y de los detectores ligados a ella se presenta en la figura 3.11 .

Se utilizaron módulos programables de CAMAC por su mayor flexibilidad con las diferentes etapas de la estructura del hardware del disparador. En las etapas del disparador de hardware, se forman funciones lógicas con las señales de los detectores adjuntos, se determina un candidato y se envía una señal a la siguiente etapa. Cada nivel acepta la señal de una decisión positiva proveniente del nivel anterior e inicia la señal de la comunicación.

La comunicación entre las etapas del disparador, corre de acuerdo al siguiente esquema: Si una etapa del disparador $T_{i}$ toma una decisión positiva, ésta transmite un señal de encendido a la etapa siguiente $T_{i+1}$. Al mismo tiempo, se bloquea la aceptación de posteriores entradas al nivel del disparador $T_{i}$, el disparador es lanzado otra vez hasta que concluyen todas las operaciones en el nivel mas alto. La disposición jerárquica del disparador es cosa indispensable, debido a que no toda la información de los detectores esta disponible al mismo tiempo, algunas causas de esto son las diferentes velocidades en las señales de los detectores y tiempos de marcha en los cables. Es así más favorable resolver primero con los detectores 
más rápidos una decisión preliminar antes de que se pregunte a una señal más lenta. De este modo el tiempo muerto del disparador que es tiempo muerto de todo el experimento, se disminuye. Puesto que con el incremento en la etapa del disparador se agregan nuevas condiciones, la taza disminuye respecto de la etapa ascendente, la razón más grande se encuentra en la etapa de T0 que se define solo con el haz entrante del haz con una taza de aceptación de hasta $1 \mathrm{MHz}$ de eventos. Solo el nivel T1 es directamente posible en el blanco por el contador de interacción y en el espectrómetro del M2 por el hodoscopio del M2 que proporciona el rastro de las multiplicidades. La razón de eventos que pasan por T1 y T2 es substancialmente reducida por esta información. Información proveniente del BTRD también puede ser requerida inclusive desde el nivel T1.

Después de un pulso del nivel T2 del disparador se seleccionan todos los datos almacenados en los detectores y su información y se pasan al sistema de adquisición de datos (DAQ $\left.{ }^{18}\right)$. Por todos los criterios programados en el disparador, hay una reducción importante en el número de eventos que pasan entre T0 a T3, de modo que no se excede la capacidad del DAQ al mismo tiempo que la señal física deseada es filtrada eficientemente.

La etapa de software del disparador (T3) está aparte del espectrómetro puesto que está conectada directamente con el DAQ. En esta etapa, ocurre un análisis de los datos en bruto antes de que se corran los programas de reconstrucción de eventos. Los datos, que fueron seleccionados por una decisión positiva de la etapa T2 del disparador, se examinan aquí con 15 procesadores en busca de un posible charm. La reducción de datos por estos filtros en linea comparado con la relación de T2:T3 asciende en promedio de 4:1 a 12:1.

\subsubsection{Disparador de la medición de la sección eficaz total}

Para las mediciones de las secciones eficaces totales se utilizó el disparador de haz (Minimum Bias Trigger). Es decir que solamente una decisión de los centelladores que están arreglados antes del blanco lanza una selección del espectrómetro. Tal disparador pertenece al equipo estándar de cada experimento de física de altas energías, puesto que con éste se

\footnotetext{
${ }^{18}$ Data AcQuisition System
} 

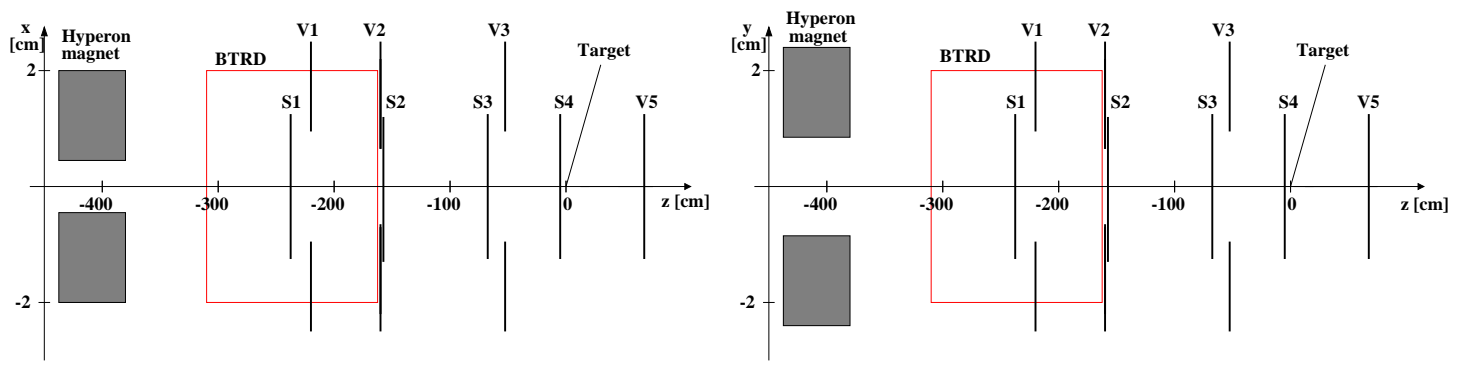

Figura 3.12: Posición y geometría de los centelladores del disparador en las proyecciones $x$ y $y$

hace la calibración de muchos detectores.

El Minimum Bias Trigger de E781 no tiene un disparador "parásito", si se carga este disparador, entonces se apagan el resto de los disparadores. El disparador del haz E781 es puesto en ejecución en etapas individuales como sigue:

En el nivel T0 se define un pulso disparador por la coincidencia

$$
T 0=S_{1} \wedge S_{2} \wedge S_{3} \wedge \neg V 1 \wedge \neg V 2 \wedge \neg V 3
$$

La posición y geometría de los centelladores se muestra en la figura 3.12. Debido a la geometría de los detectores del Vértice V1, V2 y V3 el T0 define un rango de aceptación tubular, y están alineados de tal manera que el haz pase completamente a través del blanco, el área de la región transversal del tubo de aceptancia es de $12 \times 12 \mathrm{~cm}^{2}$, definido por el hueco en V2 (coincidencia negativa), lo cual significa que un pulso T0 no indica más que el flujo de una partícula dentro de un rango definido del espacio del blanco.

Con el disparador en T0 no se agregan otras condiciones en T1 y T2 cuando éstos están en uso, el pulso T0 se pasa en directamente por un divisor de frecuencia de una etapa del disparador a la siguiente. Con los divisores de frecuencia la relación de las tarifas T0:T1 y T1:T2 se pueden ajustar, para adaptar la tarifa del T2 a la capacidad del DAQ. En la 
etapa T3 no se usa el filtro de datos del disparador del haz. Más allá del filtro los datos se distribuyen en cintas.

\subsection{El software de análisis}

El software para el análisis de los datos que se utiliza en SELEX puede dividirse en cuatro categorías: La toma de datos, el procesamiento posterior de los datos, la simulación de eventos y el análisis de los datos.

\subsubsection{La toma de los datos (DAQ) en E781}

El sistema de la toma de datos es parte del proyecto DART, que es una colaboración entre el departamento de sistemas en línea de Fermilab y seis experimentos (E781, E811, E815, E831, KTeV, E835) [15, 16]. Este sistema incluye el software usado para controlar los sistemas individuales de los detectores, el subsistema del mecanismo disparador, y el software del filtro en tiempo real. La corrida del experimento se controló por medio de una computadora Silicon Graphics Indigo (Indy). Cada uno de los detectores fueron controlados y configurados mediante la estructura de comandos y rutinas. Una vez que las condiciones para correr fueron configuradas, el control de la toma de datos fue automática basada en el mecanismo disparador. Todos los datos se coleccionaron por medio del enlace de fibra óptica con la computadora Indy. El esquema de este sistema se muestra en la figura 3.13.

Una vez que los datos pasan por el filtro de tiempo real, éstos se escriben en un disco fijo. Posteriormente son almacenados en archivos de 200 MB, los cuales son escritos en cintas de $8 \mathrm{~mm}$. La colección completa de los datos de SELEX fue almacenada en estas cintas, y después fué transladada al $\mathrm{FMSS}^{19}$, donde se pueden utilizar mediante la red para el análisis de los datos en bruto. Se tomó alrededor de medio año el procesar todas las cintas, por lo tanto el experimento se benefició con el filtro en tiempo real al disminuir el tiempo para procesar todas las cintas por un factor de 8 para obtener eventos con quark encanto.

\footnotetext{
${ }^{19}$ Fermilab Mass Storage System
} 


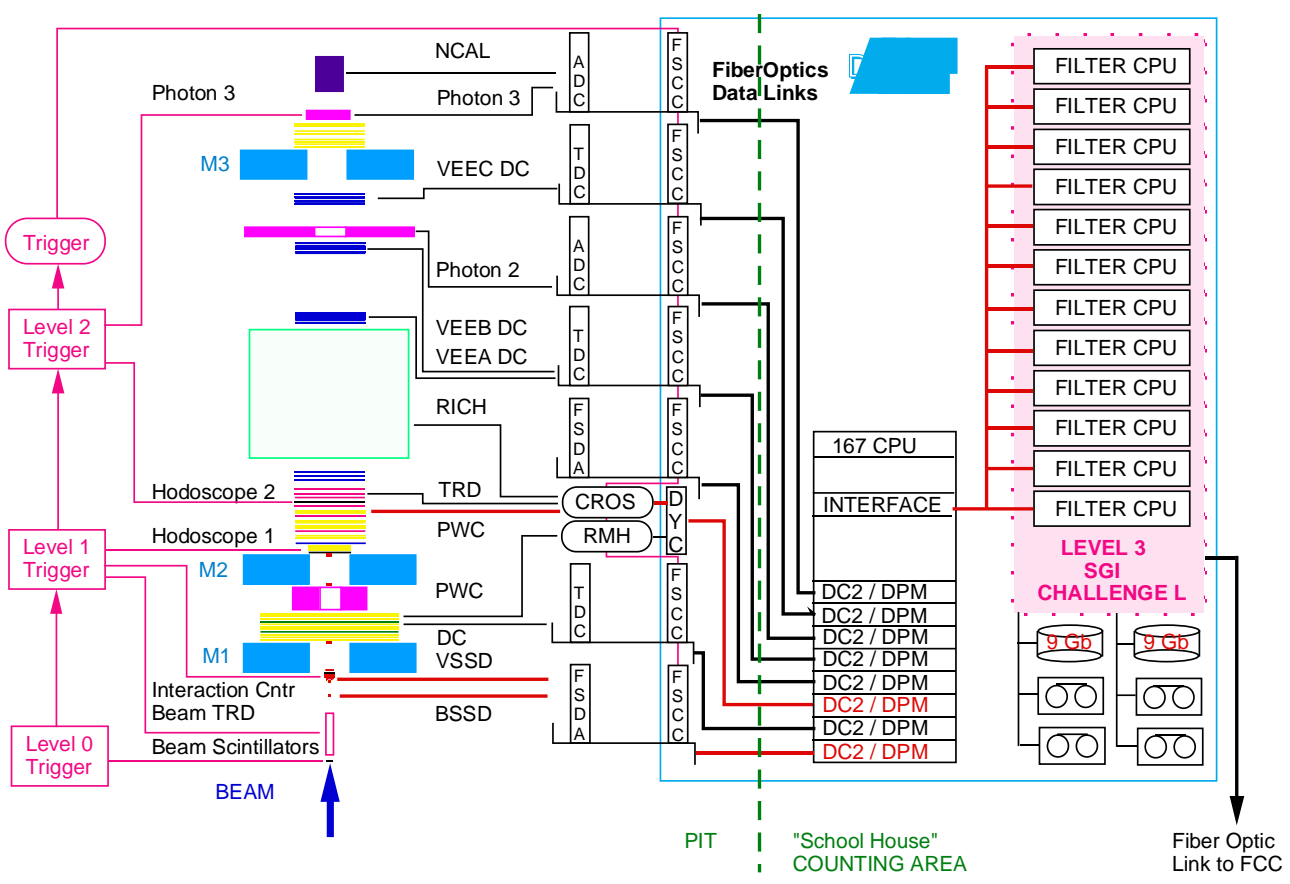

Figura 3.13: Esquema del sistema de la toma de datos

La toma de datos inició en Julio de 1996. Las primeras corridas se llevaron a cabo para verificar el mecanismo disparador y el funcionamiento de los detectores, para obtener las eficiencias de las cámaras, para calibrar los detectores de fotones, para optimizar el filtro en tiempo real, y para realizar todas aquellas tareas que lograran una alta calidad en la escritura de los datos en las cintas.

SELEX tomó datos de un total de 15,2 × $10^{9}$ interacciones inelásticas y se grabaron en las cintas un total de $1 \times 10^{9}$ eventos, tanto del haz secundario negativo como del positivo.

\subsubsection{El procesamiento posterior de los datos}

El software principal que se usa en el procesamiento posterior de los datos es el SOAP ${ }^{20}$. El código de este software también se utilizó para el filtro en tiempo real, aunque no en la misma configuración. La versión para el análisis posterior incluye software para el análisis de todos los sistemas de los detectores, basado en lo que el usuario quiera encontrar. El

\footnotetext{
${ }^{20}$ SELEX Off-line Analysis Program
} 
SOAP consiste principalmente de los siguientes paquetes: El desempacador (UNPACK), el reconstructor de la trayectoria (TRACKING), el identificador de las partículas (PID), el reconstructor del vértice (VERTEX), el Photon y en Ncal, cuya información generada se guarda en common blocks ${ }^{21}$. A continuación describiré brevemente los paquetes utilizados en el presente trabajo.

\section{UNPACK}

El primer paso es desempacar los datos de un evento en particular que fueron escritos en cintas. Para cada detector, el hardware crea una sola lista con la informción de que alambre, tira de silicio o fotomultiplicador tuvo una señal. Después, usando el sistema de coordenadas local de cada detector, el software de este paquete crea otra lista, al convertir la información de la lista anterior, en las coordenadas de los puntos espaciales de las señales. Por ejemplo, las señales de los alambres de una PWC de un evento en particular son dadas al paquete TRACKING en forma de una lista con los números de los alambres donde hubo señal y la lista correspondiente con las coordenadas de los puntos espaciales de las señales [17, 18].

\section{TRACKING}

El objetivo de este paquete es encontrar y medir los parámetros de todas las trayectorias cargadas dentro de la aceptancia del aparato de SELEX. Cinco de los ocho parámetros que se requieren para definir completamente una trayectoria cargada se determinan en la región del vértice: Las tres coordenadas espaciales donde por primera vez se observó y dos de los tres cosenos directores de las componentes del momento. Los tres restantes parámetros se determinan utilizando los espectrómetros M1 - M3: la curvatura de la trayectoria ( $p / q B)$, La identificación de la partícula y la coordenada z donde fué la última vez que se observó [18].

Tracking tiene diferentes algoritmos para encontrar las trayectorias de las partículas. La

\footnotetext{
${ }^{21}$ Bloques de memoria accesibles desde cualquier paquete del programa
} 
situación más general involucra a las PWC de M1 y M2, y el detector del vértice. Debido a que estos detectores están en regiones libres de campo magnético, las partículas cargadas deberían pasar a través de los detectores en línea recta. La reconstrucción de las trayectorias de las partículas cargadas es un proceso de tres etapas [17].

- En primer lugar, se encuentran todos los segmentos de las trayectorias cargadas en cada detector. Un algoritmo usa la lista de las coordenadas de los puntos espaciales de un detector en particular para encontrar todas las combinaciones posibles de los puntos espaciales que sean consistentes a un ajuste a una línea recta. Si el código determina que el ajuste es aceptable basado en $\chi^{2}$ y el número de puntos usados, entonces se forma con ellos un segmento de una trayectoria cargada y los puntos se suprimen de la lista de las coordenadas. Con los segmentos formados se hace una nueva lista para cada detector.

- Ahora se prueban las posibles combinaciones de segmentos para formar candidatos a trayectorias. La idea básica del algoritmo que realiza este trabajo es análogo al usado para determinar los segmentos. Todos los segmentos, en pares de espectrómetros, son ajustados a una trayectoria contínua usando como criterio de selección la $\chi^{2}$.

- Finalmente los puntos espaciales de cada plano (PWC, SSD, DC) que forman una trayectoria son ajustados para obtener el momento. Un algoritmo ajusta los puntos espaciales que forman una trayectoria a una función que la describe como la de una partícula cargada que pasa a través de los imanes y las cámaras de los espectrómetros. Los parámetros de ajuste son la pendiente, la ordenada al origen y la curvatura de la trayectoria $(p / q B)$.

\section{VERTEX}

El SOAP por medio de este paquete, busca los vértices de las interacciones de los haces secundarios con los blancos de producción, los cuales son llamados vértices primarios, y los vértices secundarios que representan las posiciones donde las partículas decaen en partículas 
cargadas o neutras, o donde las partículas de la interacción principal colisionan con el material del detector produciendo una interacción secundaria.

Para encontrar estos vértices existen, en realidad, dos paquetes: el Vertex [19] y el VTX2. El paquete que se usó en el presente trabajo fue el VTX2, el cual es un algoritmo similar al Vertex pero con una implementación diferente. El VTX2 maneja la rutina del vértice primario, la cual encuentra las coordenadas del vértice primario. La rutina del vértice secundario toma las trayectorias que no fueron asignadas al vértice primario y verifica si éstas forman un vértice secundario. Debido a que esta rutina utiliza solamente las trayectorias que fueron reconstruidas en el detector del vértice, entonces, solo encuentra vértices secundarios que estan cercanos a los primarios. Las rutinas que buscan vértices secundarios en la parte trasera del experimento no se usan en este trabajo.

Para reconstruir el vértice primario primero se encuentra el blanco de producción. Todas las trayectorias de los espectrómetros M1 y M2 son relacionadas en una sola trayectoria con el haz para encontrar la distancia de máximo acercamiento $\left(\mathrm{DCA}^{22}\right)$. EL valor de $z$ de la DCA se compara con los centros de cada uno de los cinco blancos de producción y es asignado al más cercano. La elección del blanco de producción donde ocurrió la interacción se decide por la probabilidad más alta. El siguiente paso es hallar el vértice primario, para ello se ajusta el conjunto de las trayectorias del vértice con las trayectorias del haz a un vértice (punto espacial). La $\chi^{2}$ total del ajuste debe ser menor que 3.5 para que el punto sea asignado a un vértice primario, de lo contrario la trayectoria que genere la mayor contribución es suprimida de la lista de trayectorias, y se reajusta con las trayectorias restantes. Cuando $\chi^{2}<3.5$ el proceso se detiene.

El siguiente paso es hallar el vértice secundario y asignarle sus trayectorias. Todas las trayectorias que fueron suprimidas del ajuste del vértice primario son candidatas. Se calcula la DCA a la trayectoria del haz de estas trayectorias. Las trayectorias que tienen un $\mathrm{DCA} \leq 20 \mu \mathrm{m}$ se asocian a la trayectoria del haz como candidatas del vértice secundario, las cuales son llamadas prongs. La trayectoria del haz garantiza que habrá por lo menos una prong. El siguiente paso es incluir las trayectorias que no fueron vistas en M2. Una muestra

\footnotetext{
${ }^{22}$ Distance of Closest Approach
} 
con una prong se verifíca para ver si existen trayectorias en el espectrómetro M1 que no se ajusten al vértice primario y que tengan una DCA satisfactoria con respecto a la prong. Las prongs del M1 y M2 se ajustan a un vértice. Si la $\chi^{2}<4$ entonces se ha encontrado el vértice secundario, de lo contrario se puede mejorar el ajuste removiendo el prong que más contribuye al $\chi^{2}$. Se necesita que por lo menos se ajusten dos prongs con estas condiciones para que el vértice ajustado se asigne a un vértice secundario [20].

\section{RECON}

El propósito de Recon es proveer un código estándar manejado por un lenguaje de alto nivel para reconstruir hipótesis de partículas usando la información de los paquetes Tracking, Vertex y Pid [21].

Una hipótesis de una partícula reconstruida $\left(\mathrm{RPH}^{23}\right)$ es un conjunto de tayectorias (cargadas o neutras) que fueron identificadas, las cuales se originaron en un punto común del espacio (vértice). Los parámetros para la hipótesis de la reconstrucción de una partícula son: La localización del vértice secundario y su separación del vértice primario (L) y su error $(\sigma)$, el cuadrimomento, su masa y su error, la identificación y la carga.

Una reconstrucción de una hipótesis de una partícula es llevada a cabo utilizando otros objetos reconstruidos por SOAP (vértices, trayectorias, etc) incluyendo otras hipótesis de trayectorias reconstruidas.

Son posibles diferentes métodos de búsqueda. Cada búsqueda se lleva a cabo en el orden dado en una tabla que almacena el programa de alto nivel que ejecuta Recon.

El control de todo el proceso en el SOAP se realiza por medio de un archivo de comandos (script). Cualquier paquete de SOAP puede ser ejecutado o no ejecutado utilizando este script, asi como también se puede usar para activar o desactivar diferentes opciones de cada paquete y, además puede usarse para aplicar cortes sobre diferentes variables en cada paquete.

\footnotetext{
${ }^{23}$ Reconstructed Particle Hypotesis
} 


\section{USER}

En el caso del trabajo hecho para esta tesis, la salida consiste en un conjunto de histogramas con la información contenida de las multiplicidades estudiadas.

El procedimiento hecho para reservar la memoria ocupada por estos histogramas, seleccionar la información, y finalmente llenarlos, es hecho mediante un programa llamado User, el cual no esta incluido como parte de los programas de análisis de SOAP, es escrito por el usuario del paquete, puede ser compilado junto con SOAP y llamado mediante un switch incluido en la hoja de comandos. Esta rutina se discutirá más tarde con mayor detalle 


\section{Capítulo 4}

\section{Toma y análisis de los datos}

\subsection{Toma de datos}

Los datos utilizados en este análisis son datos tomados en una corrida especial de SELEX hecha en julio de 1997, con el objetivo de medir la sección eficaz total.

La toma de estos datos requirió del uso de varios blancos y el uso exclusivo del disparador Minimum Bias con un haz de muy baja intensidad, gracias a lo cual los detectores durante esta corrida operaron produciendo muy poco ruido.

En este capítulo decribiré brevemente las condiciones en que fueron tomados los datos.

\subsubsection{Los blancos}

Para esta toma de datos se construyeron unos blancos especiales con una base adaptada al sistema mecánico de colocación. Las pautas para las características mecánicas y físicas de los blancos eran las siguientes:

- Los blancos se debían insertar entre el S4 y el contador de efecto recíproco, debido a esta delimitación del lugar permitido, el grueso del blanco no podía exceder los $7 \mathrm{~cm}$. 
- Para mantener pequeña la influencia de la dispersión múltiple, el grueso de la blanco debe ser tan pequeño que el ensanchamiento de la distribución del ángulo de dispersión quede por debajo en la resolución angular medida de aproximadamente $20 \mu \mathrm{rad}$.

- El haz de hiperones tiene un diámetro de aproximadamente 1,2 cm y debe ser cubierto totalmente por el blanco.

- La idea de un blanco de hidrógeno que era el ideal para el estudio de la sección transversal fue desechada por razones de ingeniería y en su lugar se construyó uno de carbón y uno de polietileno $\mathrm{CH}_{2}$.

La tabla 4.1 contiene una descripción de las características físicas y mecánicas de todos los blancos que fueron utilizados durante este periodo de operación del experimento, $X_{i n t}$ es la longitud nuclear de interacción, $X_{\text {coll }}$ es la longitud nuclear de colisión. Estos se definen de la siguiente manera:

$$
X_{\text {coll }}=\frac{A}{N_{A} \rho_{\text {Tgt }}^{*} \sigma_{\text {tot }}} \quad X_{\text {int }}=\frac{A}{N_{A} \rho_{\text {Tgt }}^{*} \sigma_{\text {inel }}}
$$

Donde $N_{A}$ es la constante de Avogadro, $\sigma_{t o t}$ es la sección transversal total, $\sigma_{\text {inel }}$ es la sección transversal inelástica total, $X_{\text {rad }}{ }^{1}$ que entre otras cosas, describe el ángulo de apertura del haz y el multiple scattering, $\rho_{T g t}^{*}$ es la densidad en $\frac{\mathrm{grm}}{\mathrm{cm}^{3}}$ y $\sigma_{\theta}$ de acuerdo con la fórmula de Moliere [22]

\subsubsection{Saturación del DAQ}

Para la medición de la sección eficaz solo se dispuso de dos días efectivos de tiempo de haz, por lo que en el tiempo más corto debía intentarse grabar la mayor cantidad de

\footnotetext{
${ }^{1}$ rad: Radiation Length
} 


\begin{tabular}{|c|c|cc|c|c|c|c|c|}
\hline \hline Material & $\begin{array}{c}\text { Ancho }(\mathrm{z}) \\
L_{\text {Tgt }}(\mathrm{mm})\end{array}$ & $\begin{array}{c}\text { seccioń transversal } \\
\mathrm{x}[\mathrm{mm}] \mathrm{y}[\mathrm{mm}]\end{array}$ & $\begin{array}{c}\rho_{\text {Tgt }}^{*} \\
\frac{\mathrm{grm}}{\mathrm{cm}^{3}}\end{array}$ & $\begin{array}{c}\sigma_{\theta} \\
\mu \mathrm{rad}\end{array}$ & $\begin{array}{c}X_{\text {int }} \\
{[\%]}\end{array}$ & $\begin{array}{c}X_{\text {coll }} \\
{[\%]}\end{array}$ & $\begin{array}{c}X_{\text {rad }} \\
{[\%]}\end{array}$ \\
\hline Berilio & 50.92 & 30.7 & 51.2 & $1.848 \pm 0.002$ & 8.3 & 12.5 & 16.86 & 14.4 \\
Carbón & 15.459 & 30.0 & 30.0 & $2.199 \pm 0.003$ & 6.0 & 3.8 & 5.40 & 7.7 \\
Polietileno & 40.858 & 30.0 & 25.0 & $0.9291 \pm 0.0008$ & 6.3 & 4.8 & 6.66 & 8.5 \\
Cobre & 1.00 & 30.0 & 30.0 & 8.96 & 5.7 & 0.66 & 1.05 & 7.0 \\
\hline
\end{tabular}

Tabla 4.1: Características físicas y mecánicas de los blancos

datos útiles en un volumen fijo. El máximo número de eventos, por ciclo del acelerador, que se pueden escribir en el volumen, está limitado por la velocidad de grabado de los mecanismos de las cintas (Máx 1,2 × $10^{5} \mathrm{KByte} / \mathrm{min}$ ), ésto aunado al efecto de empalme en los datos provenientes de los eventos individuales ${ }^{2}$ son parámetros que forzaron a modificar las condiciones del haz, siendo necesario modificar en primer lugar la intensidad de este, consiguiendose adicionalmente los siguientes beneficios:

- Con un haz de gran intensidad las colisiones que producen muchas multiplicidades en los detectores de silicon ocupan mucho tiempo de CPU en la recostrucción de trayectorias que más adelante no se usan en los análisis. Esto se soluciona bajando la intensidad del haz.

- Eventos con una tasa de alrededor de $5 \times 10^{4} \mathrm{~T} 0 /$ spill presentan poco ruido dentro de los detectores VSSD, y pueden ser capturados todos los datos, esto no siempre es posible con tasas más altas, en estos casos son los detectores del vértice los que deciden cuales eventos se escriben siendo el máximo de 50 por spill. En los eventos en los cuales se excede este límite el hardware avanza de manera ineficiente.

- No se presenta ningun error del sistema de RMH en los compartimientos para la selección del M1-MWP con cuentas pequeñas.

- Debido a las bajas cuentas las trayectorias en los detectores, éstas pueden reconstruirse con poca Ambigüedad y en detalle sin cortes en la multiplicidad.

\footnotetext{
${ }^{2}$ Pile-up efect
} 


\begin{tabular}{|c|c|c|}
\hline \hline BEAM & BLANCO & ENERGIA $(\mathrm{GeV})$ \\
\hline Pos & Be & 572 \\
Neg & Be & 650 \\
Pos & $\mathrm{C}$ & $375,250,500$ \\
Neg & $\mathrm{C}$ & 570 \\
Neg & $\mathrm{Cu}$ & 650,570 \\
Neg & $\mathrm{CH} 2$ & 650,570 \\
Neg & $\mathrm{Al}$ & 650,570 \\
\hline \hline
\end{tabular}

Tabla 4.2: Condiciones del haz

\subsubsection{Ejecución de la toma de datos}

La toma de datos para la medición de la sección transversal con el haz negativo (con partículas negativas) ocurrió en el periodo 21.7.97 - 31.7.97. La toma de datos con el haz positivo ocurrió en 3.7.97, 11.7.97 y 18.8.97. Debido a las condiciones experimentales convenientes, estos datos también se usaron para el estudio de la polarización en la lproducción de hiperones. Esto tenía como consecuencia menos favorable para este trabajo que el ángulo de incidencia del haz de protones de $800 \mathrm{G}$ eV en la blanco de producción fue cambiado a menudo, por lo que los expedientes de datos presentan distintas condiciones de haz (tabla 4.2).

La intensidad en el haz de hiperones logro bajarse, disminuyendo la intensidad del haz de protones primario y modificando el ángulo de incidencia de este con el blanco de producción de hiperones, esto último era además necesario para la medición de la polarización de los hiperones [23]. La intensidad del haz fue seleccionada de tal manera que pasen tantas partículas por Spill directamente por el espectrómetro, como eventos se puedan escribir del DAQ por minuto en las cintas, de modo que el ángulo de incidencia del haz sobre el blanco de producción de hiperones fue de $\pm 2 \mathrm{mrad}$ con una intensidad media del haz de protones de $5 \times 10^{10}$ protones/spill, con lo que se observó una tarifa de $5 \times 10^{4}-6 \times 10^{4} \mathrm{~T} 0 / \mathrm{spill}$.

Para la medición de la sección eficaz no se necesita información de todos los detectores, por lo tanto estos detectores se deben quitar de la secuencia de datos del DAQ, para alcanzar 
otra reducción del tamaño del evento. Para maximizar la capacidad de escribir, el DAQ uso de manera simultánea 4 mecanismos de impresión en cinta, logrando grabar 16 millones de eventos.

Vale de paso mencionar que durante estas corridas especiales, el imán de M1 estuvo apagado para optimizar los mecanismos de reconstrucción de las trayectorias de $\Sigma-$.

\subsection{Análisis de los datos}

Para la realización de este trabajo de tesis se utilizó SOAP en el análisis de los datos, hechando mano principalmente de la parte User de este mismo programa. El User, como ya se mencionó antes es ecrito por el propio usuario (yo, en este caso), para la manipulación de la información obtenida en el análisis realizado por el resto del programa.

El User fué utilizado con el fin de llenar histogramas con la información requerida, para esto el User incluye información que generan principalmente los paquetes tracking y vertex. Esta información es guardada en variables globales que después son usadas en User a través de archivos tipo include, siendo los más importantes los siguientes:

- tseg_bk.inc: Aqui se encuentra la información de todos los parámetros para cada segmento en cada espectrómetro, donde entendemos por segmento a un segmento de recta parametrizada por dos pendientes y dos intercepciones.

- trk_bk.inc: En este archivo se encuentra la información de los ajustes de las trayectorias y de sus momentos.

- vtx2_bk.inc: Contiene la información de todos los parámetros de ajuste a todas las hipotesis de un vértice, donde entendemos por vértice a un conjunto de dos o más trayectorias que ajustan a cierta hipótesis compartiendo un punto común en el espacio.

- beam_bk.inc: Contiene información sobre distintas rutinas que tratan de encontrar el segmento correspondiente al haz. 


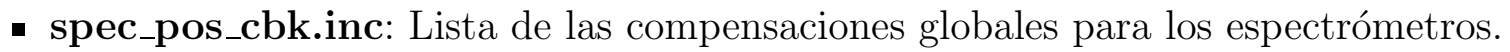

- btr_evnt.inc: Contiene toda la información que genera el Detector de Radiación de Transición (BTRD).

- user_par.inc: Define algunos parámetros necesarios para controlar la subrutina User.

- idump_bk.inc: Contiene las variables cuya información puede tener salida en pantalla o un archivo de texto.

- mcmatch_par.inc: Este archivo define los parámetros necesarios para acceder a los cortes y controles de la subrutina MCMATCH.

Fue necesario incluir este archivo, asi como la subrutina debido a que en algun punto del análisis fue necesario hacer simulación, para hacer pruebas al software, encontrar y corregir errores, y medir la aceptancia en ángulo del experimento.

En User se filtra la información usando algunos cortes locales, basados en los siguientes requerimientos:

- Sólo se analizaron eventos con un segmento de haz.

- Sólo se analizaron eventos con más de una trayectoria en la región del vértice, de modo que en casi todos los casos se pudiera reconstruir el vértice

- Se requería diferenciar entre bariones y mesones, para esto se aplicó un corte basado en los planos prendidos en el BTRD para cada partícula.

- Se requería conocer el momento de cada trayectoria y de ser posible identificarla con la información proveniente del RICH.

En User se separa memoria para cada histograma y se llena. Existen histogramas que no contienen directamente información acerca de las multiplicidades en los eventos pero que son utilizados como control. Estos histogramas son los siguientes: 
- Coordenadas del vértice primario. Con éste histograma se puede reproducir la posición exacta del blanco y la información cotenida es aplicada para eliminar los eventos cuyo vértice primario se encuentra fuera de esta región.

- Momento del haz. Dadas las variadas condiciones en que se tomaron los datos, la distribución de momento de las partículas provenientes del haz secundario varía de una sección de los datos a otra. Usando estos histogramas se encontraron diferencias en cuanto a estas distribuciones entre lo que se lista en las bases de datos y los archivos, pudiendose así corregir errores en en análisis.

- Planos prendidos en BTRD. La Información aquí contenida es útil al aplicar los cortes que determinan que partícula es considerada meson o barion, asi como para determinar la contaminación de otras partículas debido al translape de las distribuciones $^{3}$.

Sin duda los histogramas más importantes son aquellos que contienen la información acerca de las multiplicidades, como tales y en función de su momento:

- Multiplicidad en la región del vértice.

- Segmentos en la región del vértice con momento.

- Multiplicidad en la región del vértice como función de momento.

- Multiplicidad en la región del vértice como función del tipo de partícula.

- Distribución angular de los eventos.

\footnotetext{
${ }^{3}$ Sección 2.4 .1
} 


\section{Capítulo 5}

\section{Resultados}

En este Capítulo se mostrarán los resultados obtenidos a partir del análisis explicado en el capítulo anterior.

Los histogramas, en su mayoría muestran la información por separado dependiendo de si el la partícula proveniente del haz era un meson o un barion.

Primero se presentan los histogramas de control que verifican la posición en la coordenada z del blanco, se muestran para los cuatro casos posible

Despues se muestran los resultados de acuerdo a las condiciones presentes en el experimento durante en la toma de datos, en todos los casos siguiendo el mismo orden.

Primero se muestran histogramas generales de control:

La distribución de momento del haz

Los planos prendidos en el detector BTRD que nos muestra la composición bariónica y mesónica del haz para cada paquete de datos.

La coordenada en $z$ de la la posición del vértice primario de los eventos analizados para los cuales se aplico el corte de tomar solo aquellos cuya interacción ocurrió dentro de la región ocupada por el blanco

En los histogramas de resultados primero se muestran los de multiplicidades en la región del vértice, en primer lugar la distribución para todos los eventos y después para aquellos 
que tuvieron una interacción en la región del blanco, es decir, aquellos con multiplicidad $\geq 2$.

De todos aquellos eventos que tuvieron alguna interacción en la región del vértice en algunos casos las trayectorias de estas partículas resultantes alcanzan los imanes y se les puede medir el momento, pueden ser desde una sola hasta todas las partículas producidas en la interacción.

A continuación se mostrará para cada paquete de datos como es esta relación entre las partículas producidas en la interacción y aquellas a las que se les pudo medir el momento satisfactoriamente, asi como la relación entre la multiplicidad total y el momento reproducido de estos eventos.

Se muestran finalmente para cada paquete de datos las distribuciones de momento de las combinaciones útiles ${ }^{1}$, de multiplicidades y multilpicidades con momento medido, primero mostrando el momento total que se pudo reproducir de cada evento tomando en cuenta la carga de las partículas, después nuevamente todas las combinaciones pero mostrando solamente el modulo del momento de cada evento, y finalmente las combinaciones mostrando el momento de cada trayectoria.

Al final de este capítulo se muestra un estudio de la distribución angular de todos los eventos analizados. Este se realizó para conocer la distribución y compararla con los resultados obtenidos en el análisis Montecarlo de aceptancia en ángulo del experimento realizado también como parte de esta tesis y hacer las correcciones pertinentes.

\footnotetext{
${ }^{1}$ a juicio de la autora
} 


\subsection{Vértice primario (coordenada $z$ ) sin corte en la región del blanco}
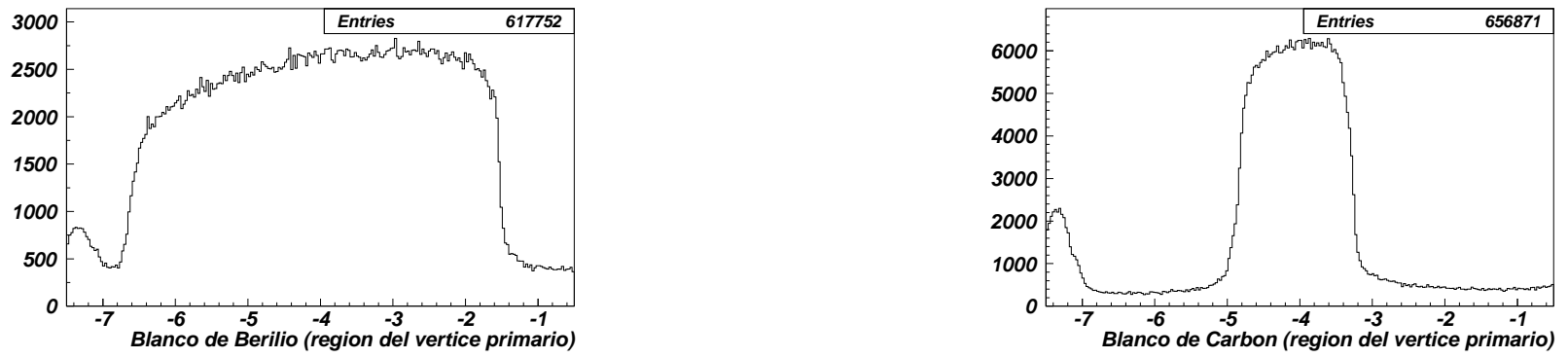

Figura 5.1: Izquierda: blanco de berilio. Derecha: blanco de carbón.
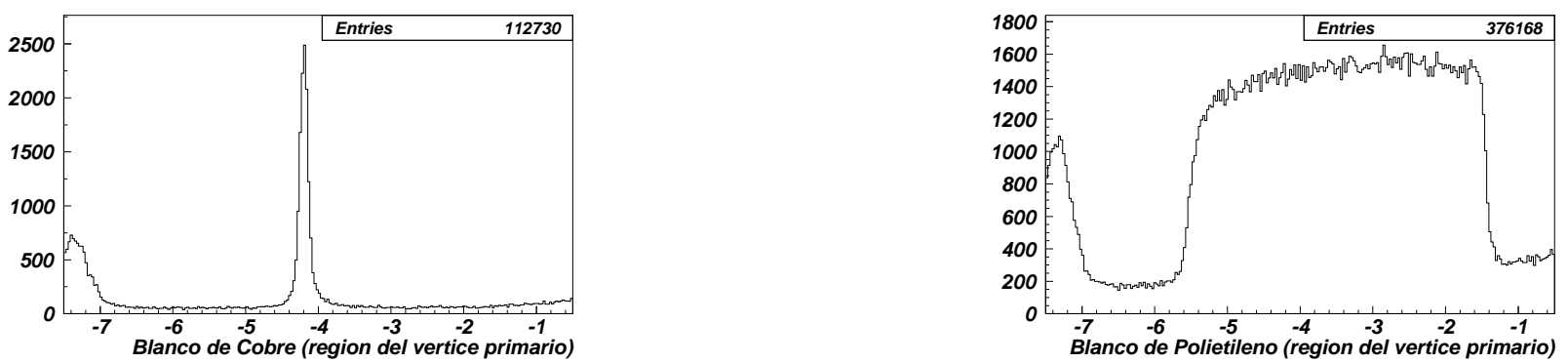

Figura 5.2: Izquierda: blanco de cobre. Derecha: blanco de Polietileno $\left(\mathrm{CH}_{2}\right)$. 


\subsection{Haz de polaridad negativa, con momento $650 \mathrm{GeV}$, con blanco de producción para el haz secundario de berilio}

\subsubsection{Histogramas de control}
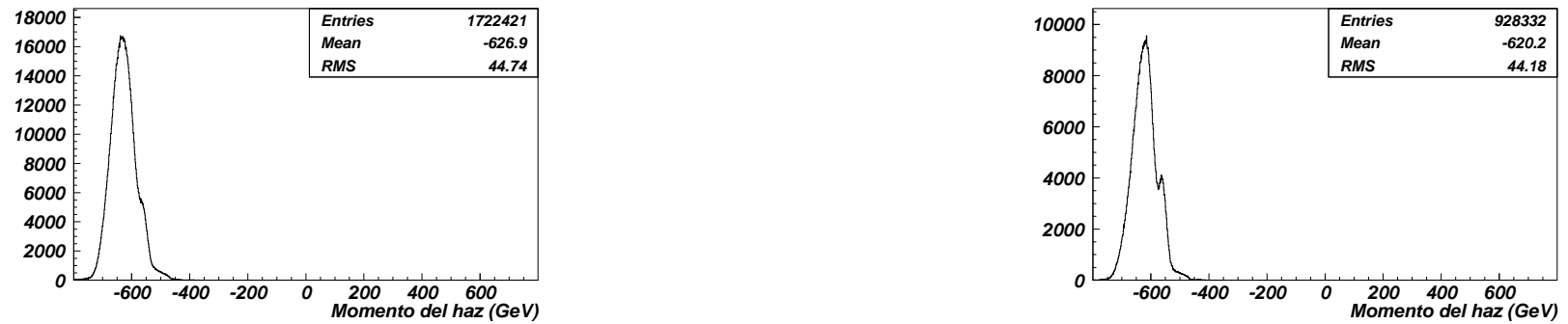

Figura 5.3: Distribución de momento del haz primario. Izquierda: bariones. Derecha: mesones (neg $650 \mathrm{Be})$.

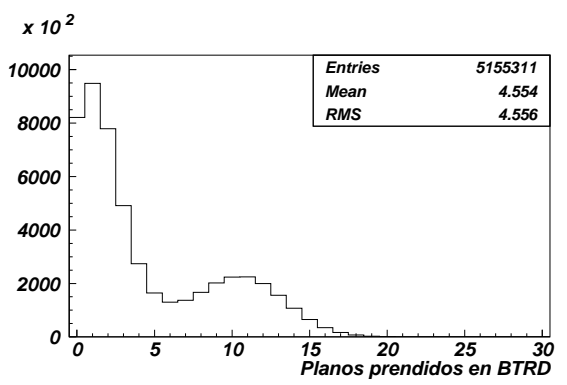

Figura 5.4: Planos prendidos en BTRD. Proporción bariónica y mesónica del haz primario.(neg $650 \mathrm{Be})$
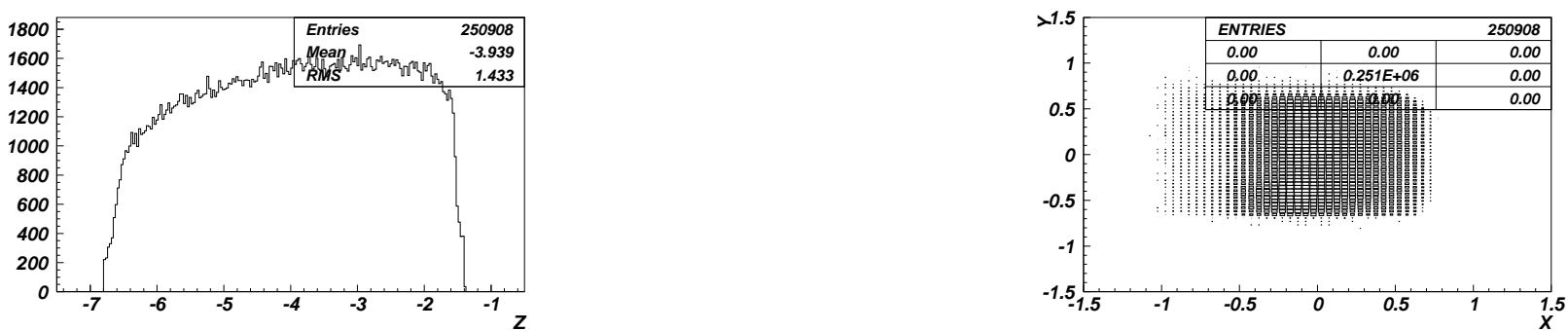

Figura 5.5: Vértice primario. Izquierda: coordenada z. Derecha: proyección x,y (neg 650 Be). 


\subsubsection{Multiplicidad en la región del vértice}
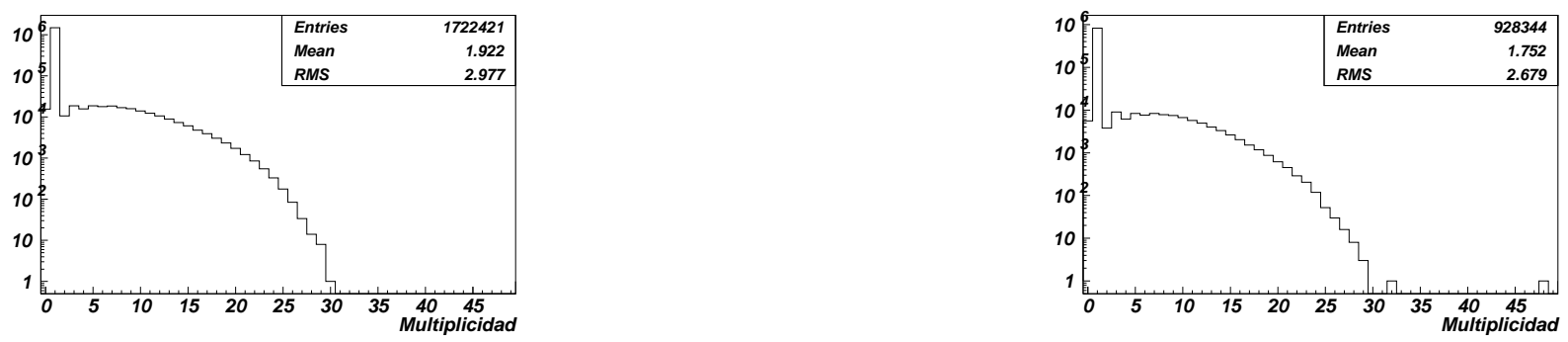

Figura 5.6: Multiplicidad total. Izquierda: haz de bariones. Derecha: haz de mesones (neg $650 \mathrm{Be})$.
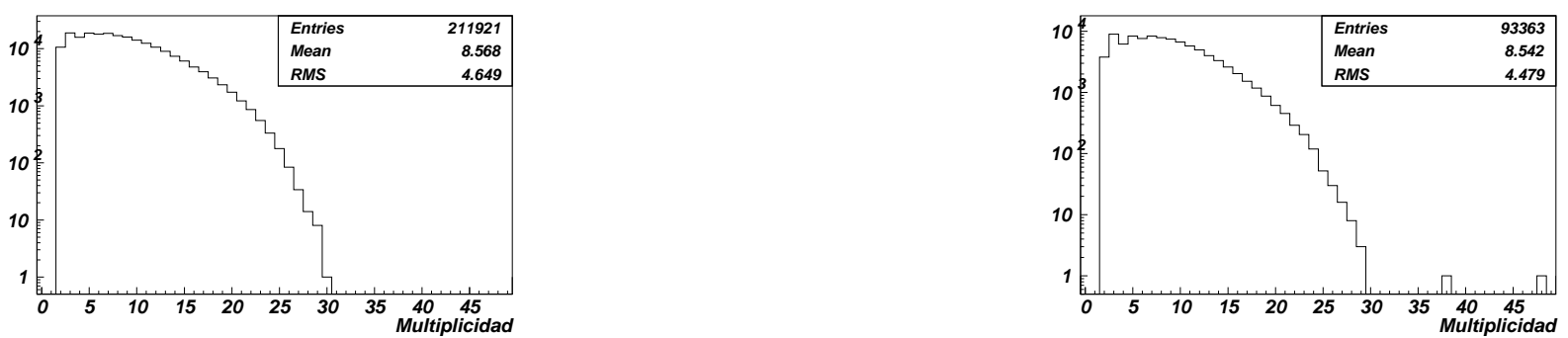

Figura 5.7: Multiplicidad en eventos con más de una trayectoria en la región del vértice. Izquierda: haz de bariones. Derecha: haz de mesones (neg $650 \mathrm{Be}$ ). 


\subsubsection{Distribuciones de multiplicidad y momento}
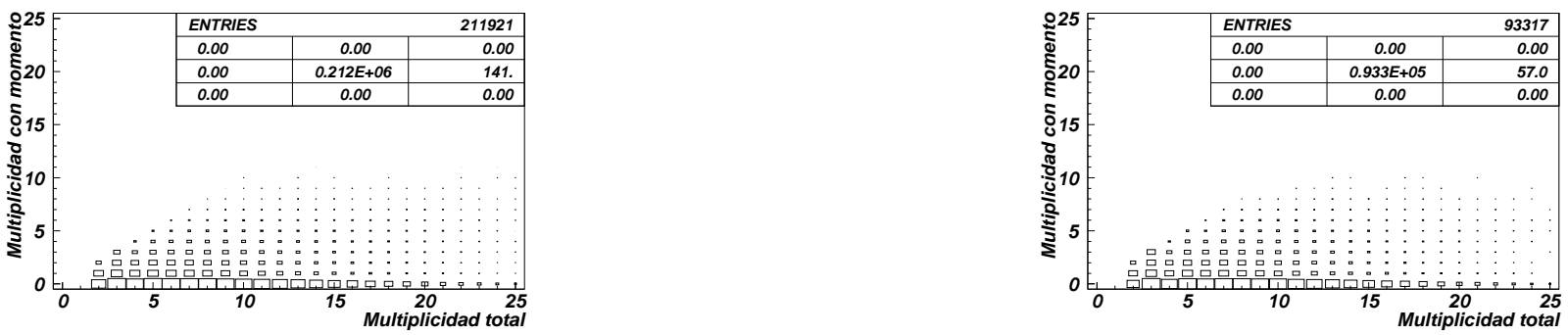

Figura 5.8: Multiplicidad total contra multiplicidad con momento medido. Izquierda: haz de bariones. Derecha: haz de mesones (neg $650 \mathrm{Be}$ ).
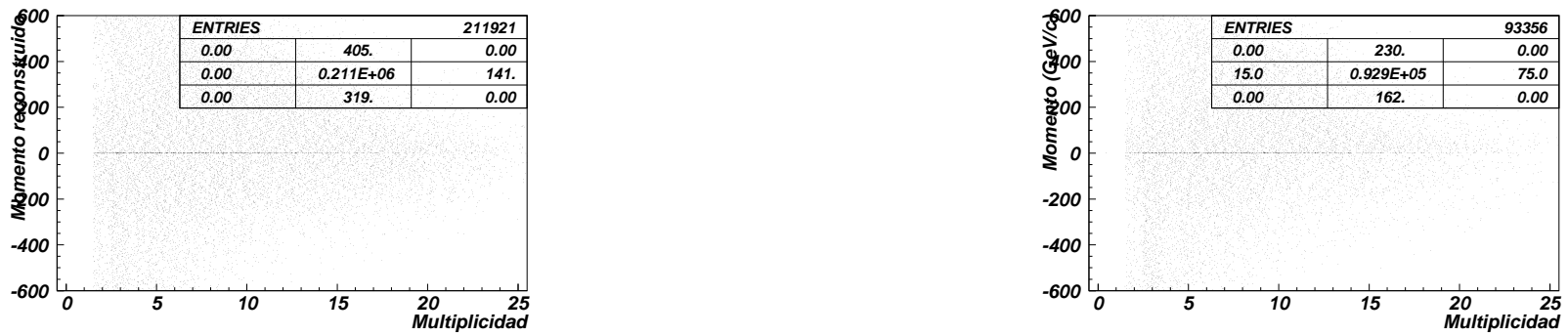

Figura 5.9: Multiplicidad contra momento.Izquierda: haz de bariones. Derecha: haz de mesones (neg $650 \mathrm{Be}$ ). 
Distribuciones de momento total para eventos producidos por un haz de bariones
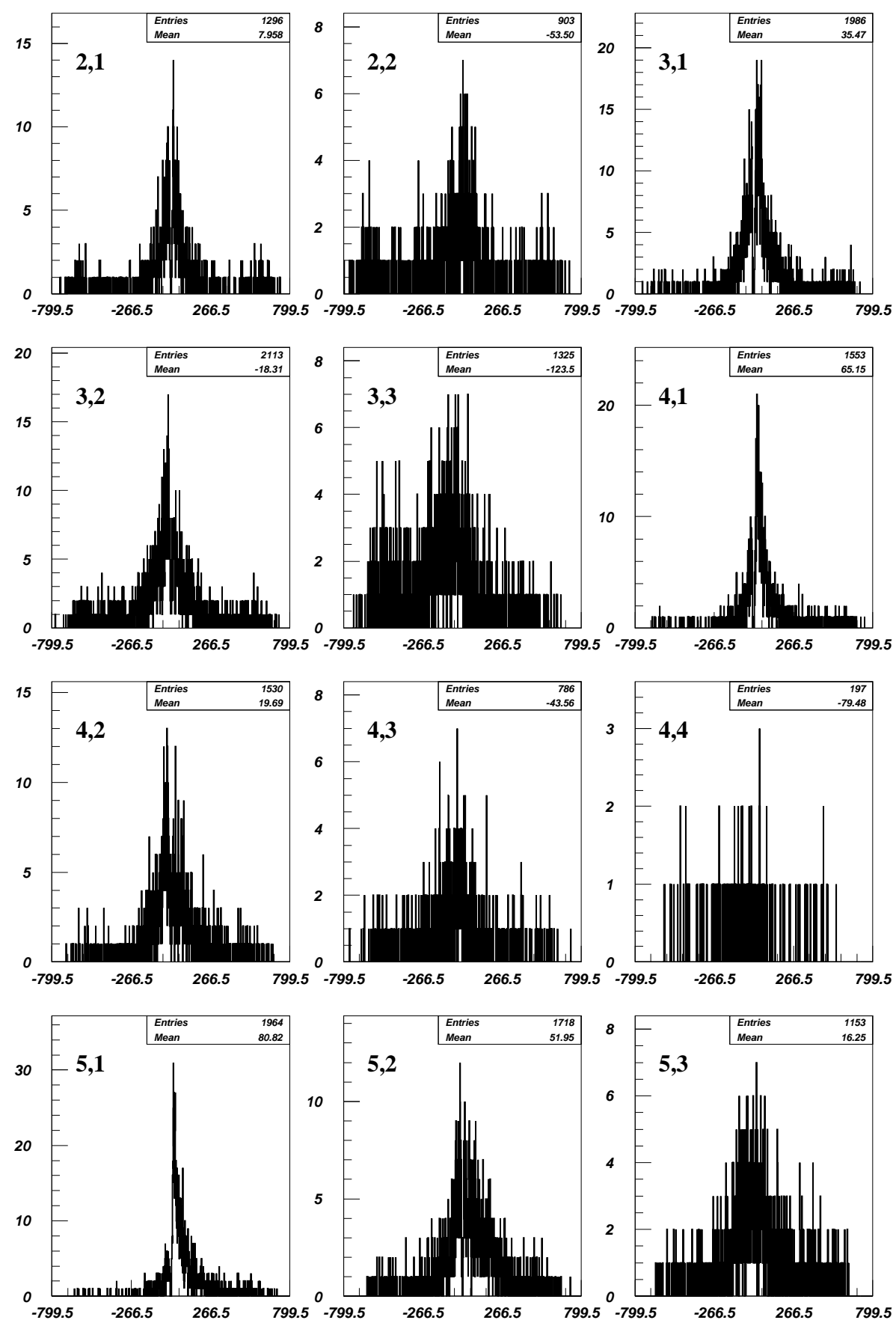

Figura 5.10: Distribuciones de momento. El primer indice: multiplicidad total, el segundo: multiplicidad con momento (neg $650 \mathrm{Be}$ ). 

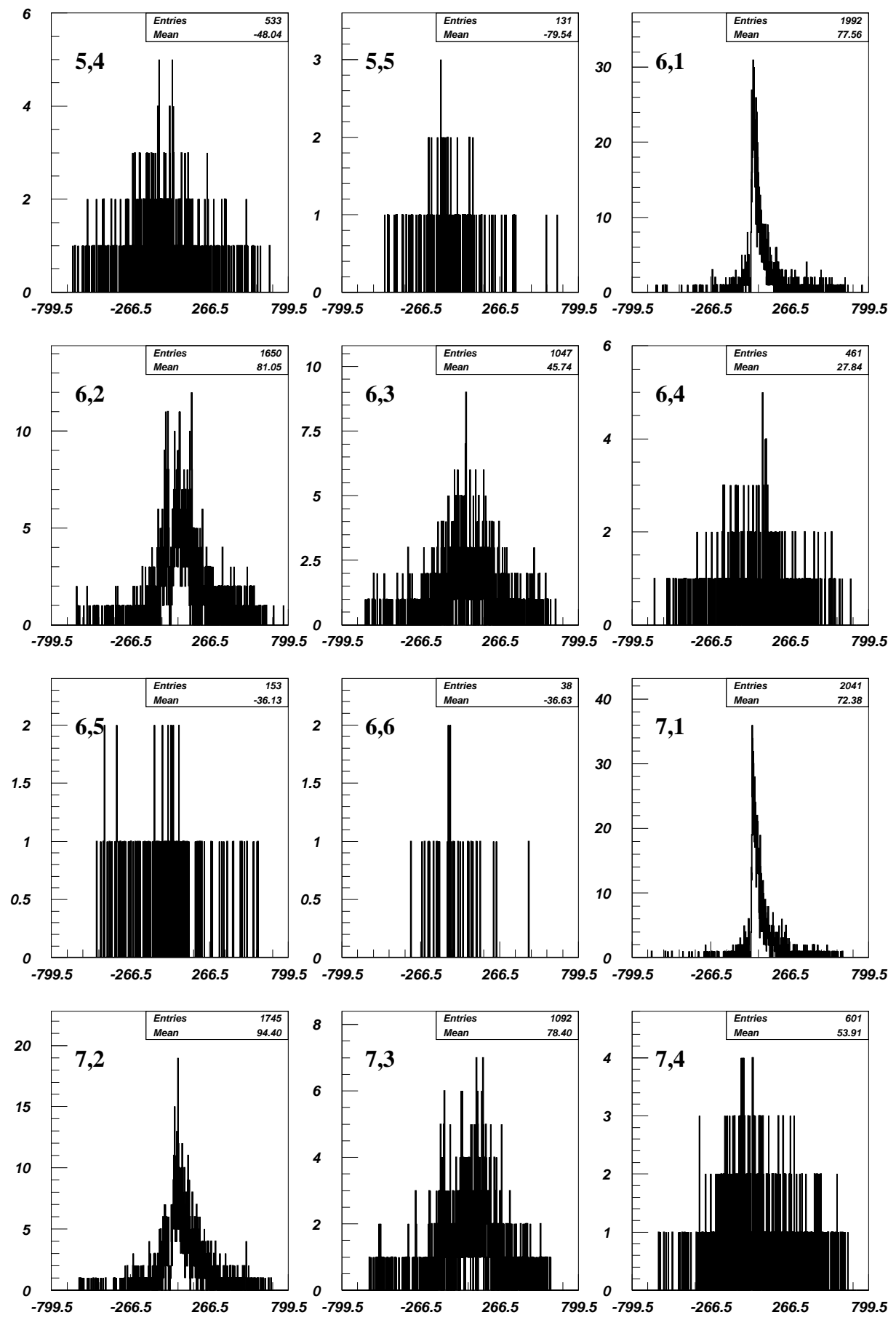

Figura 5.11: Distribuciones de momento. El primer indice: multiplicidad total, el segundo: multiplicidad con momento (neg $650 \mathrm{Be}$ ). 

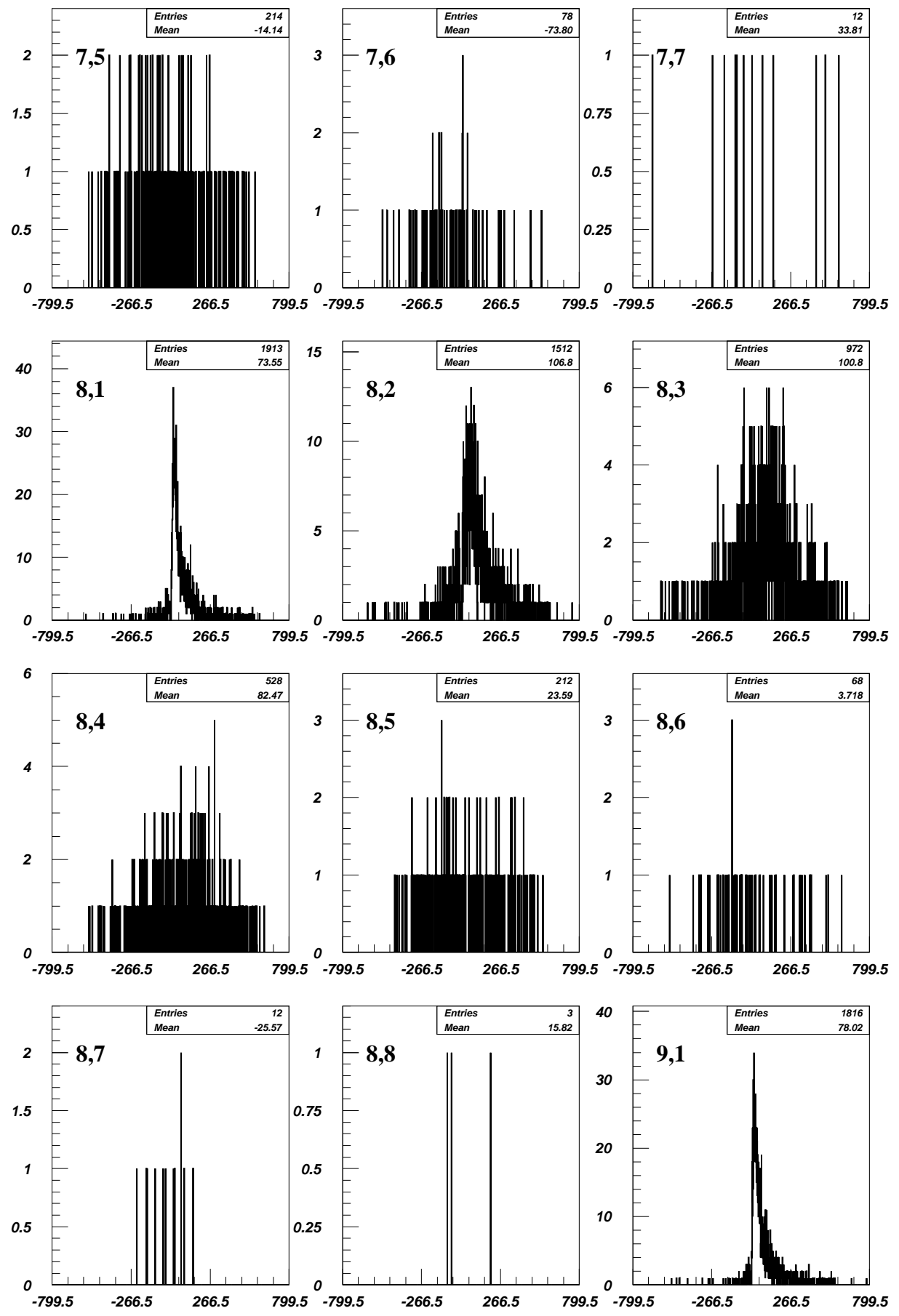

Figura 5.12: Distribuciones de momento. El primer indice: multiplicidad total, el segundo: multiplicidad con momento (neg $650 \mathrm{Be}$ ) 

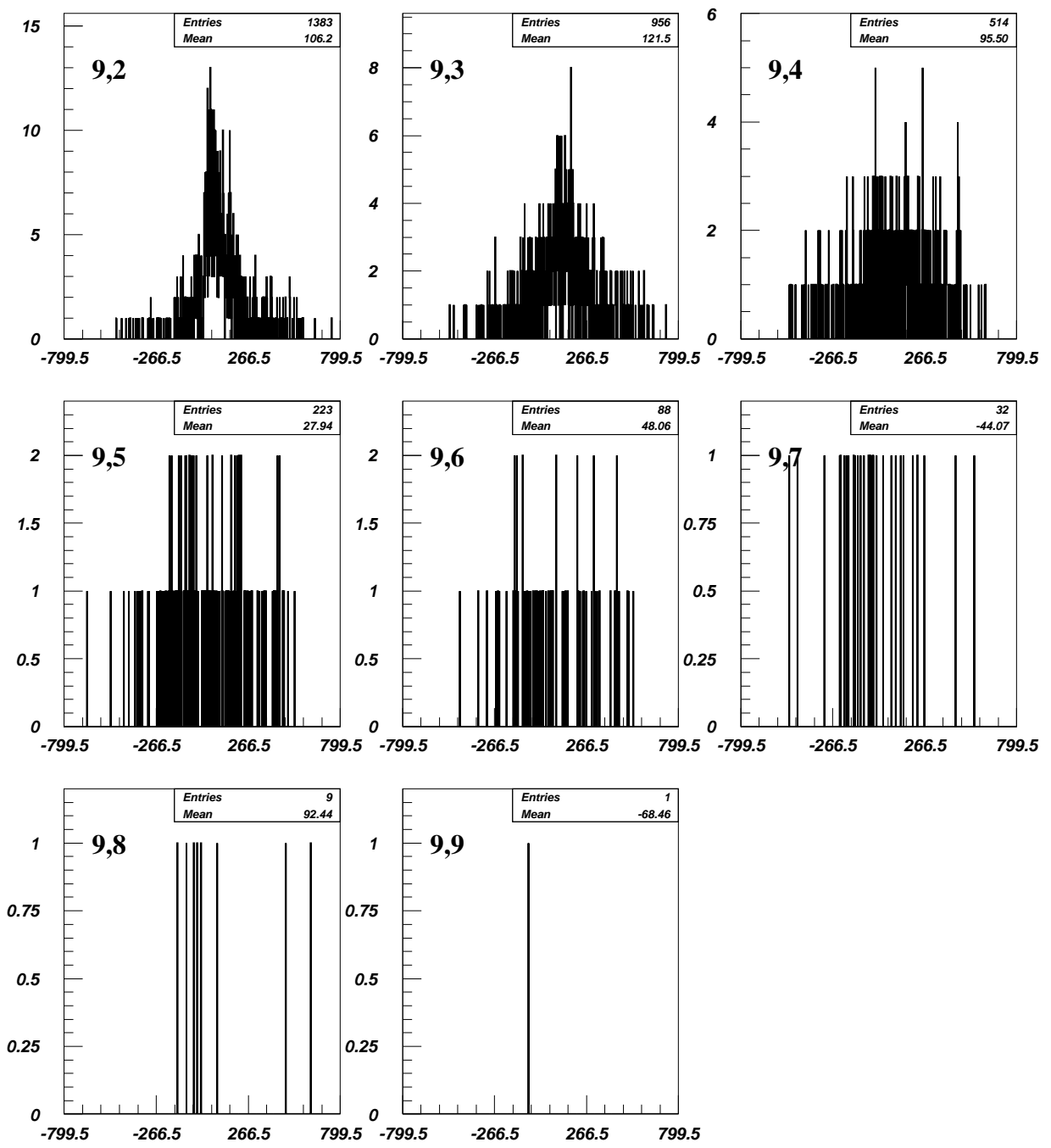

Figura 5.13: Distribuciones de momento. El primer indice: multiplicidad total, el segundo: multiplicidad con momento (neg $650 \mathrm{Be}$ ). 
Distribuciones de momento total para eventos producidos por un haz de mesones
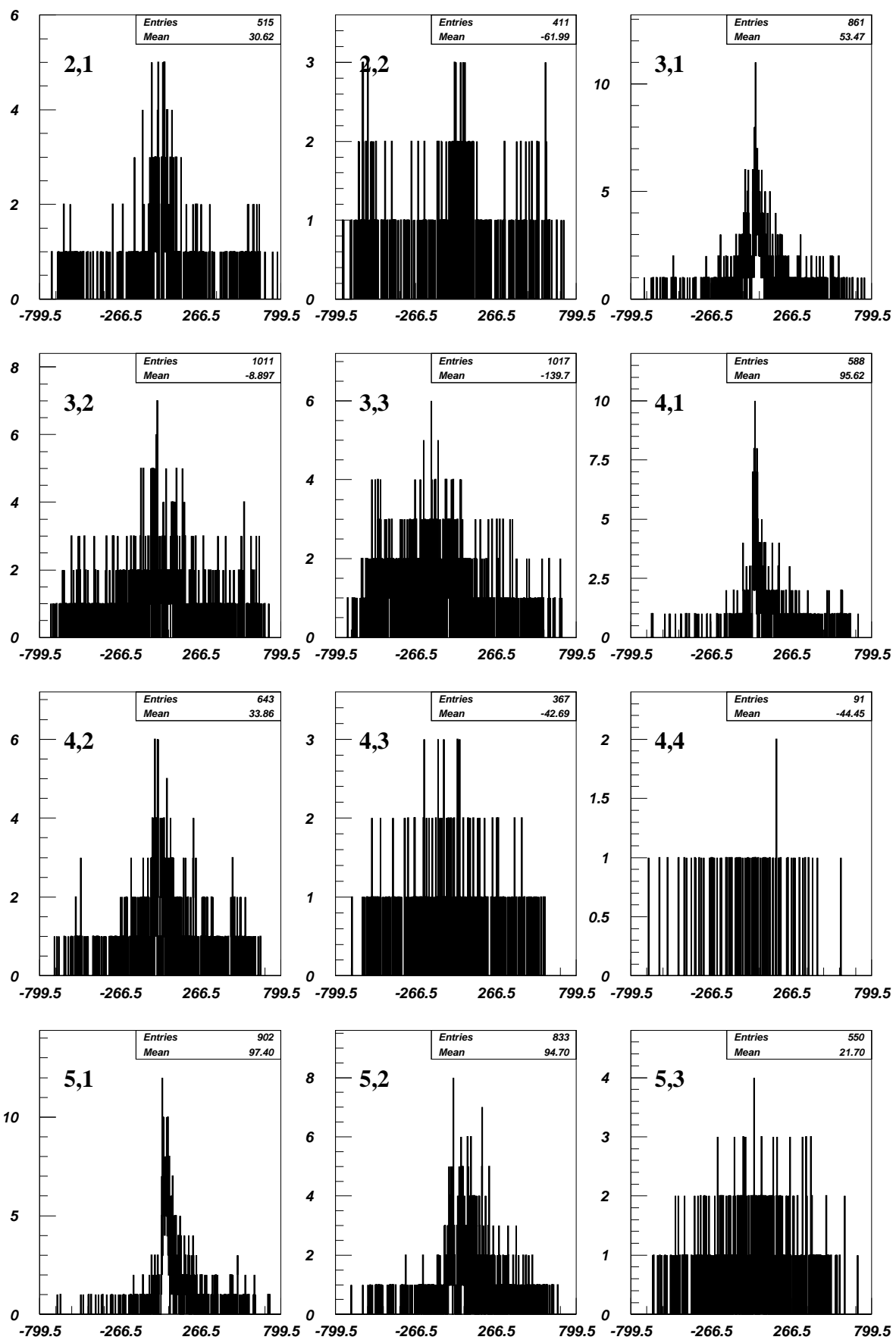

Figura 5.14: Distribuciones de momento. El primer indice: multiplicidad total, el segundo: multiplicidad con momento (neg $650 \mathrm{Be}$ ). 

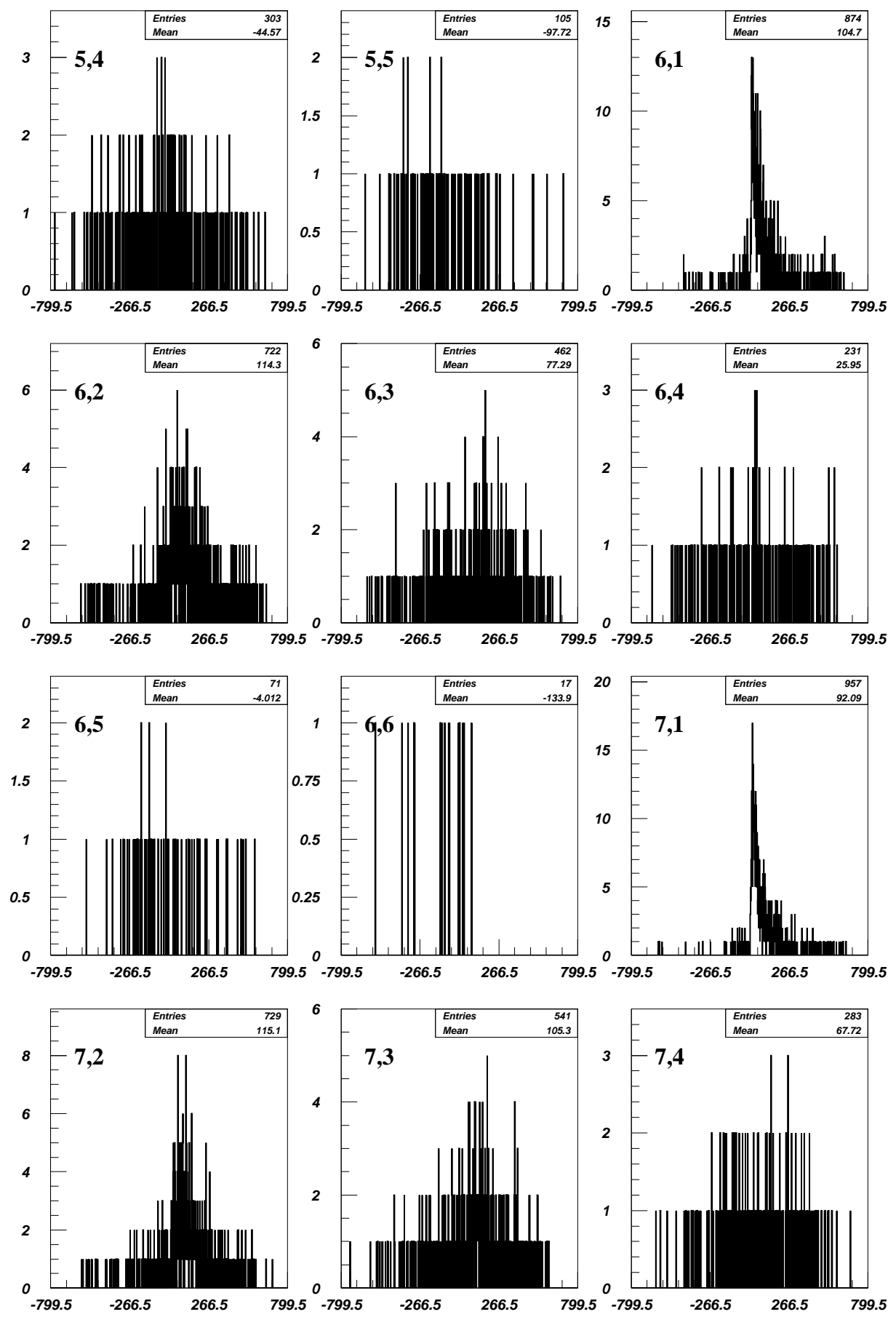

Figura 5.15: Distribuciones de momento. El primer índice: multiplicidad total, el segundo: multiplicidad con momento (neg $650 \mathrm{Be}$ ). 

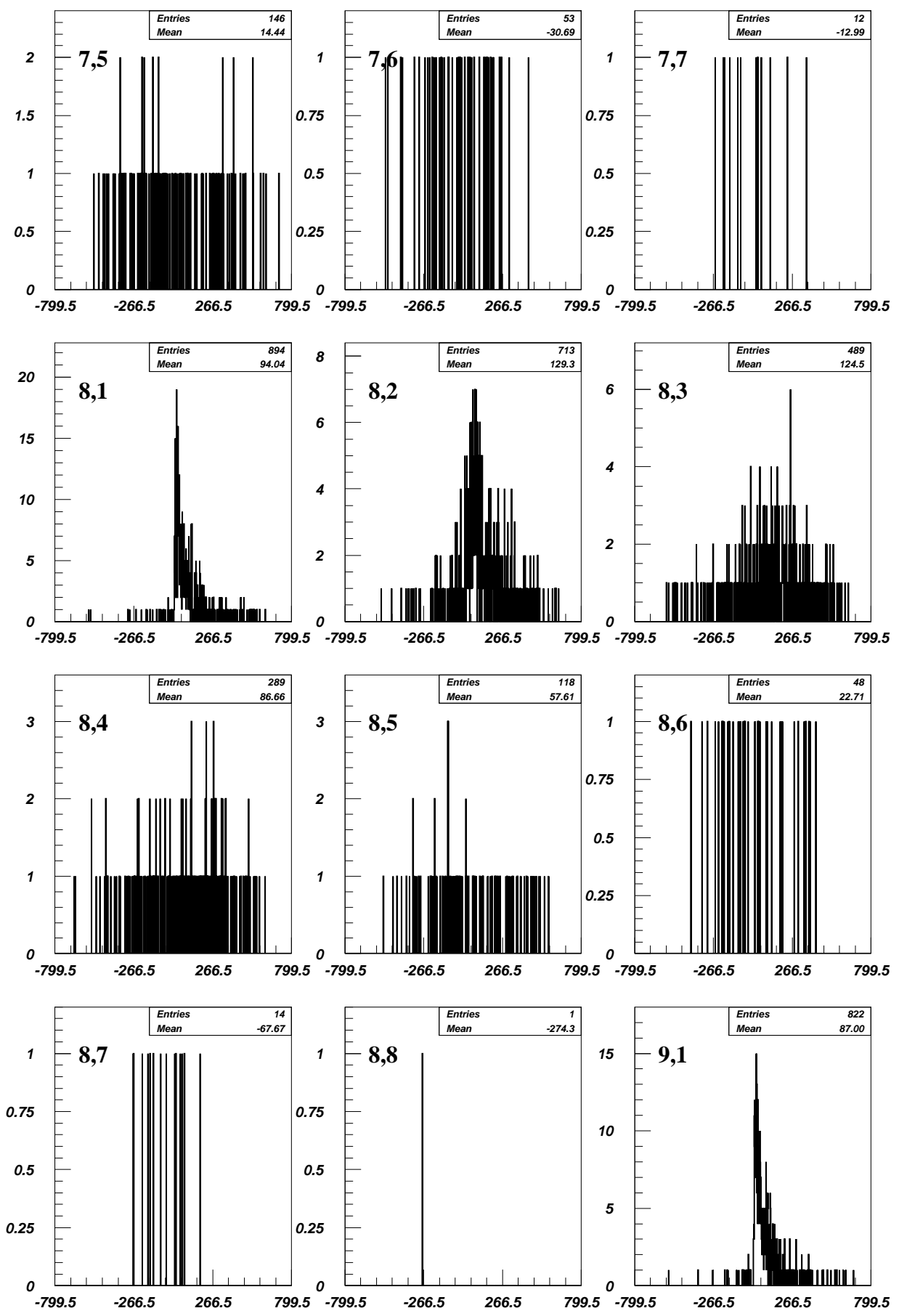

Figura 5.16: Distribuciones de momento. El primer índice: multiplicidad total, el segundo: multiplicidad con momento (neg $650 \mathrm{Be}$ ). 

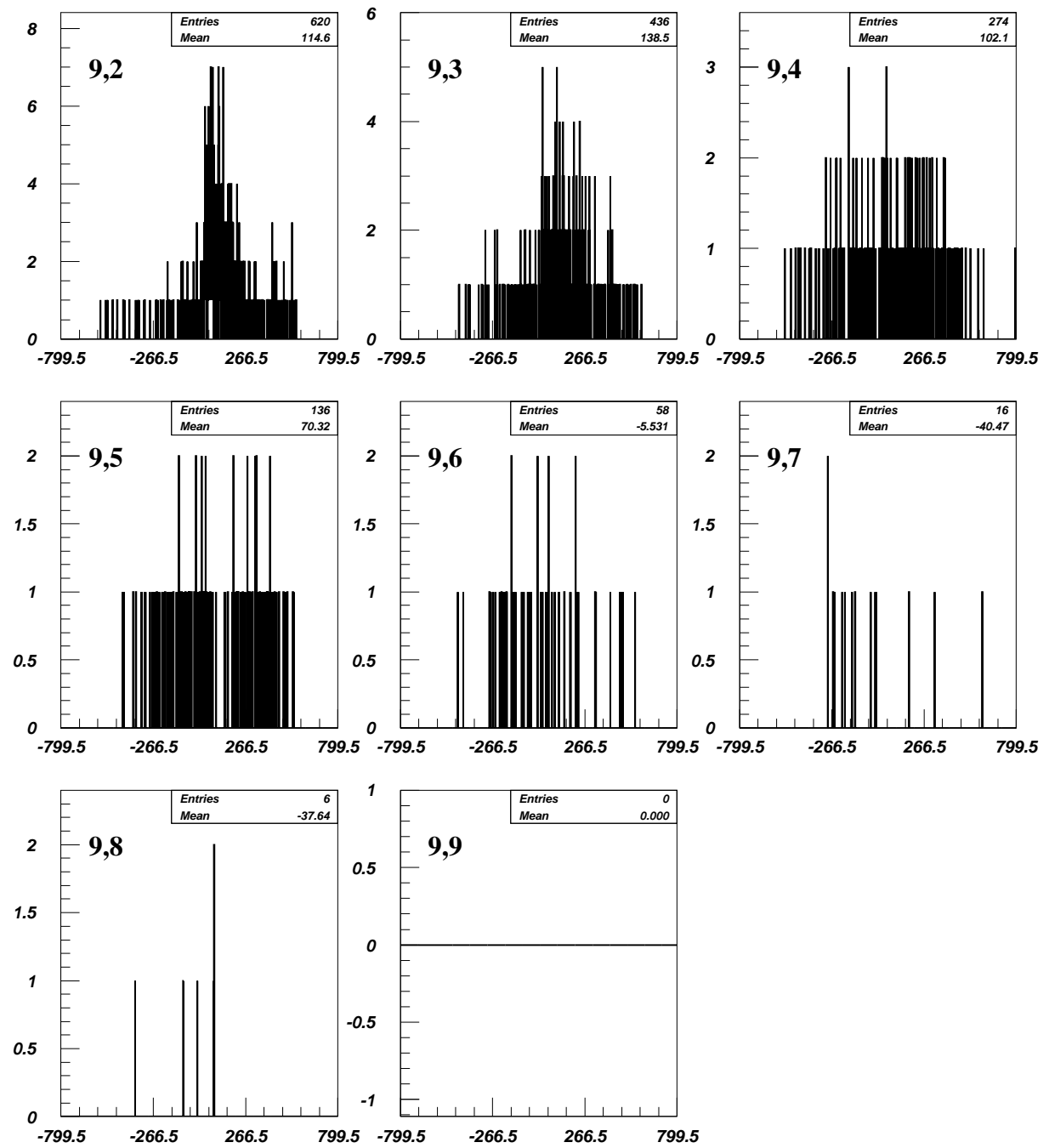

Figura 5.17: Distribuciones de momento. El primer índice: multiplicidad total, el segundo: multiplicidad con momento (neg $650 \mathrm{Be}$ ). 
Distribuciones del valor absoluto del momento total para eventos producidos por un haz de bariones
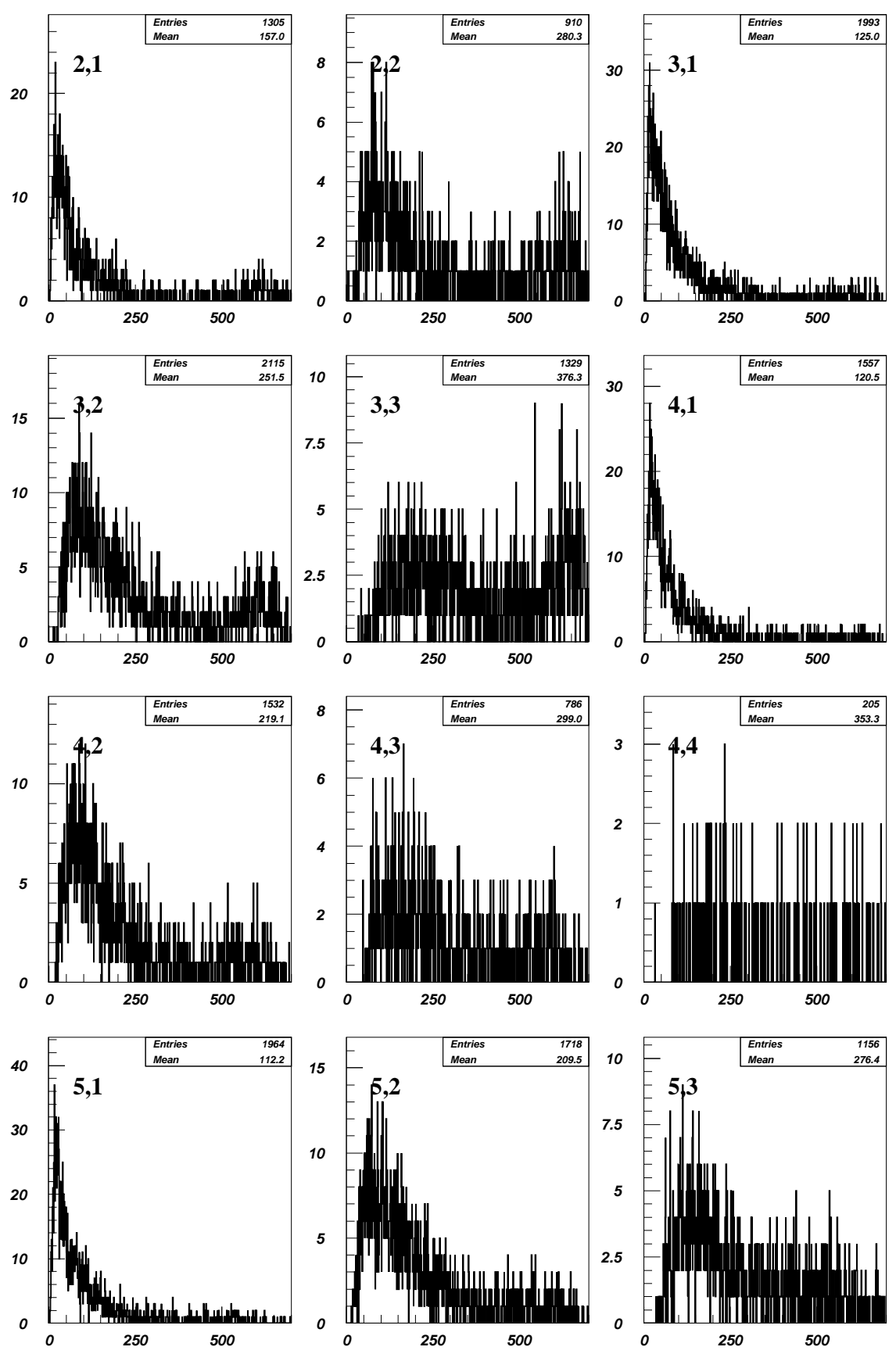

Figura 5.18: Distribuciones de momento. El primer indice: multiplicidad total, el segundo: multiplicidad con momento (neg $650 \mathrm{Be}$ ). 

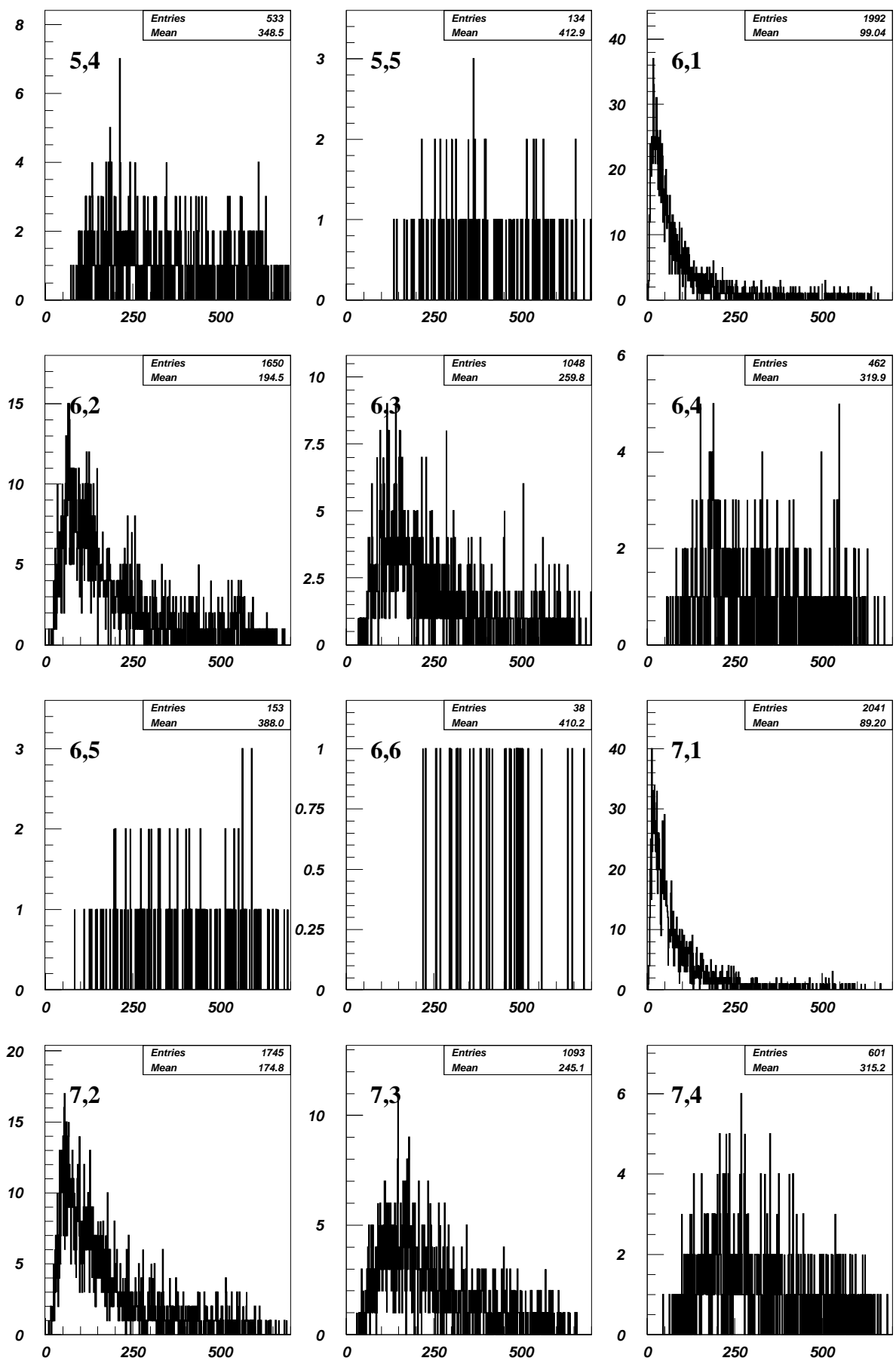

Figura 5.19: Distribuciones de momento. El primer índice: multiplicidad total, el segundo: multiplicidad con momento (neg $650 \mathrm{Be}$ ). 

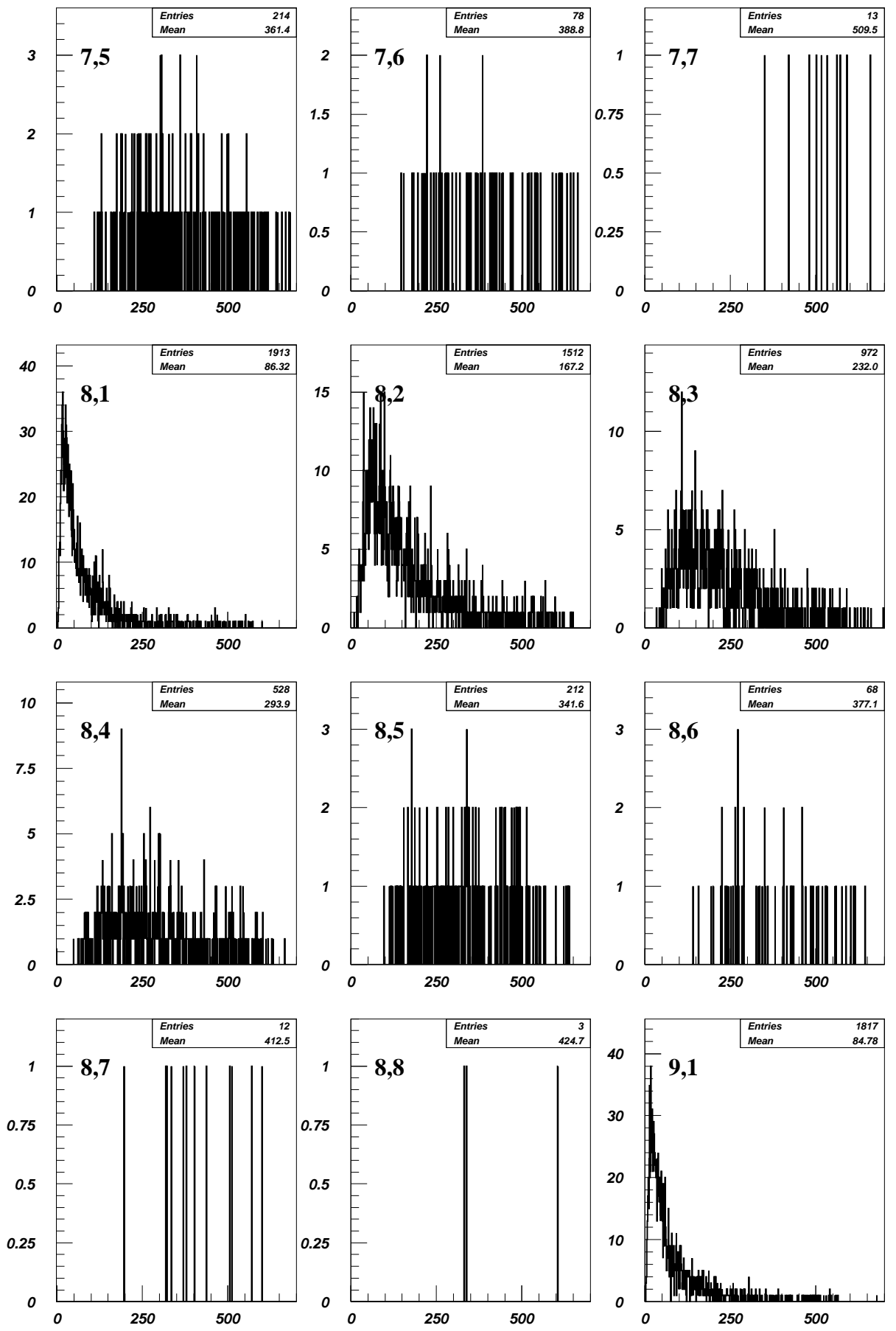

Figura 5.20: Distribuciones de momento. El primer índice: multiplicidad total, el segundo: multiplicidad con momento (neg $650 \mathrm{Be}$ ). 

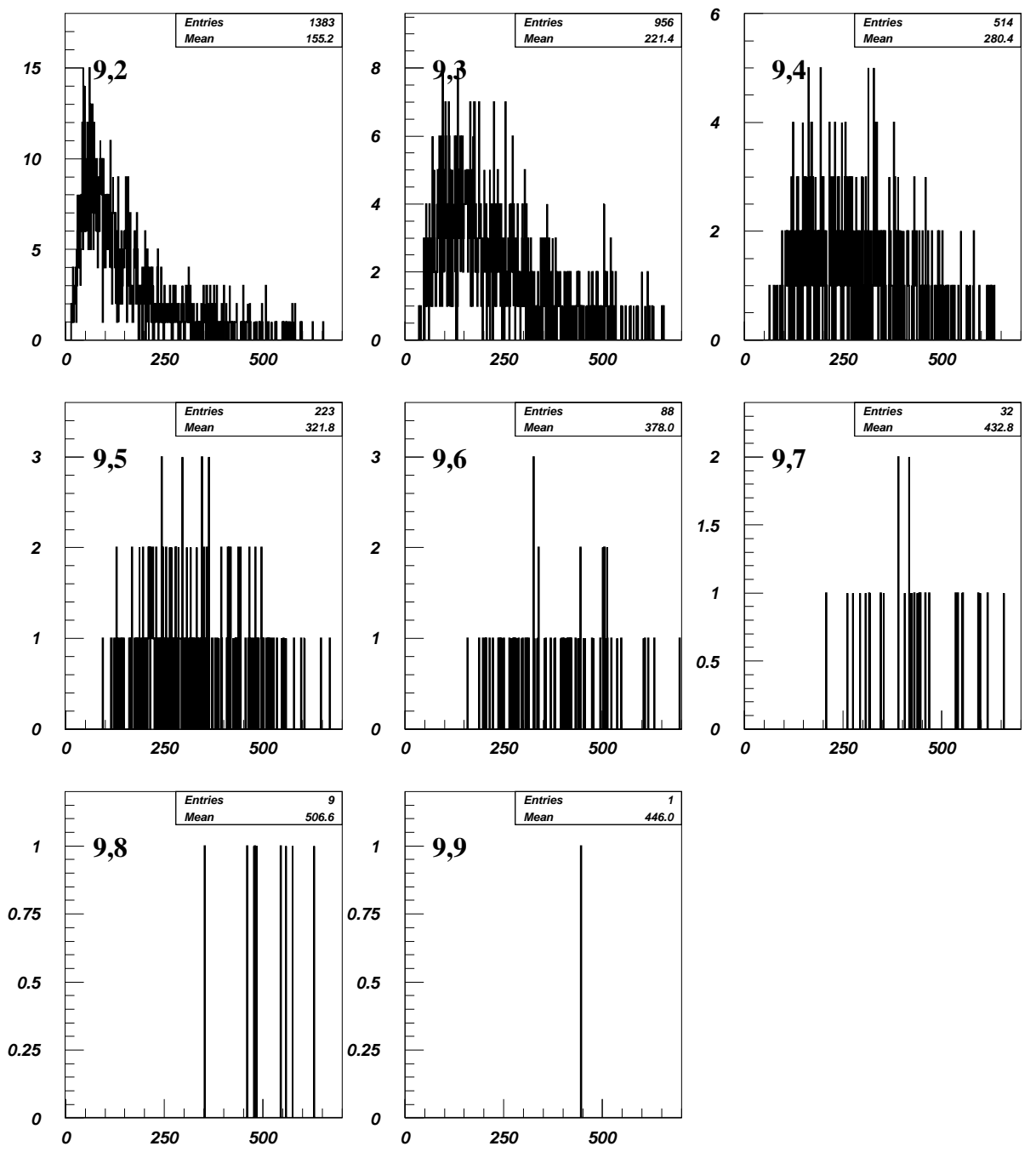

Figura 5.21: Distribuciones de momento. El primer índice: multiplicidad total, el segundo: multiplicidad con momento (neg $650 \mathrm{Be}$ ). 
Distribuciones del valor absoluto del momento total para eventos producidos por un haz de mesones
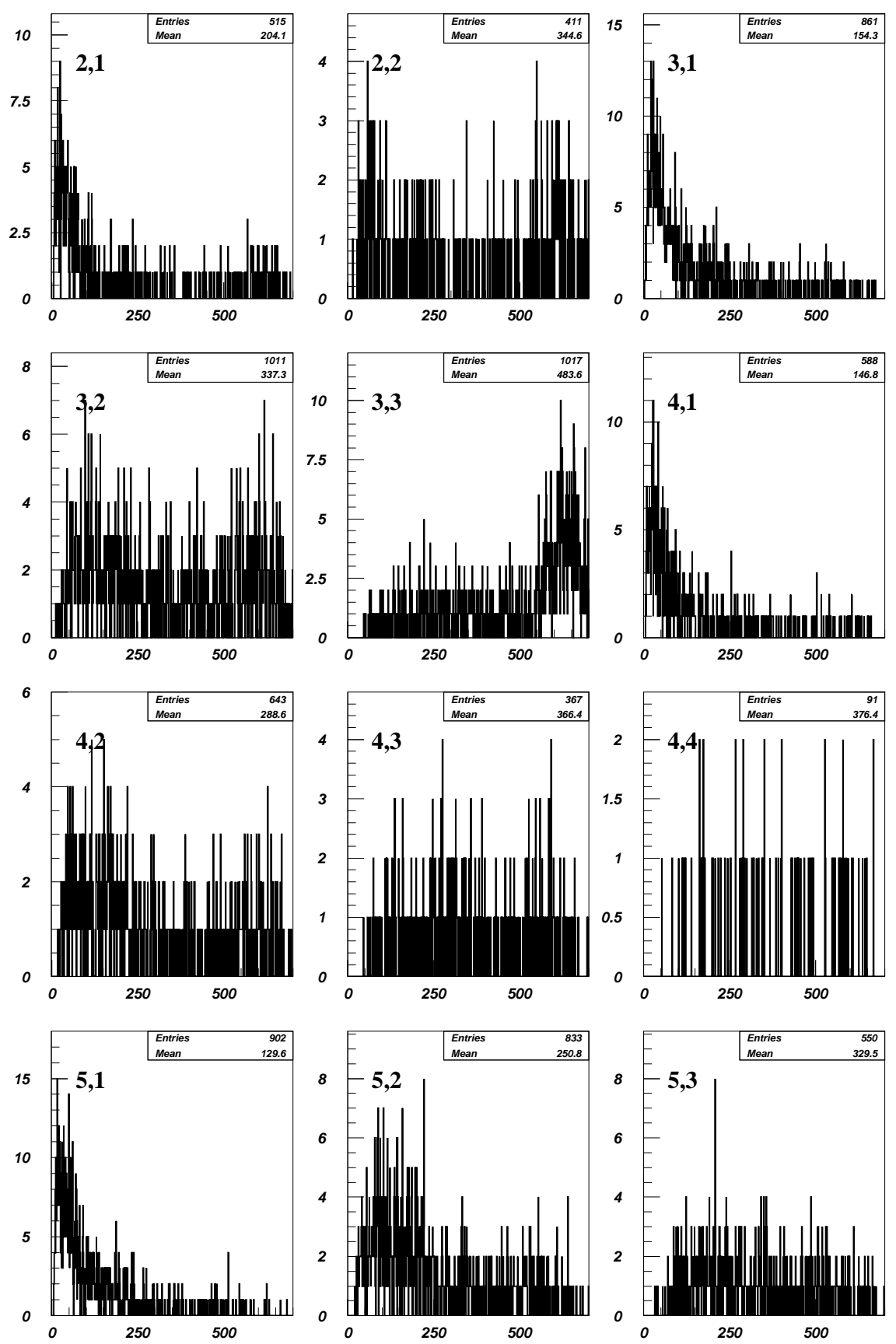

Figura 5.22: Distribuciones de momento. El primer indice: multiplicidad total, el segundo: multiplicidad con momento (neg $650 \mathrm{Be}$ ). 

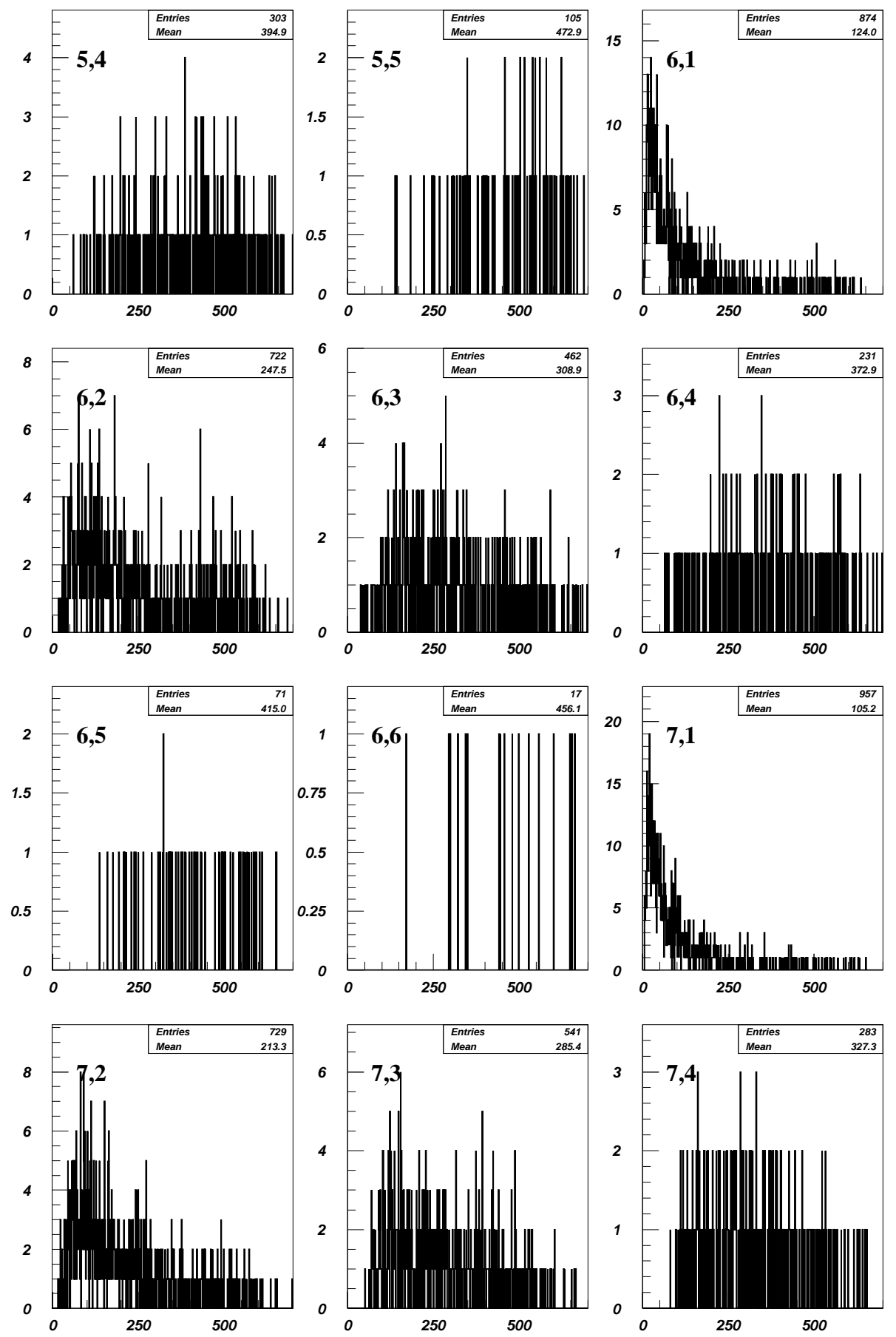

Figura 5.23: Distribuciones de momento. El primer índice: multiplicidad total, el segundo: multiplicidad con momento (neg $650 \mathrm{Be}$ ). 

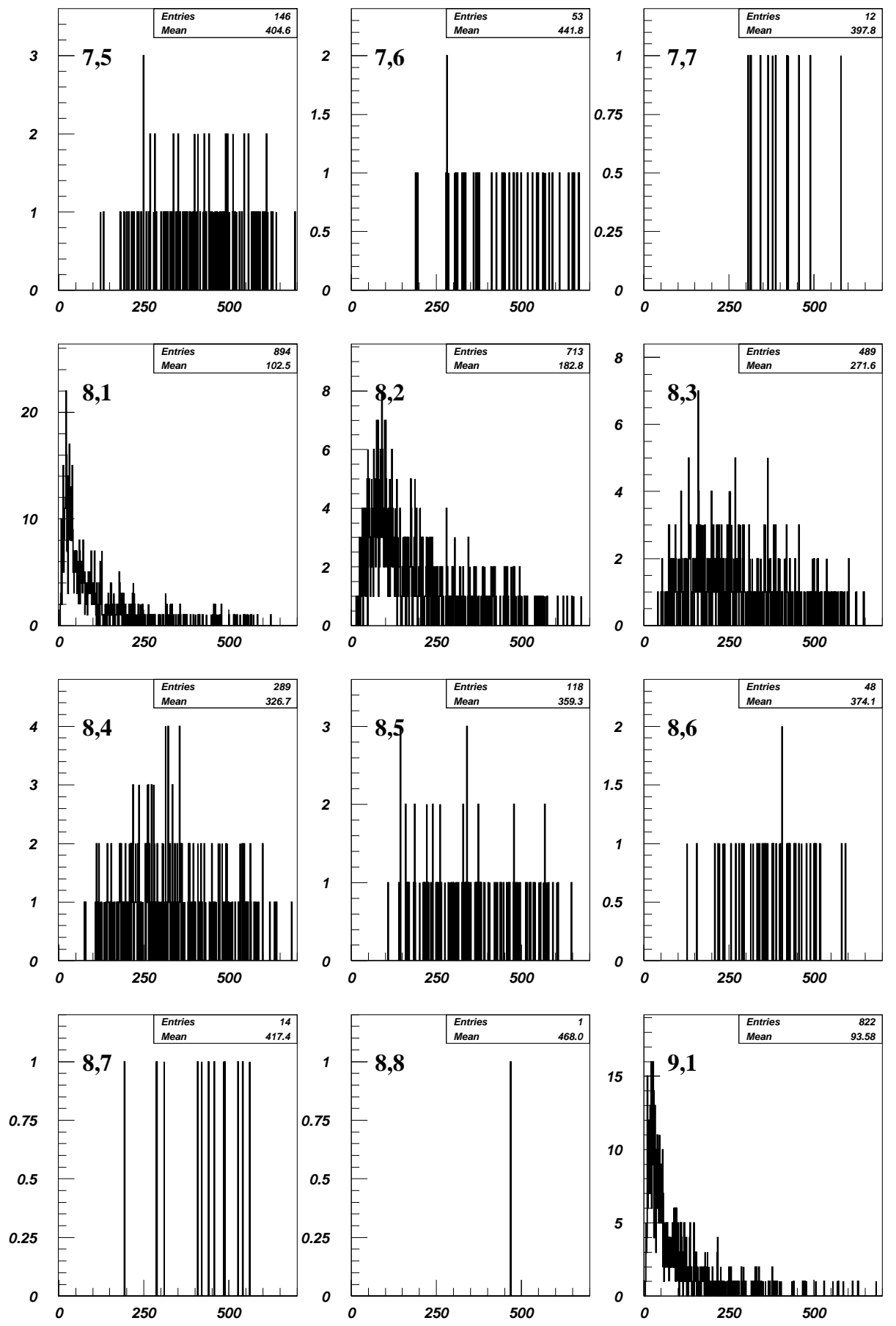

Figura 5.24: Distribuciones de momento. El primer índice: multiplicidad total, el segundo: multiplicidad con momento (neg $650 \mathrm{Be}$ ). 

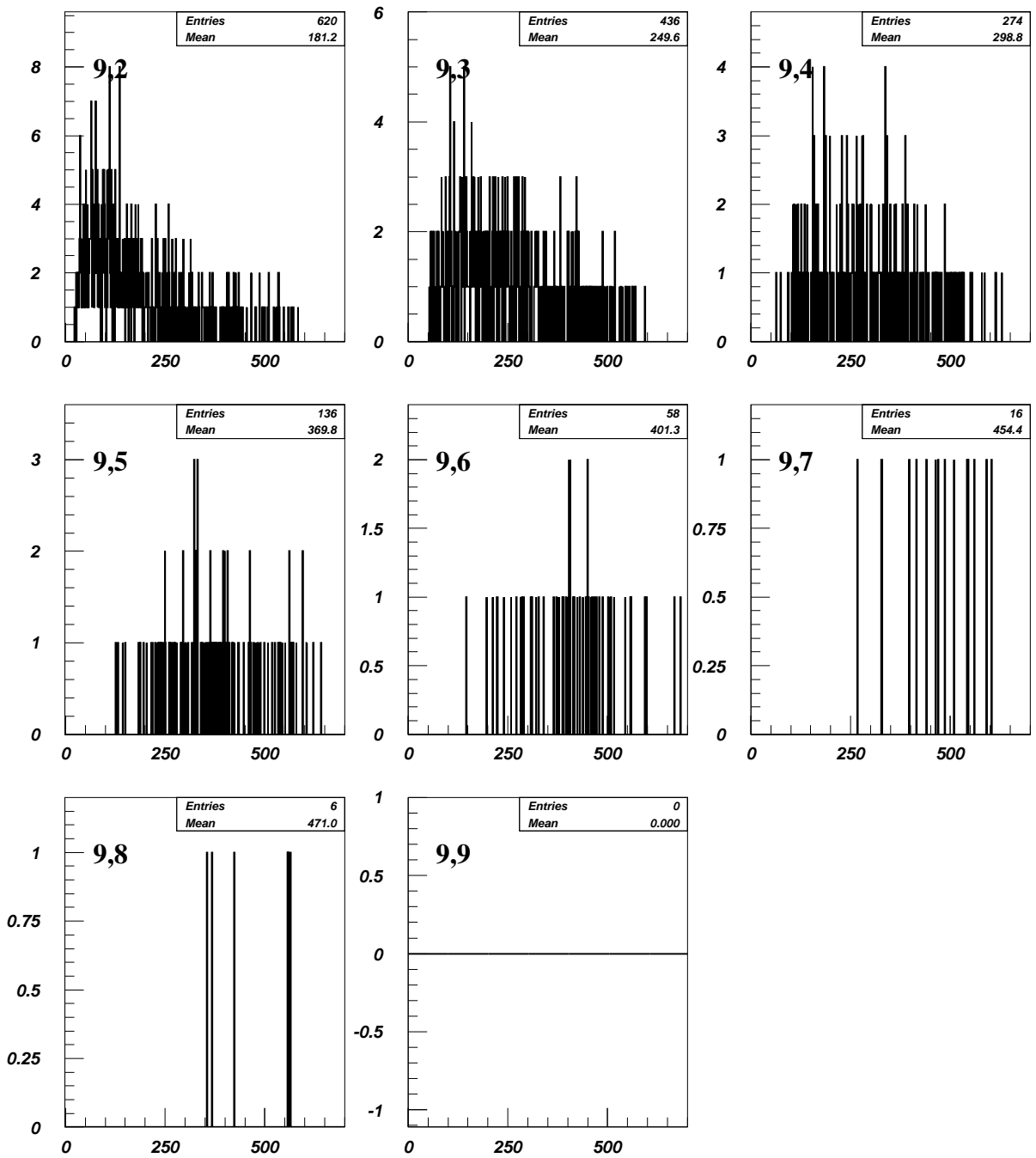

Figura 5.25: Distribuciones de momento. El primer índice: multiplicidad total, el segundo: multiplicidad con momento (neg $650 \mathrm{Be}$ ). 
Distribuciones del momento de las trayectorias para eventos producidos por un haz de bariones
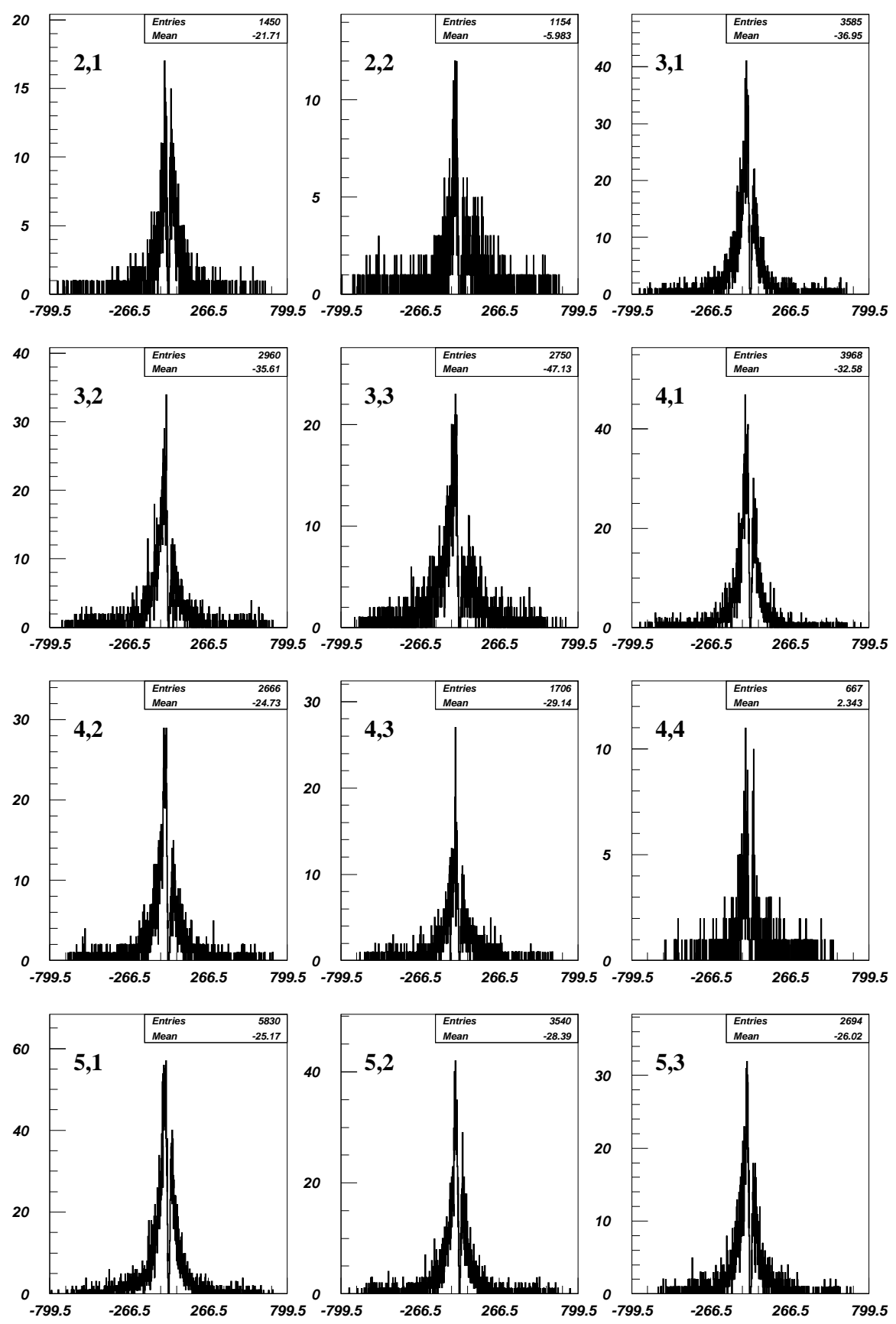

Figura 5.26: Distribuciones de momento. El primer indice: multiplicidad total, el segundo: multiplicidad con momento (neg $650 \mathrm{Be}$ ). 

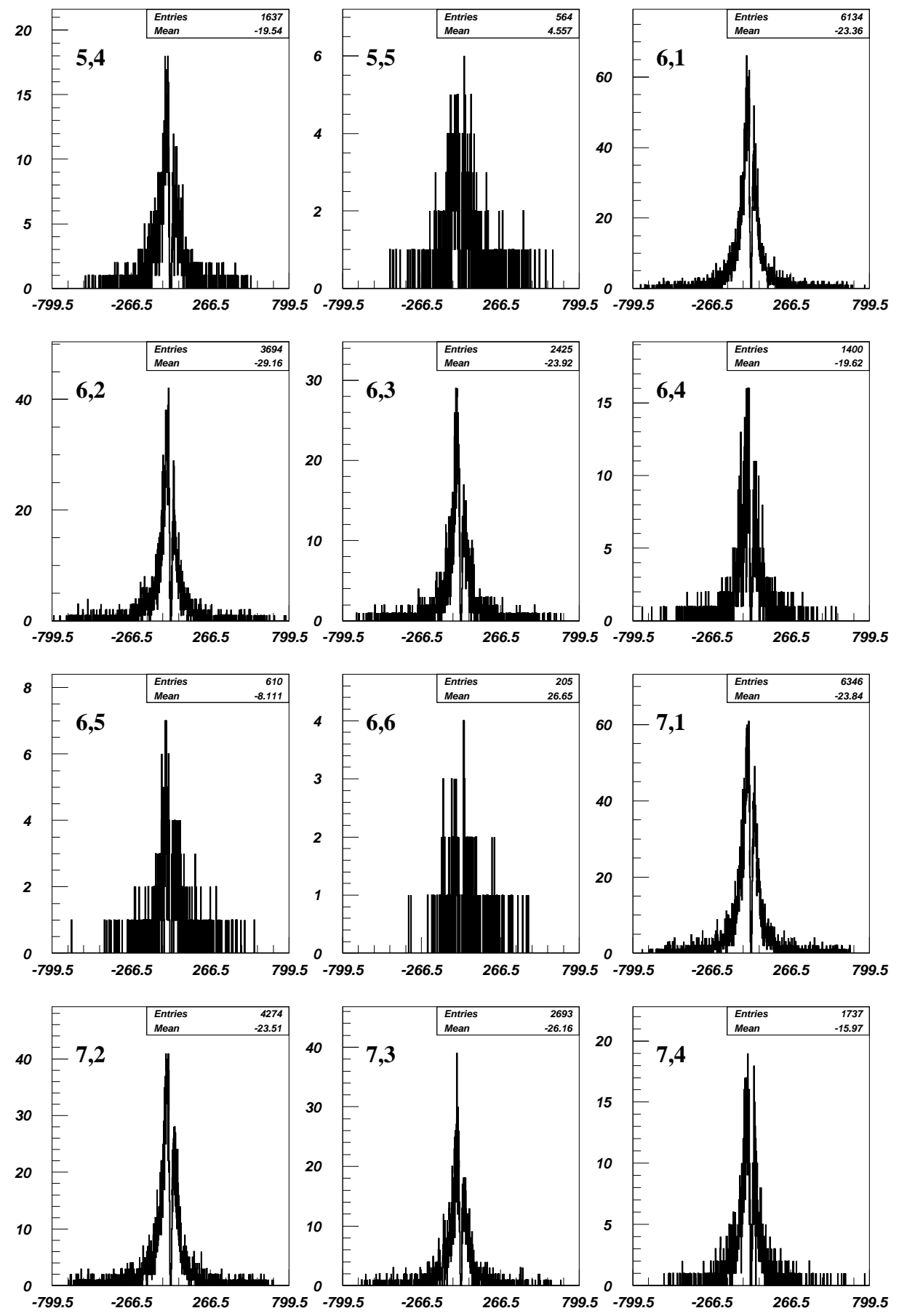

Figura 5.27: Distribuciones de momento. El primer índice: multiplicidad total, el segundo: multiplicidad con momento (neg $650 \mathrm{Be}$ ). 

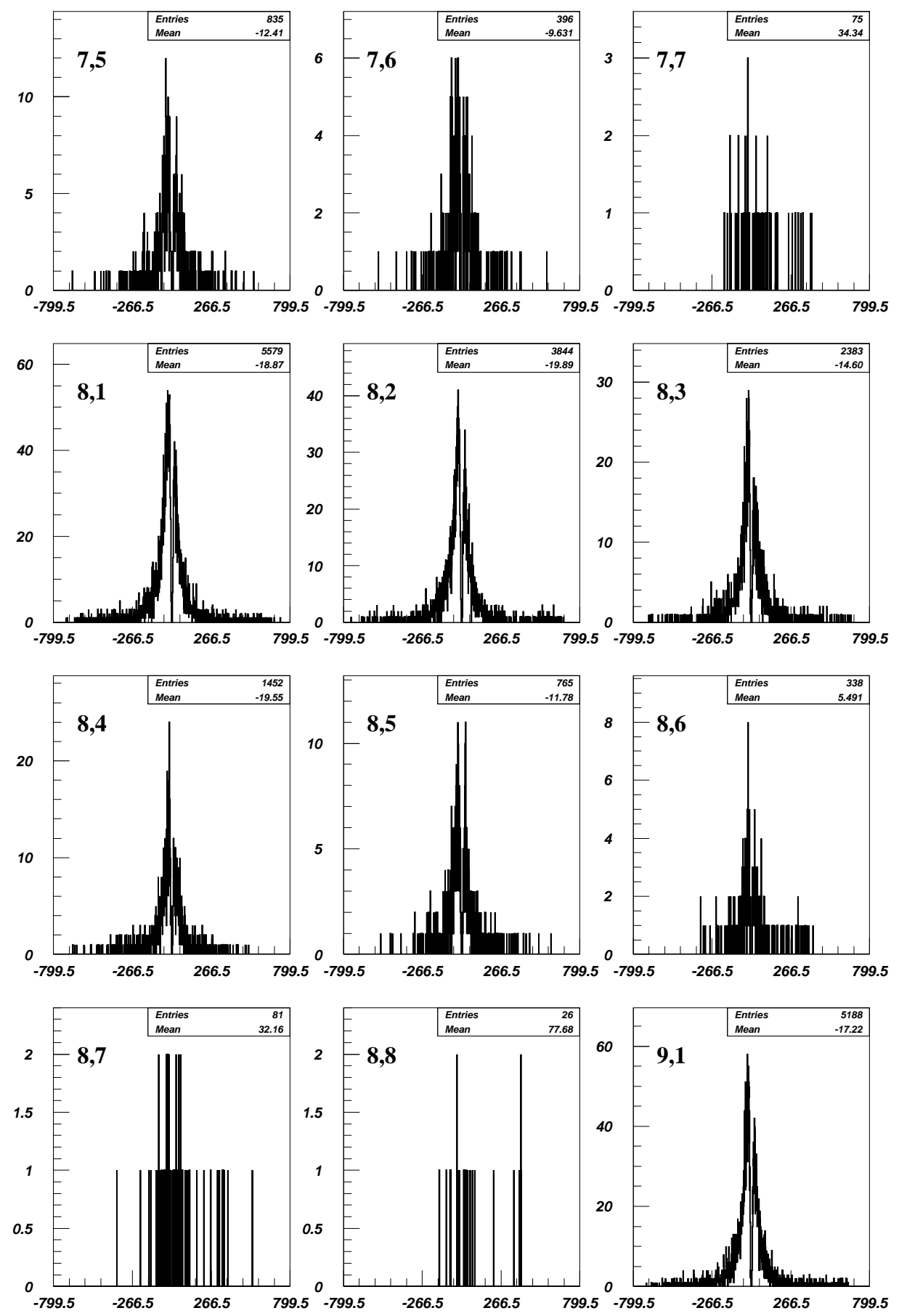

Figura 5.28: Distribuciones de momento. El primer índice: multiplicidad total, el segundo: multiplicidad con momento (neg $650 \mathrm{Be}$ ). 

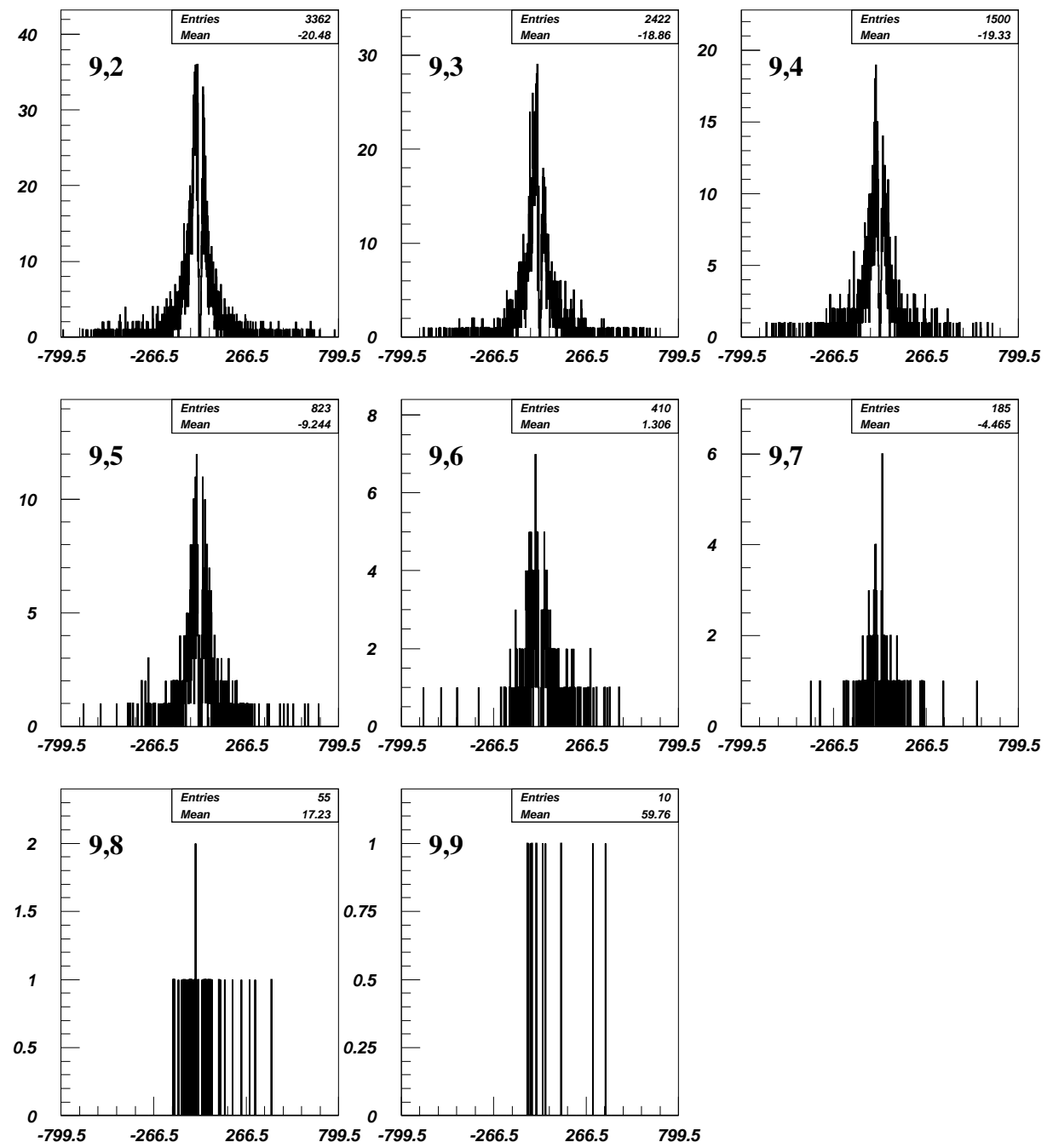

Figura 5.29: Distribuciones de momento. El primer índice: multiplicidad total, el segundo: multiplicidad con momento (neg $650 \mathrm{Be}$ ). 
Distribuciones del momento de las trayectorias para eventos producidos por un haz de mesones
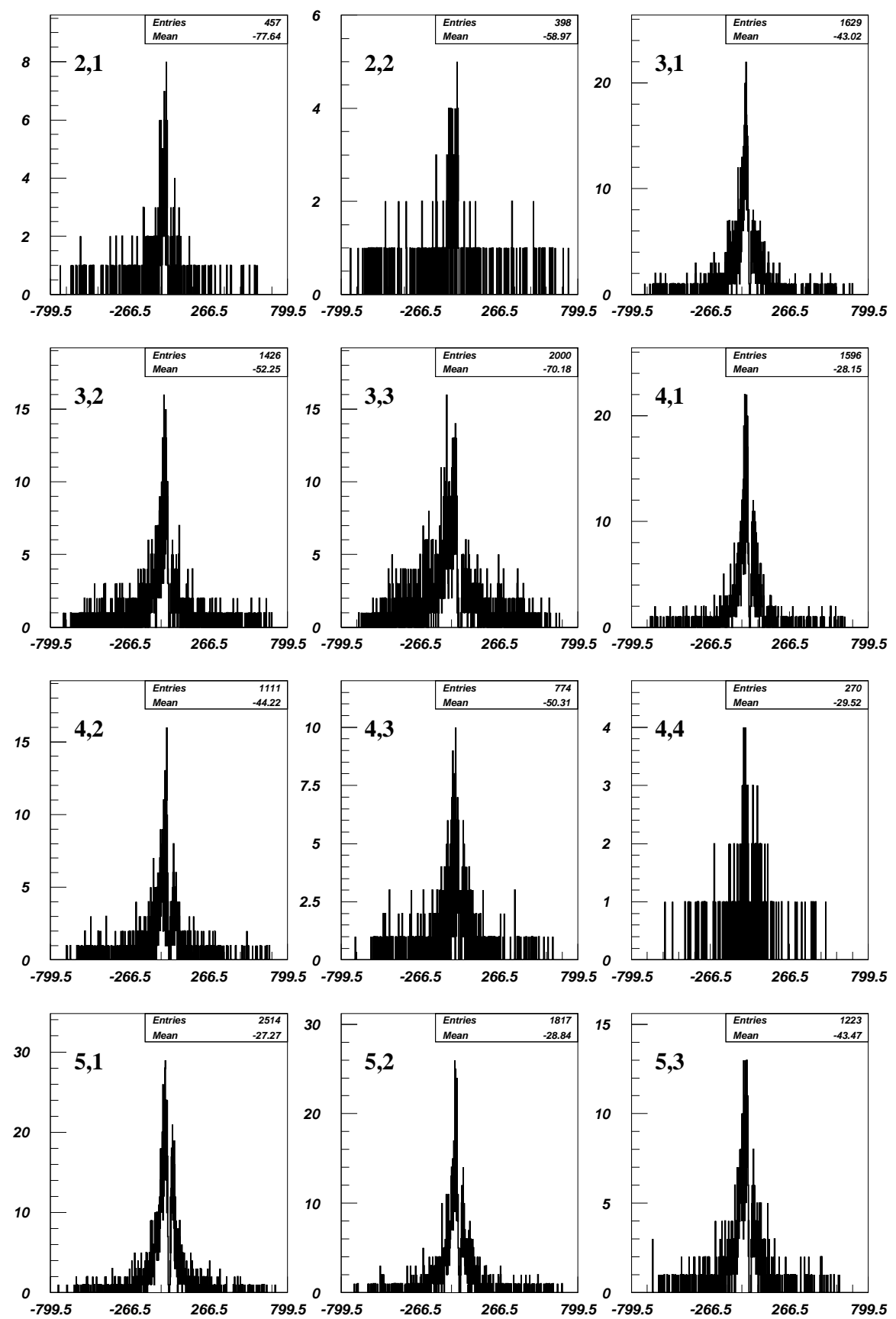

Figura 5.30: Distribuciones de momento. El primer indice: multiplicidad total, el segundo: multiplicidad con momento (neg $650 \mathrm{Be}$ ). 

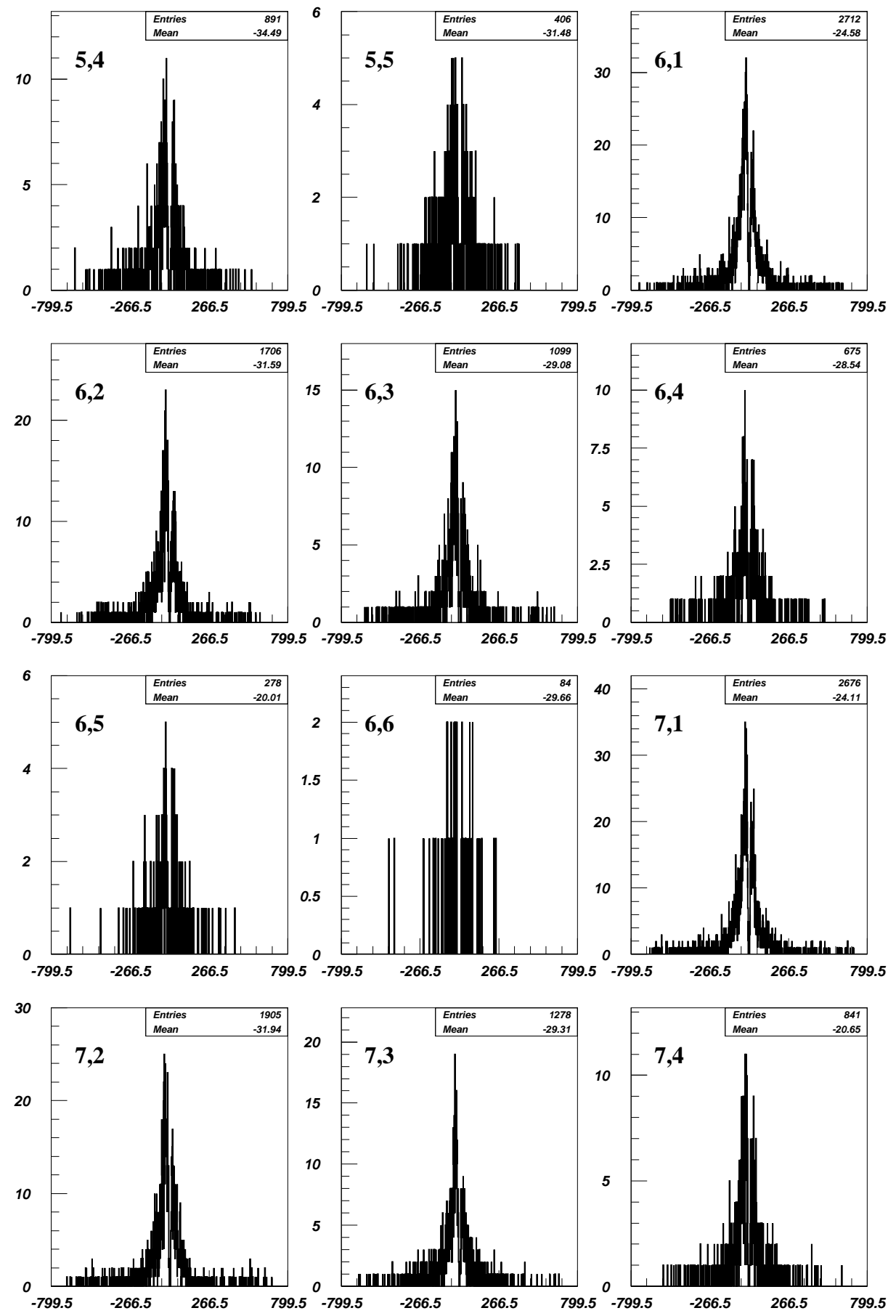

Figura 5.31: Distribuciones de momento. El primer índice: multiplicidad total, el segundo: multiplicidad con momento (neg $650 \mathrm{Be}$ ). 

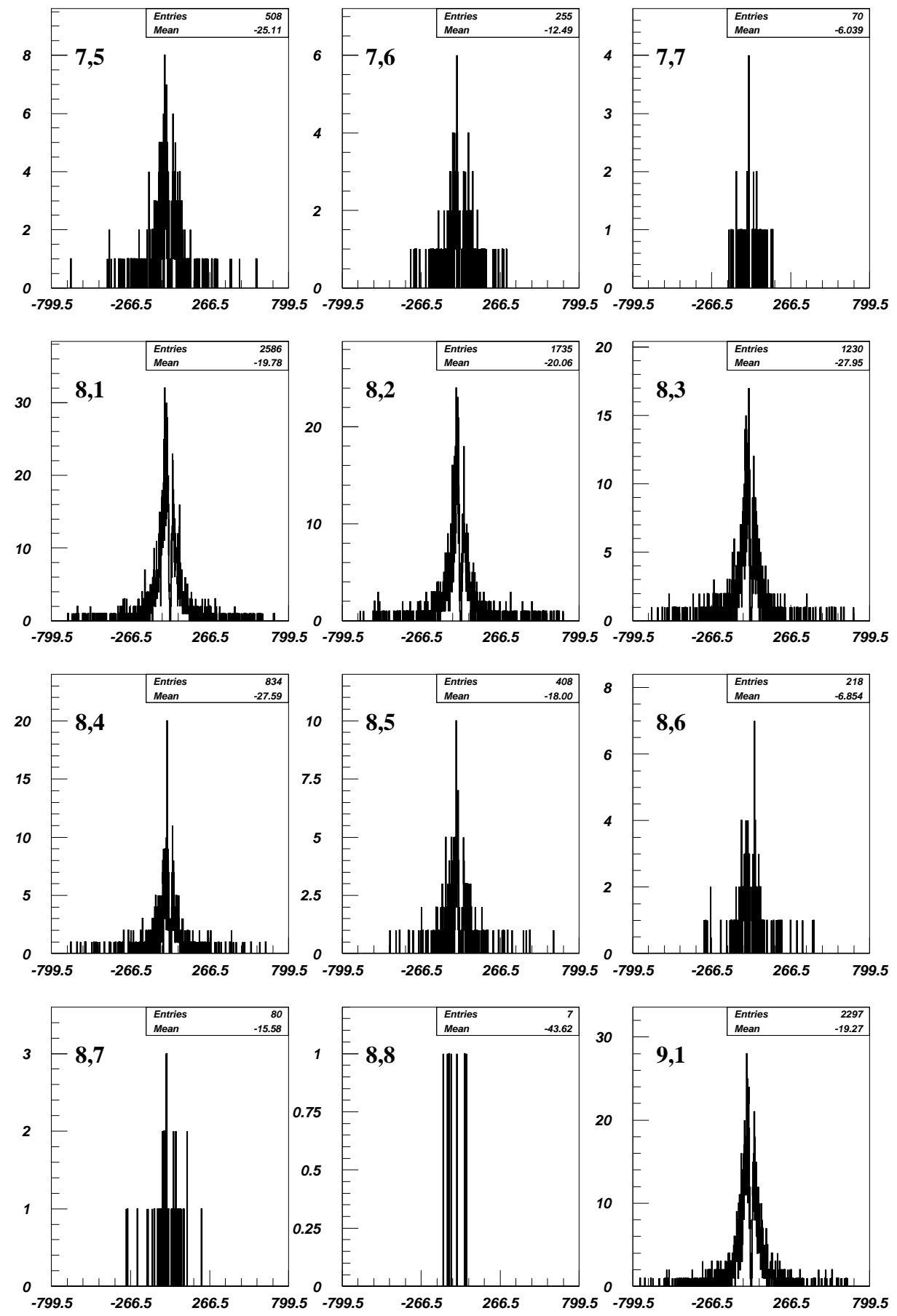

Figura 5.32: Distribuciones de momento. El primer índice: multiplicidad total, el segundo: multiplicidad con momento (neg $650 \mathrm{Be}$ ). 

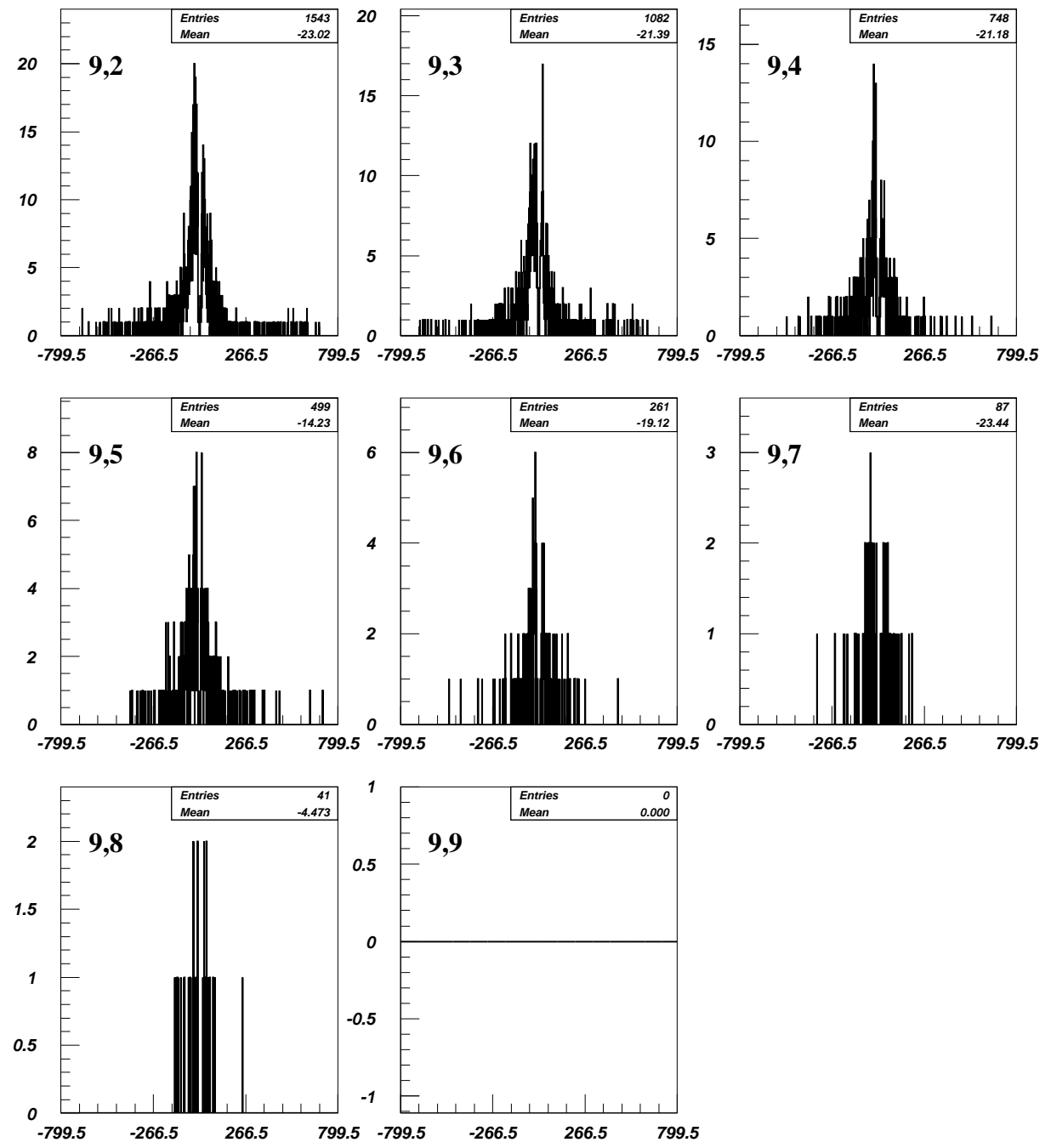

Figura 5.33: Distribuciones de momento. El primer índice: multiplicidad total, el segundo: multiplicidad con momento (neg $650 \mathrm{Be}$ ). 


\subsection{Haz de polaridad negativa, con momento $570 \mathrm{GeV}$, con blanco de producción para el haz secundario de carbón}

\subsubsection{Histogramas de control}
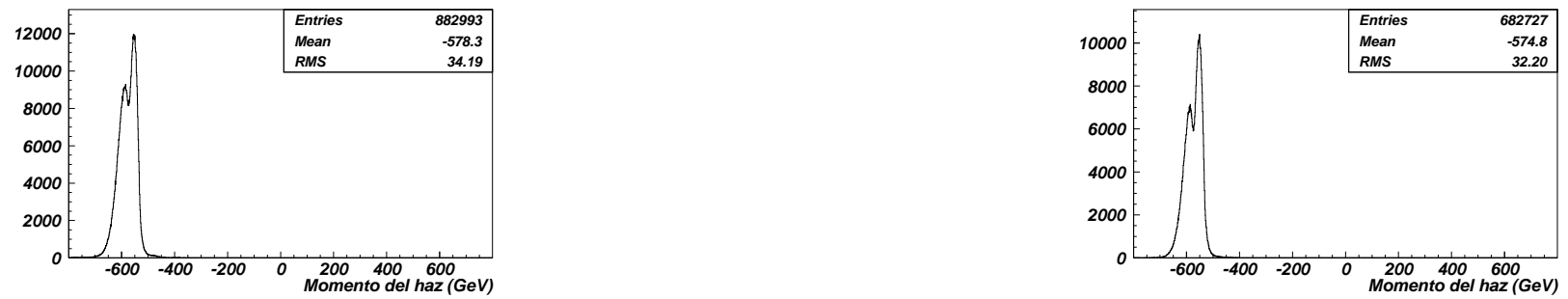

Figura 5.34: Distribución de momento del haz primario. Izquierda: bariones. Derecha: mesones (neg $578 \mathrm{C})$.

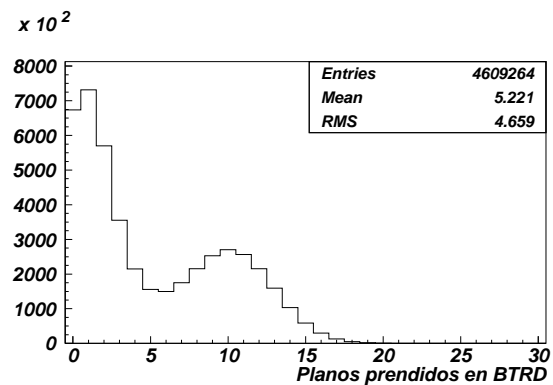

Figura 5.35: Planos prendidos en BTRD. Proporción bariónica y mesónica del haz primario (neg $578 \mathrm{C})$.
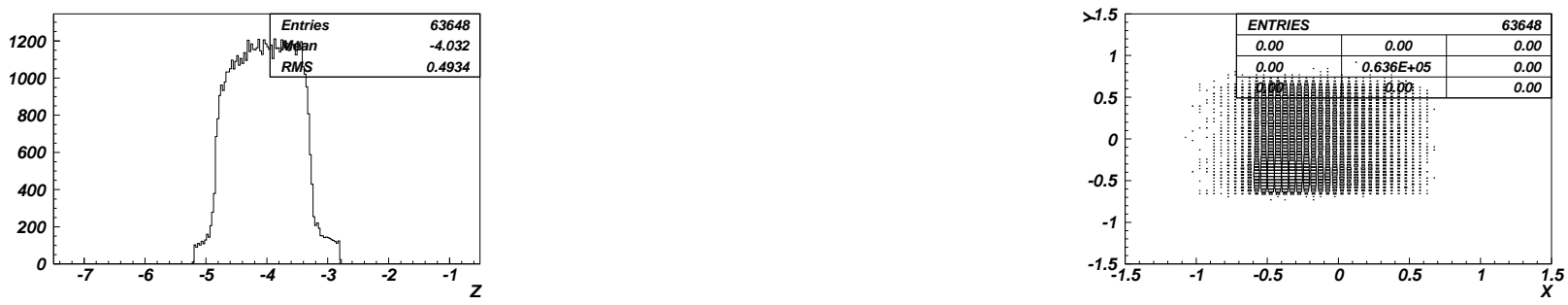

Figura 5.36: Vértice primario. Izquierda: coordenada z. Derecha: proyección x,y (neg 578 C). 


\subsubsection{Multiplicidad en la región del vértice}
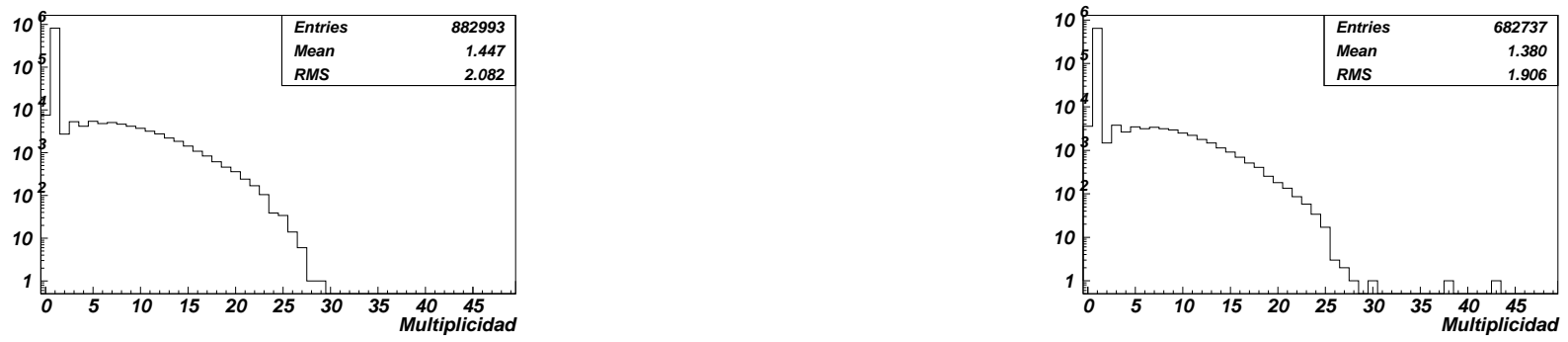

Figura 5.37: Multiplicidad total. Izquierda: haz de bariones. Derecha: haz de mesones (neg $578 \mathrm{C})$.
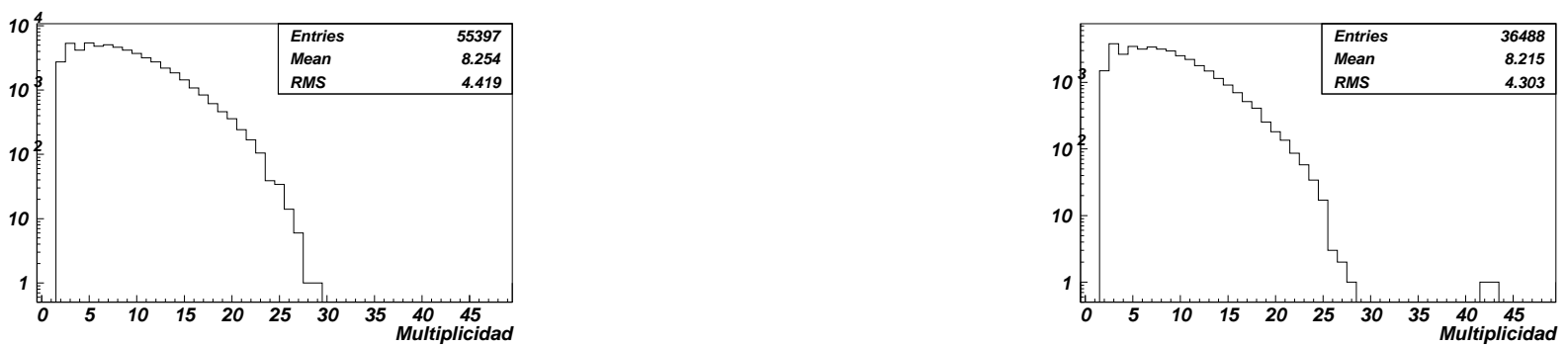

Figura 5.38: Multiplicidad en eventos con más de una trayectoria en la región del vértice. Izquierda: haz de bariones. Derecha: haz de mesones (neg $578 \mathrm{C}$ ). 


\subsubsection{Distribuciones de multiplicidad y momento}
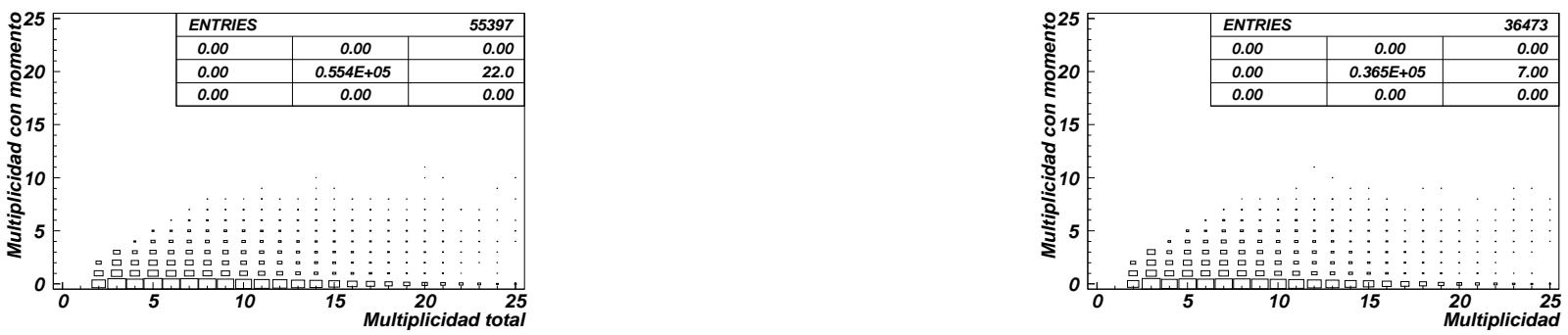

Figura 5.39: Multiplicidad total contra multiplicidad con momento medido. Izquierda: haz de bariones. Derecha: haz de mesones (neg $578 \mathrm{C}$ ).
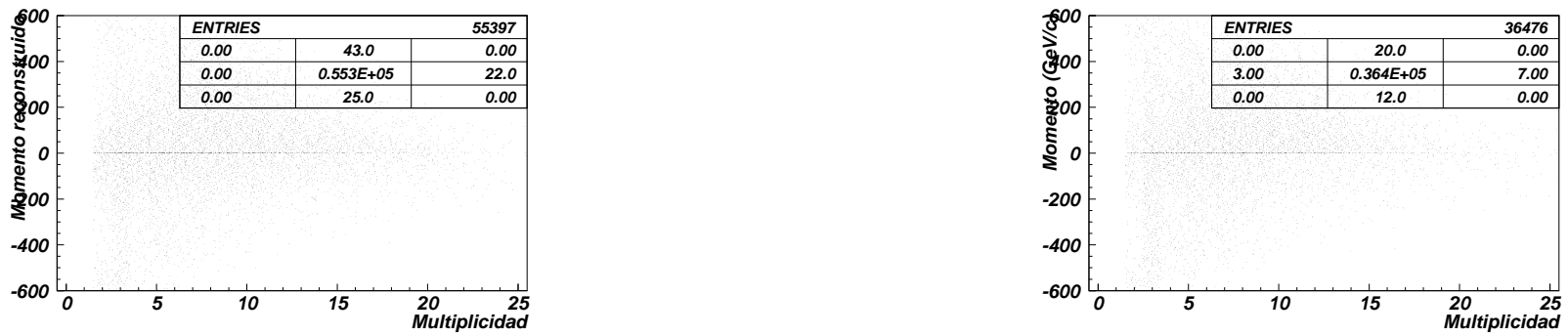

Figura 5.40: Multiplicidad contra momento.Izquierda: haz de bariones. Derecha: haz de mesones (neg $578 \mathrm{C}$ ). 
Distribuciones de momento total para eventos producidos por un haz de bariones
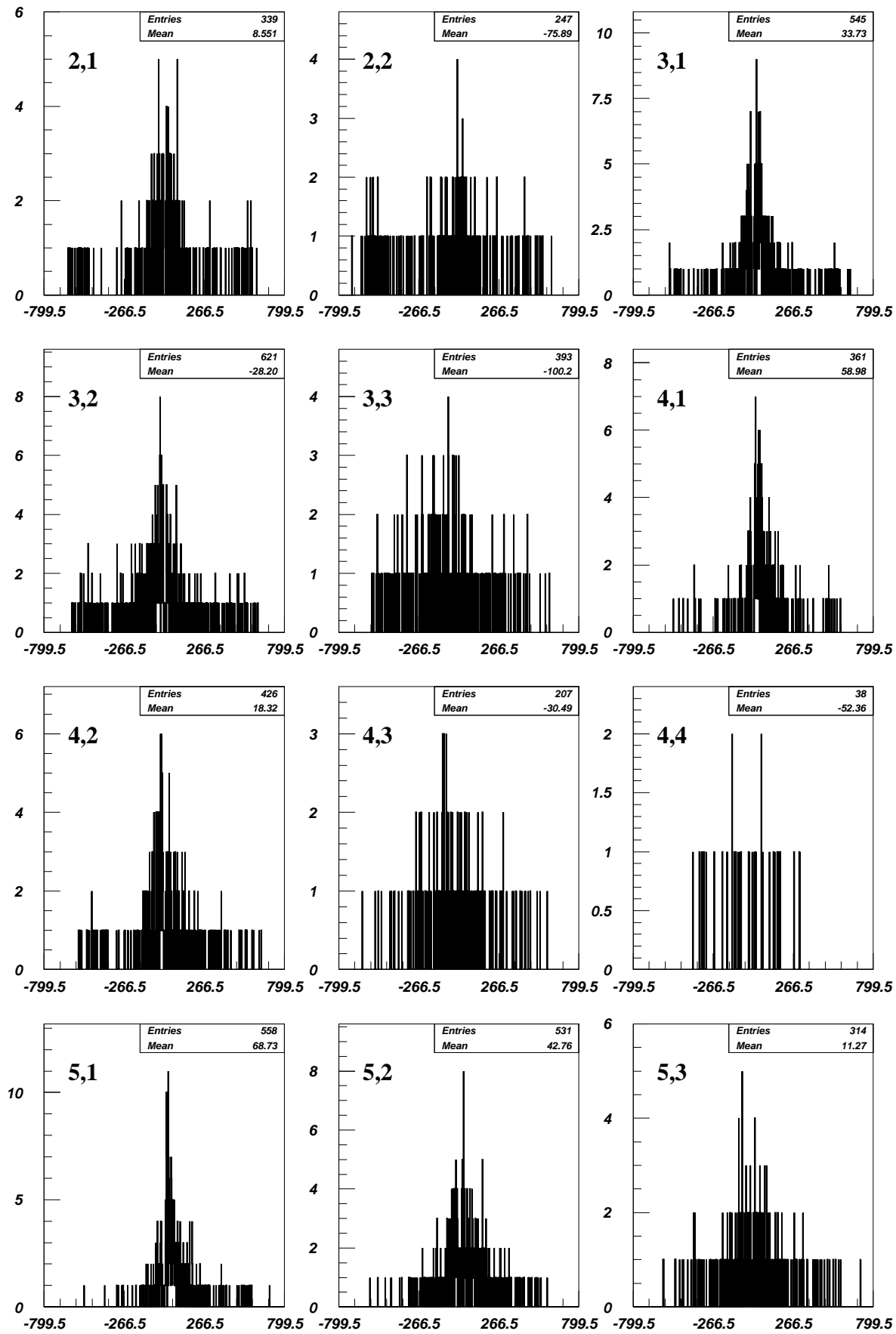

Figura 5.41: Distribuciones de momento. El primer indice: multiplicidad total, el segundo: multiplicidad con momento (neg $578 \mathrm{C}$ ). 

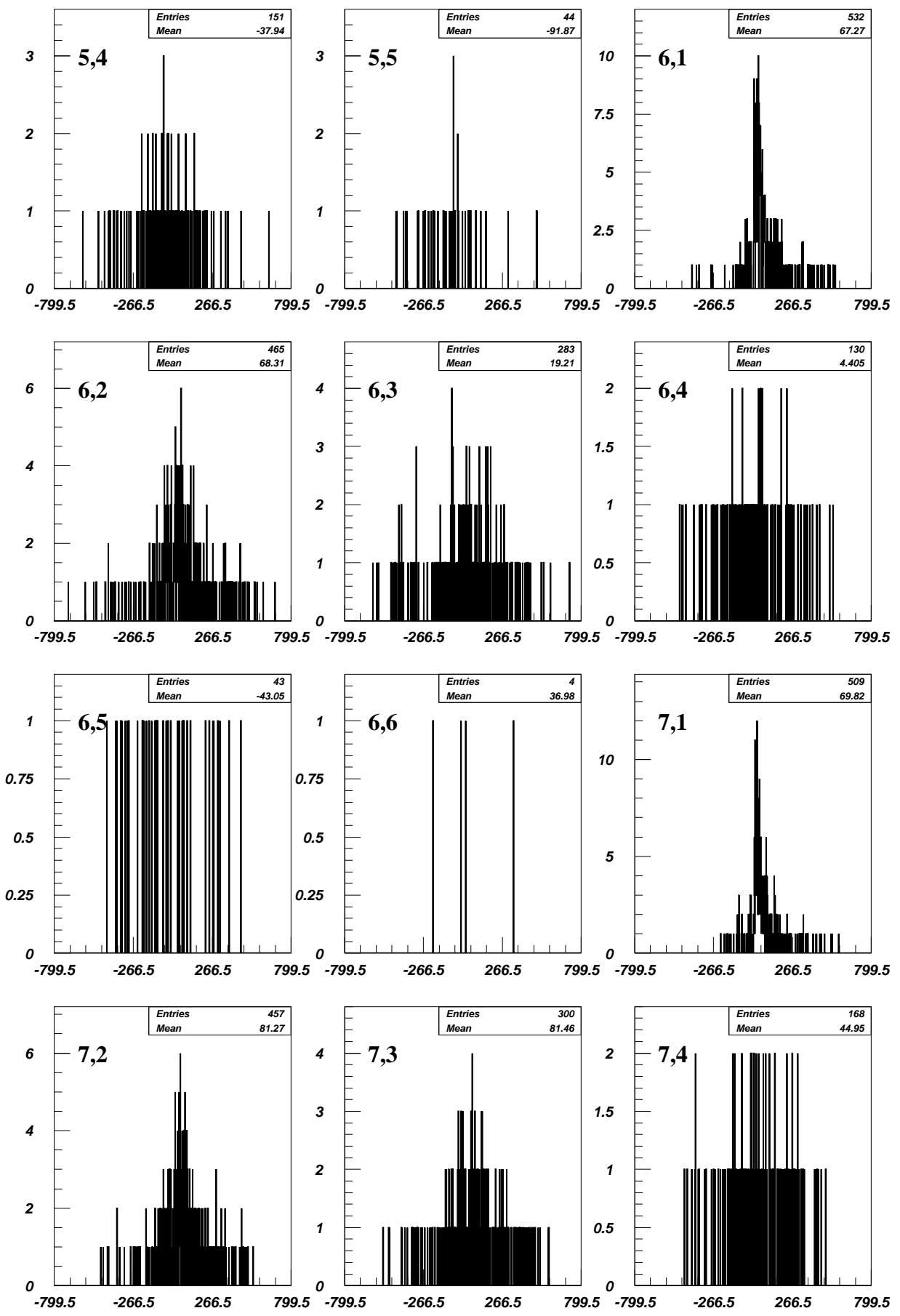

Figura 5.42: Distribuciones de momento. El primer índice: multiplicidad total, el segundo: multiplicidad con momento (neg $578 \mathrm{C}$ ). 

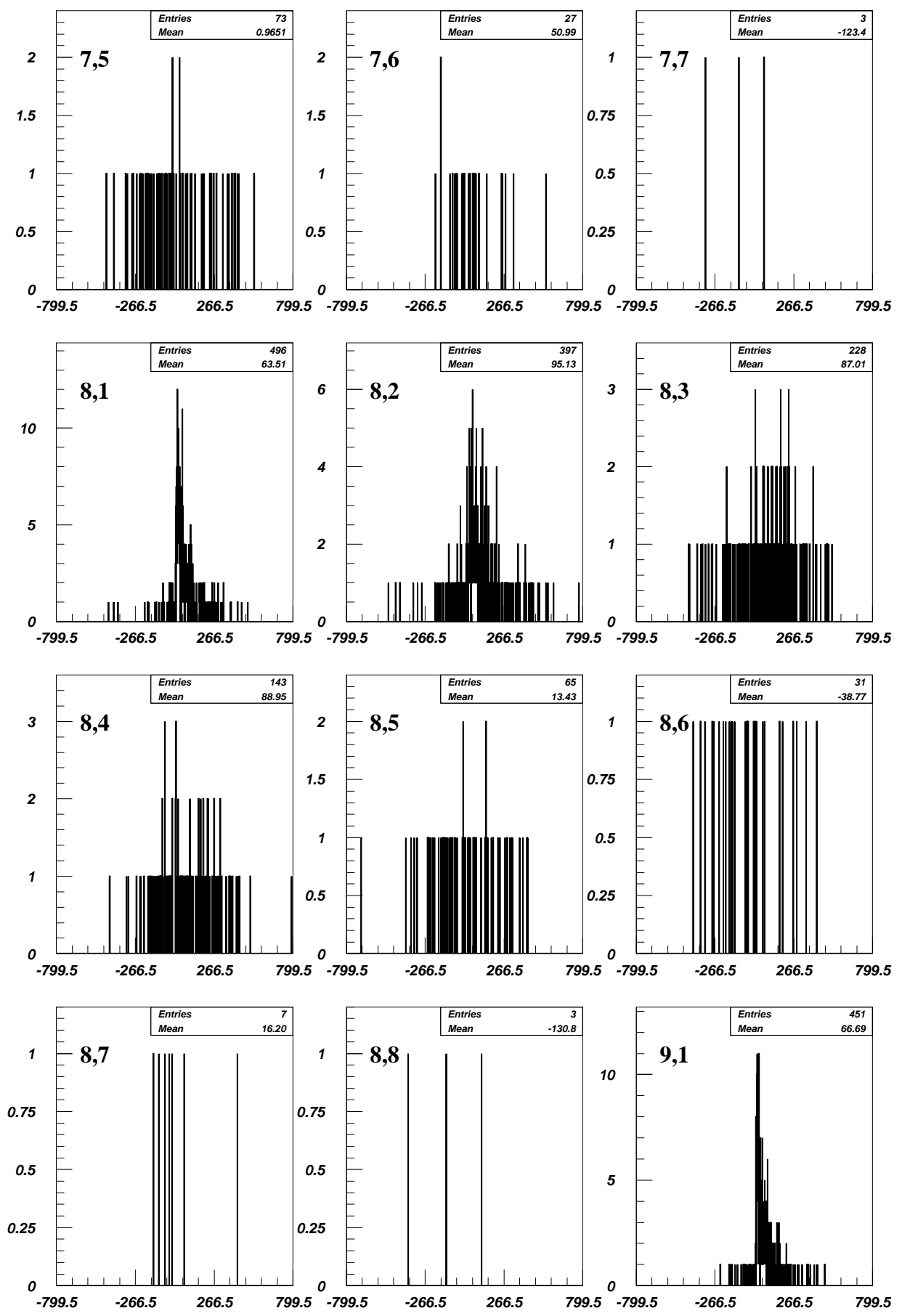

Figura 5.43: Distribuciones de momento. El primer índice: multiplicidad total, el segundo: multiplicidad con momento (neg $578 \mathrm{C}$ ). 

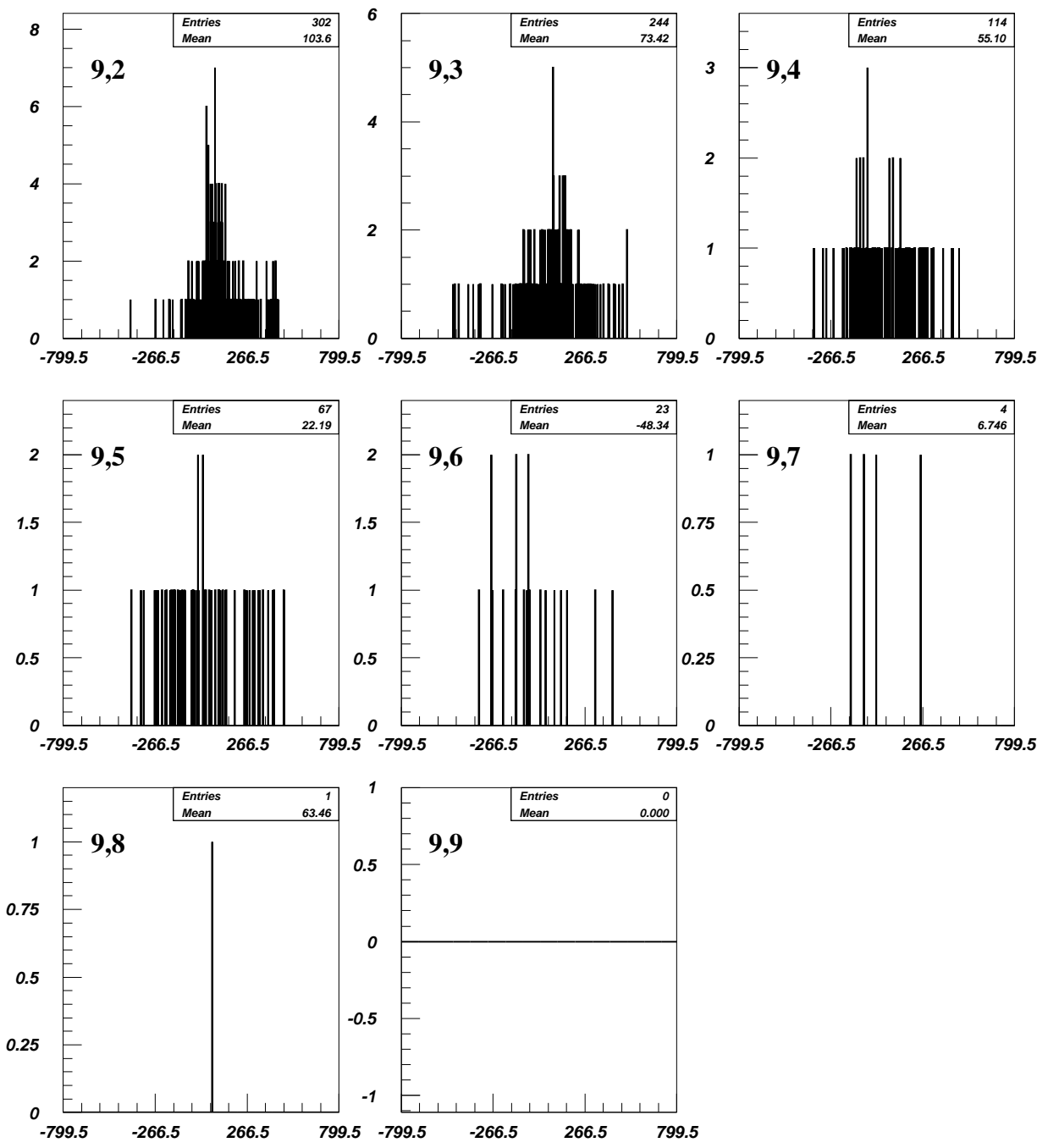

Figura 5.44: Distribuciones de momento. El primer índice: multiplicidad total, el segundo: multiplicidad con momento (neg $578 \mathrm{C}$ ). 
Distribuciones de momento total para eventos producidos por un haz de mesones
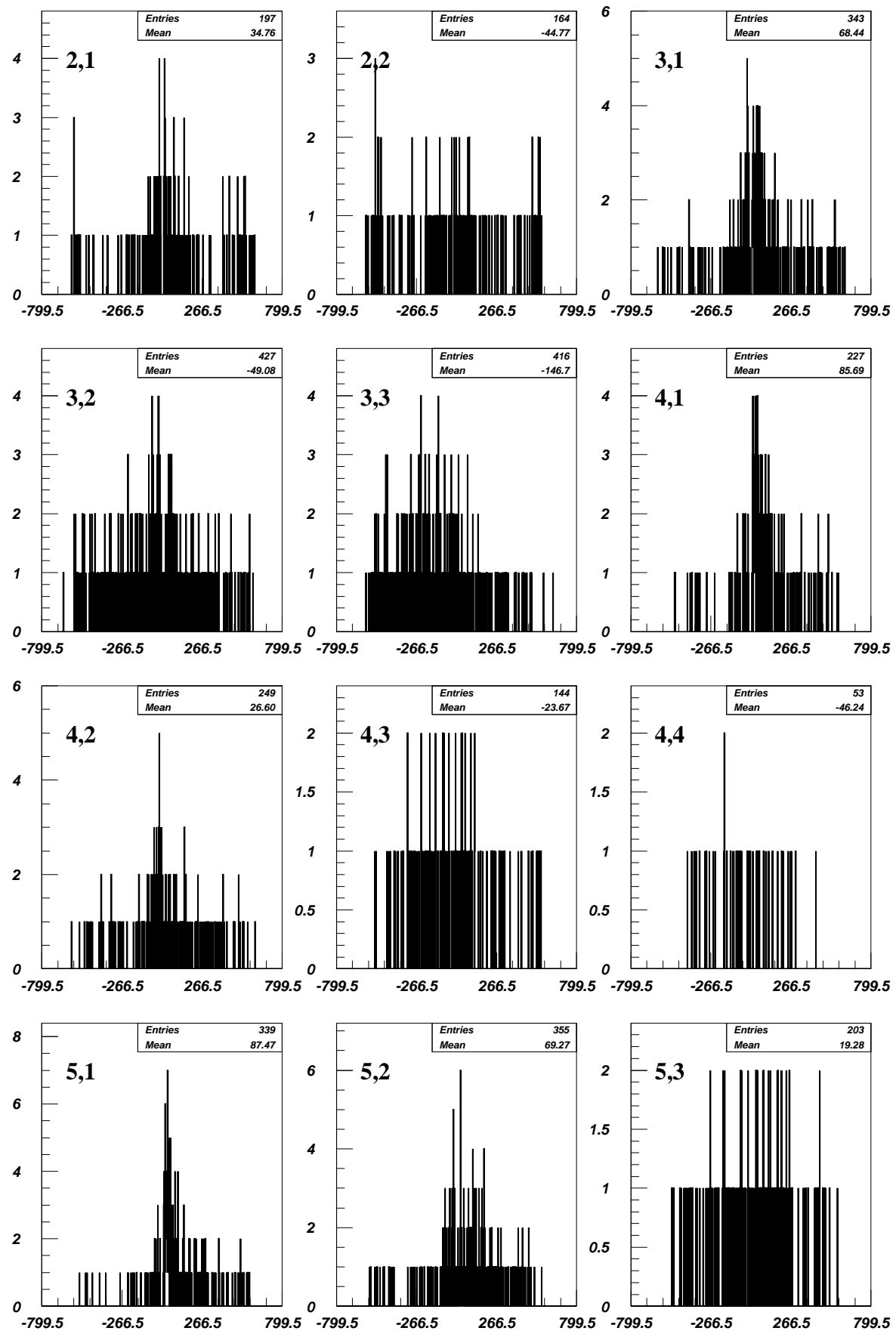

Figura 5.45: Distribuciones de momento. El primer indice: multiplicidad total, el segundo: multiplicidad con momento (neg $578 \mathrm{C}$ ). 

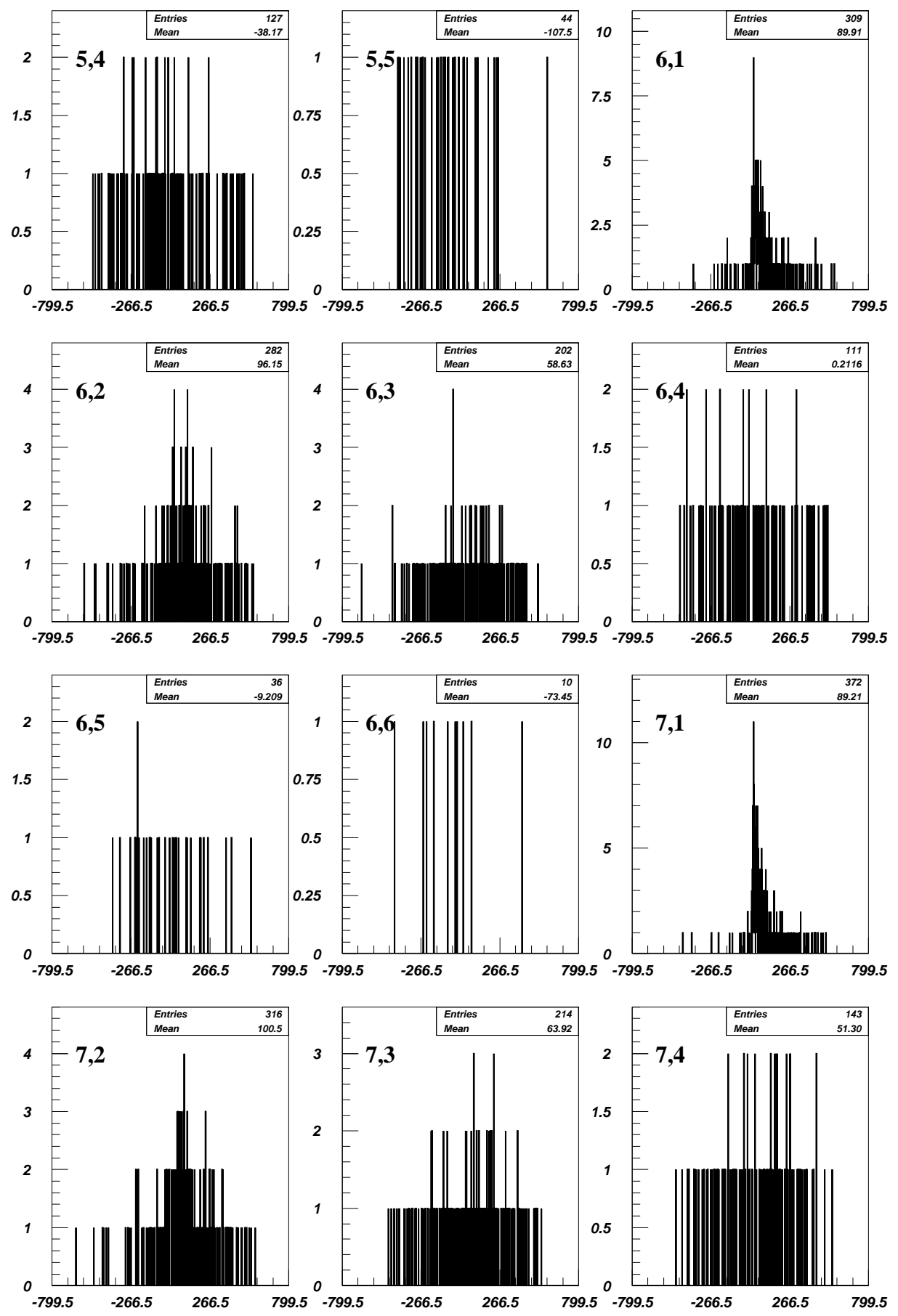

Figura 5.46: Distribuciones de momento. El primer índice: multiplicidad total, el segundo: multiplicidad con momento (neg $578 \mathrm{C}$ ). 

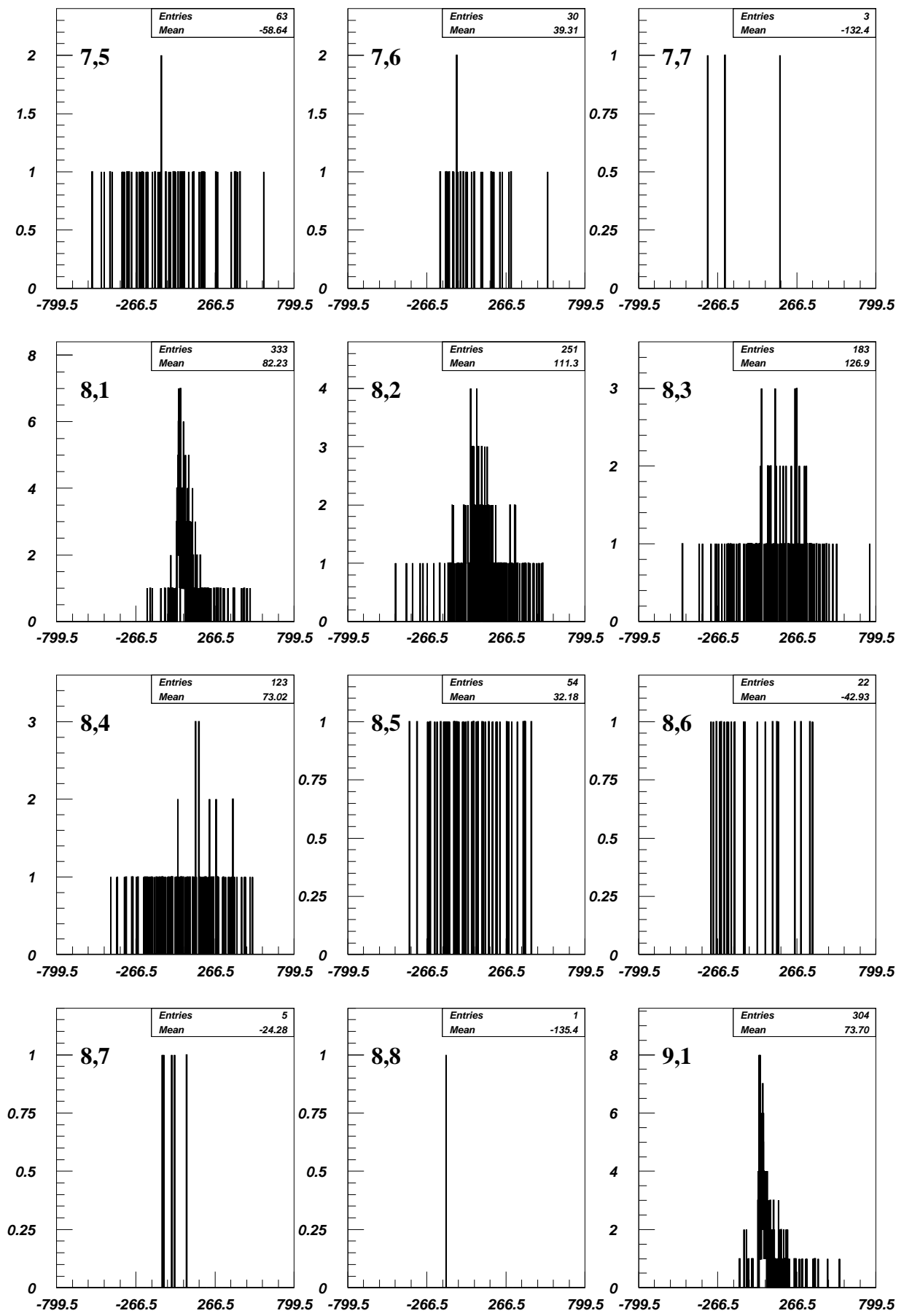

Figura 5.47: Distribuciones de momento. El primer índice: multiplicidad total, el segundo: multiplicidad con momento (neg $578 \mathrm{C}$ ). 

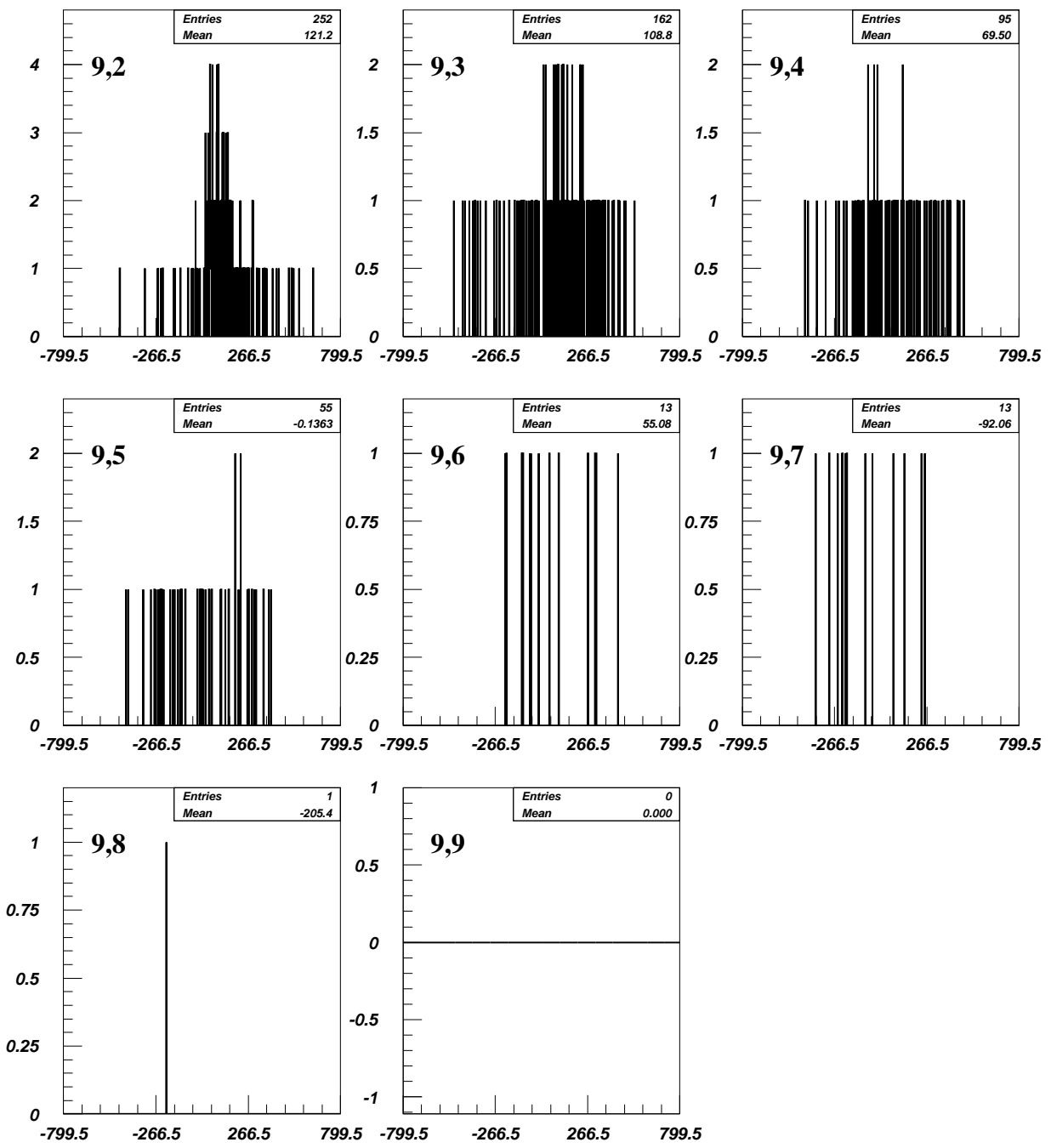

Figura 5.48: Distribuciones de momento. El primer índice: multiplicidad total, el segundo: multiplicidad con momento (neg $578 \mathrm{C}$ ). 
Distribuciones del valor absoluto del momento total para eventos producidos por un haz de bariones
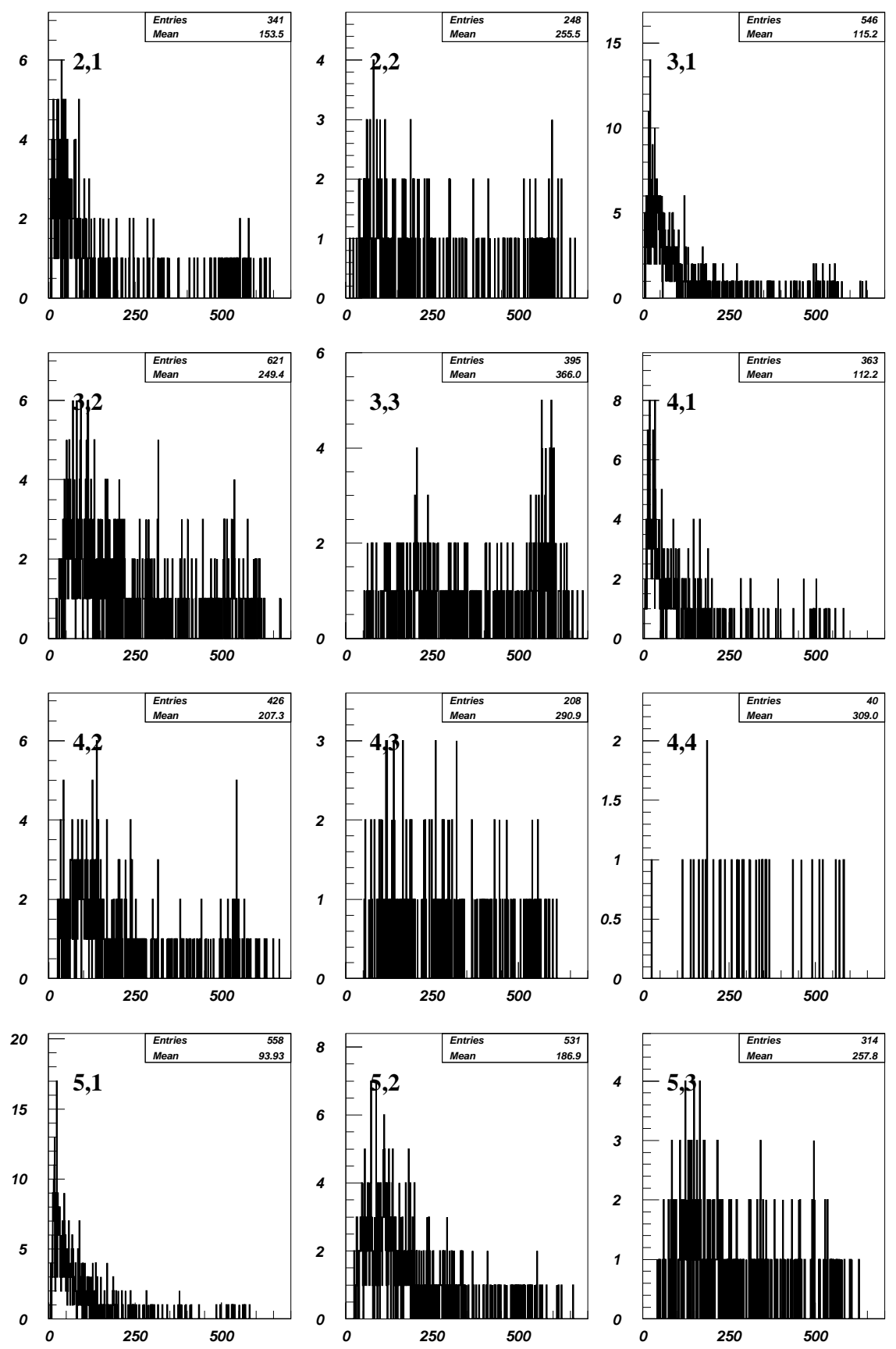

Figura 5.49: Distribuciones de momento. El primer indice: multiplicidad total, el segundo: multiplicidad con momento (neg $578 \mathrm{C}$ ). 

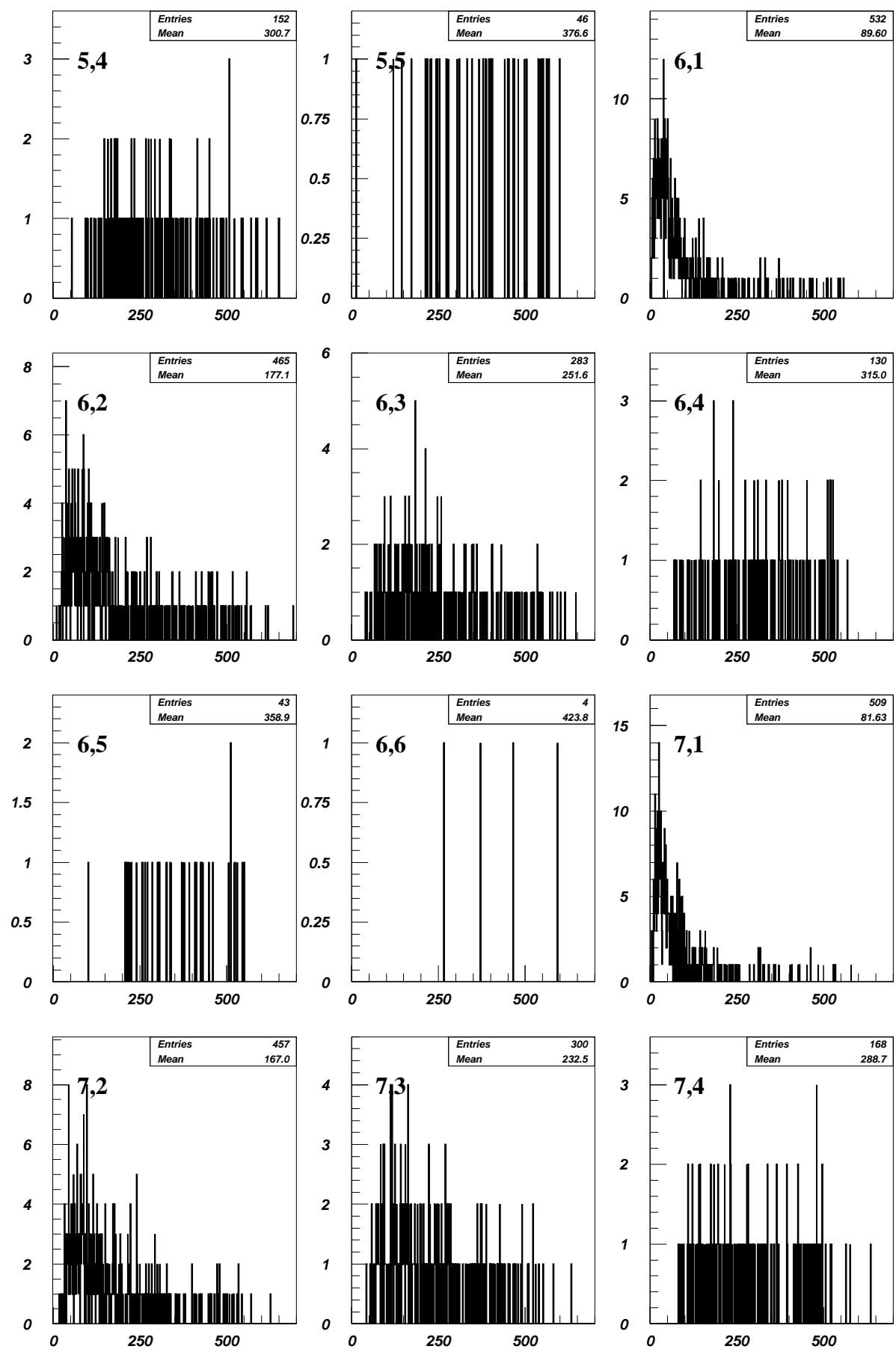

Figura 5.50: Distribuciones de momento. El primer índice: multiplicidad total, el segundo: multiplicidad con momento (neg $578 \mathrm{C}$ ). 

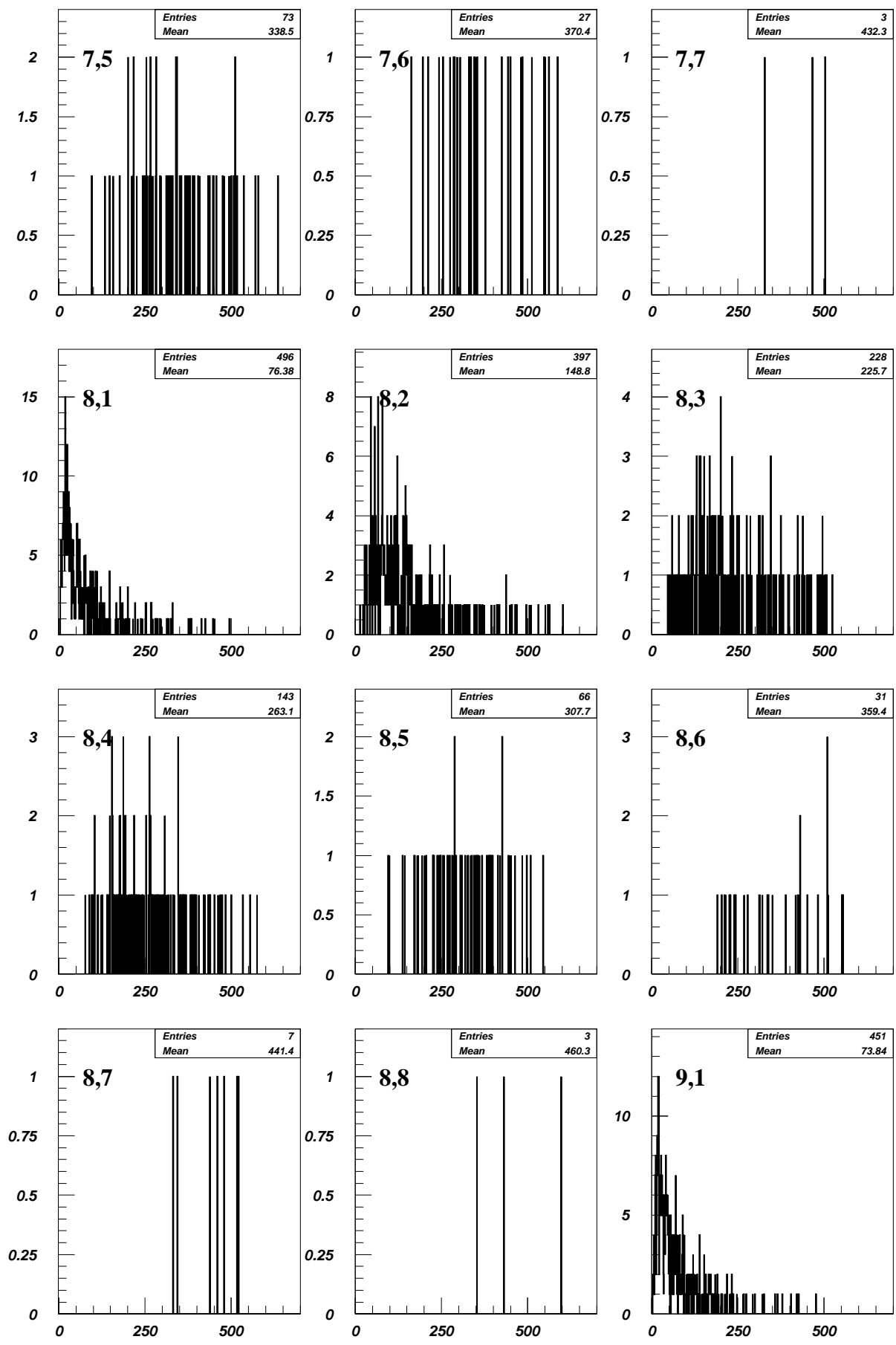

Figura 5.51: Distribuciones de momento. El primer índice: multiplicidad total, el segundo: multiplicidad con momento (neg $578 \mathrm{C}$ ). 

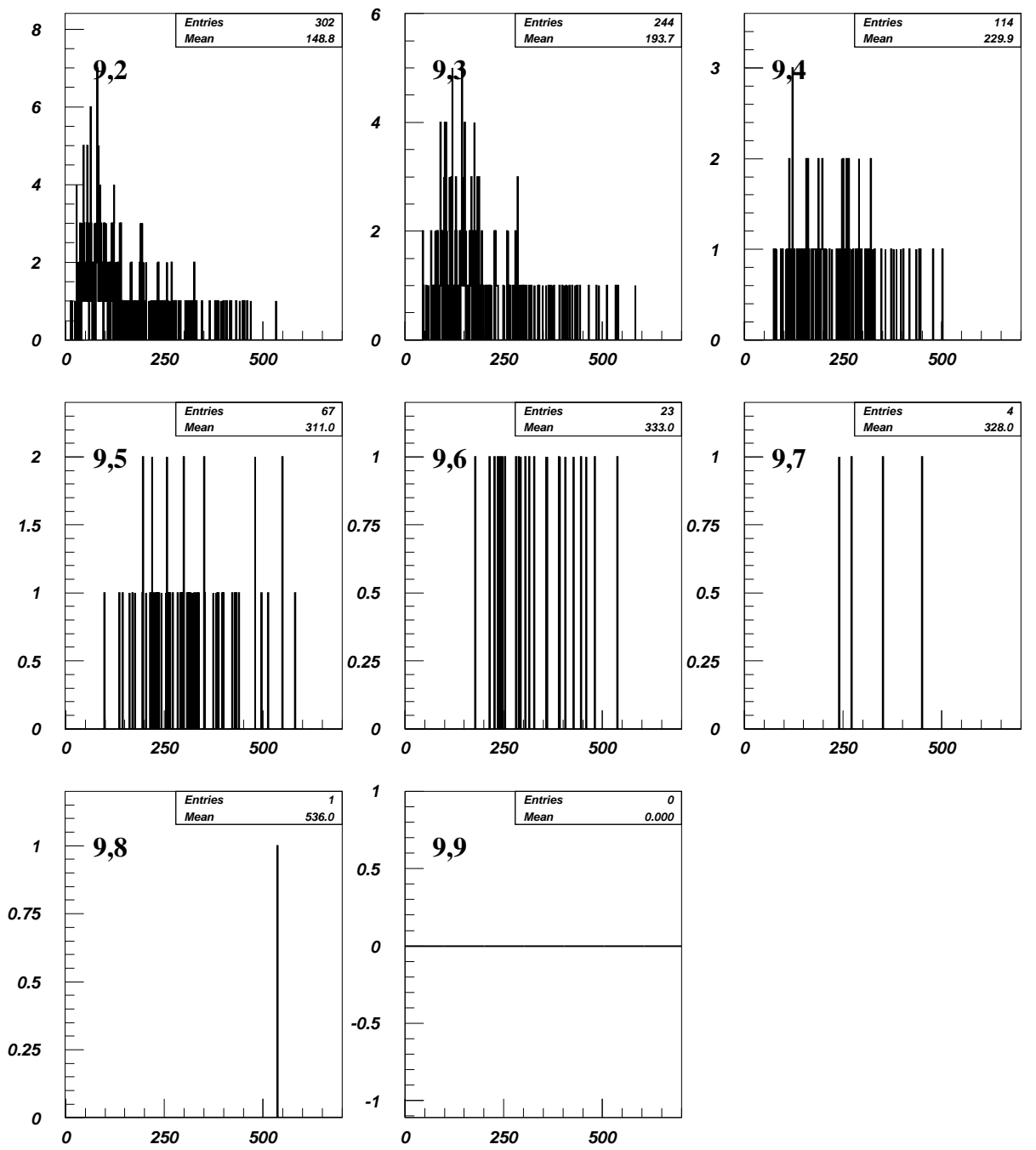

Figura 5.52: Distribuciones de momento. El primer índice: multiplicidad total, el segundo: multiplicidad con momento (neg $578 \mathrm{C}$ ). 
Distribuciones del valor absoluto del momento total para eventos producidos por un haz de mesones
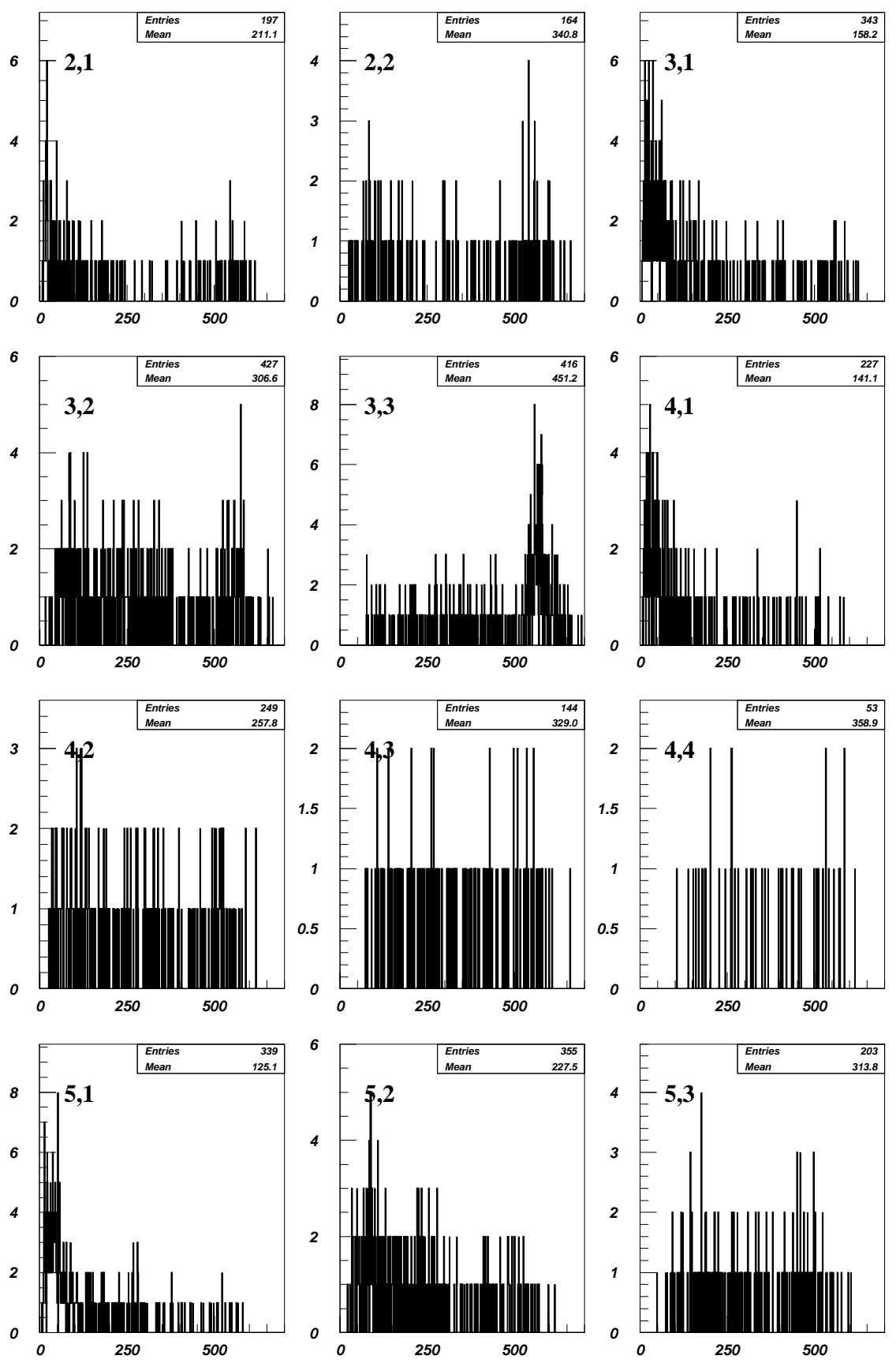

Figura 5.53: Distribuciones de momento. El primer indice: multiplicidad total, el segundo: multiplicidad con momento (neg $578 \mathrm{C}$ ). 

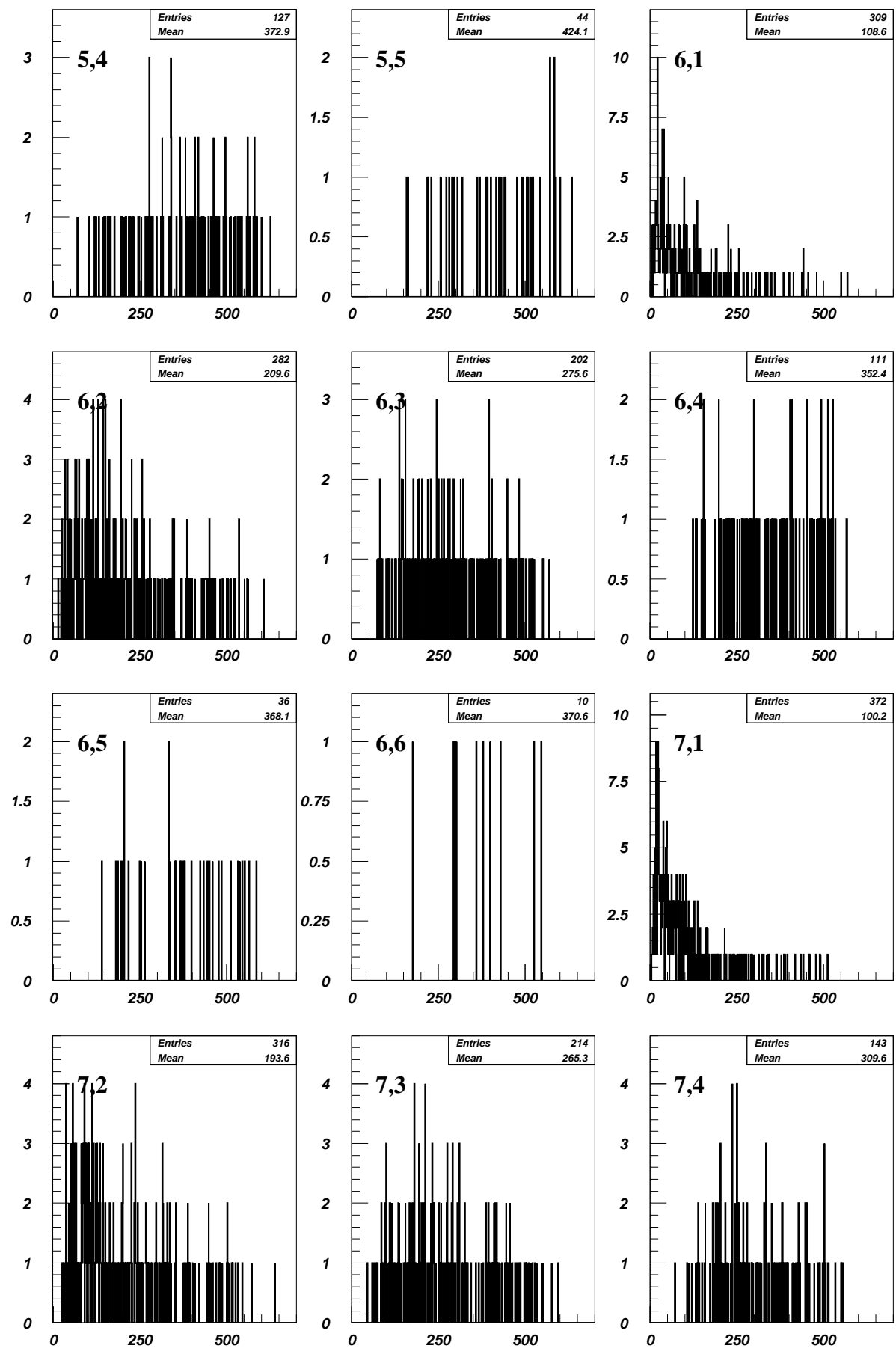

Figura 5.54: Distribuciones de momento. El primer índice: multiplicidad total, el segundo: multiplicidad con momento (neg $578 \mathrm{C}$ ). 

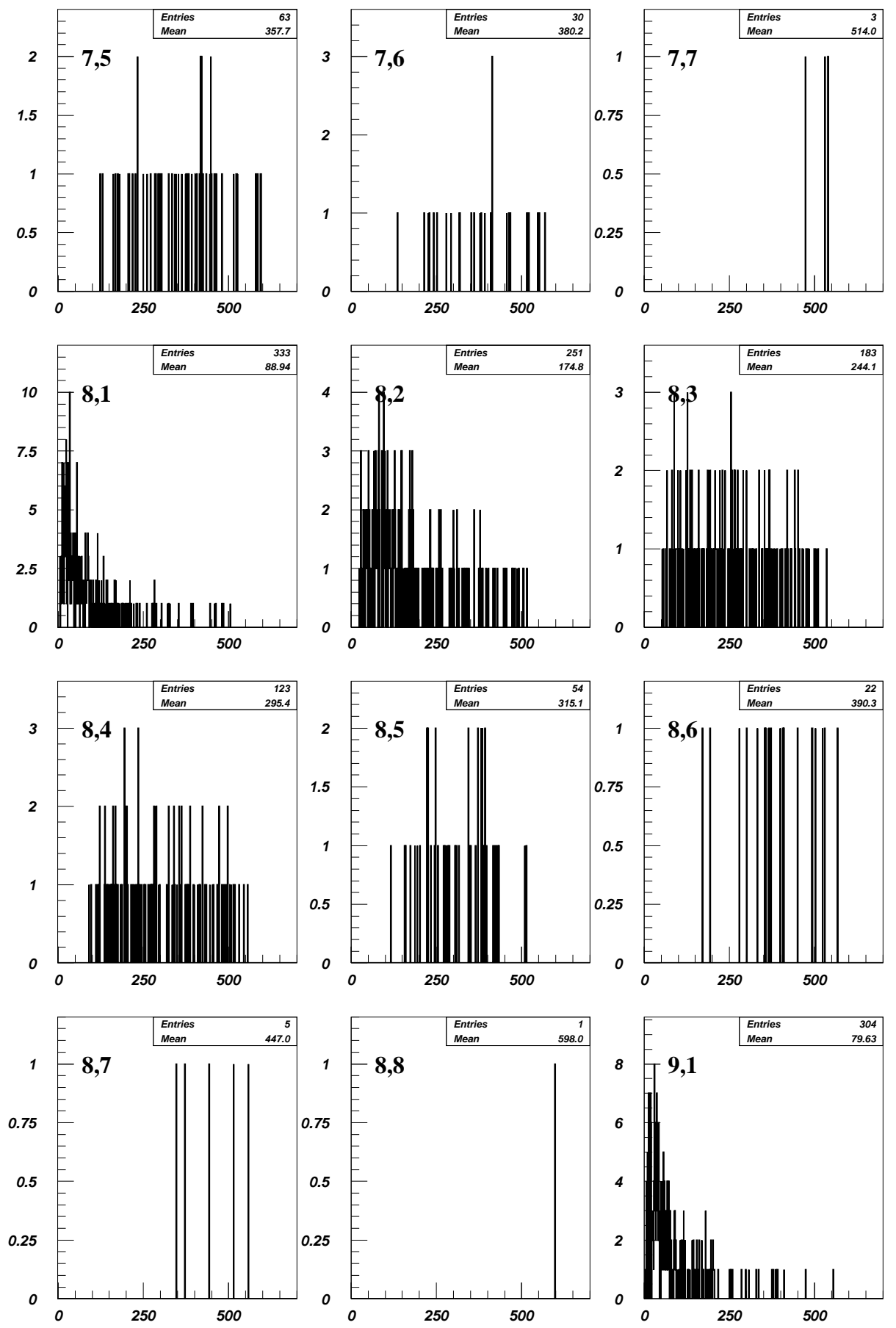

Figura 5.55: Distribuciones de momento. El primer índice: multiplicidad total, el segundo: multiplicidad con momento (neg $578 \mathrm{C}$ ). 

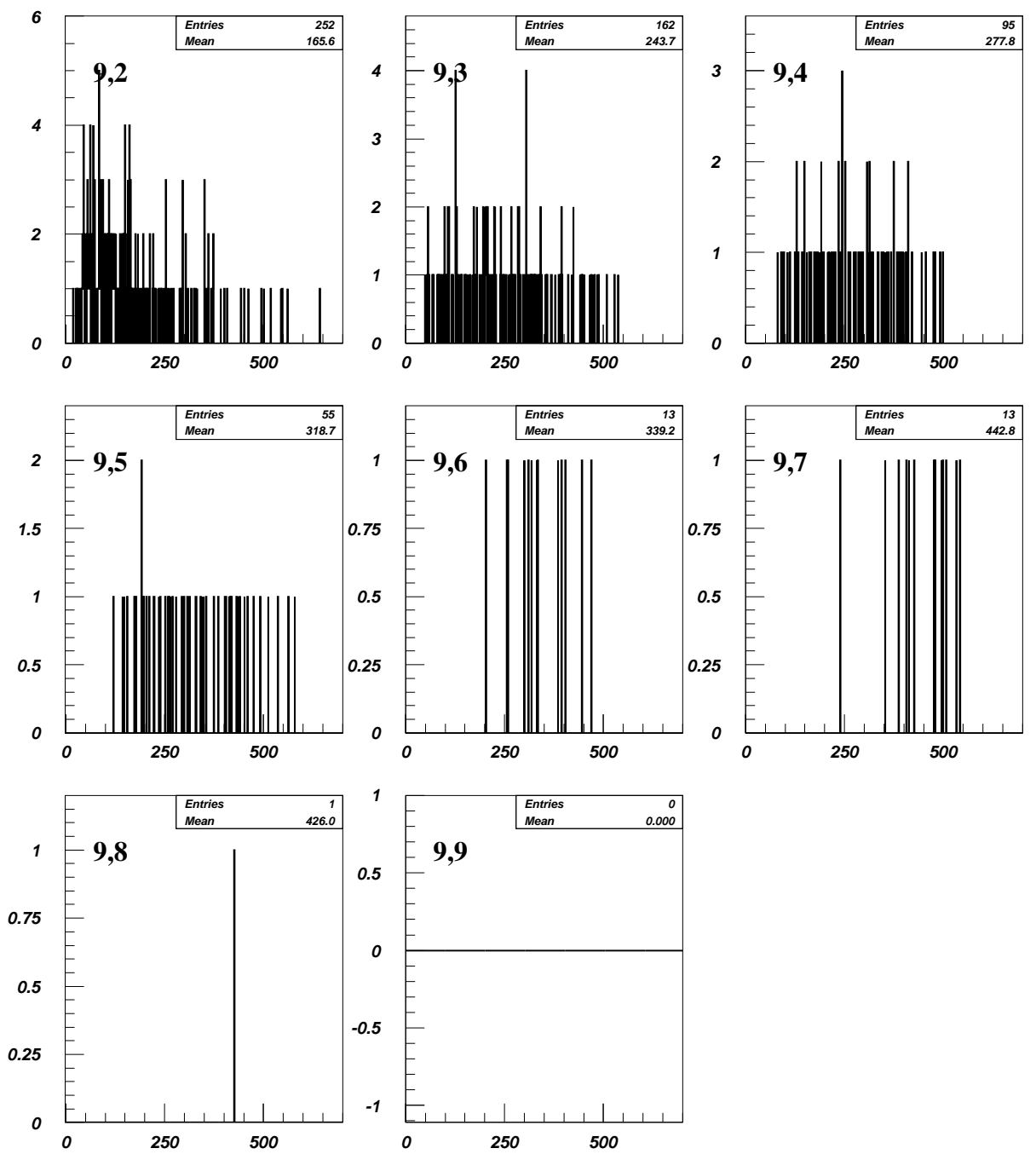

Figura 5.56: Distribuciones de momento. El primer índice: multiplicidad total, el segundo: multiplicidad con momento (neg $578 \mathrm{C}$ ). 
Distribuciones del momento de las trayectorias para eventos producidos por un haz de bariones
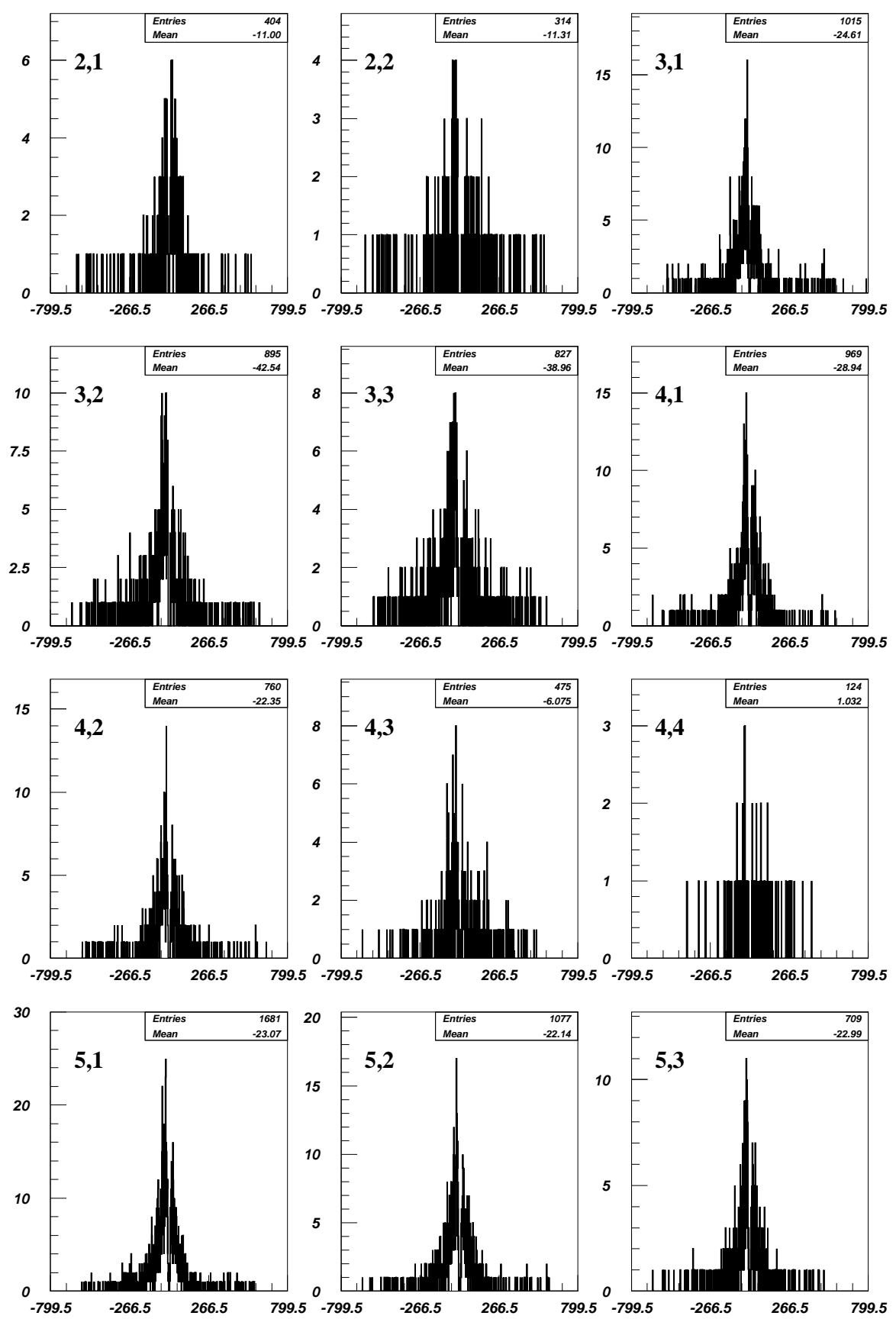

Figura 5.57: Distribuciones de momento. El primer indice: multiplicidad total, el segundo: multiplicidad con momento (neg $578 \mathrm{C}$ ). 

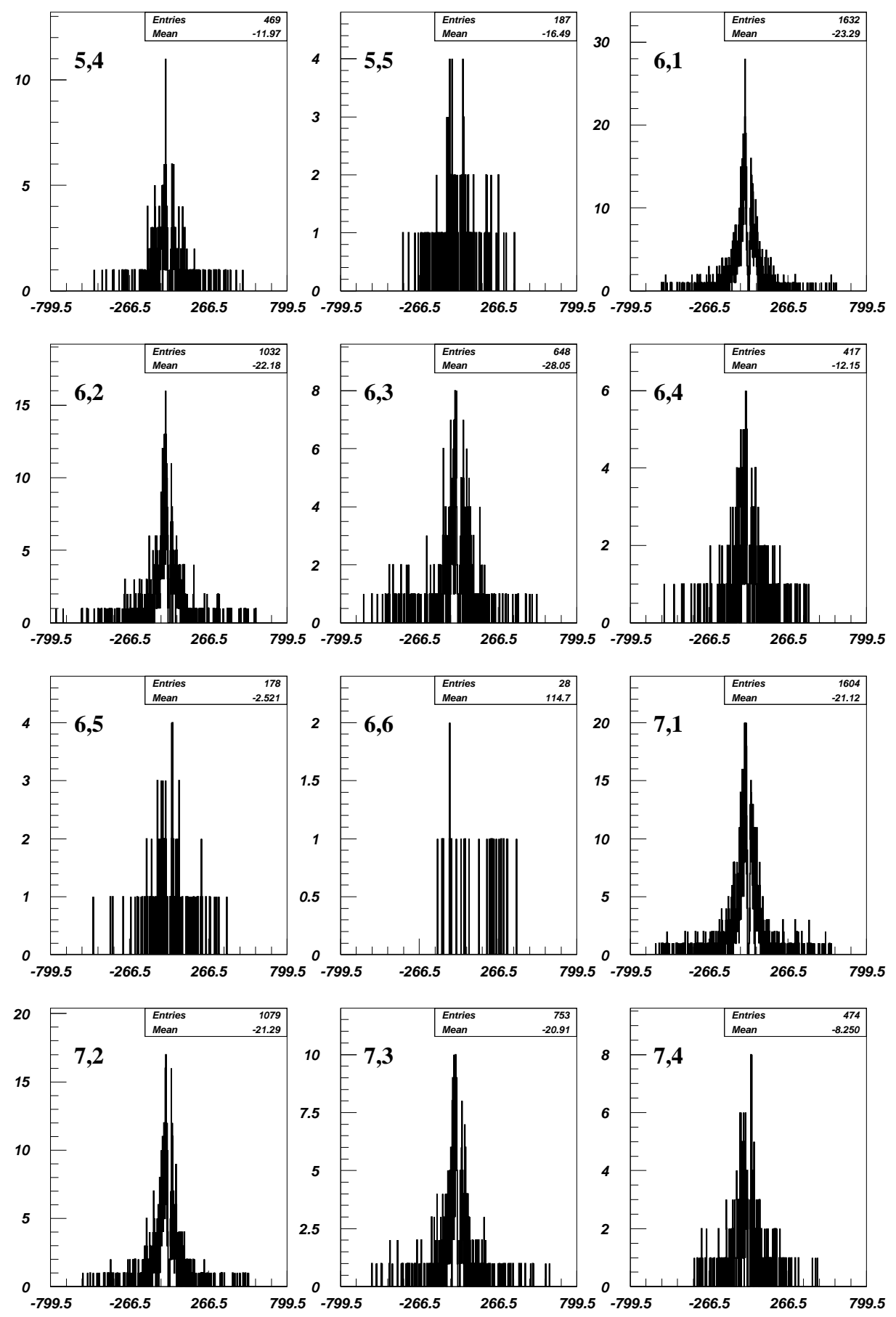

Figura 5.58: Distribuciones de momento. El primer índice: multiplicidad total, el segundo: multiplicidad con momento (neg $578 \mathrm{C}$ ). 

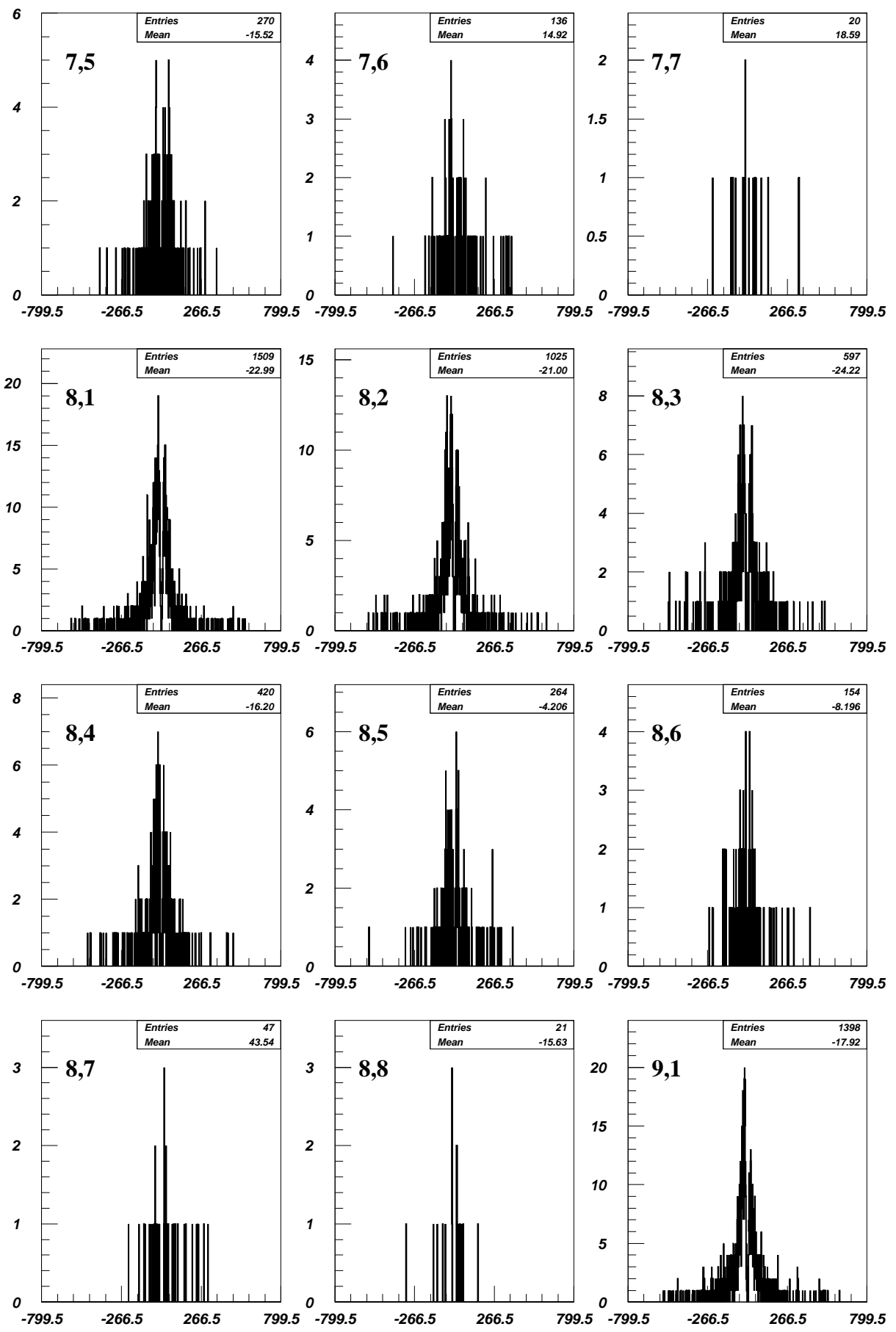

Figura 5.59: Distribuciones de momento. El primer índice: multiplicidad total, el segundo: multiplicidad con momento (neg $578 \mathrm{C}$ ). 

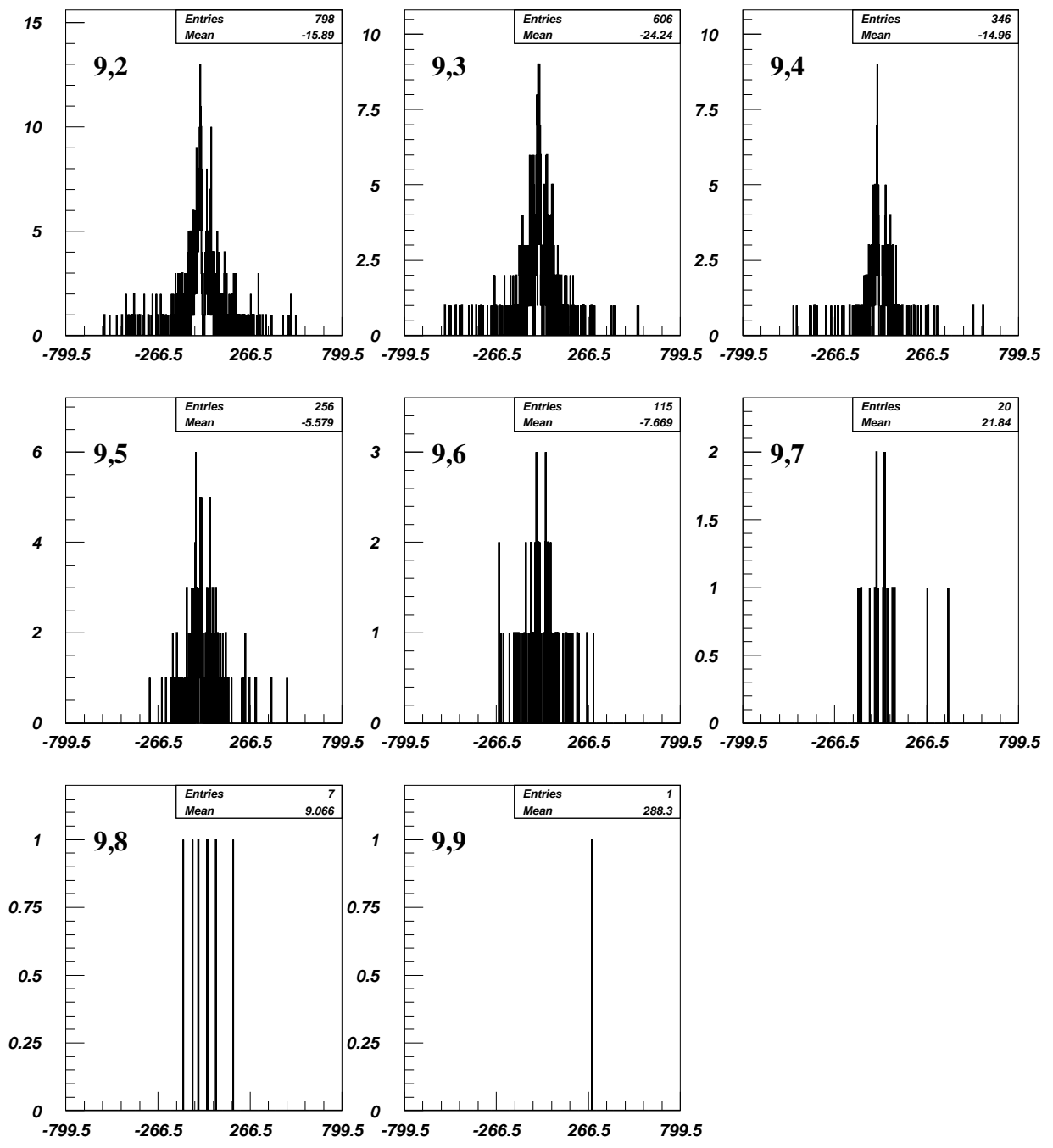

Figura 5.60: Distribuciones de momento. El primer índice: multiplicidad total, el segundo: multiplicidad con momento (neg $578 \mathrm{C}$ ). 
Distribuciones del momento de las trayectorias para eventos producidos por un haz de mesones
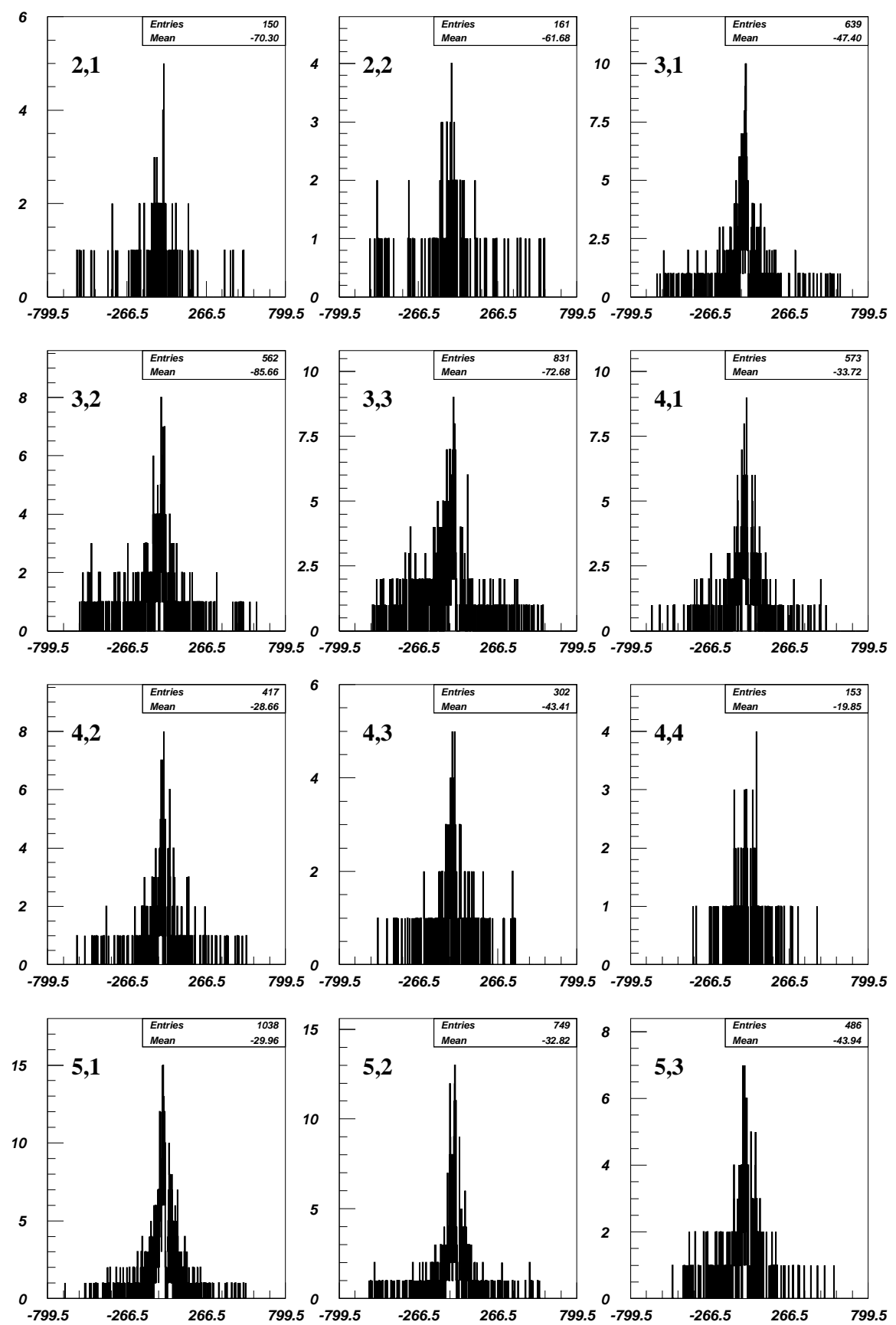

Figura 5.61: Distribuciones de momento. El primer indice: multiplicidad total, el segundo: multiplicidad con momento (neg $578 \mathrm{C}$ ). 

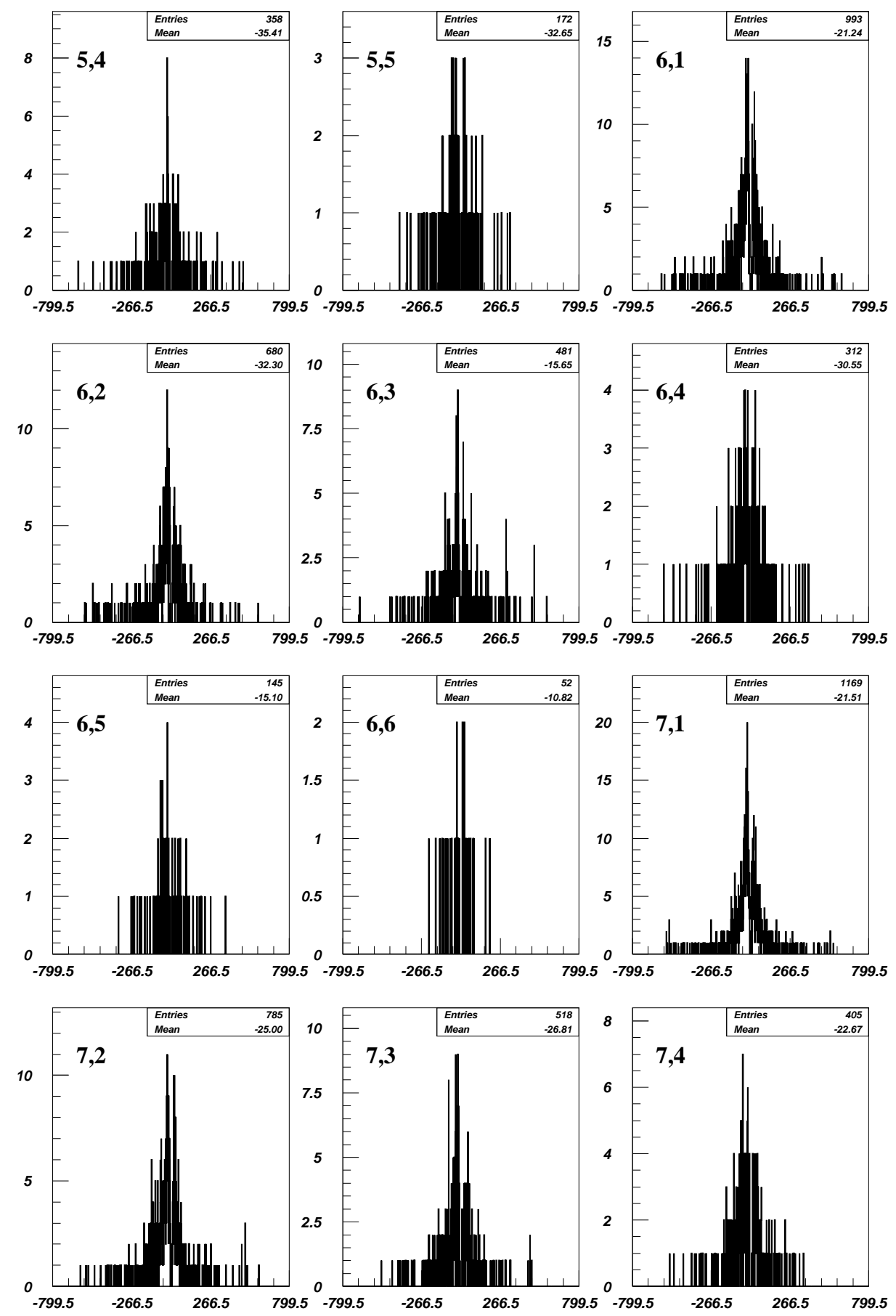

Figura 5.62: Distribuciones de momento. El primer índice: multiplicidad total, el segundo: multiplicidad con momento (neg $578 \mathrm{C}$ ). 

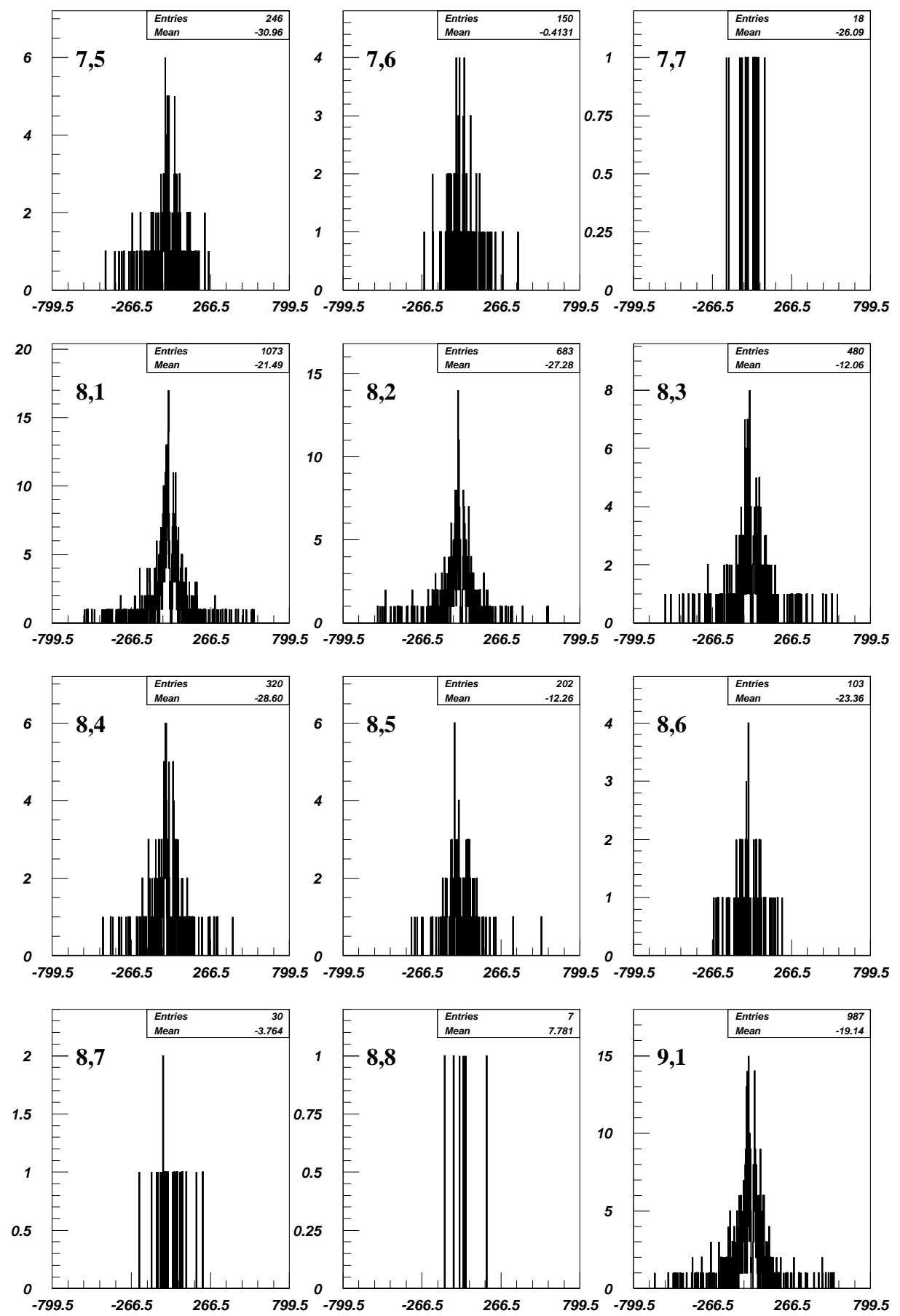

Figura 5.63: Distribuciones de momento. El primer índice: multiplicidad total, el segundo: multiplicidad con momento (neg $578 \mathrm{C}$ ). 

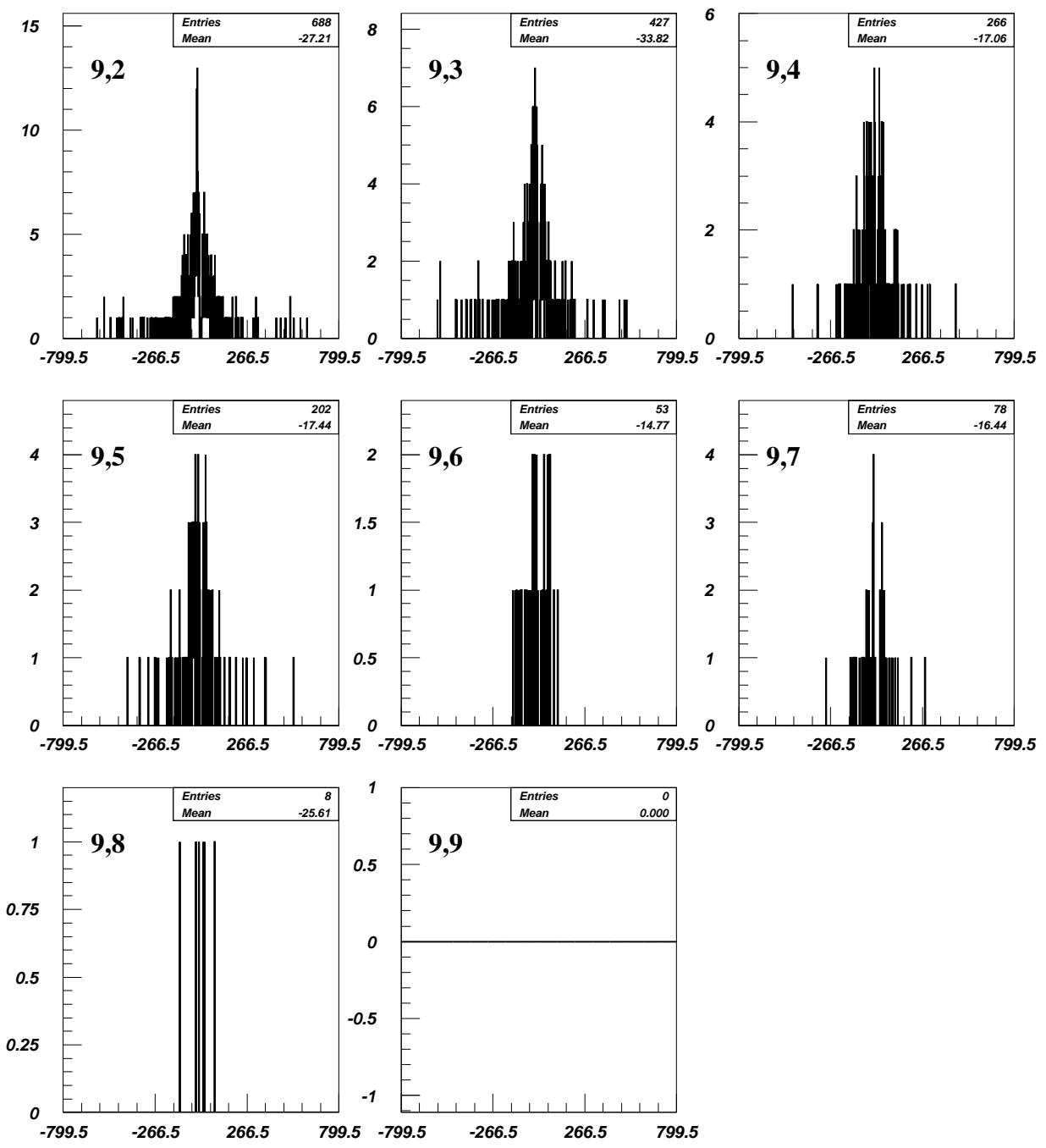

Figura 5.64: Distribuciones de momento. El primer índice: multiplicidad total, el segundo: multiplicidad con momento (neg $578 \mathrm{C}$ ). 


\subsection{Haz de polaridad negativa, con momento $614 \mathrm{GeV}$, con blanco de producción para el haz secundario de carbón}

\subsubsection{Histogramas de control}
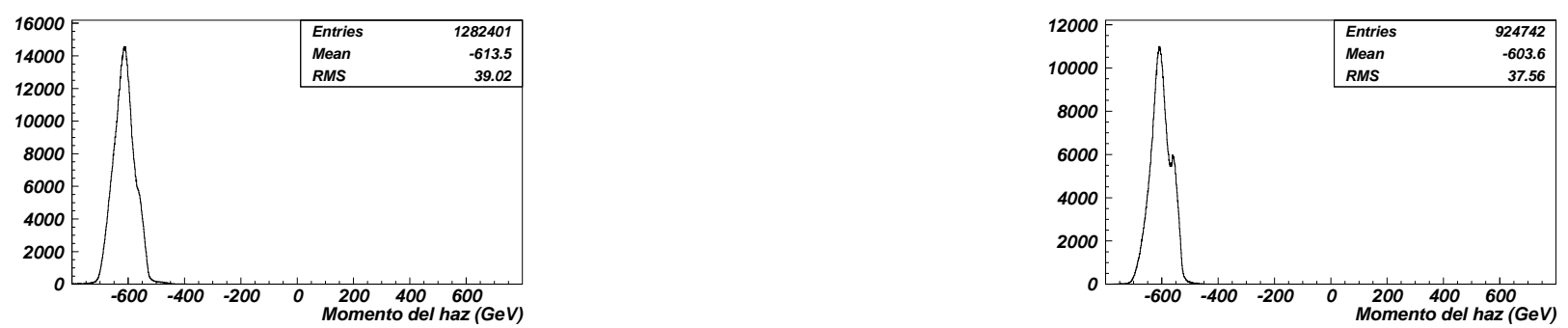

Figura 5.65: Distribución de momento del haz primario. Izquierda: bariones. Derecha: mesones (neg $614 \mathrm{C})$.

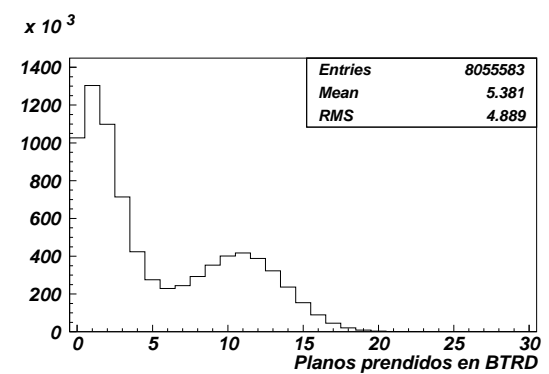

Figura 5.66: Planos prendidos en BTRD. Proporción bariónica y mesónica del haz primario (neg $614 \mathrm{C})$.
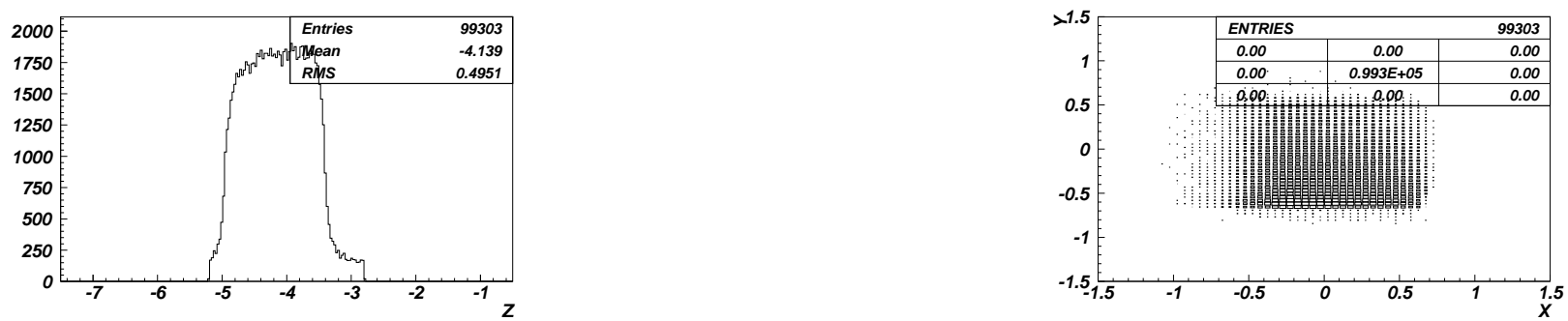

Figura 5.67: Vértice primario. Izquierda: coordenada z. Derecha: proyección x,y (neg 614 C). 


\subsubsection{Multiplicidad en la región del vértice}
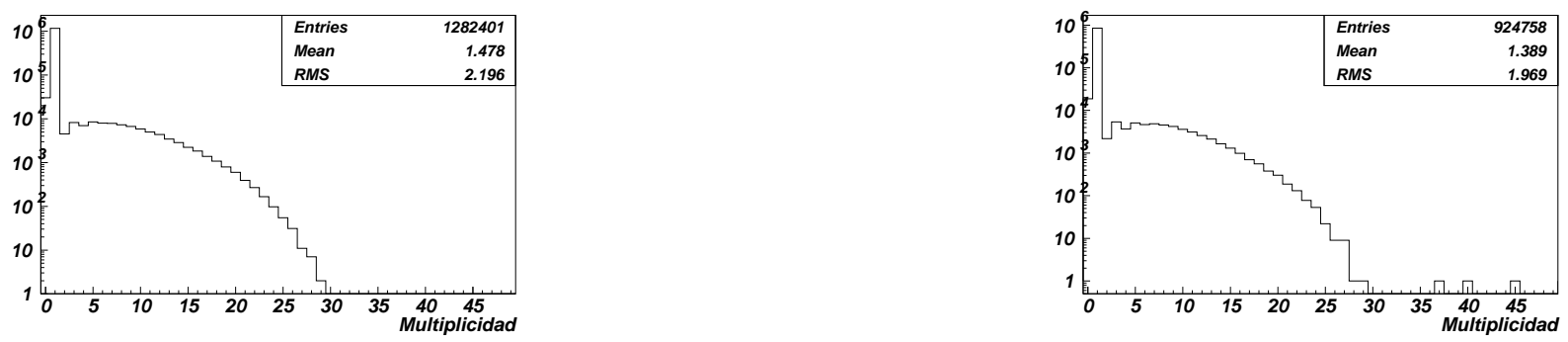

Figura 5.68: Multiplicidad total. Izquierda: haz de bariones. Derecha: haz de mesones (neg $614 \mathrm{C})$.
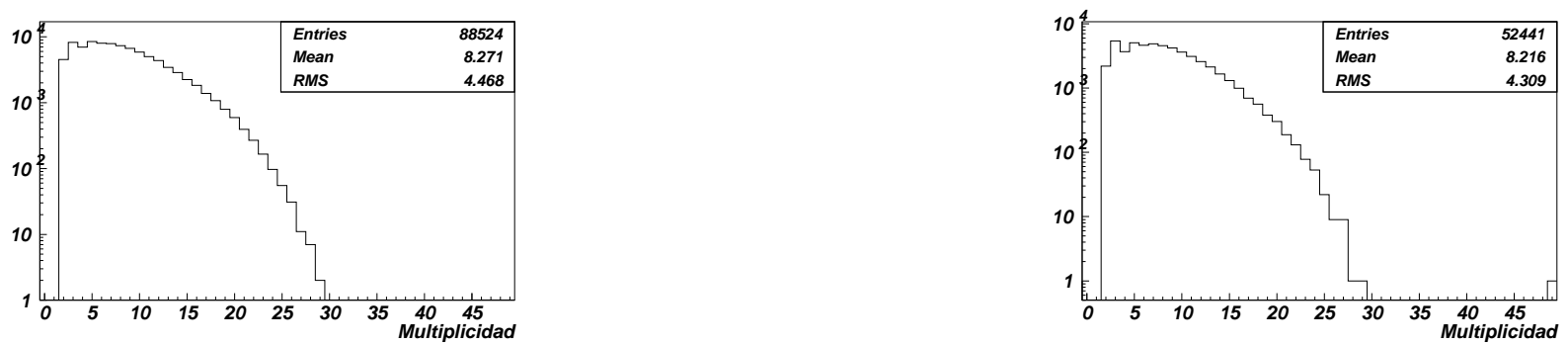

Figura 5.69: Multiplicidad en eventos con más de una trayectoria en la región del vértice. Izquierda: haz de bariones. Derecha: haz de mesones (neg $614 \mathrm{C}$ ). 


\subsubsection{Distribuciones de multiplicidad y momento}
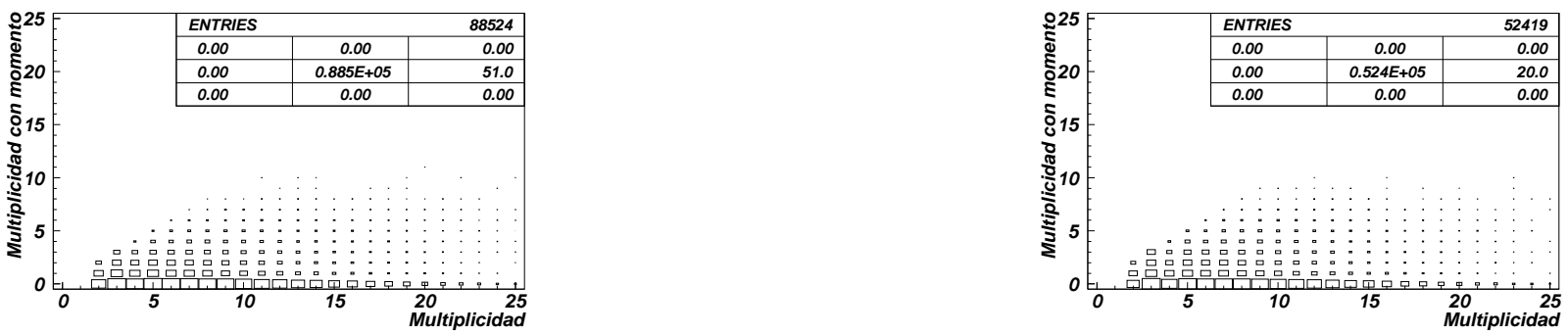

Figura 5.70: Multiplicidad total contra multiplicidad con momento medido. Izquierda: haz de bariones. Derecha: haz de mesones (neg 614 C).
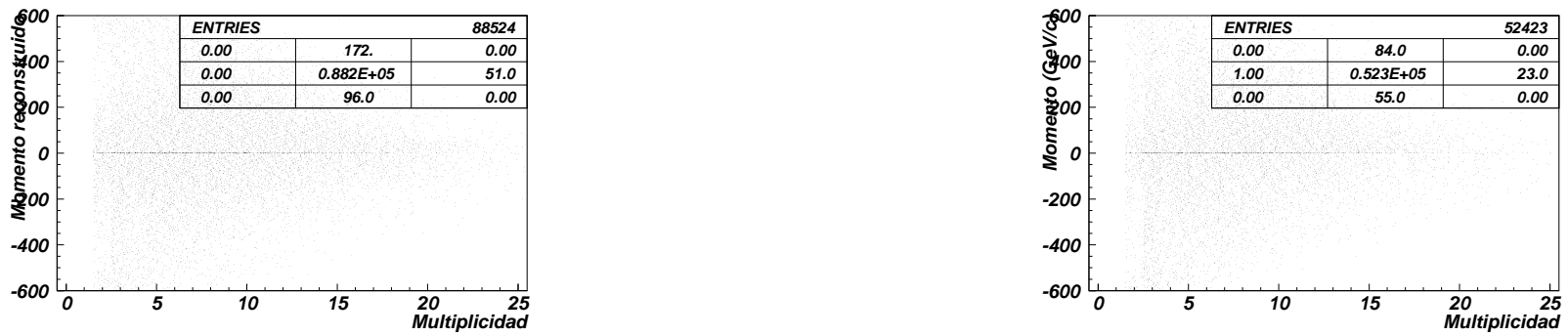

Figura 5.71: Multiplicidad contra momento.Izquierda: haz de bariones. Derecha: haz de mesones (neg $614 \mathrm{C})$. 
Distribuciones de momento total para eventos producidos por un haz de bariones
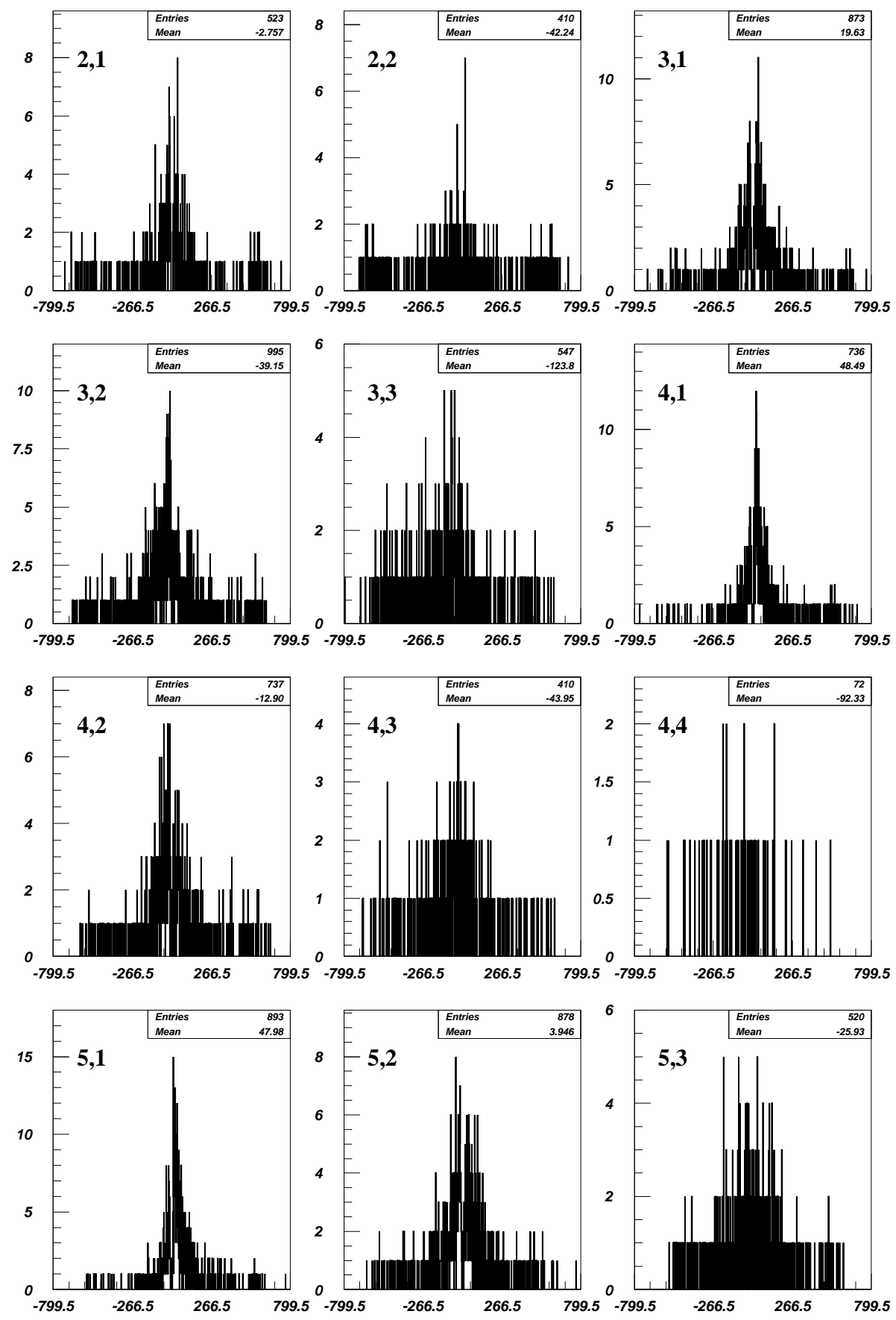

Figura 5.72: Distribuciones de momento. El primer indice: multiplicidad total, el segundo: multiplicidad con momento (neg $614 \mathrm{C}$ ). 

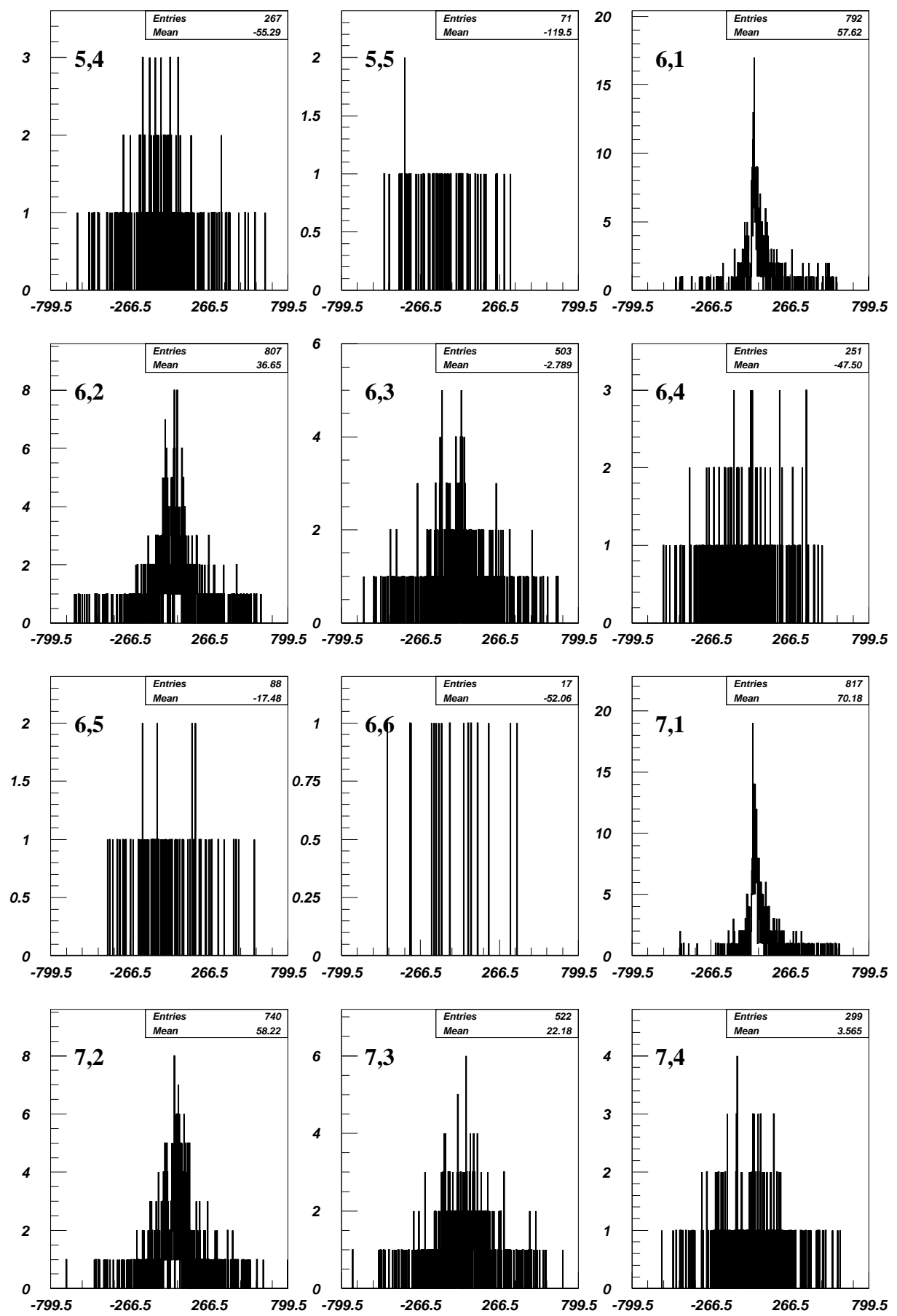

Figura 5.73: Distribuciones de momento. El primer índice: multiplicidad total, el segundo: multiplicidad con momento (neg $614 \mathrm{C}$ ). 

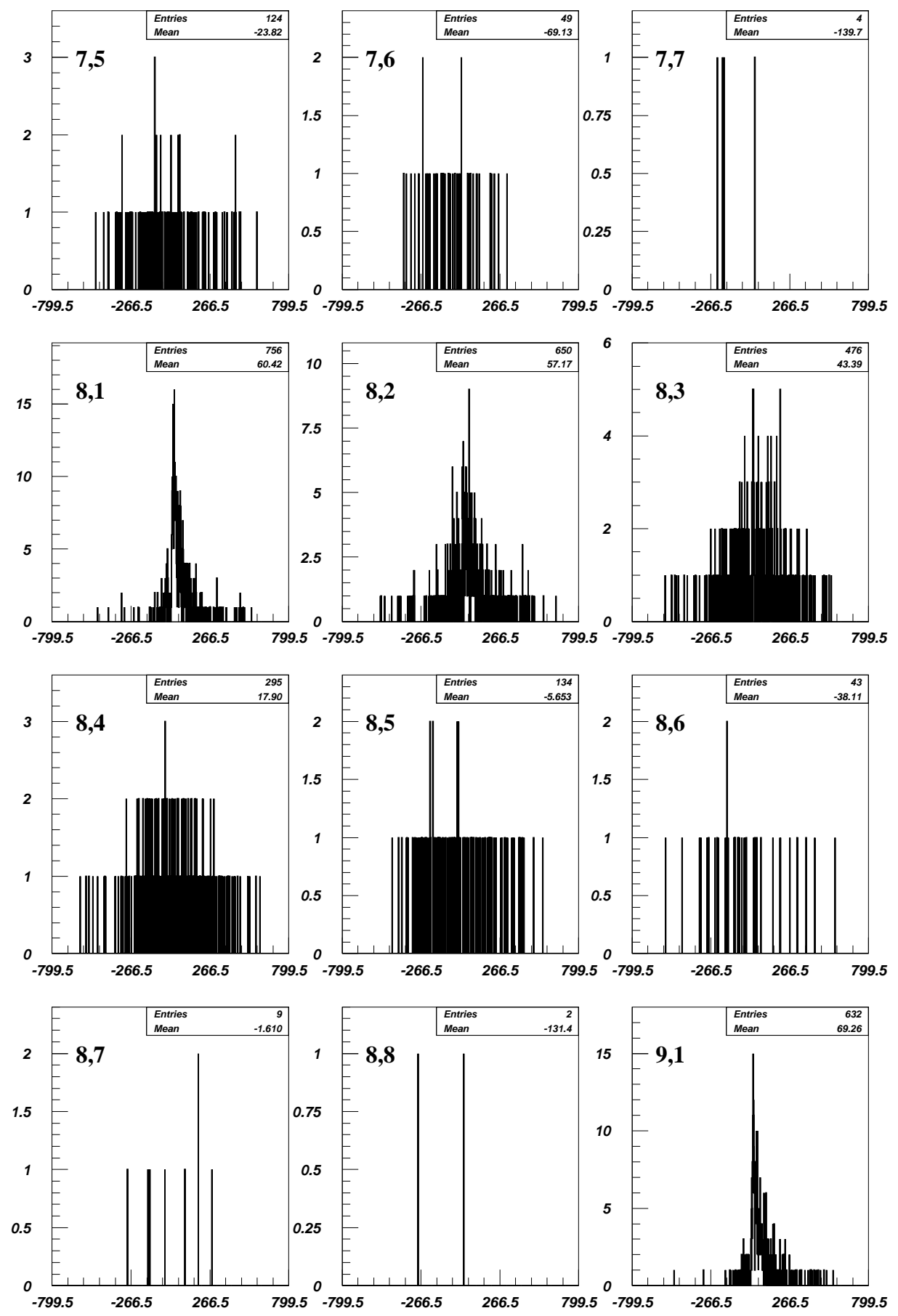

Figura 5.74: Distribuciones de momento. El primer índice: multiplicidad total, el segundo: multiplicidad con momento (neg $614 \mathrm{C}$ ). 

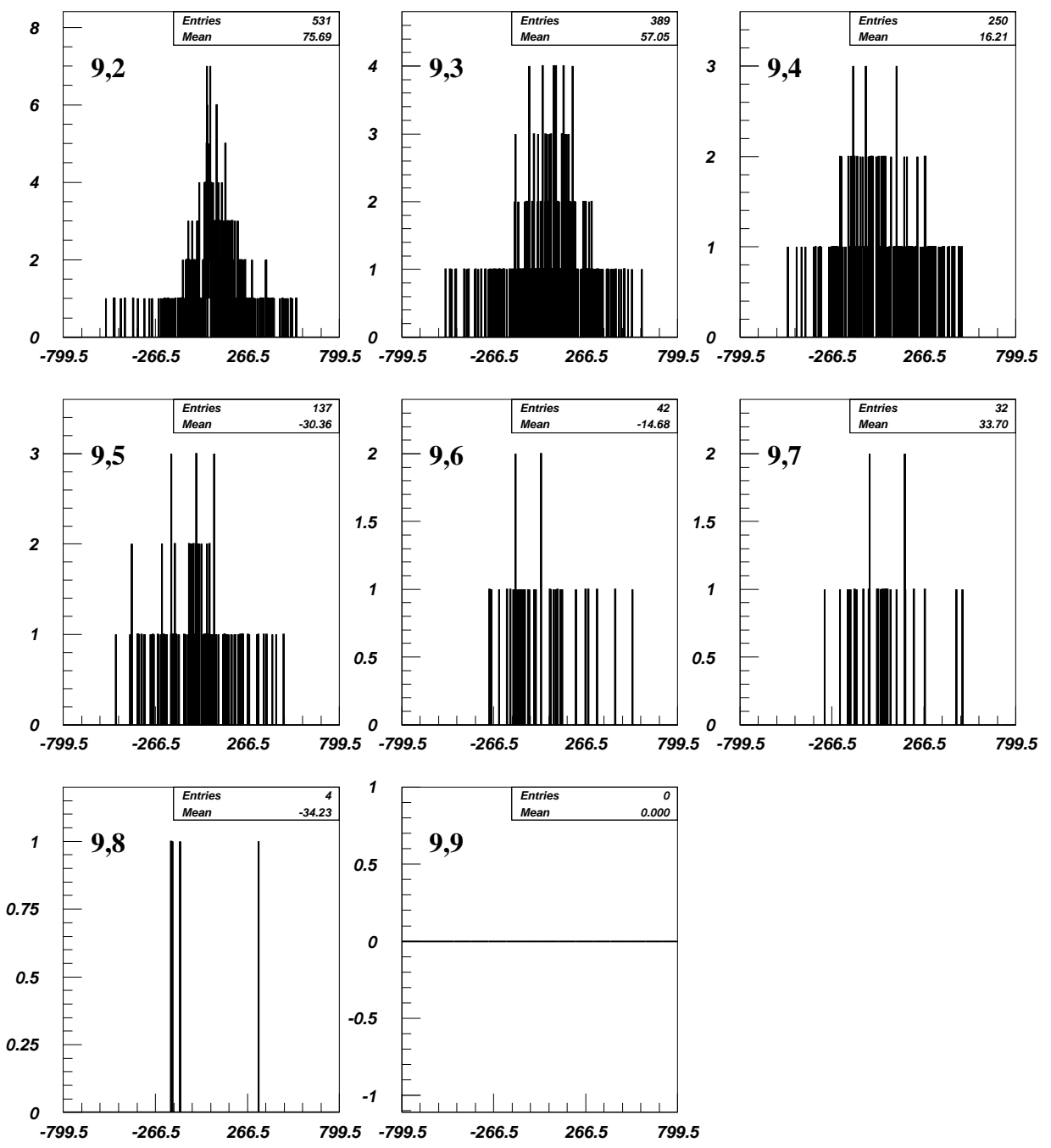

Figura 5.75: Distribuciones de momento. El primer índice: multiplicidad total, el segundo: multiplicidad con momento (neg $614 \mathrm{C}$ ). 
Distribuciones de momento total para eventos producidos por un haz de mesones
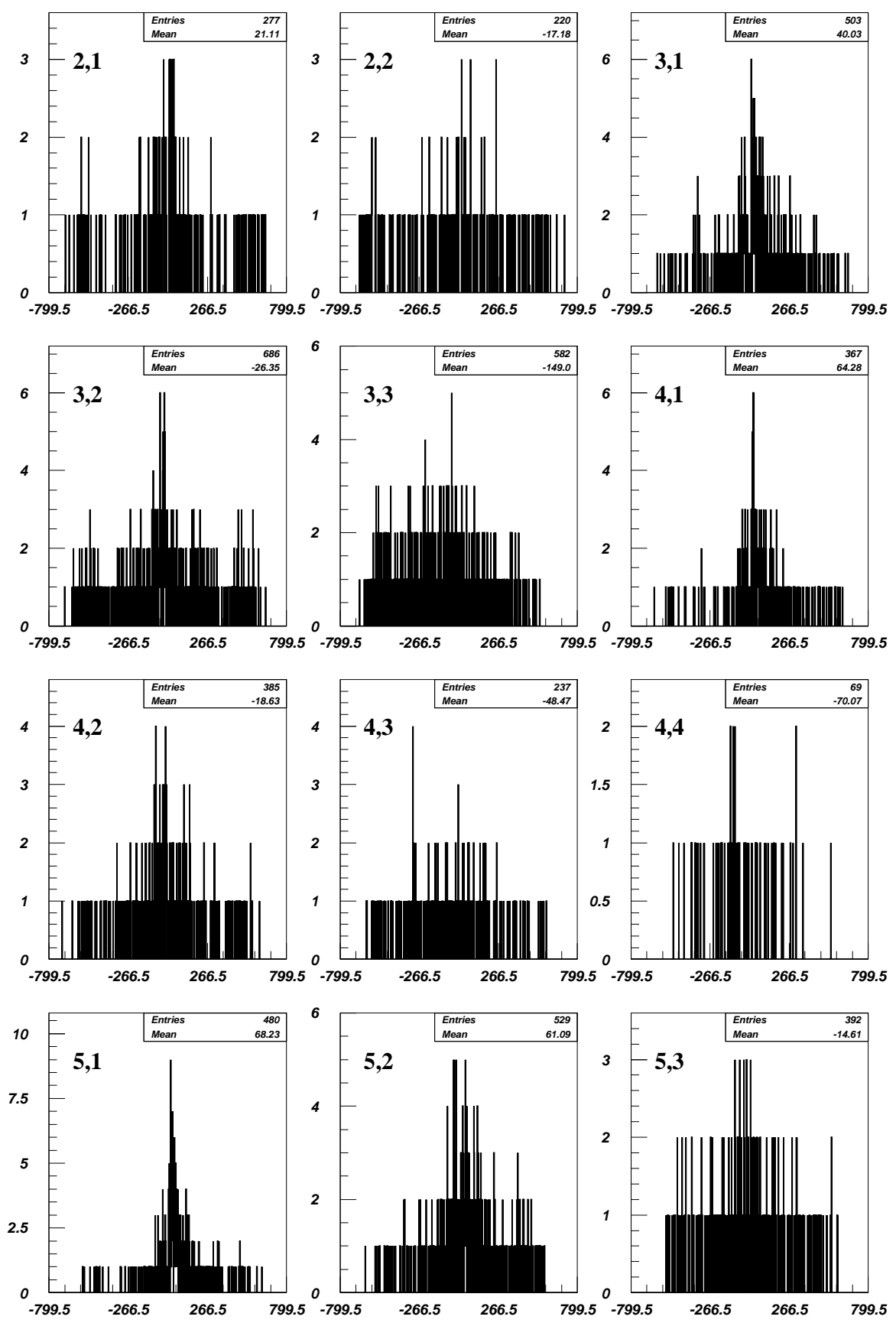

Figura 5.76: Distribuciones de momento. El primer indice: multiplicidad total, el segundo: multiplicidad con momento (neg $614 \mathrm{C}$ ). 

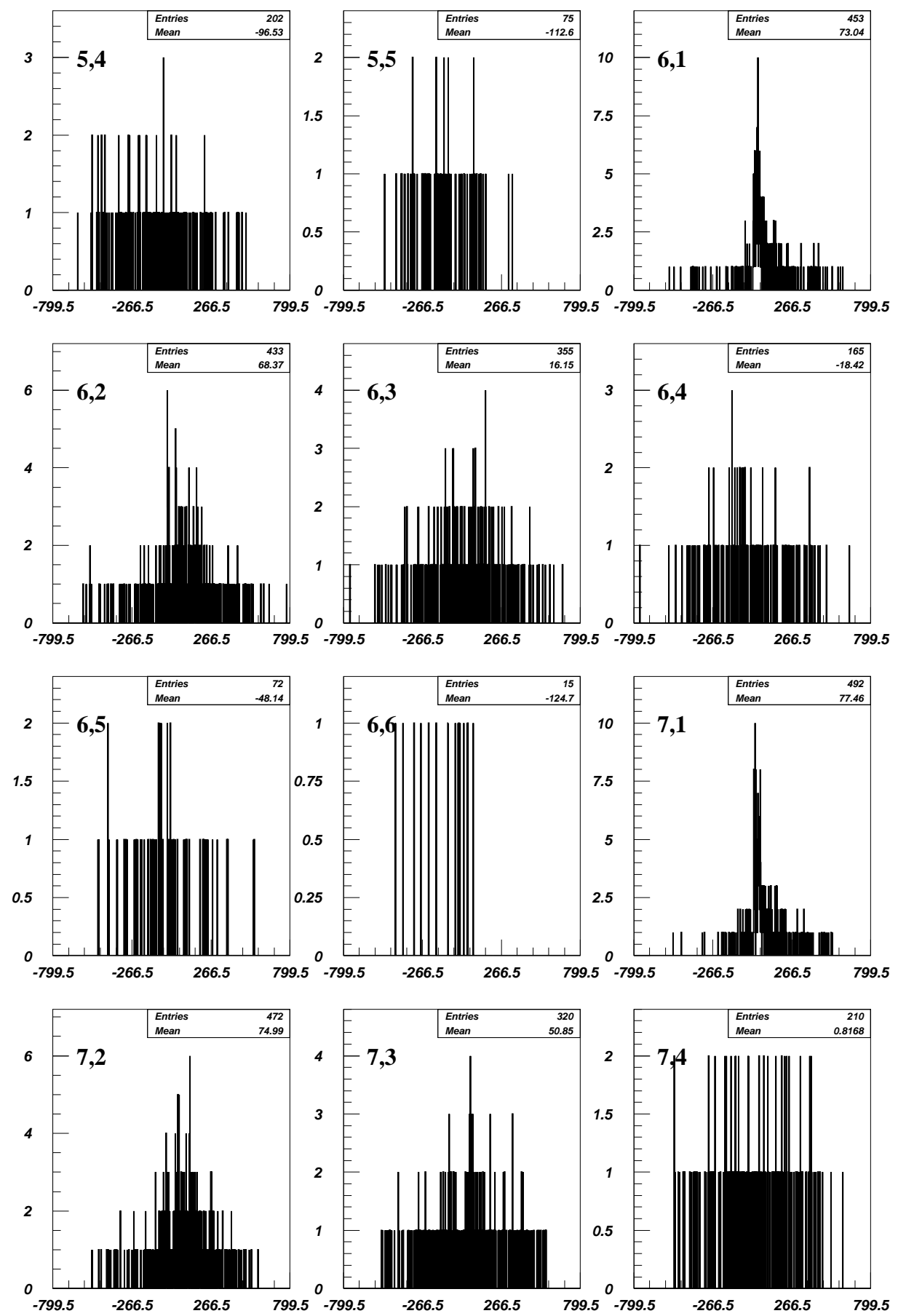

Figura 5.77: Distribuciones de momento. El primer índice: multiplicidad total, el segundo: multiplicidad con momento (neg $614 \mathrm{C}$ ). 

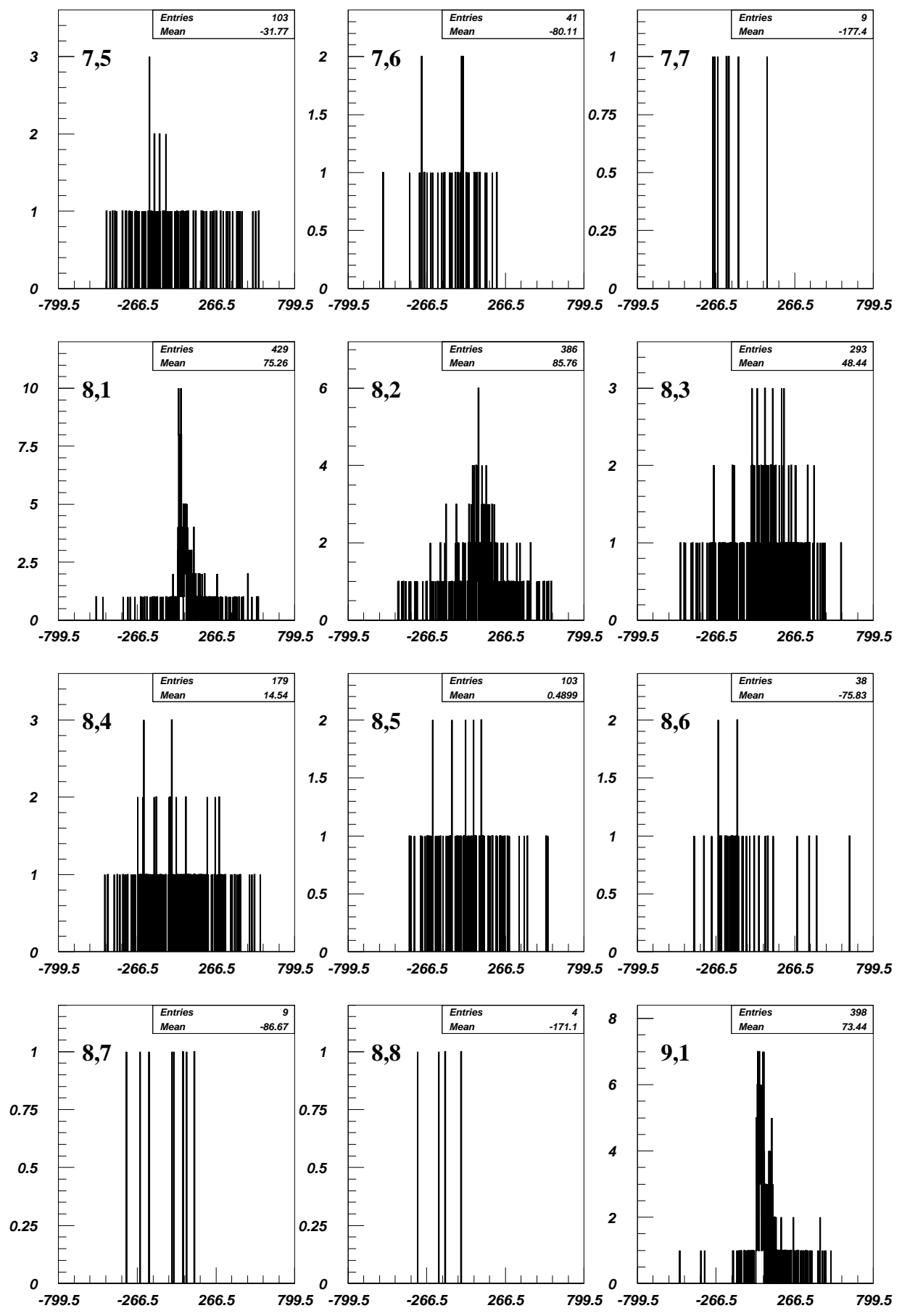

Figura 5.78: Distribuciones de momento. El primer índice: multiplicidad total, el segundo: multiplicidad con momento (neg $614 \mathrm{C}$ ). 

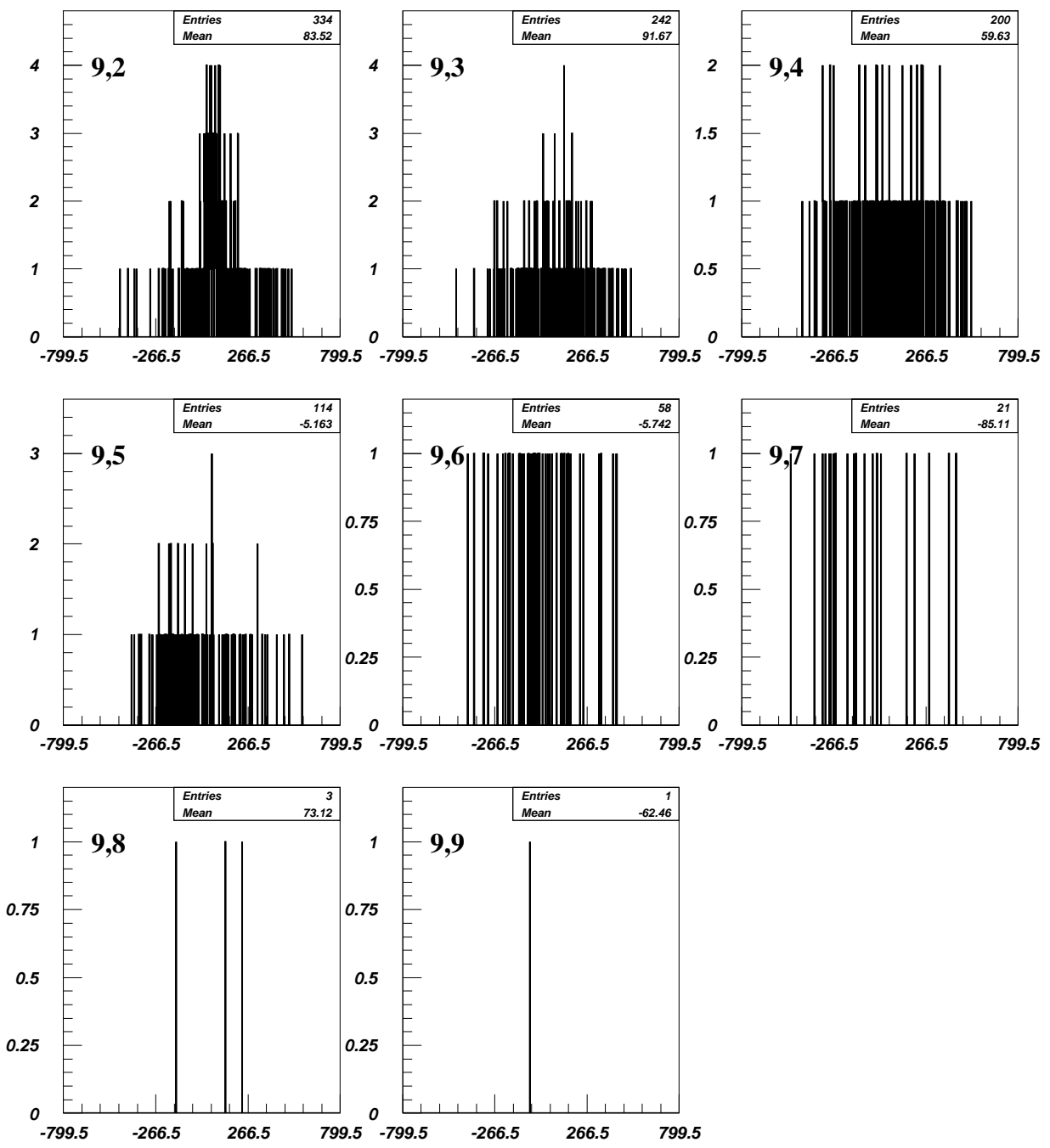

Figura 5.79: Distribuciones de momento. El primer índice: multiplicidad total, el segundo: multiplicidad con momento (neg $614 \mathrm{C}$ ). 
Distribuciones del valor absoluto del momento total para eventos producidos por un haz de bariones
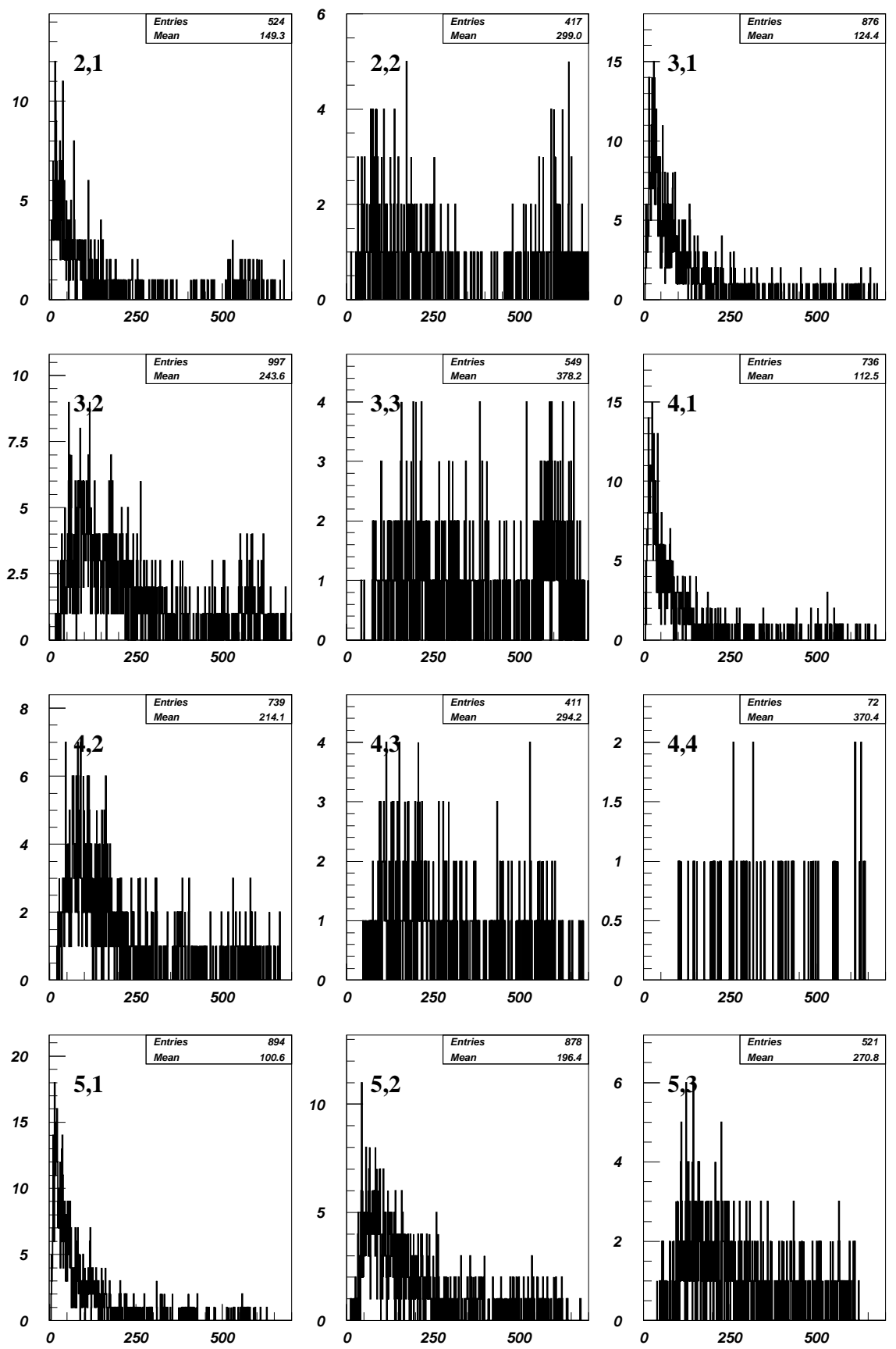

Figura 5.80: Distribuciones de momento. El primer indice: multiplicidad total, el segundo: multiplicidad con momento (neg $614 \mathrm{C}$ ). 

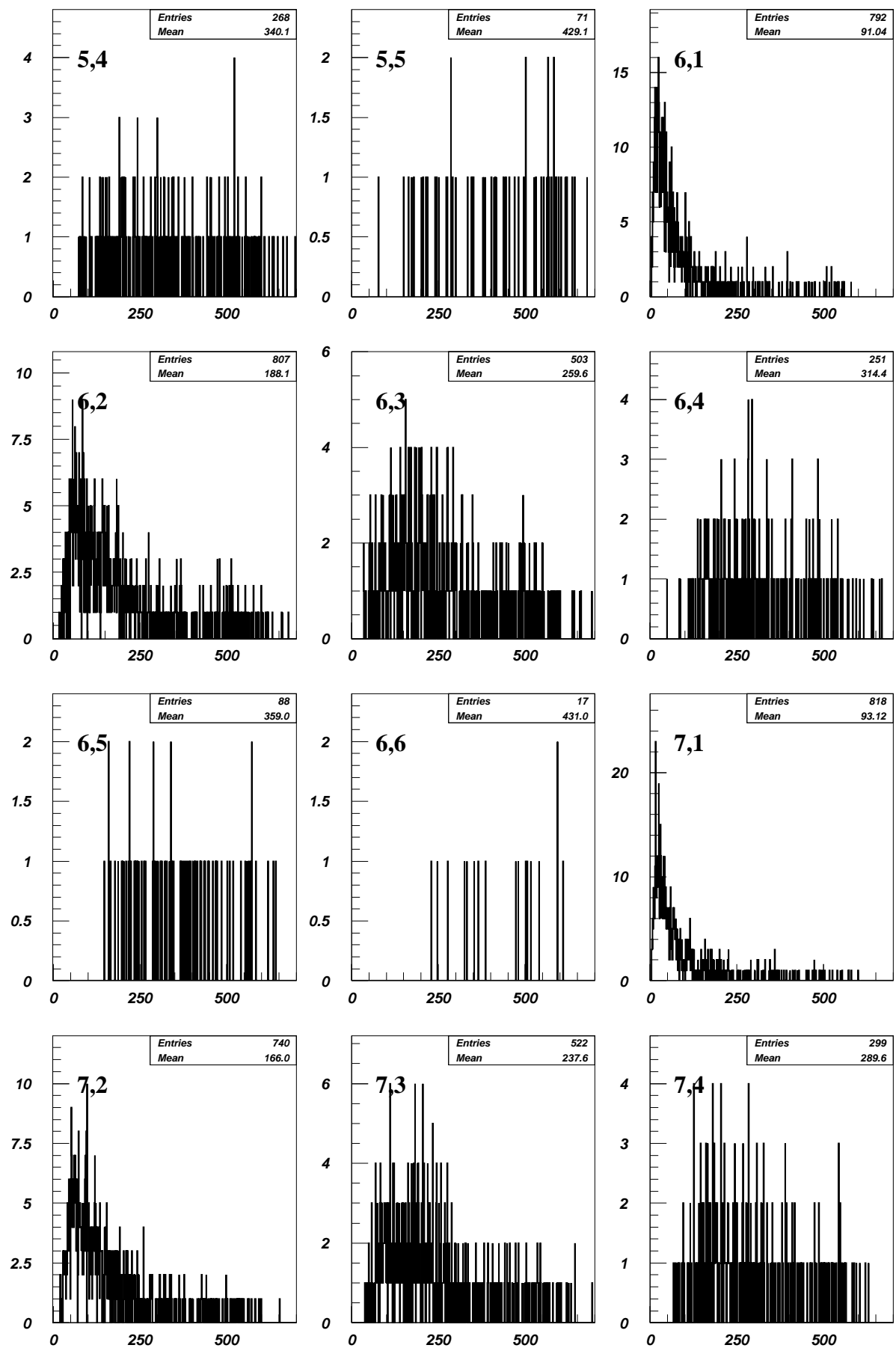

Figura 5.81: Distribuciones de momento. El primer índice: multiplicidad total, el segundo: multiplicidad con momento (neg $614 \mathrm{C}$ ). 

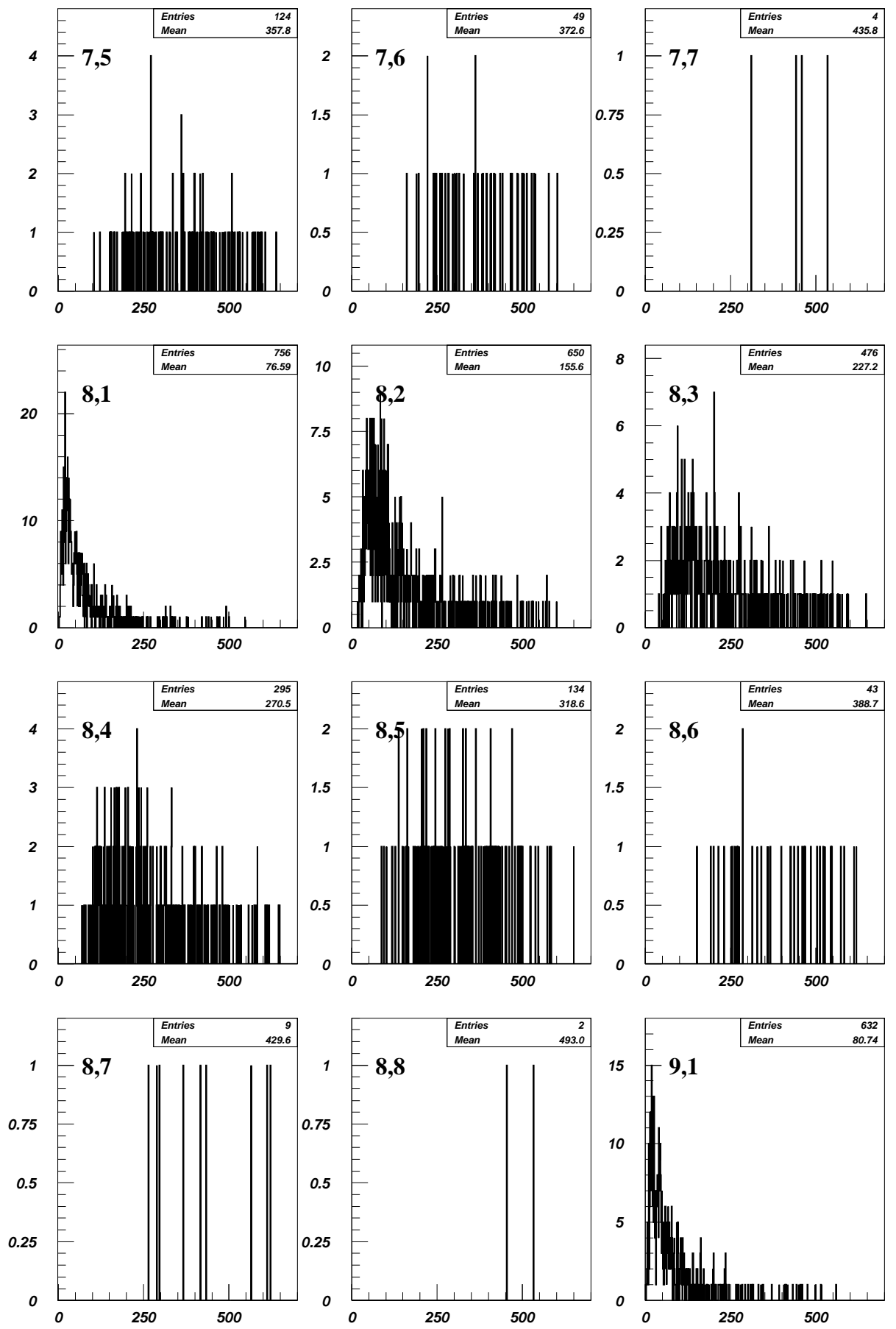

Figura 5.82: Distribuciones de momento. El primer índice: multiplicidad total, el segundo: multiplicidad con momento (neg $614 \mathrm{C}$ ). 

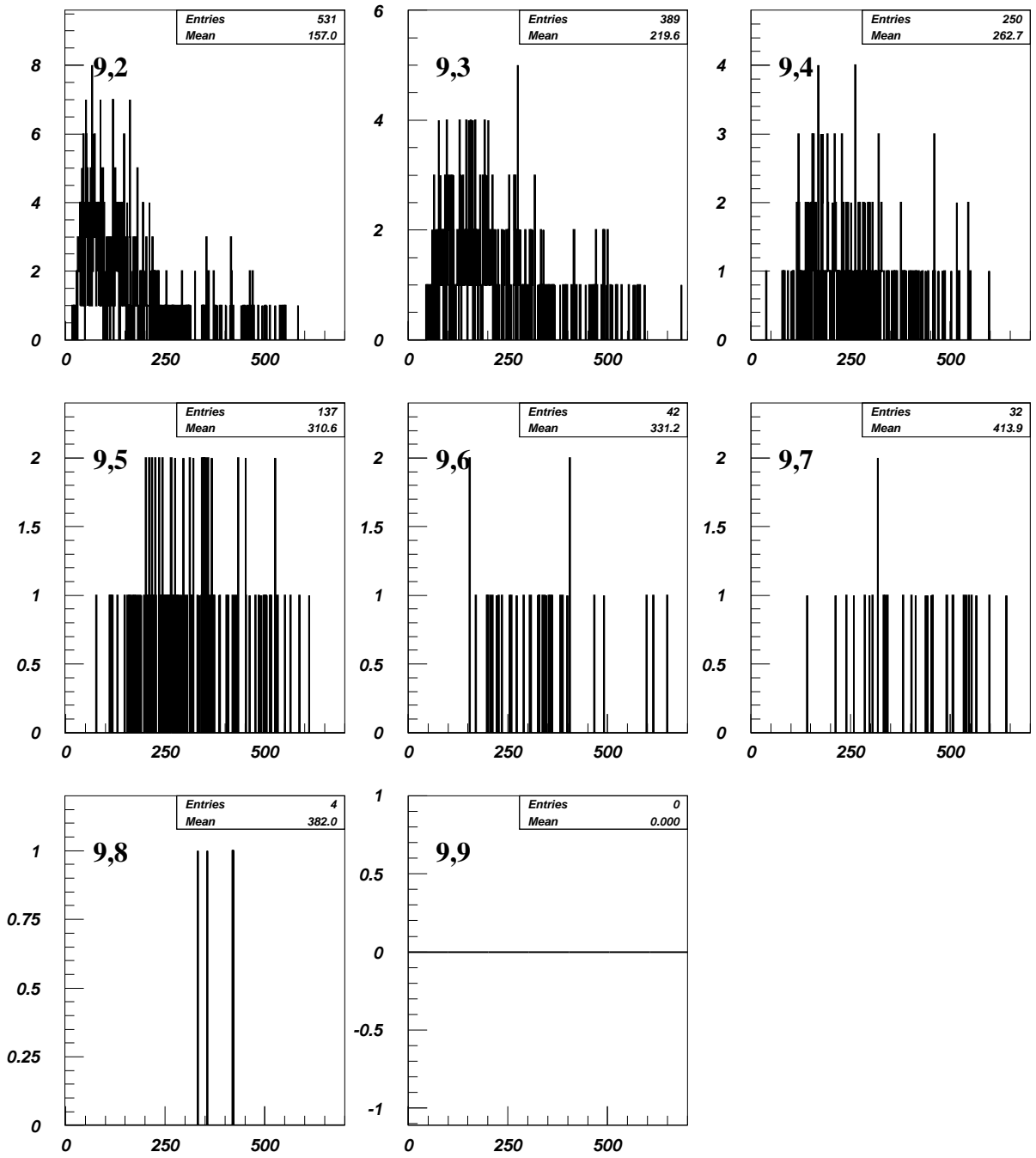

Figura 5.83: Distribuciones de momento. El primer índice: multiplicidad total, el segundo: multiplicidad con momento (neg $614 \mathrm{C}$ ). 
Distribuciones del valor absoluto del momento total para eventos producidos por un haz de mesones
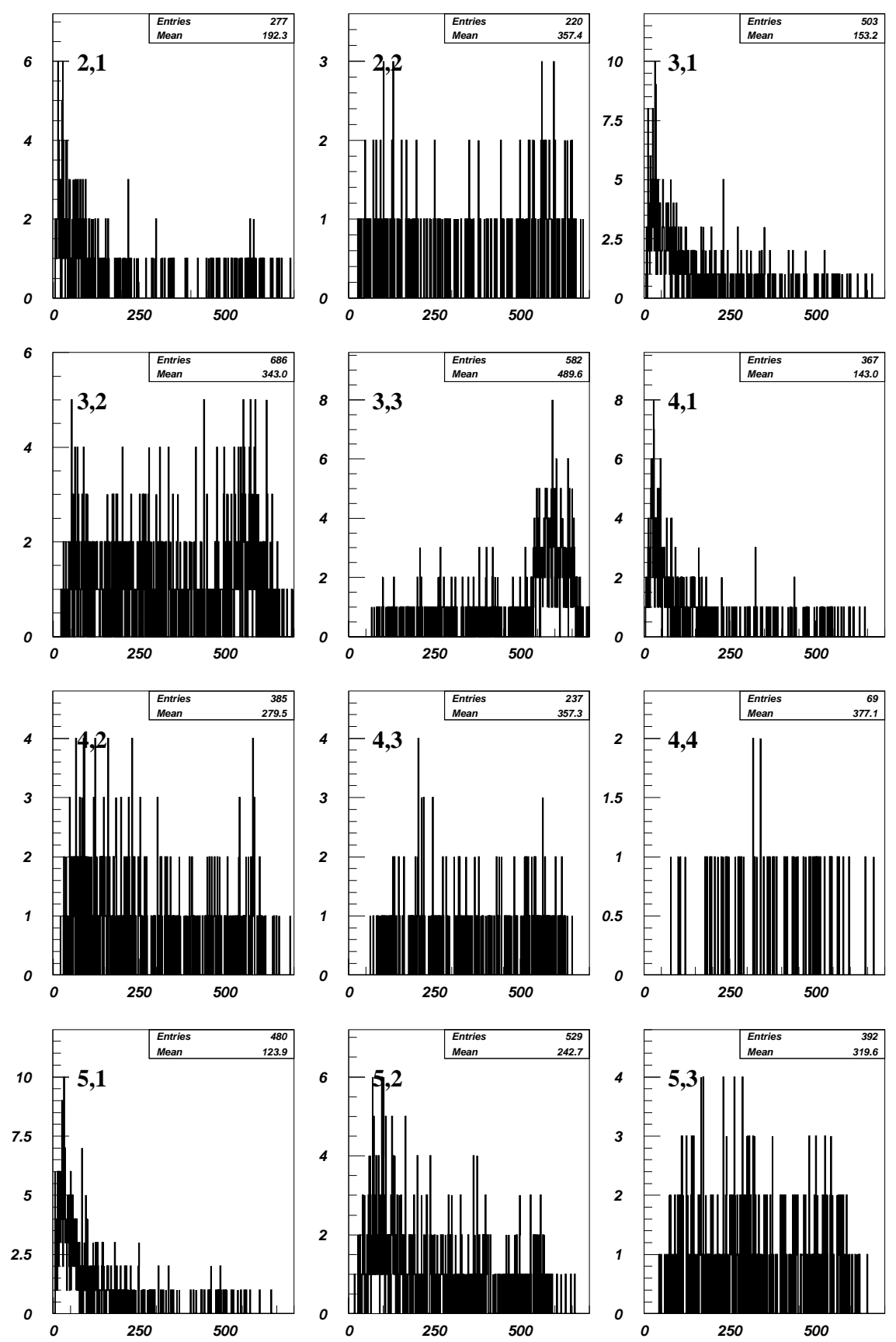

Figura 5.84: Distribuciones de momento. El primer indice: multiplicidad total, el segundo: multiplicidad con momento (neg $614 \mathrm{C}$ ). 

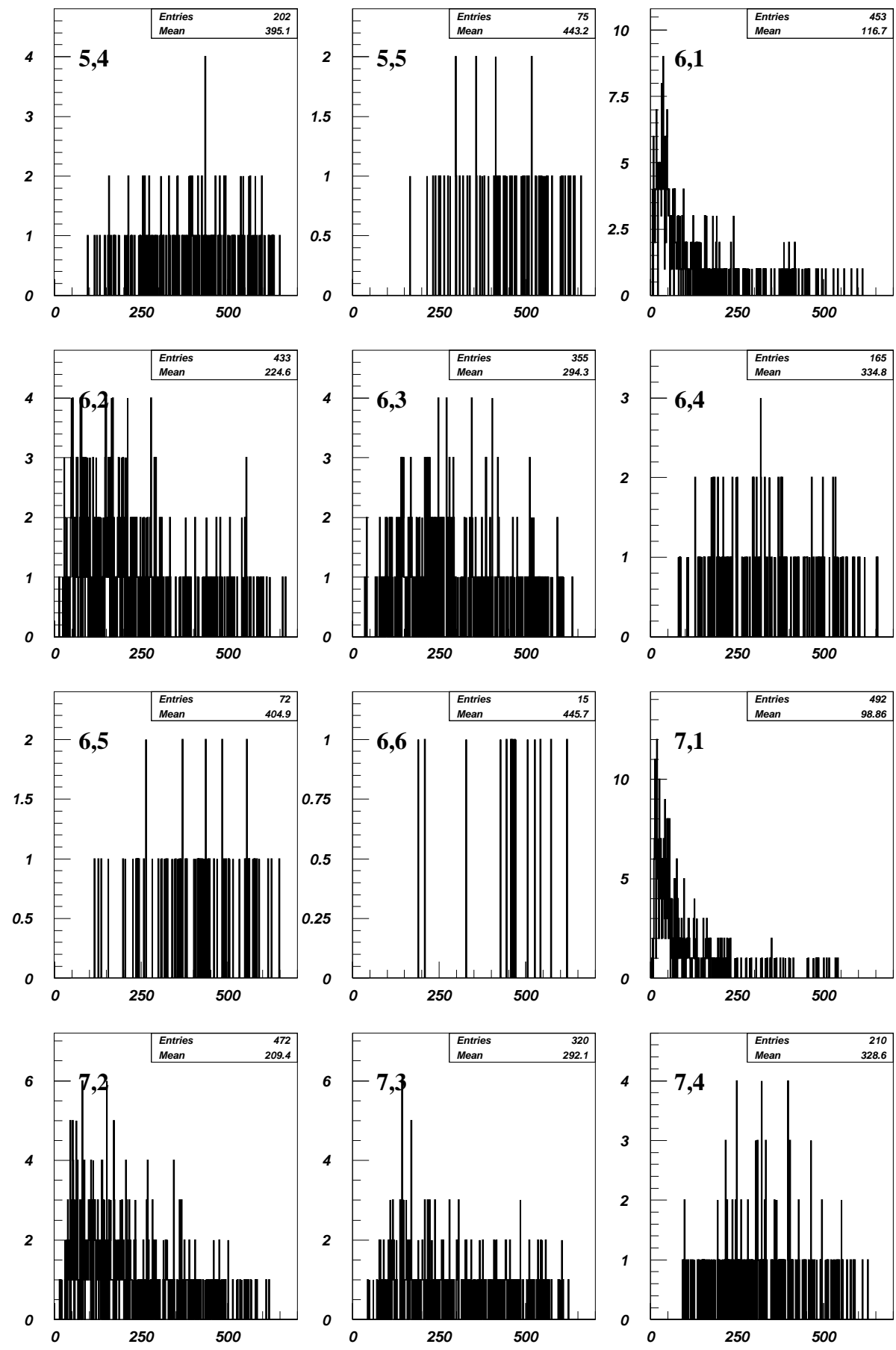

Figura 5.85: Distribuciones de momento. El primer índice: multiplicidad total, el segundo: multiplicidad con momento (neg $614 \mathrm{C}$ ). 

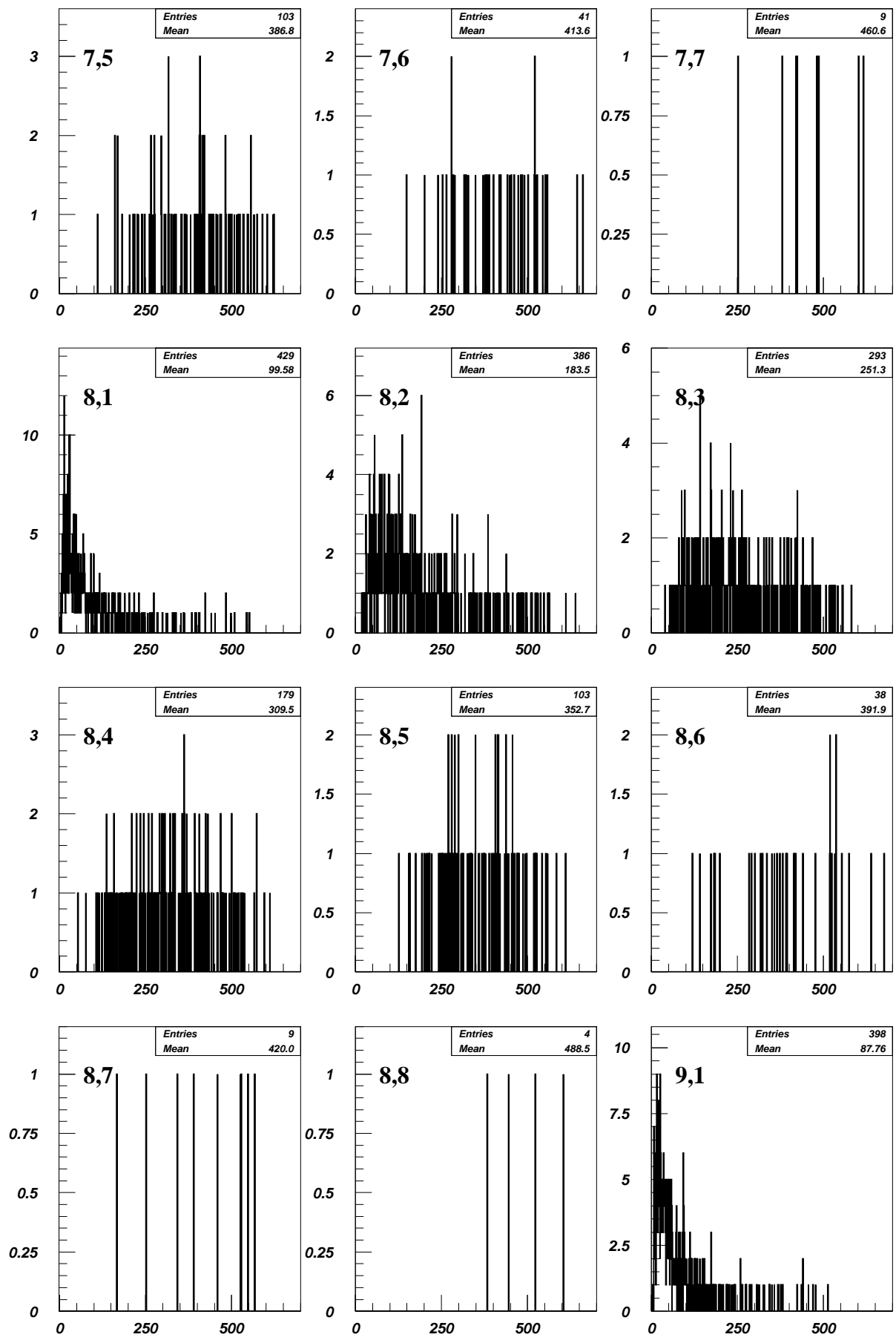

Figura 5.86: Distribuciones de momento. El primer índice: multiplicidad total, el segundo: multiplicidad con momento (neg $614 \mathrm{C}$ ). 

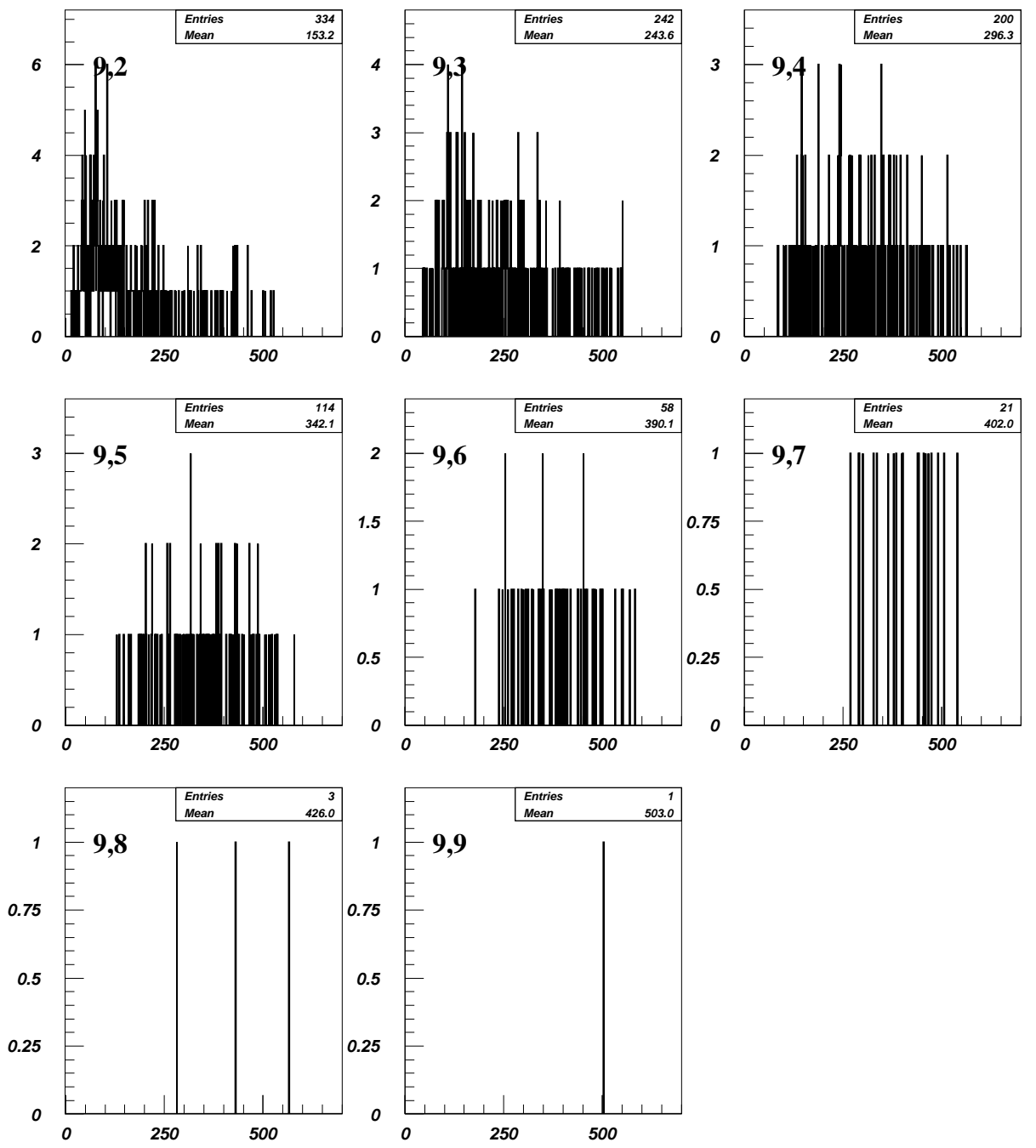

Figura 5.87: Distribuciones de momento. El primer índice: multiplicidad total, el segundo: multiplicidad con momento (neg $614 \mathrm{C}$ ). 
Distribuciones del momento de las trayectorias para eventos producidos por un haz de bariones
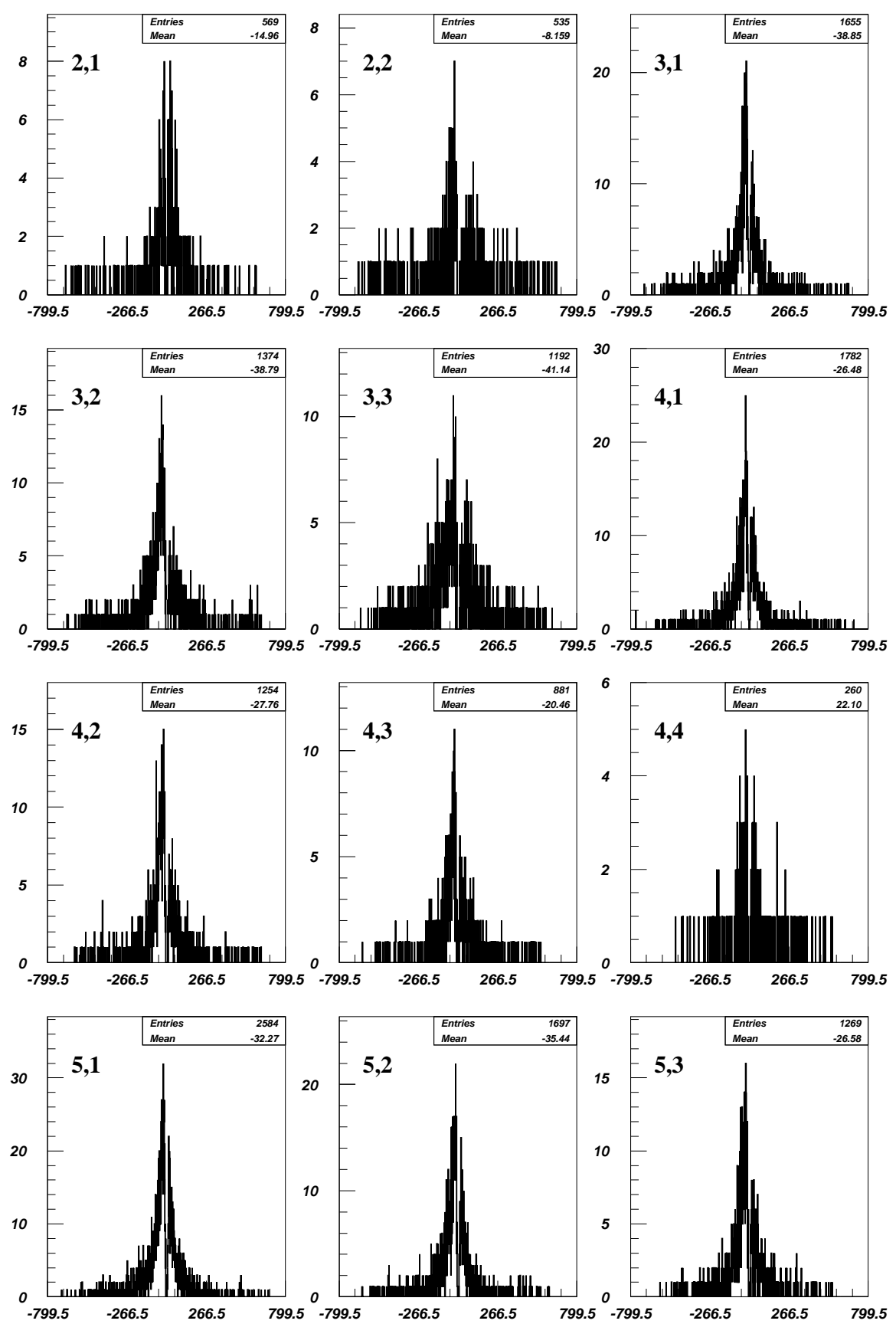

Figura 5.88: Distribuciones de momento. El primer indice: multiplicidad total, el segundo: multiplicidad con momento (neg $614 \mathrm{C}$ ). 

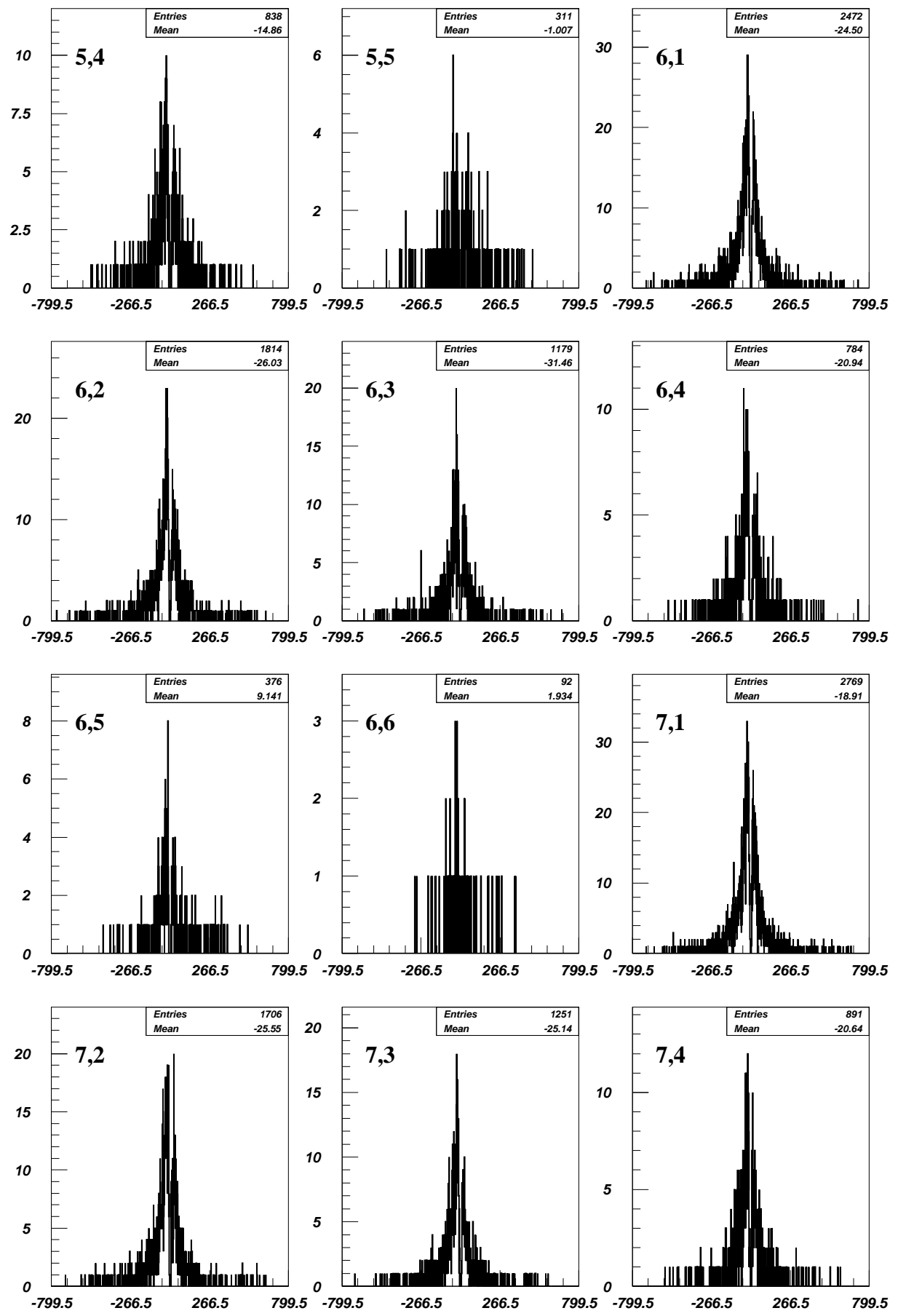

Figura 5.89: Distribuciones de momento. El primer índice: multiplicidad total, el segundo: multiplicidad con momento (neg $614 \mathrm{C}$ ). 

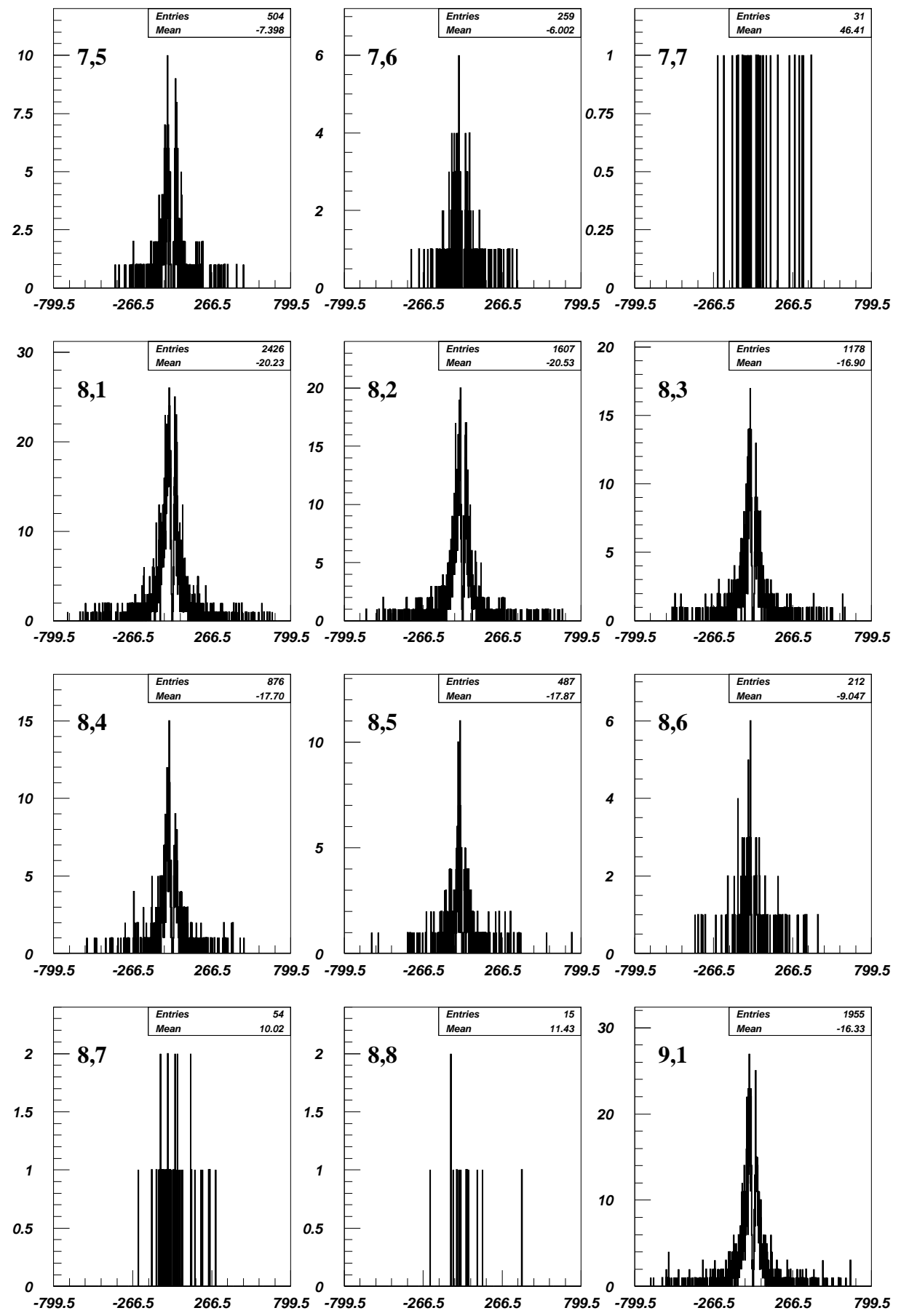

Figura 5.90: Distribuciones de momento. El primer índice: multiplicidad total, el segundo: multiplicidad con momento (neg $614 \mathrm{C}$ ). 

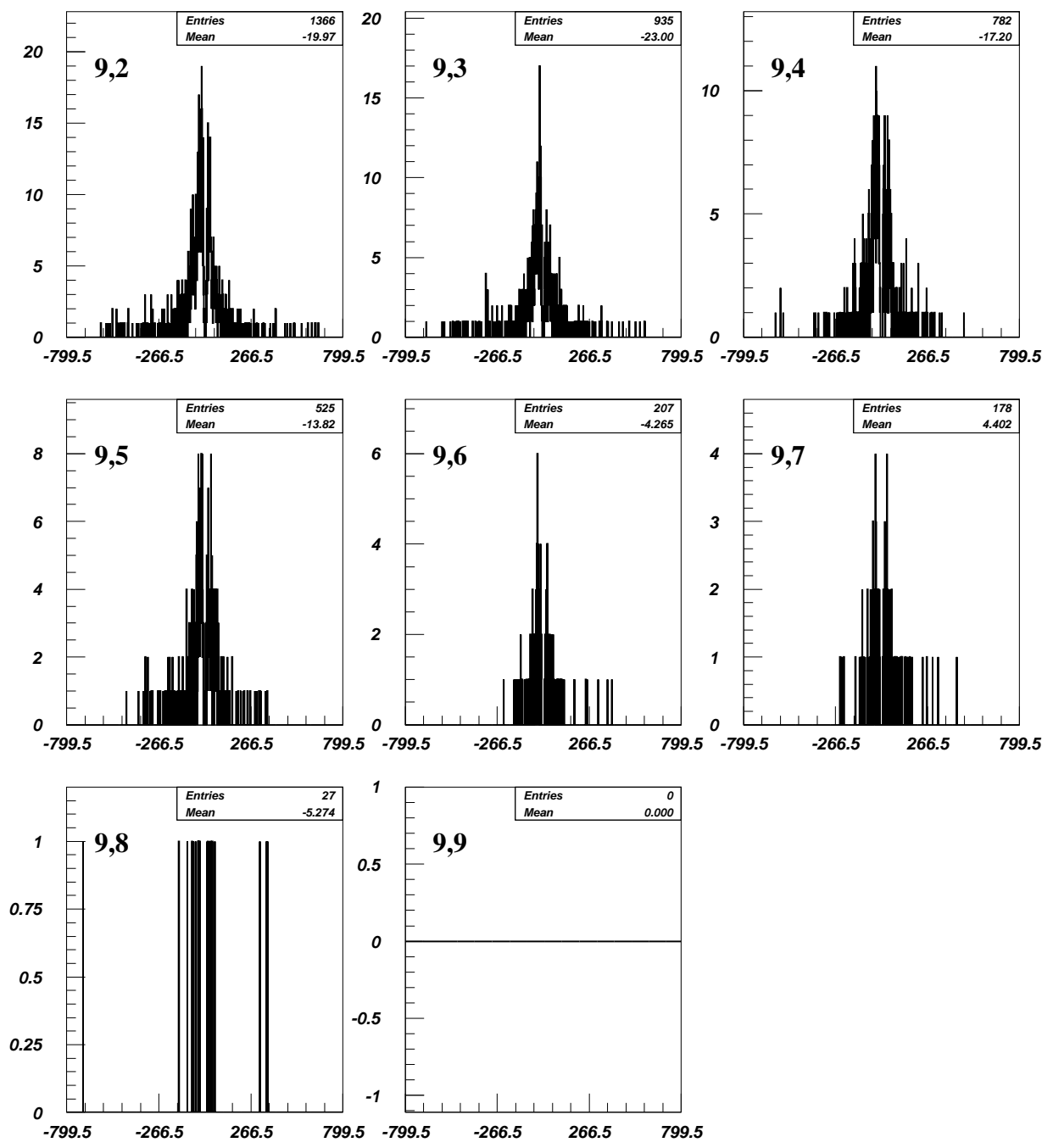

Figura 5.91: Distribuciones de momento. El primer índice: multiplicidad total, el segundo: multiplicidad con momento (neg $614 \mathrm{C}$ ). 
Distribuciones del momento de las trayectorias para eventos producidos por un haz de mesones
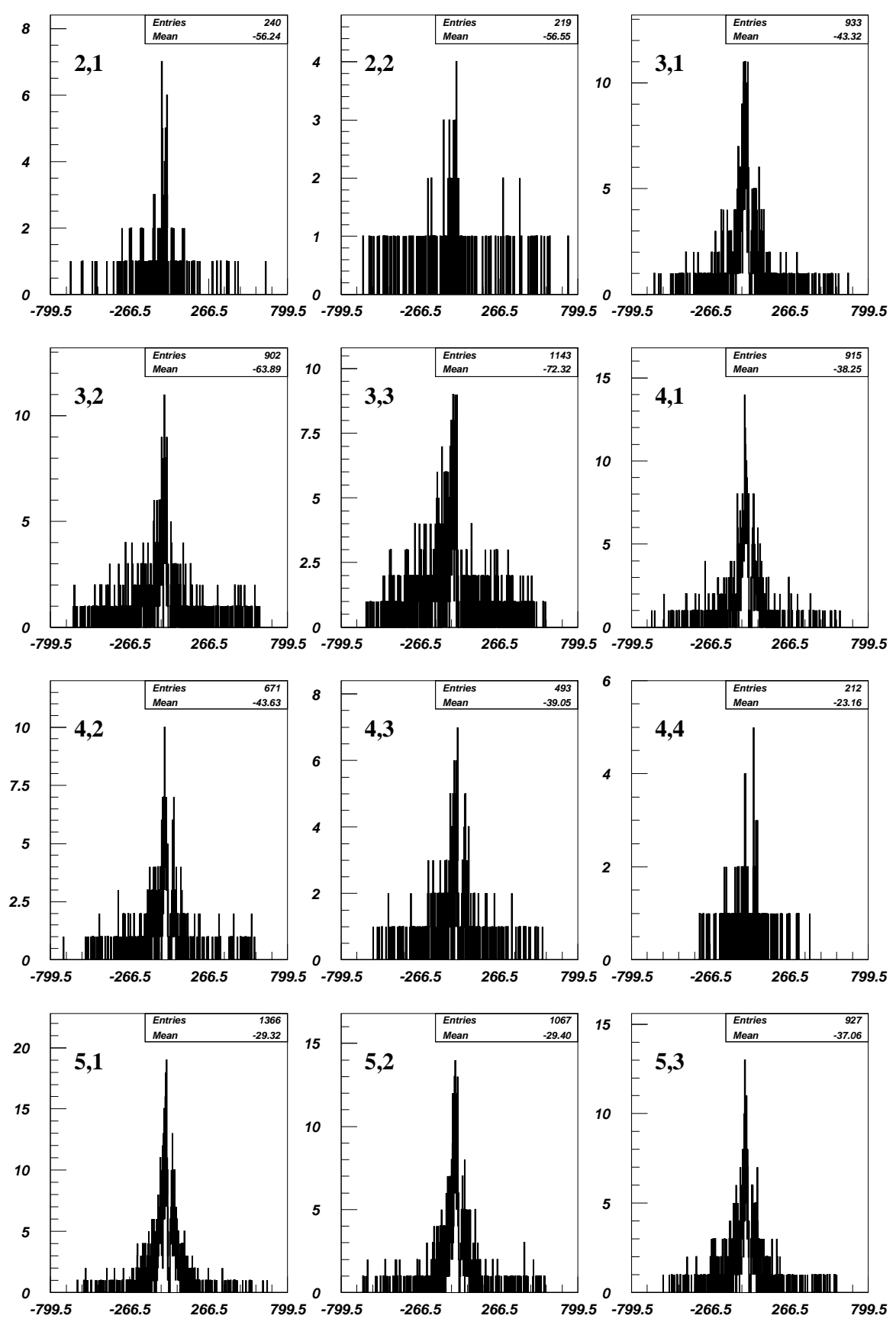

Figura 5.92: Distribuciones de momento. El primer indice: multiplicidad total, el segundo: multiplicidad con momento (neg $614 \mathrm{C}$ ). 

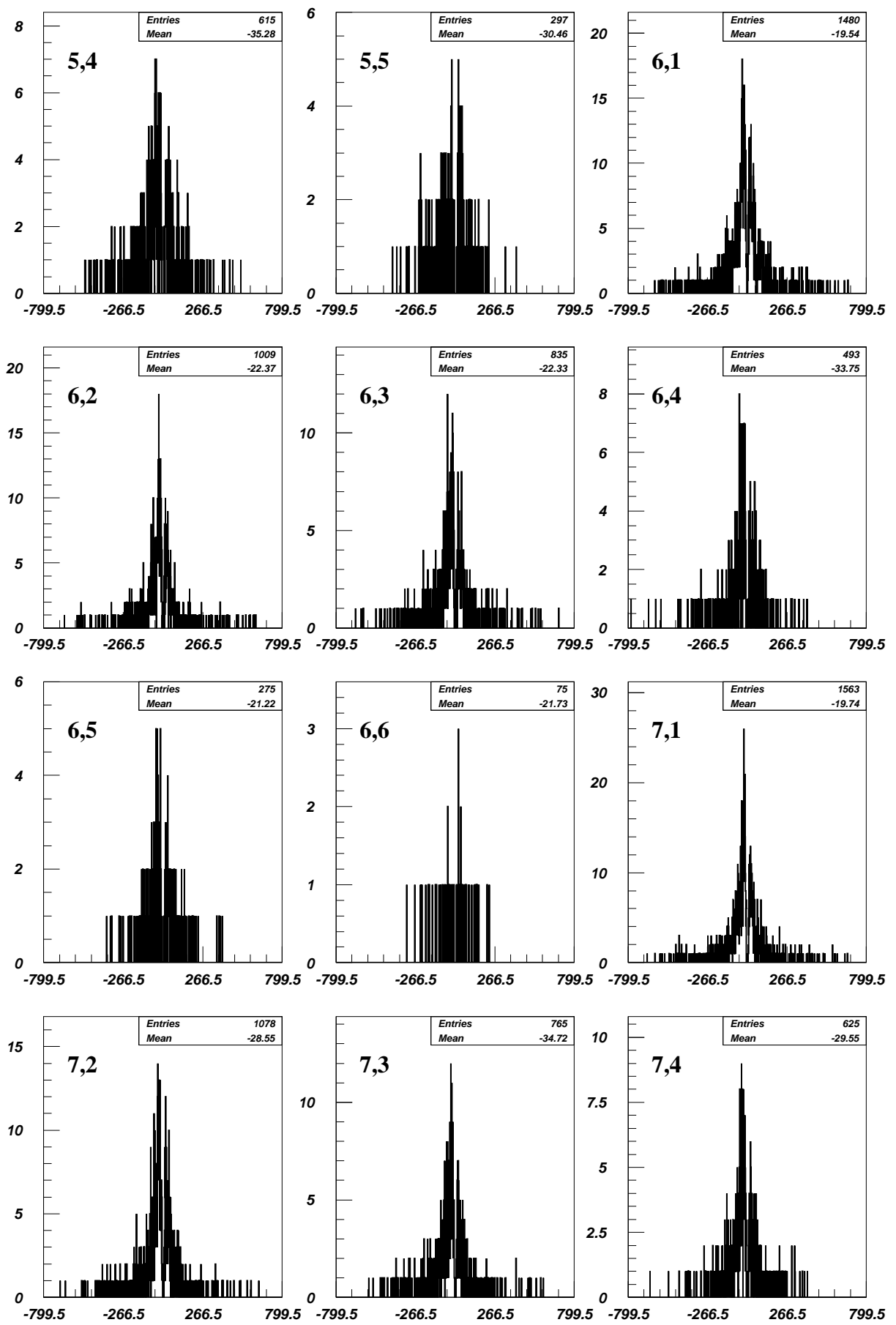

Figura 5.93: Distribuciones de momento. El primer índice: multiplicidad total, el segundo: multiplicidad con momento (neg $614 \mathrm{C}$ ). 

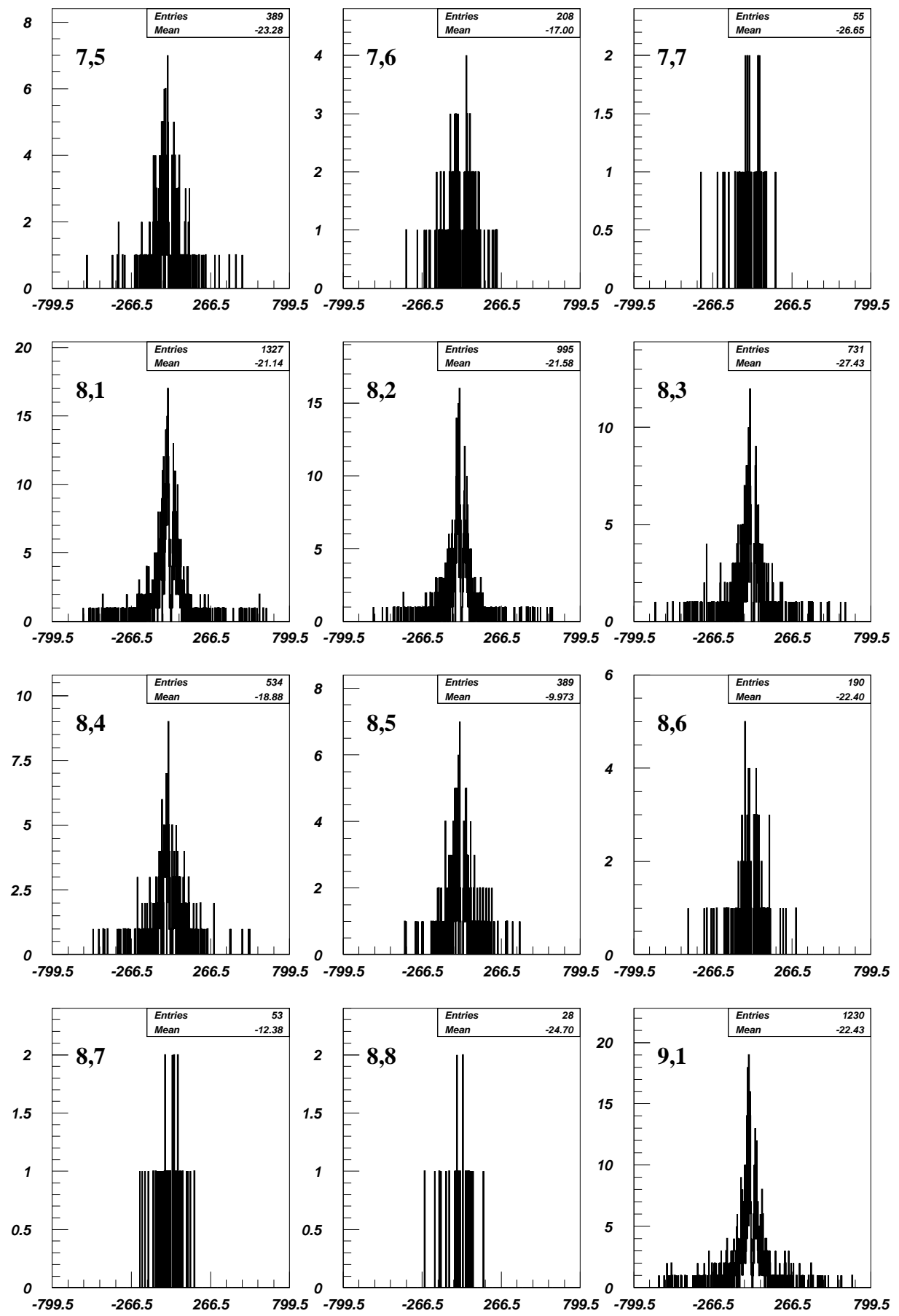

Figura 5.94: Distribuciones de momento. El primer índice: multiplicidad total, el segundo: multiplicidad con momento (neg $614 \mathrm{C}$ ). 

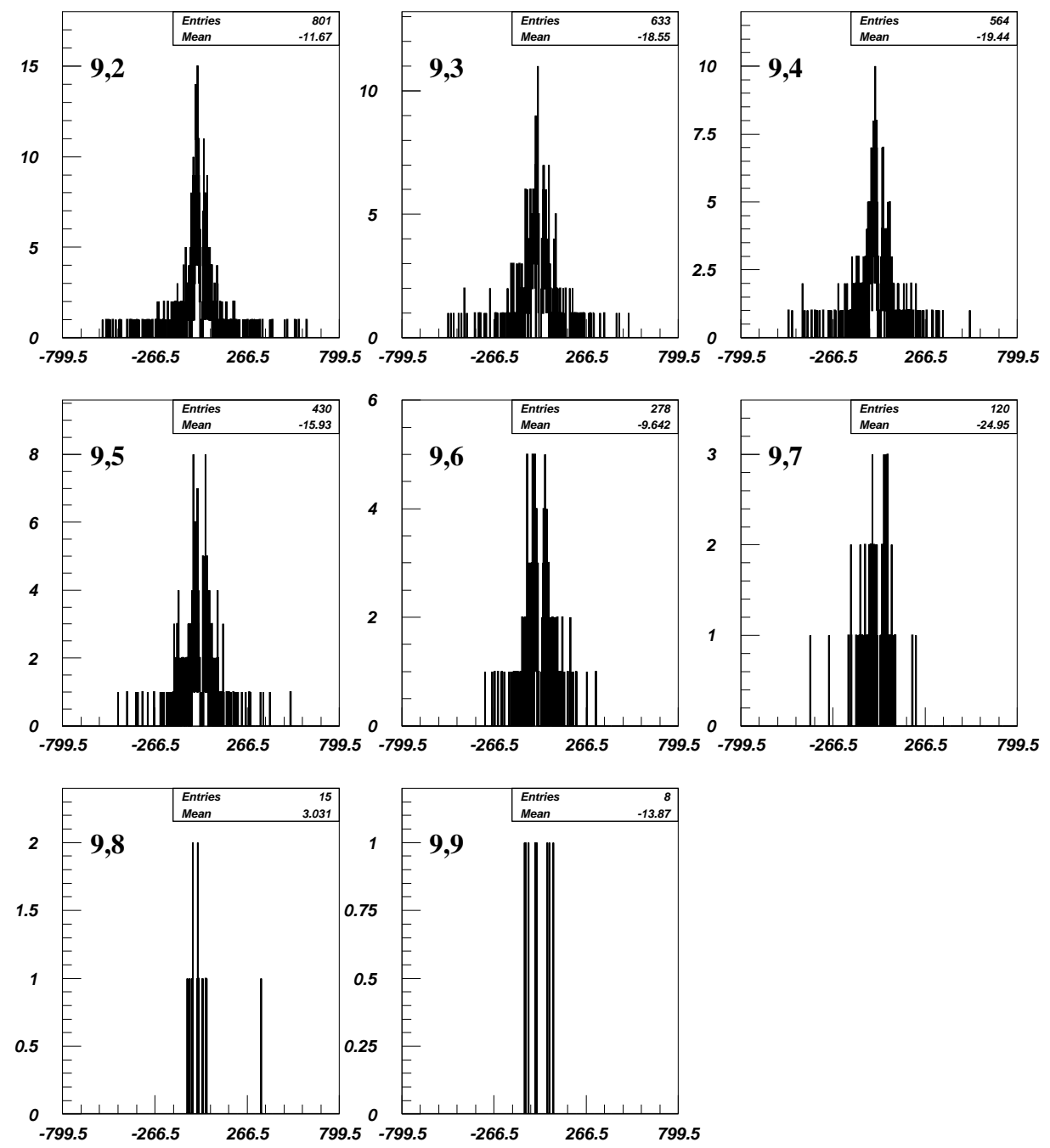

Figura 5.95: Distribuciones de momento. El primer índice: multiplicidad total, el segundo: multiplicidad con momento (neg $614 \mathrm{C}$ ). 


\subsection{Haz de polaridad negativa, con momento $580 \mathrm{GeV}$, con blanco de producción para el haz secundario de polietileno}

\subsubsection{Histogramas de control}
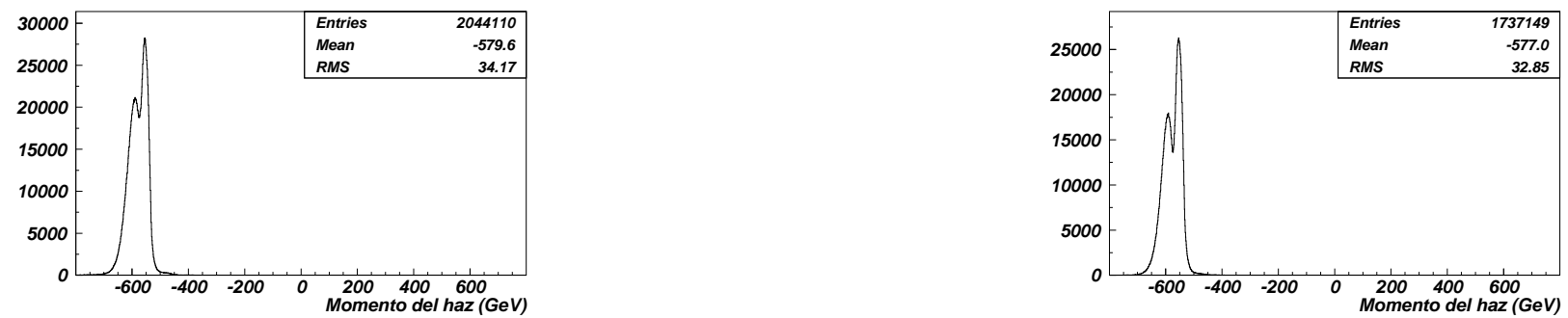

Figura 5.96: Distribución de momento del haz primario. Izquierda: bariones. Derecha: mesones (neg $580 \mathrm{CH}_{2}$ ).

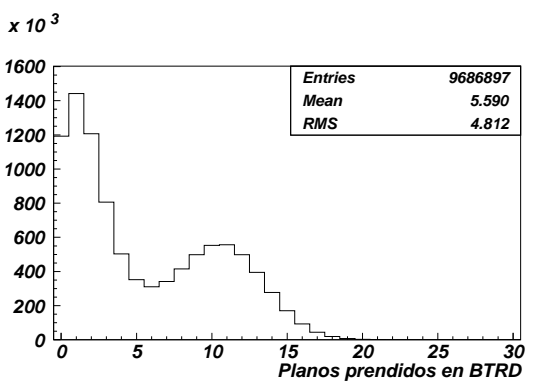

Figura 5.97: Planos prendidos en BTRD. Proporción bariónica y mesónica del haz primario (neg $580 \mathrm{CH}_{2}$ ). 

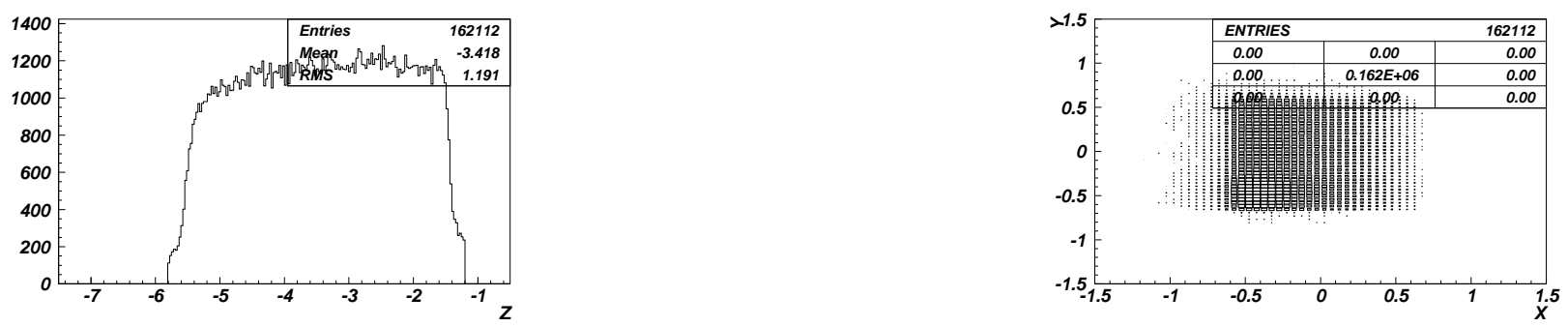

Figura 5.98: Vértice primario. Izquierda: coordenada z. Derecha: proyección x,y (neg 580 $\mathrm{CH}_{2}$ ). 


\subsubsection{Multiplicidad en la región del vértice}
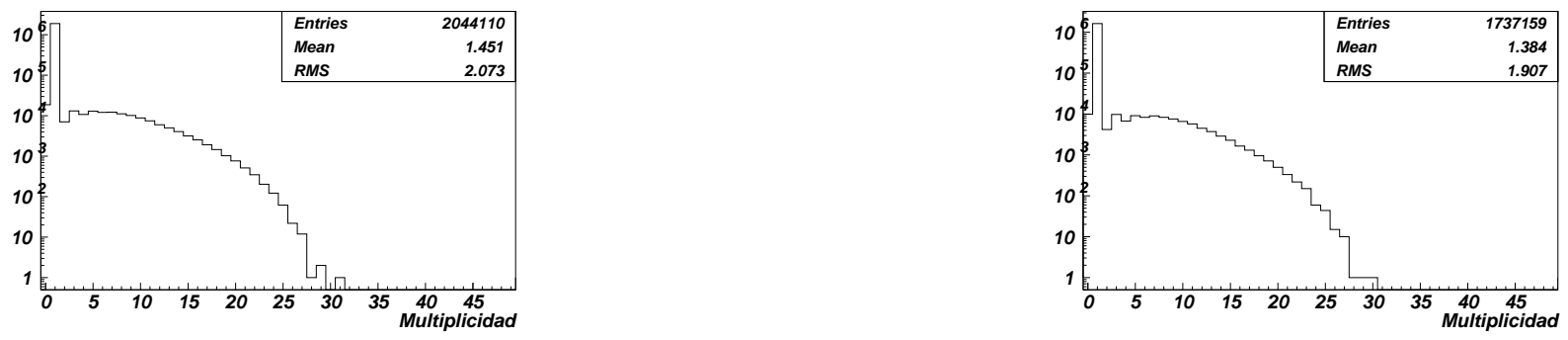

Figura 5.99: Multiplicidad total. Izquierda: haz de bariones. Derecha: haz de mesones(neg $\left.580 \mathrm{CH}_{2}\right)$.
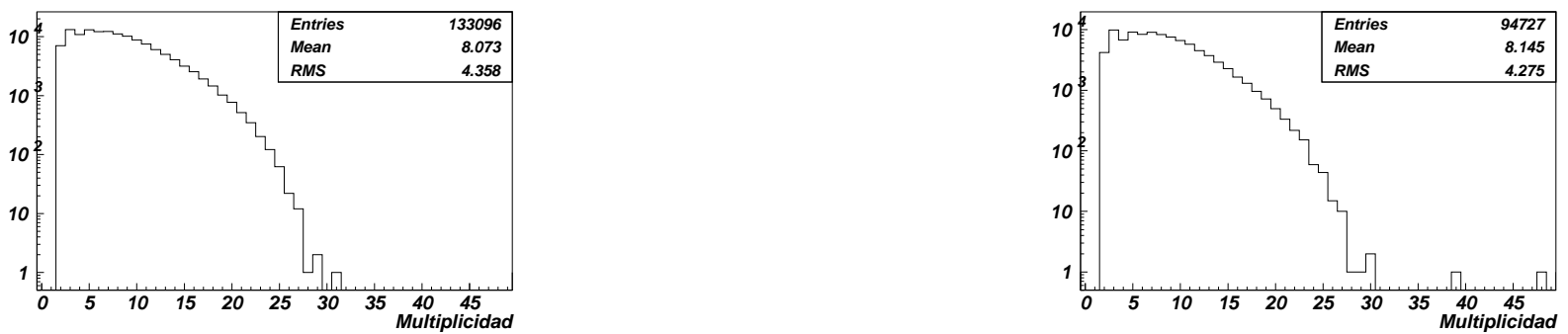

Figura 5.100: Multiplicidad en eventos con más de una trayectoria en la región del vértice. Izquierda: haz de bariones. Derecha: haz de mesones (neg $580 \mathrm{CH}_{2}$ ). 


\subsubsection{Distribuciones de multiplicidad y momento}
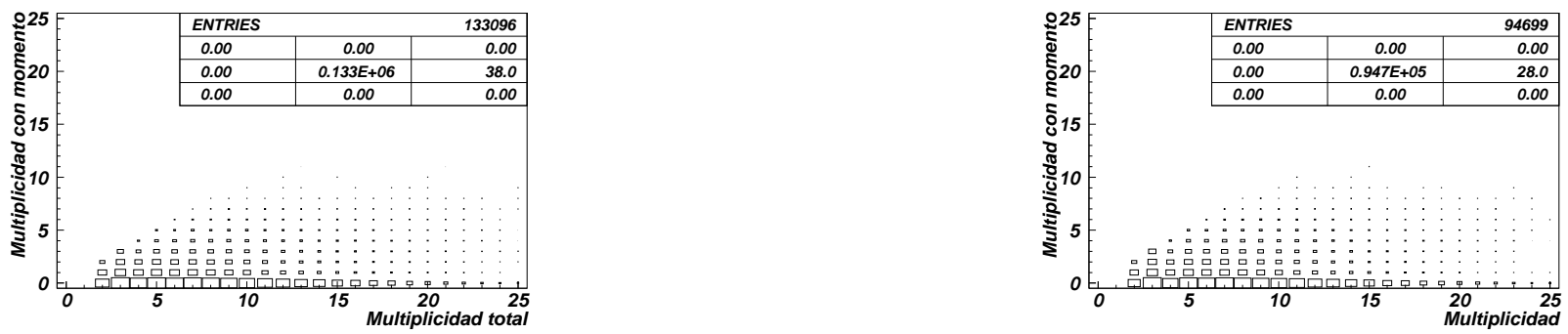

Figura 5.101: Multiplicidad total contra multiplicidad con momento medido. Izquierda: haz de bariones. Derecha: haz de mesones (neg $580 \mathrm{CH}_{2}$ ).
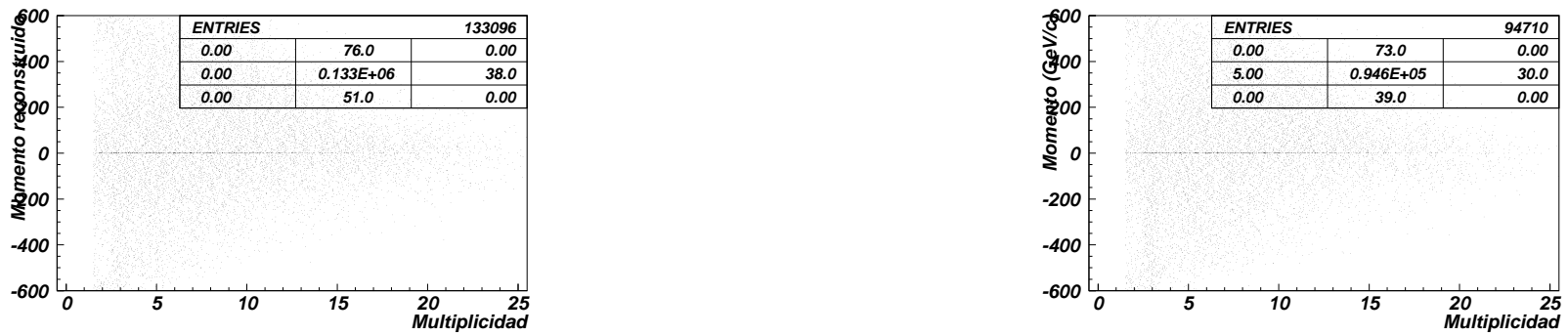

Figura 5.102: Multiplicidad contra momento.Izquierda: haz de bariones. Derecha: haz de mesones (neg $580 \mathrm{CH}_{2}$ ). 
Distribuciones de momento total para eventos producidos por un haz de bariones
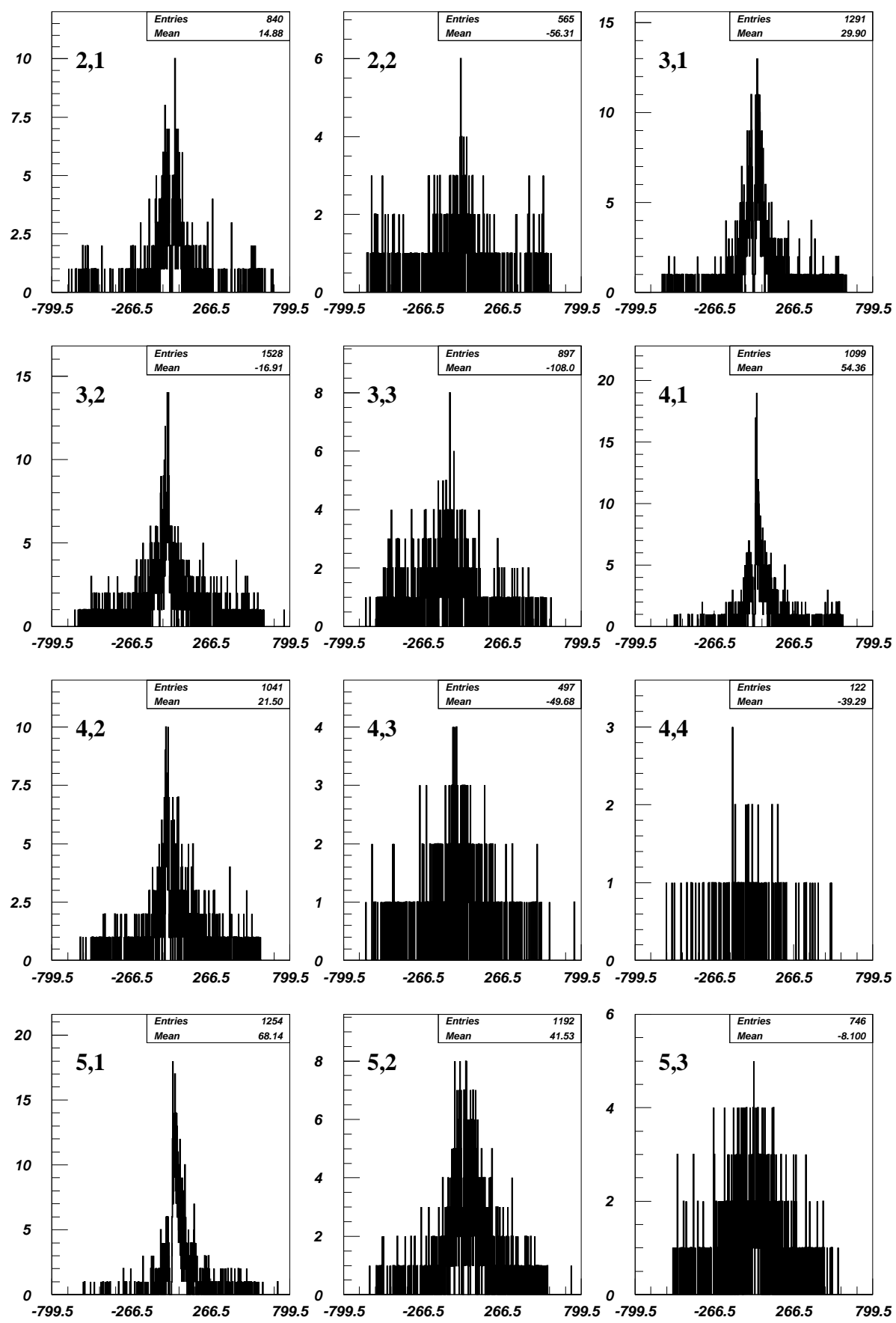

Figura 5.103: Distribuciones de momento. El primer indice: multiplicidad total, el segundo: multiplicidad con momento (neg $580 \mathrm{CH}_{2}$ ) 

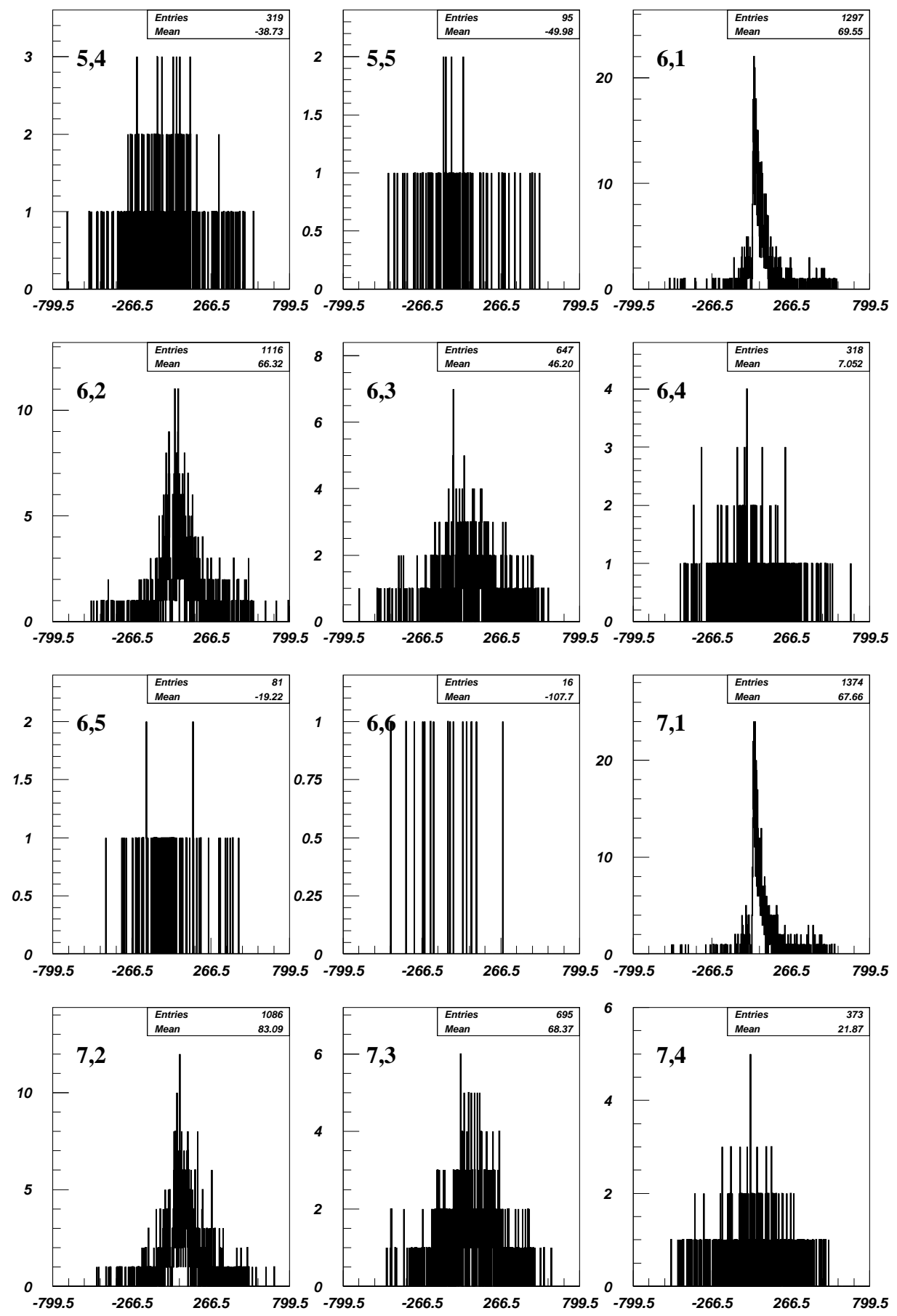

Figura 5.104: Distribuciones de momento. El primer índice: multiplicidad total, el segundo: multiplicidad con momento (neg $580 \mathrm{CH}_{2}$ ). 

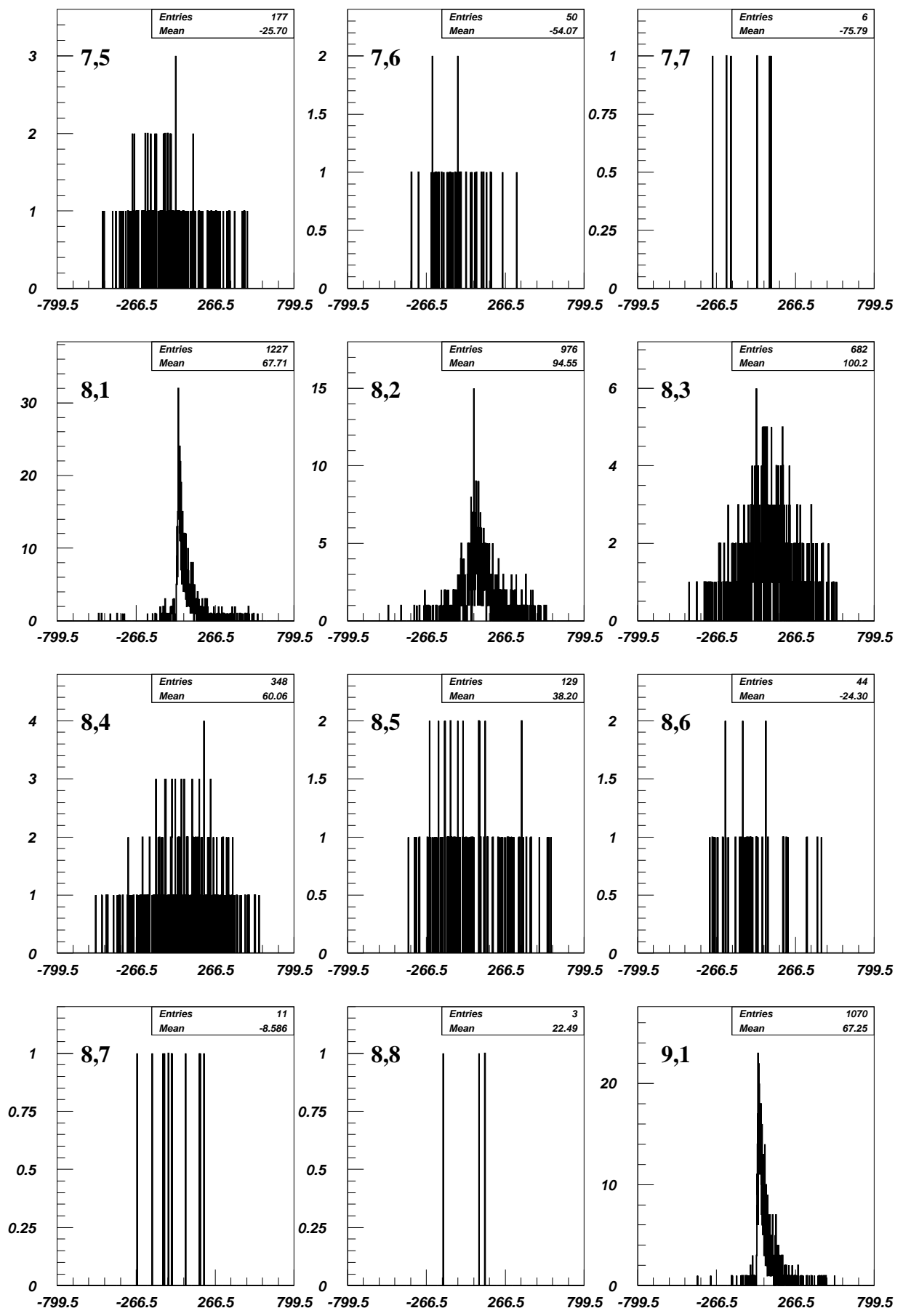

Figura 5.105: Distribuciones de momento. El primer índice: multiplicidad total, el segundo: multiplicidad con momento (neg $580 \mathrm{CH}_{2}$ ). 

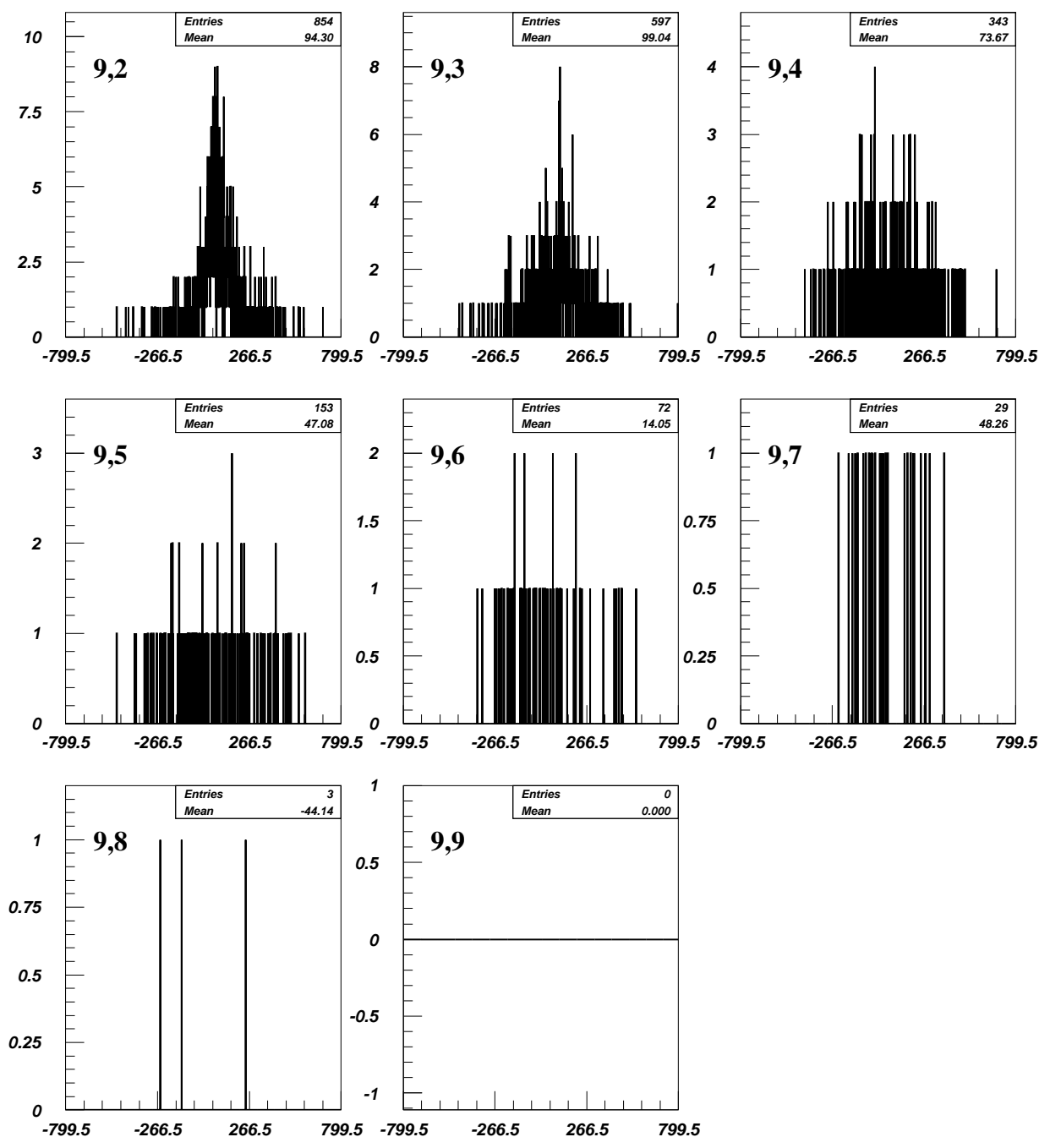

Figura 5.106: Distribuciones de momento. El primer índice: multiplicidad total, el segundo: multiplicidad con momento (neg $580 \mathrm{CH}_{2}$ ). 
Distribuciones de momento total para eventos producidos por un haz de mesones
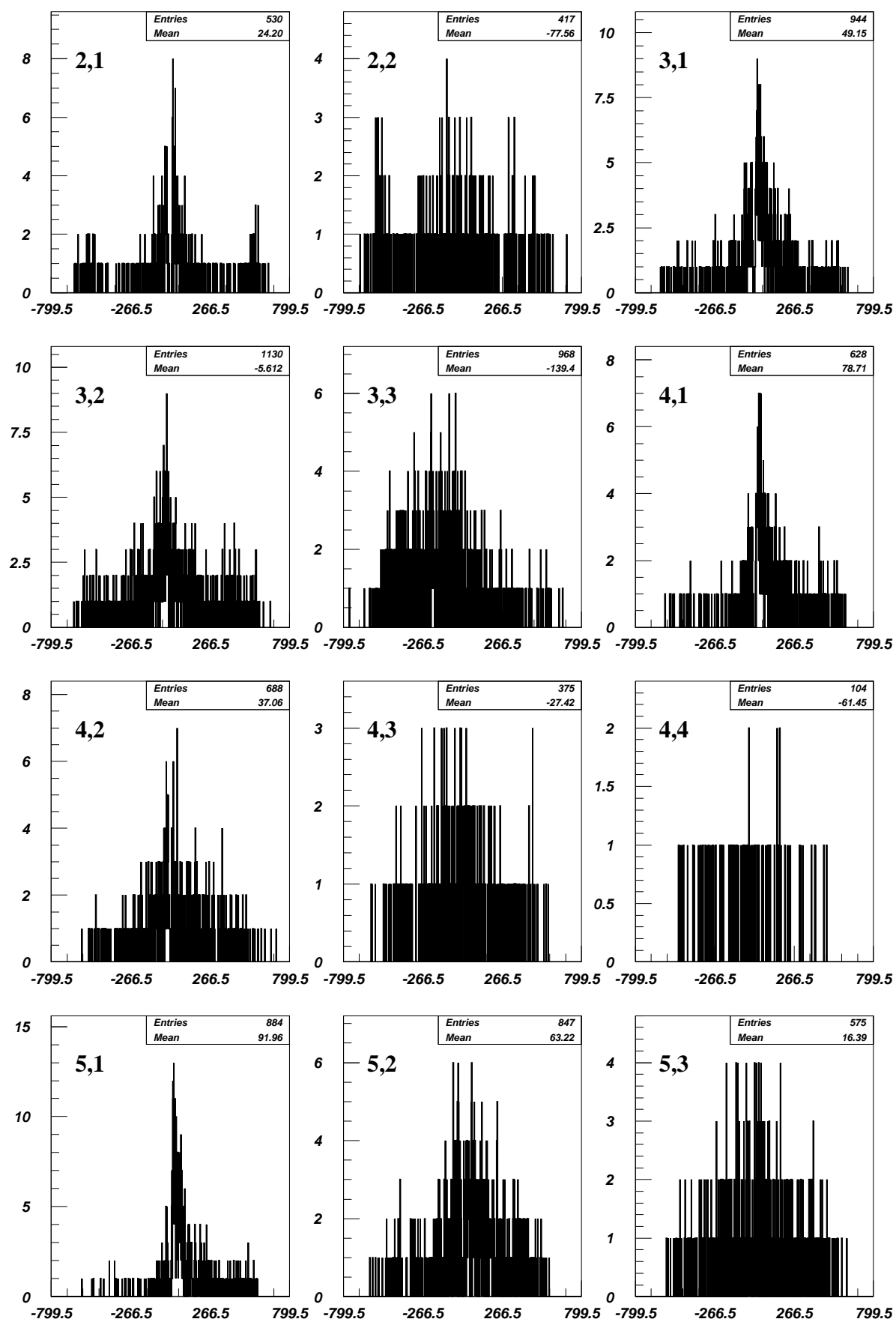

Figura 5.107: Distribuciones de momento. El primer indice: multiplicidad total, el segundo: multiplicidad con momento (neg $580 \mathrm{CH}_{2}$ ). 

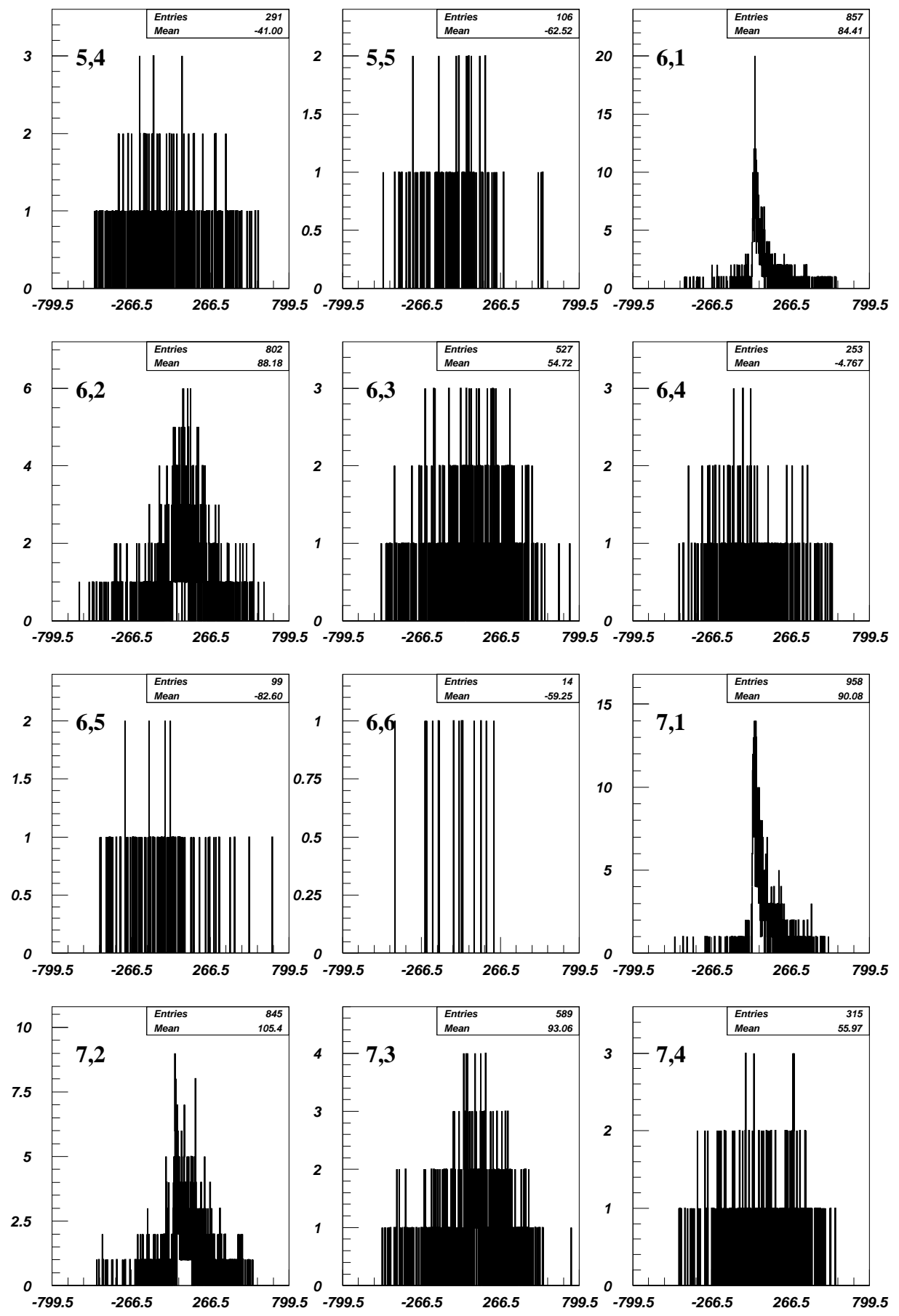

Figura 5.108: Distribuciones de momento. El primer índice: multiplicidad total, el segundo: multiplicidad con momento (neg $580 \mathrm{CH}_{2}$ ). 

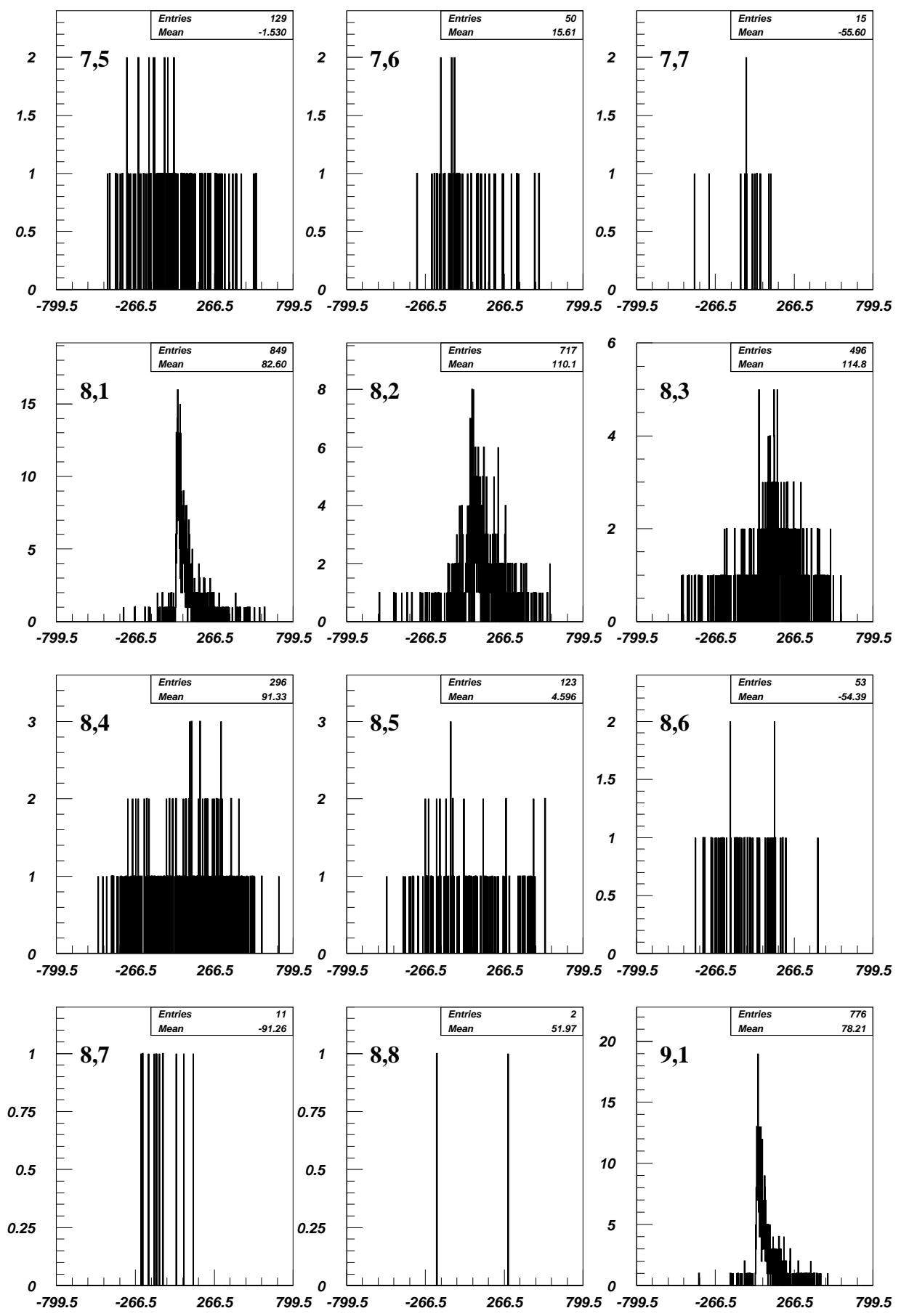

Figura 5.109: Distribuciones de momento. El primer índice: multiplicidad total, el segundo: multiplicidad con momento (neg $580 \mathrm{CH}_{2}$ ). 

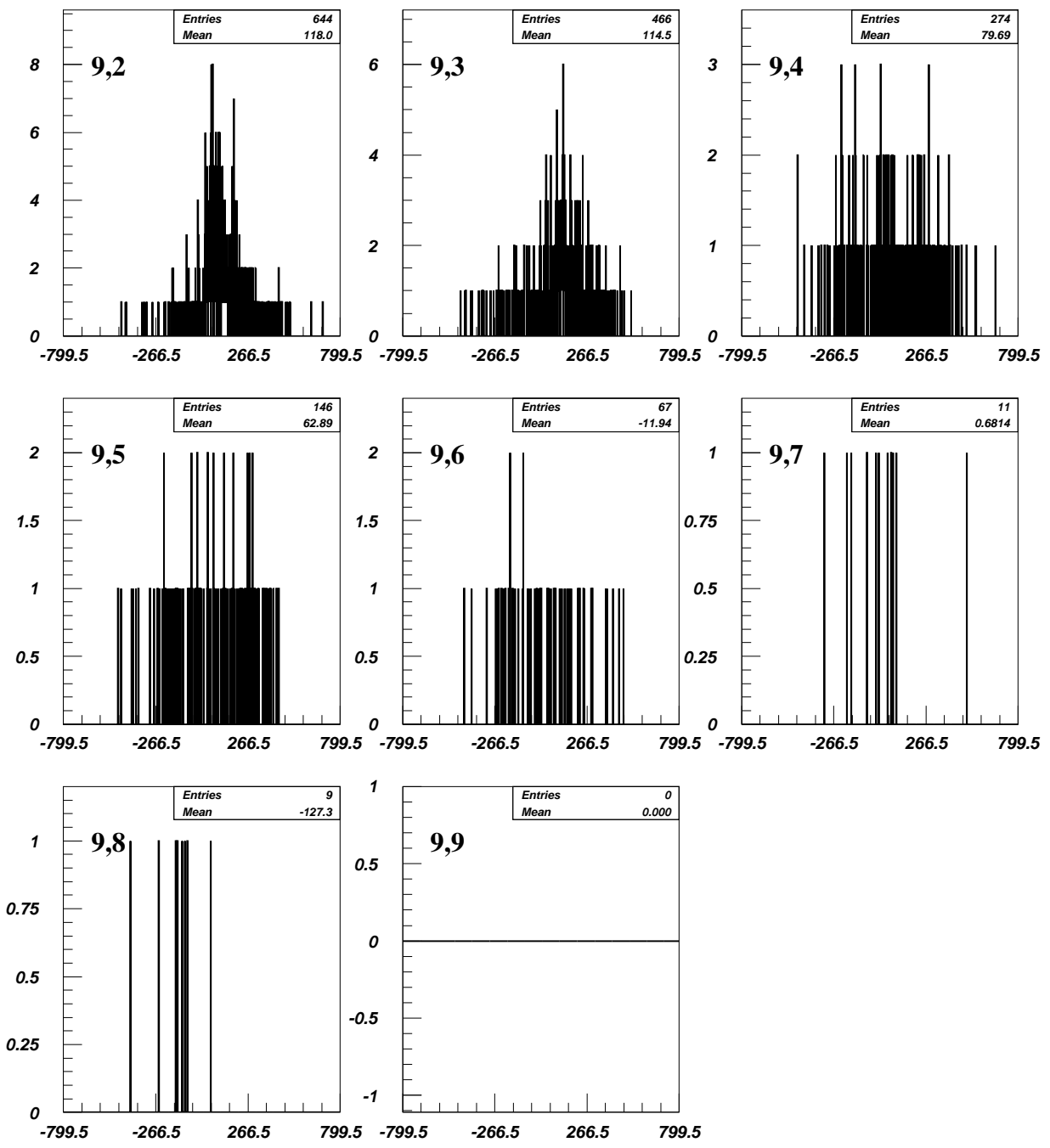

Figura 5.110: Distribuciones de momento. El primer índice: multiplicidad total, el segundo: multiplicidad con momento (neg $580 \mathrm{CH}_{2}$ ). 
Distribuciones del valor absoluto del momento total para eventos producidos por un haz de bariones
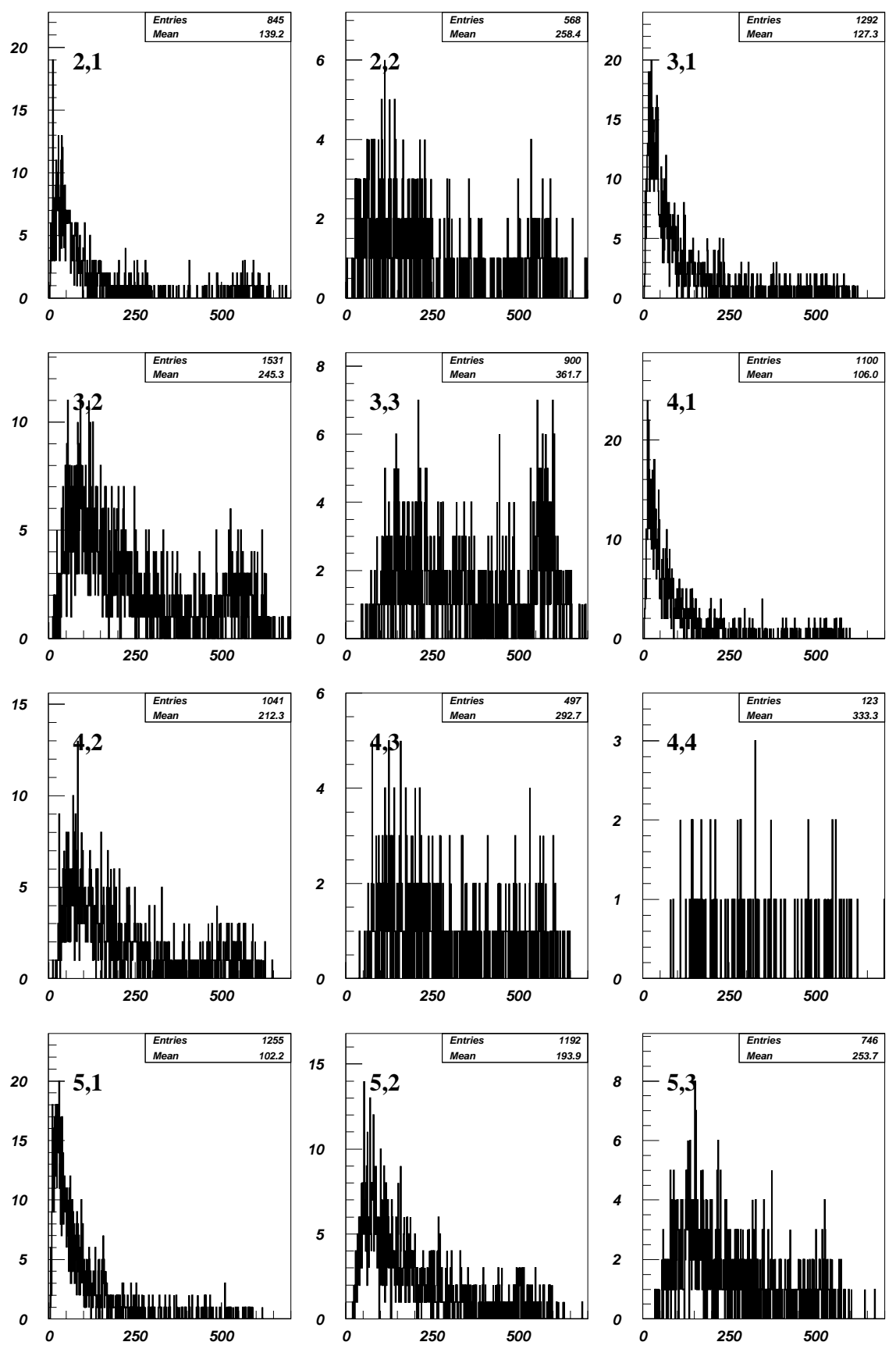

Figura 5.111: Distribuciones de momento. El primer indice: multiplicidad total, el segundo: multiplicidad con momento (neg $580 \mathrm{CH}_{2}$ ). 

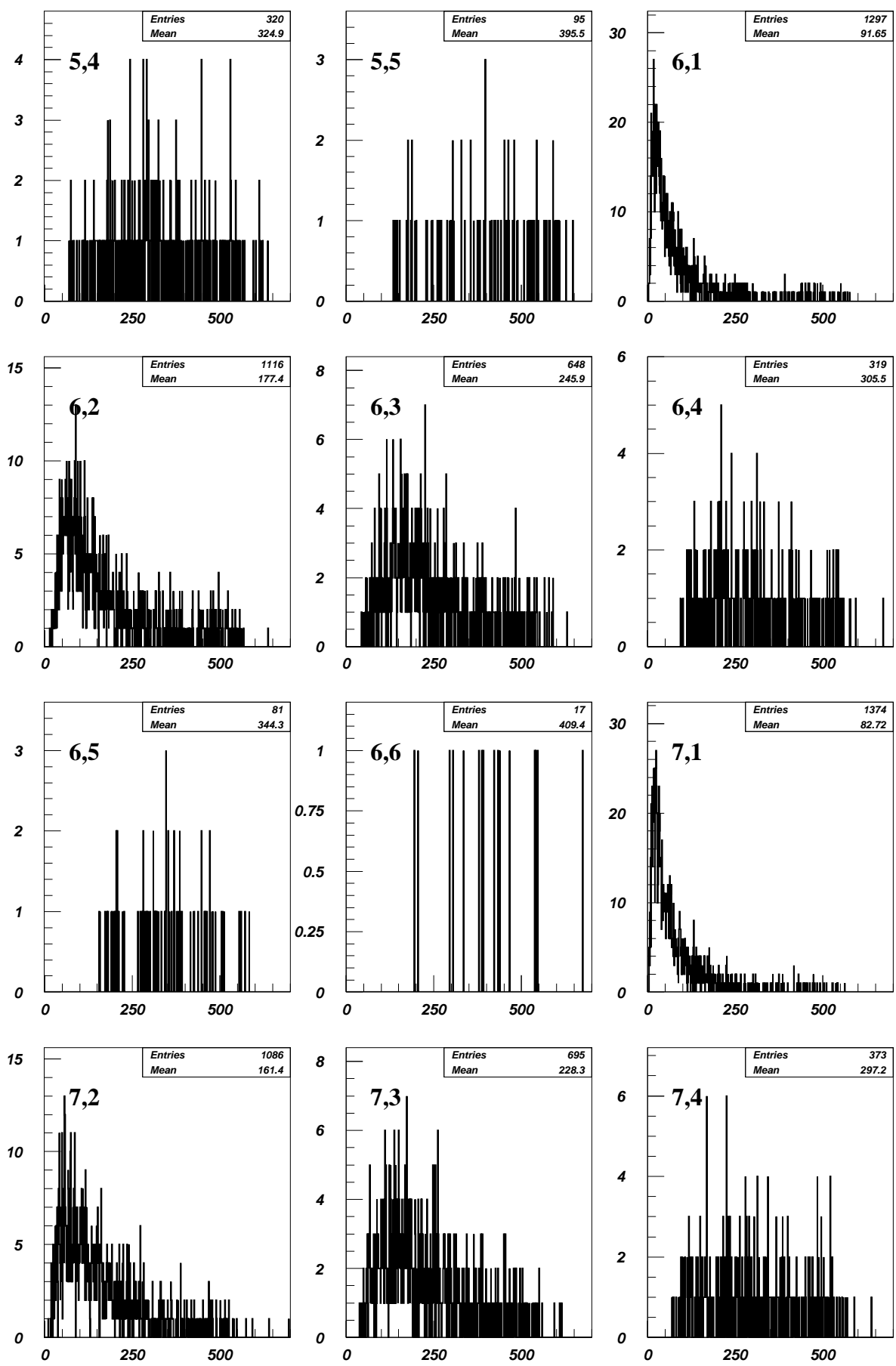

Figura 5.112: Distribuciones de momento. El primer índice: multiplicidad total, el segundo: multiplicidad con momento (neg $580 \mathrm{CH}_{2}$ ). 

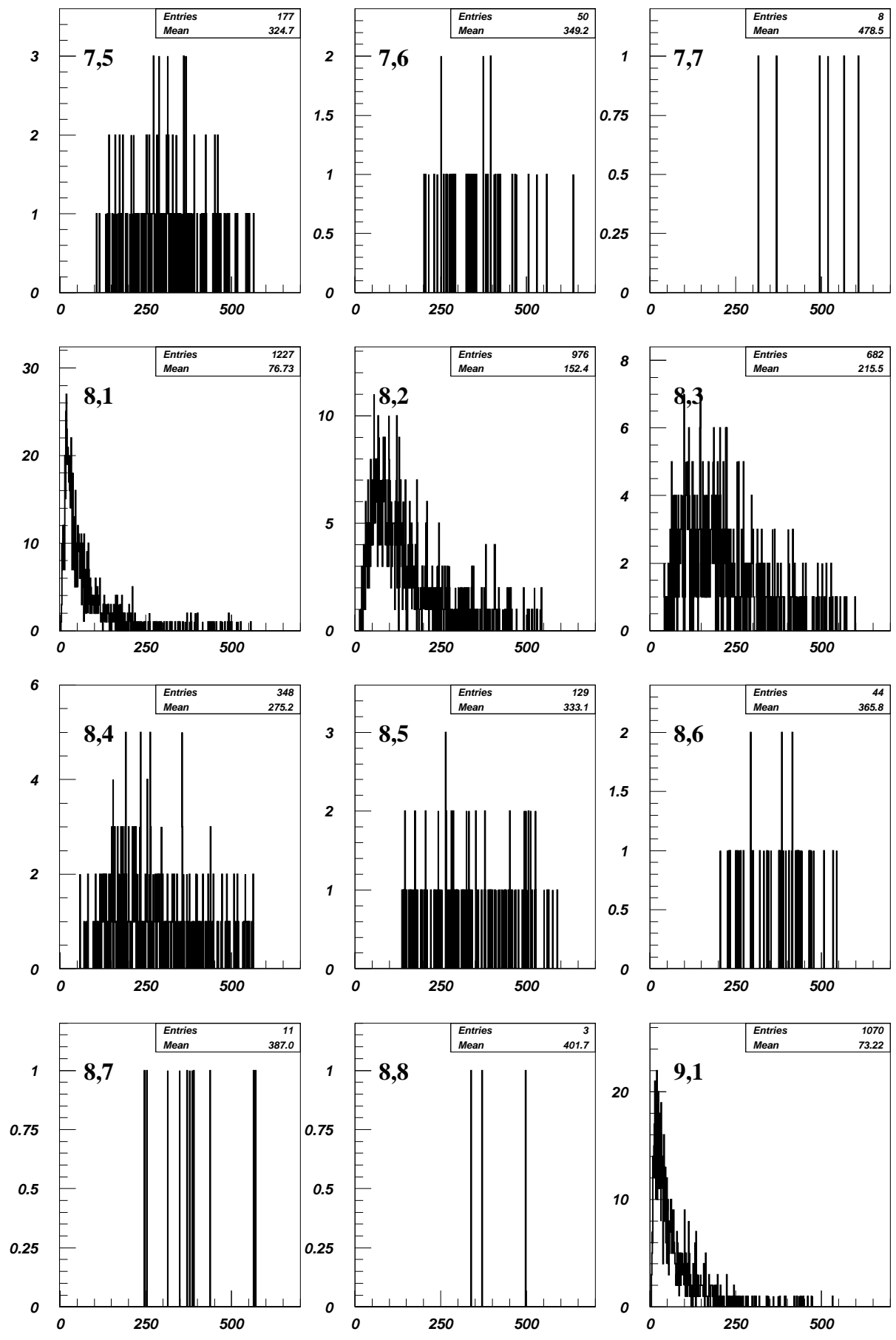

Figura 5.113: Distribuciones de momento. El primer índice: multiplicidad total, el segundo: multiplicidad con momento (neg $580 \mathrm{CH}_{2}$ ). 

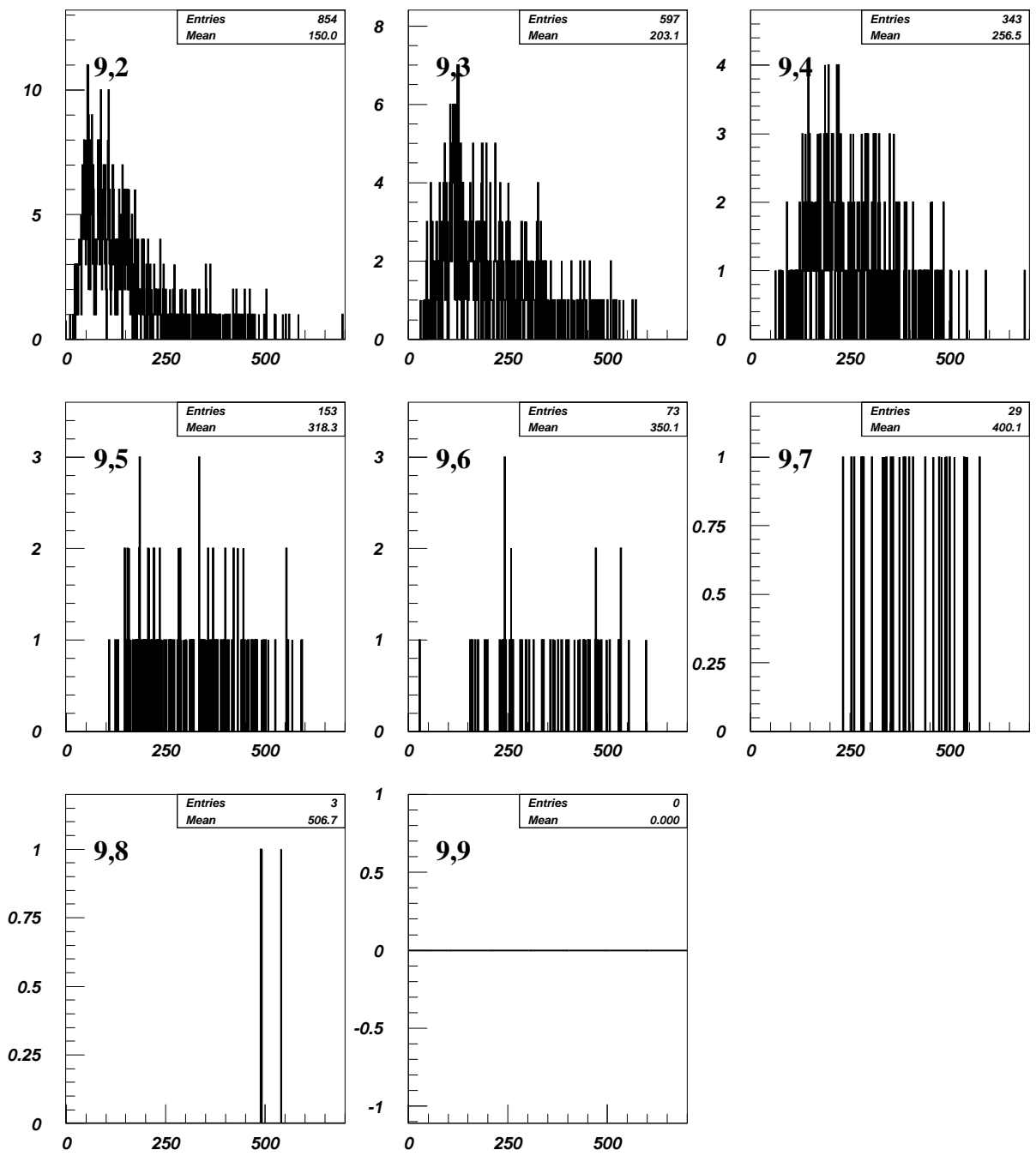

Figura 5.114: Distribuciones de momento. El primer índice: multiplicidad total, el segundo: multiplicidad con momento (neg $580 \mathrm{CH}_{2}$ ). 
Distribuciones del valor absoluto del momento total para eventos producidos por un haz de mesones
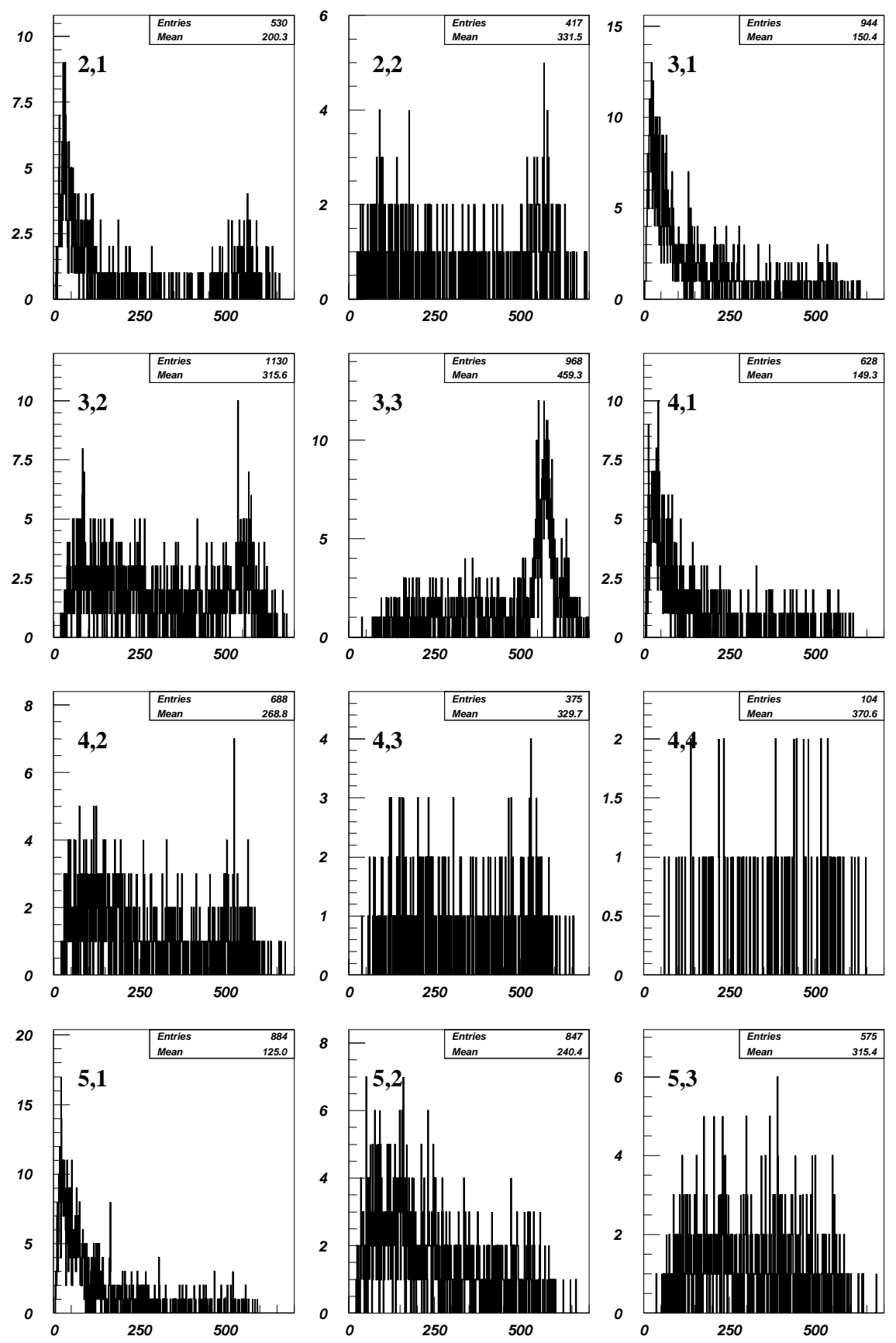

Figura 5.115: Distribuciones de momento. El primer indice: multiplicidad total, el segundo: multiplicidad con momento (neg $580 \mathrm{CH}_{2}$ ). 

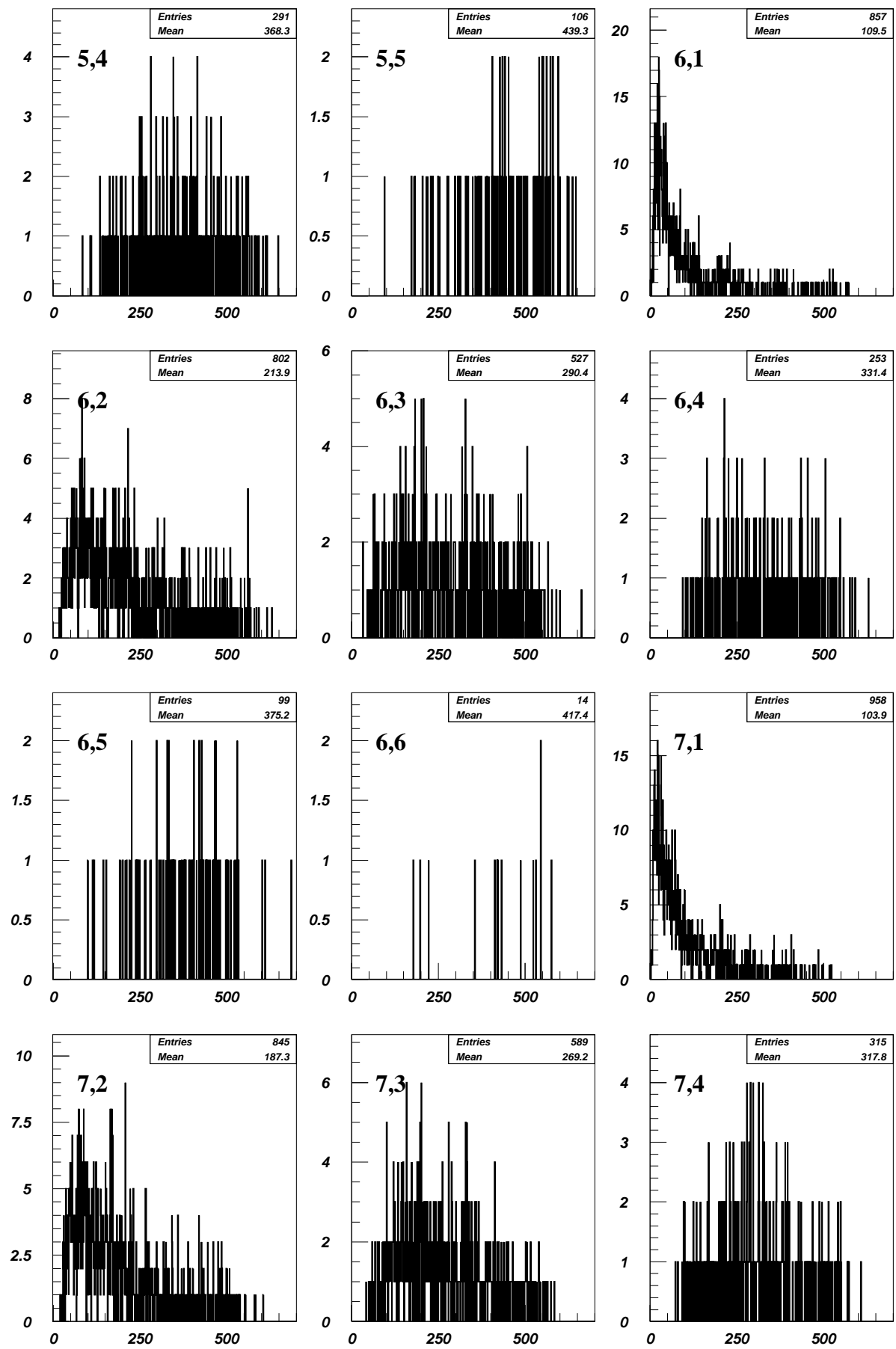

Figura 5.116: Distribuciones de momento. El primer índice: multiplicidad total, el segundo: multiplicidad con momento (neg $580 \mathrm{CH}_{2}$ ). 

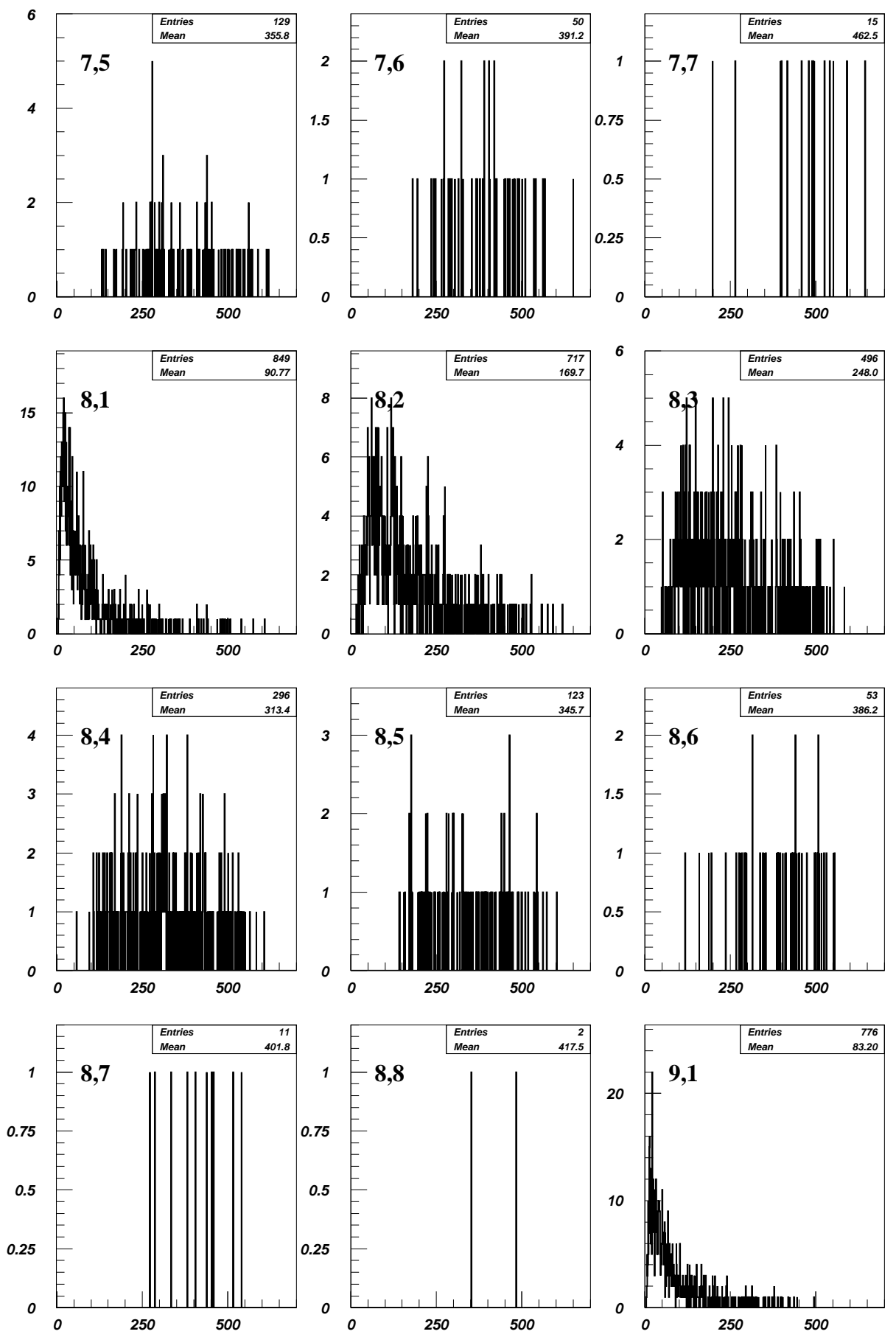

Figura 5.117: Distribuciones de momento. El primer índice: multiplicidad total, el segundo: multiplicidad con momento (neg $580 \mathrm{CH}_{2}$ ). 

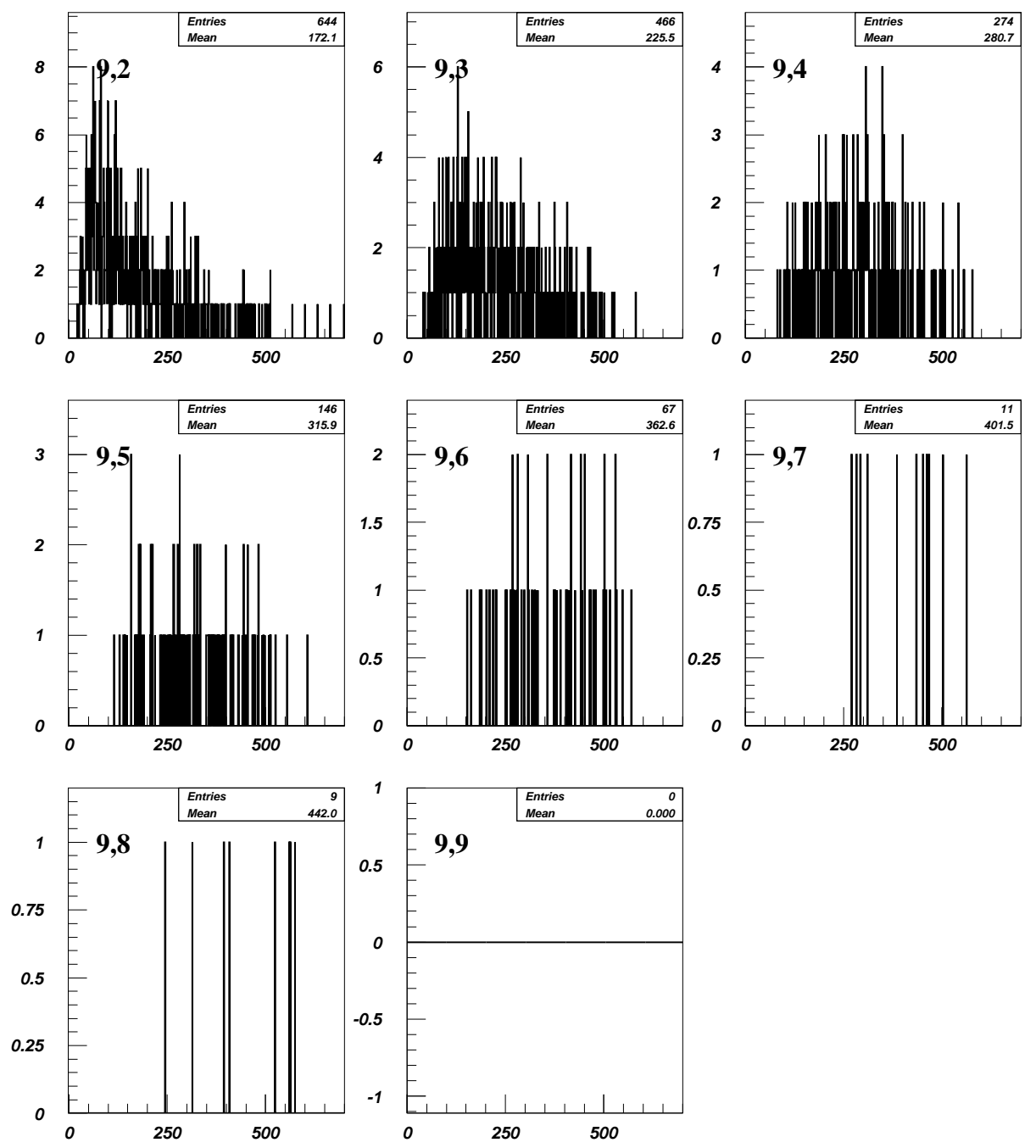

Figura 5.118: Distribuciones de momento. El primer índice: multiplicidad total, el segundo: multiplicidad con momento (neg $580 \mathrm{CH}_{2}$ ). 
Distribuciones del momento de las trayectorias para eventos producidos por un haz de bariones
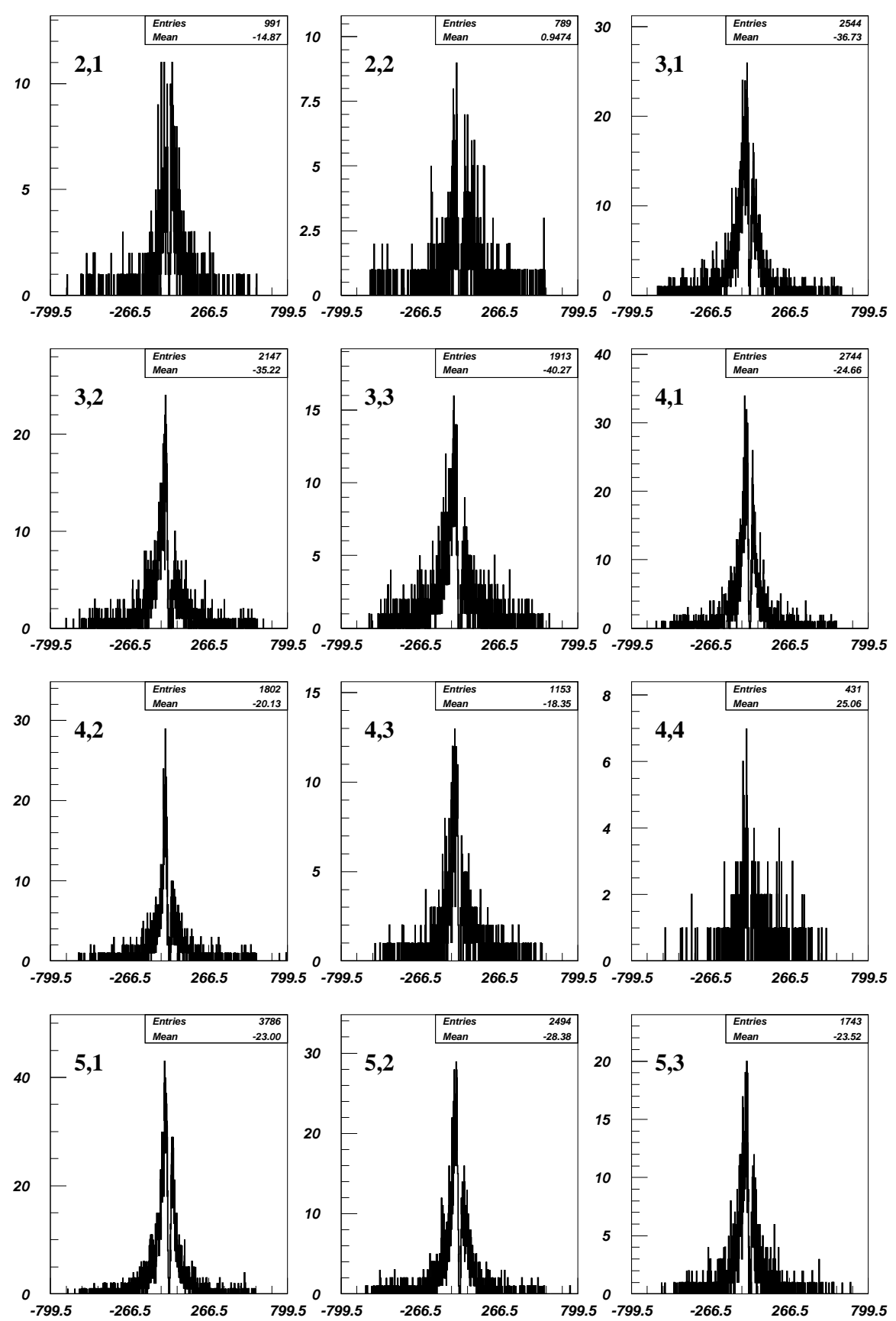

Figura 5.119: Distribuciones de momento. El primer indice: multiplicidad total, el segundo: multiplicidad con momento (neg $580 \mathrm{CH}_{2}$ ). 

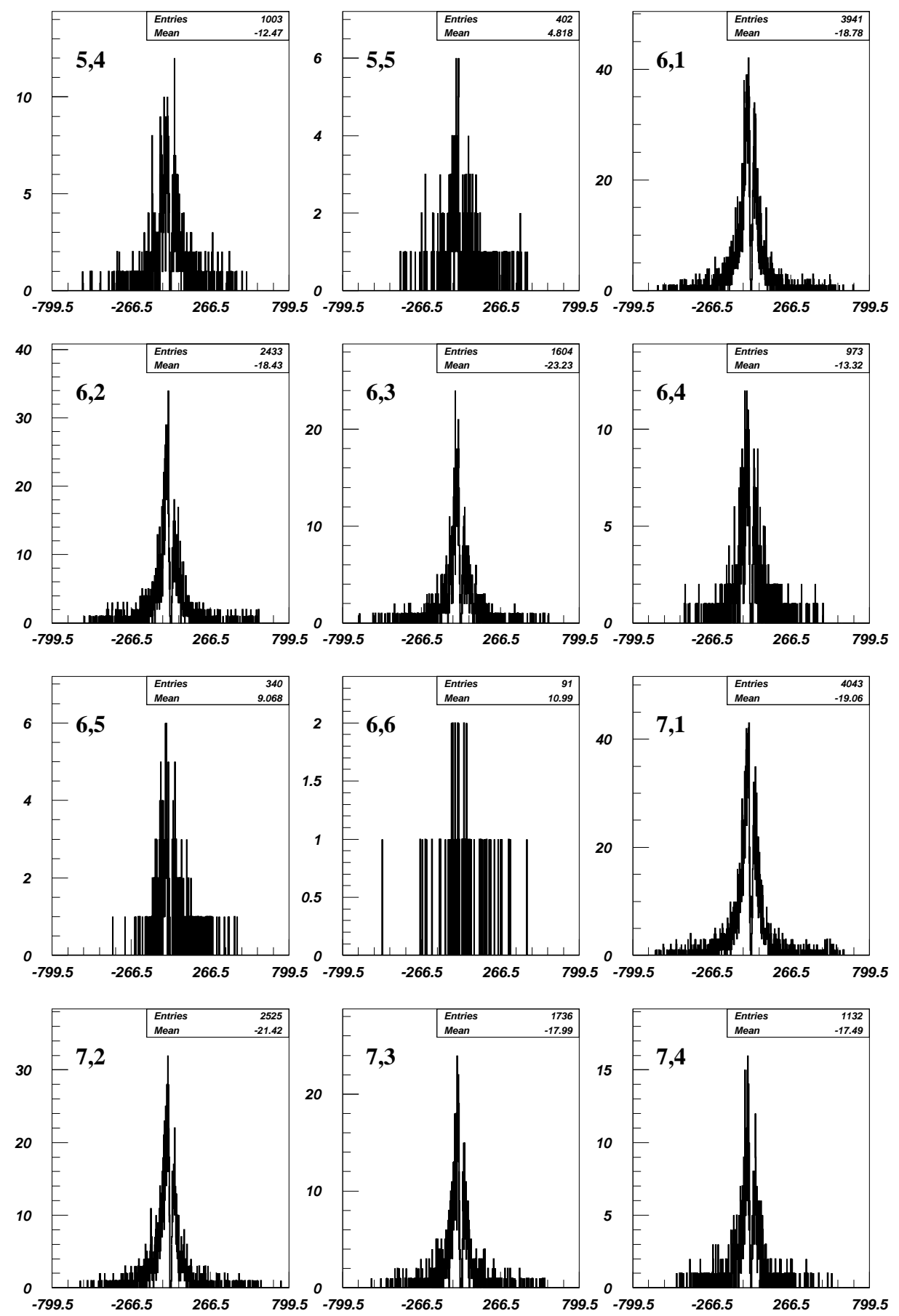

Figura 5.120: Distribuciones de momento. El primer índice: multiplicidad total, el segundo: multiplicidad con momento (neg $580 \mathrm{CH}_{2}$ ). 

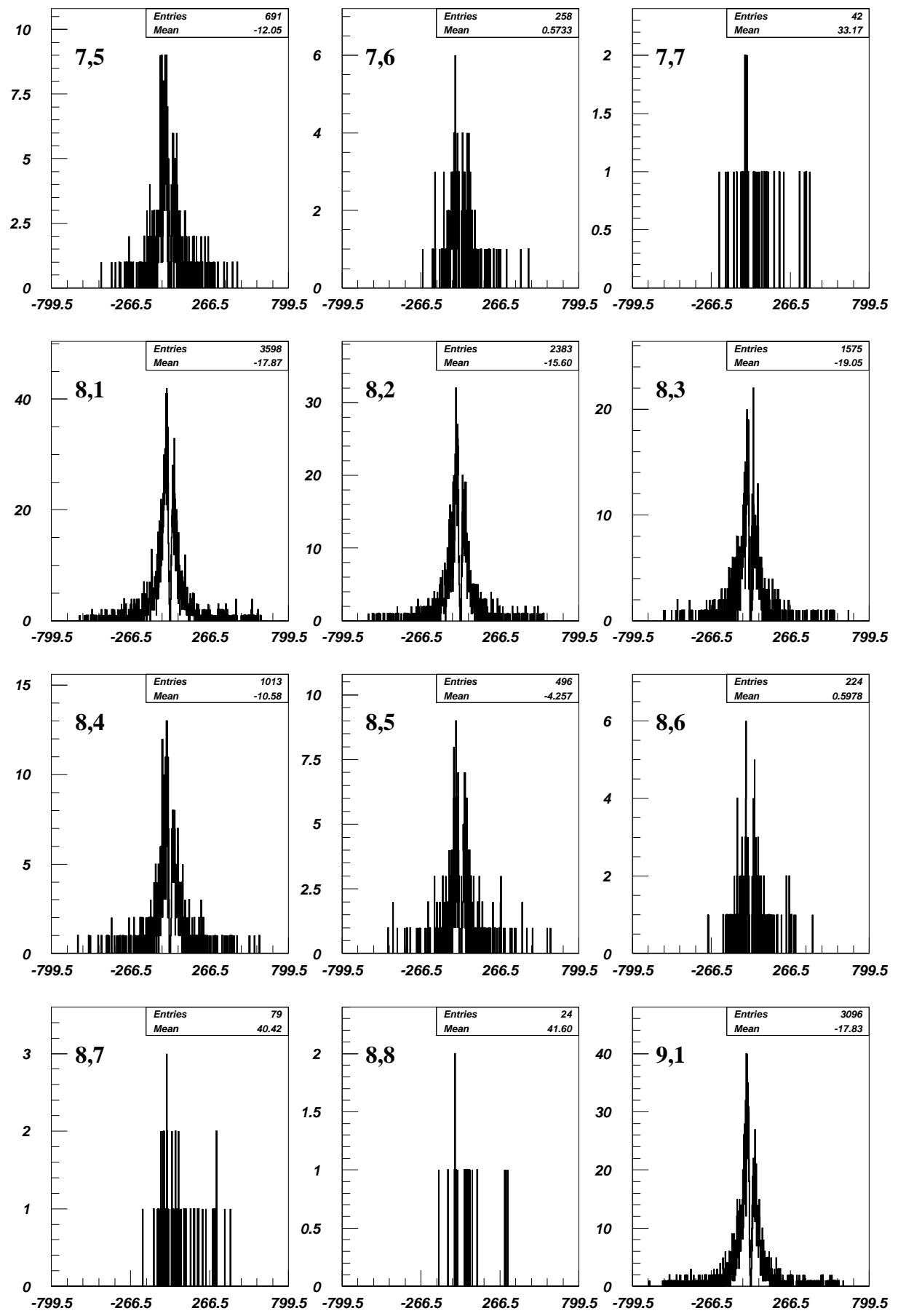

Figura 5.121: Distribuciones de momento. El primer índice: multiplicidad total, el segundo: multiplicidad con momento (neg $580 \mathrm{CH}_{2}$ ). 

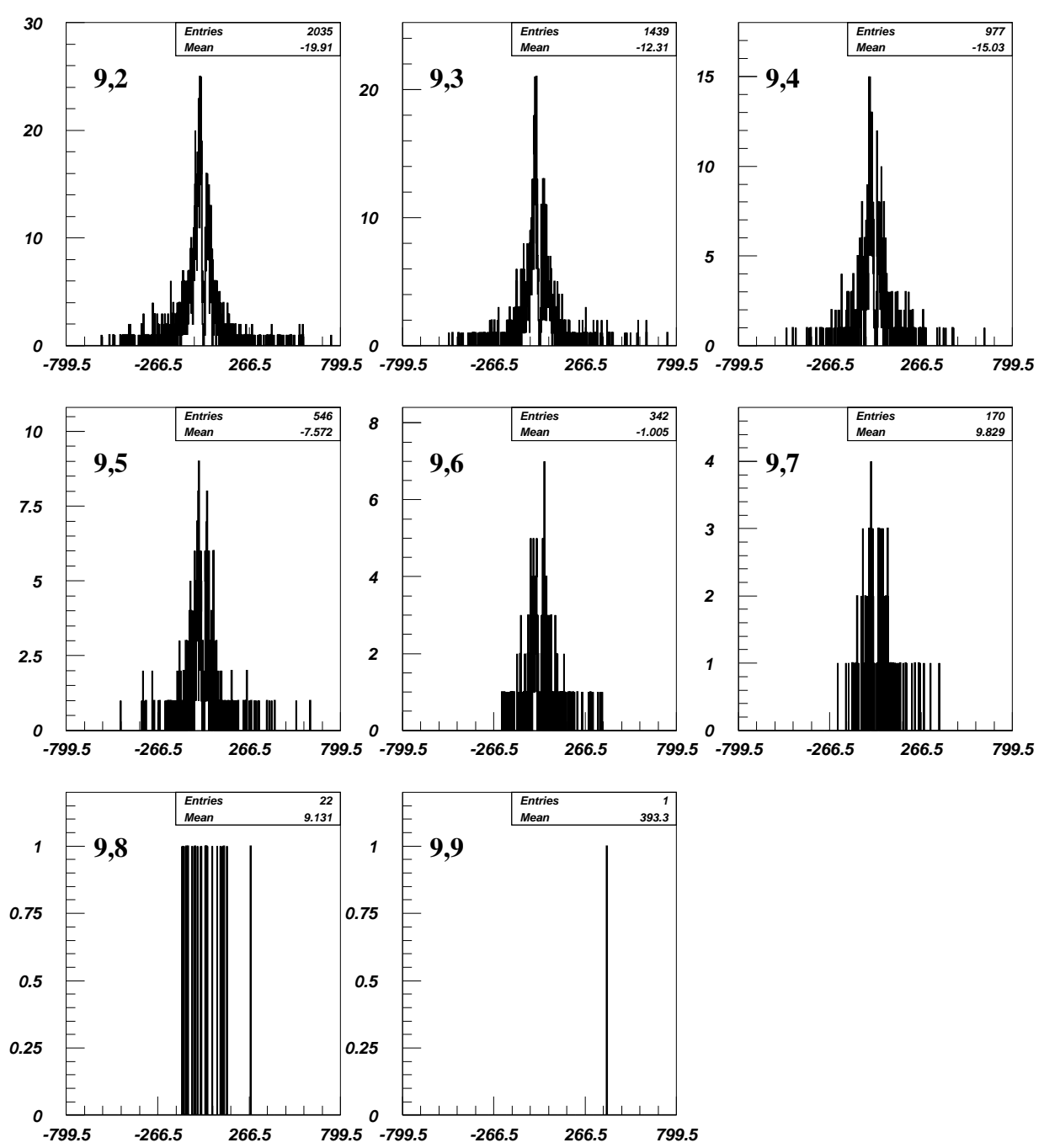

Figura 5.122: Distribuciones de momento. El primer índice: multiplicidad total, el segundo: multiplicidad con momento (neg $580 \mathrm{CH}_{2}$ ). 
Distribuciones del momento de las trayectorias para eventos producidos por un haz de mesones
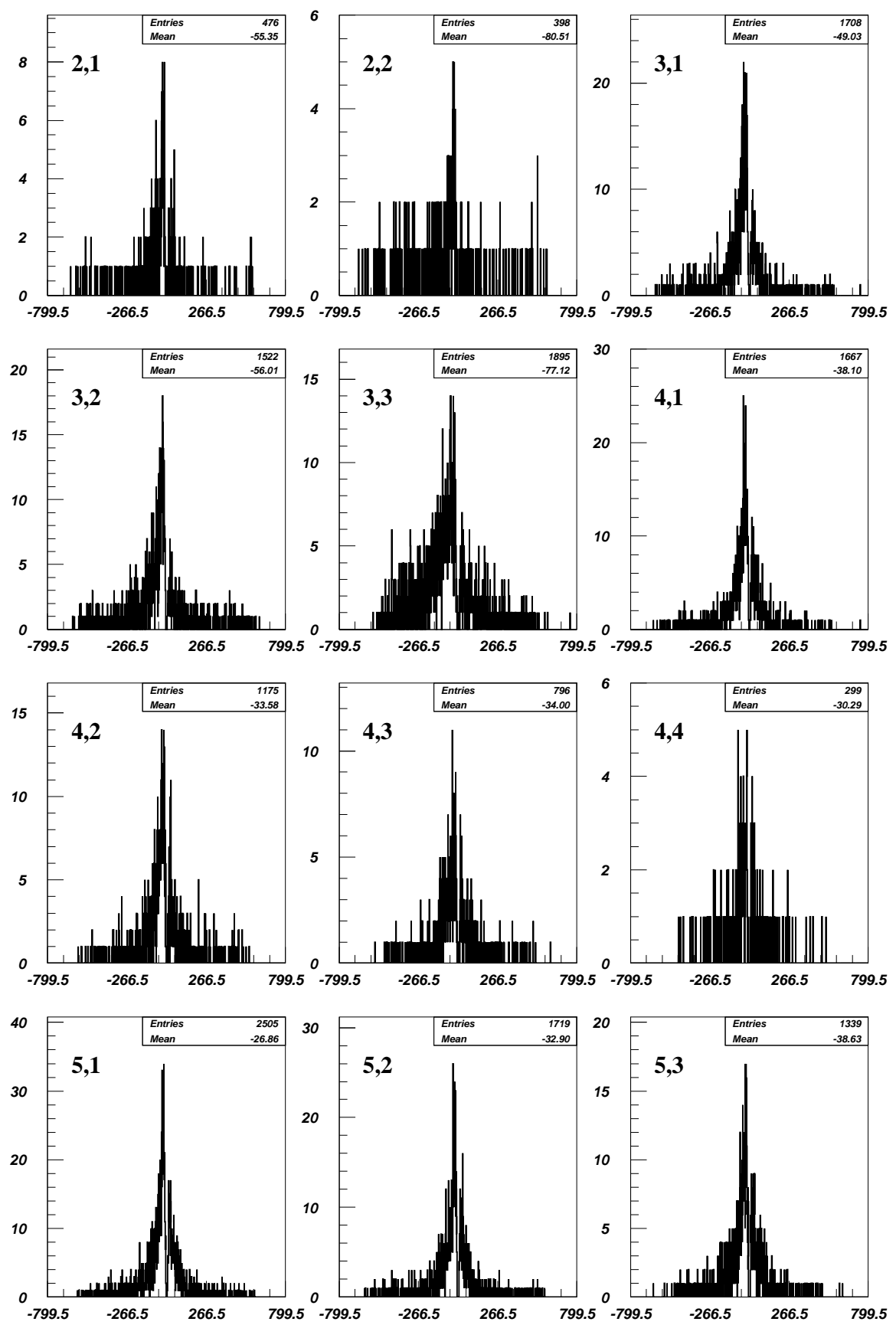

Figura 5.123: Distribuciones de momento. El primer indice: multiplicidad total, el segundo: multiplicidad con momento (neg $580 \mathrm{CH}_{2}$ ). 

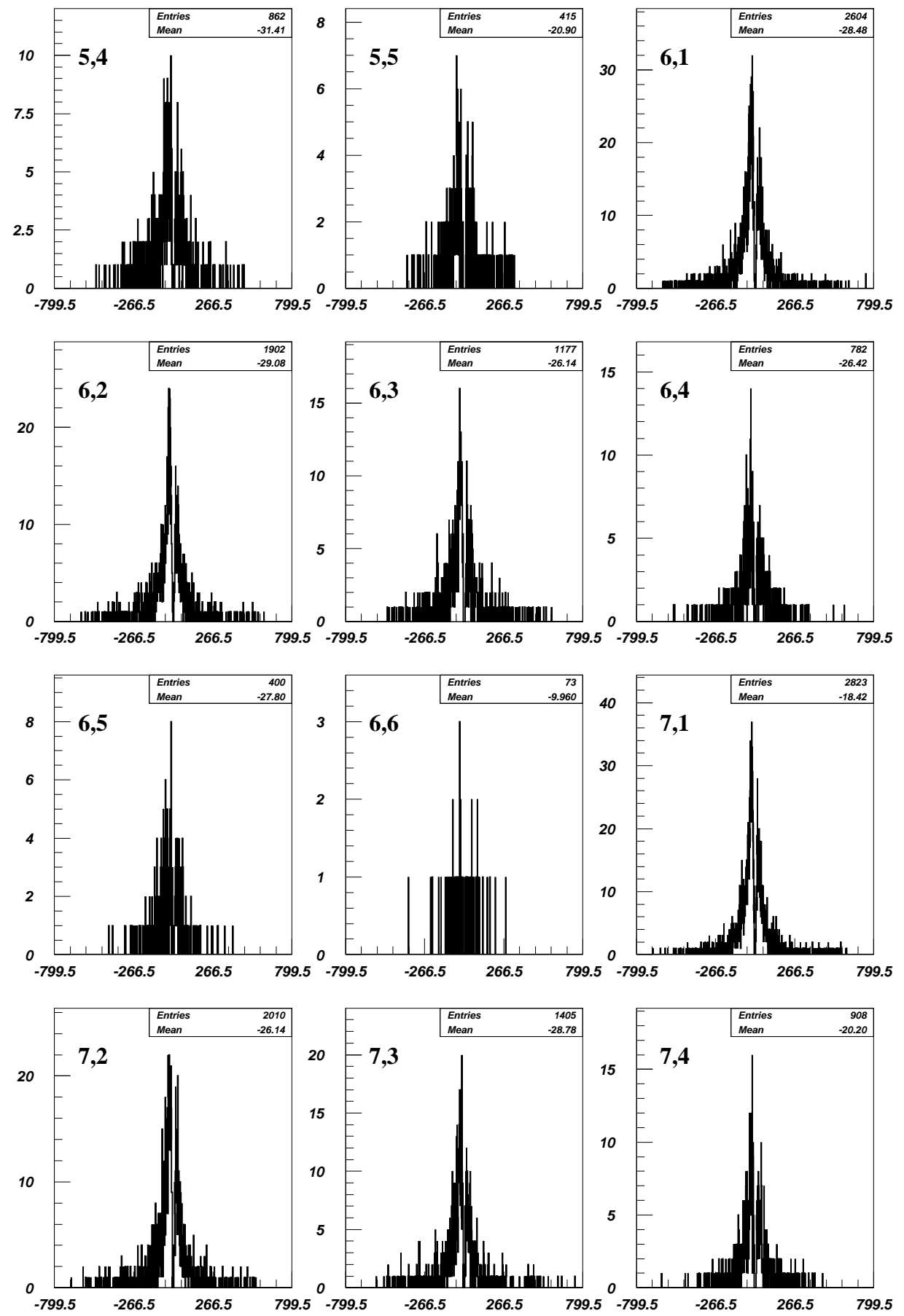

Figura 5.124: Distribuciones de momento. El primer índice: multiplicidad total, el segundo: multiplicidad con momento (neg $580 \mathrm{CH}_{2}$ ). 

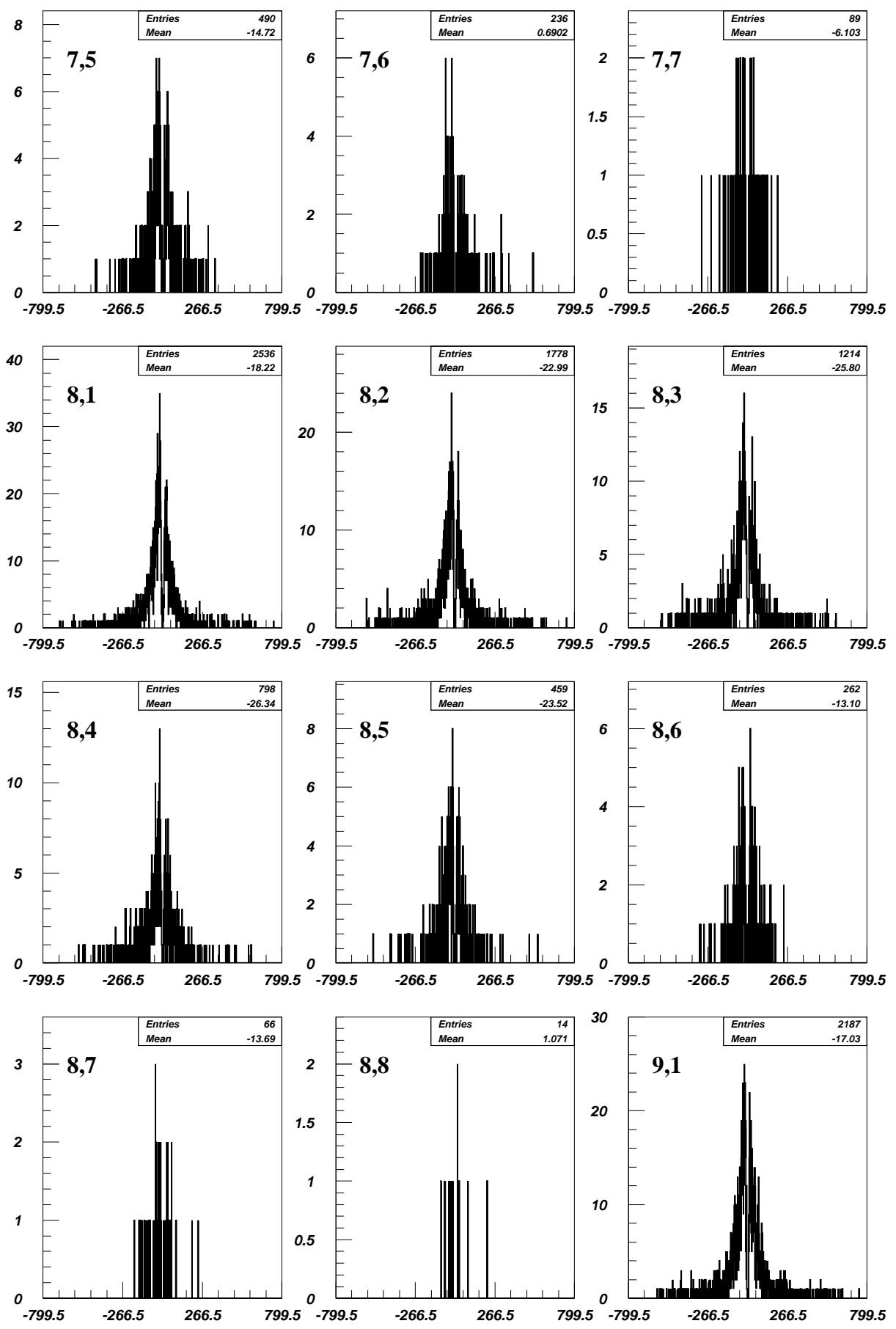

Figura 5.125: Distribuciones de momento. El primer índice: multiplicidad total, el segundo: multiplicidad con momento (neg $580 \mathrm{CH}_{2}$ ). 

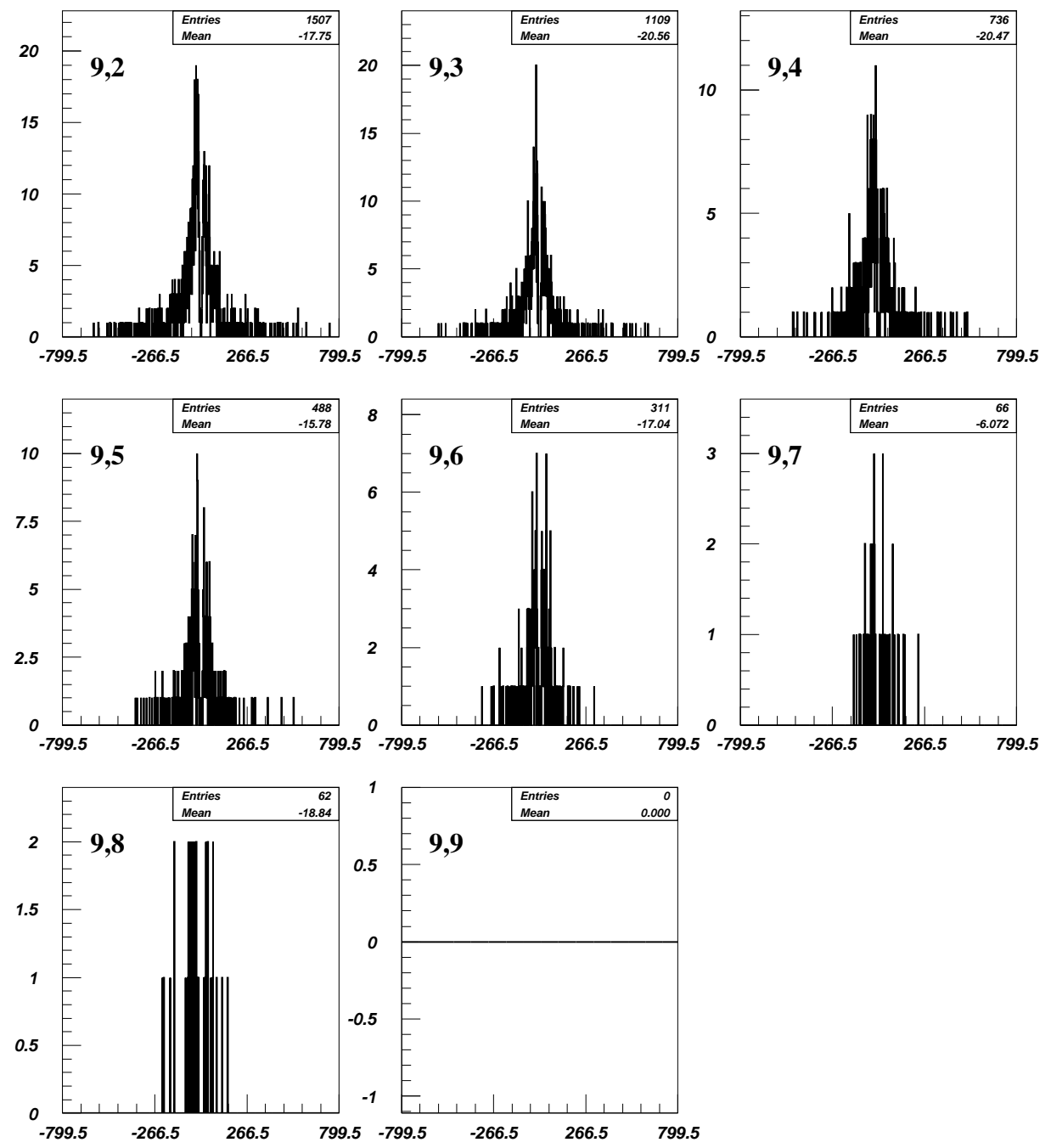

Figura 5.126: Distribuciones de momento. El primer índice: multiplicidad total, el segundo: multiplicidad con momento (neg $580 \mathrm{CH}_{2}$ ). 


\subsection{Haz de polaridad negativa, con momento $614 \mathrm{GeV}$, con blanco de producción para el haz secundario de polietileno}

\subsubsection{Histogramas de control}
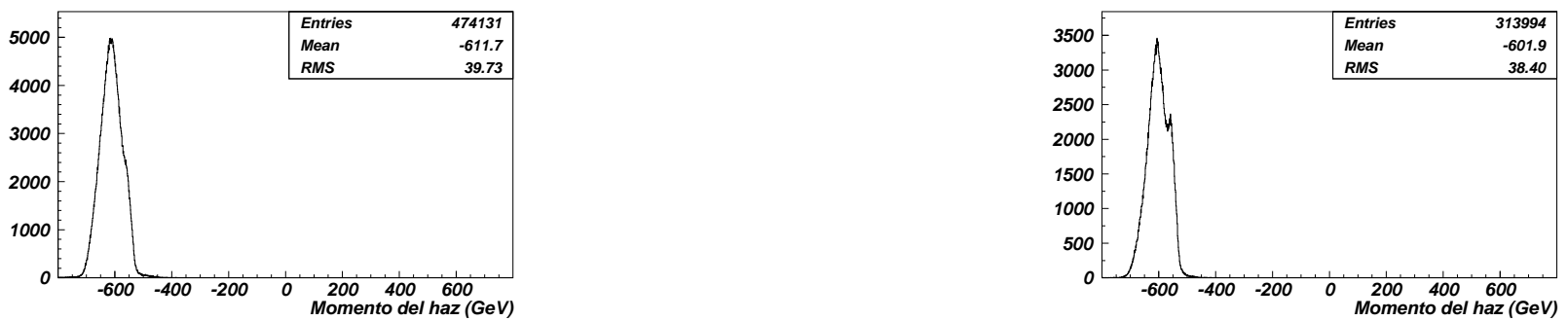

Figura 5.127: Distribución de momento del haz primario. Izquierda: bariones. Derecha: mesones (neg $614 \mathrm{CH}_{2}$ ).

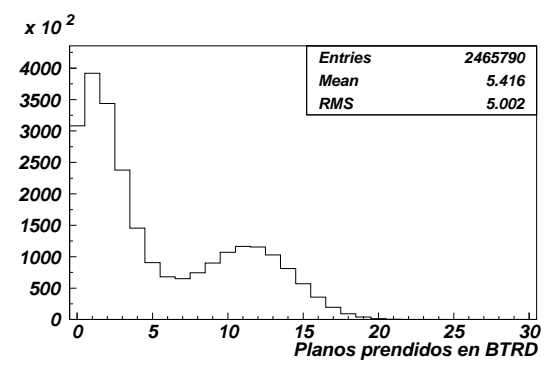

Figura 5.128: Planos prendidos en BTRD. Proporción bariónica y mesónica del haz primario (neg $614 \mathrm{CH}_{2}$ ).
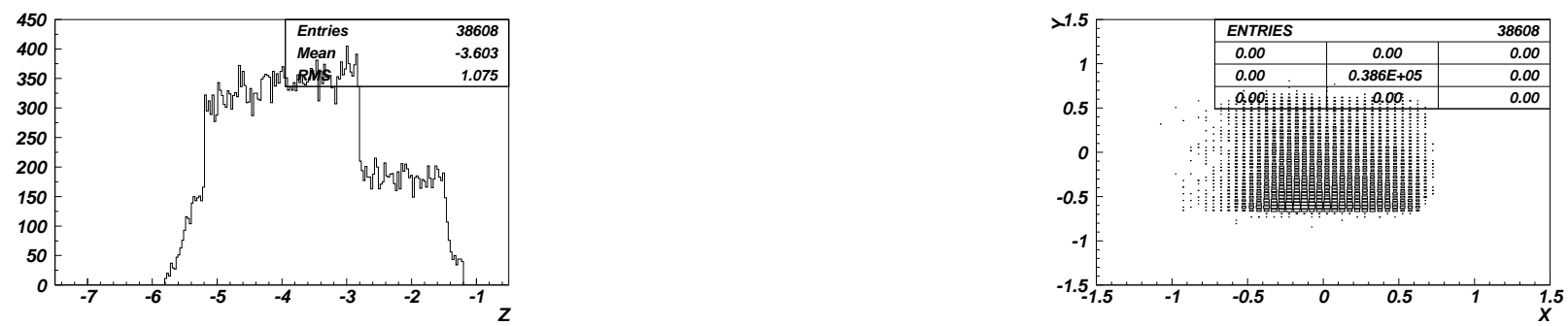

Figura 5.129: Vértice primario. Izquierda: coordenada z. Derecha: proyección x,y (neg 614 $\left.\mathrm{CH}_{2}\right)$. 


\subsubsection{Multiplicidad en la región del vértice}
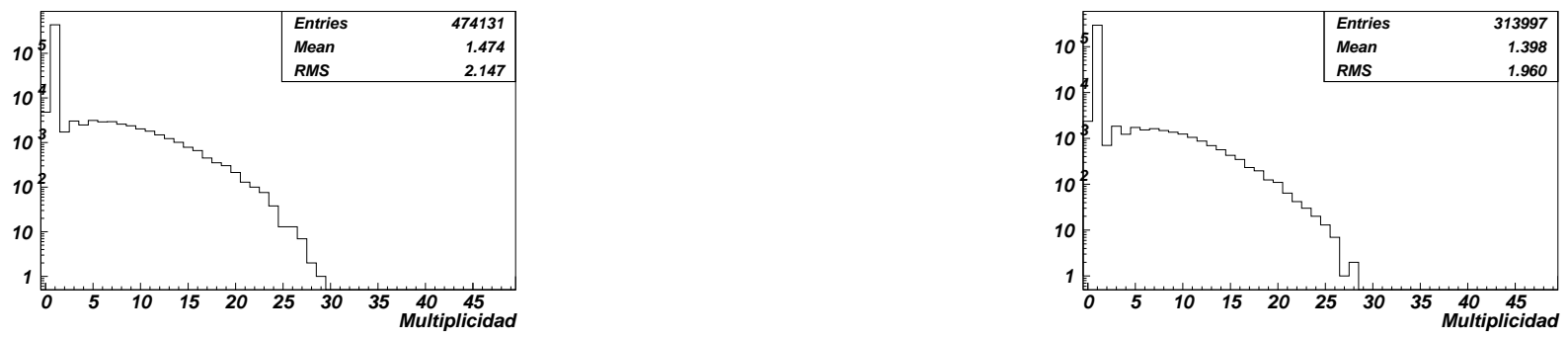

Figura 5.130: Multiplicidad total. Izquierda: haz de bariones. Derecha: haz de mesones(neg $\left.614 \mathrm{CH}_{2}\right)$.
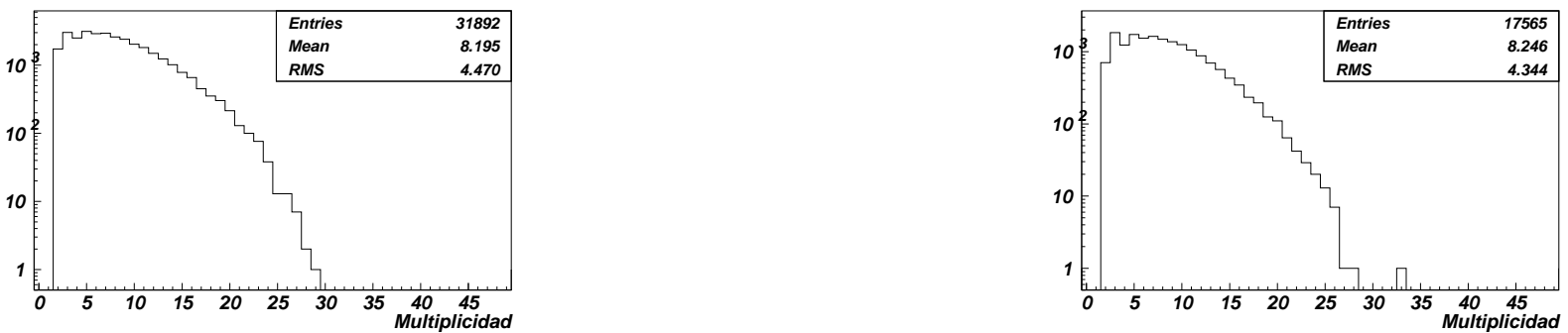

Figura 5.131: Multiplicidad en eventos con más de una trayectoria en la región del vértice. Izquierda: haz de bariones. Derecha: haz de mesones(neg $614 \mathrm{CH}_{2}$ ). 


\subsubsection{Distribuciones de multiplicidad y momento}
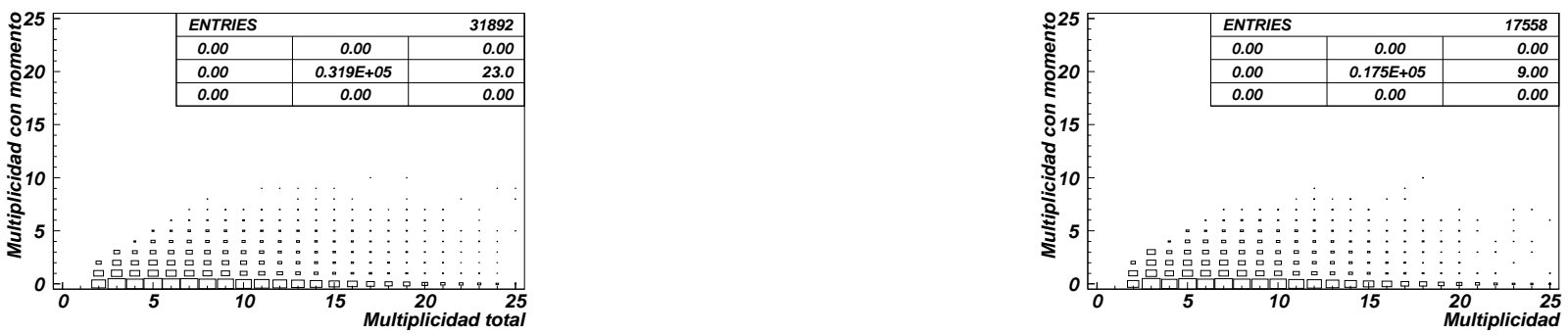

Figura 5.132: Multiplicidad total contra multiplicidad con momento medido. Izquierda: haz de bariones. Derecha: haz de mesones(neg $614 \mathrm{CH}_{2}$ ).
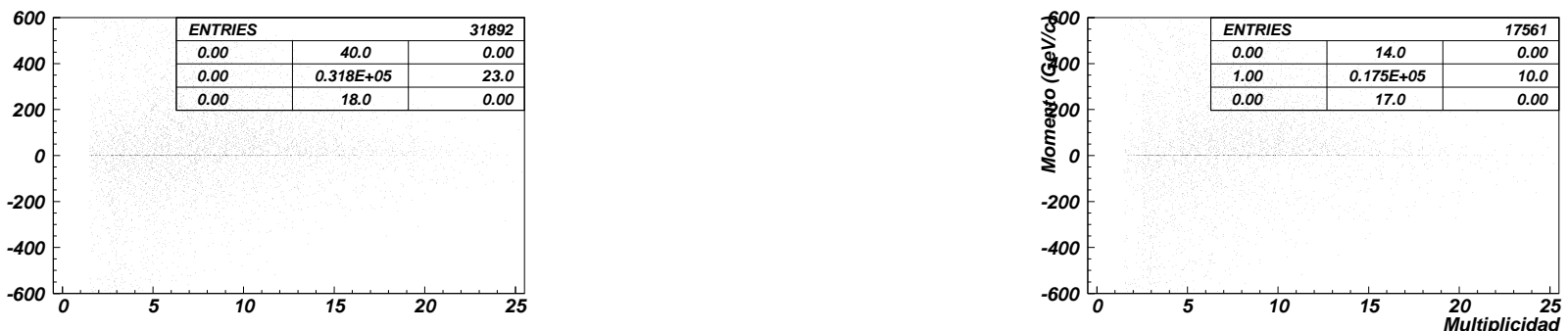

Figura 5.133: Multiplicidad contra momento.Izquierda: haz de bariones. Derecha: haz de mesones(neg $614 \mathrm{CH}_{2}$ ). 
Distribuciones de momento total para eventos producidos por un haz de bariones
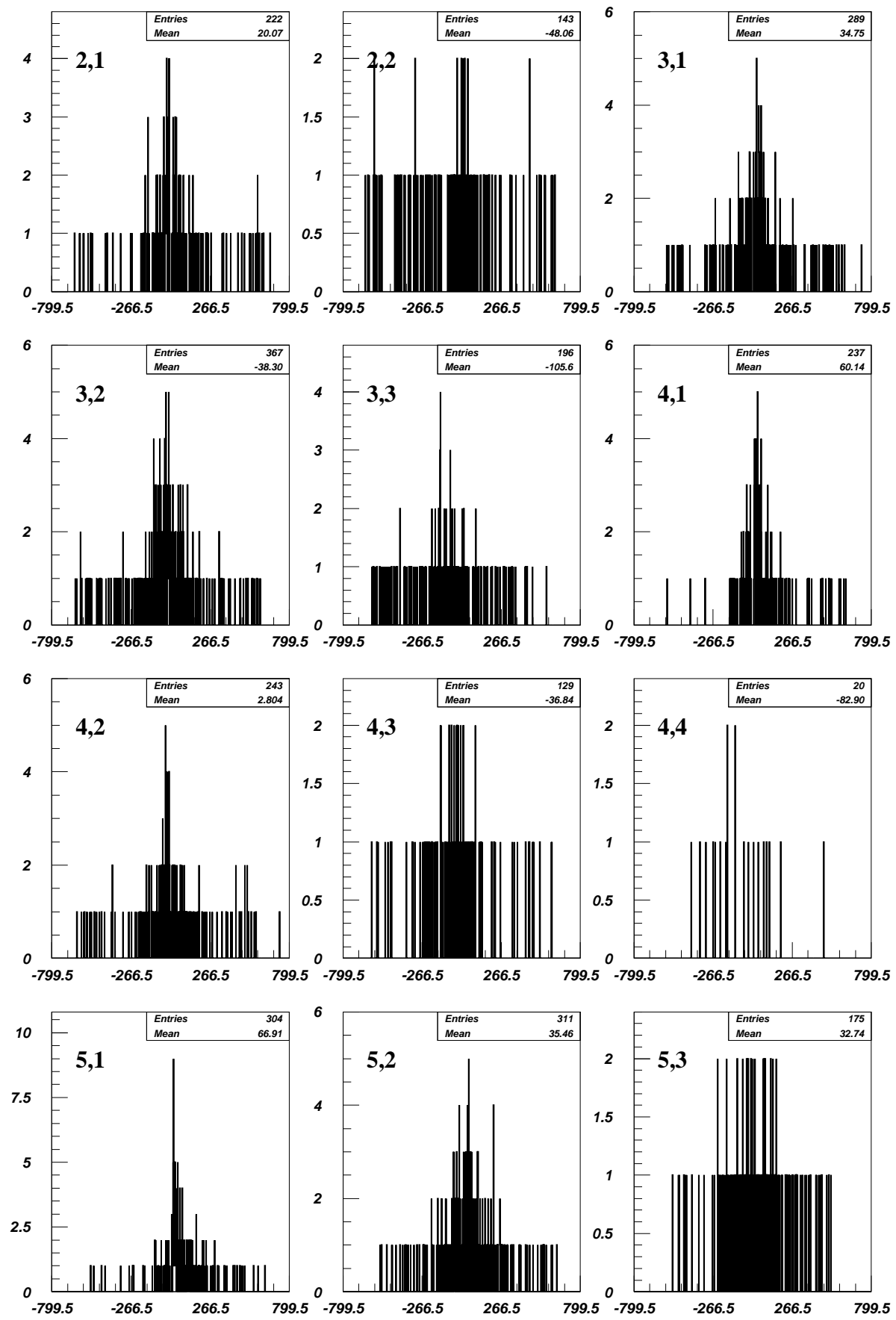

Figura 5.134: Distribuciones de momento. El primer indice: multiplicidad total, el segundo: multiplicidad con momento (neg $614 \mathrm{CH}_{2}$ ) 

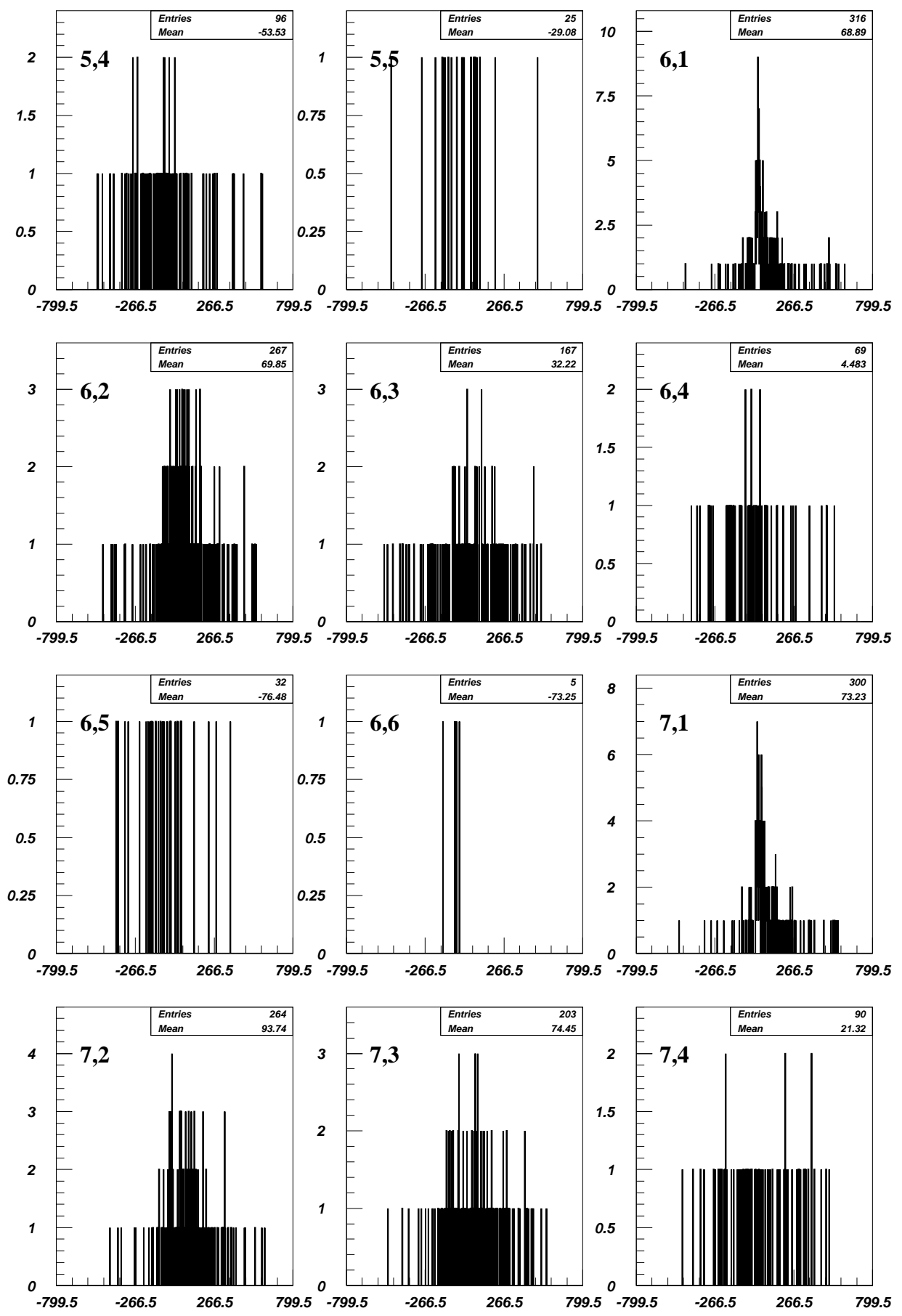

Figura 5.135: Distribuciones de momento. El primer índice: multiplicidad total, el segundo: multiplicidad con momento (neg $614 \mathrm{CH}_{2}$ ). 

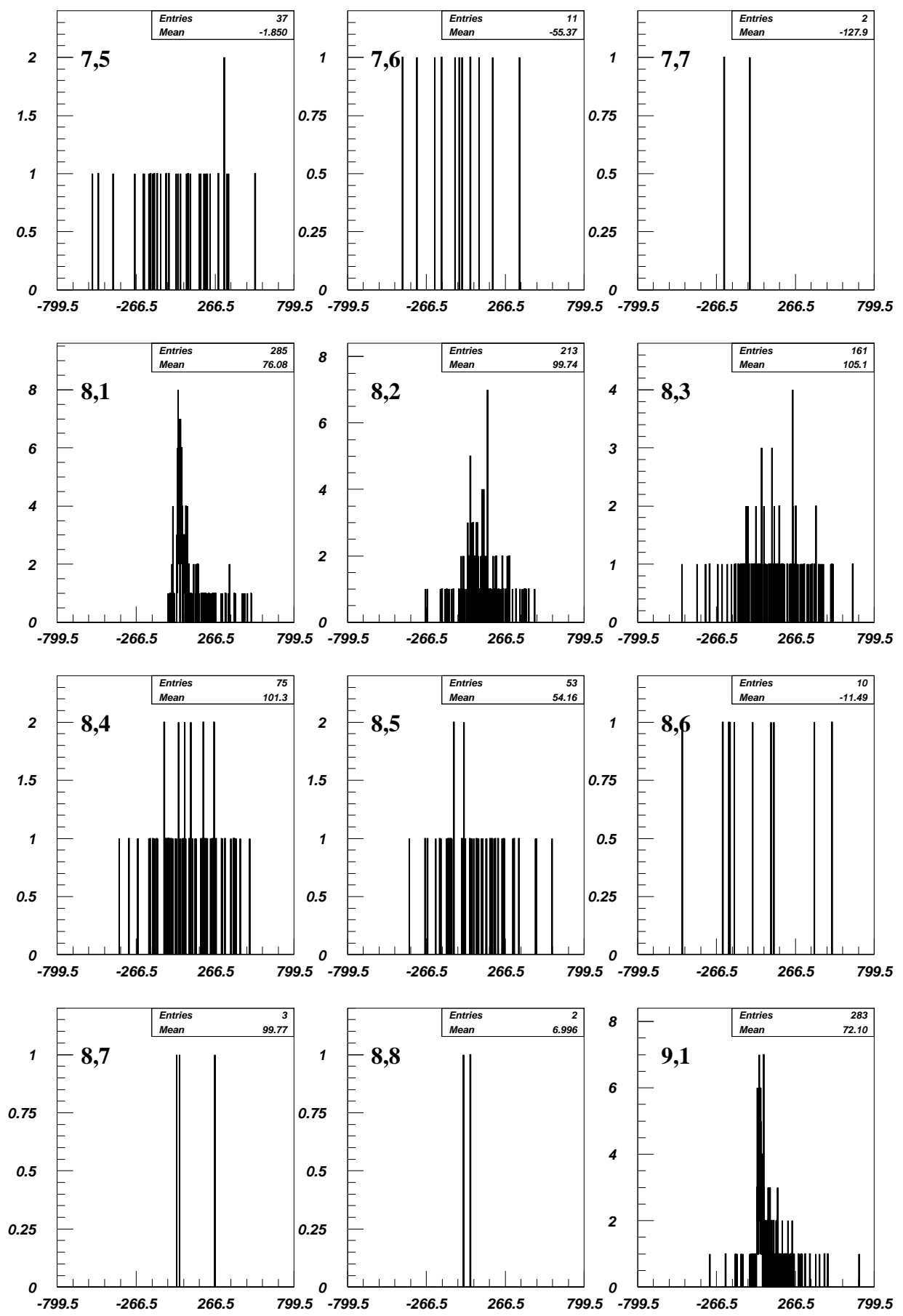

Figura 5.136: Distribuciones de momento. El primer índice: multiplicidad total, el segundo: multiplicidad con momento (neg $614 \mathrm{CH}_{2}$ ). 

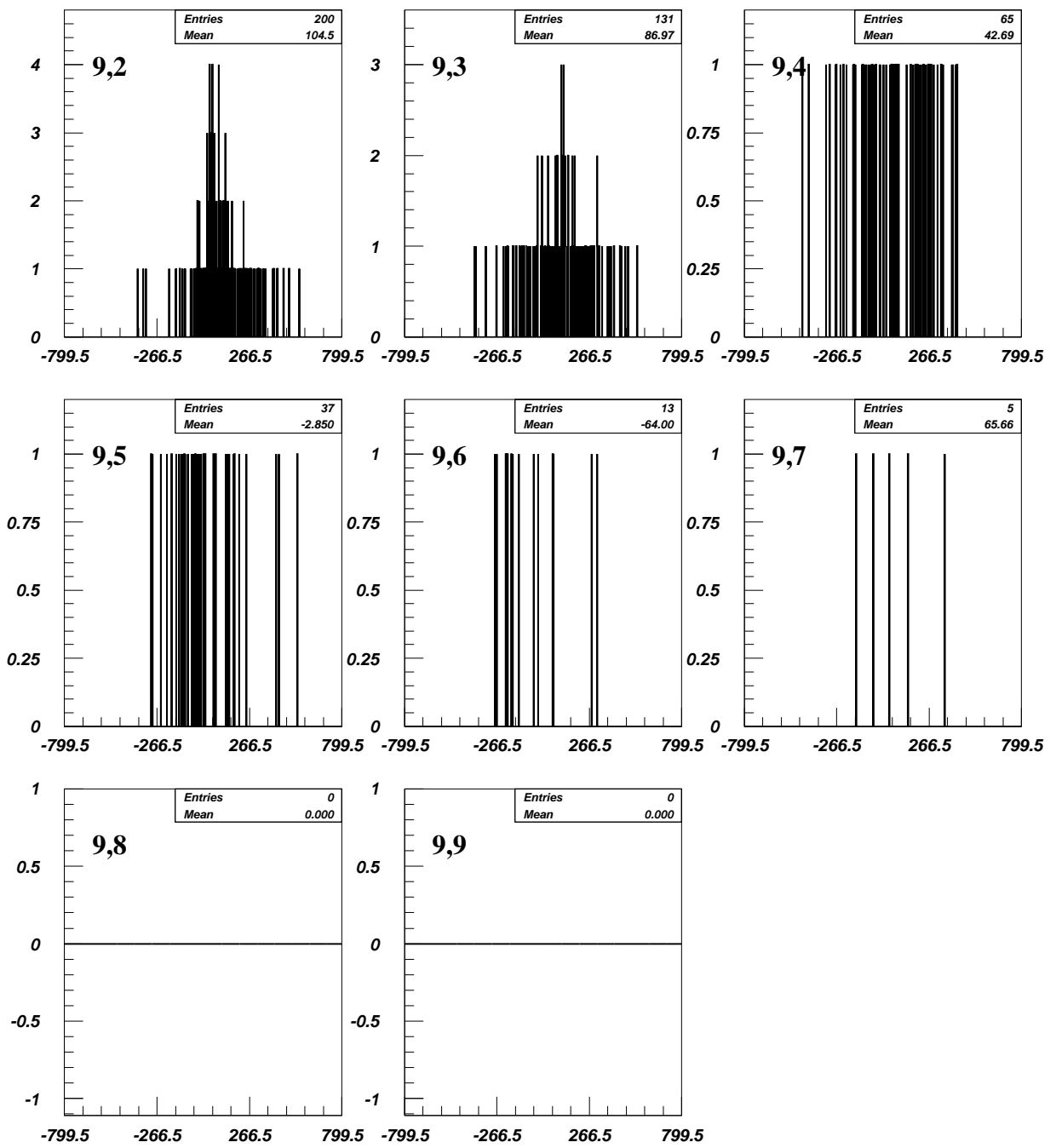

Figura 5.137: Distribuciones de momento. El primer índice: multiplicidad total, el segundo: multiplicidad con momento (neg $614 \mathrm{CH}_{2}$ ). 
Distribuciones de momento total para eventos producidos por un haz de mesones
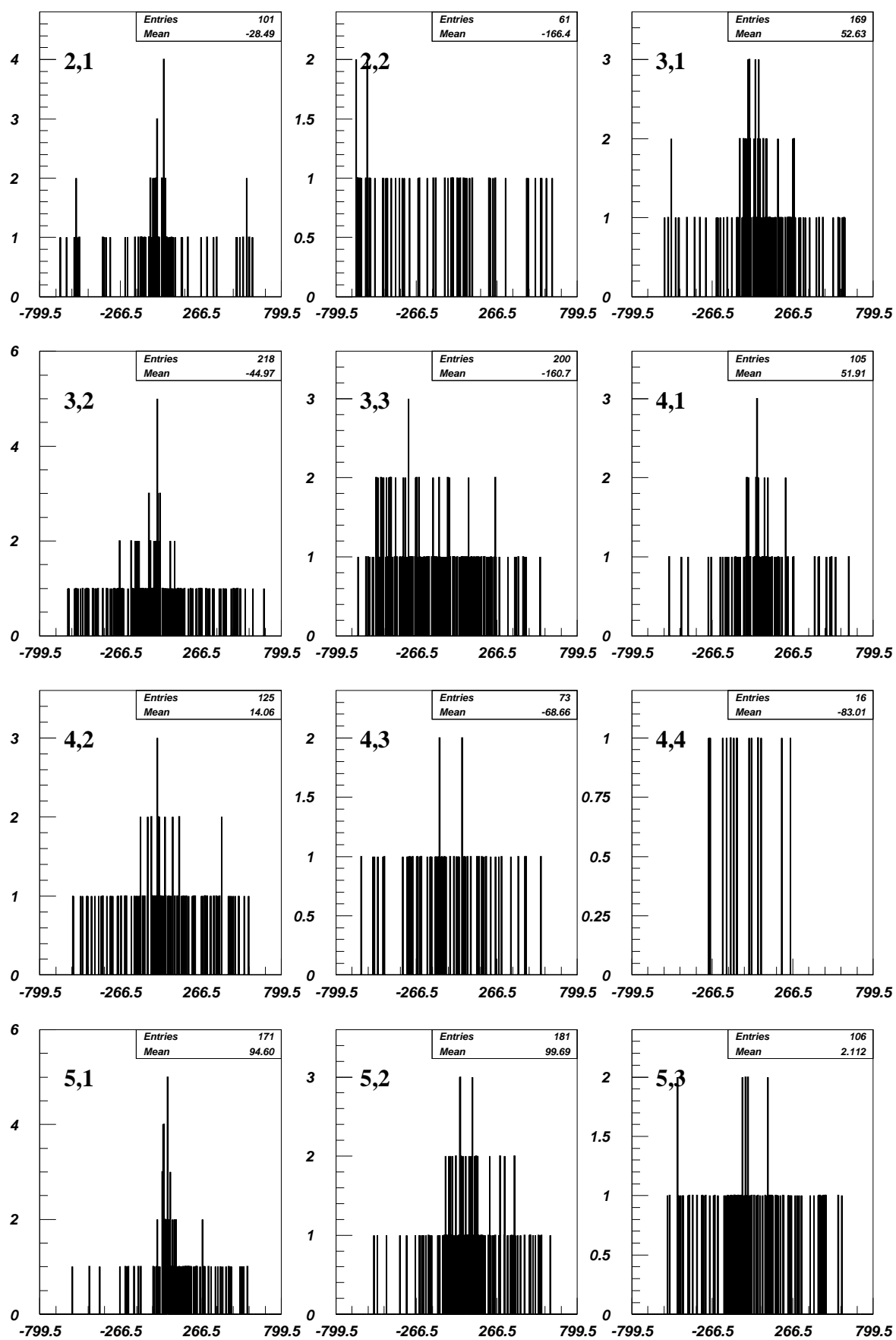

Figura 5.138: Distribuciones de momento. El primer indice: multiplicidad total, el segundo: multiplicidad con momento (neg $614 \mathrm{CH}_{2}$ ). 

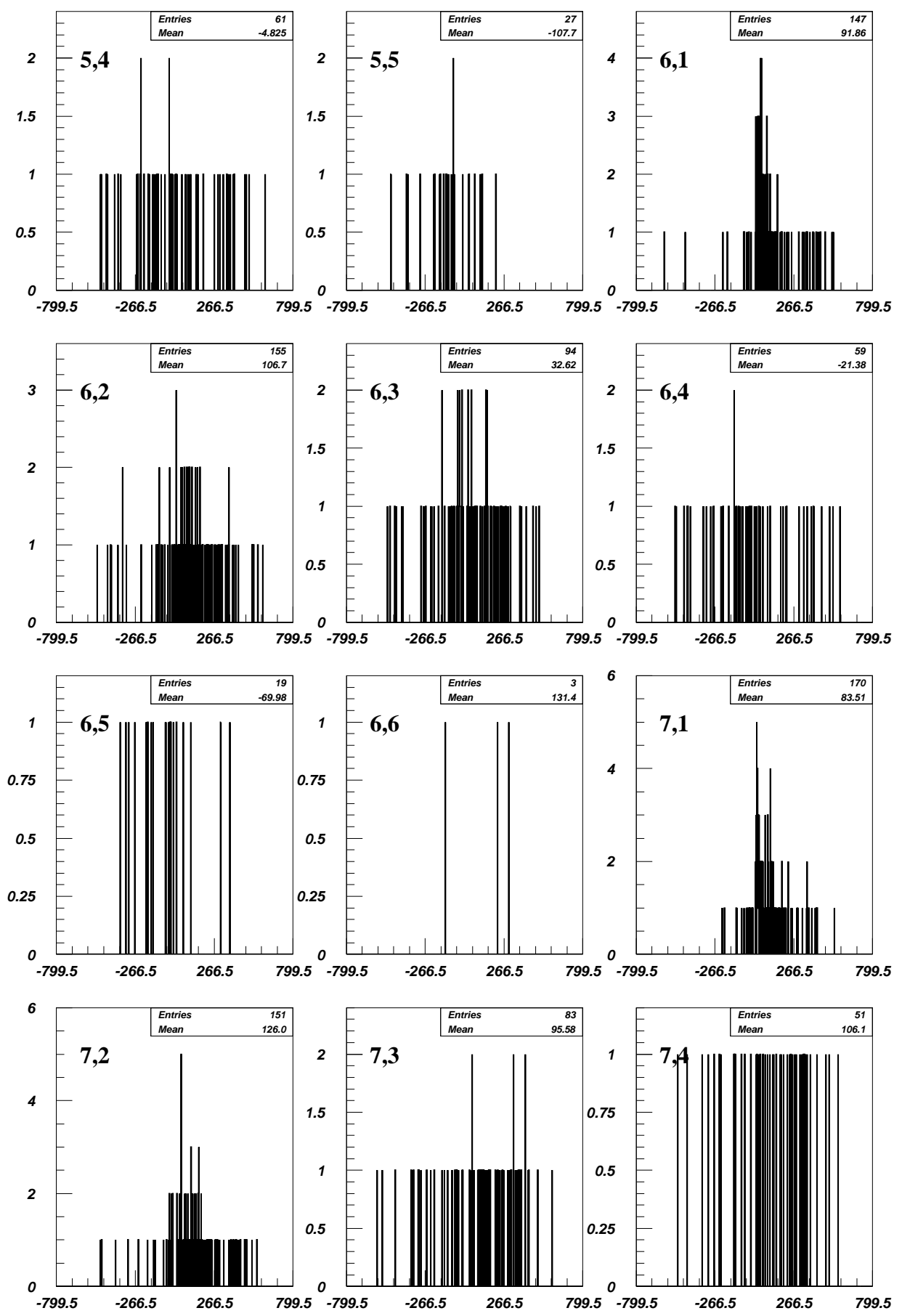

Figura 5.139: Distribuciones de momento. El primer índice: multiplicidad total, el segundo: multiplicidad con momento (neg $614 \mathrm{CH}_{2}$ ). 

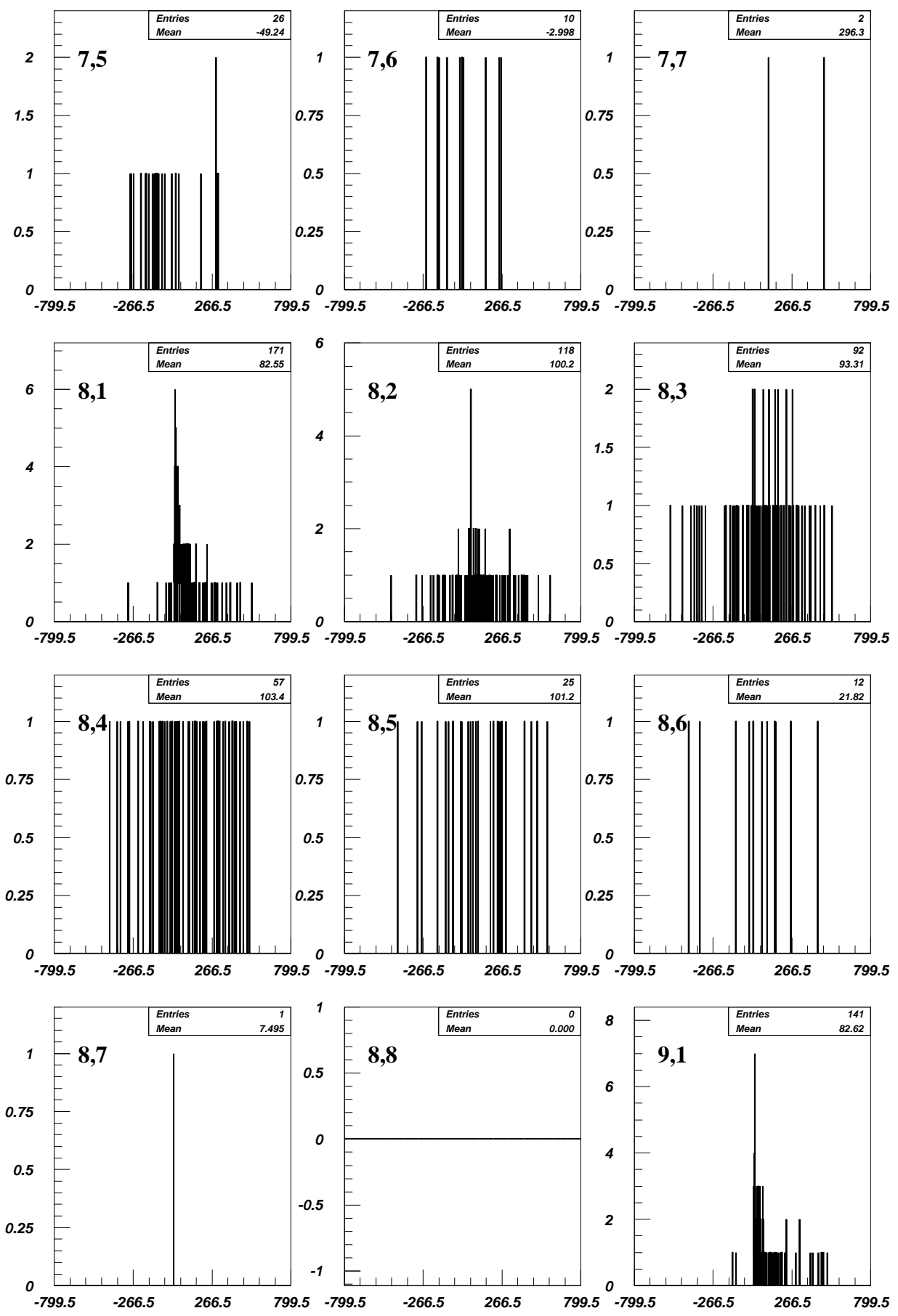

Figura 5.140: Distribuciones de momento. El primer índice: multiplicidad total, el segundo: multiplicidad con momento (neg $614 \mathrm{CH}_{2}$ ). 

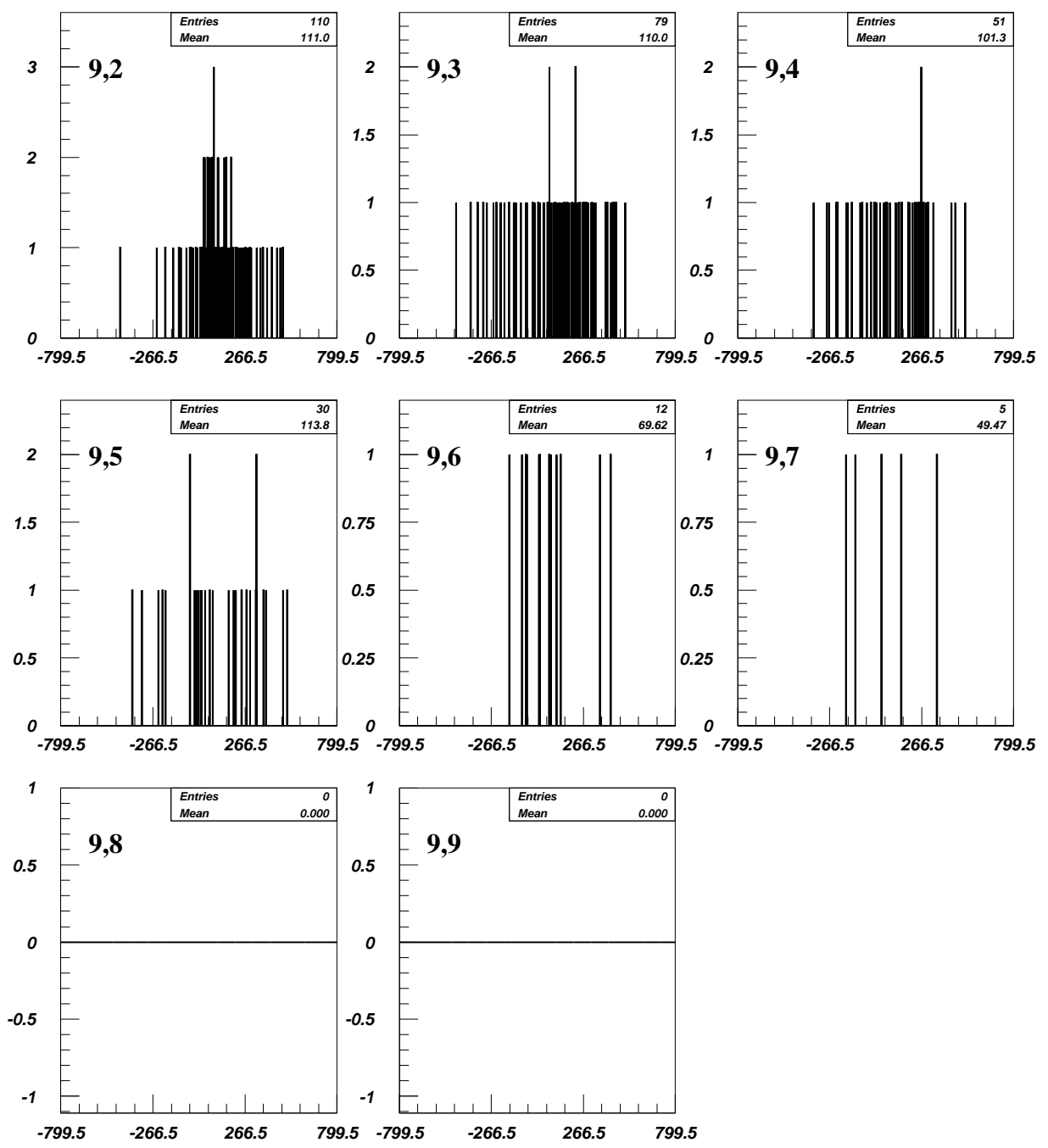

Figura 5.141: Distribuciones de momento. El primer índice: multiplicidad total, el segundo: multiplicidad con momento (neg $614 \mathrm{CH}_{2}$ ). 
Distribuciones del valor absoluto del momento total para eventos producidos por un haz de bariones
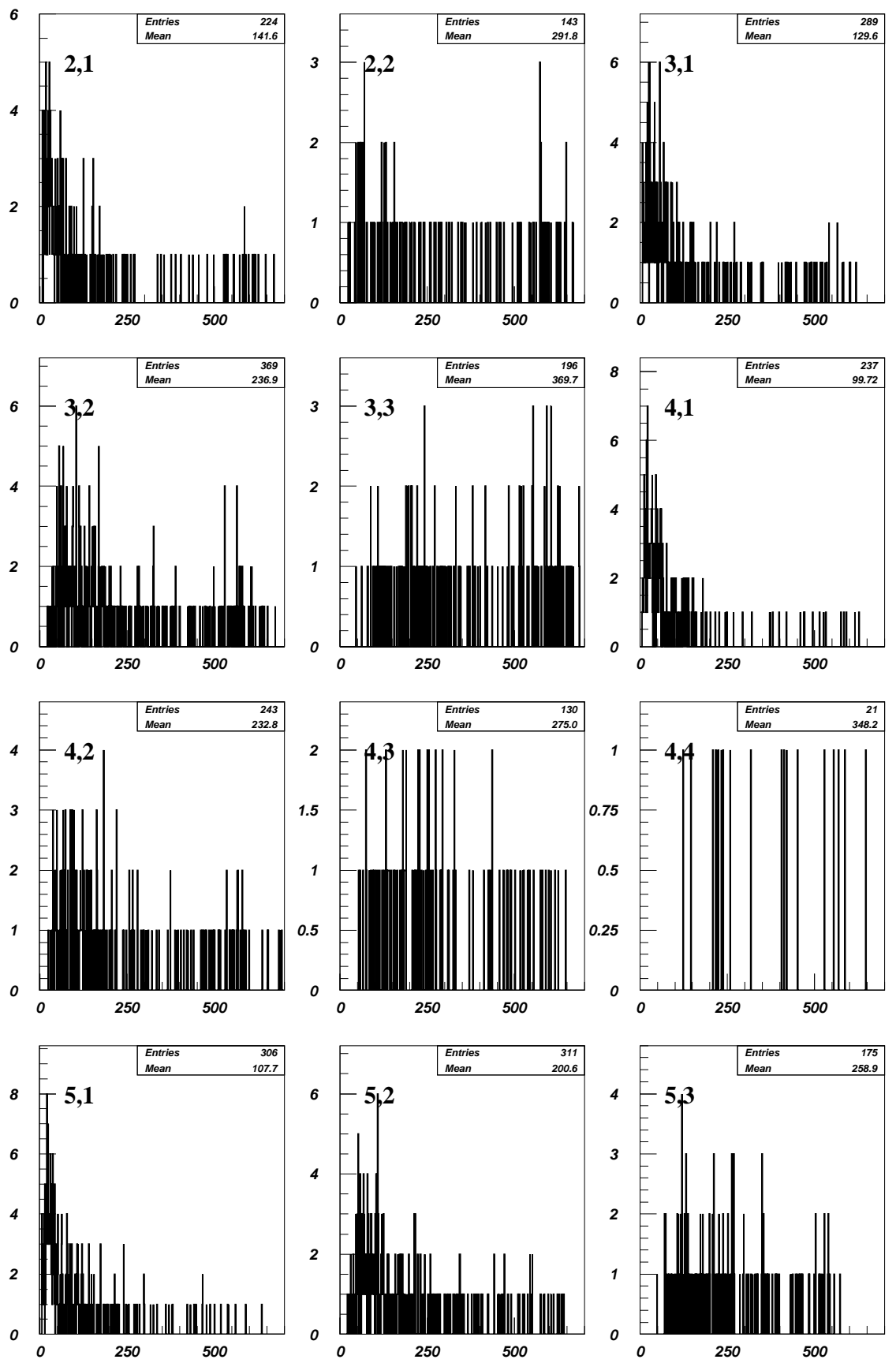

Figura 5.142: Distribuciones de momento. El primer indice: multiplicidad total, el segundo: multiplicidad con momento (neg $614 \mathrm{CH}_{2}$ ) 

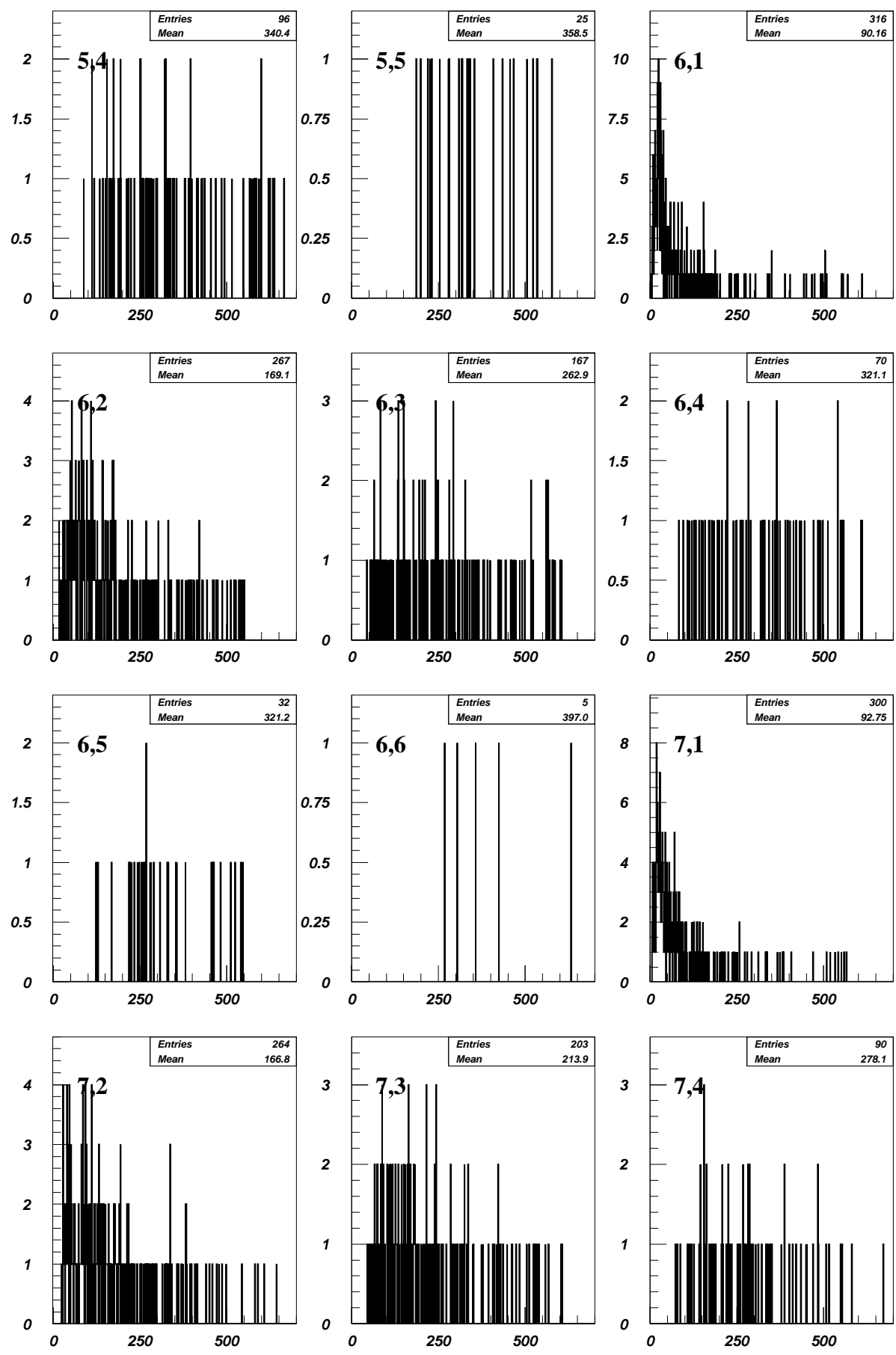

Figura 5.143: Distribuciones de momento. El primer índice: multiplicidad total, el segundo: multiplicidad con momento(neg $614 \mathrm{CH}_{2}$ ). 

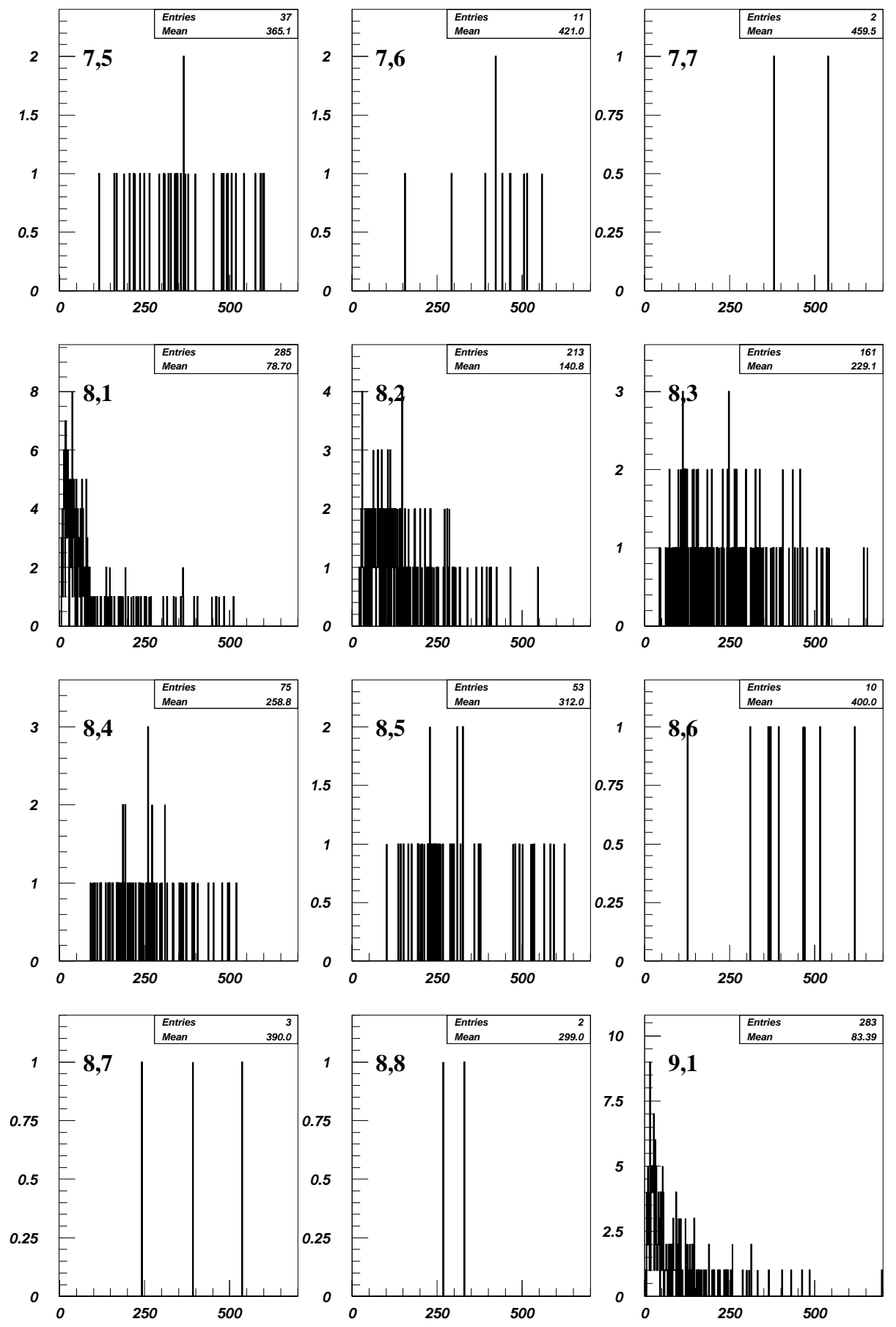

Figura 5.144: Distribuciones de momento. El primer índice: multiplicidad total, el segundo: multiplicidad con momento (neg $614 \mathrm{CH}_{2}$ ). 

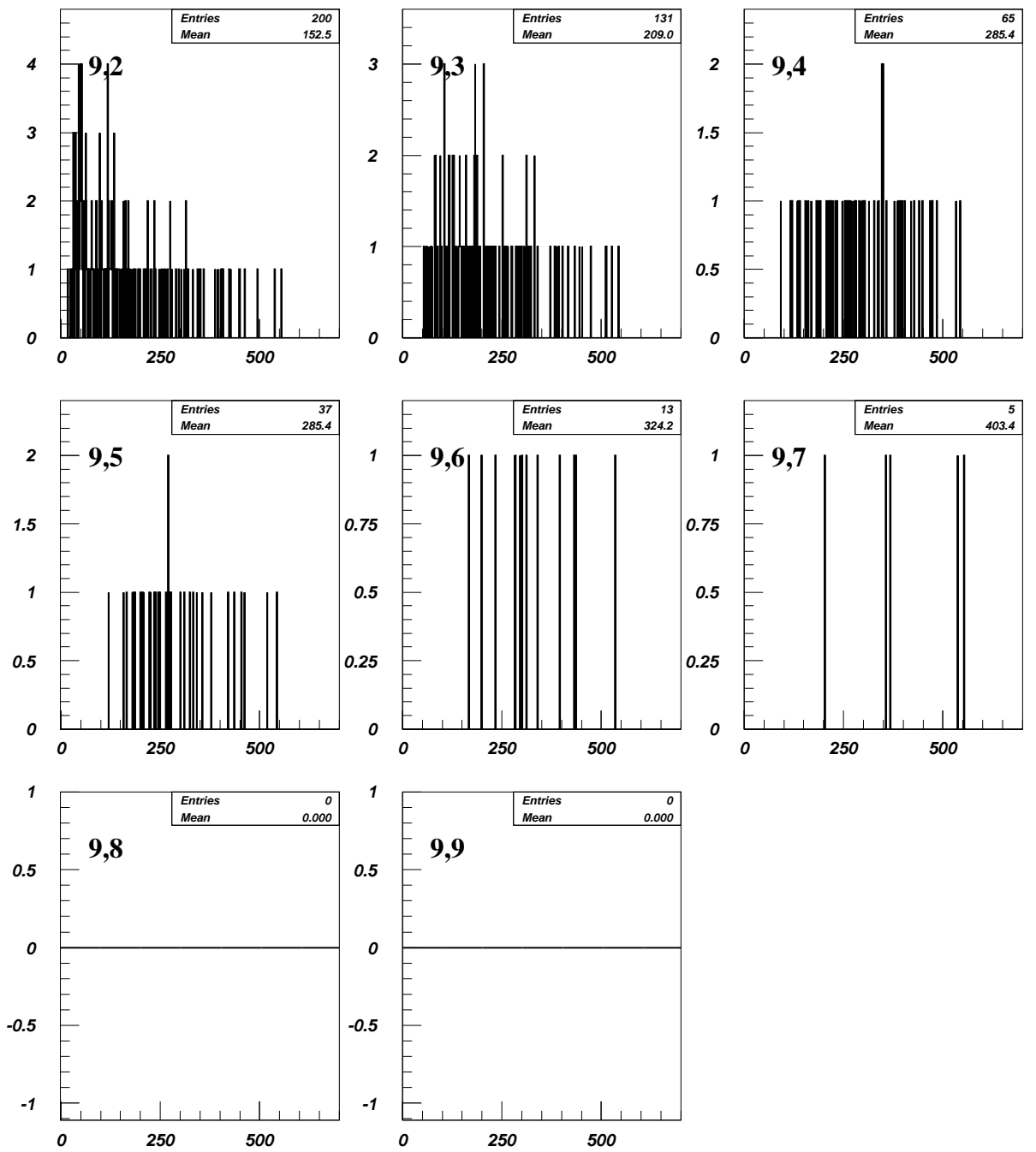

Figura 5.145: Distribuciones de momento. El primer índice: multiplicidad total, el segundo: multiplicidad con momento(neg $614 \mathrm{CH}_{2}$ ). 
Distribuciones del valor absoluto del momento total para eventos producidos por un haz de mesones
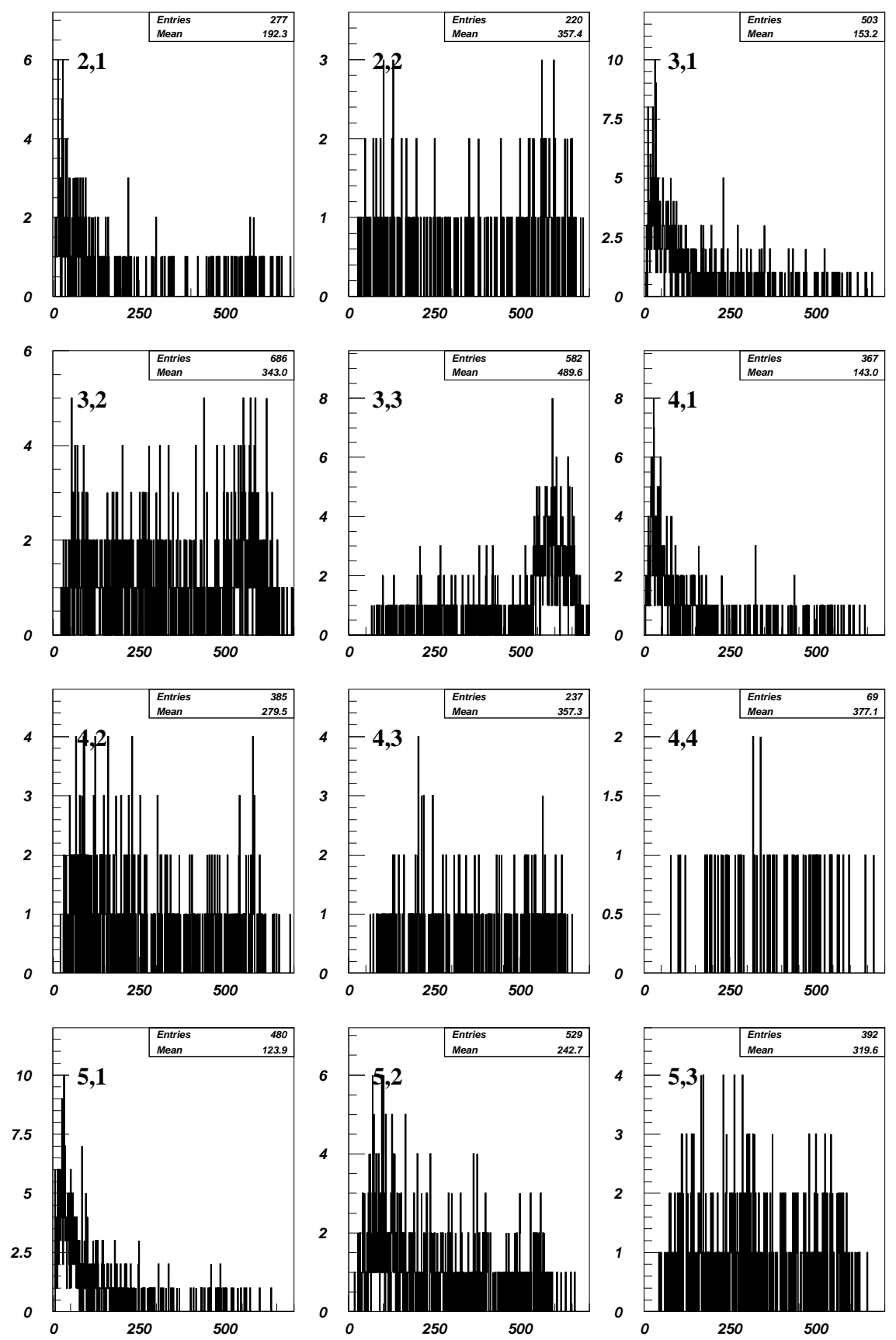

Figura 5.146: Distribuciones de momento. El primer indice: multiplicidad total, el segundo: multiplicidad con momento (neg $614 \mathrm{CH}_{2}$ ). 

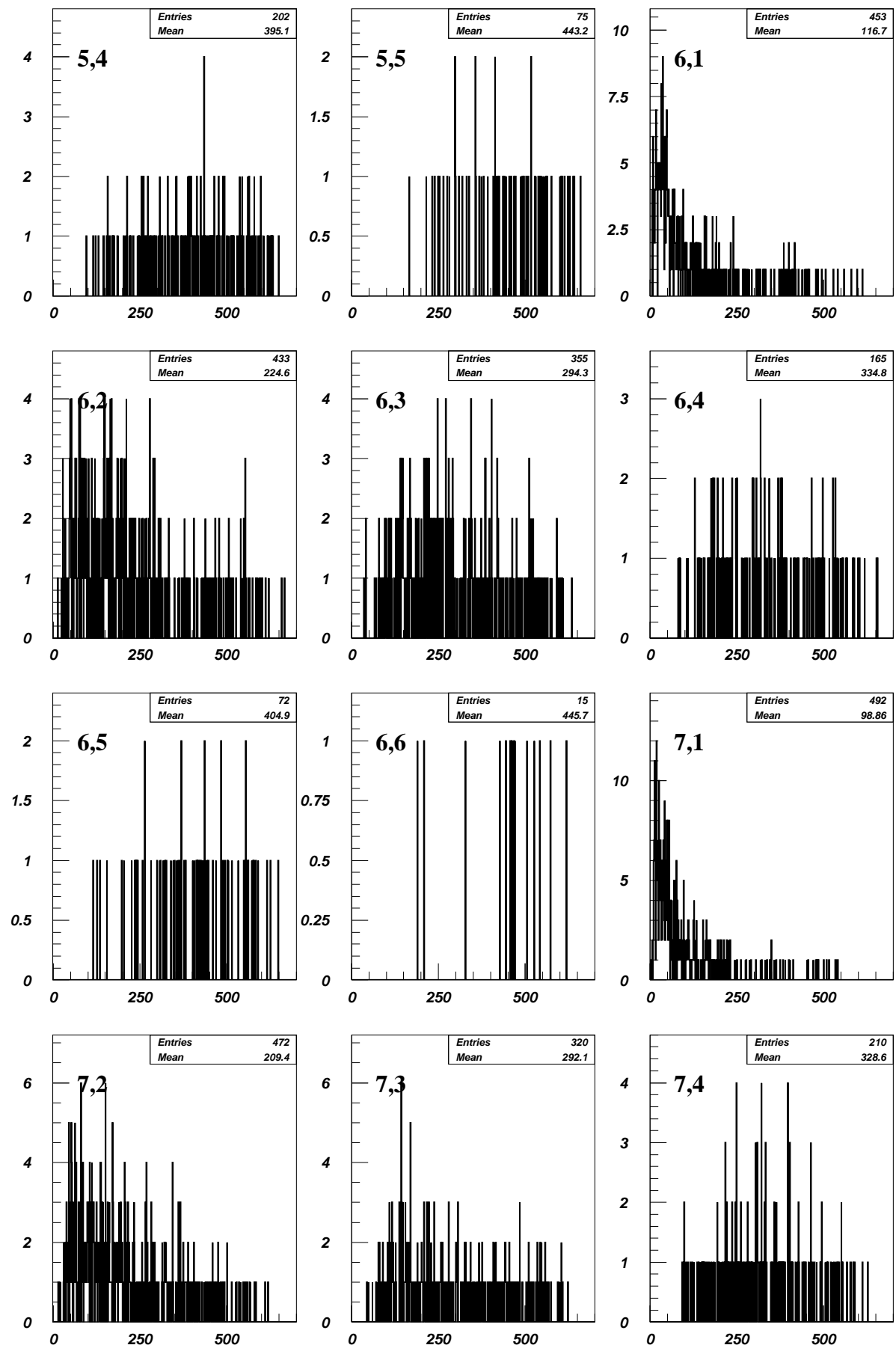

Figura 5.147: Distribuciones de momento. El primer índice: multiplicidad total, el segundo: multiplicidad con momento (neg $614 \mathrm{CH}_{2}$ ). 

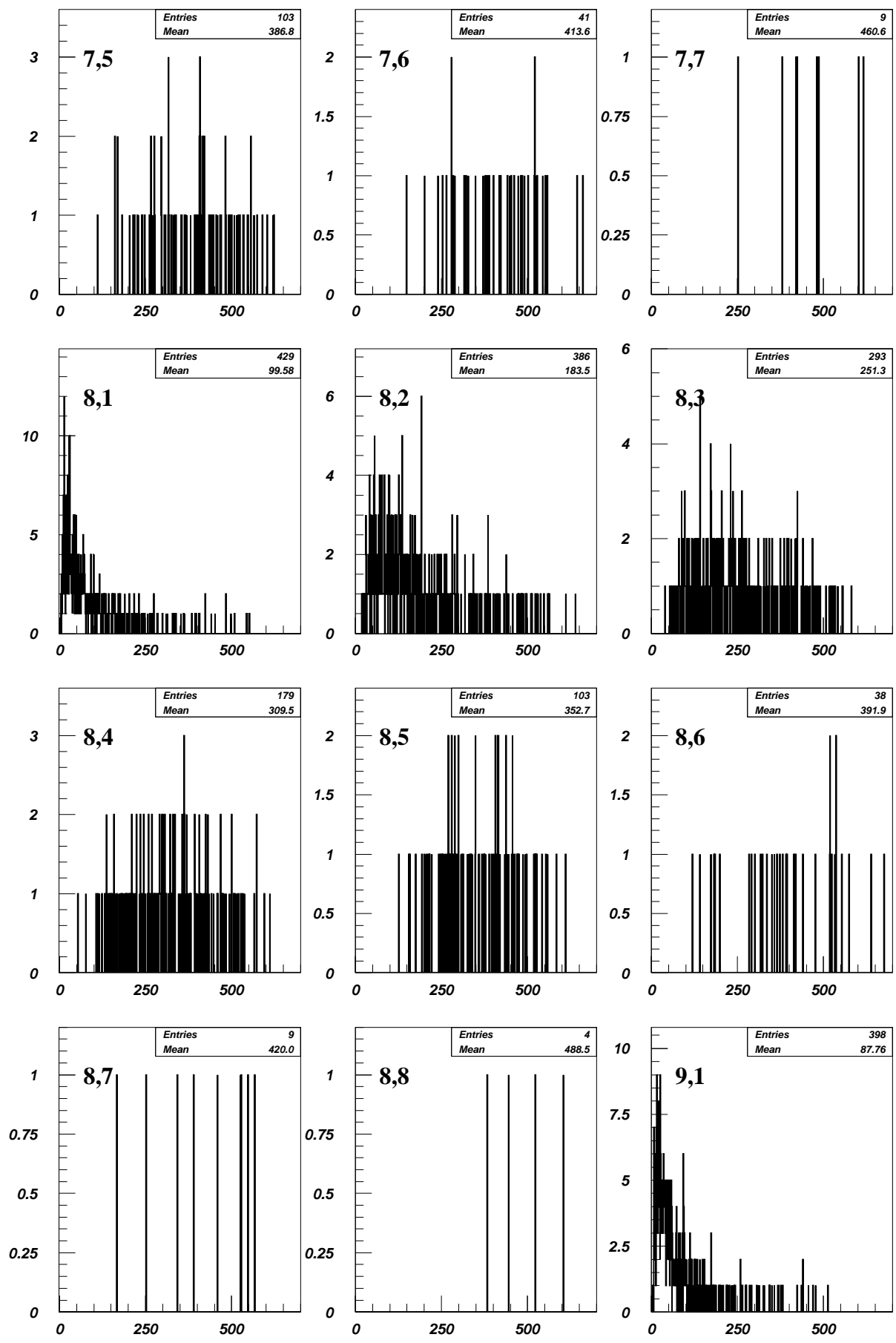

Figura 5.148: Distribuciones de momento. El primer índice: multiplicidad total, el segundo: multiplicidad con momento (neg $614 \mathrm{CH}_{2}$ ). 

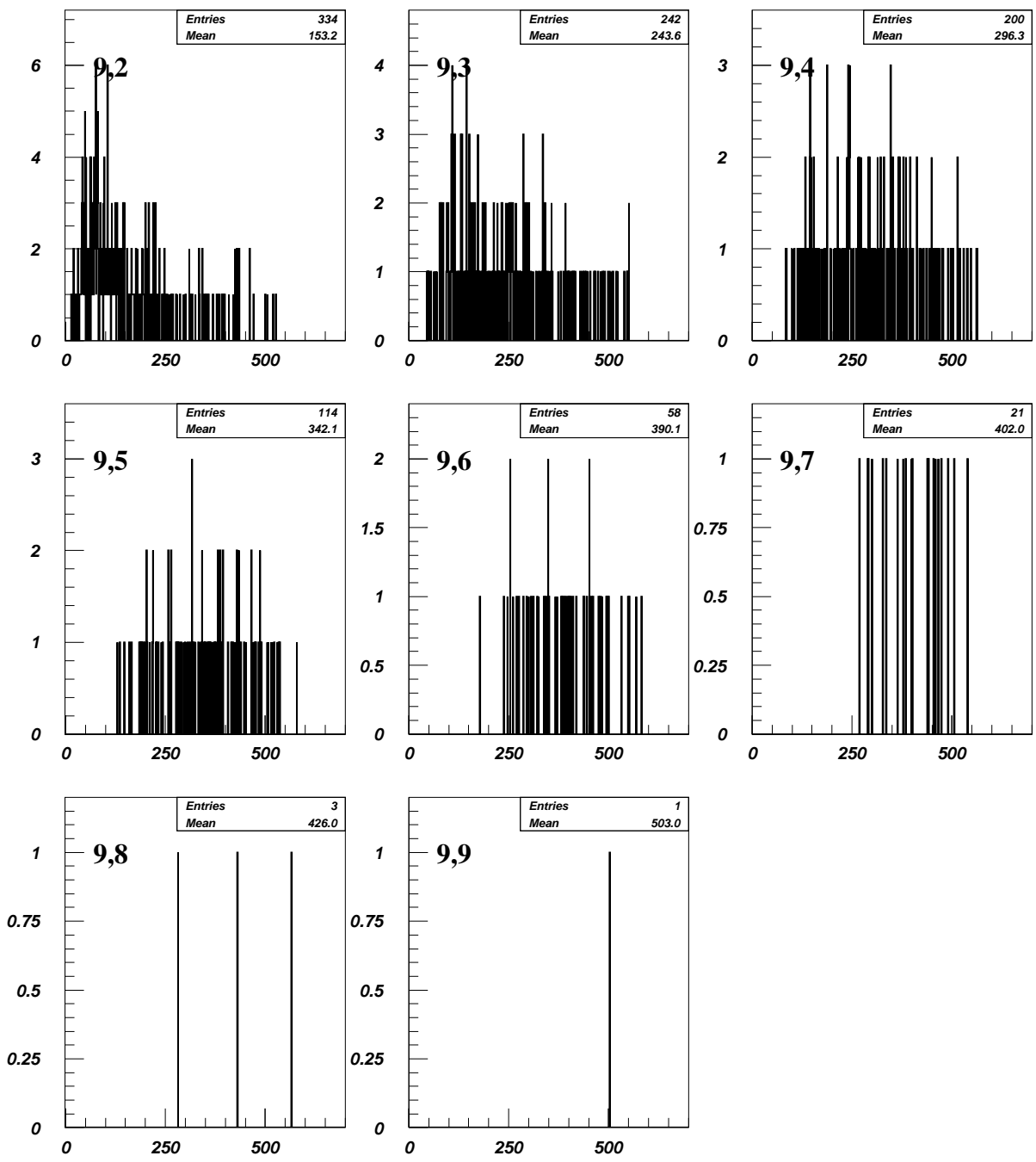

Figura 5.149: Distribuciones de momento. El primer índice: multiplicidad total, el segundo: multiplicidad con momento (neg $614 \mathrm{CH}_{2}$ ). 
Distribuciones del momento de las trayectorias para eventos producidos por un haz de bariones
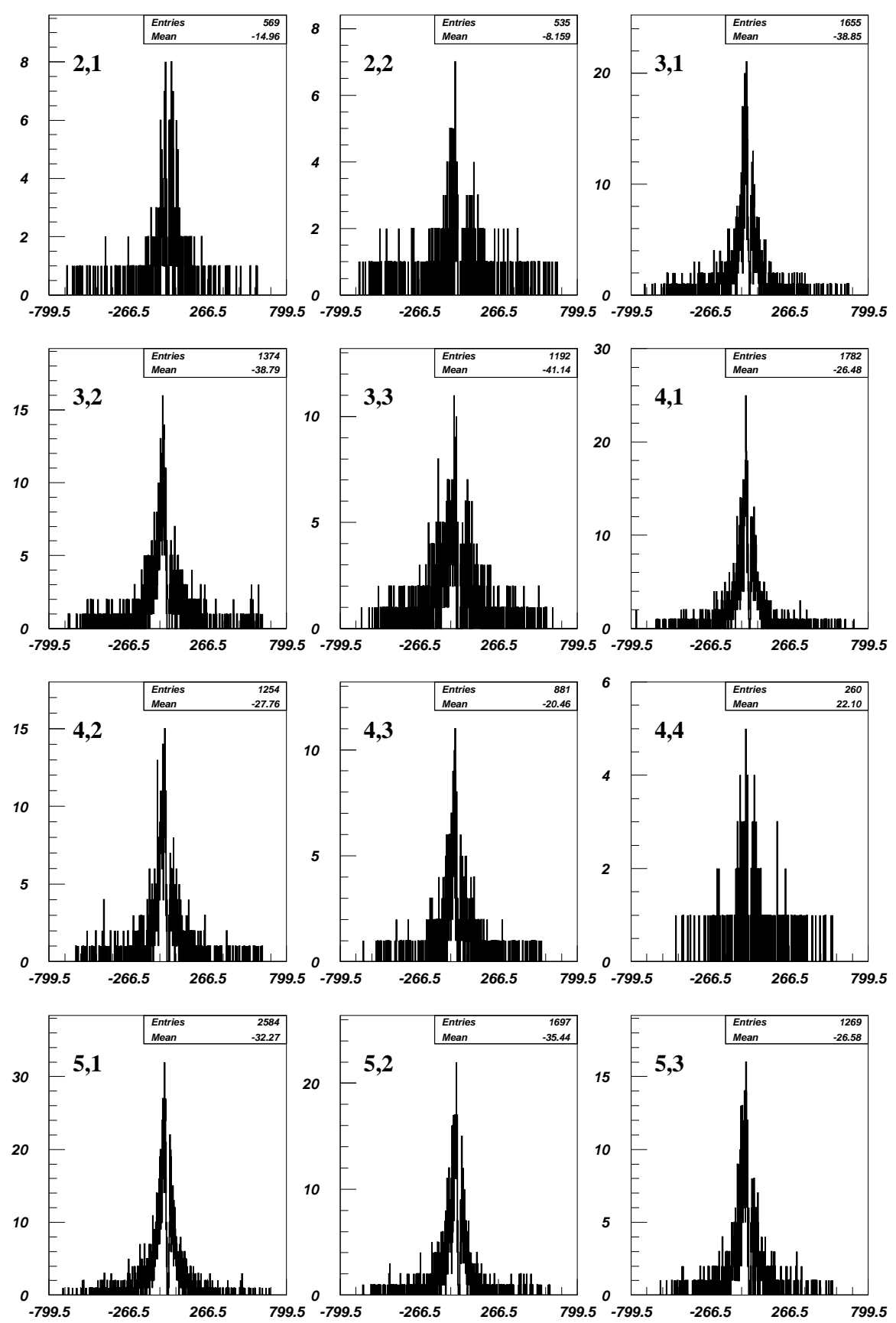

Figura 5.150: Distribuciones de momento. El primer indice: multiplicidad total, el segundo: multiplicidad con momento (neg $614 \mathrm{CH}_{2}$ ). 

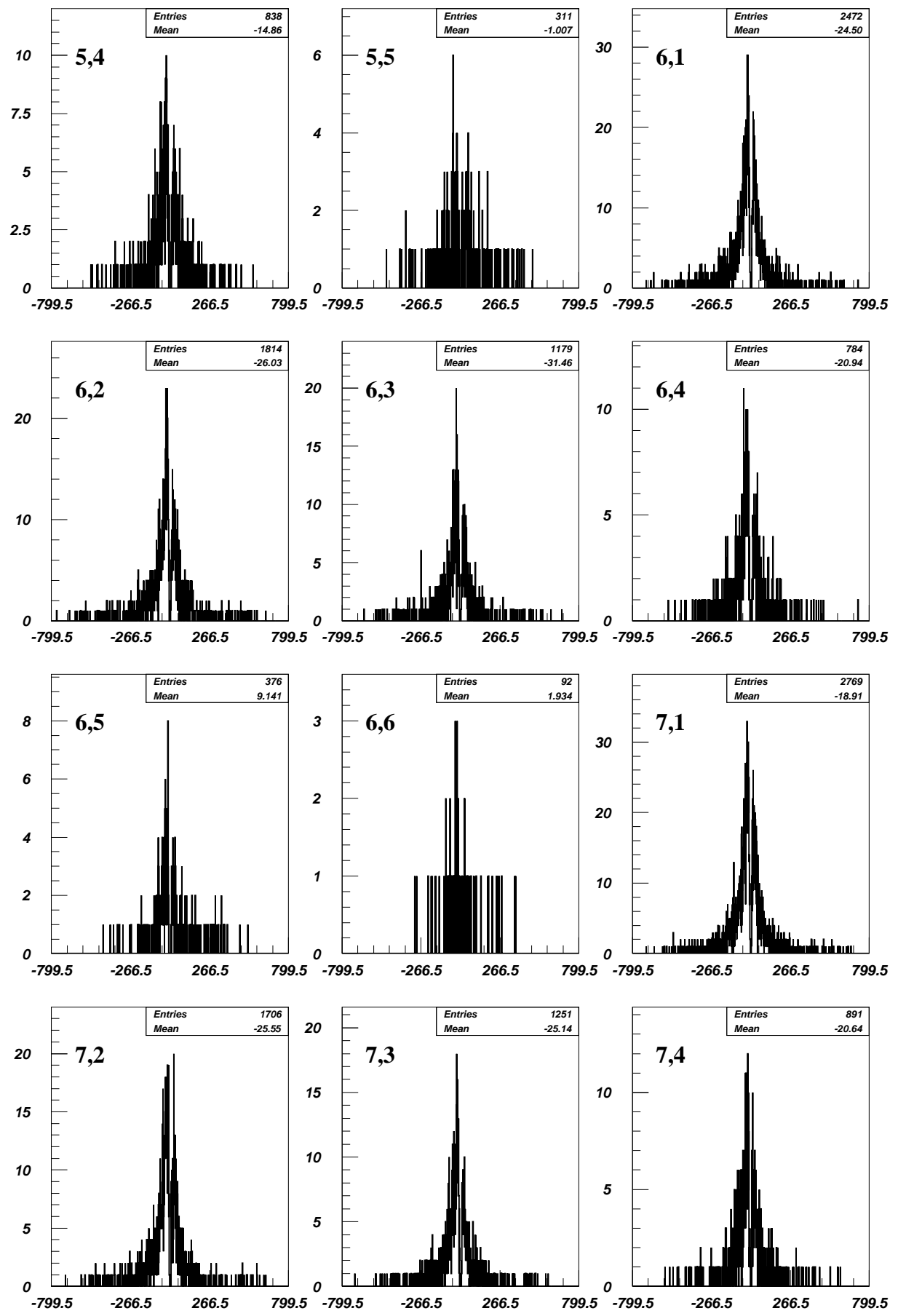

Figura 5.151: Distribuciones de momento. El primer índice: multiplicidad total, el segundo: multiplicidad con momento (neg $614 \mathrm{CH}_{2}$ ). 

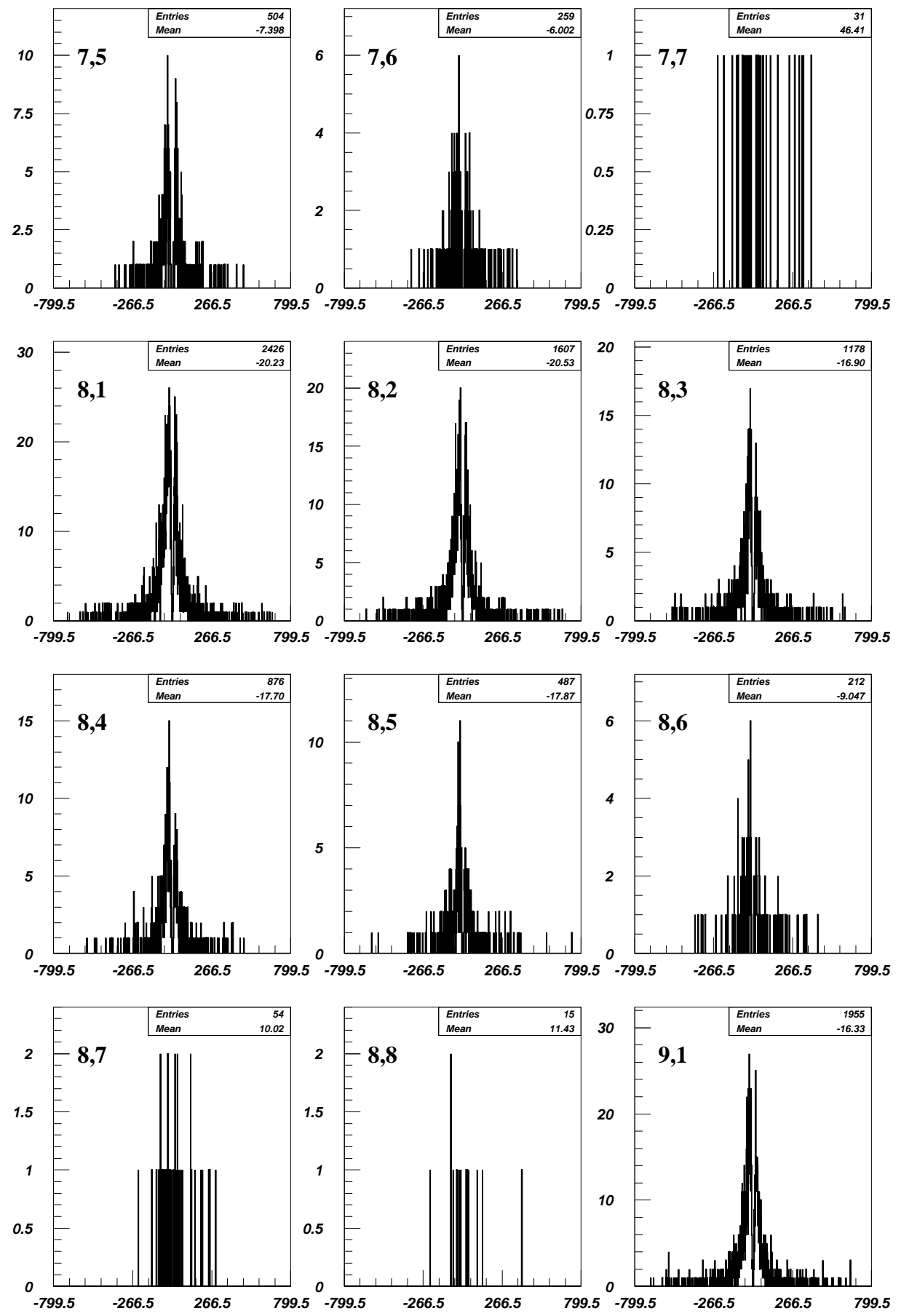

Figura 5.152: Distribuciones de momento. El primer índice: multiplicidad total, el segundo: multiplicidad con momento (neg $614 \mathrm{CH}_{2}$ ). 

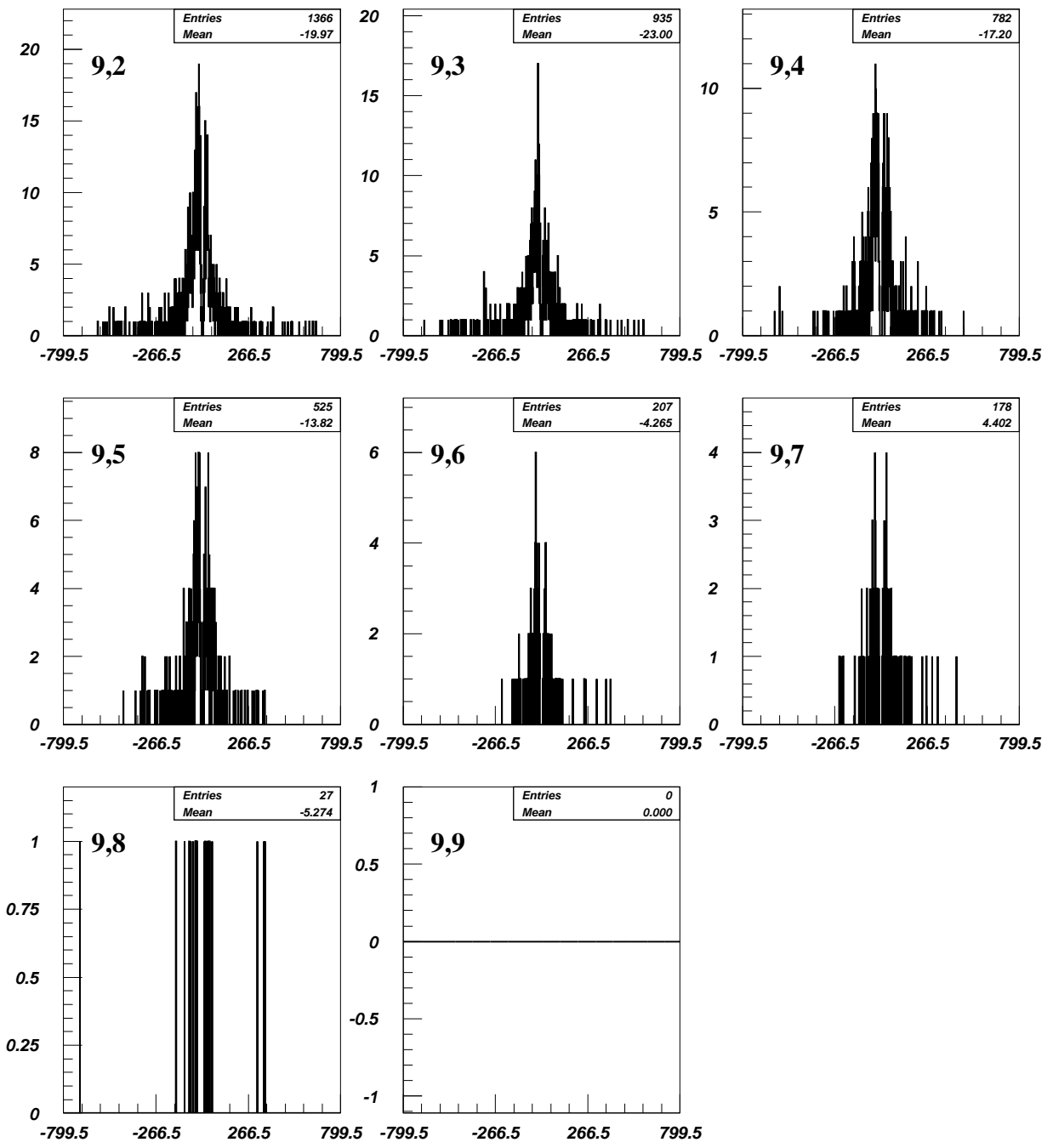

Figura 5.153: Distribuciones de momento. El primer índice: multiplicidad total, el segundo: multiplicidad con momento (neg $614 \mathrm{CH}_{2}$ ). 
Distribuciones del momento de las trayectorias para eventos producidos por un haz de mesones
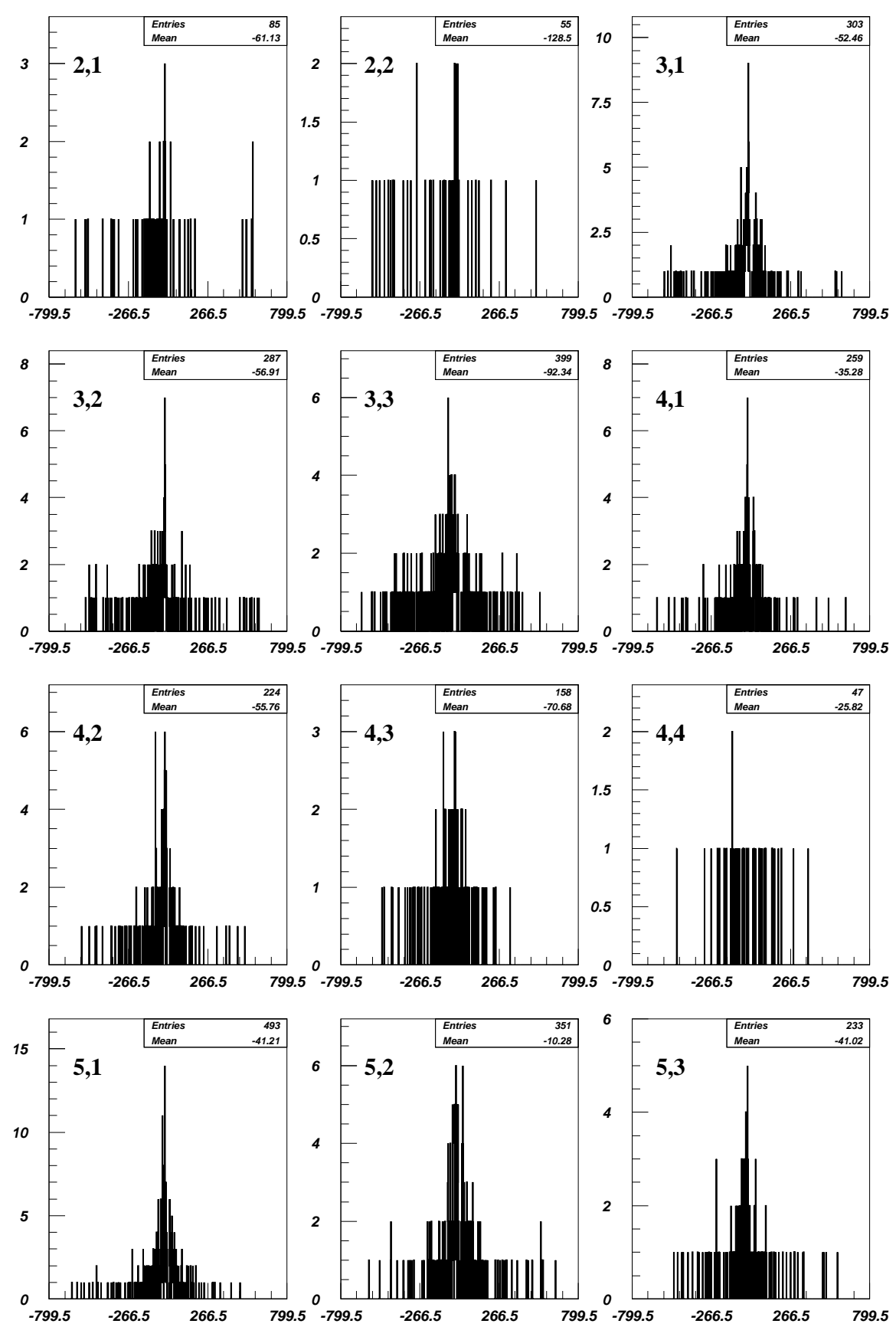

Figura 5.154: Distribuciones de momento. El primer indice: multiplicidad total, el segundo: multiplicidad con momento (neg $614 \mathrm{CH}_{2}$ ) 

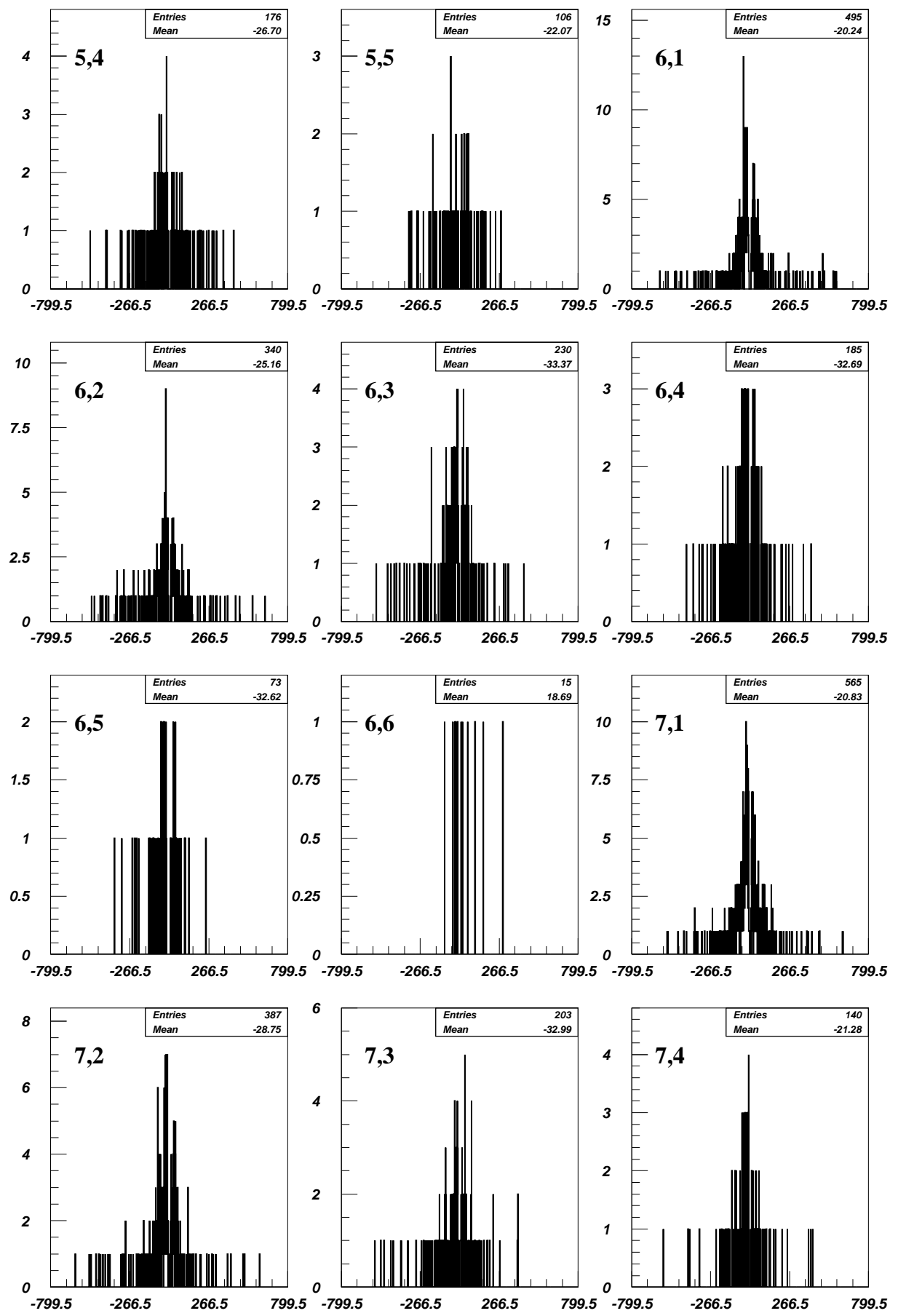

Figura 5.155: Distribuciones de momento. El primer índice: multiplicidad total, el segundo: multiplicidad con momento. 

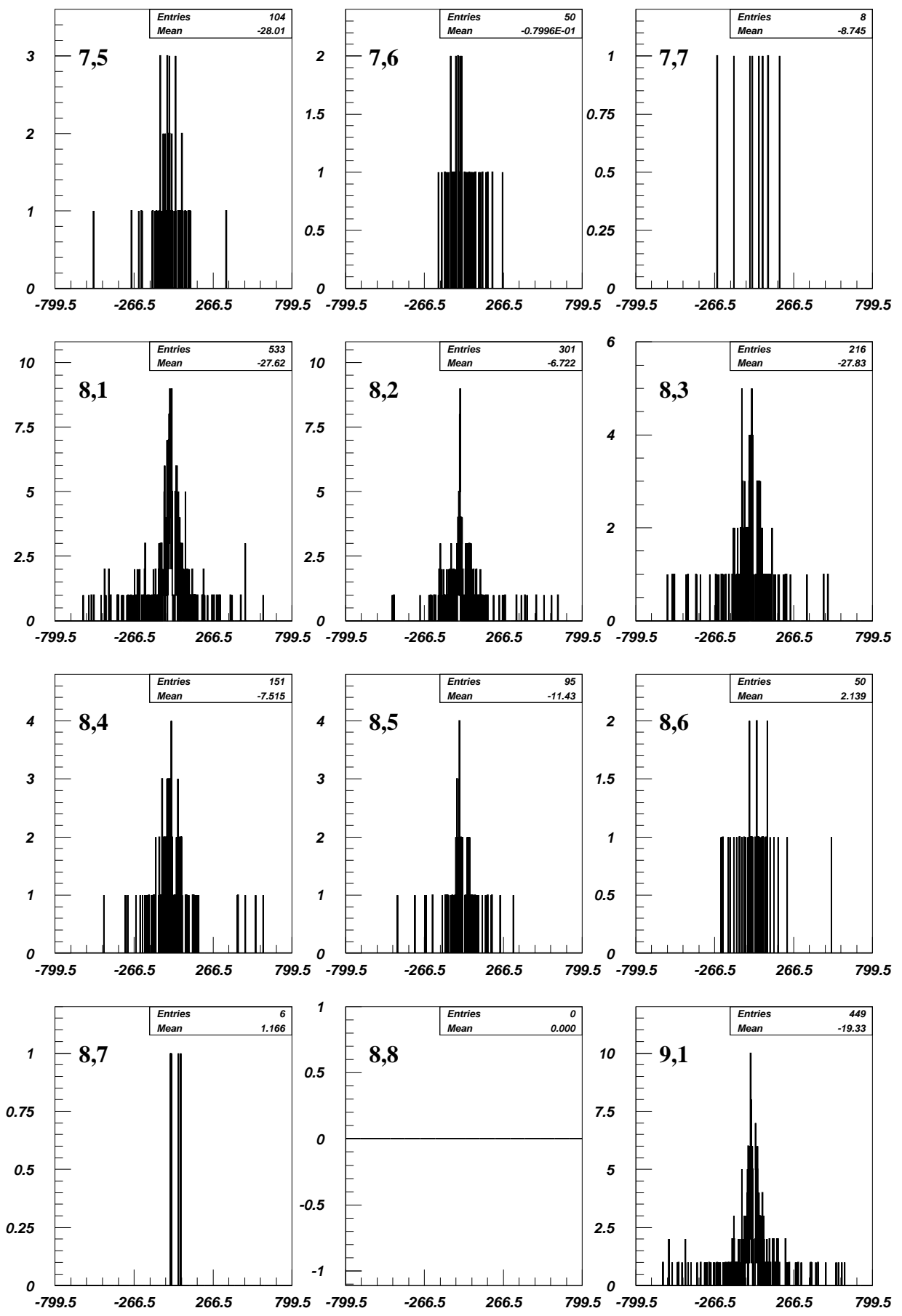

Figura 5.156: Distribuciones de momento. El primer índice: multiplicidad total, el segundo: multiplicidad con momento (neg $614 \mathrm{CH}_{2}$ ). 

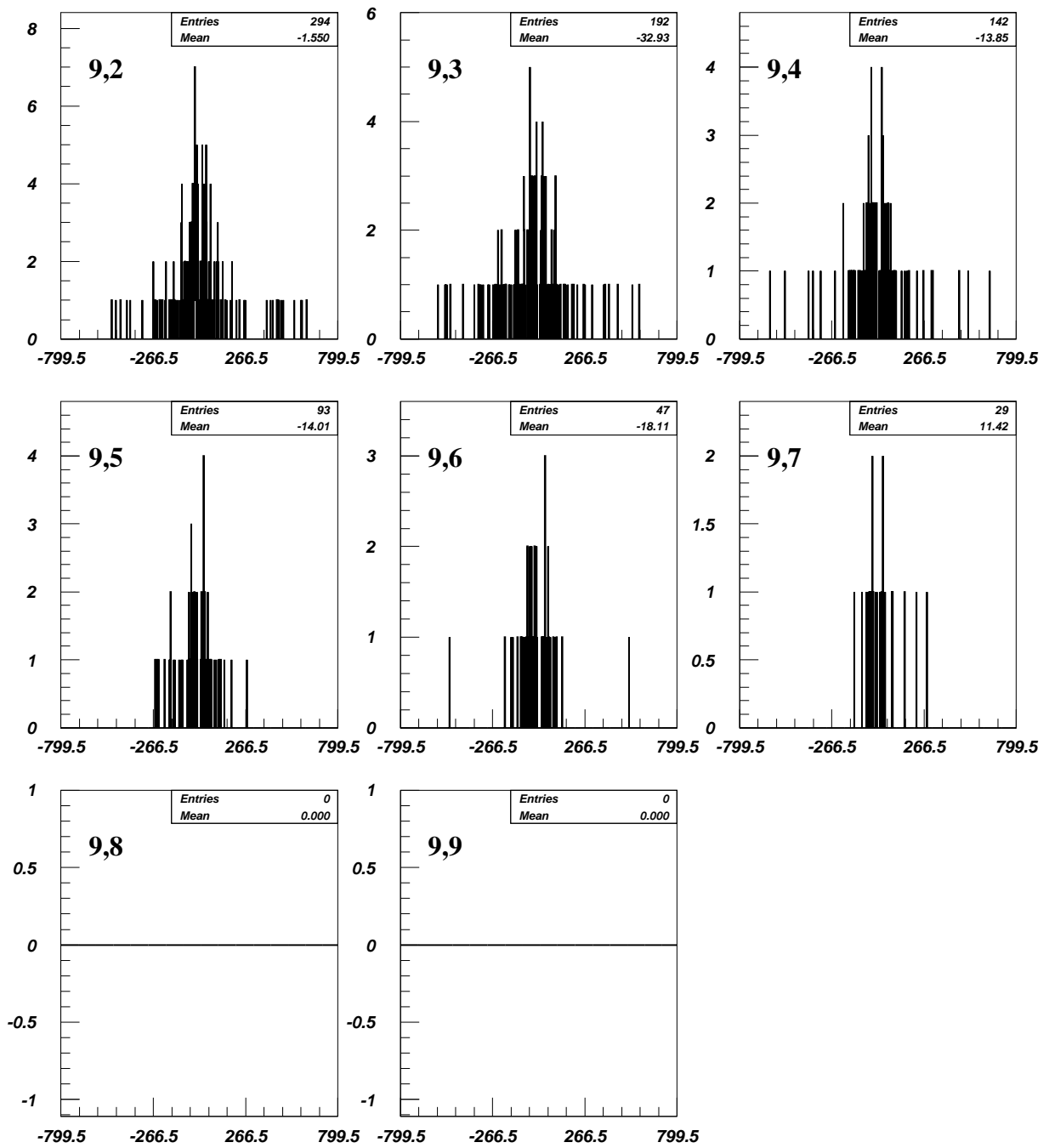

Figura 5.157: Distribuciones de momento. El primer índice: multiplicidad total, el segundo: multiplicidad con momento (neg $614 \mathrm{CH}_{2}$ ). 


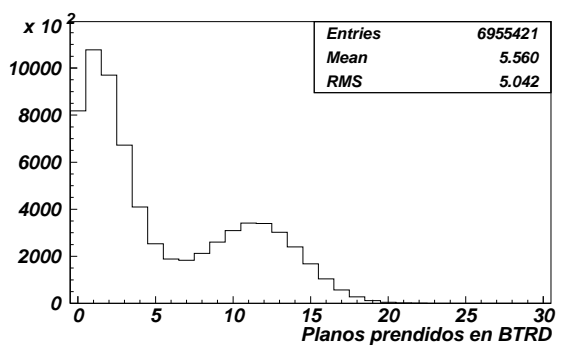

Figura 5.159: Planos prendidos en BTRD. Proporción bariónica y mesónica del haz primario (neg $614 \mathrm{Cu}$ ).
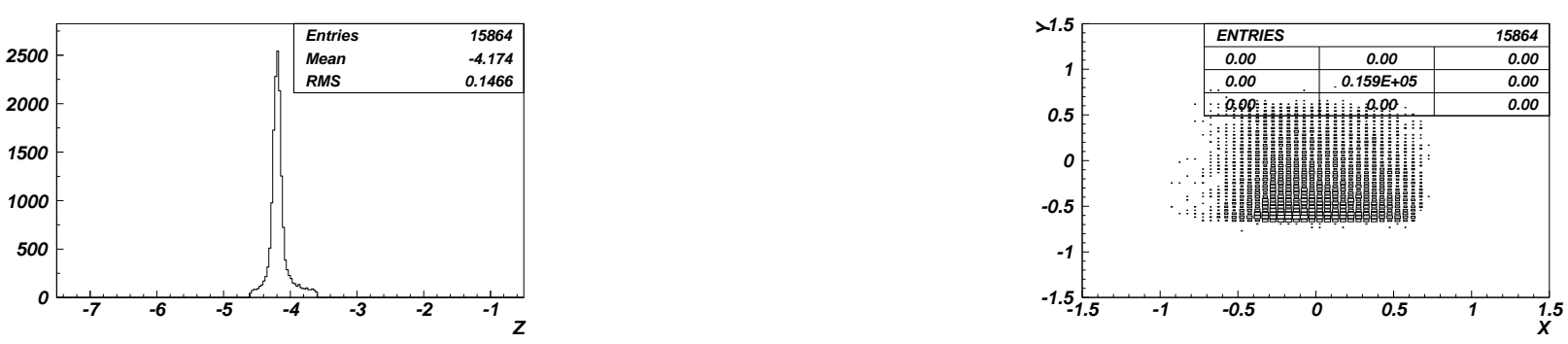

Figura 5.160: Vértice primario. Izquierda: coordenada z. Derecha: proyección x,y (neg 614 $\mathrm{Cu})$. 
5.7. Haz de polaridad negativa, con momento $614 \mathrm{GeV}$, con blanco de producción para el haz secundario de cobre

5.7.1. Histogramas de control
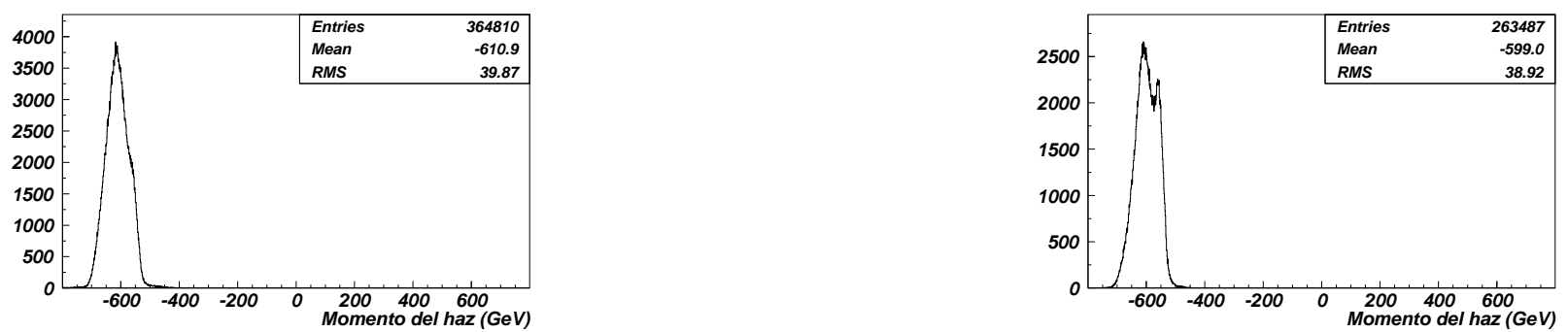

Figura 5.158: Distribución de momento del haz primario. Izquierda: bariones. Derecha: mesones (neg $614 \mathrm{Cu}$ ). 


\subsubsection{Multiplicidad en la región del vértice}
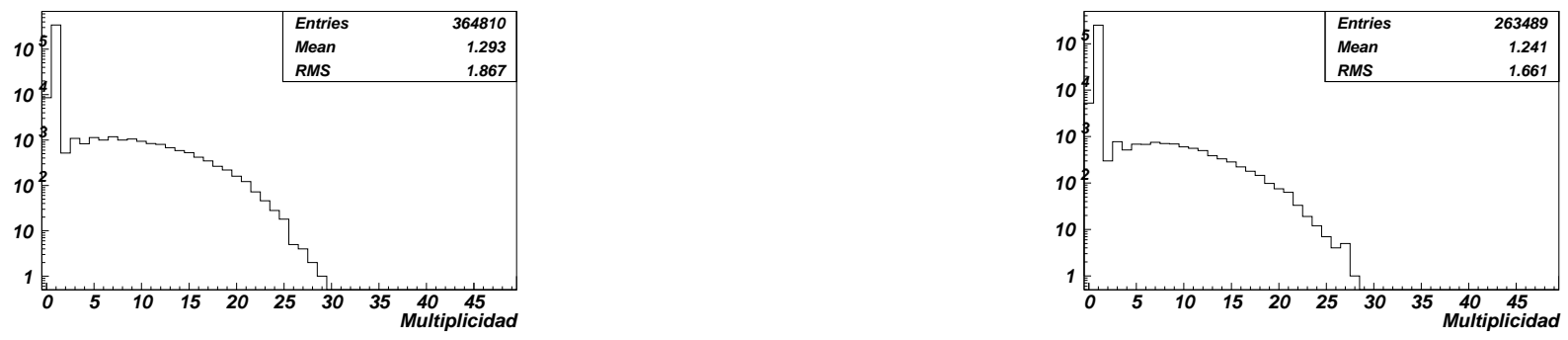

Figura 5.161: Multiplicidad total. Izquierda: haz de bariones. Derecha: haz de mesones(neg $614 \mathrm{Cu})$.
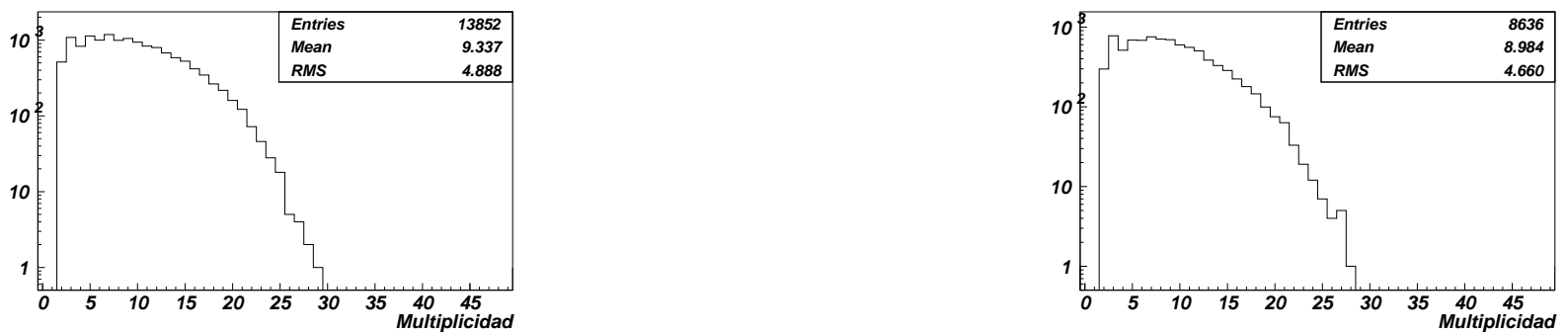

Figura 5.162: Multiplicidad en eventos con más de una trayectoria en la región del vértice. Izquierda: haz de bariones. Derecha: haz de mesones(neg $614 \mathrm{Cu}$ ). 


\subsubsection{Distribuciones de multiplicidad y momento}
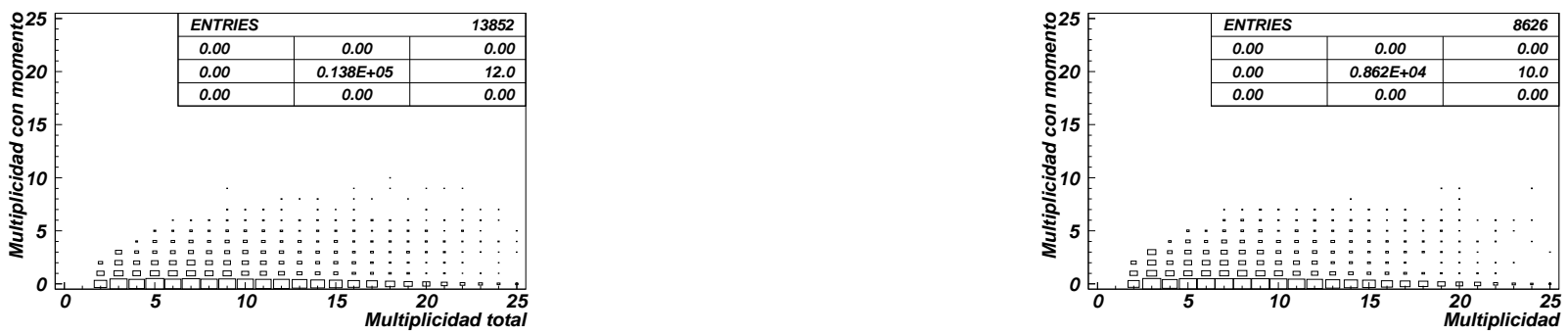

Figura 5.163: Multiplicidad total contra multiplicidad con momento medido. Izquierda: haz de bariones. Derecha: haz de mesones(neg $614 \mathrm{Cu})$.
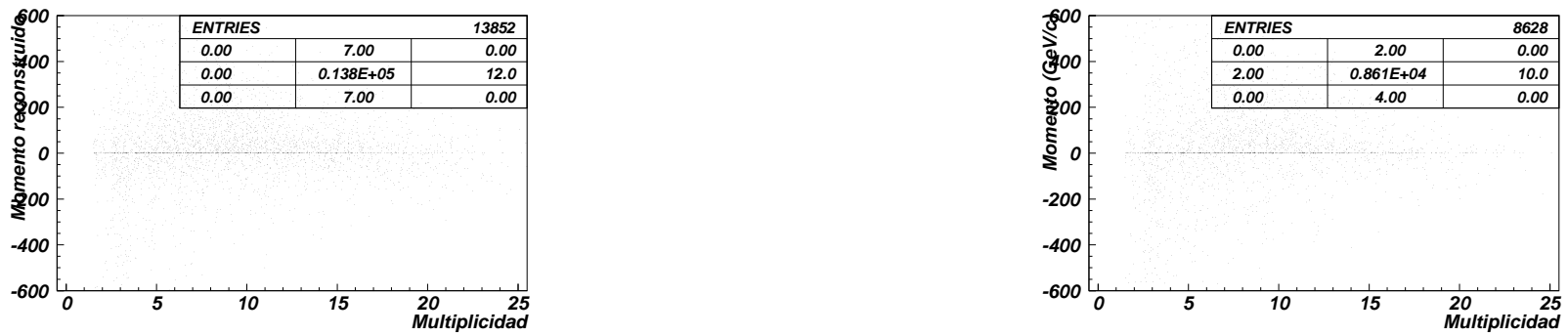

Figura 5.164: Multiplicidad contra momento.Izquierda: haz de bariones. Derecha: haz de mesones(neg $614 \mathrm{Cu})$. 
Distribuciones de momento total para eventos producidos por un haz de bariones
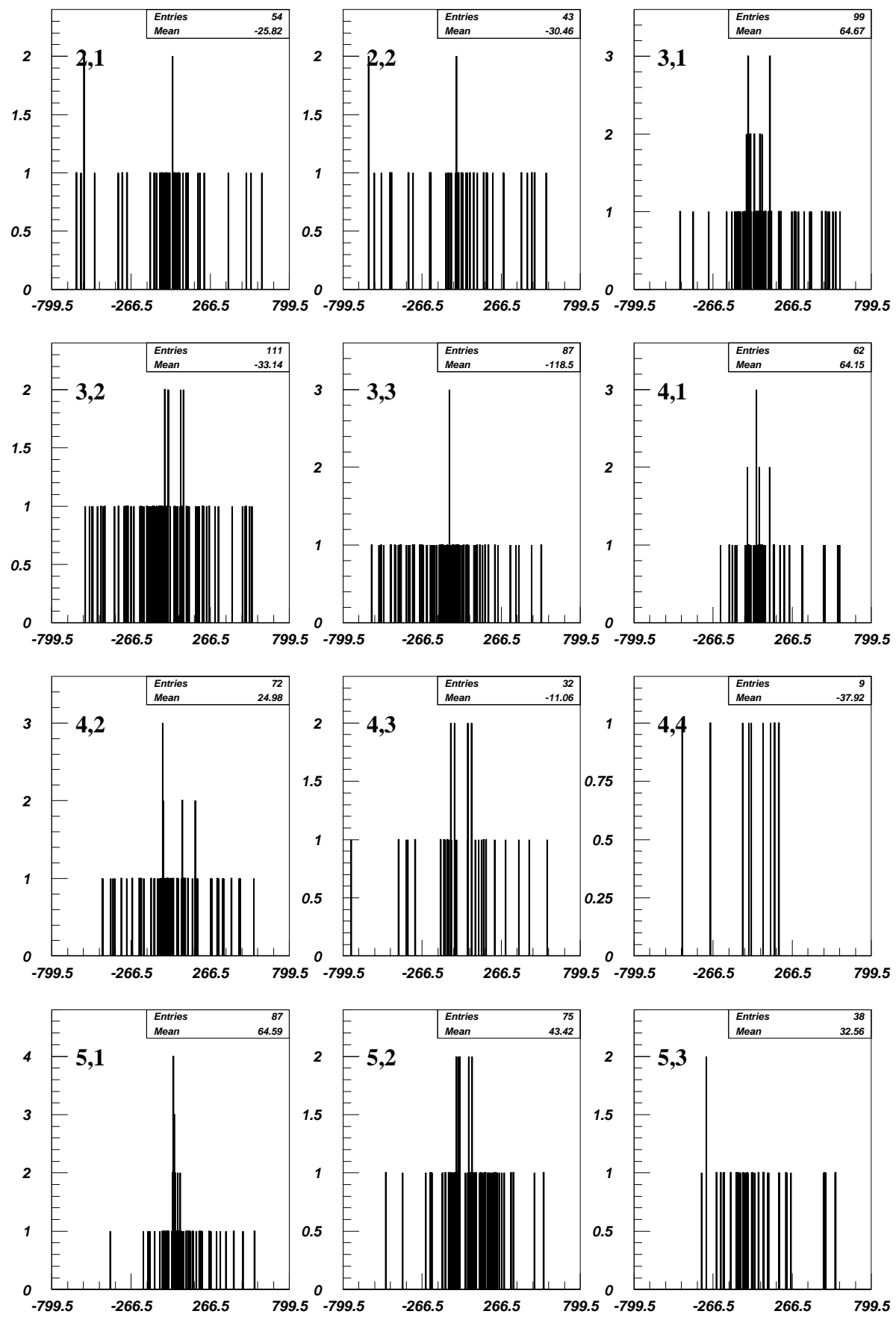

Figura 5.165: Distribuciones de momento. El primer indice: multiplicidad total, el segundo: multiplicidad con momento (neg $614 \mathrm{Cu}$ ) 

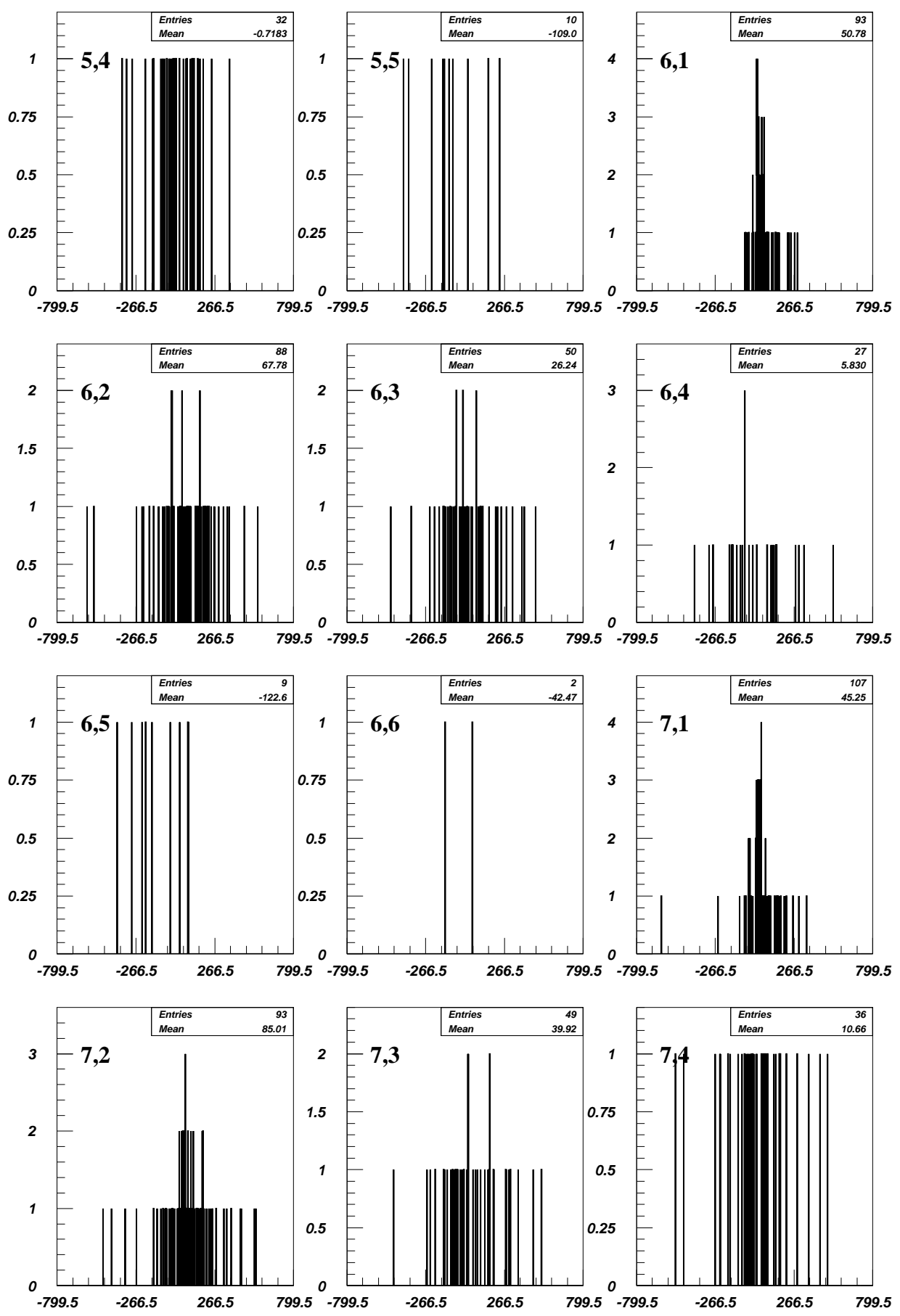

Figura 5.166: Distribuciones de momento. El primer índice: multiplicidad total, el segundo: multiplicidad con momento (neg $614 \mathrm{Cu}$ ). 

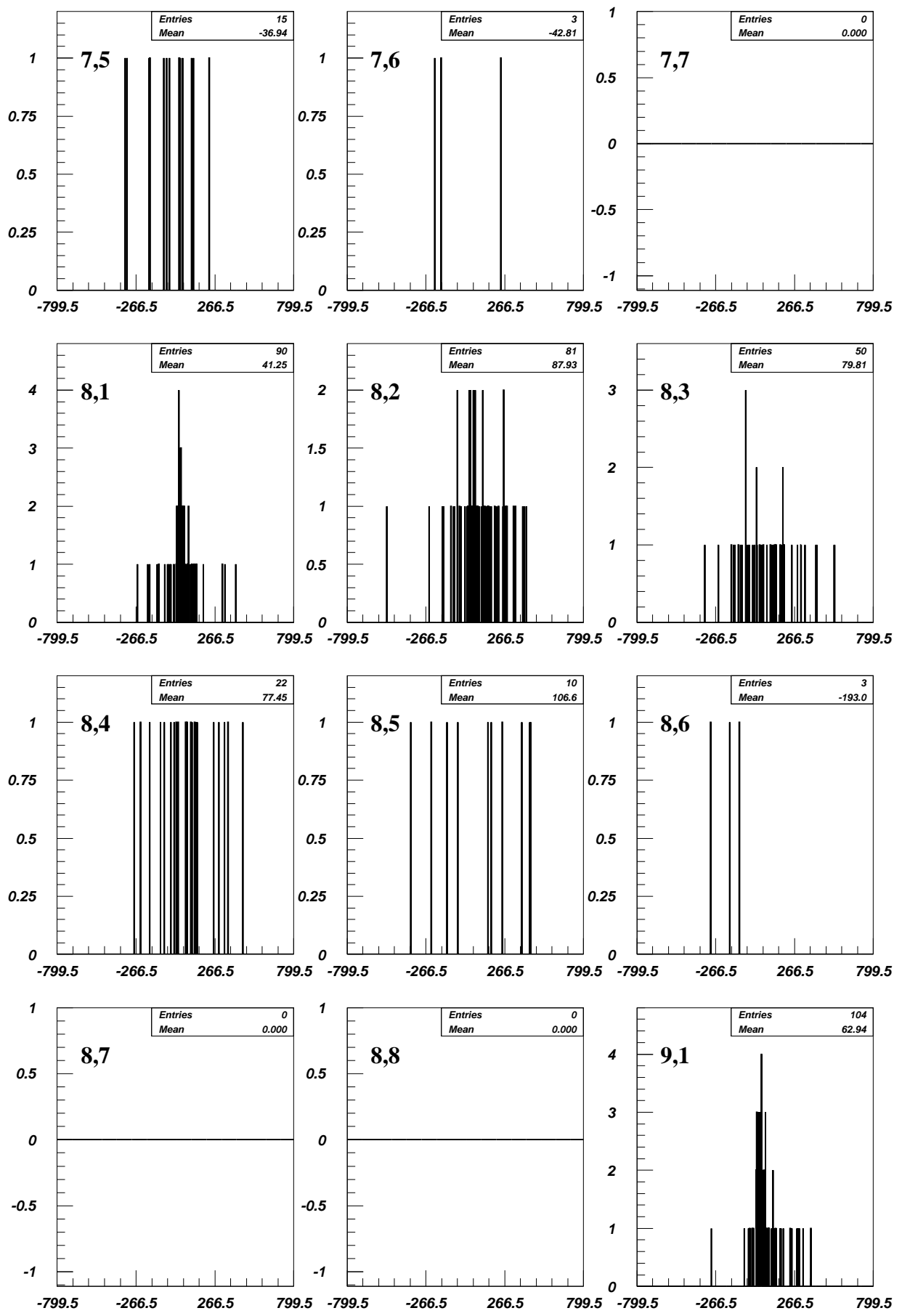

Figura 5.167: Distribuciones de momento. El primer índice: multiplicidad total, el segundo: multiplicidad con momento (neg $614 \mathrm{Cu}$ ). 

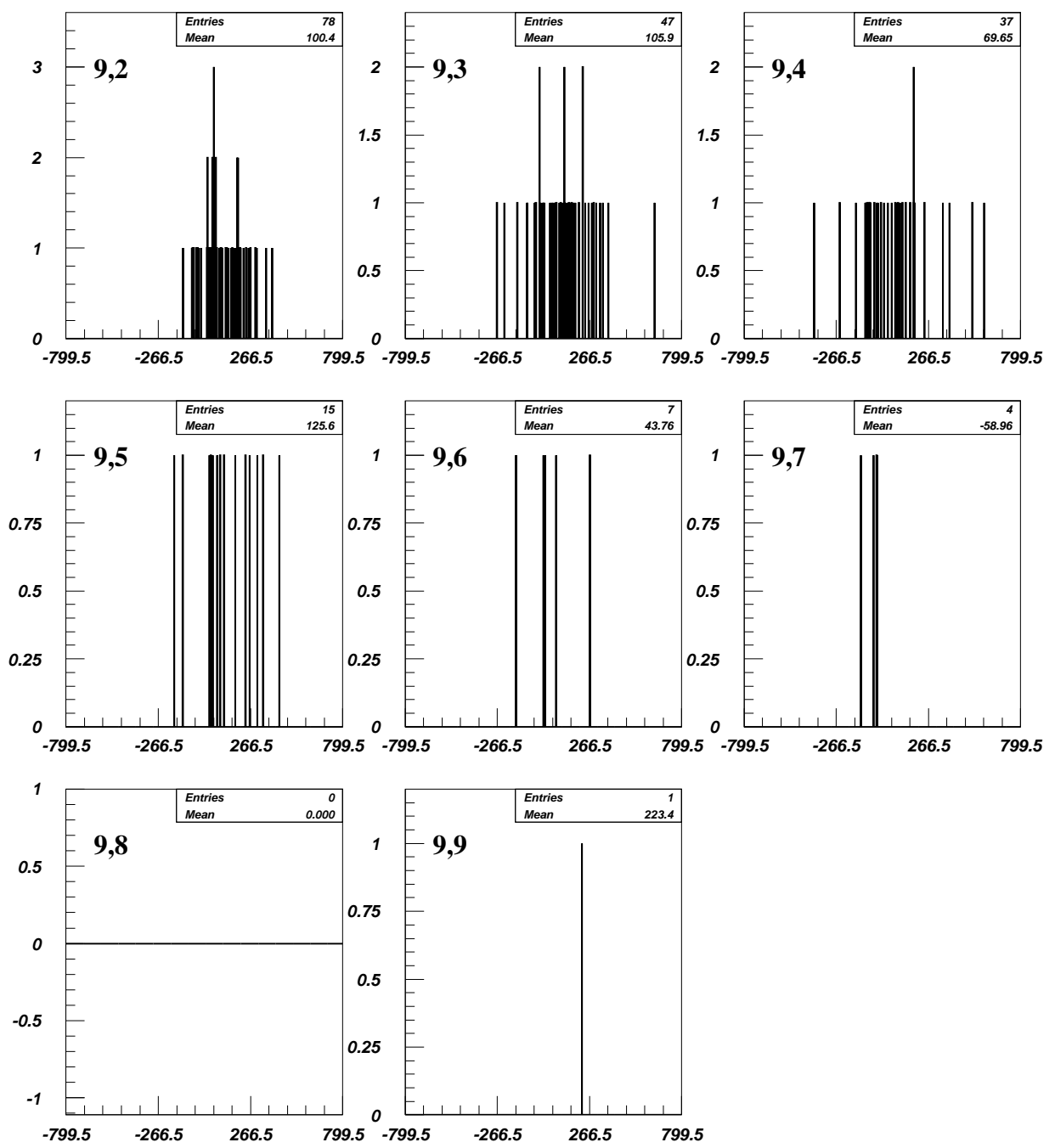

Figura 5.168: Distribuciones de momento. El primer índice: multiplicidad total, el segundo: multiplicidad con momento (neg $614 \mathrm{Cu}$ ). 
Distribuciones de momento total para eventos producidos por un haz de mesones
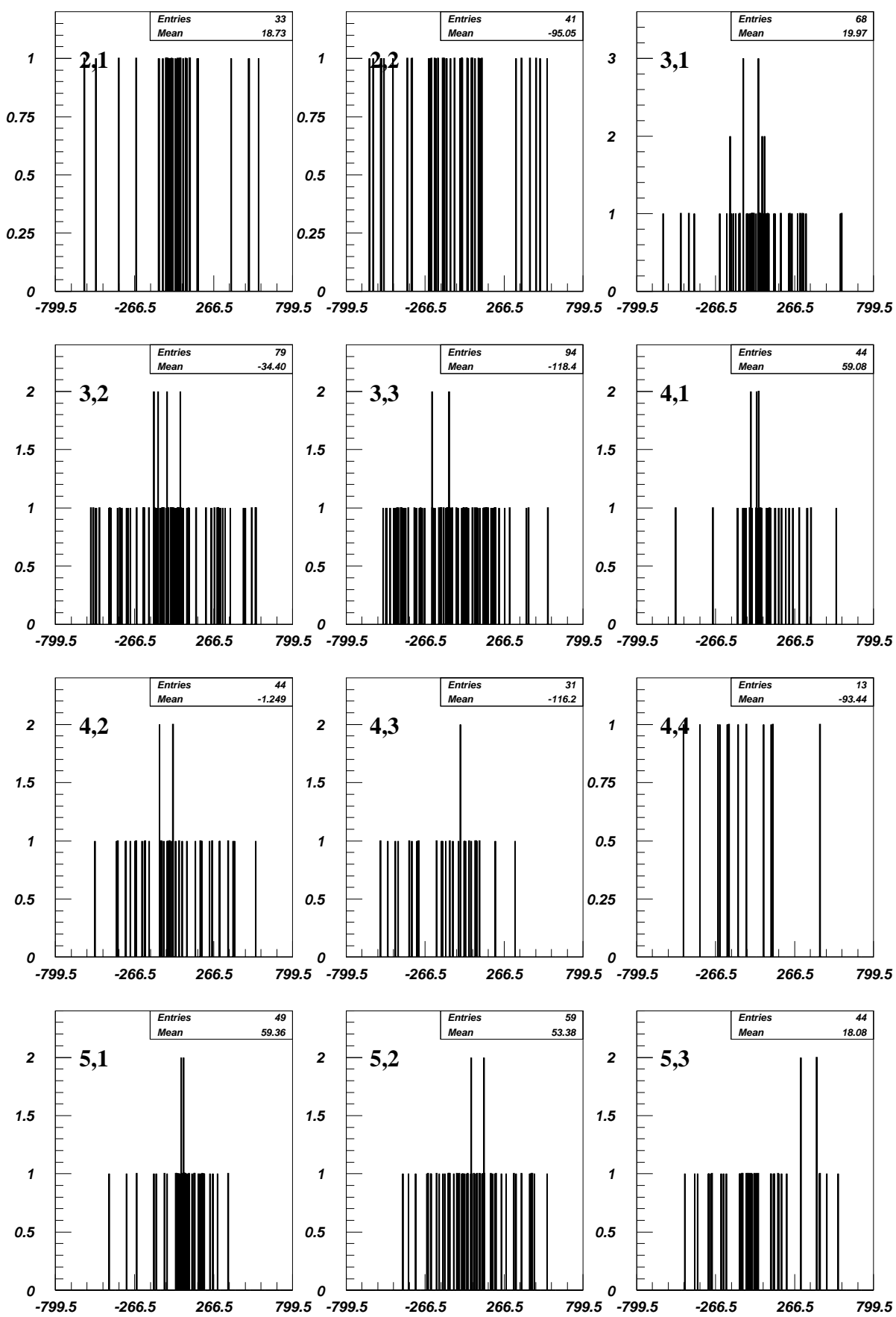

Figura 5.169: Distribuciones de momento. El primer indice: multiplicidad total, el segundo: multiplicidad con momento (neg $614 \mathrm{Cu}$ ) 

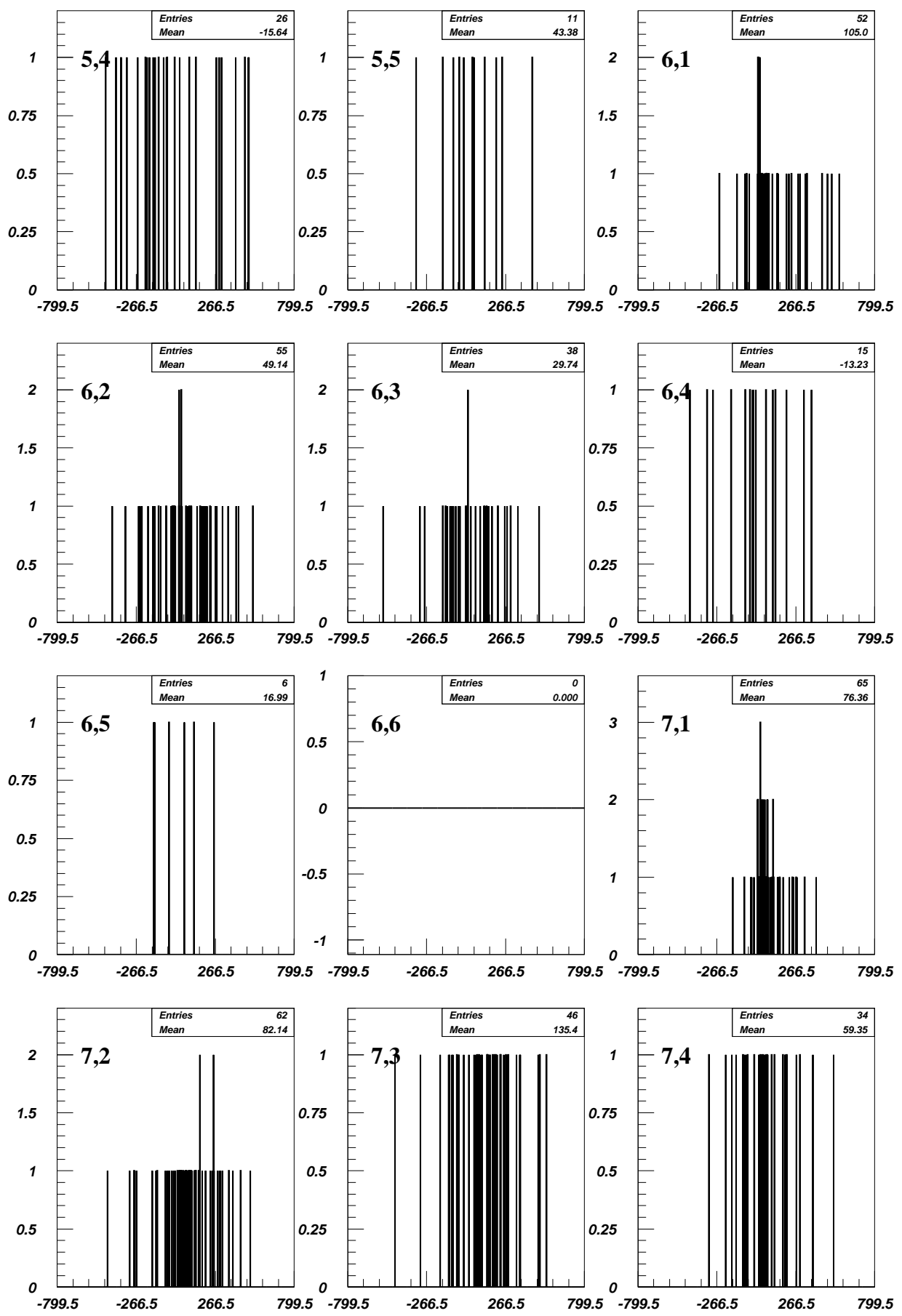

Figura 5.170: Distribuciones de momento. El primer índice: multiplicidad total, el segundo: multiplicidad con momento (neg $614 \mathrm{Cu}$ ). 

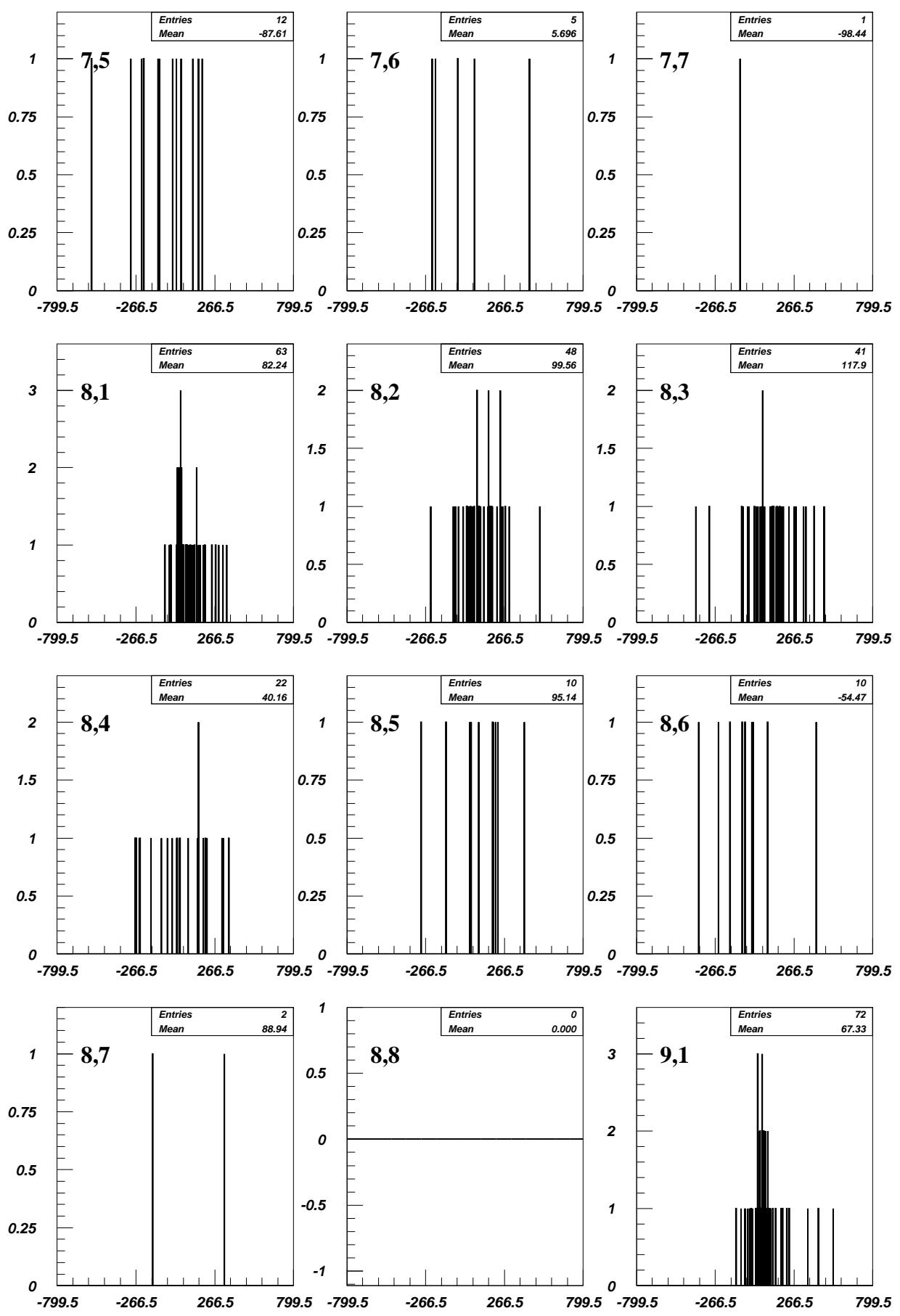

Figura 5.171: Distribuciones de momento. El primer índice: multiplicidad total, el segundo: multiplicidad con momento (neg $614 \mathrm{Cu}$ ). 

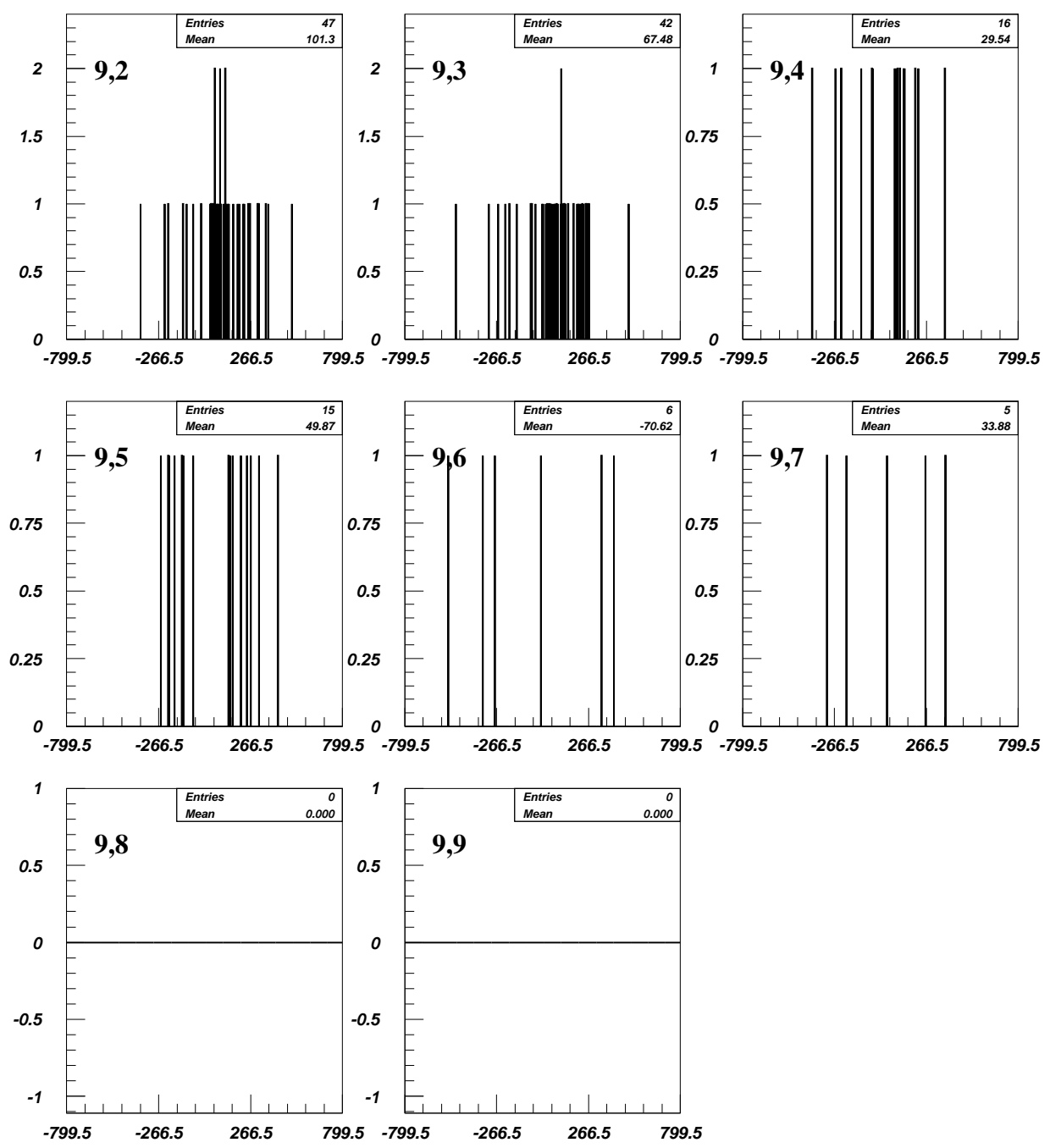

Figura 5.172: Distribuciones de momento. El primer índice: multiplicidad total, el segundo: multiplicidad con momento (neg $614 \mathrm{Cu}$ ). 
Distribuciones del valor absoluto del momento total para eventos producidos por un haz de bariones
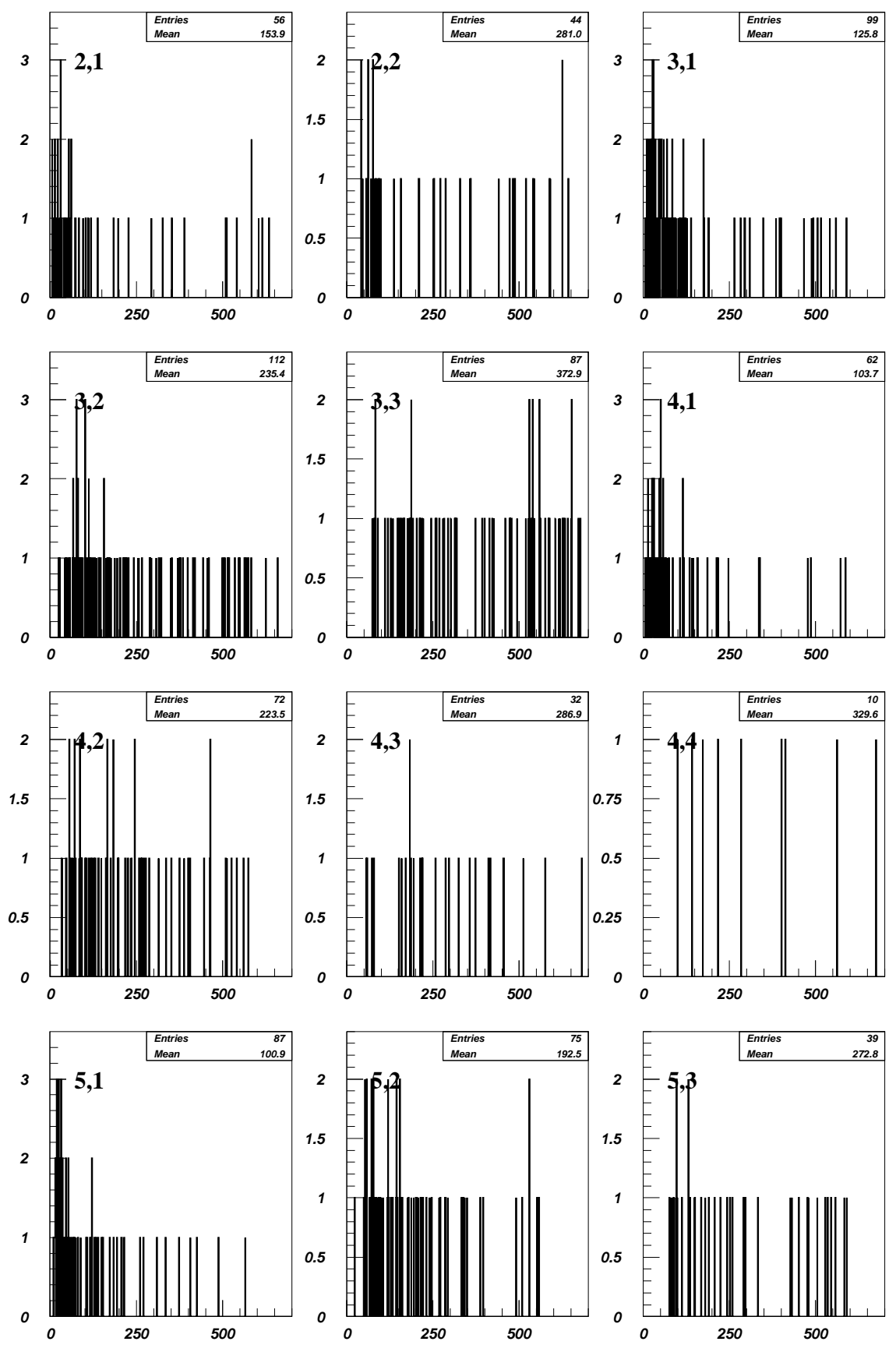

Figura 5.173: Distribuciones de momento. El primer indice: multiplicidad total, el segundo: multiplicidad con momento (neg $614 \mathrm{Cu}$ ). 

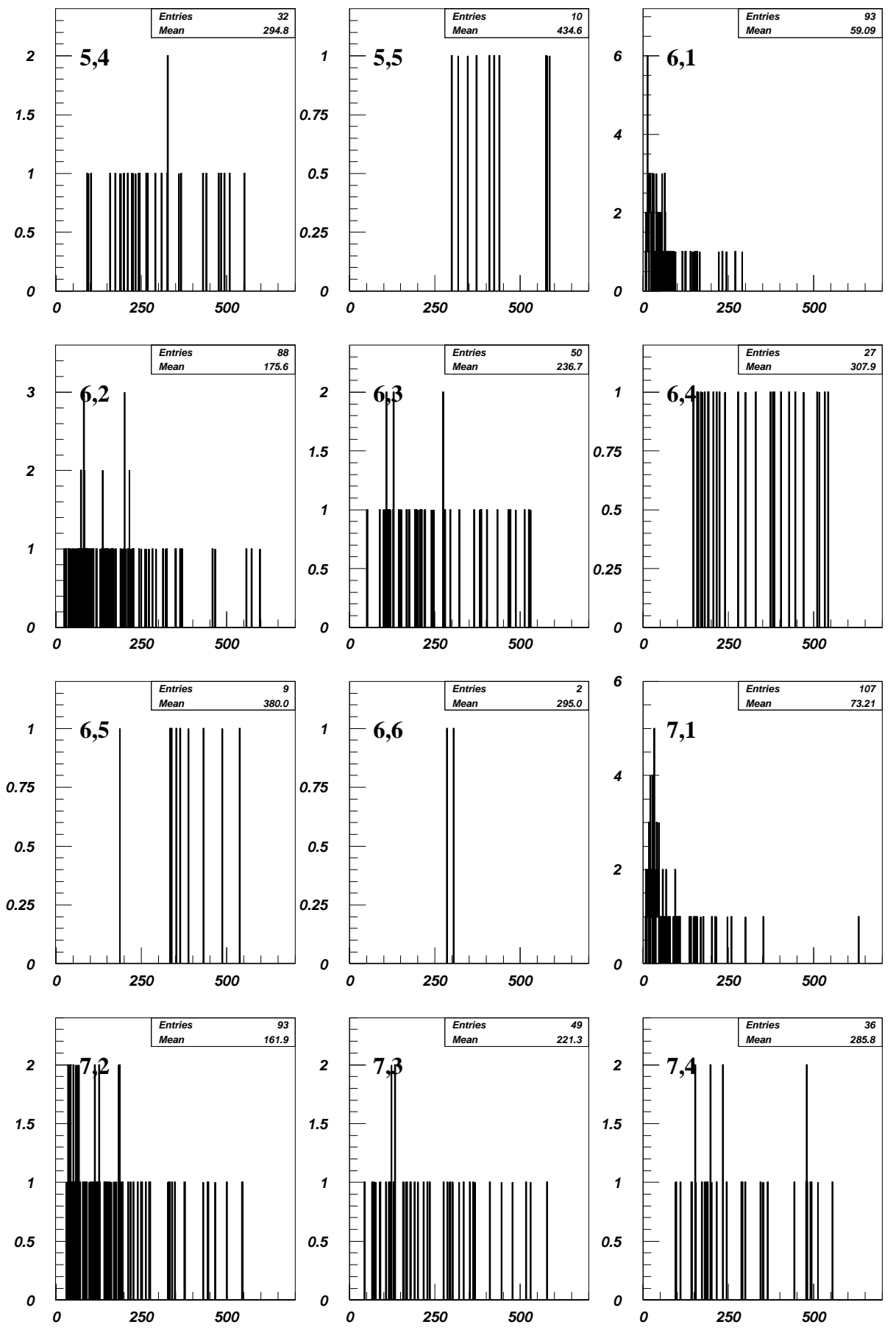

Figura 5.174: Distribuciones de momento. El primer índice: multiplicidad total, el segundo: multiplicidad con momento (neg $614 \mathrm{Cu}$ ). 

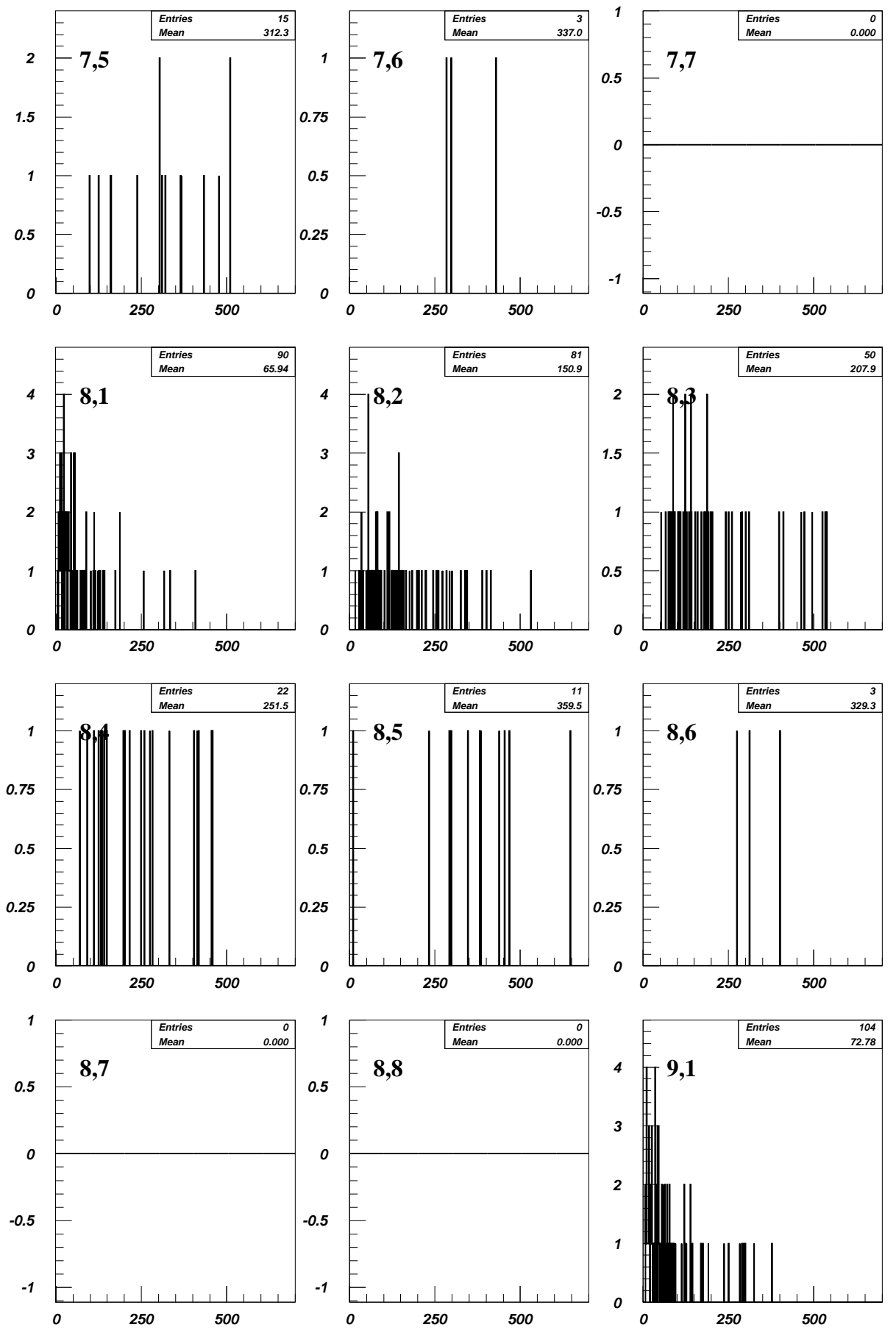

Figura 5.175: Distribuciones de momento. El primer índice: multiplicidad total, el segundo: multiplicidad con momento (neg $614 \mathrm{Cu}$ ). 

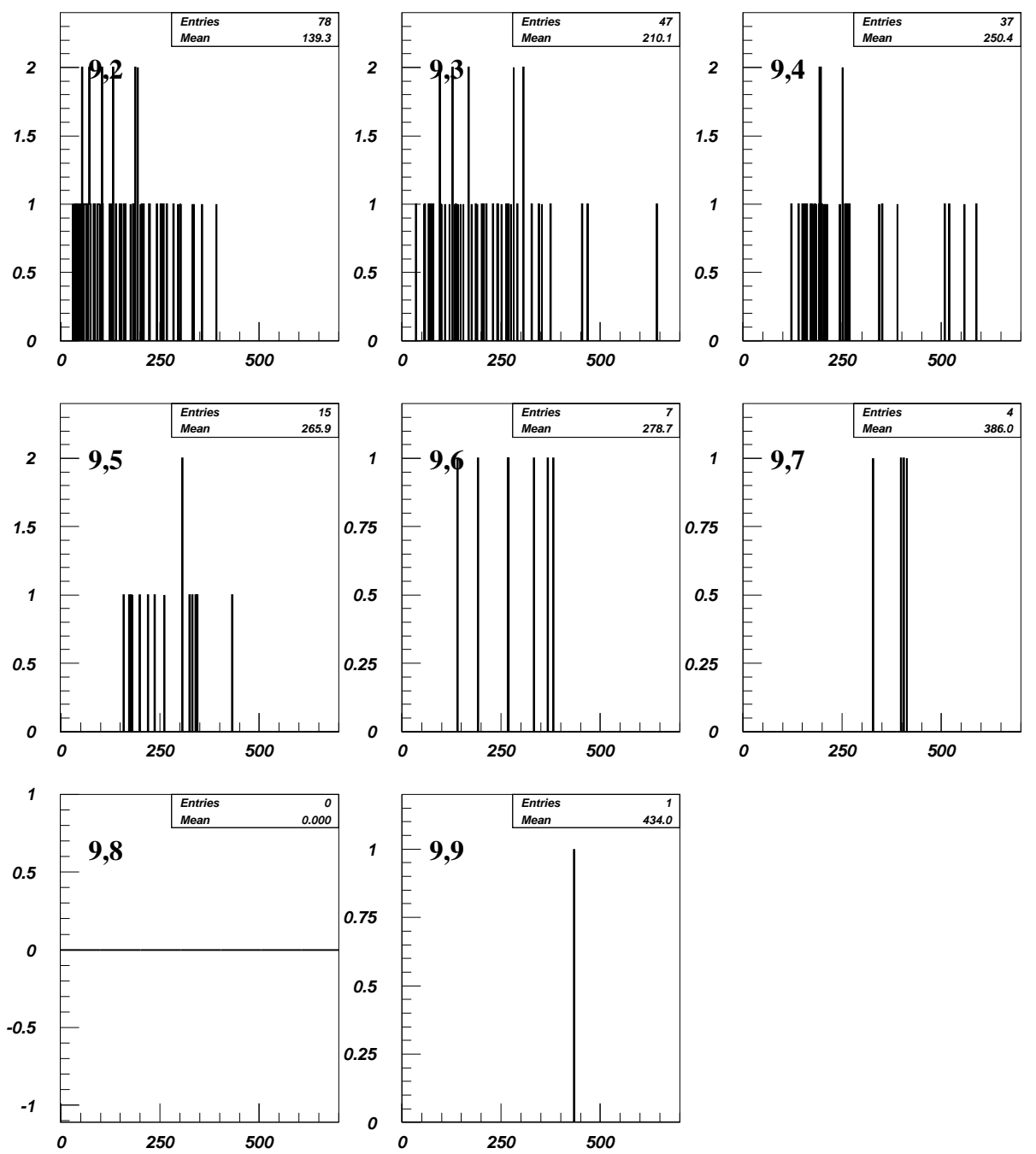

Figura 5.176: Distribuciones de momento. El primer índice: multiplicidad total, el segundo: multiplicidad con momento (neg $614 \mathrm{Cu}$ ). 
Distribuciones del valor absoluto del momento total para eventos producidos por un haz de mesones
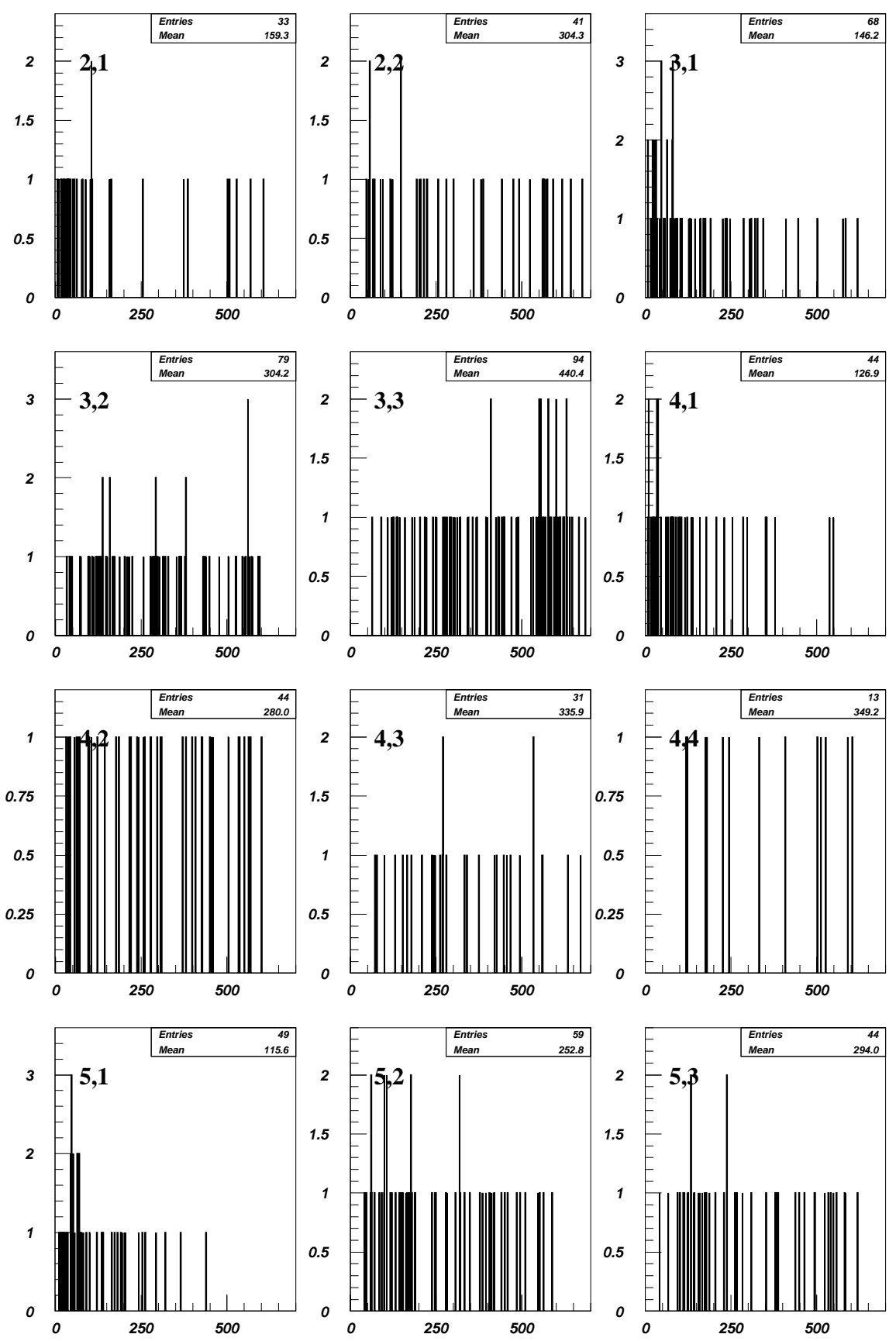

Figura 5.177: Distribuciones de momento. El primer indice: multiplicidad total, el segundo: multiplicidad con momento (neg $614 \mathrm{Cu}$ ). 

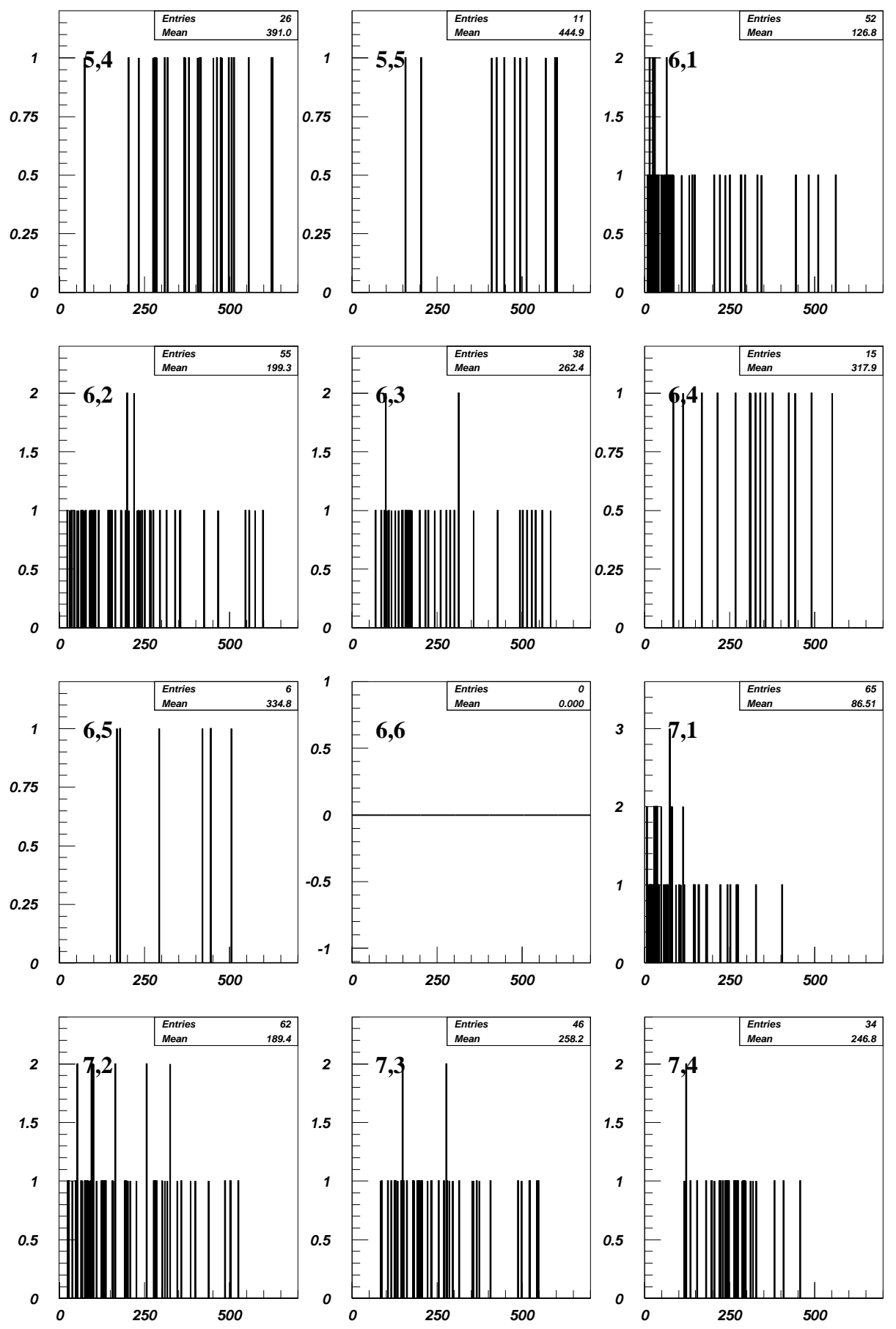

Figura 5.178: Distribuciones de momento. El primer índice: multiplicidad total, el segundo: multiplicidad con momento (neg $614 \mathrm{Cu}$ ). 

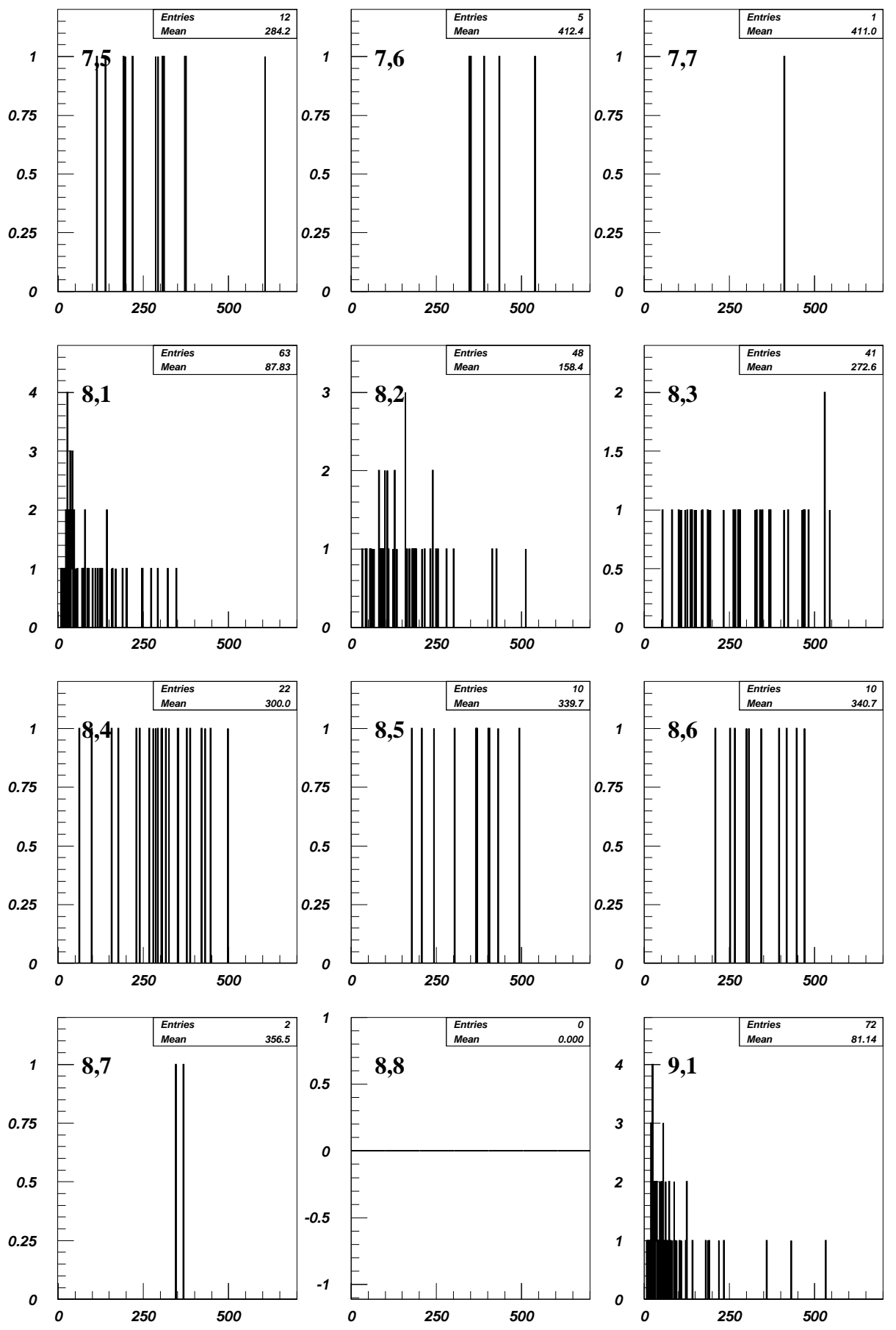

Figura 5.179: Distribuciones de momento. El primer índice: multiplicidad total, el segundo: multiplicidad con momento (neg $614 \mathrm{Cu}$ ). 

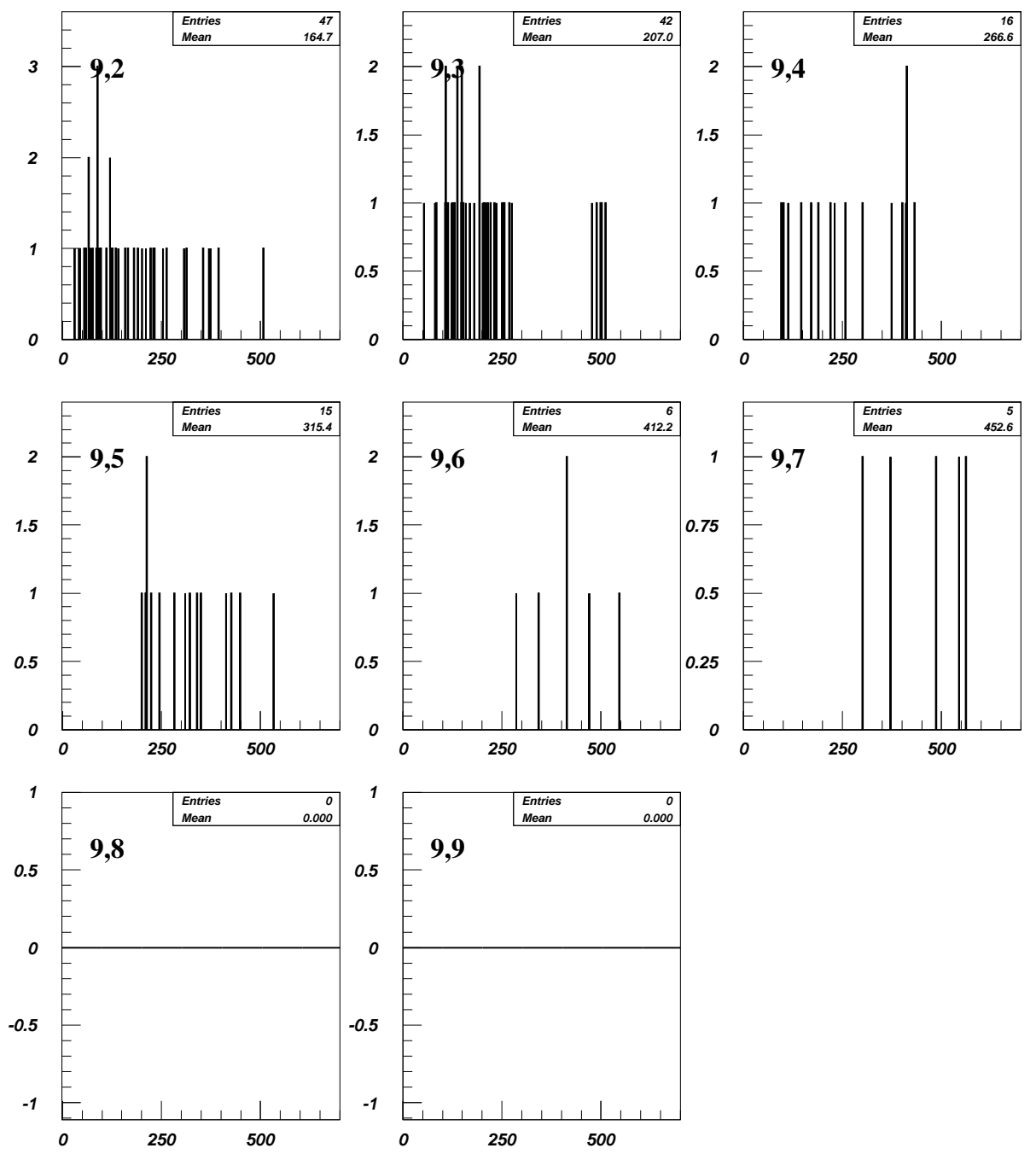

Figura 5.180: Distribuciones de momento. El primer índice: multiplicidad total, el segundo: multiplicidad con momento (neg $614 \mathrm{Cu}$ ). 
Distribuciones del momento de las trayectorias para eventos producidos por un haz de bariones
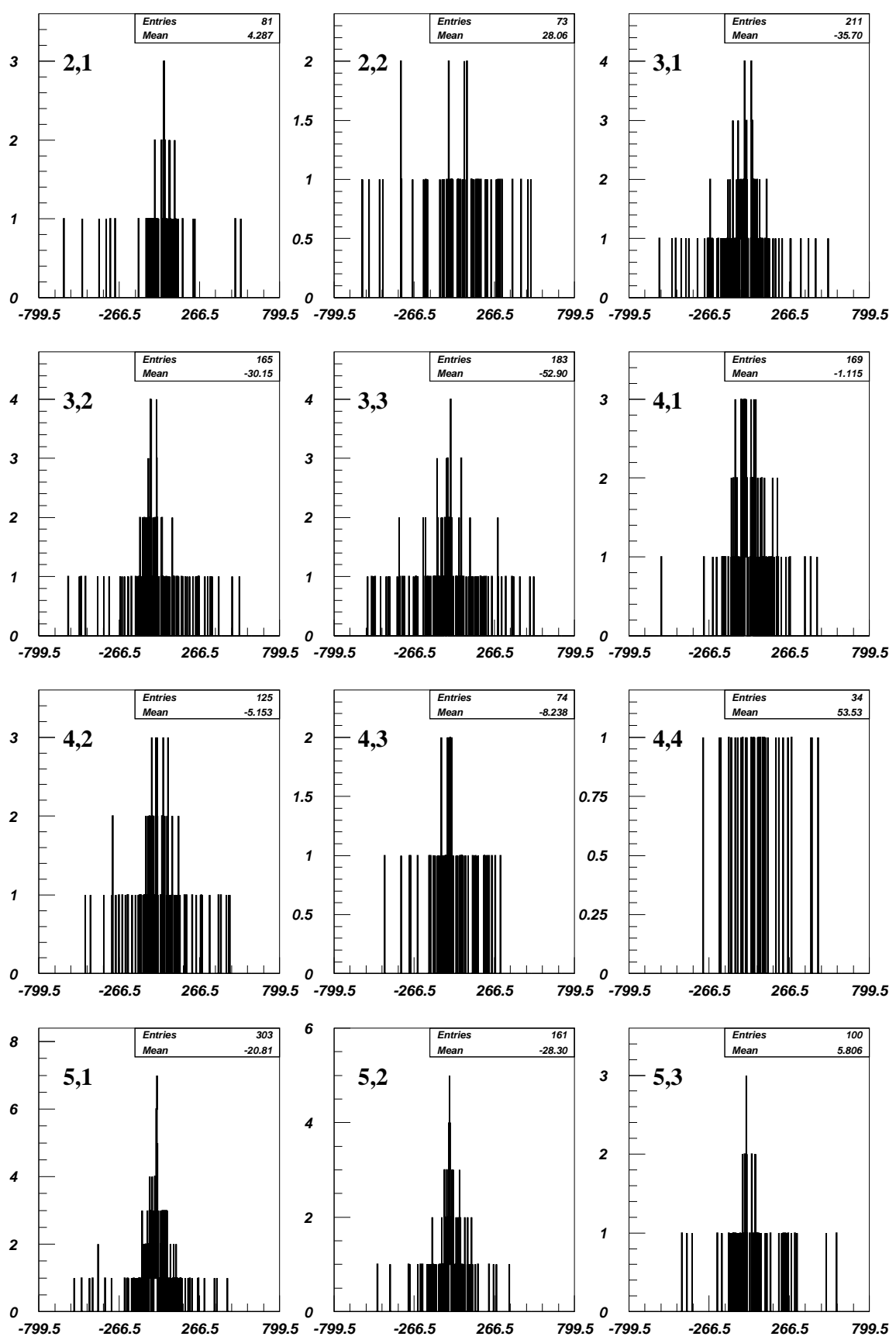

Figura 5.181: Distribuciones de momento. El primer indice: multiplicidad total, el segundo: multiplicidad con momento (neg $614 \mathrm{Cu}$ ). 

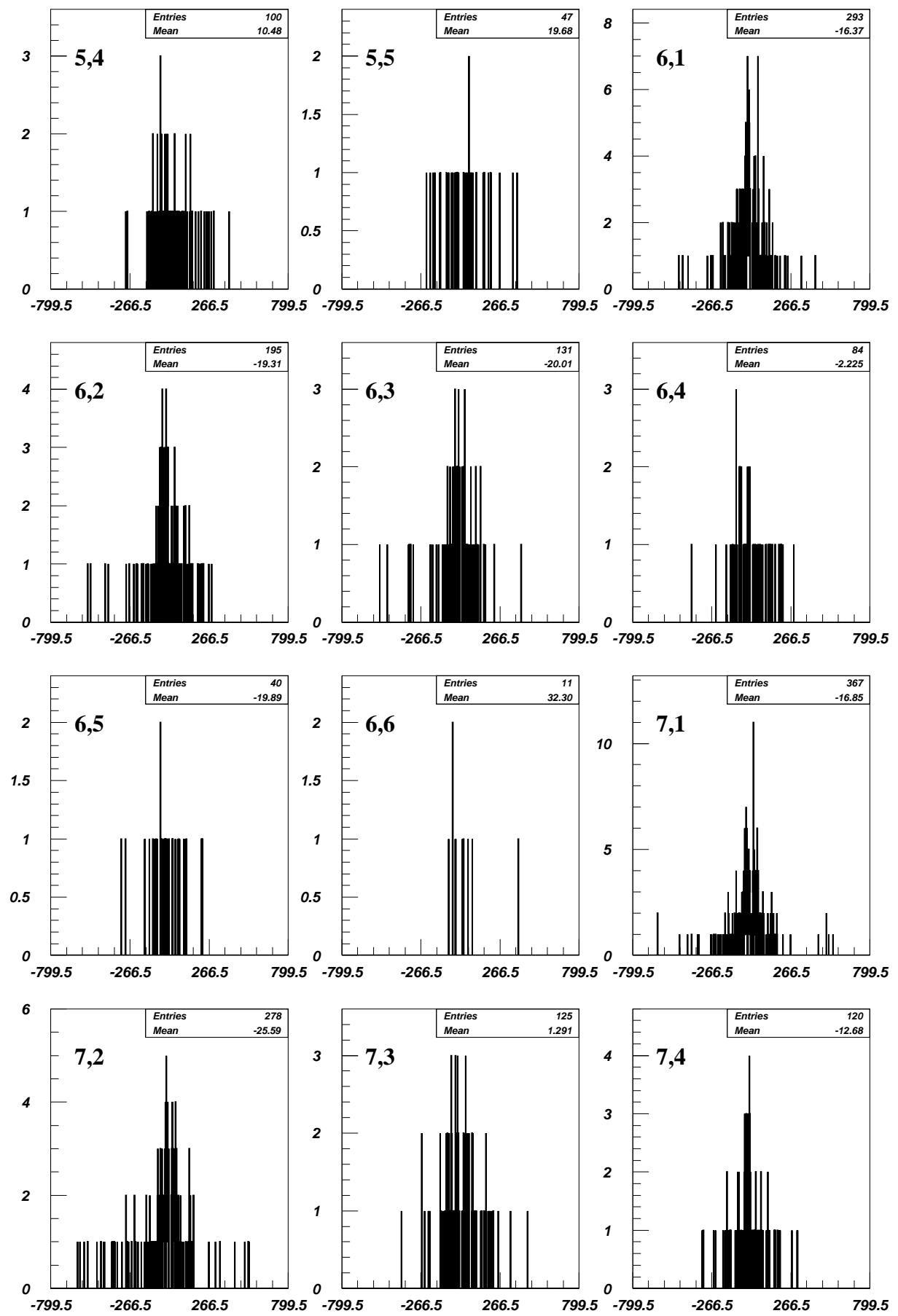

Figura 5.182: Distribuciones de momento. El primer índice: multiplicidad total, el segundo: multiplicidad con momento (neg $614 \mathrm{Cu}$ ). 

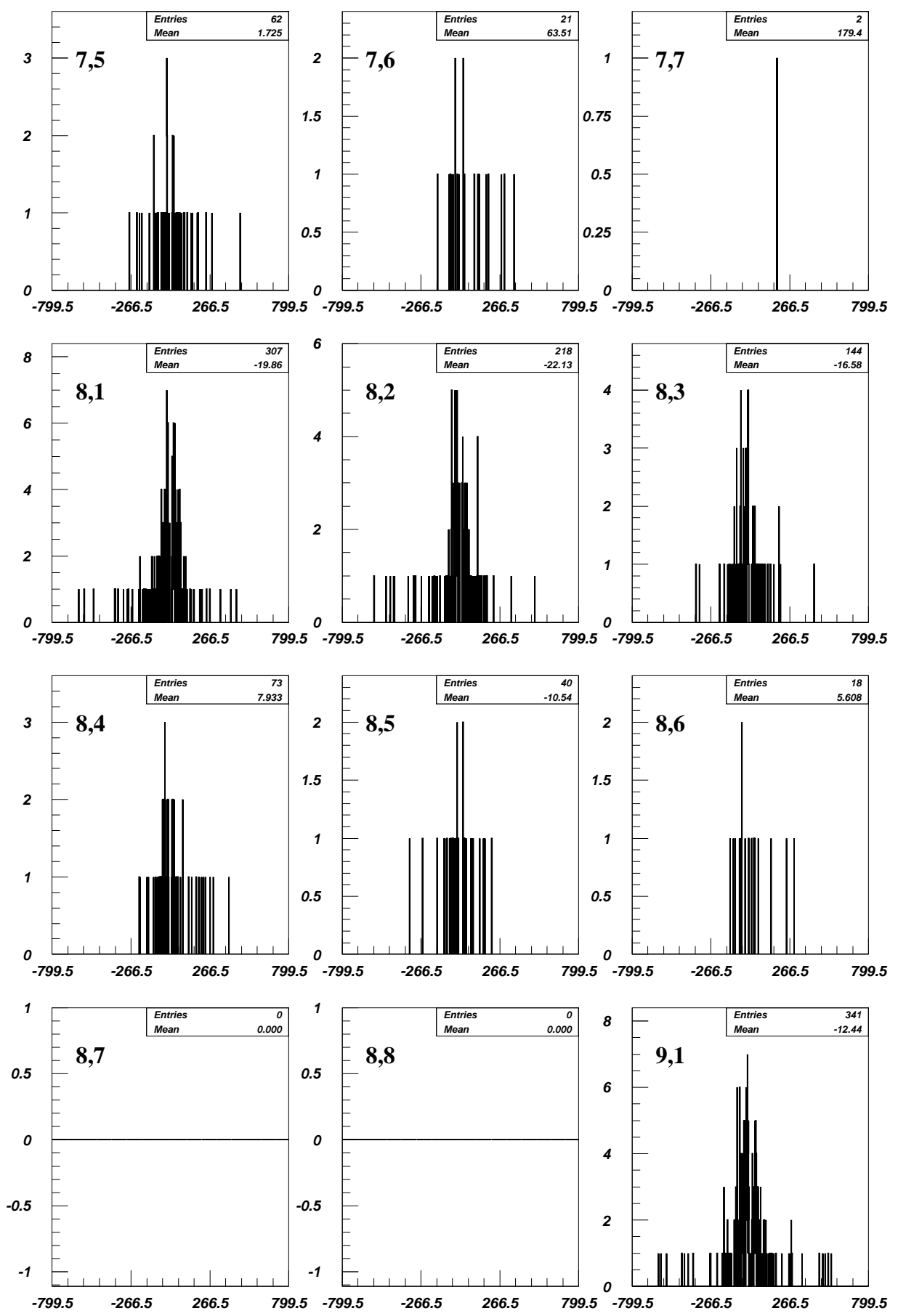

Figura 5.183: Distribuciones de momento. El primer índice: multiplicidad total, el segundo: multiplicidad con momento (neg $614 \mathrm{Cu})$. 

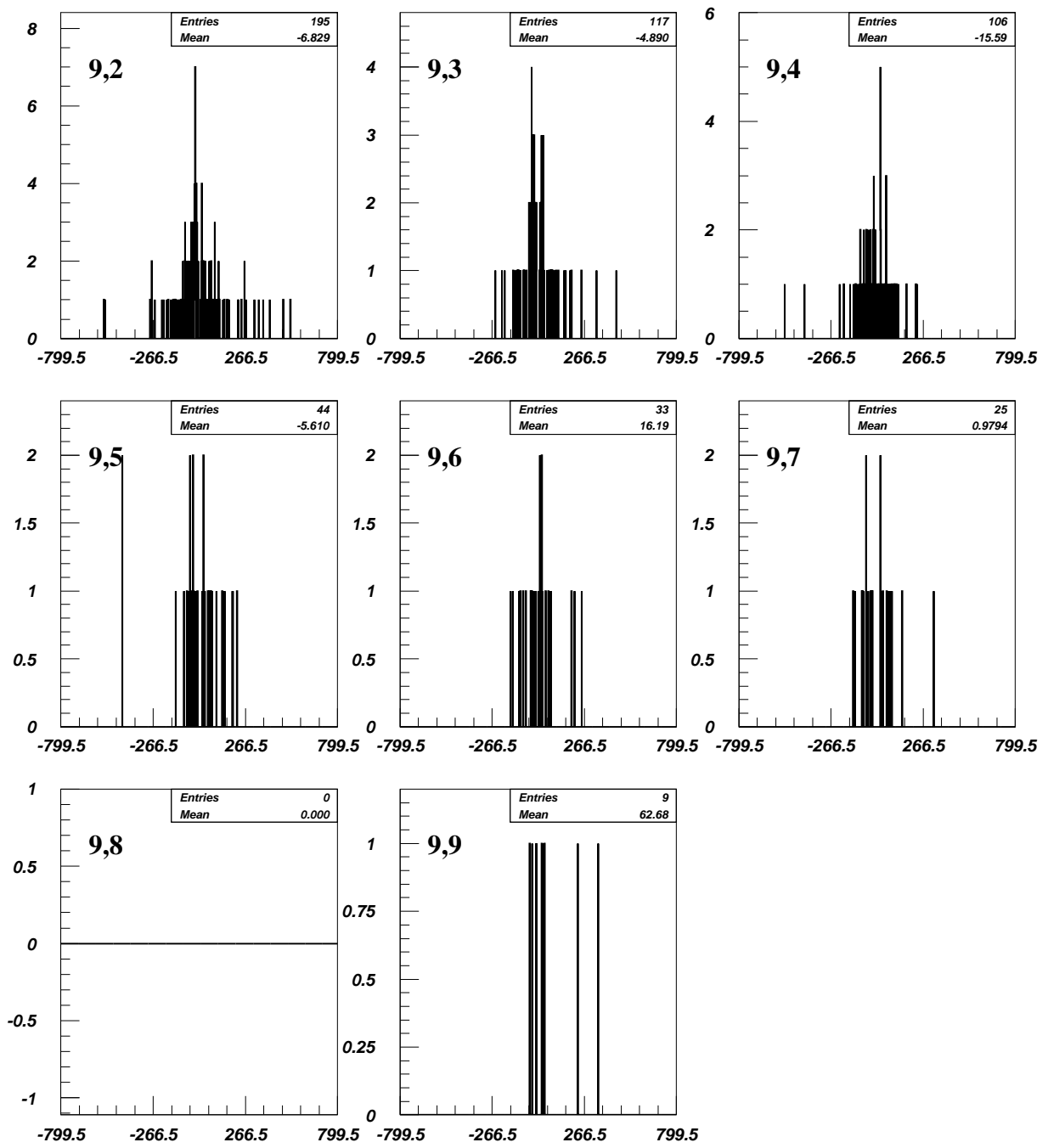

Figura 5.184: Distribuciones de momento. El primer índice: multiplicidad total, el segundo: multiplicidad con momento (neg $614 \mathrm{Cu}$ ). 
Distribuciones del momento de las trayectorias para eventos producidos por un haz de mesones
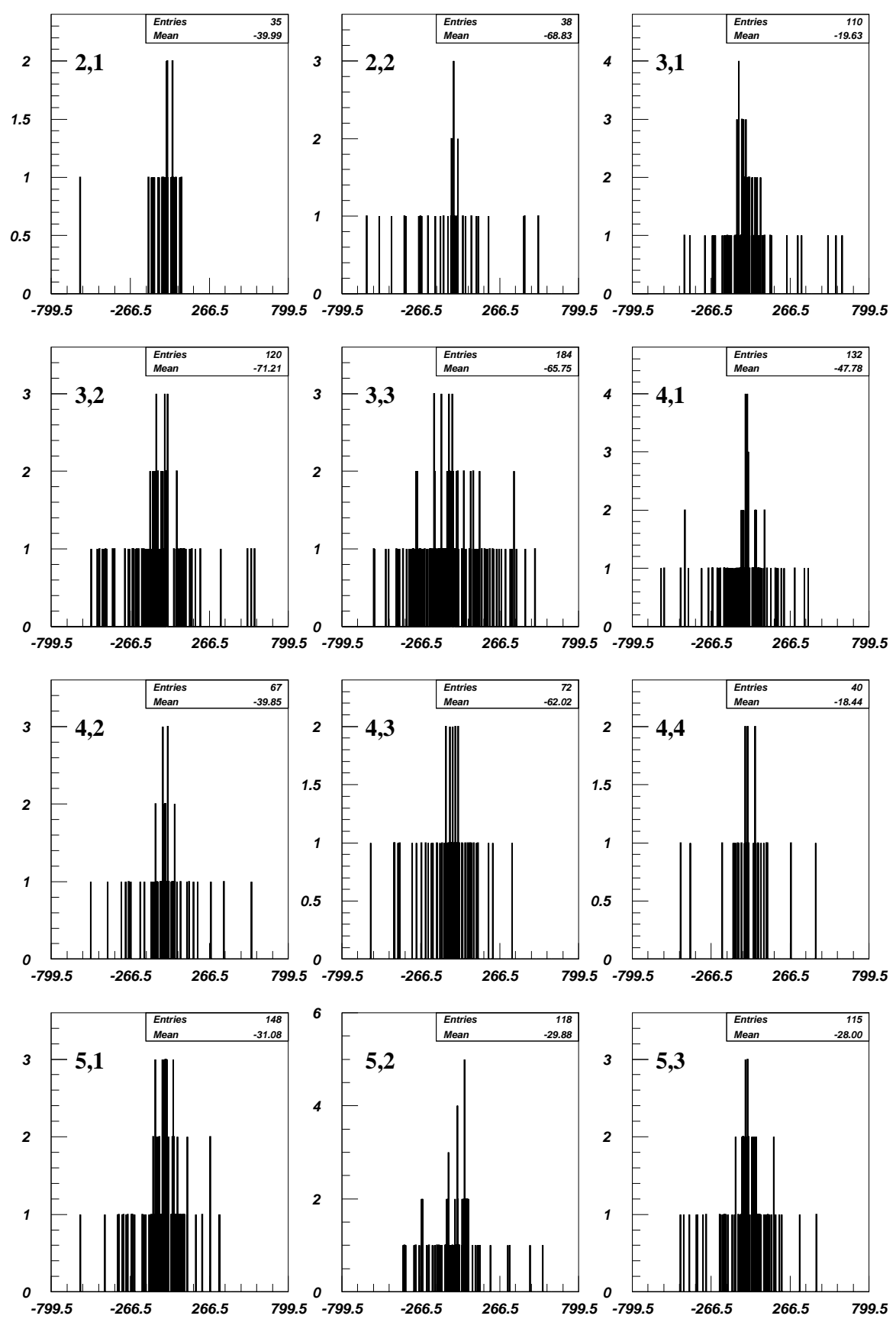

Figura 5.185: Distribuciones de momento. El primer indice: multiplicidad total, el segundo: multiplicidad con momento (neg $614 \mathrm{Cu}$ ) 

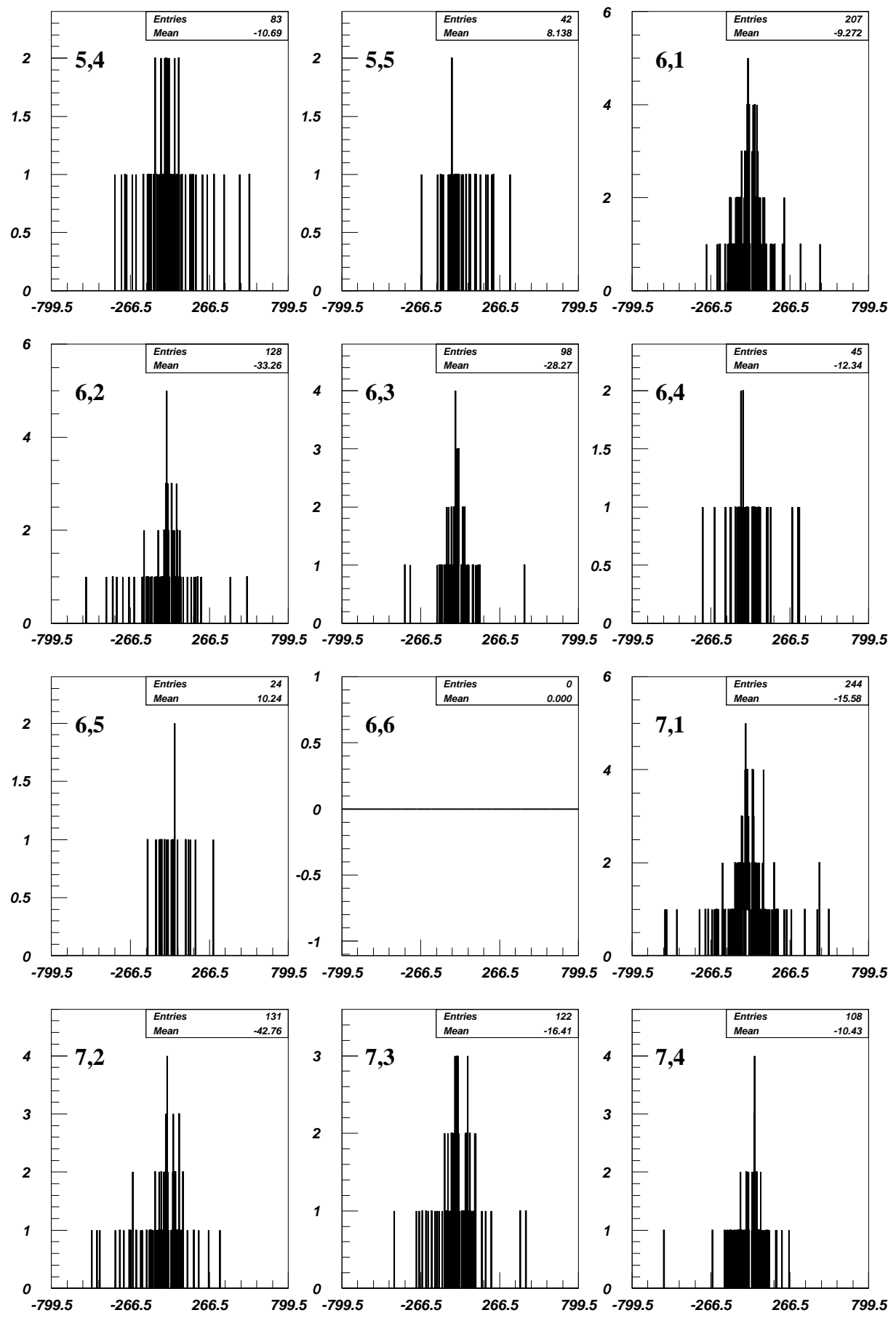

Figura 5.186: Distribuciones de momento. El primer índice: multiplicidad total, el segundo: multiplicidad con momento (neg $614 \mathrm{Cu}$ ). 

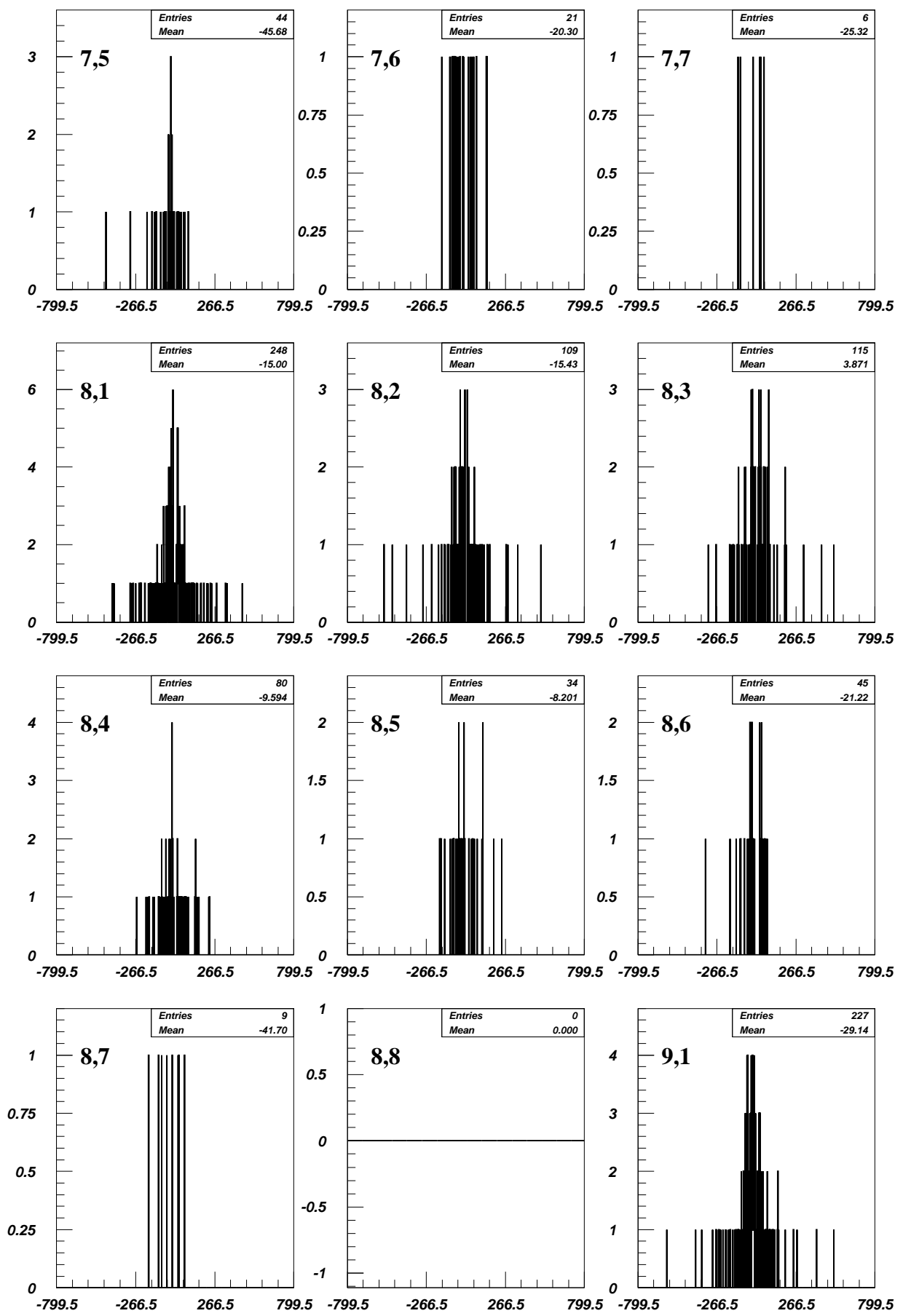

Figura 5.187: Distribuciones de momento. El primer índice: multiplicidad total, el segundo: multiplicidad con momento (neg $614 \mathrm{Cu}$ ). 

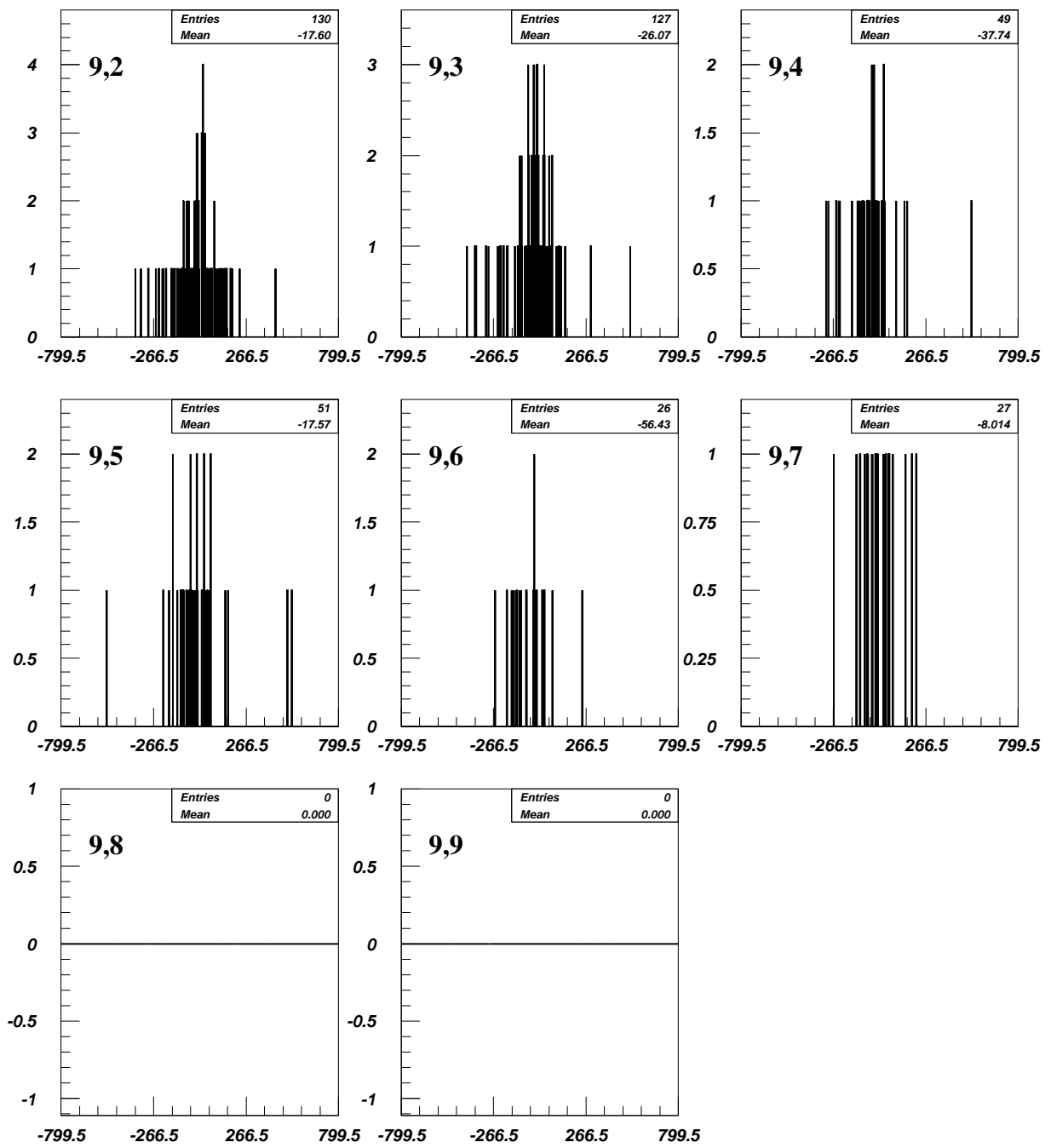

Figura 5.188: Distribuciones de momento. El primer índice: multiplicidad total, el segundo: multiplicidad con momento (neg $614 \mathrm{Cu}$ ). 


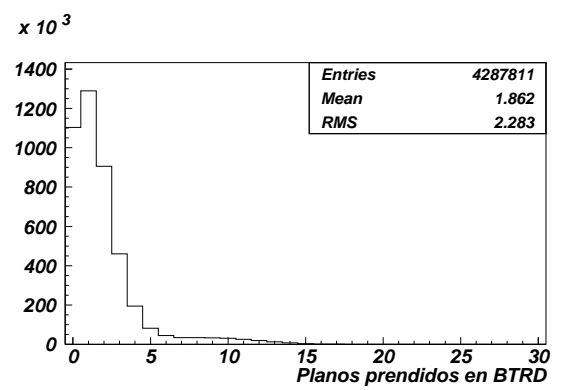

Figura 5.190: Planos prendidos en BTRD. Proporción bariónica y mesónica del haz primario (pos $570 \mathrm{Be})$.
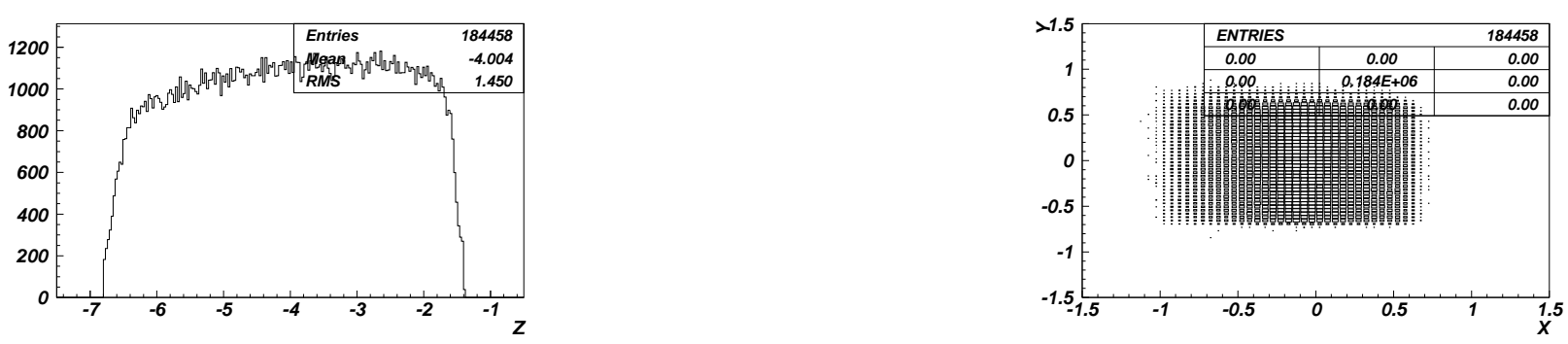

Figura 5.191: Vértice primario. Izquierda: coordenada z. Derecha: proyección x,y (pos 570 $\mathrm{Be})$. 
5.8. Haz de polaridad positiva, con momento $570 \mathrm{GeV}$, con blanco de producción para el haz secundario de berilio

\subsubsection{Histogramas de control}
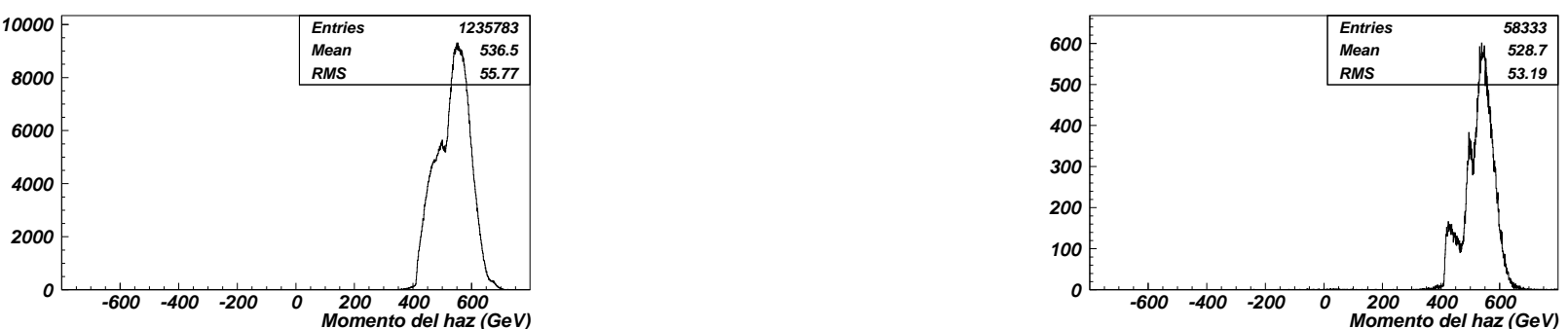

Figura 5.189: Distribución de momento del haz primario. Izquierda: bariones. Derecha: mesones (pos $570 \mathrm{Be})$. 


\subsubsection{Multiplicidad en la región del vértice}
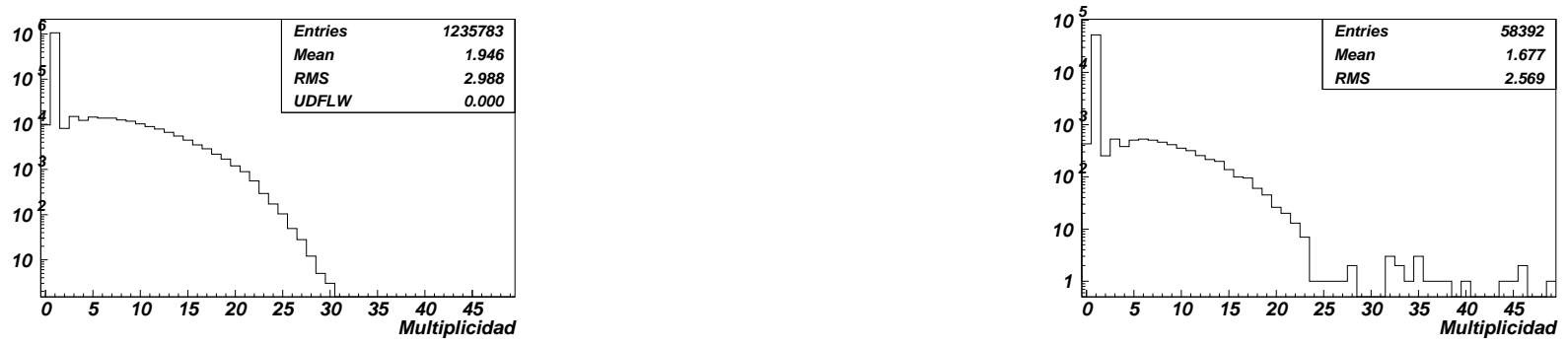

Figura 5.192: Multiplicidad total. Izquierda: haz de bariones. Derecha: haz de mesones(pos $570 \mathrm{Be})$.
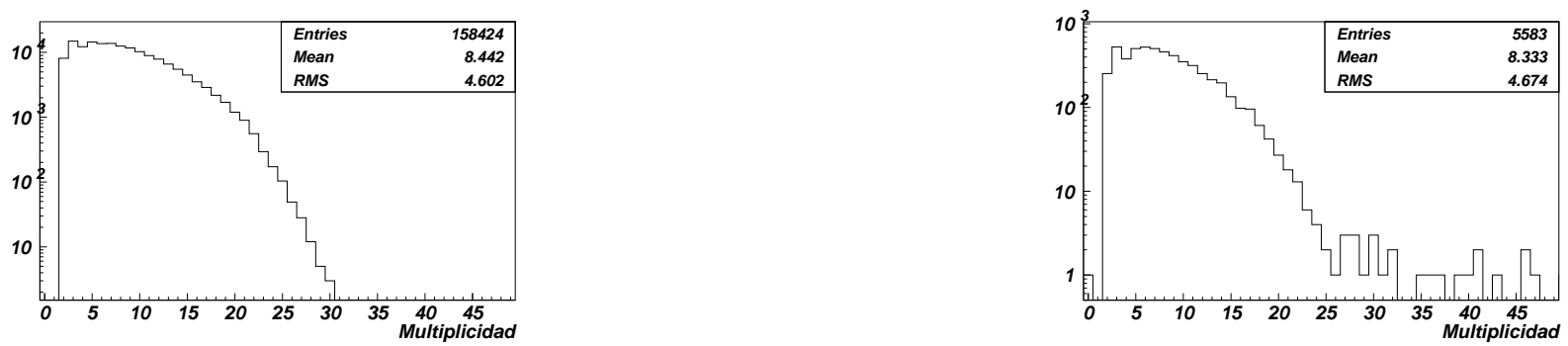

Figura 5.193: Multiplicidad en eventos con más de una trayectoria en la región del vértice. Izquierda: haz de bariones. Derecha: haz de mesones(pos $570 \mathrm{Be}$ ). 


\subsubsection{Distribuciones de multiplicidad y momento}
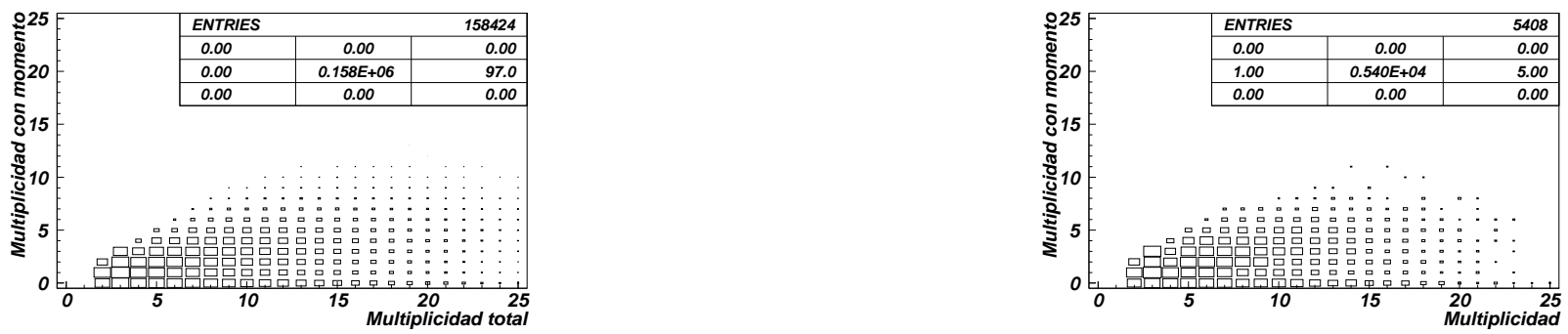

Figura 5.194: Multiplicidad total contra multiplicidad con momento medido. Izquierda: haz de bariones. Derecha: haz de mesones(pos 570 Be).
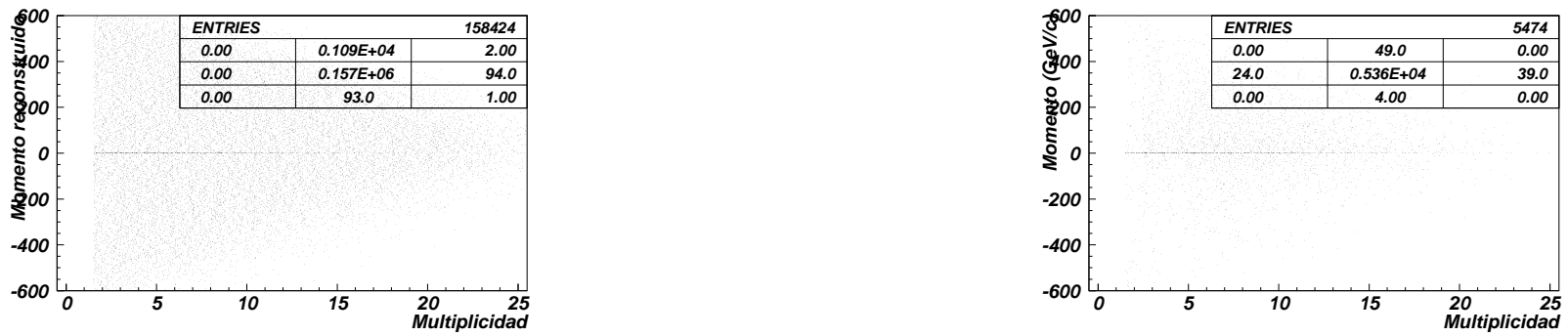

Figura 5.195: Multiplicidad contra momento.Izquierda: haz de bariones. Derecha: haz de mesones(pos $570 \mathrm{Be})$. 
Distribuciones de momento total para eventos producidos por un haz de bariones
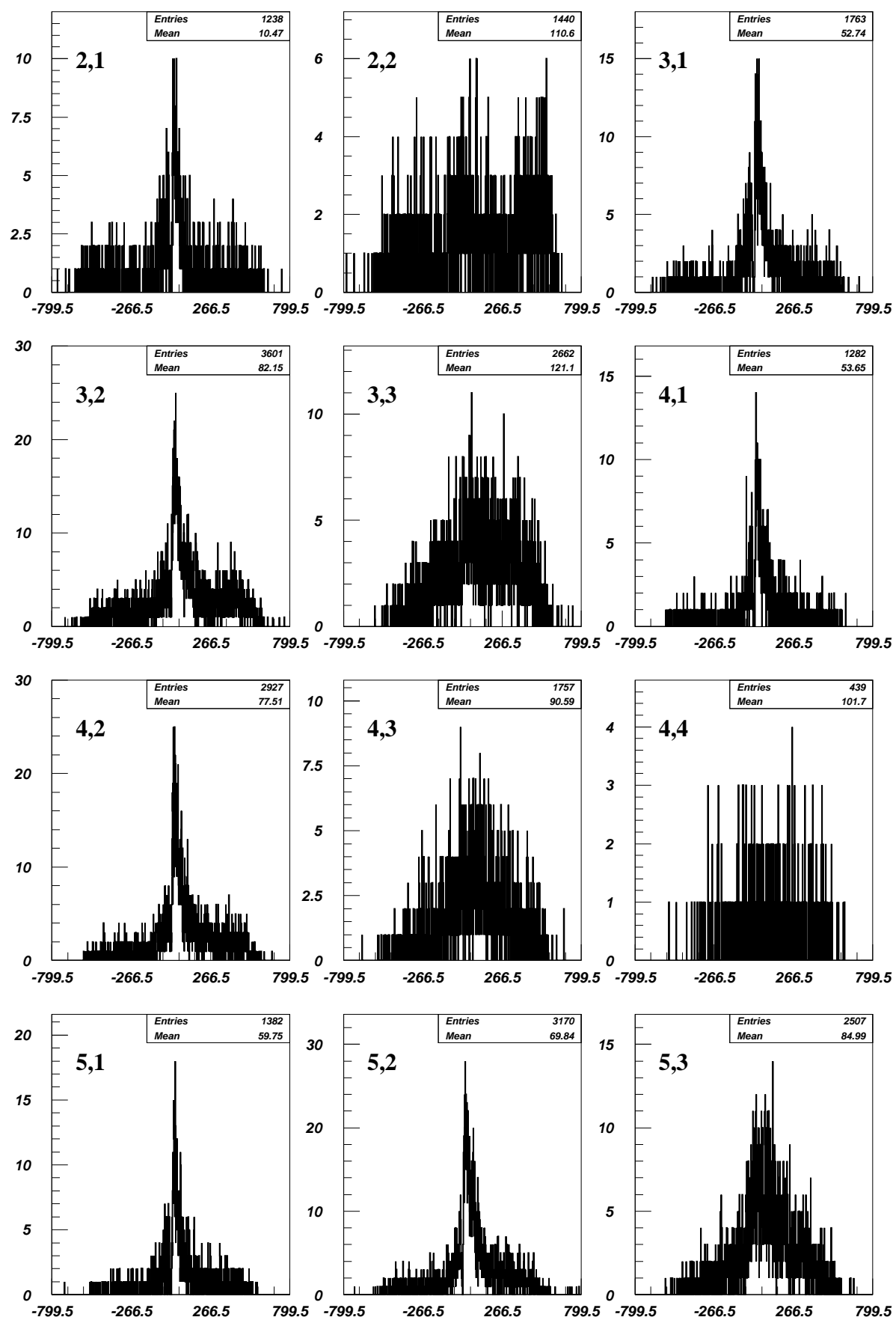

Figura 5.196: Distribuciones de momento. El primer indice: multiplicidad total, el segundo: multiplicidad con momento (pos $570 \mathrm{Be}$ ) 

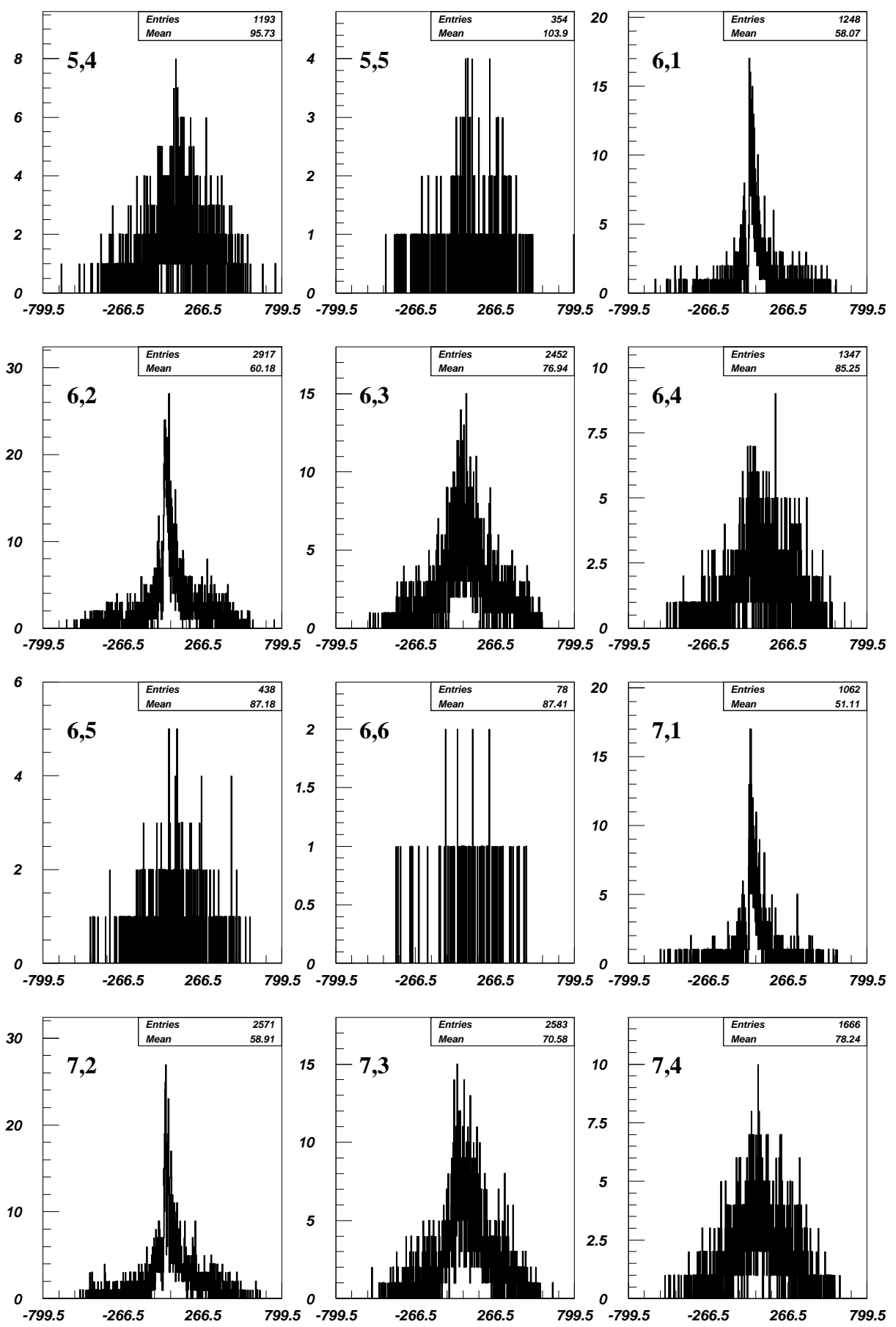

Figura 5.197: Distribuciones de momento. El primer índice: multiplicidad total, el segundo: multiplicidad con momento (pos $570 \mathrm{Be}$ ). 

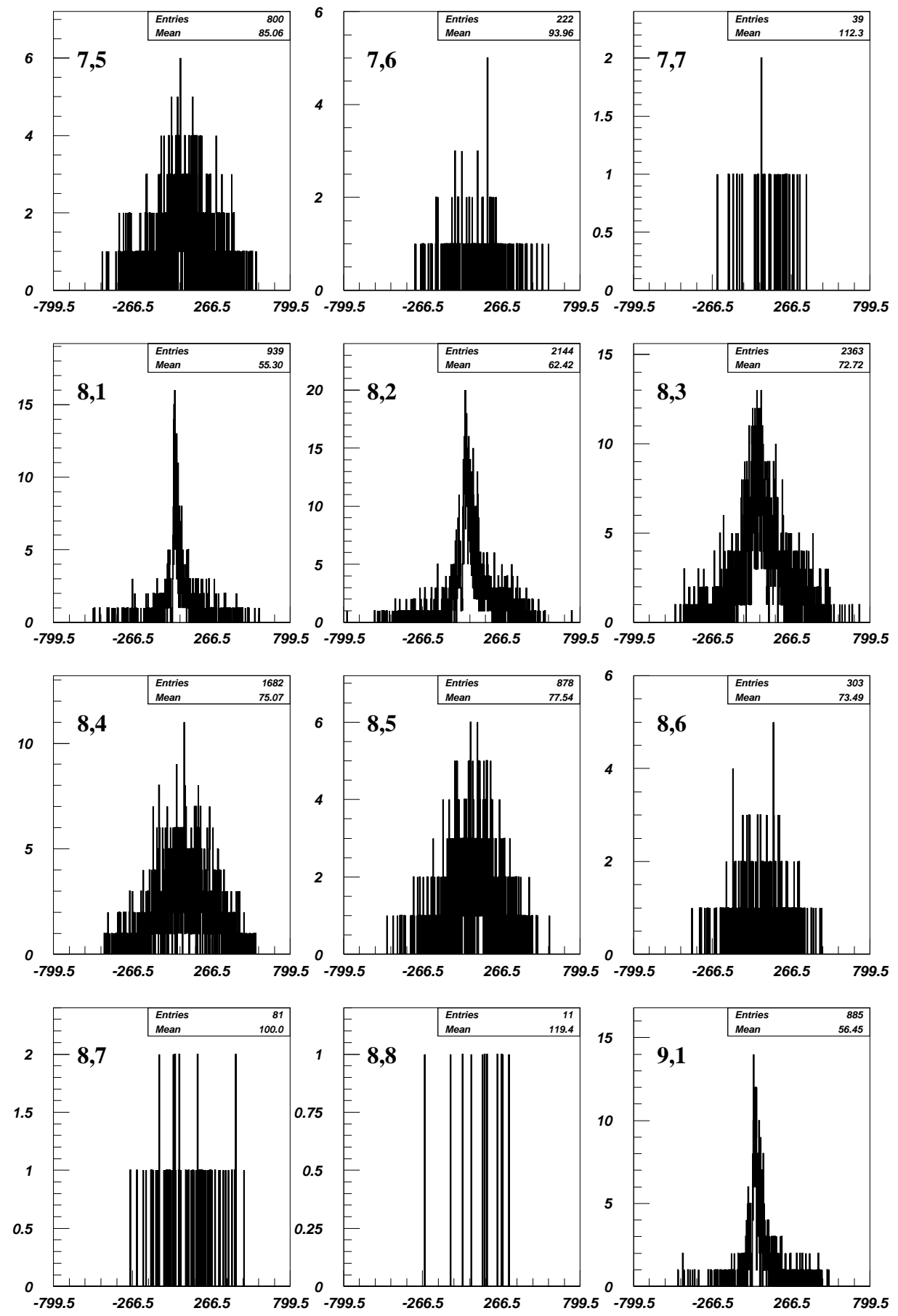

Figura 5.198: Distribuciones de momento. El primer índice: multiplicidad total, el segundo: multiplicidad con momento (pos $570 \mathrm{Be}$ ). 

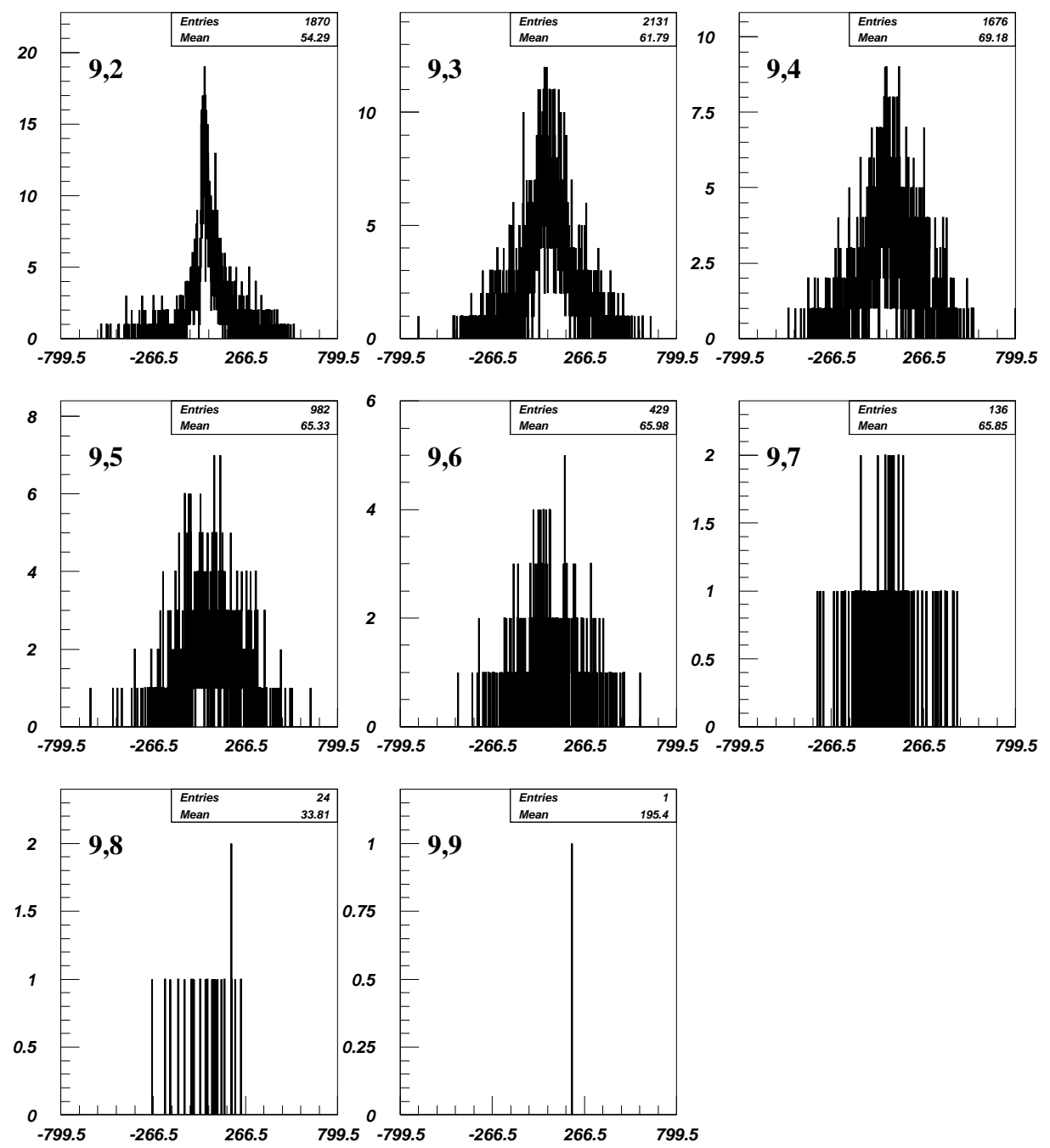

Figura 5.199: Distribuciones de momento. El primer índice: multiplicidad total, el segundo: multiplicidad con momento (pos $570 \mathrm{Be}$ ). 
Distribuciones de momento total para eventos producidos por un haz de mesones
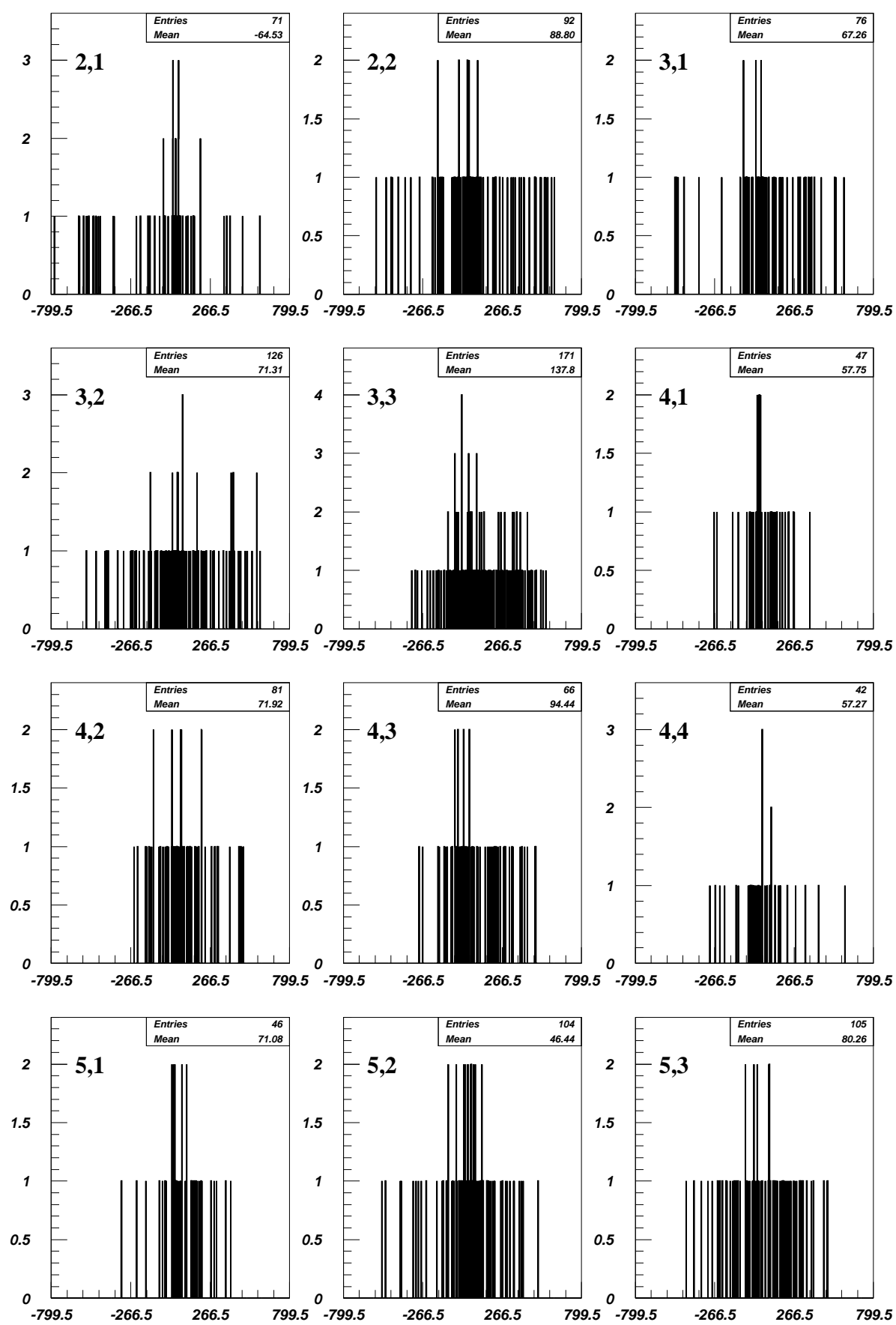

Figura 5.200: Distribuciones de momento. El primer indice: multiplicidad total, el segundo: multiplicidad con momento (pos $570 \mathrm{Be}$ ) 

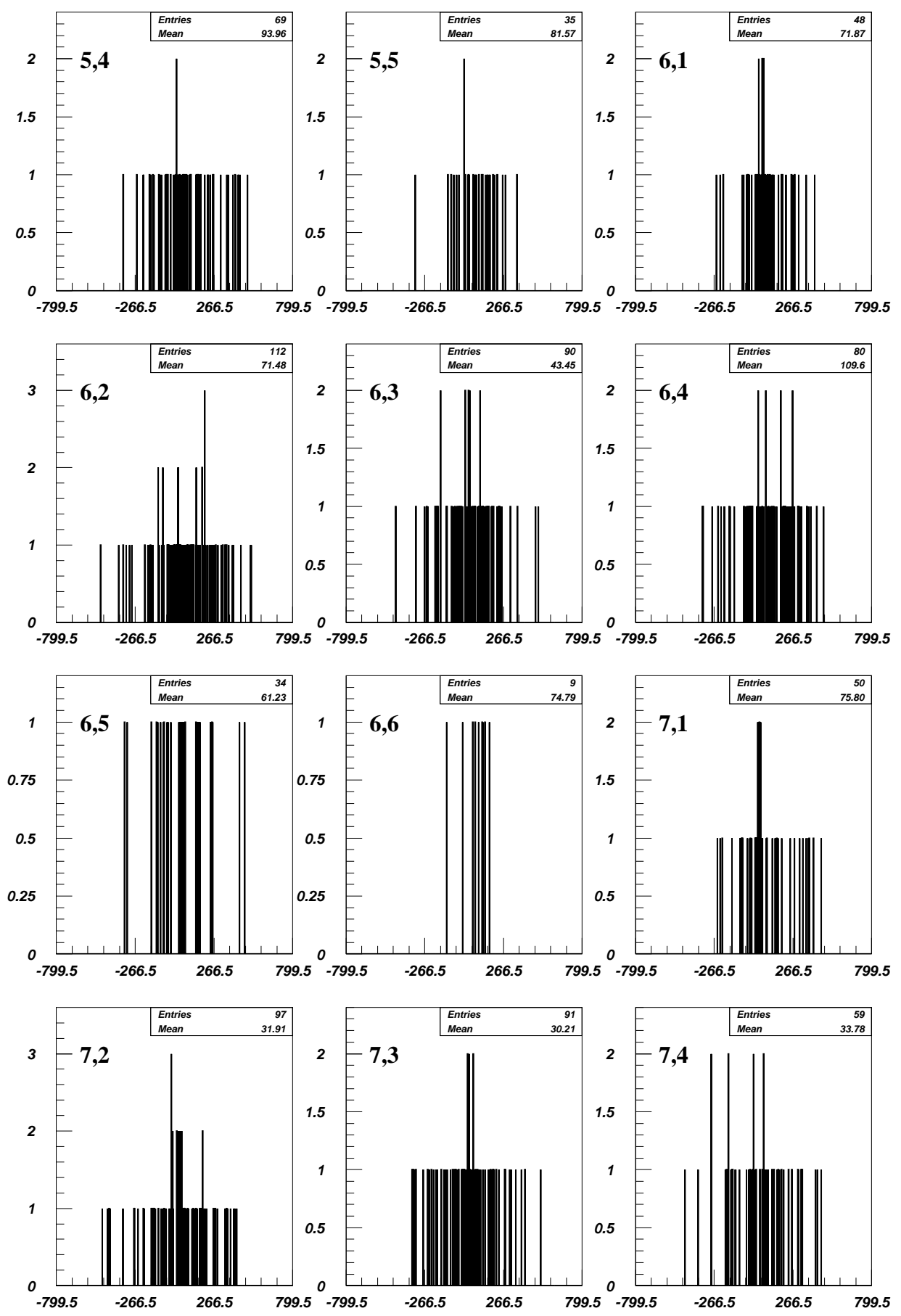

Figura 5.201: Distribuciones de momento. El primer índice: multiplicidad total, el segundo: multiplicidad con momento (pos $570 \mathrm{Be}$ ). 

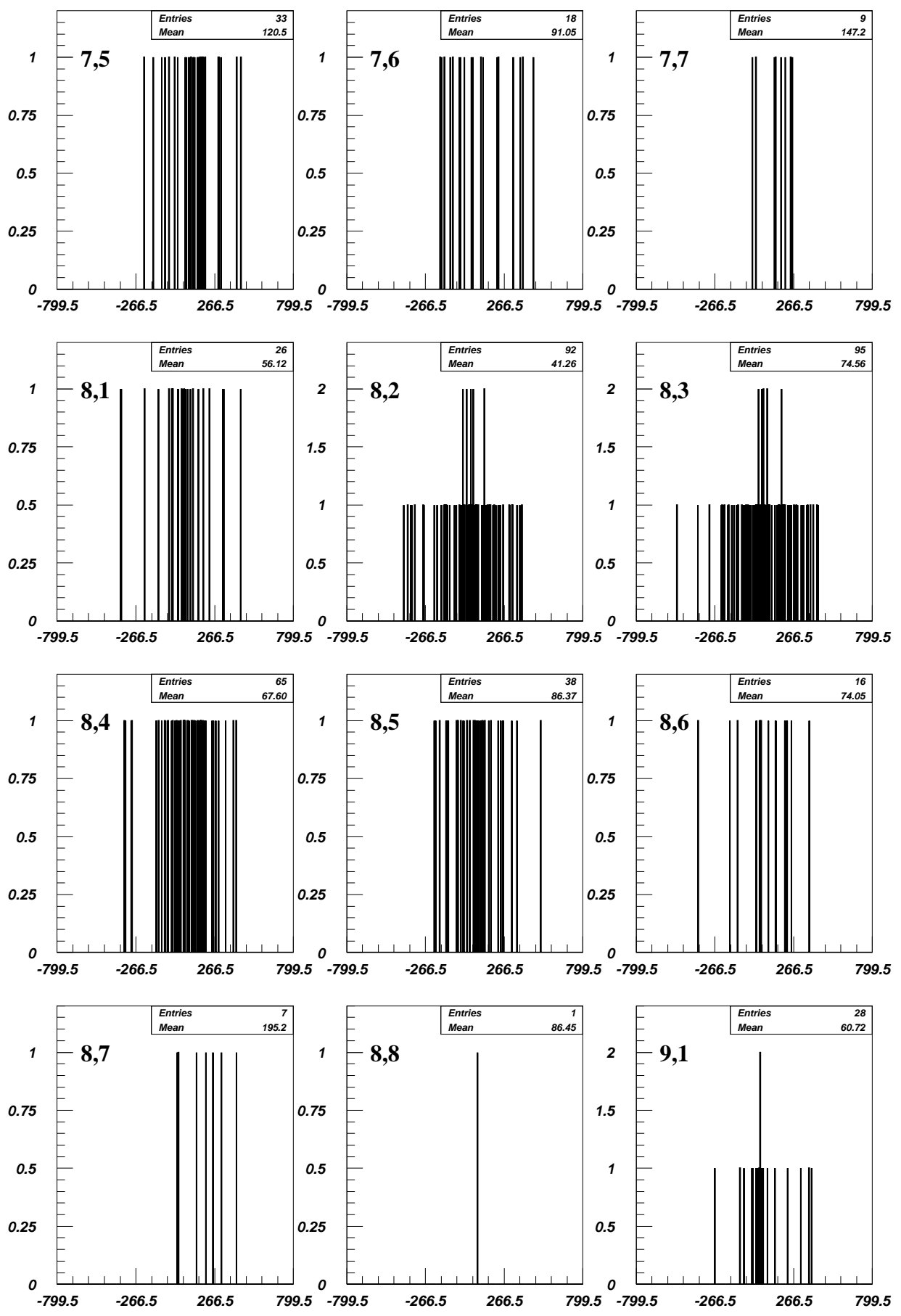

Figura 5.202: Distribuciones de momento. El primer índice: multiplicidad total, el segundo: multiplicidad con momento (pos $570 \mathrm{Be}$ ). 

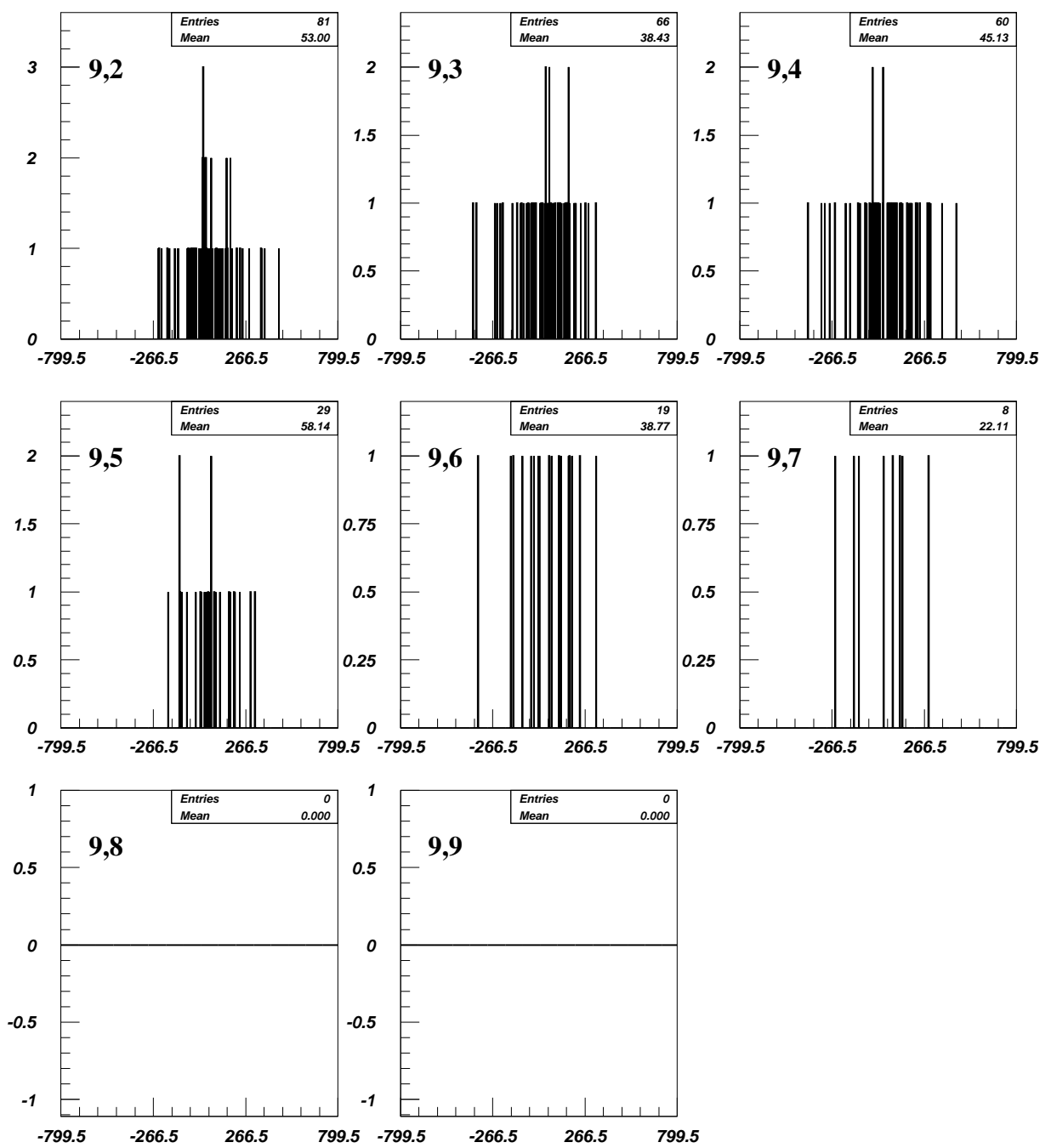

Figura 5.203: Distribuciones de momento. El primer índice: multiplicidad total, el segundo: multiplicidad con momento (pos $570 \mathrm{Be}$ ). 
Distribuciones del valor absoluto del momento total para eventos producidos por un haz de bariones
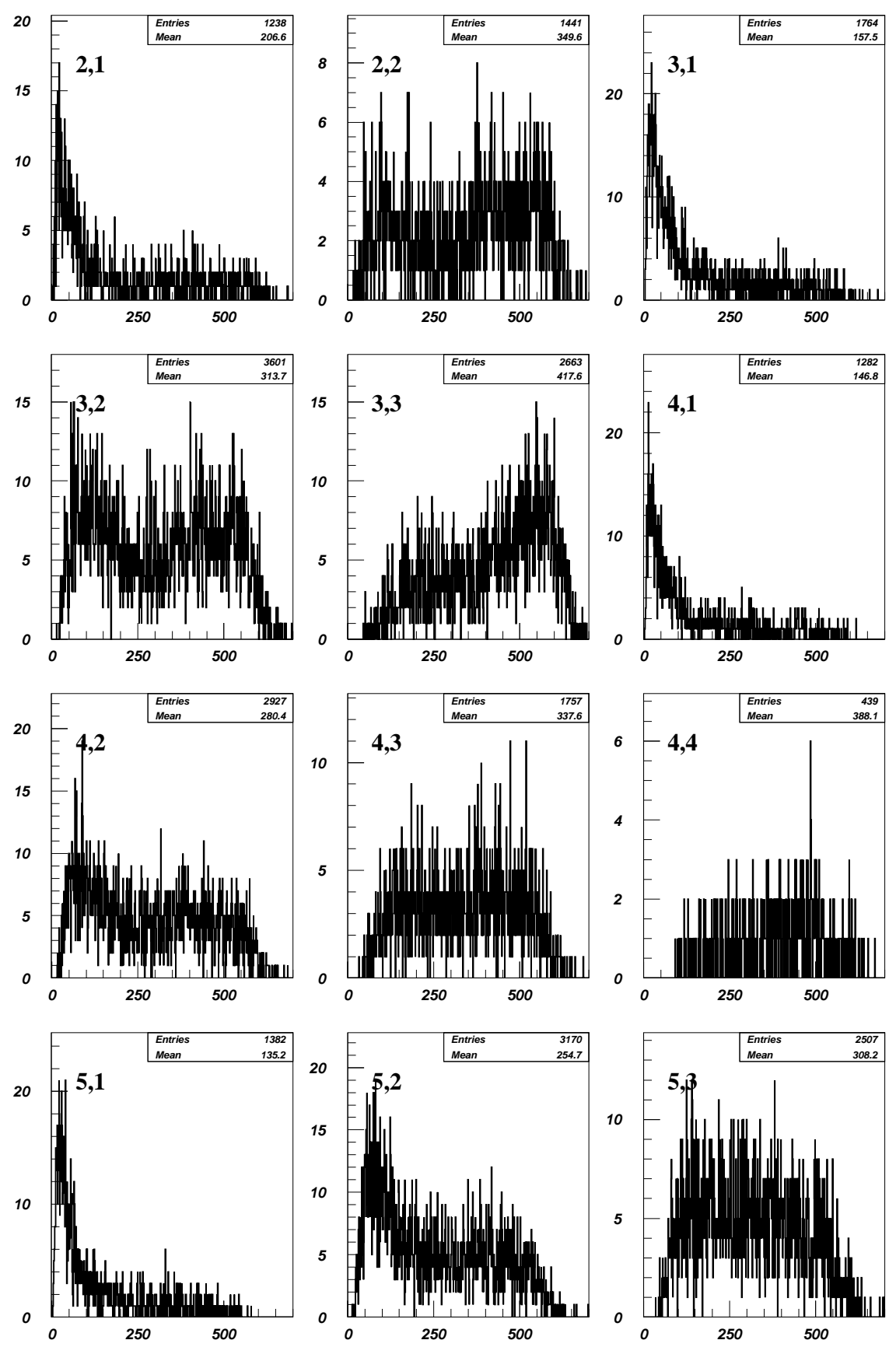

Figura 5.204: Distribuciones de momento. El primer indice: multiplicidad total, el segundo: multiplicidad con momento (pos $570 \mathrm{Be}$ ). 

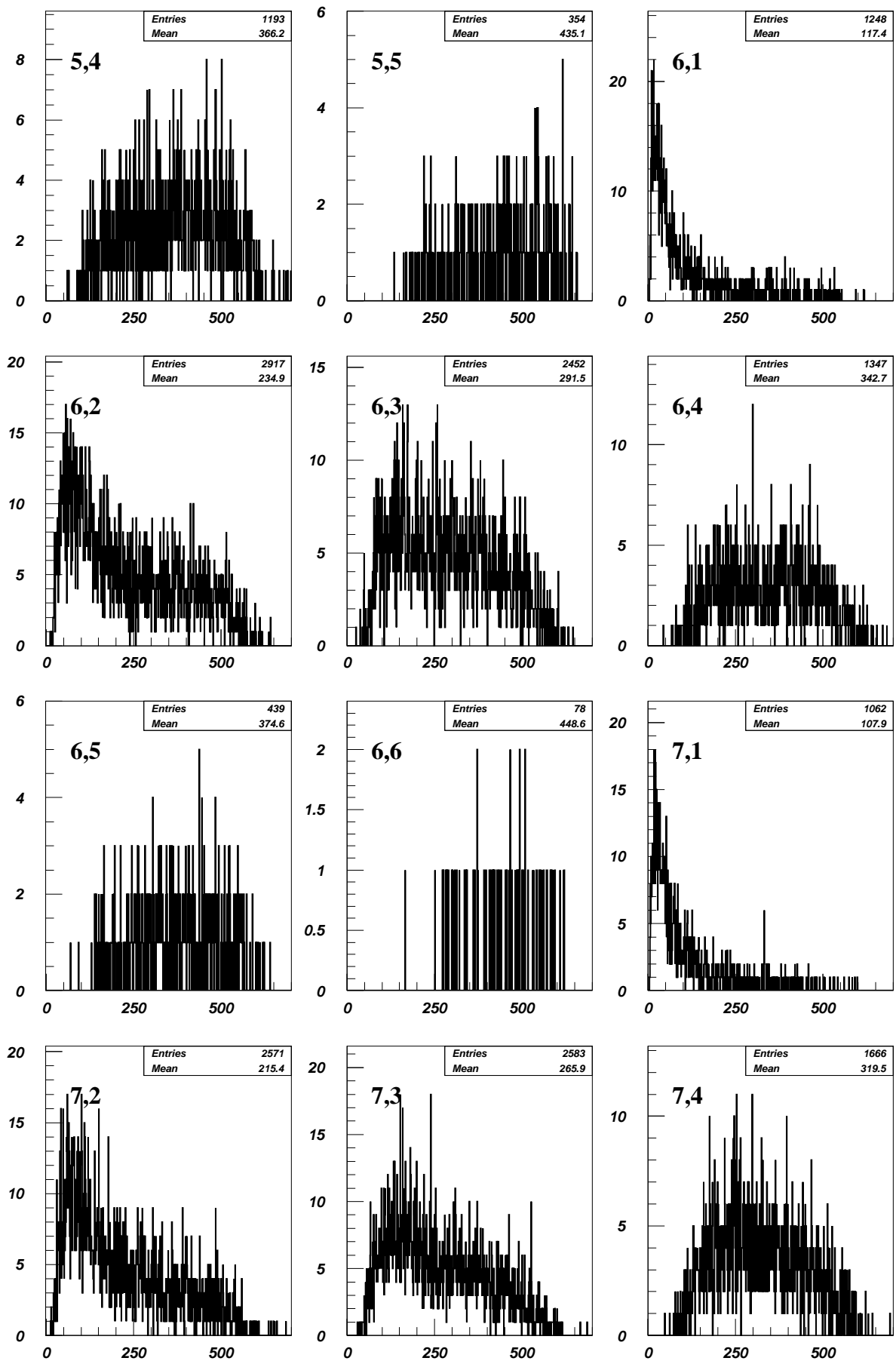

Figura 5.205: Distribuciones de momento. El primer índice: multiplicidad total, el segundo: multiplicidad con momento (pos $570 \mathrm{Be}$ ). 

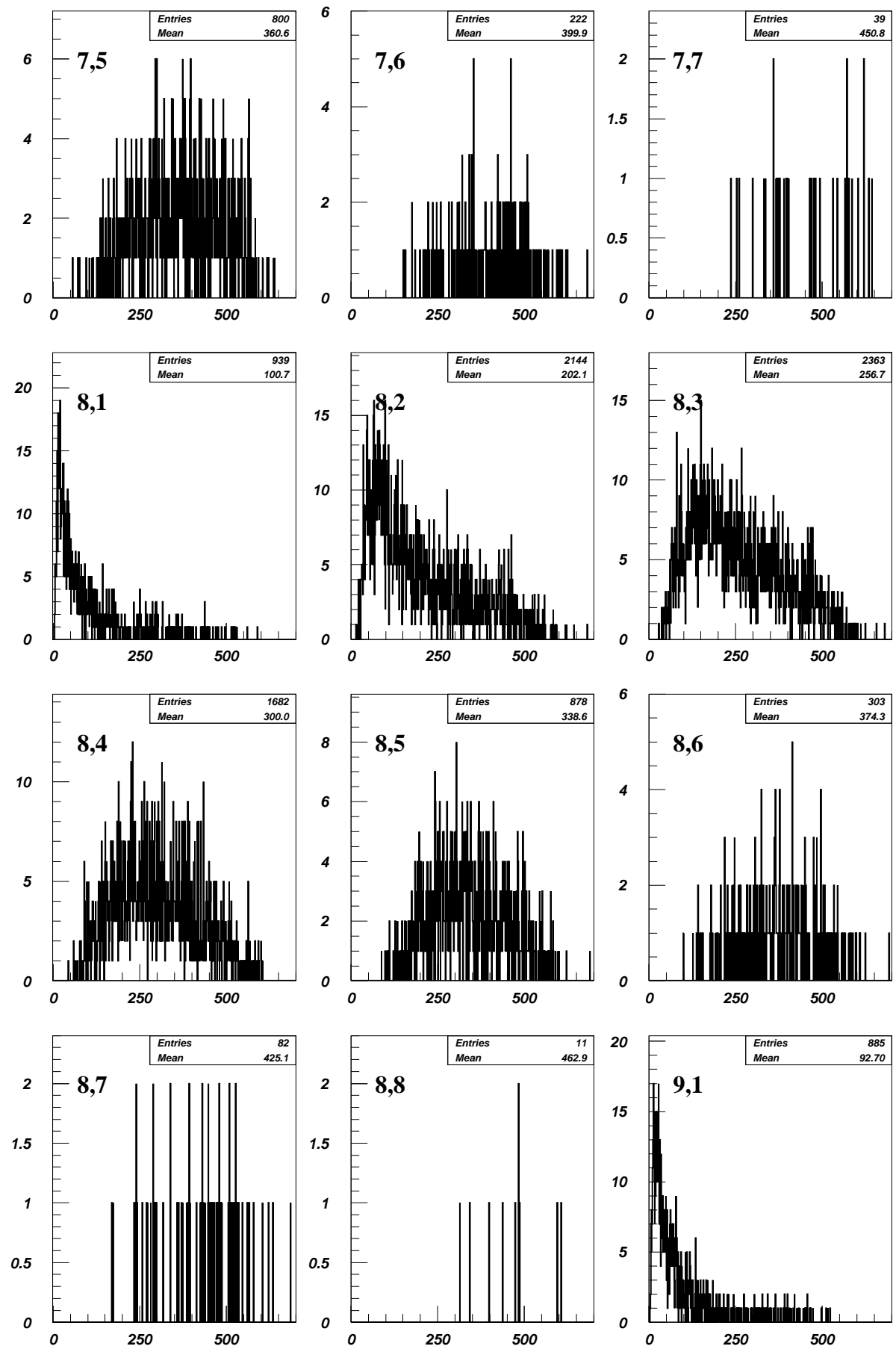

Figura 5.206: Distribuciones de momento. El primer índice: multiplicidad total, el segundo: multiplicidad con momento (pos $570 \mathrm{Be}$ ). 

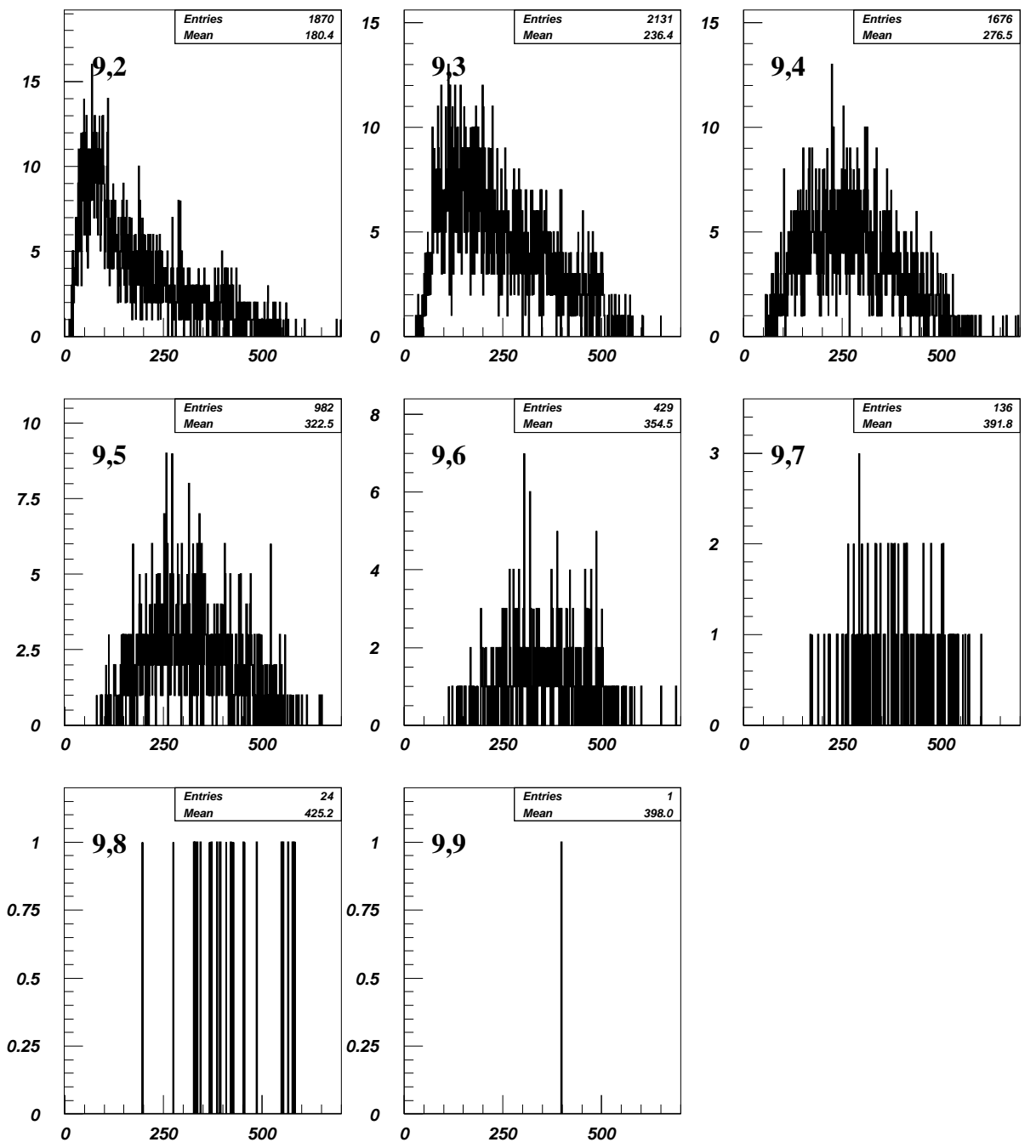

Figura 5.207: Distribuciones de momento. El primer índice: multiplicidad total, el segundo: multiplicidad con momento (pos $570 \mathrm{Be}$ ). 
Distribuciones del valor absoluto del momento total para eventos producidos por un haz de mesones
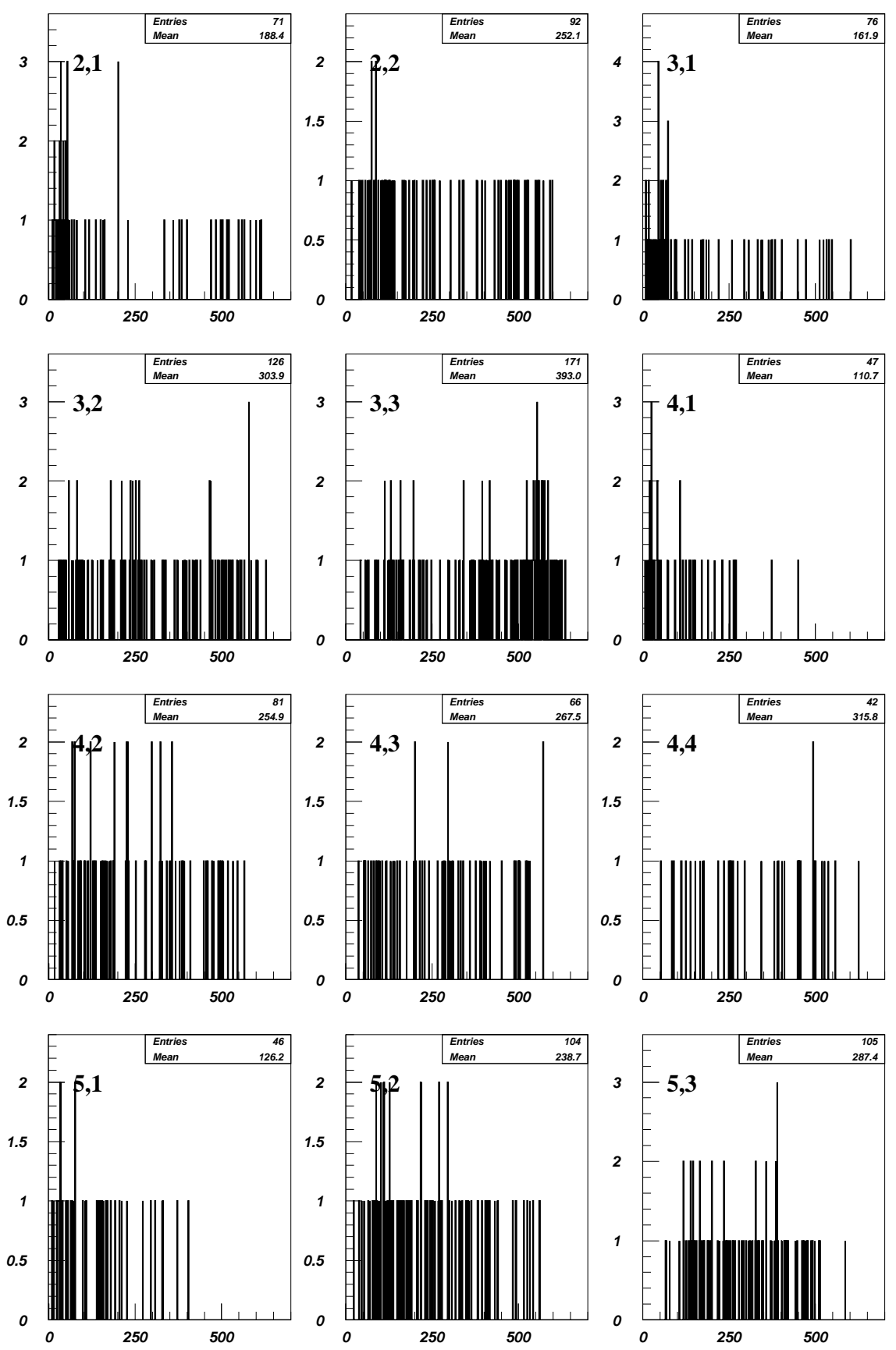

Figura 5.208: Distribuciones de momento. El primer indice: multiplicidad total, el segundo: multiplicidad con momento (pos $570 \mathrm{Be}$ ). 

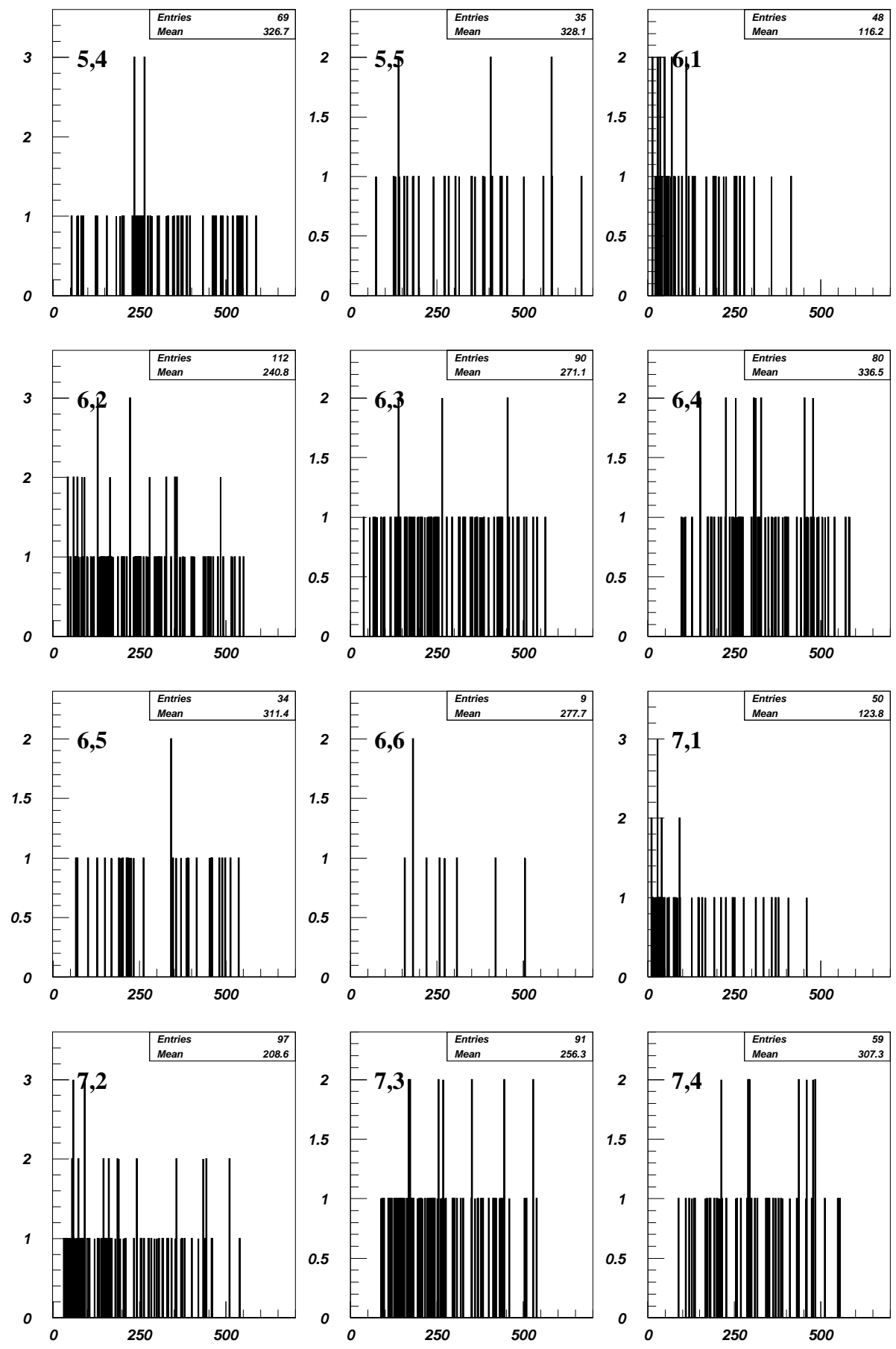

Figura 5.209: Distribuciones de momento. El primer índice: multiplicidad total, el segundo: multiplicidad con momento (pos $570 \mathrm{Be}$ ). 

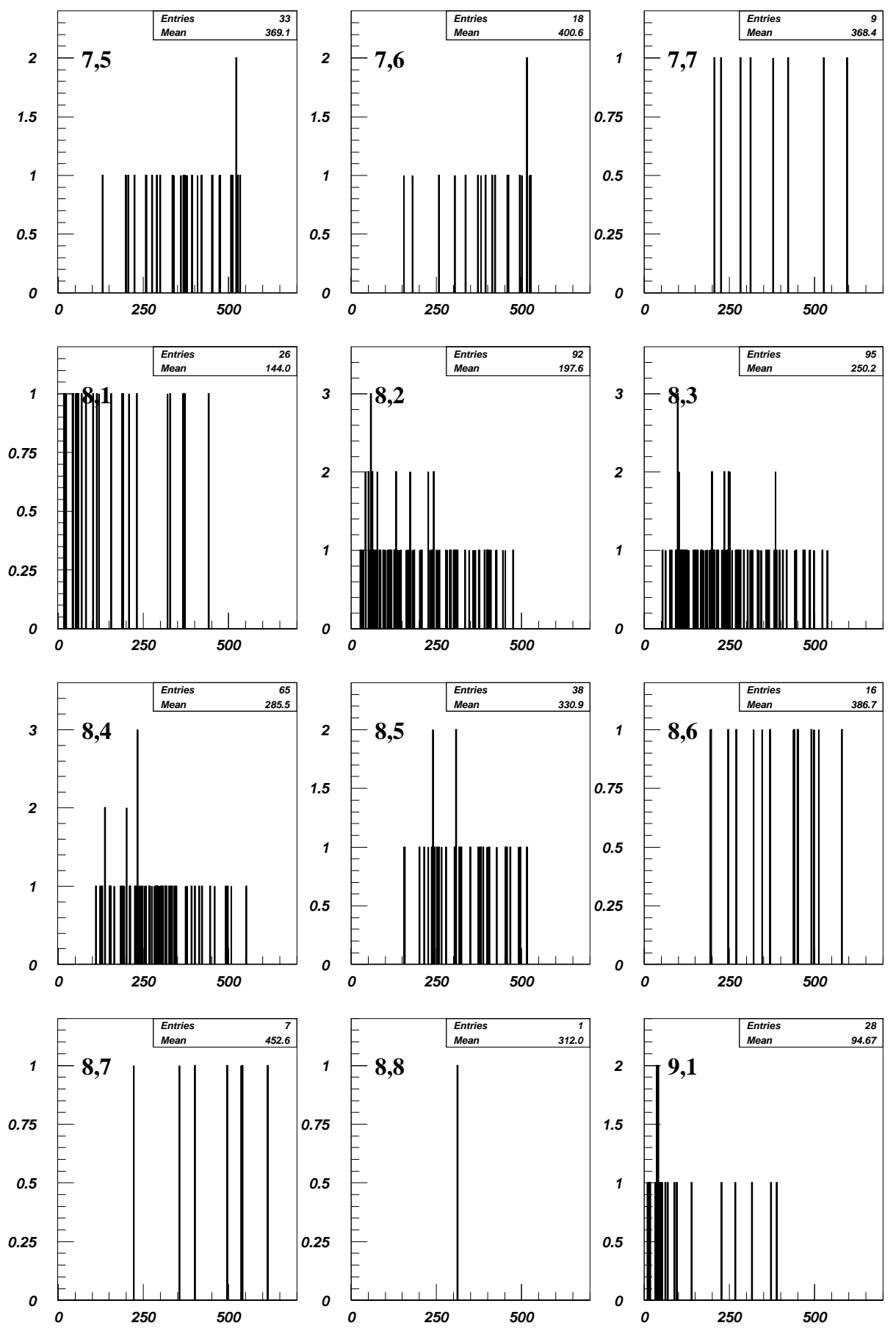

Figura 5.210: Distribuciones de momento. El primer índice: multiplicidad total, el segundo: multiplicidad con momento (pos $570 \mathrm{Be}$ ). 

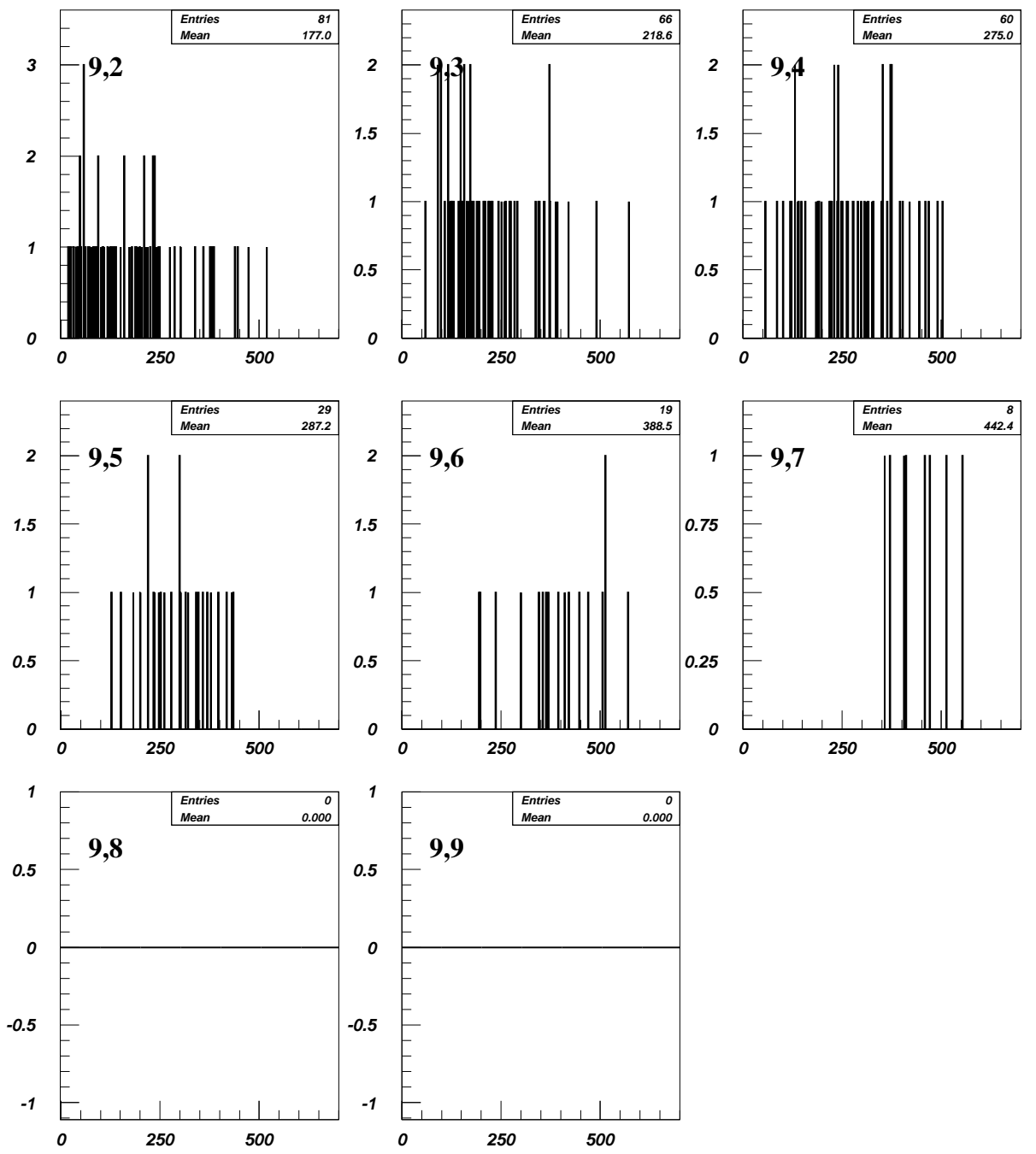

Figura 5.211: Distribuciones de momento. El primer índice: multiplicidad total, el segundo: multiplicidad con momento (pos $570 \mathrm{Be}$ ). 
Distribuciones del momento de las trayectorias para eventos producidos por un haz de bariones
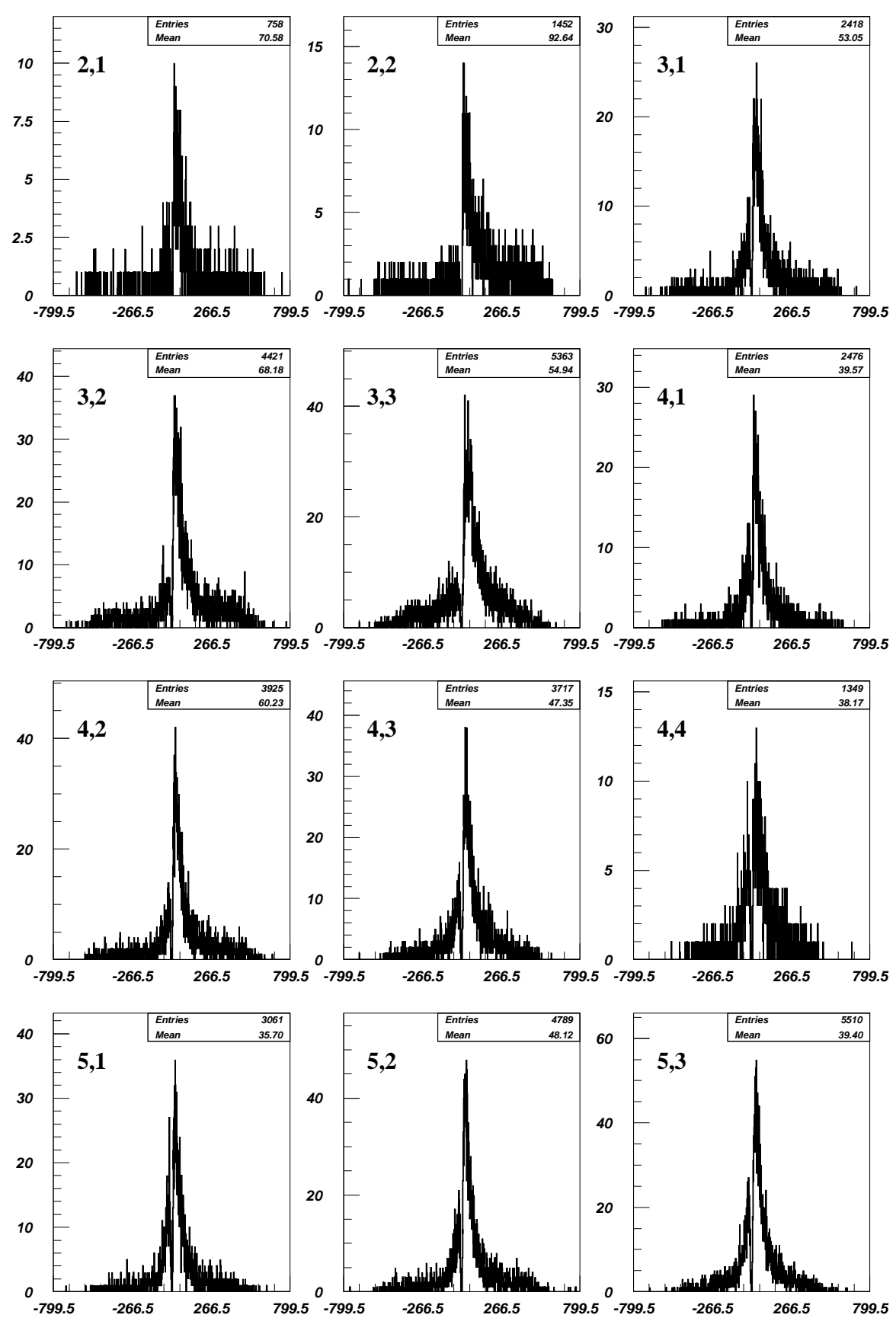

Figura 5.212: Distribuciones de momento. El primer indice: multiplicidad total, el segundo: multiplicidad con momento (pos $570 \mathrm{Be}$ ) 

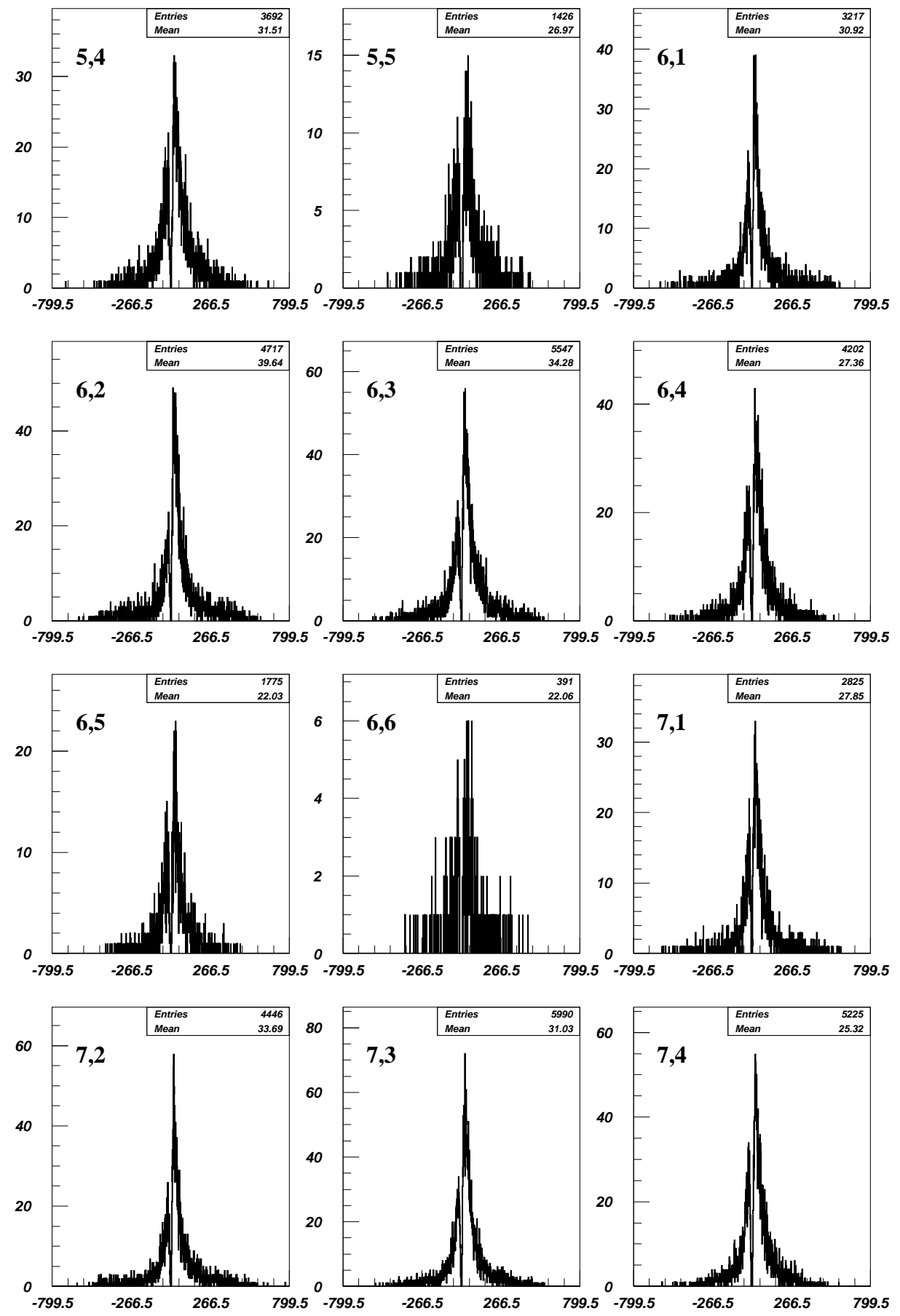

Figura 5.213: Distribuciones de momento. El primer índice: multiplicidad total, el segundo: multiplicidad con momento (pos $570 \mathrm{Be}$ ). 

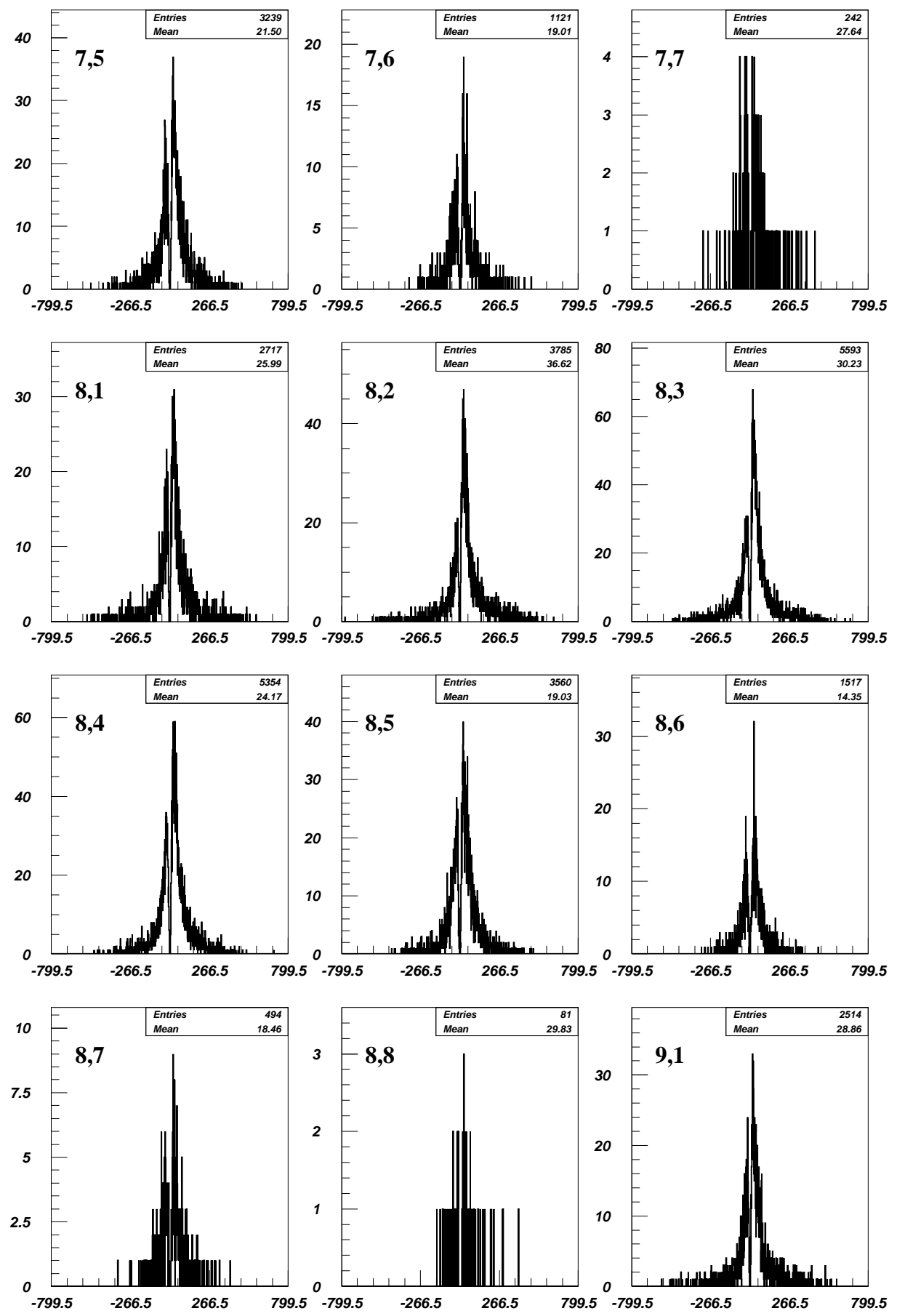

Figura 5.214: Distribuciones de momento. El primer índice: multiplicidad total, el segundo: multiplicidad con momento(pos $570 \mathrm{Be})$. 

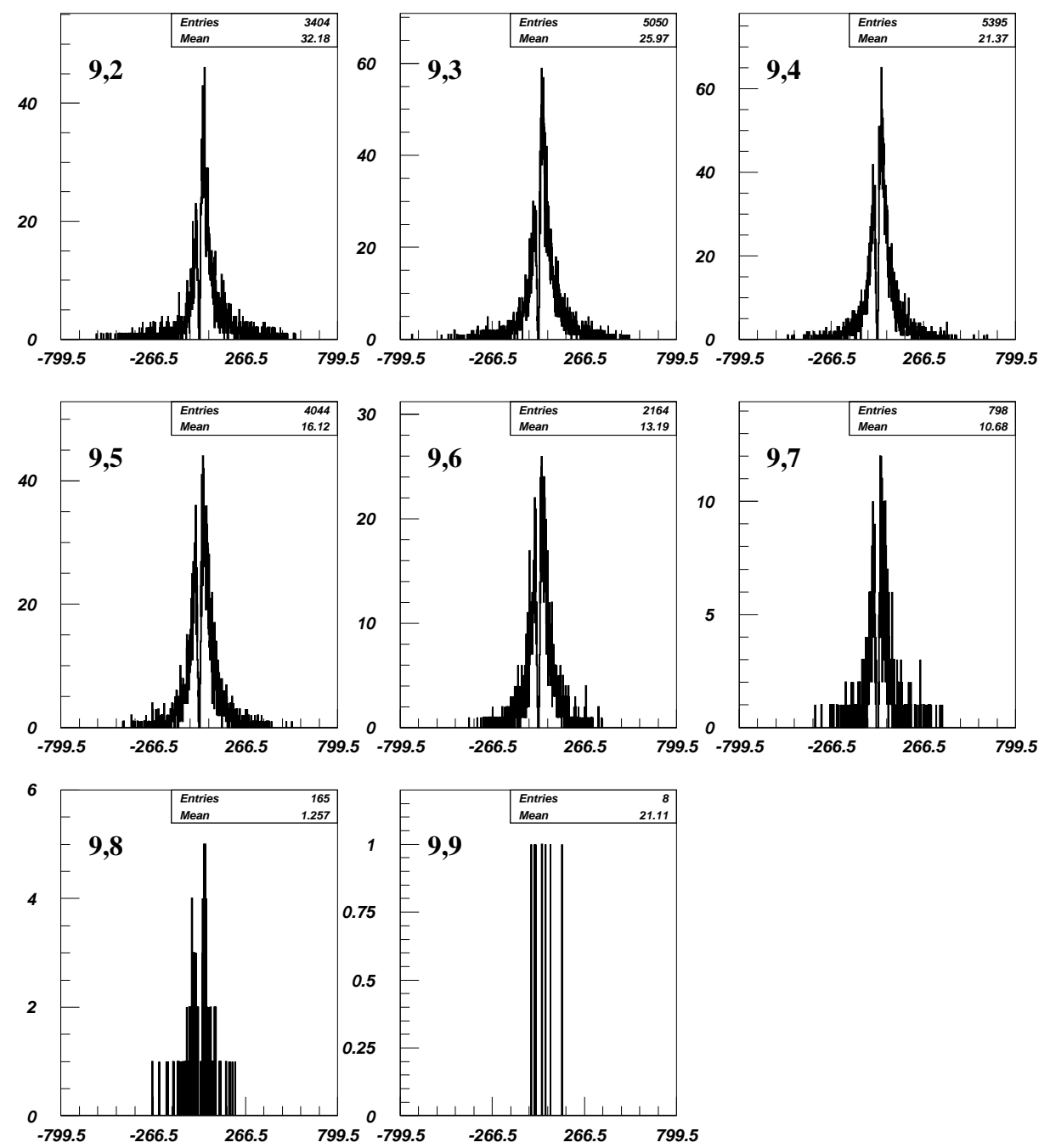

Figura 5.215: Distribuciones de momento. El primer índice: multiplicidad total, el segundo: multiplicidad con momento (pos $570 \mathrm{Be}$ ). 
Distribuciones del momento de las trayectorias para eventos producidos por un haz de mesones
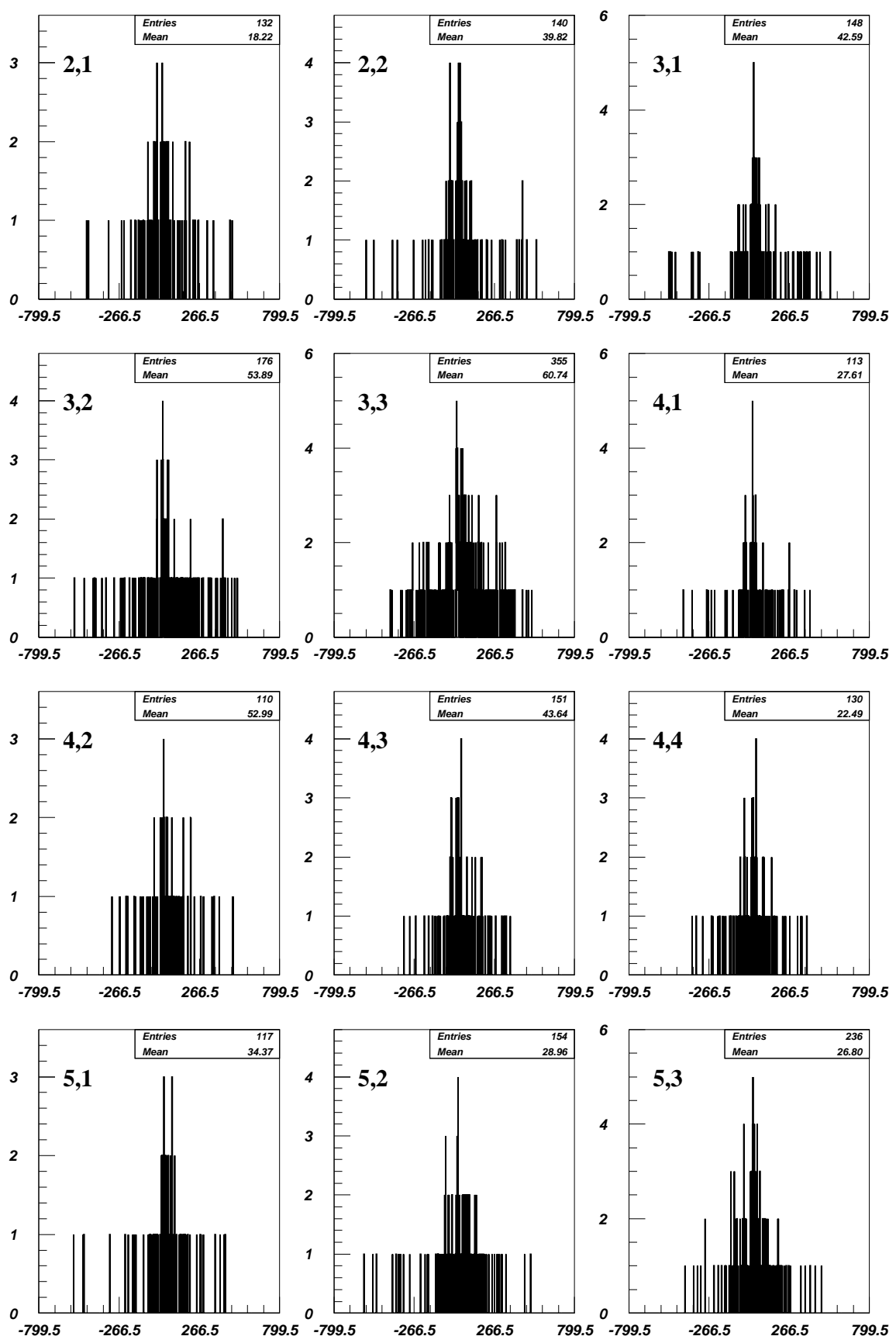

Figura 5.216: Distribuciones de momento. El primer indice: multiplicidad total, el segundo: multiplicidad con momento (pos $570 \mathrm{Be}$ ). 

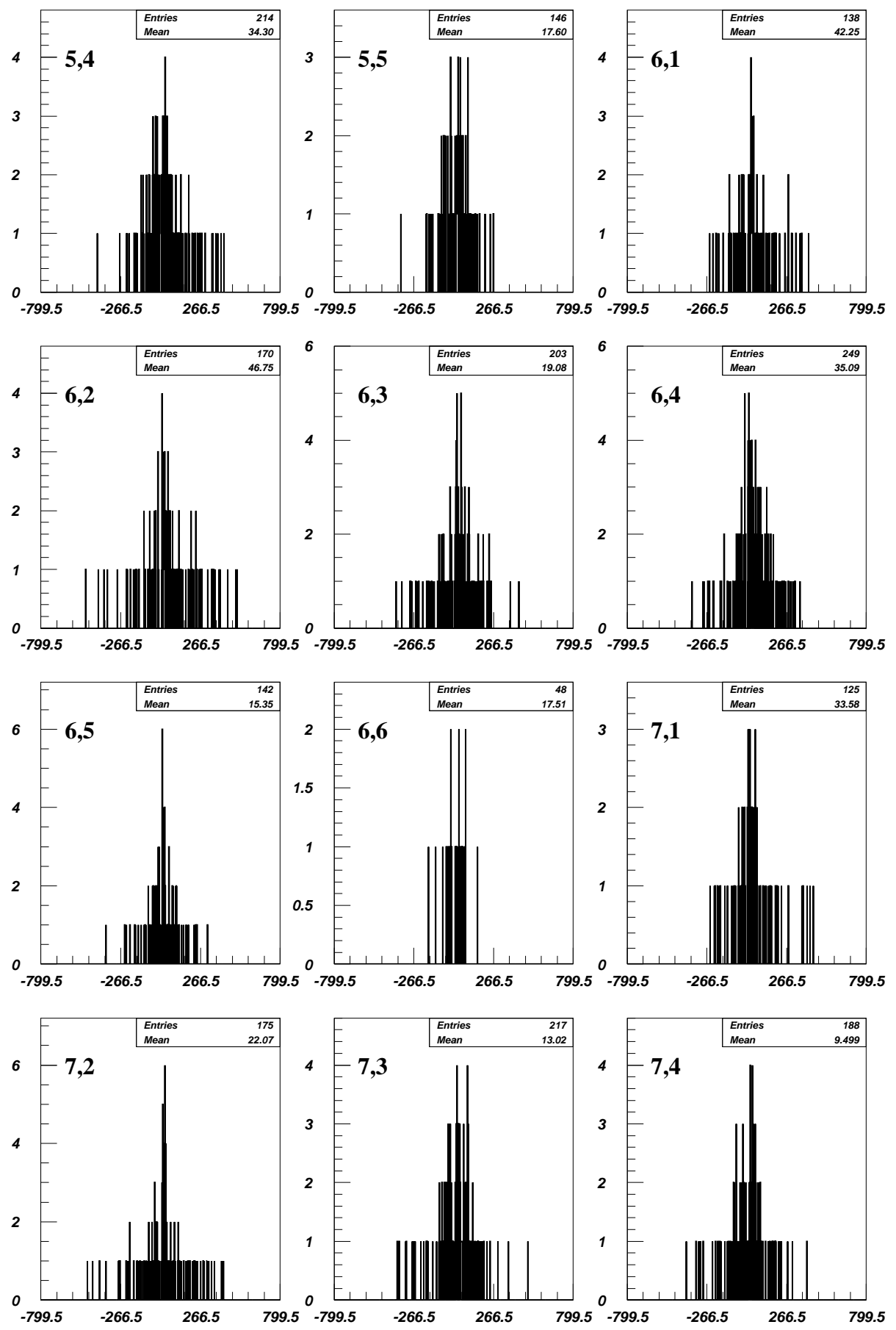

Figura 5.217: Distribuciones de momento. El primer índice: multiplicidad total, el segundo: multiplicidad con momento (pos $570 \mathrm{Be}$ ). 

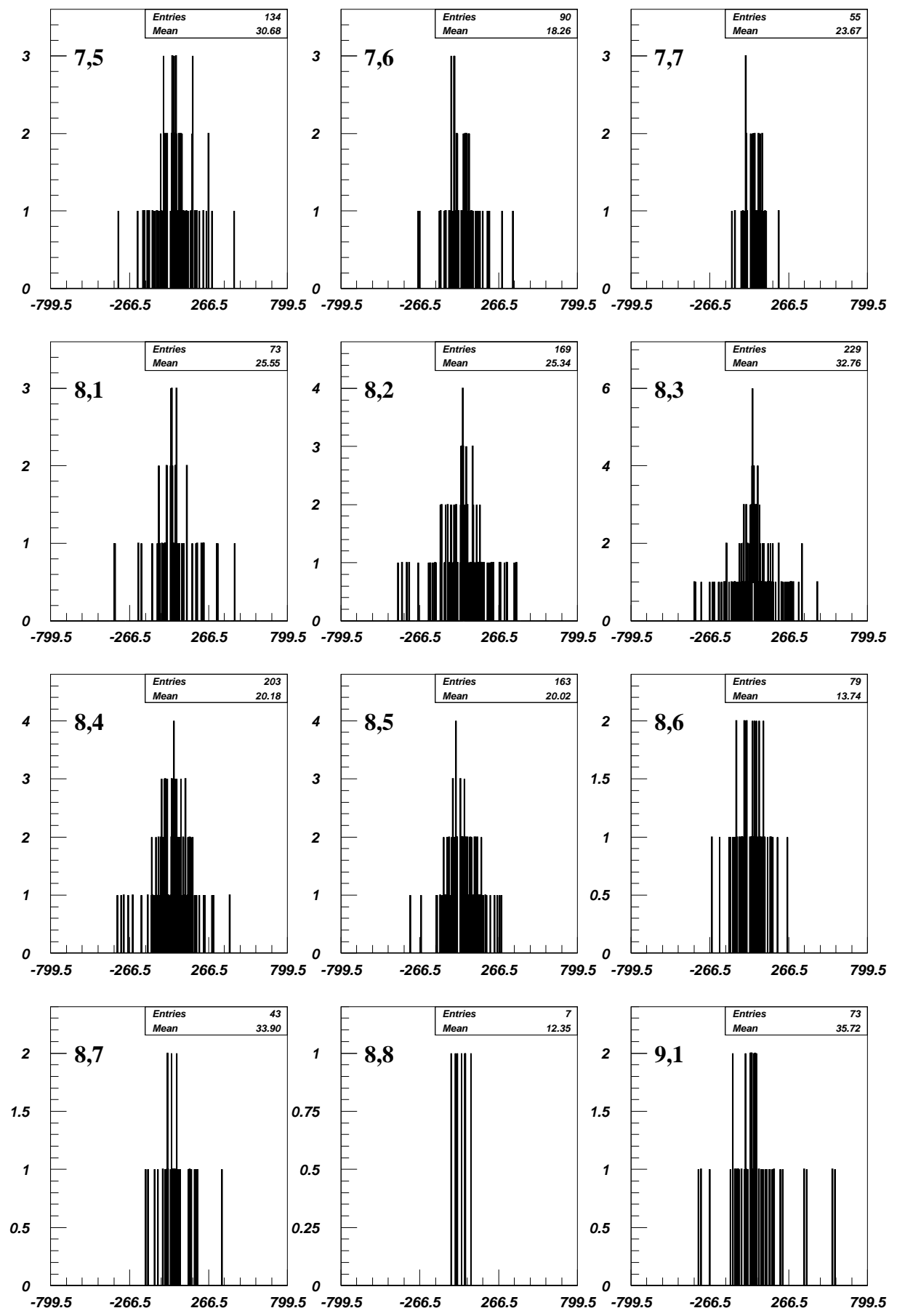

Figura 5.218: Distribuciones de momento. El primer índice: multiplicidad total, el segundo: multiplicidad con momento (pos $570 \mathrm{Be}$ ). 

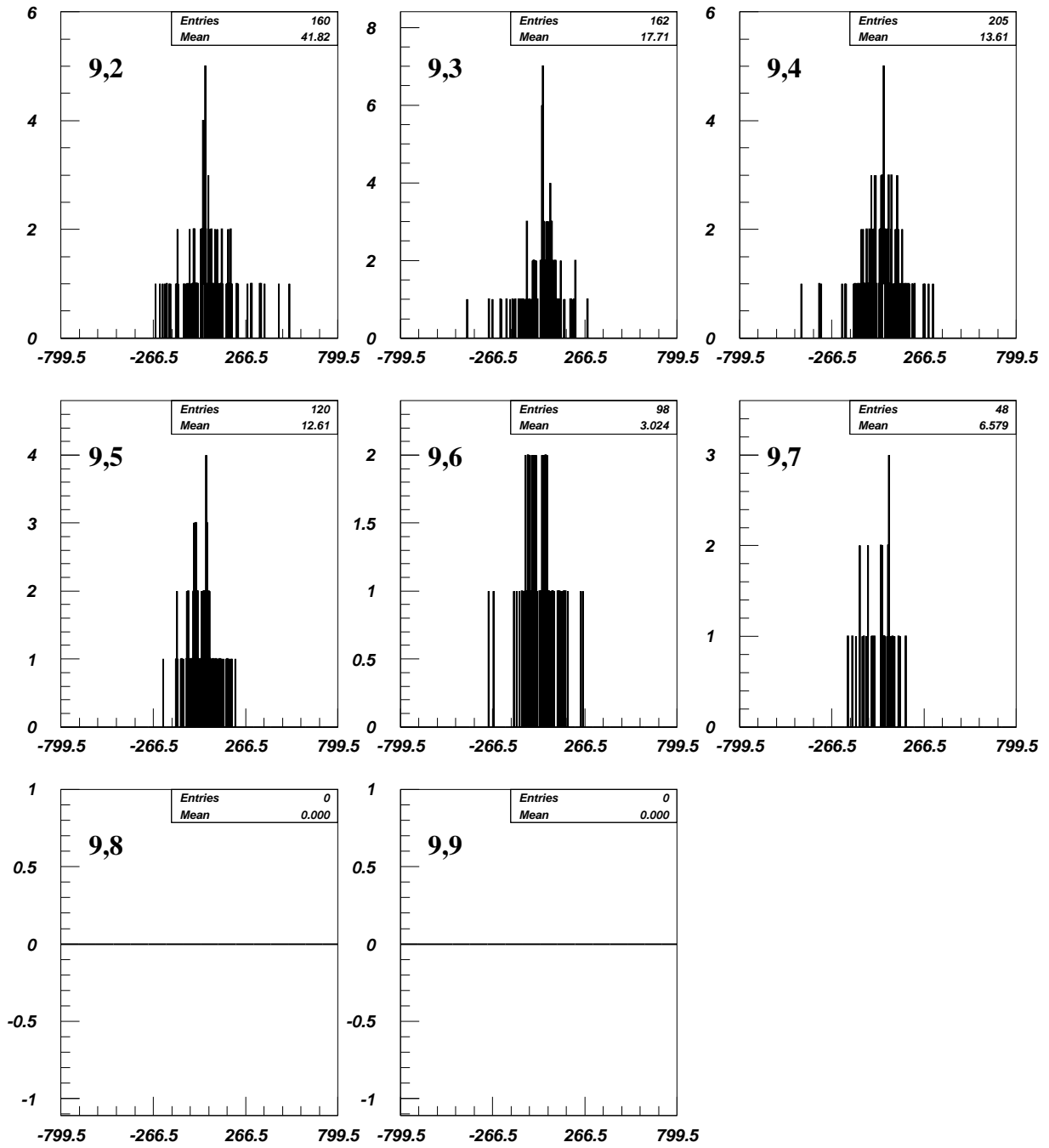

Figura 5.219: Distribuciones de momento. El primer índice: multiplicidad total, el segundo: multiplicidad con momento (pos $570 \mathrm{Be}$ ). 


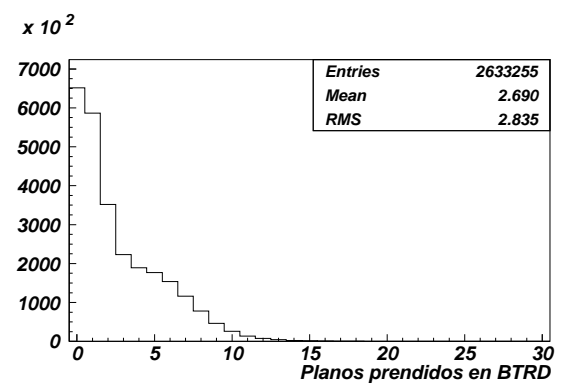

Figura 5.221: Planos prendidos en BTRD. Proporción bariónica y mesónica del haz primario (pos $250 \mathrm{C})$.
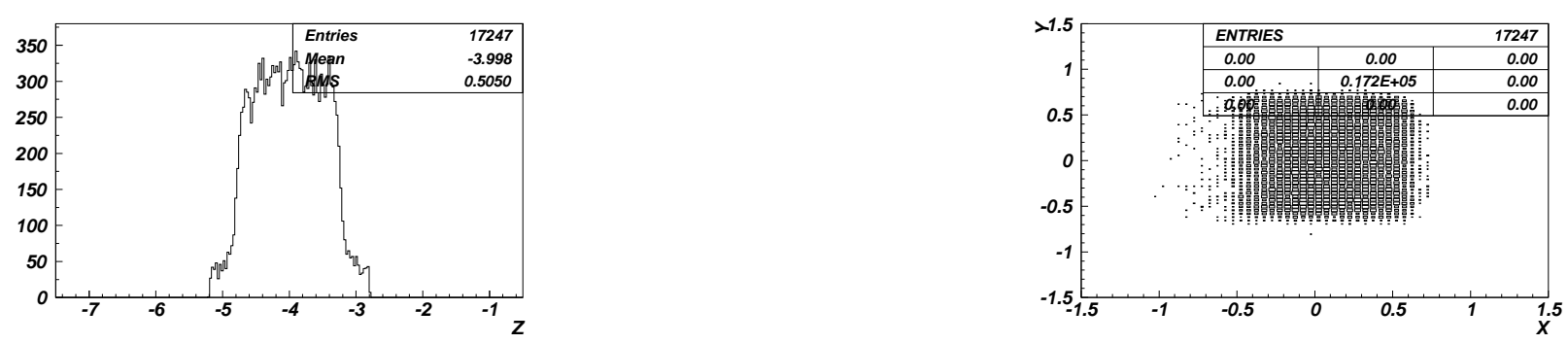

Figura 5.222: Vértice primario. Izquierda: coordenada z. Derecha: proyección x,y (pos 250 C). 
5.9. Haz de polaridad positiva, con momento $250 \mathrm{GeV}$, con blanco de producción para el haz secundario de carbón

\subsubsection{Histogramas de control}
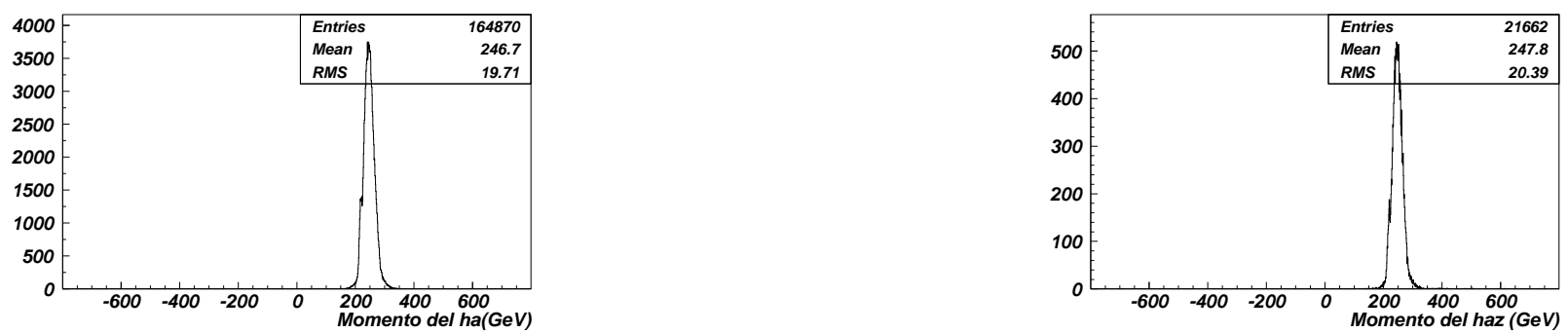

Figura 5.220: Distribución de momento del haz primario. Izquierda: bariones. Derecha: mesones (pos $250 \mathrm{C})$. 


\subsubsection{Multiplicidad en la región del vértice}
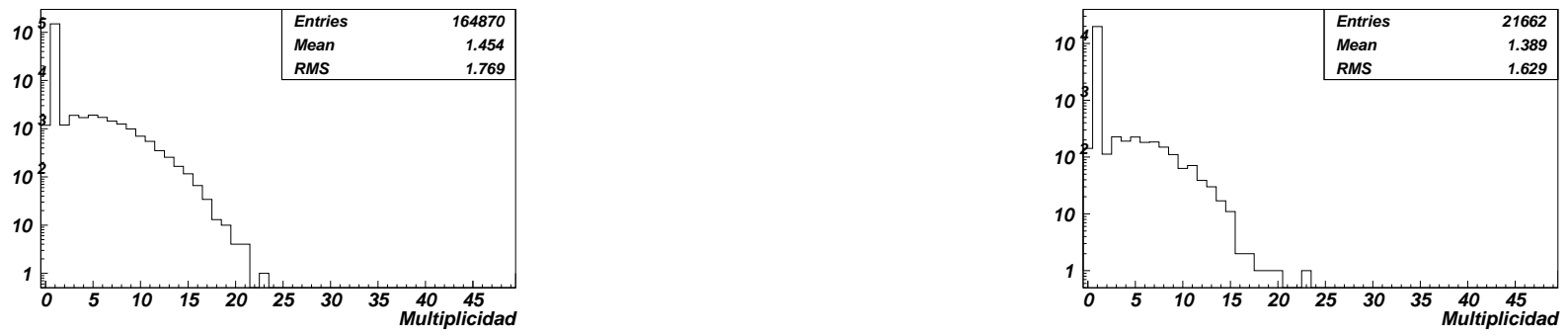

Figura 5.223: Multiplicidad total. Izquierda: haz de bariones. Derecha: haz de mesones(pos $250 \mathrm{C})$.
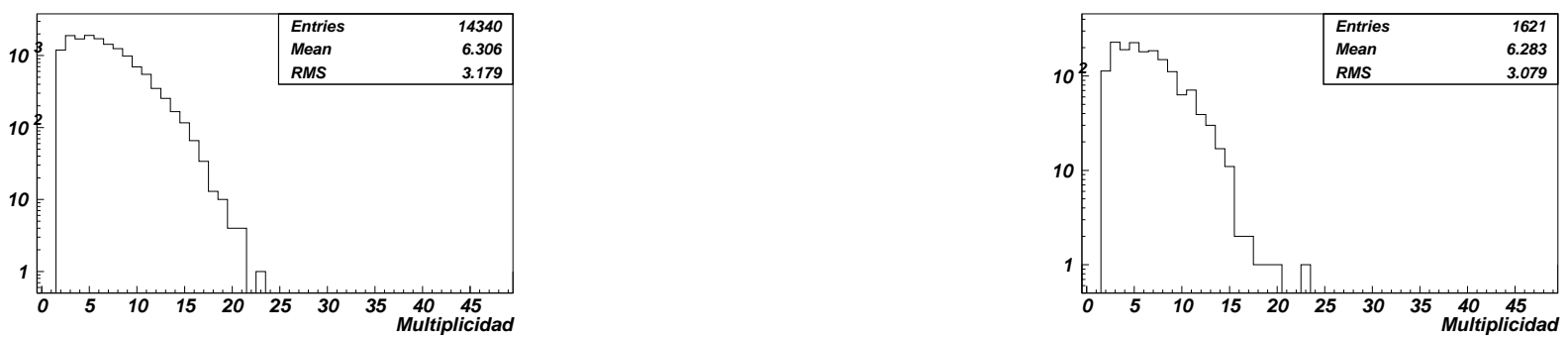

Figura 5.224: Multiplicidad en eventos con más de una trayectoria en la región del vértice. Izquierda: haz de bariones. Derecha: haz de mesones(pos $250 \mathrm{C}$ ). 


\subsubsection{Distribuciones de multiplicidad y momento}
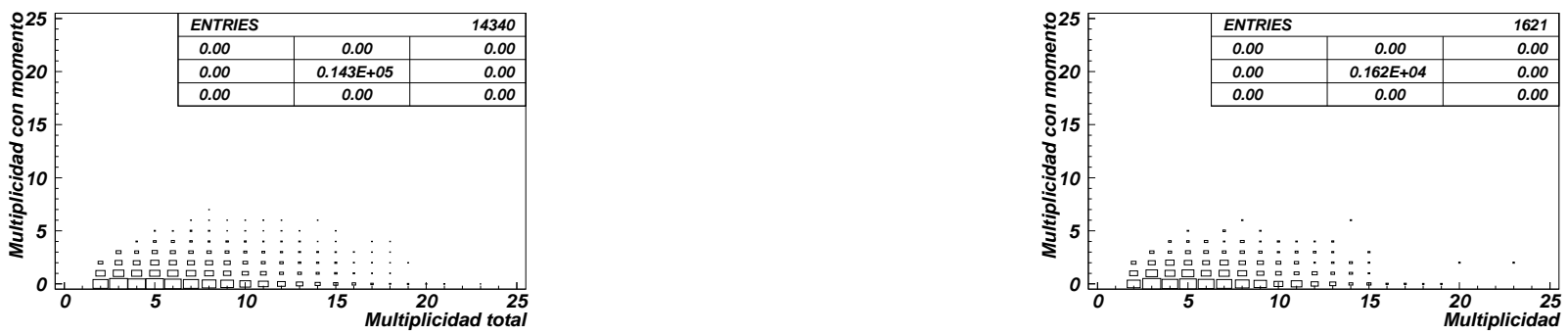

Figura 5.225: Multiplicidad total contra multiplicidad con momento medido. Izquierda: haz de bariones. Derecha: haz de mesones(pos $250 \mathrm{C}$ ).
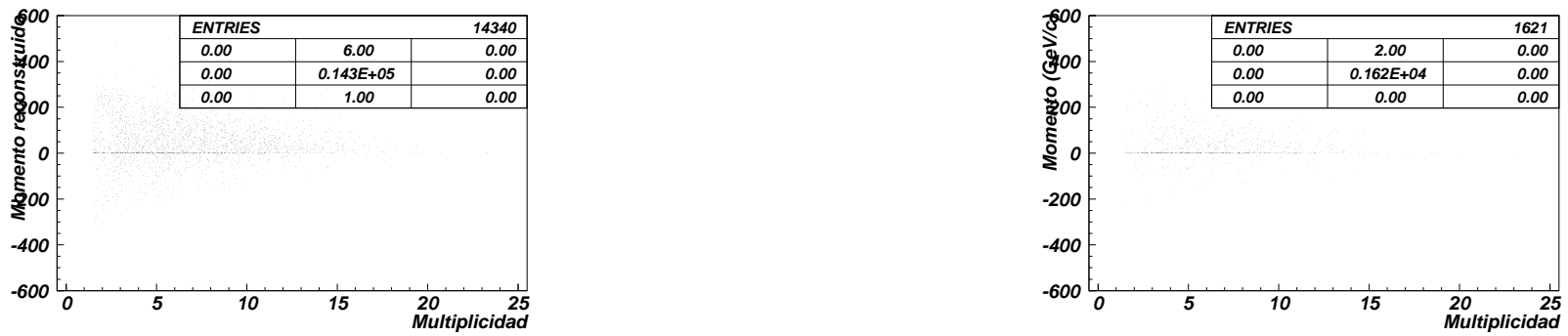

Figura 5.226: Multiplicidad contra momento.Izquierda: haz de bariones. Derecha: haz de mesones(pos $250 \mathrm{C})$. 
Distribuciones de momento total para eventos producidos por un haz de bariones
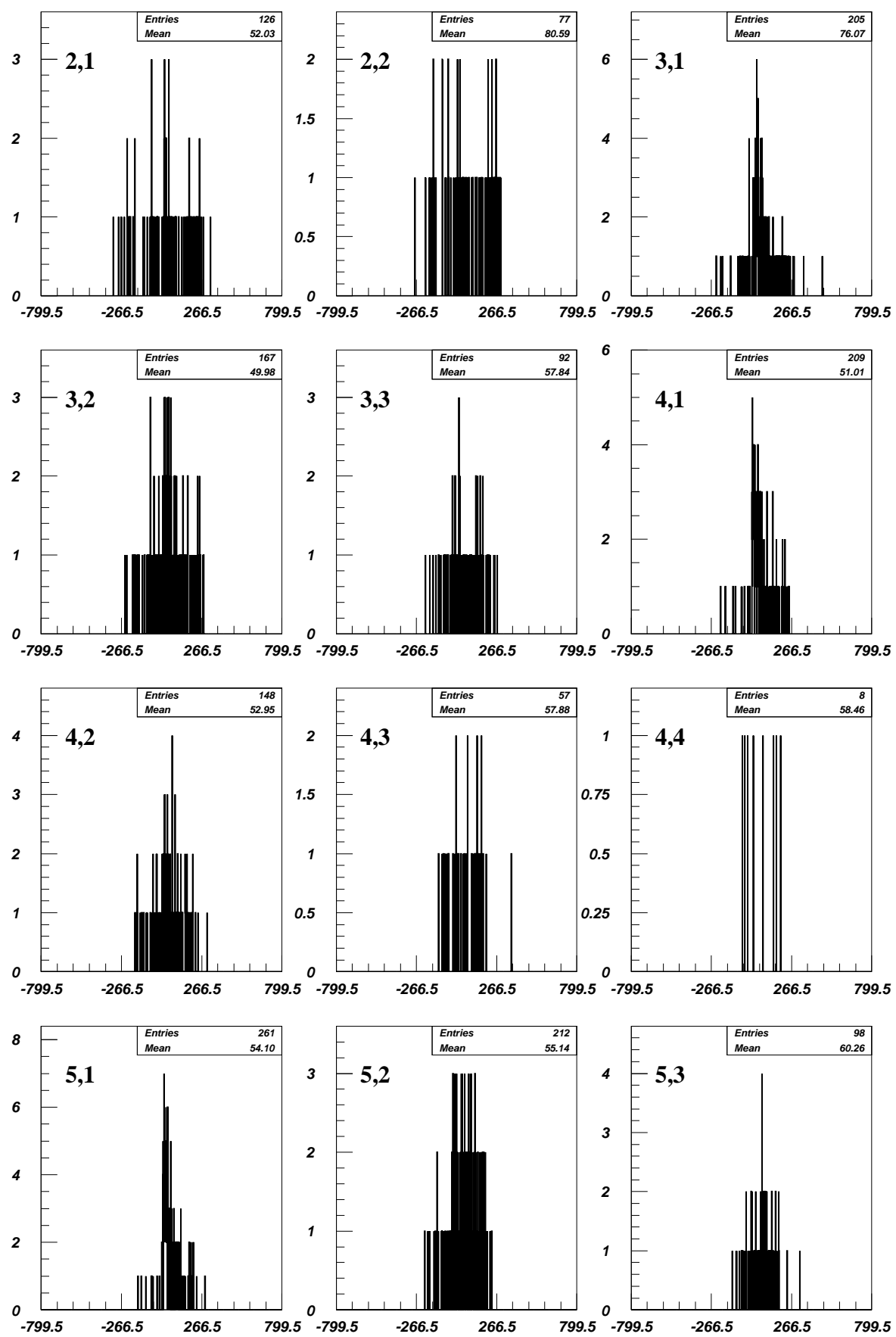

Figura 5.227: Distribuciones de momento. El primer indice: multiplicidad total, el segundo: multiplicidad con momento (pos $250 \mathrm{C}$ ) 

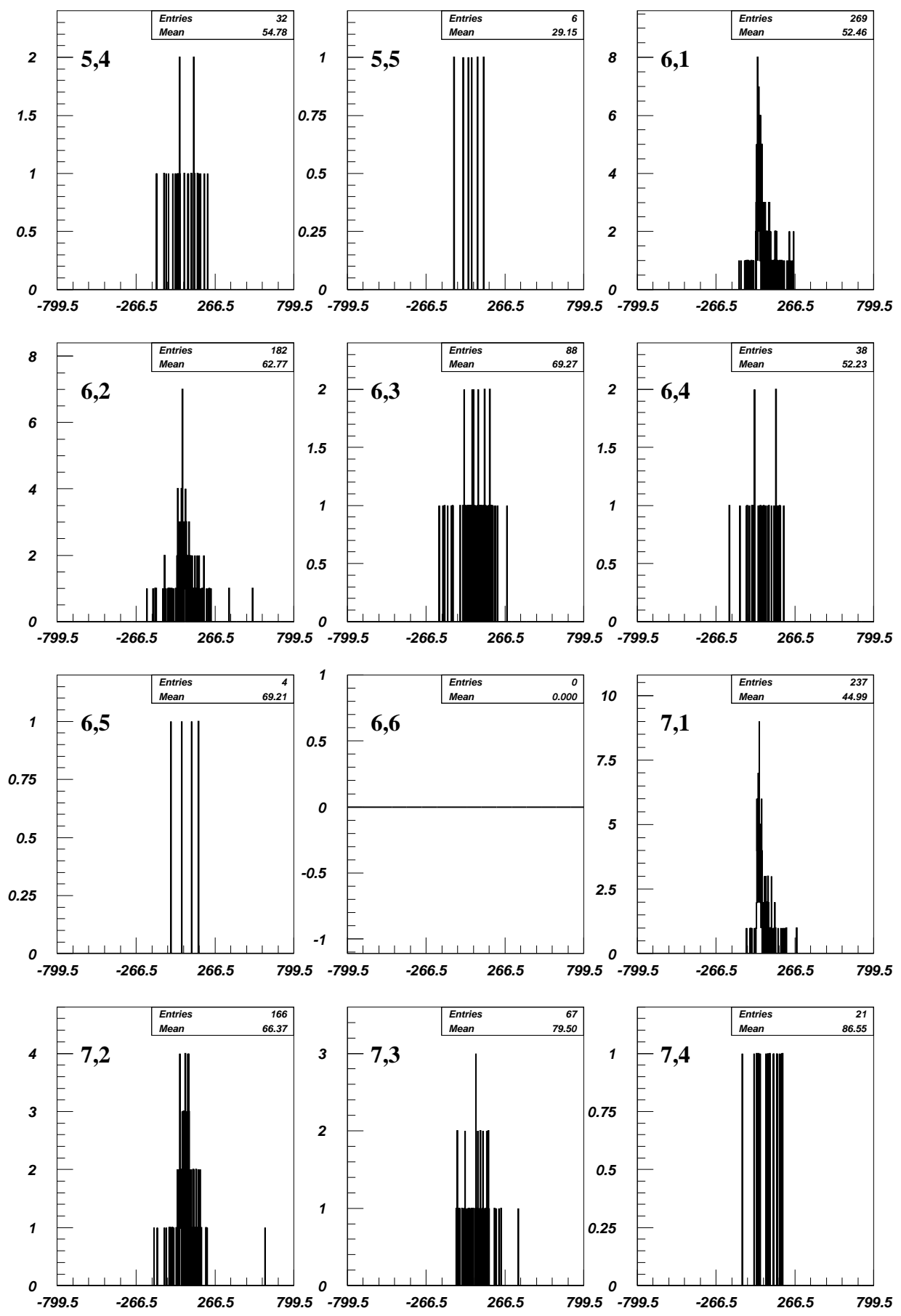

Figura 5.228: Distribuciones de momento. El primer índice: multiplicidad total, el segundo: multiplicidad con momento (pos $250 \mathrm{C}$ ). 

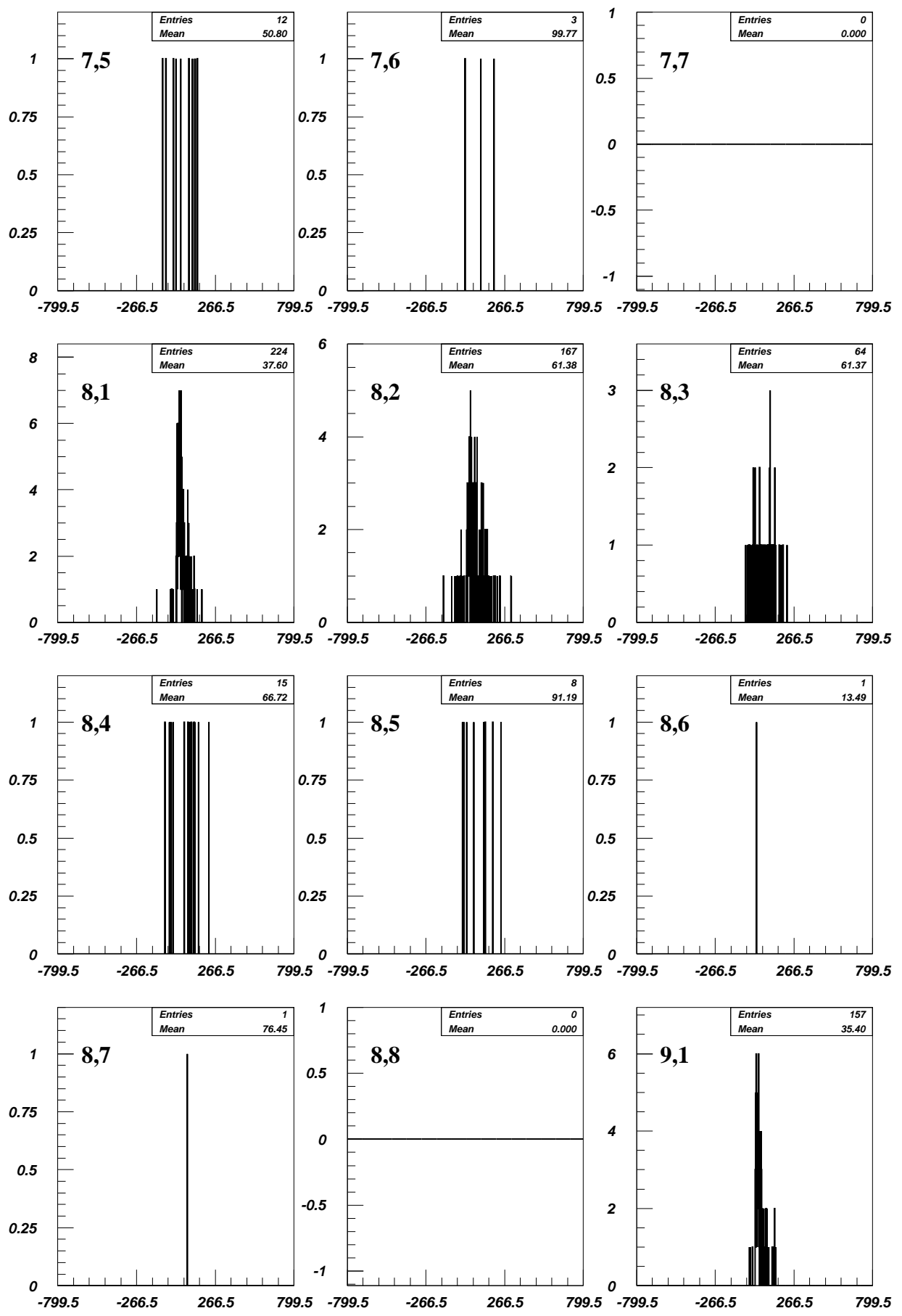

Figura 5.229: Distribuciones de momento. El primer índice: multiplicidad total, el segundo: multiplicidad con momento(pos $250 \mathrm{C})$. 

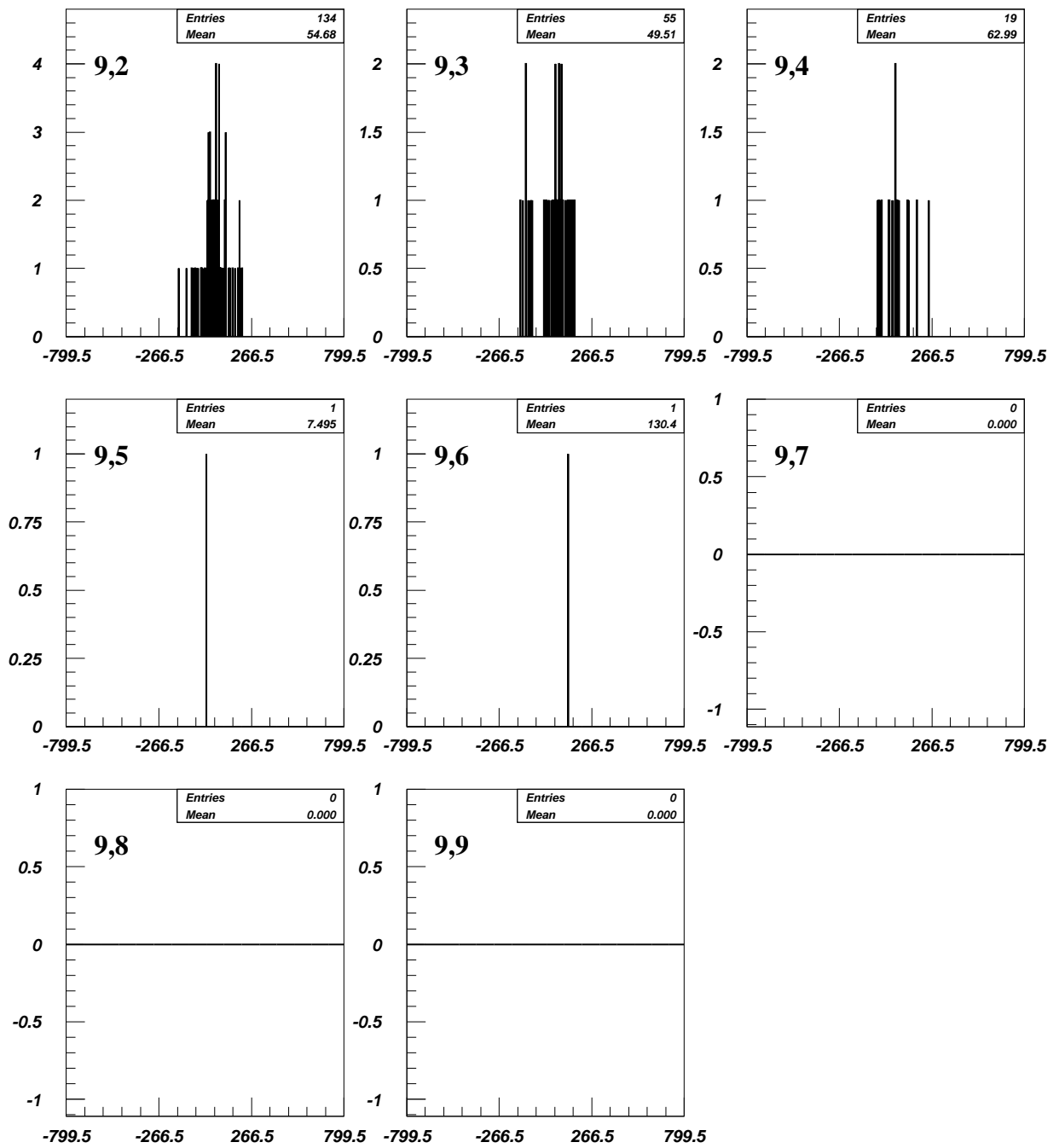

Figura 5.230: Distribuciones de momento. El primer índice: multiplicidad total, el segundo: multiplicidad con momento (pos $250 \mathrm{C}$ ). 
Distribuciones de momento total para eventos producidos por un haz de mesones
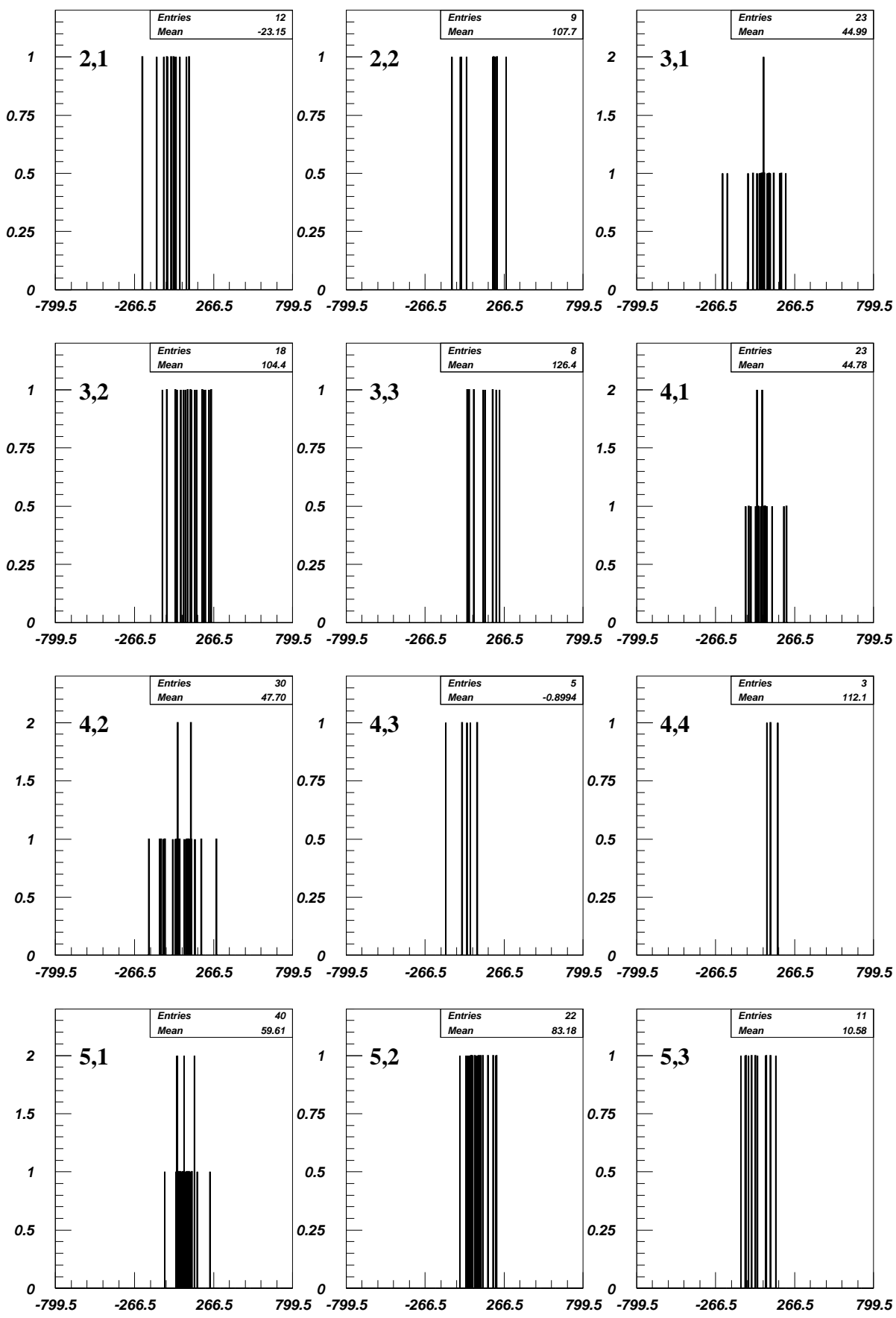

Figura 5.231: Distribuciones de momento. El primer indice: multiplicidad total, el segundo: multiplicidad con momento (pos $250 \mathrm{C}$ ). 

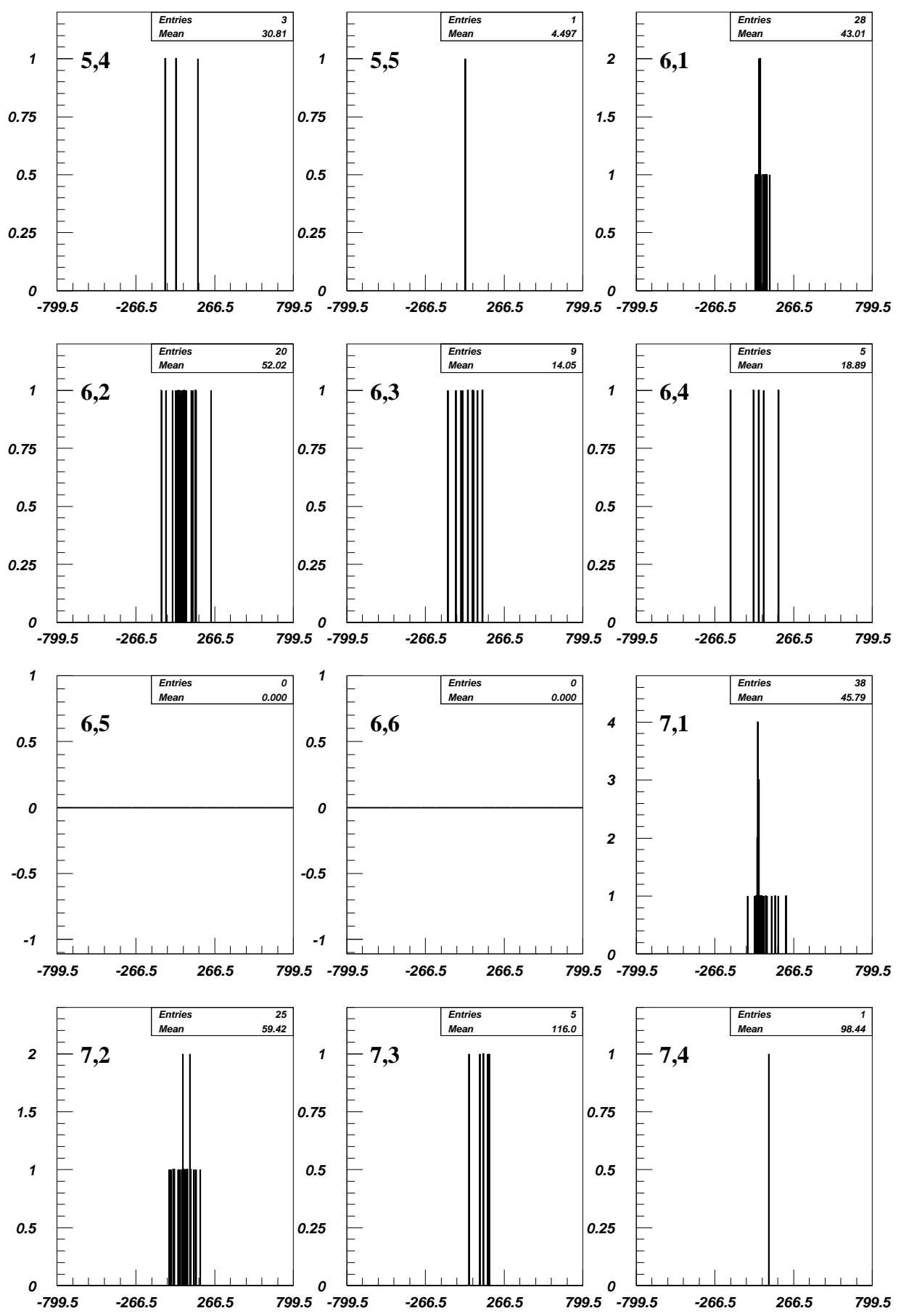

Figura 5.232: Distribuciones de momento. El primer índice: multiplicidad total, el segundo: multiplicidad con momento (pos $250 \mathrm{C}$ ). 

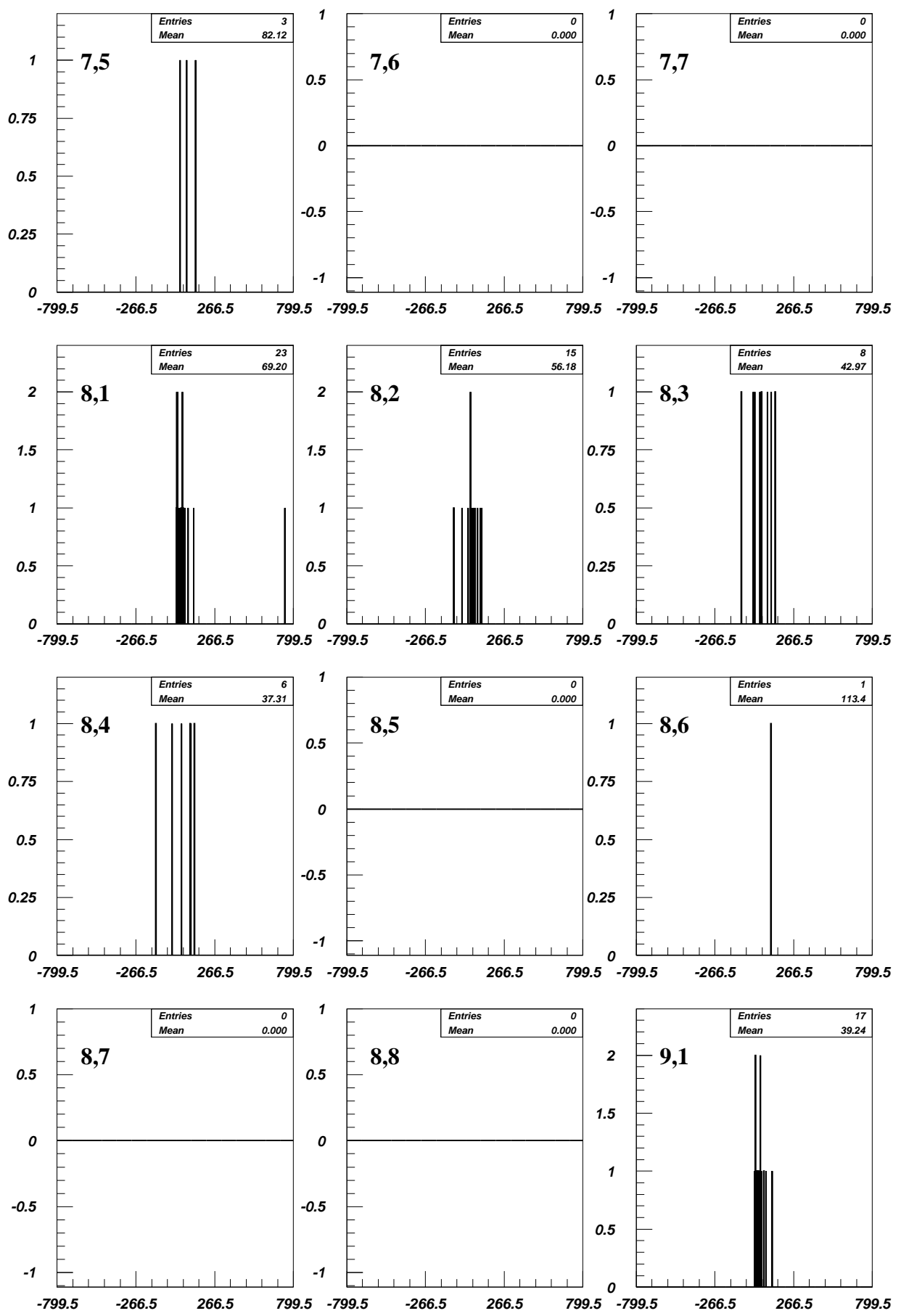

Figura 5.233: Distribuciones de momento. El primer índice: multiplicidad total, el segundo: multiplicidad con momento (pos $250 \mathrm{C}$ ). 

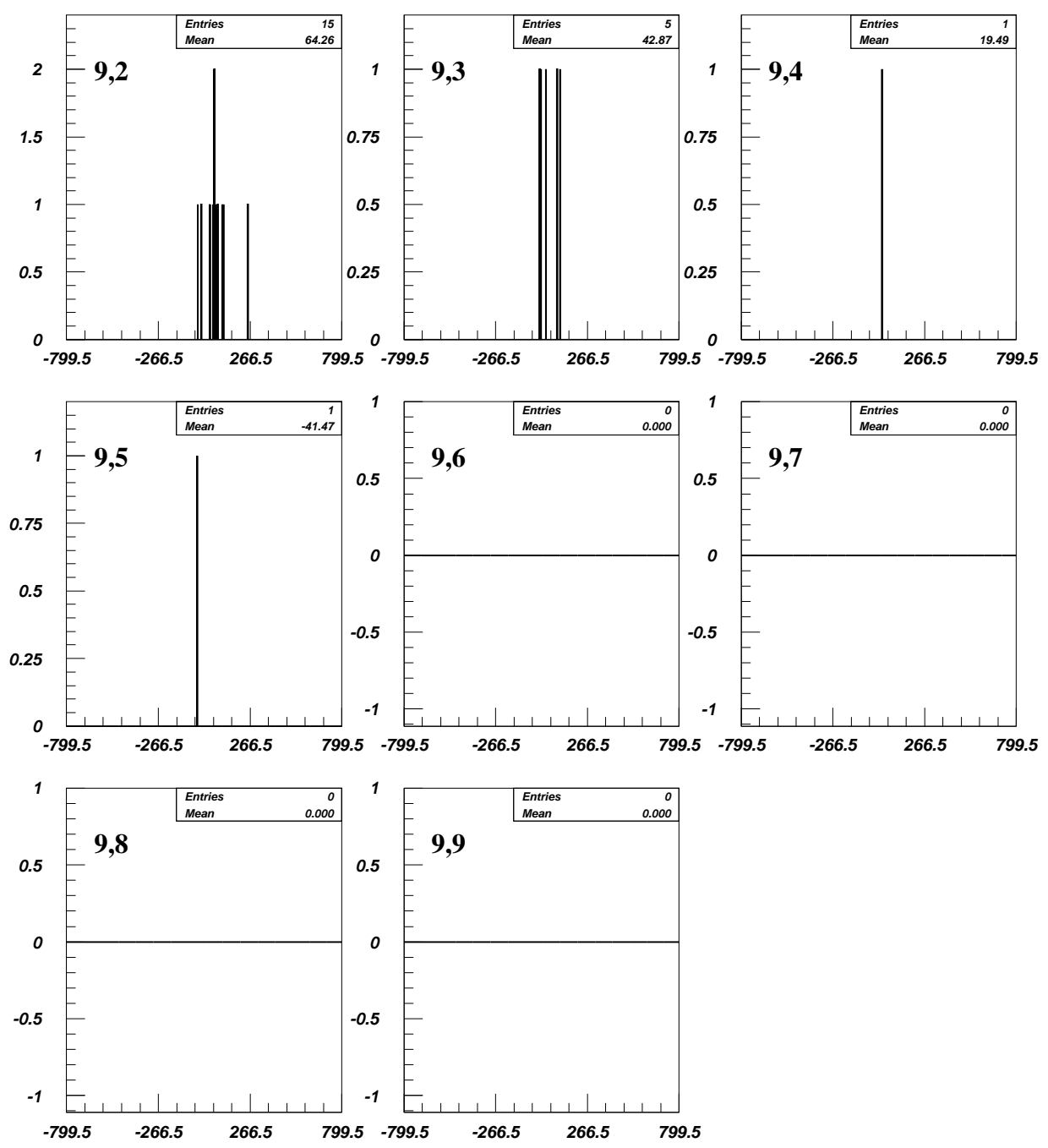

Figura 5.234: Distribuciones de momento. El primer índice: multiplicidad total, el segundo: multiplicidad con momento (pos $250 \mathrm{C}$ ). 
Distribuciones del valor absoluto del momento total para eventos producidos por un haz de bariones
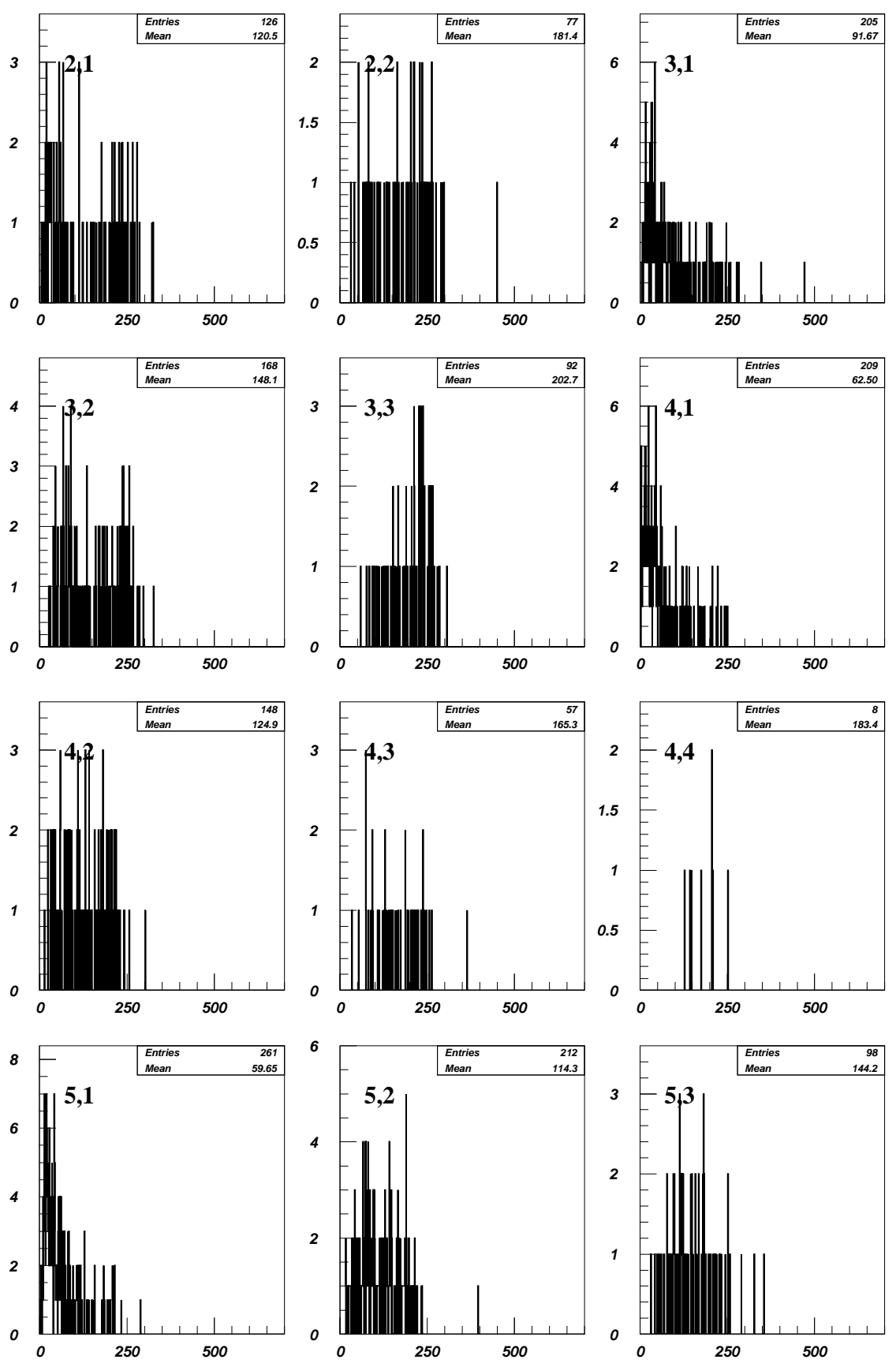

Figura 5.235: Distribuciones de momento. El primer indice: multiplicidad total, el segundo: multiplicidad con momento (pos $250 \mathrm{C}$ ). 

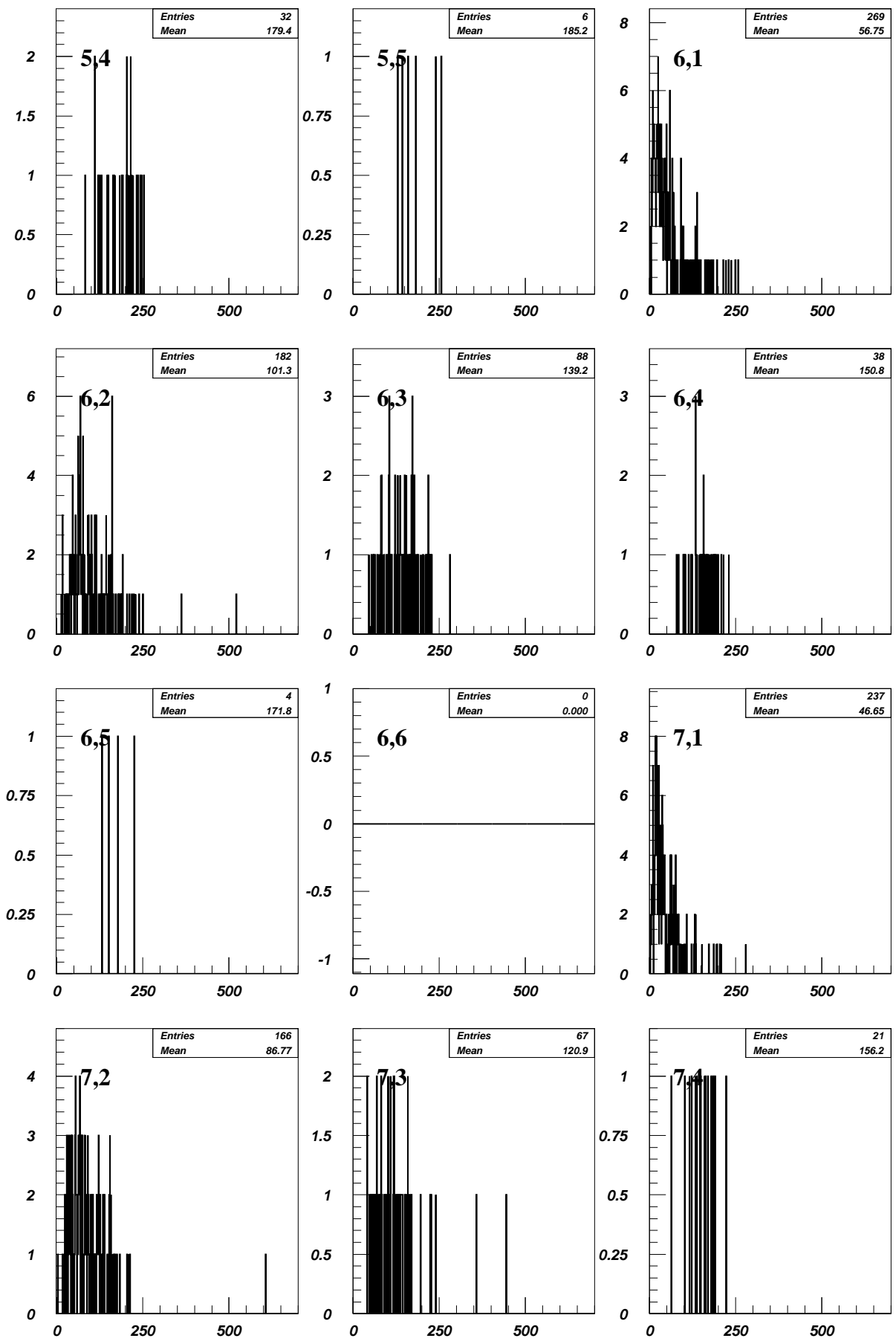

Figura 5.236: Distribuciones de momento. El primer índice: multiplicidad total, el segundo: multiplicidad con momento (pos $250 \mathrm{C}$ ). 

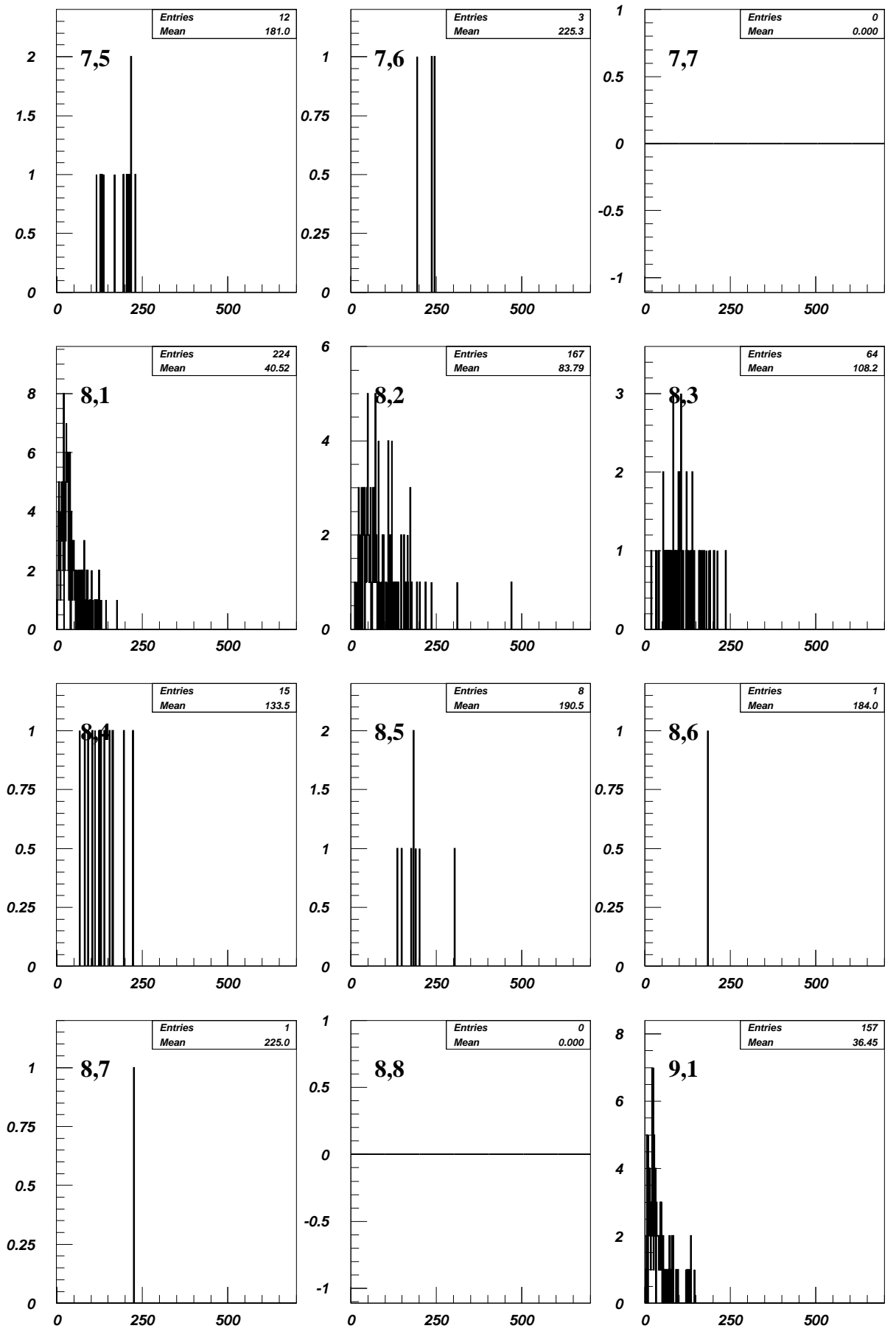

Figura 5.237: Distribuciones de momento. El primer índice: multiplicidad total, el segundo: multiplicidad con momento (pos $250 \mathrm{C}$ ). 

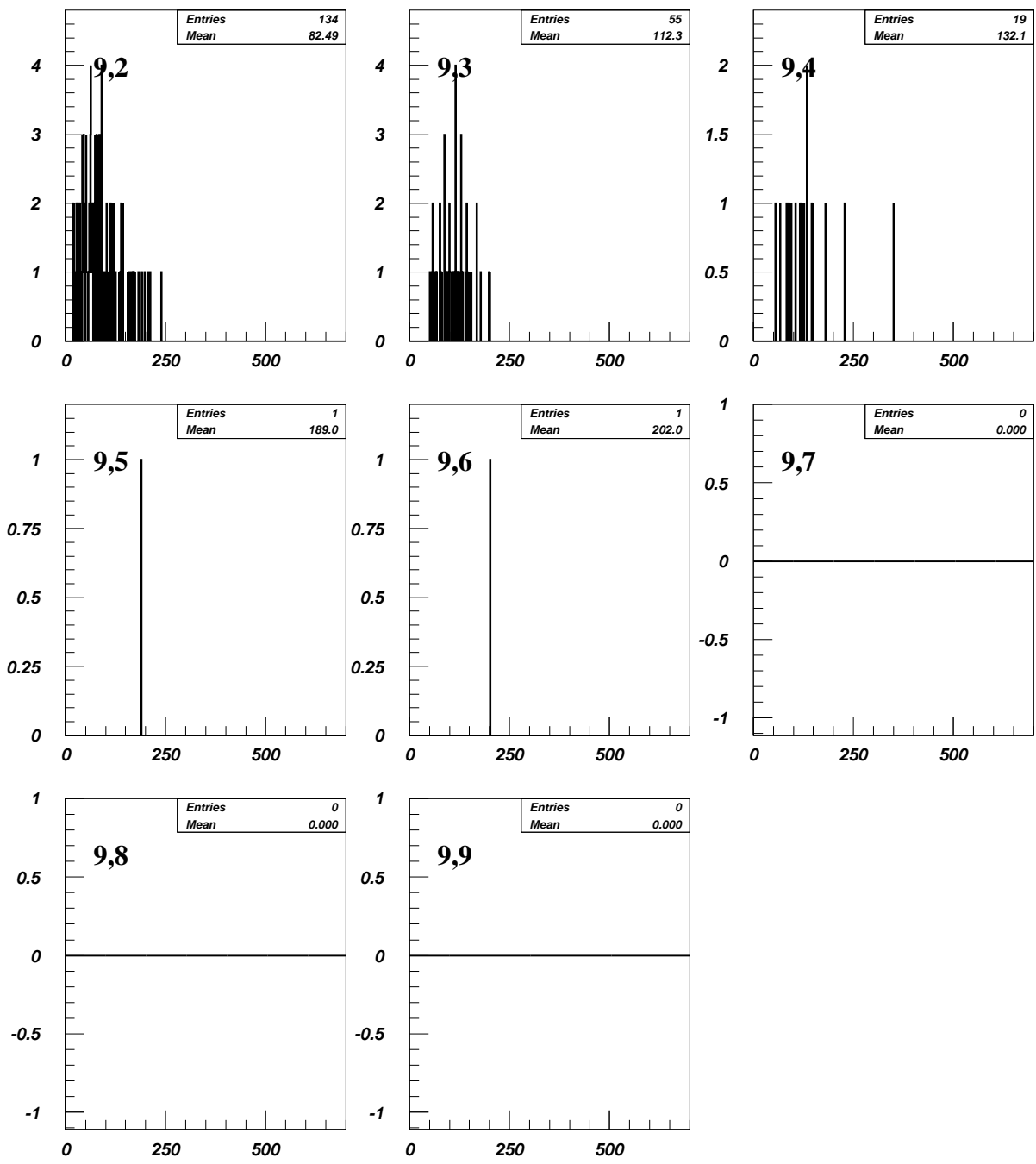

Figura 5.238: Distribuciones de momento. El primer índice: multiplicidad total, el segundo: multiplicidad con momento (pos $250 \mathrm{C}$ ). 
Distribuciones del valor absoluto del momento total para eventos producidos por un haz de mesones
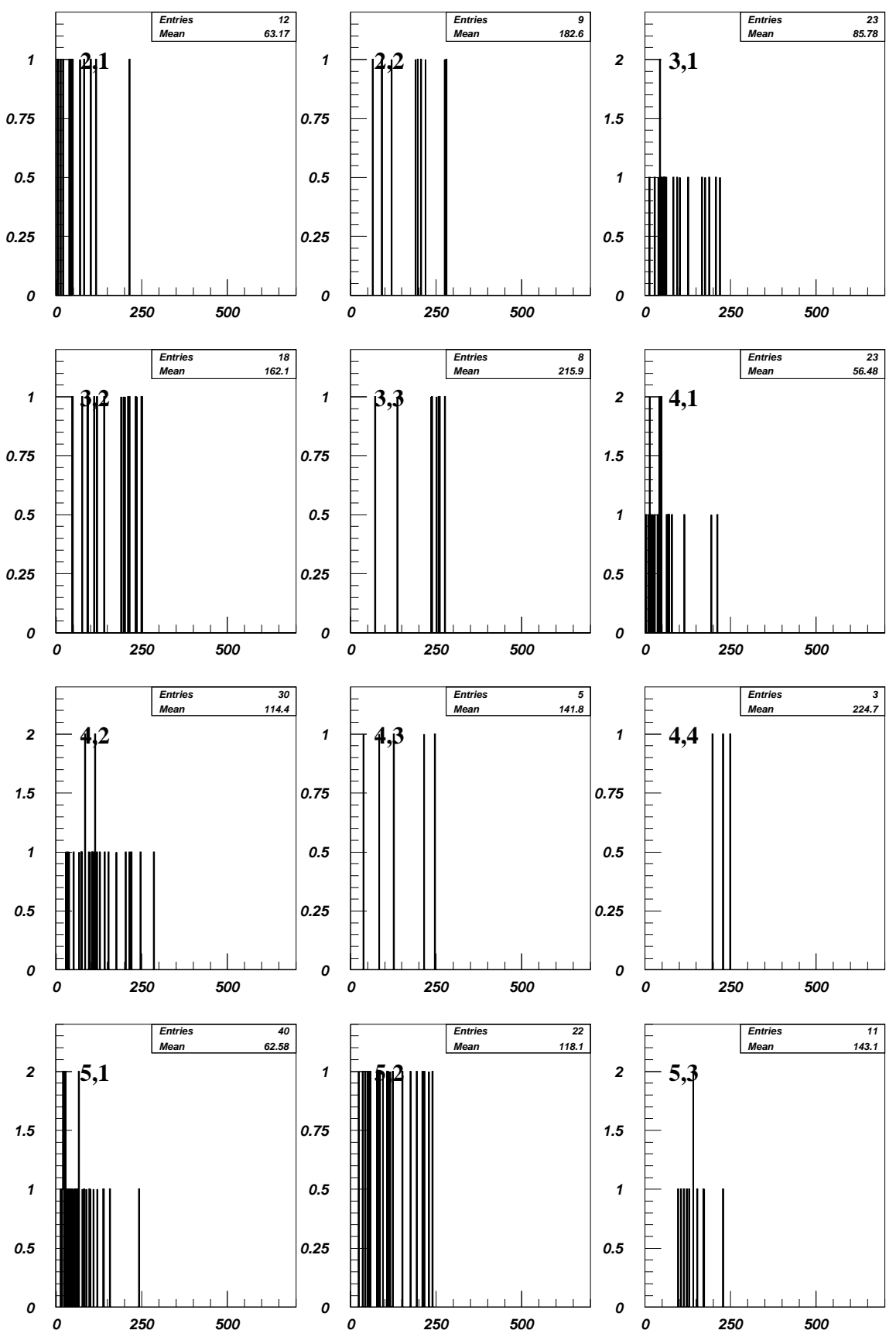

Figura 5.239: Distribuciones de momento. El primer indice: multiplicidad total, el segundo: multiplicidad con momento (pos $250 \mathrm{C}$ ). 

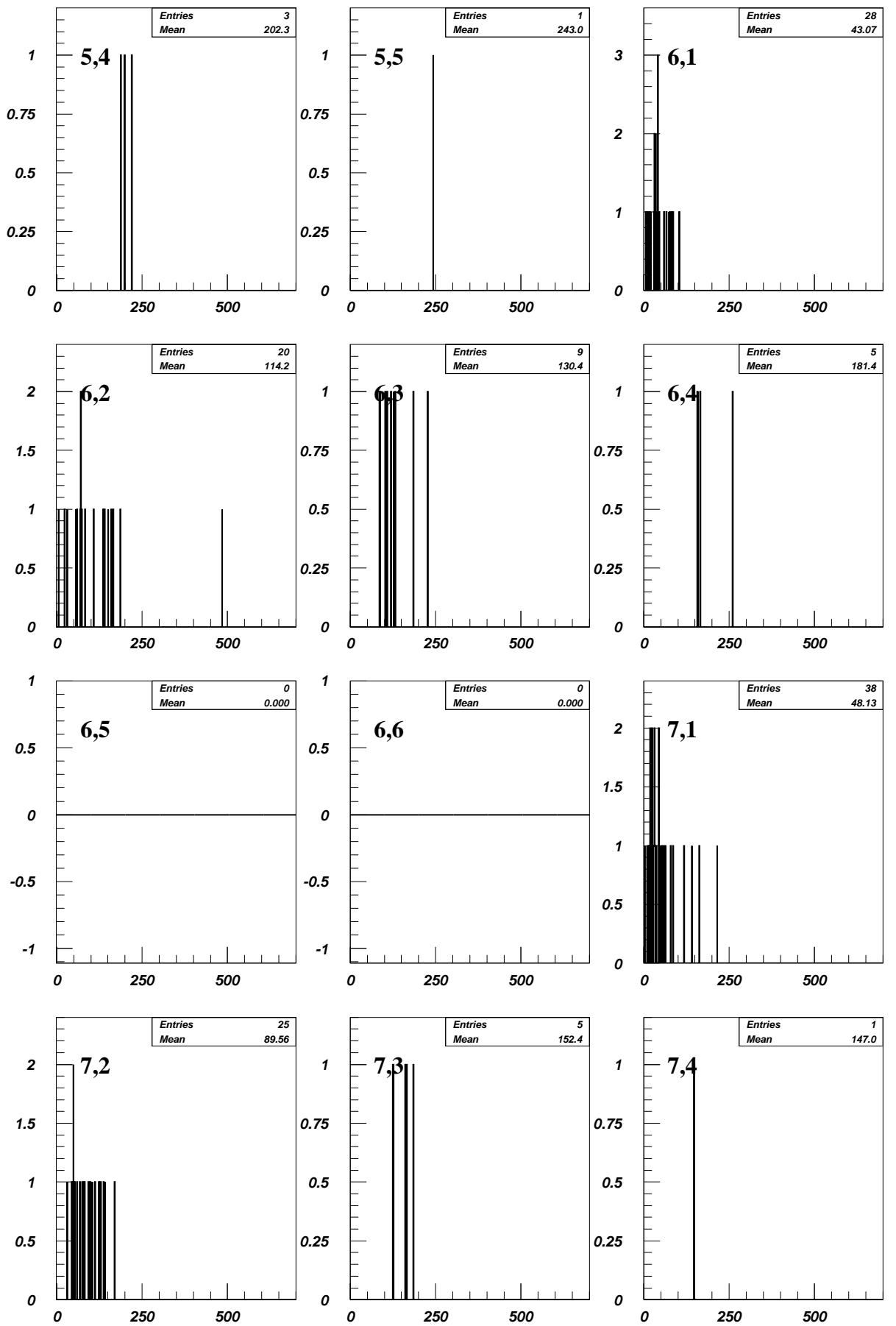

Figura 5.240: Distribuciones de momento. El primer índice: multiplicidad total, el segundo: multiplicidad con momento (pos $250 \mathrm{C}$ ). 

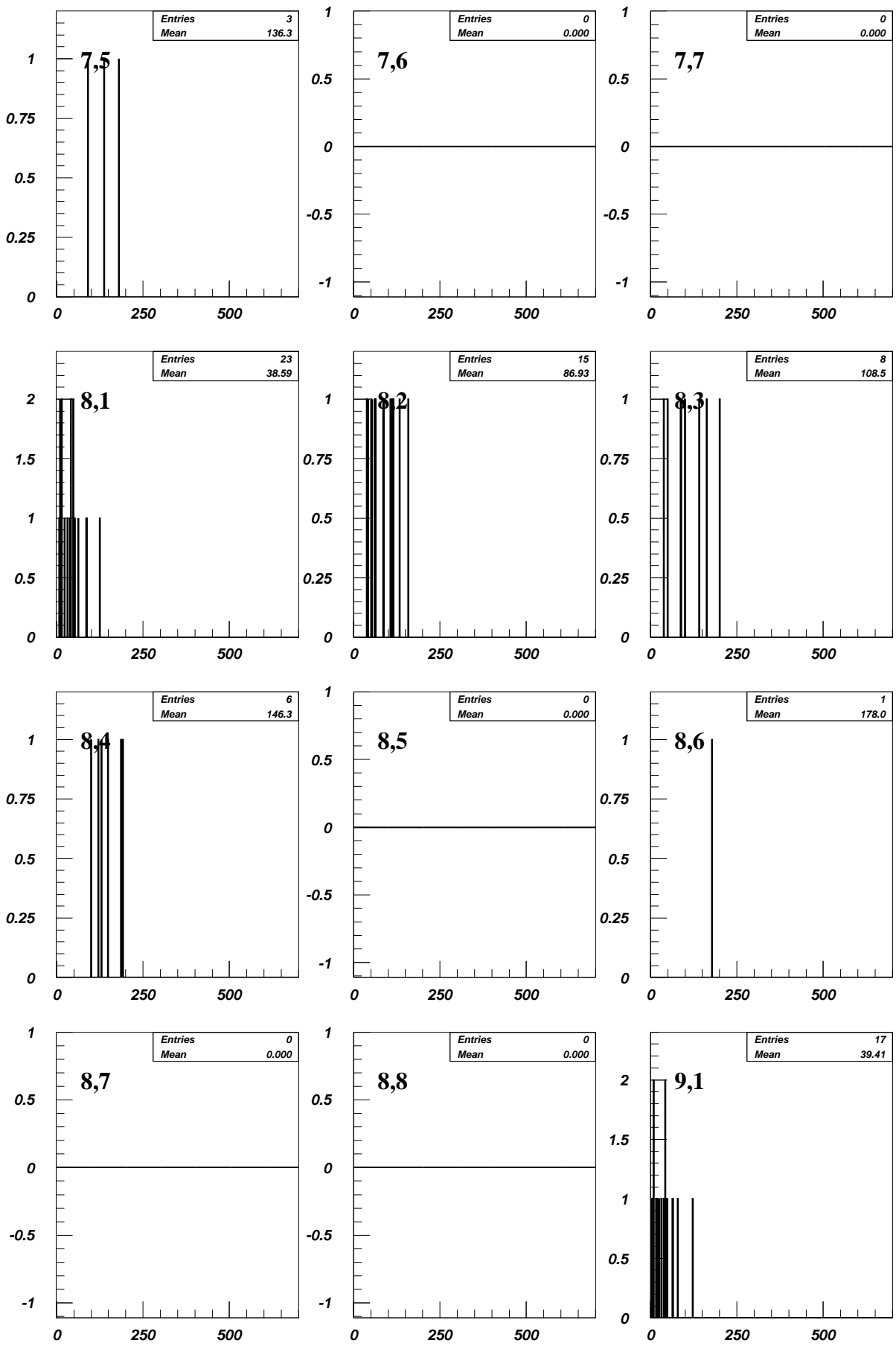

Figura 5.241: Distribuciones de momento. El primer índice: multiplicidad total, el segundo: multiplicidad con momento (pos $250 \mathrm{C}$ ). 

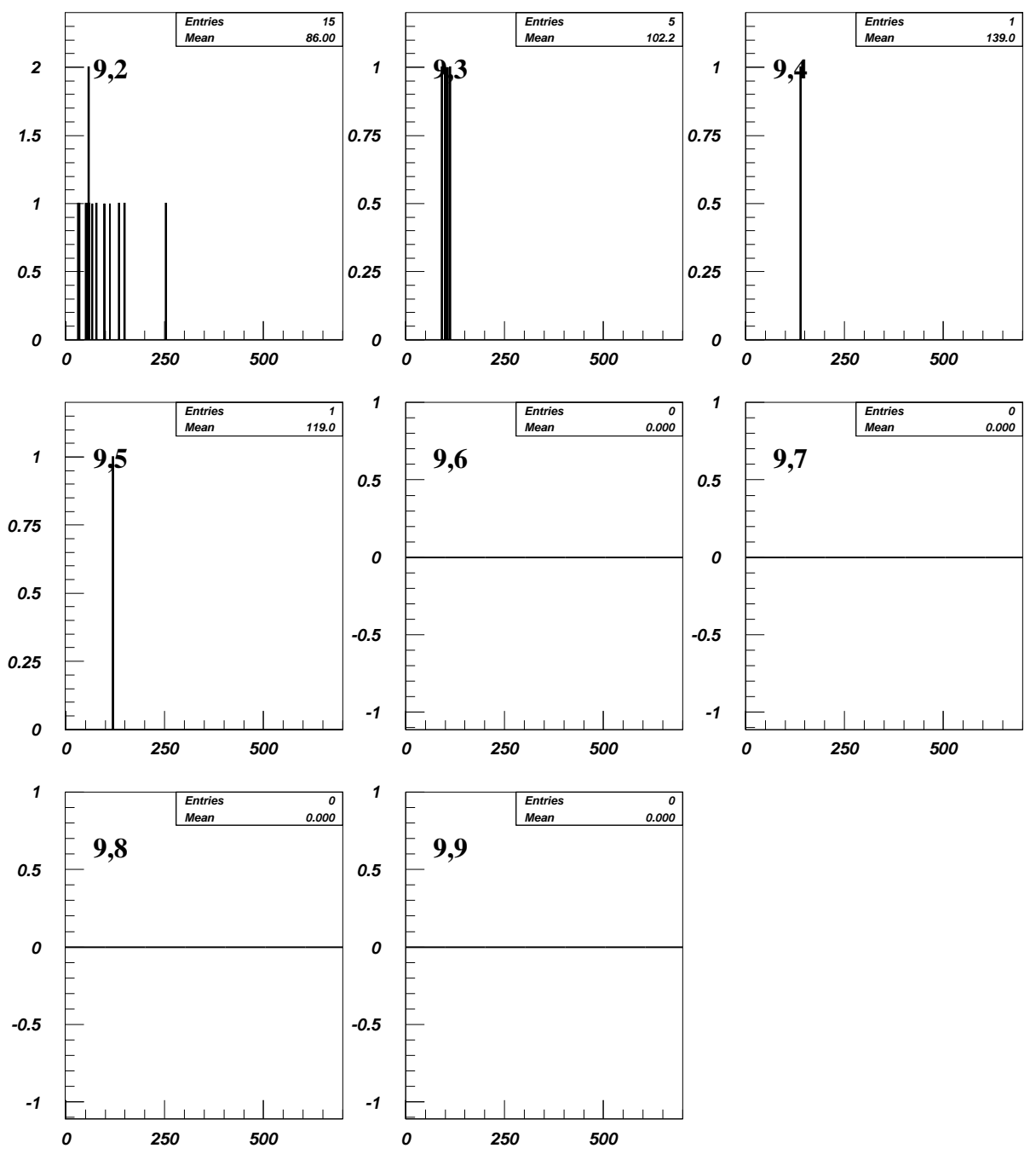

Figura 5.242: Distribuciones de momento. El primer índice: multiplicidad total, el segundo: multiplicidad con momento (pos $250 \mathrm{C}$ ). 
Distribuciones del momento de las trayectorias para eventos producidos por un haz de bariones
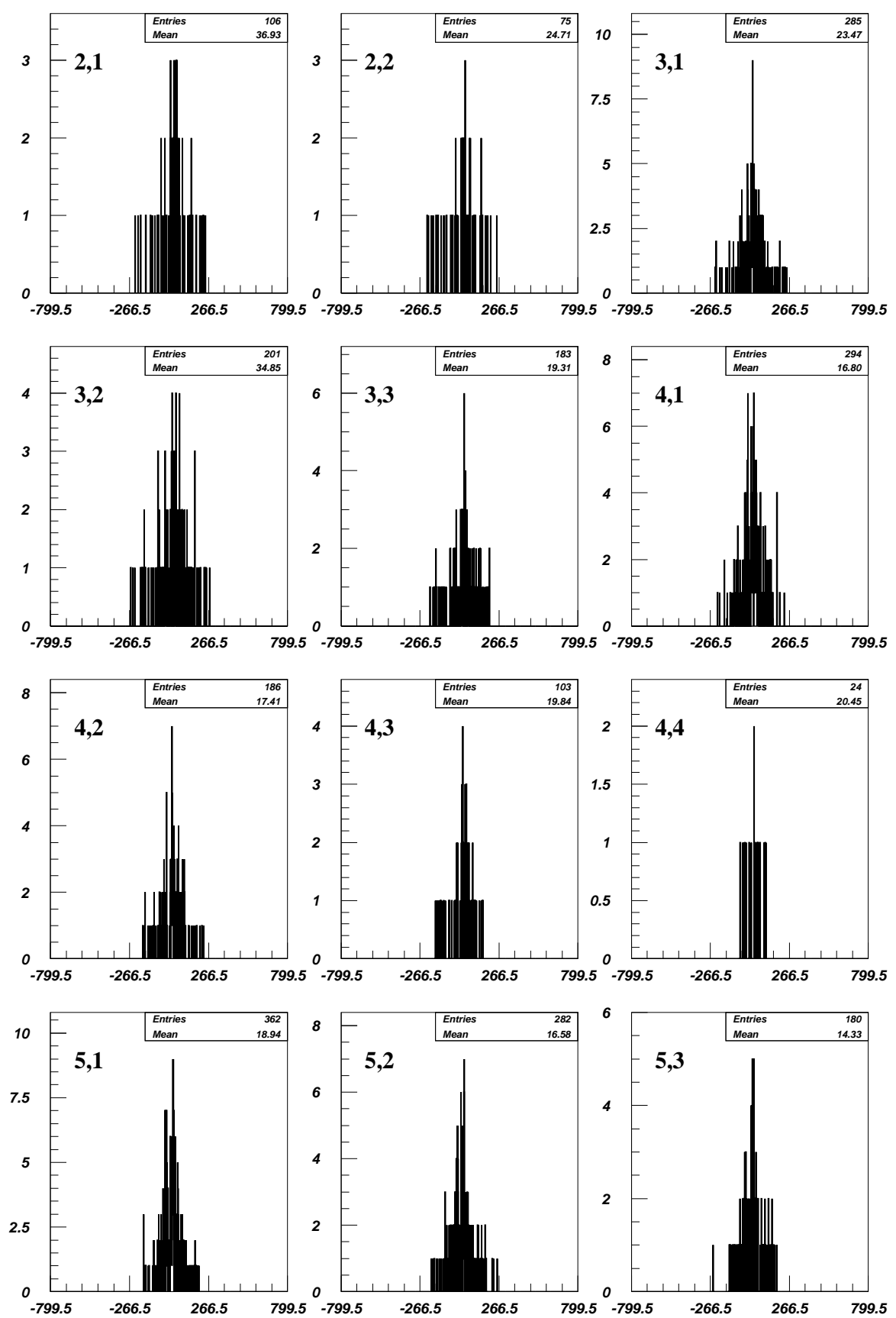

Figura 5.243: Distribuciones de momento. El primer indice: multiplicidad total, el segundo: multiplicidad con momento (pos $250 \mathrm{C}$ ) 

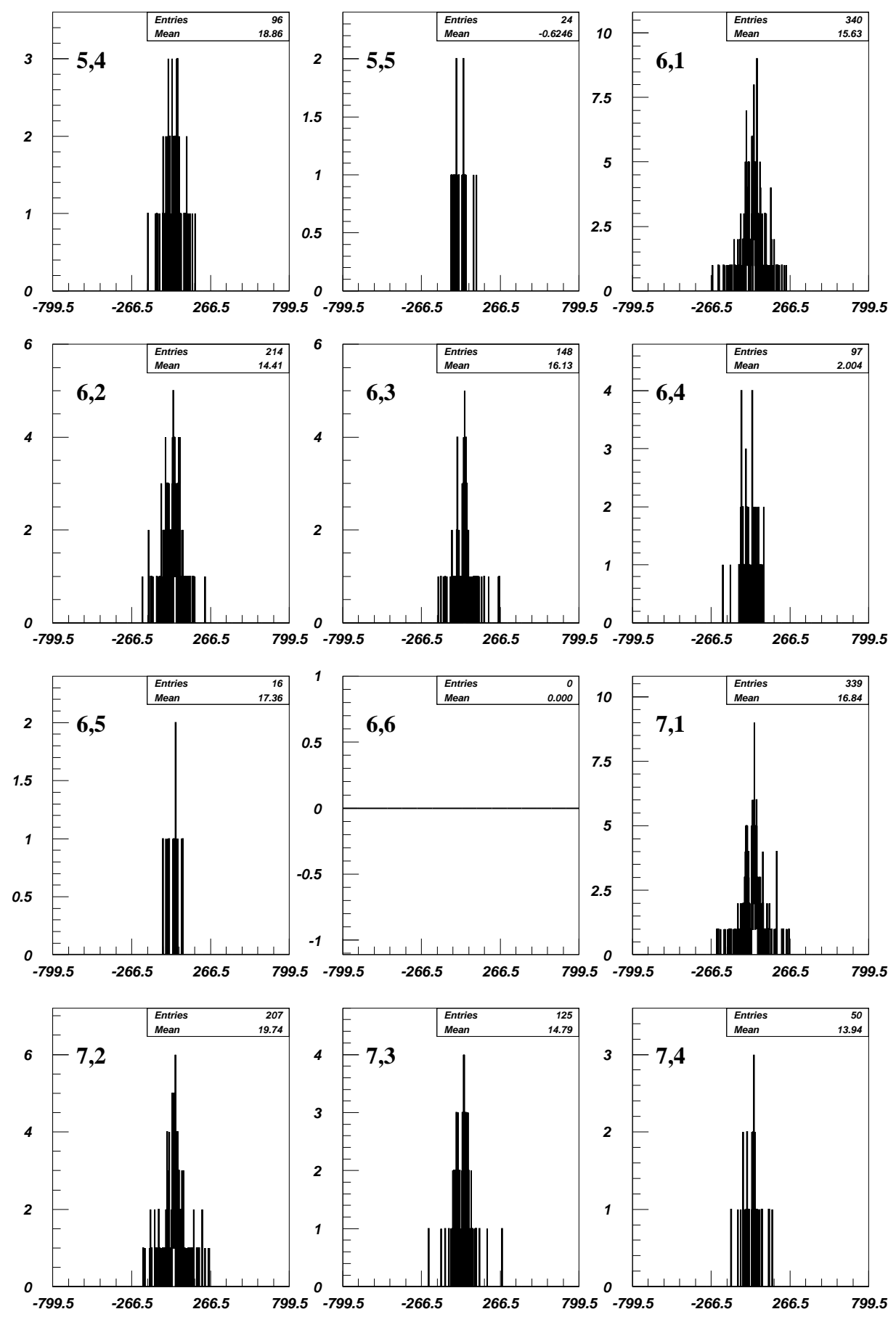

Figura 5.244: Distribuciones de momento. El primer índice: multiplicidad total, el segundo: multiplicidad con momento (pos $250 \mathrm{C}$ ). 

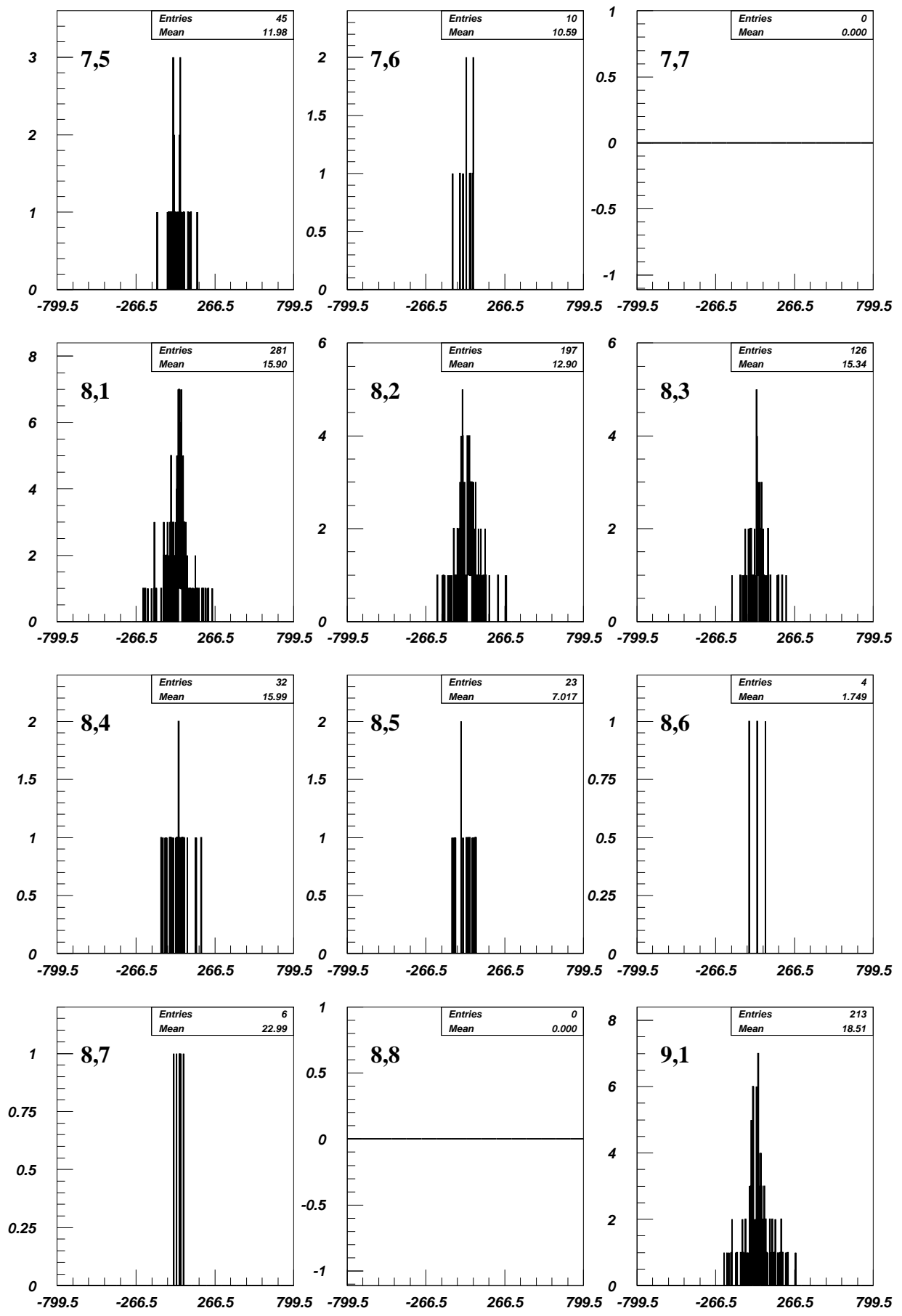

Figura 5.245: Distribuciones de momento. El primer índice: multiplicidad total, el segundo: multiplicidad con momento (pos $250 \mathrm{C}$ ). 

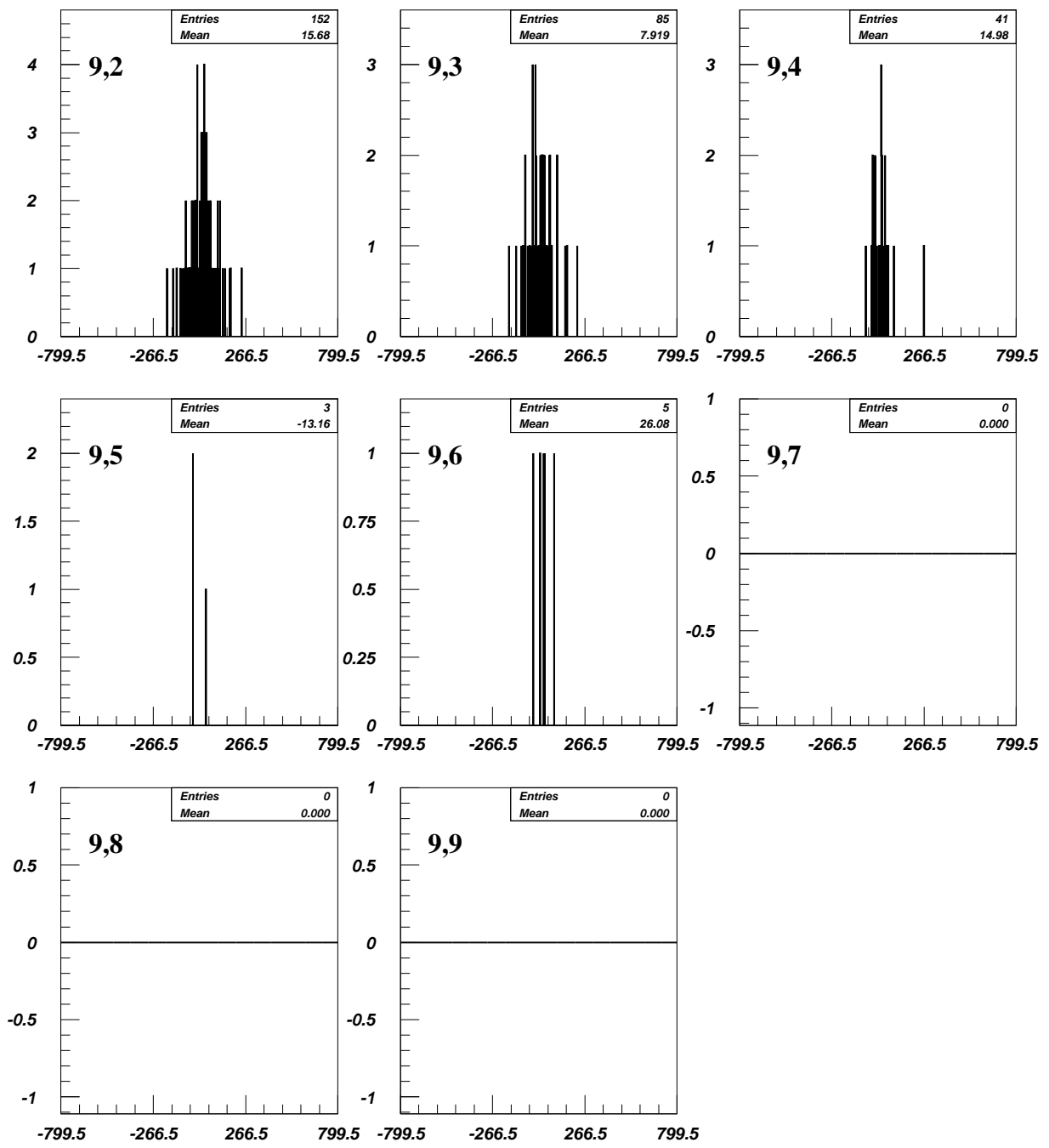

Figura 5.246: Distribuciones de momento. El primer índice: multiplicidad total, el segundo: multiplicidad con momento (pos $250 \mathrm{C}$ ). 
Distribuciones del momento de las trayectorias para eventos producidos por un haz de mesones
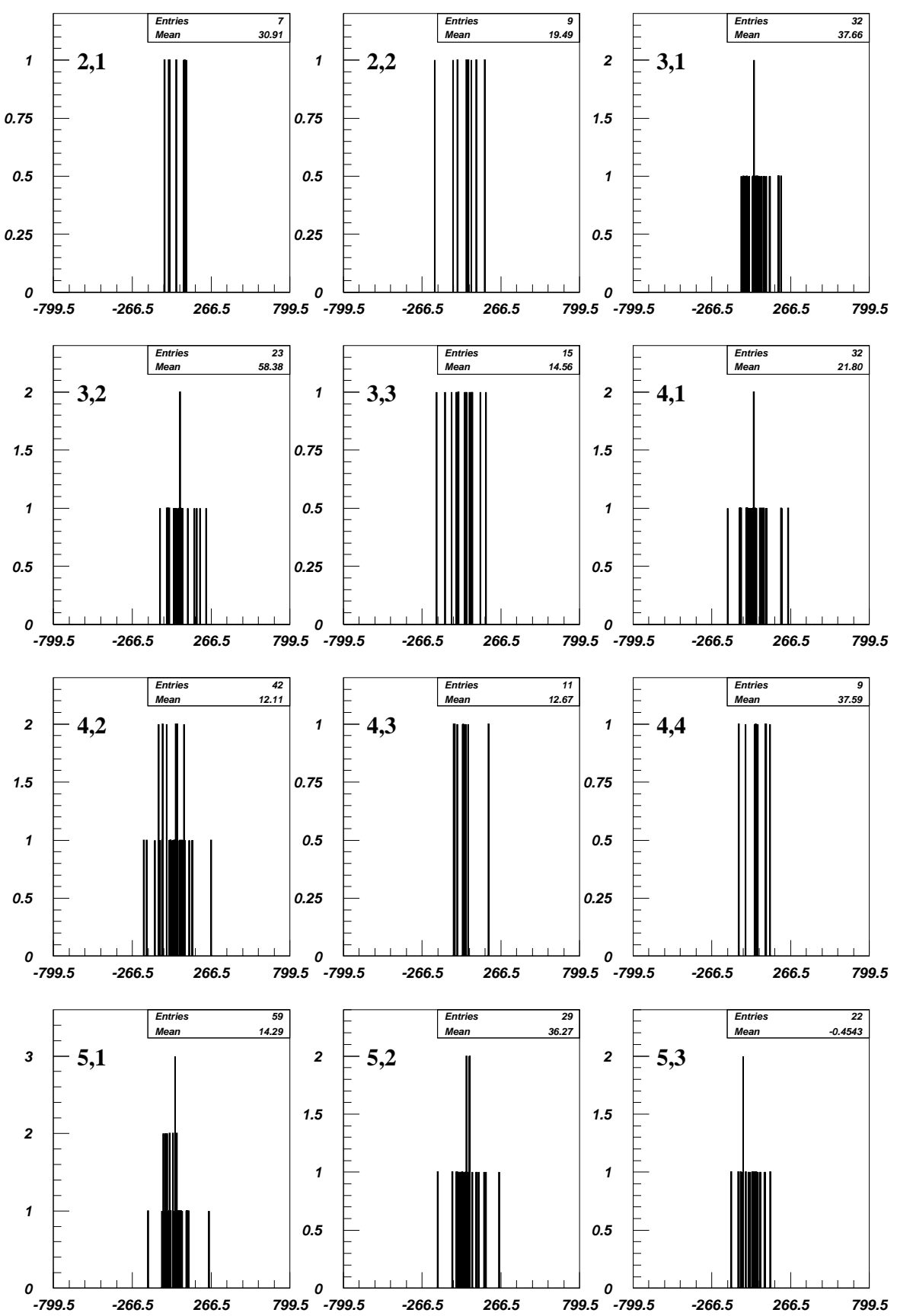

Figura 5.247: Distribuciones de momento. El primer indice: multiplicidad total, el segundo: multiplicidad con momento (pos $250 \mathrm{C}$ ) 

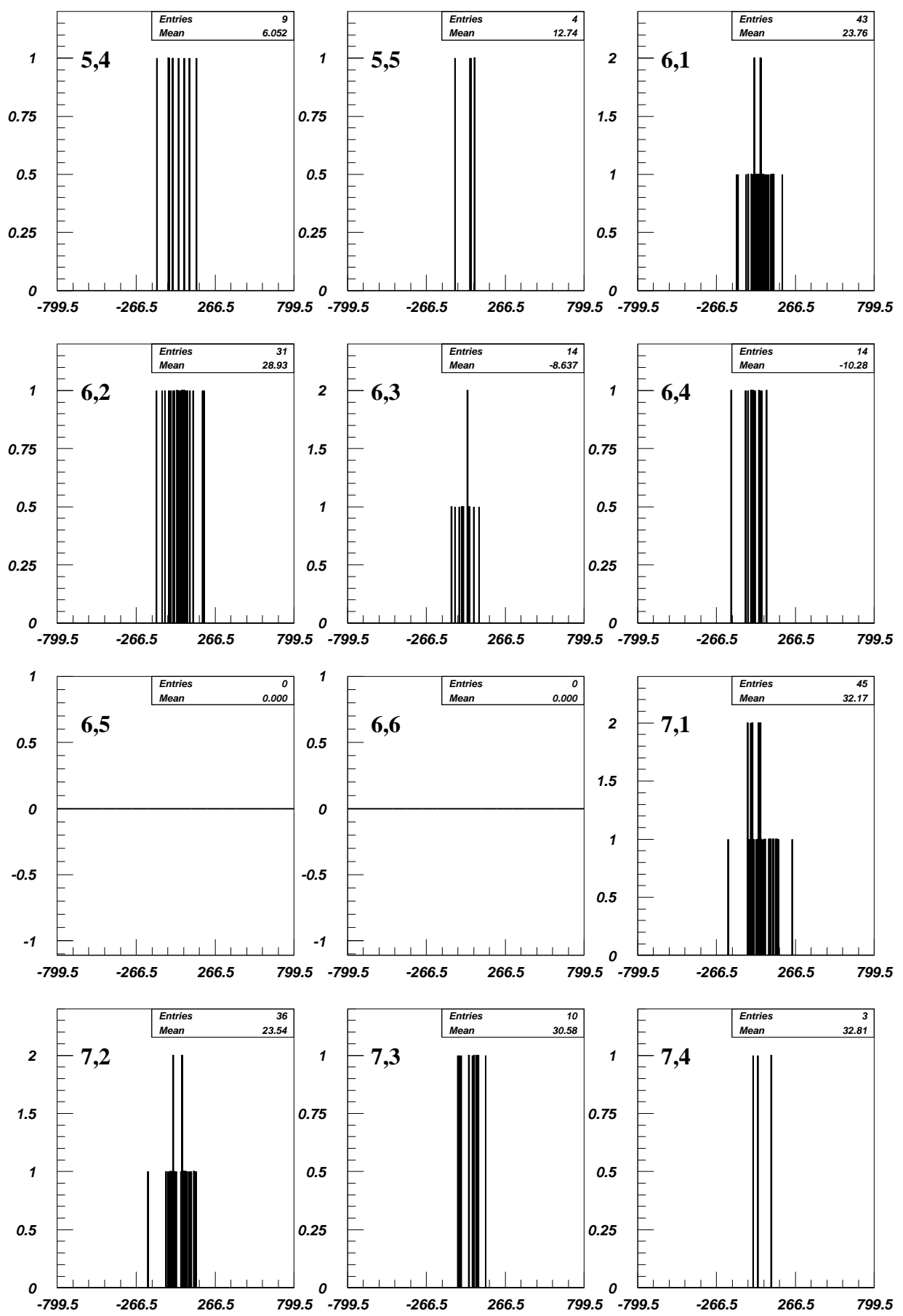

Figura 5.248: Distribuciones de momento. El primer índice: multiplicidad total, el segundo: multiplicidad con momento (pos $250 \mathrm{C}$ ). 

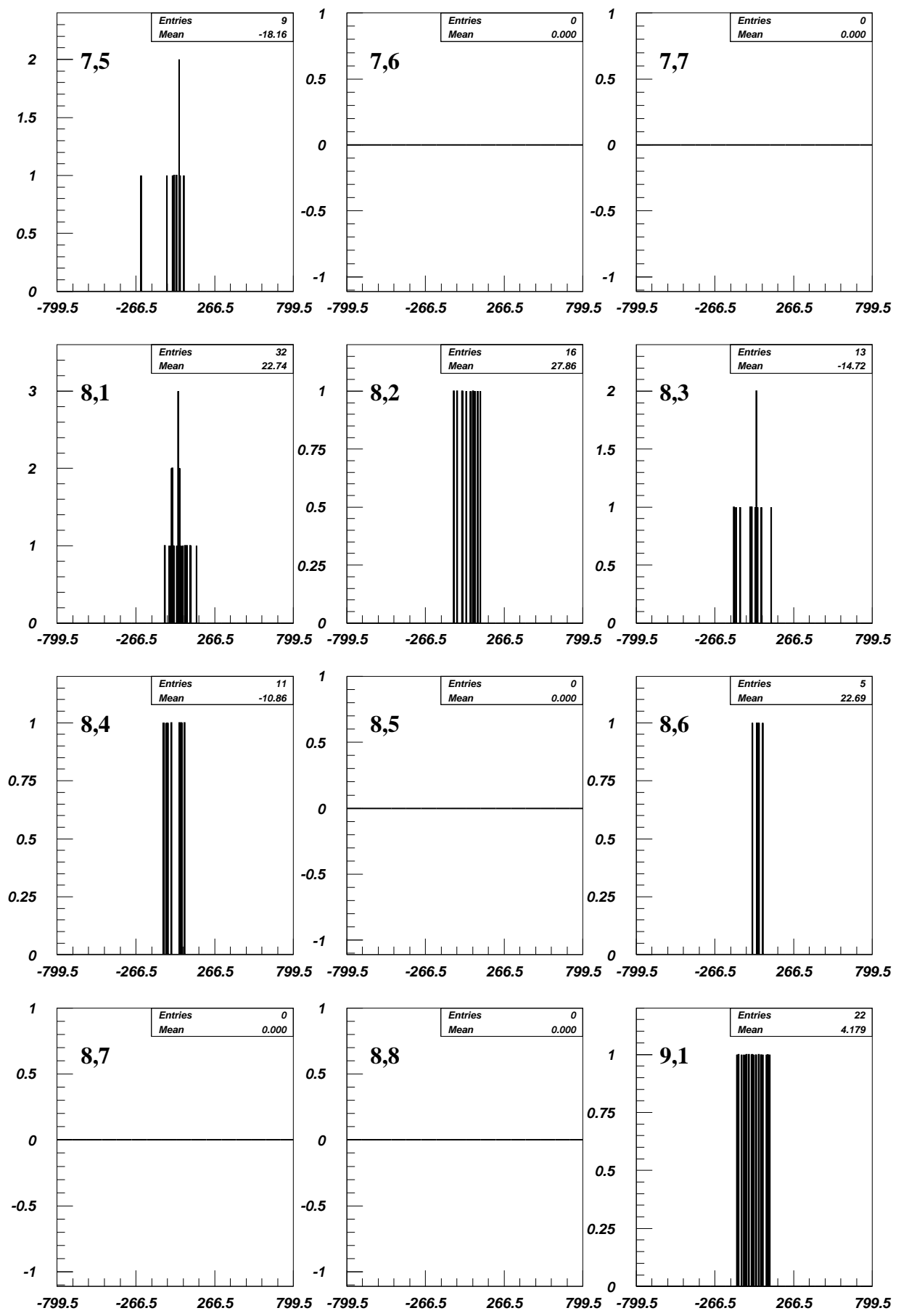

Figura 5.249: Distribuciones de momento. El primer índice: multiplicidad total, el segundo: multiplicidad con momento (pos $250 \mathrm{C}$ ). 

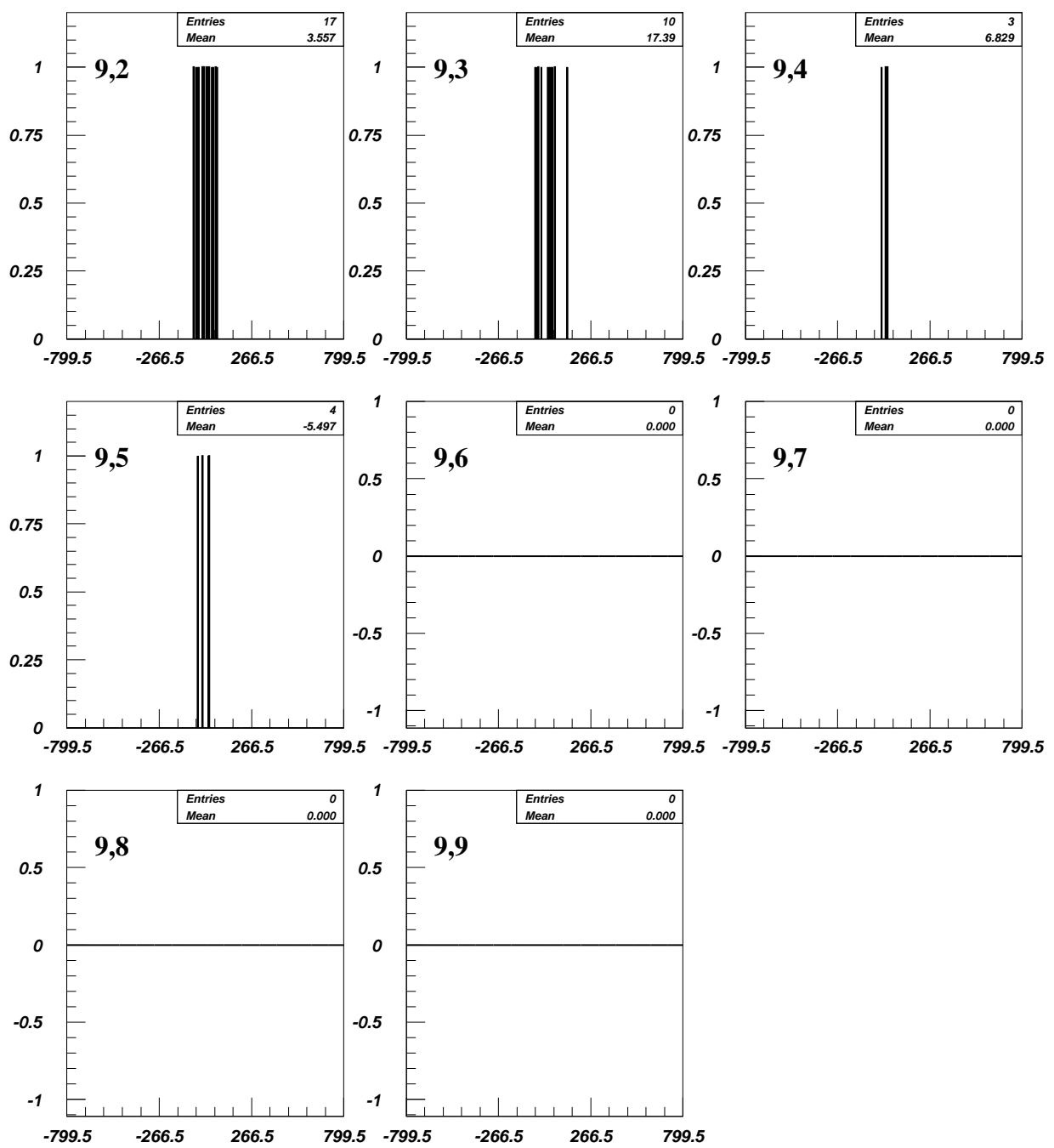

Figura 5.250: Distribuciones de momento. El primer índice: multiplicidad total, el segundo: multiplicidad con momento (pos $250 \mathrm{C}$ ). 


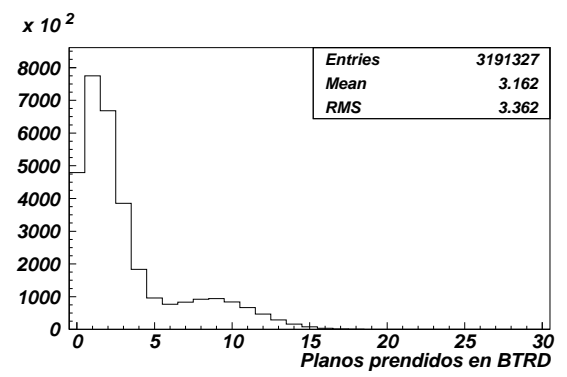

Figura 5.252: Planos prendidos en BTRD. Proporción bariónica y mesónica del haz primario (pos $375 \mathrm{C})$.
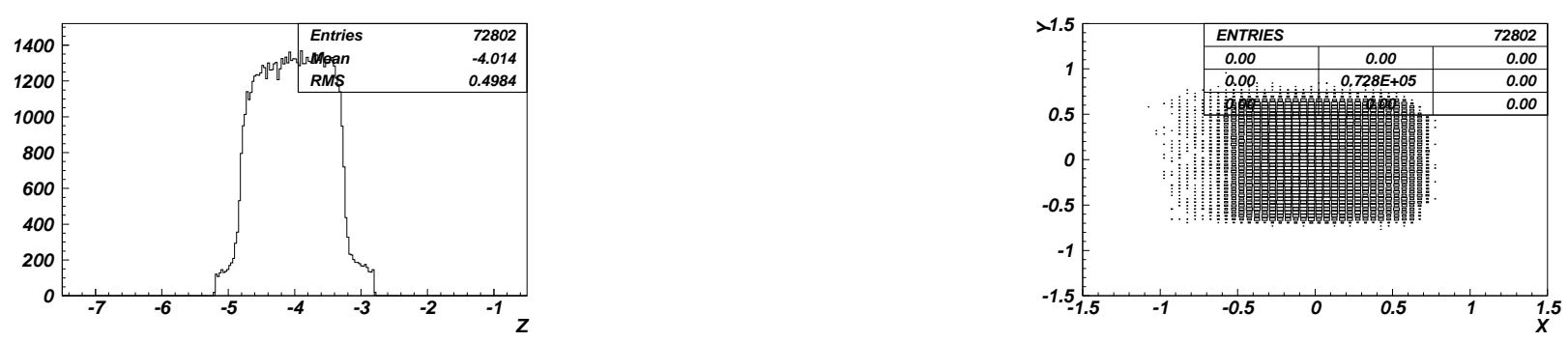

Figura 5.253: Vértice primario. Izquierda: coordenada z. Derecha: proyección x,y (pos 375 C). 
5.10. Haz de polaridad positiva, con momento $375 \mathrm{GeV}$, con blanco de producción para el haz secundario de carbón

5.10.1. Histogramas de control
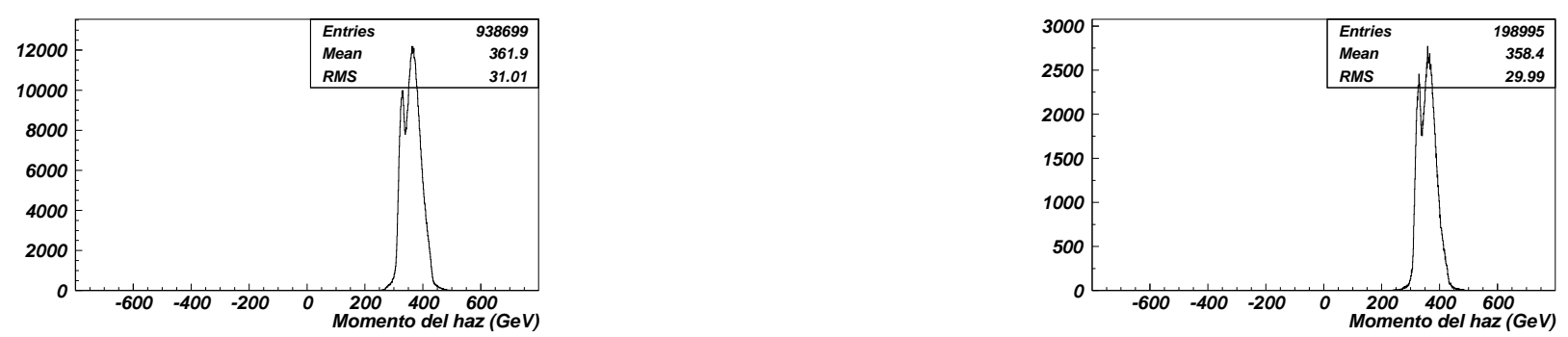

Figura 5.251: Distribución de momento del haz primario. Izquierda: bariones. Derecha: mesones (pos $375 \mathrm{C})$. 


\subsubsection{Multiplicidad en la region del vértice}
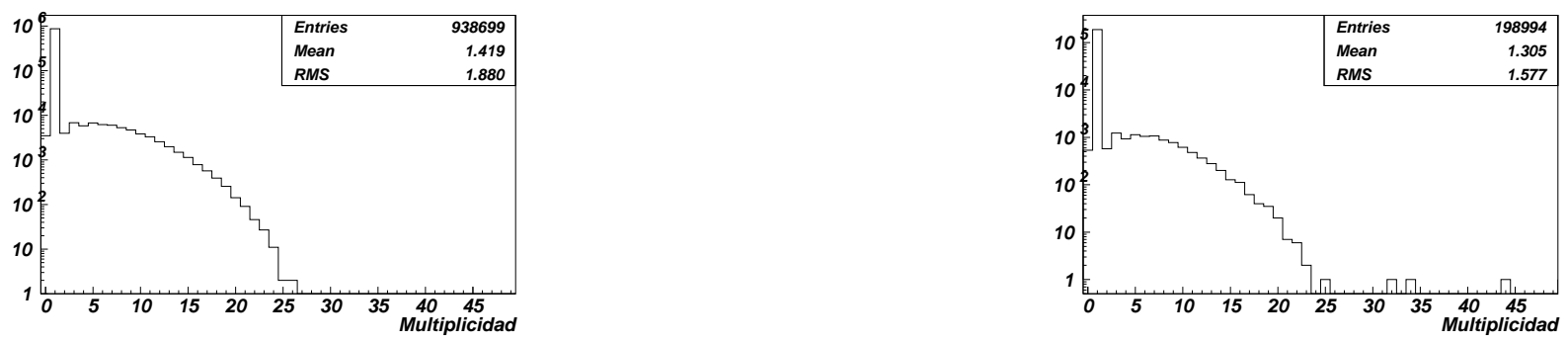

Figura 5.254: Multiplicidad total. Izquierda: haz de bariones. Derecha: haz de mesones(pos $375 \mathrm{C})$.
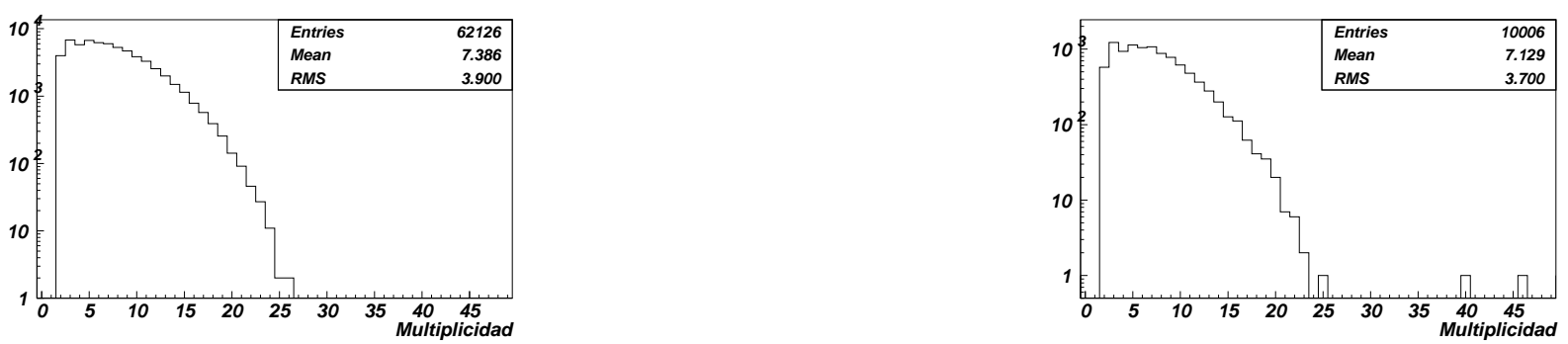

Figura 5.255: Multiplicidad en eventos con más de una trayectoria en la región del vértice. Izquierda: haz de bariones. Derecha: haz de mesones(pos 375 C). 


\subsubsection{Distribuciones de multiplicidad y momento}
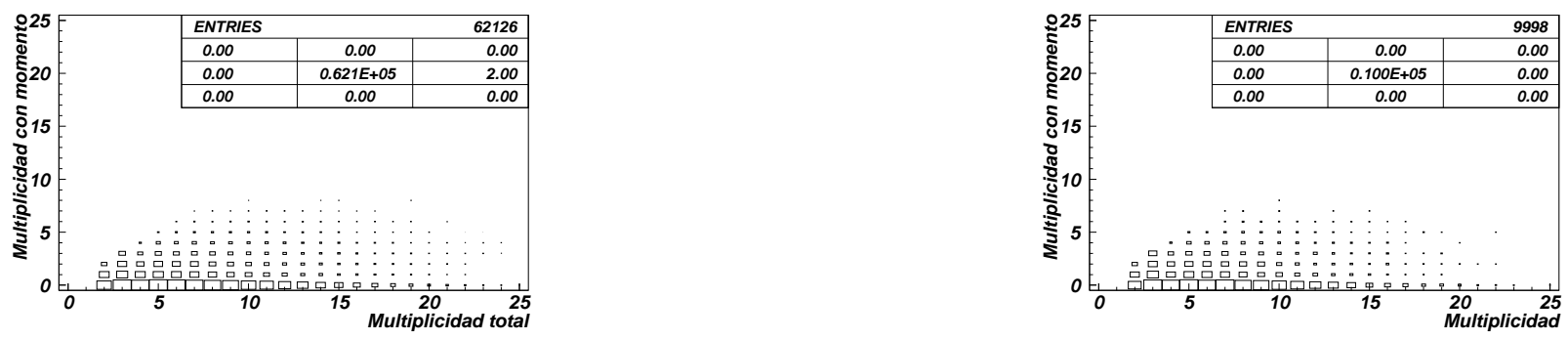

Figura 5.256: Multiplicidad total contra multiplicidad con momento medido. Izquierda: haz de bariones. Derecha: haz de mesones(pos $375 \mathrm{C})$.
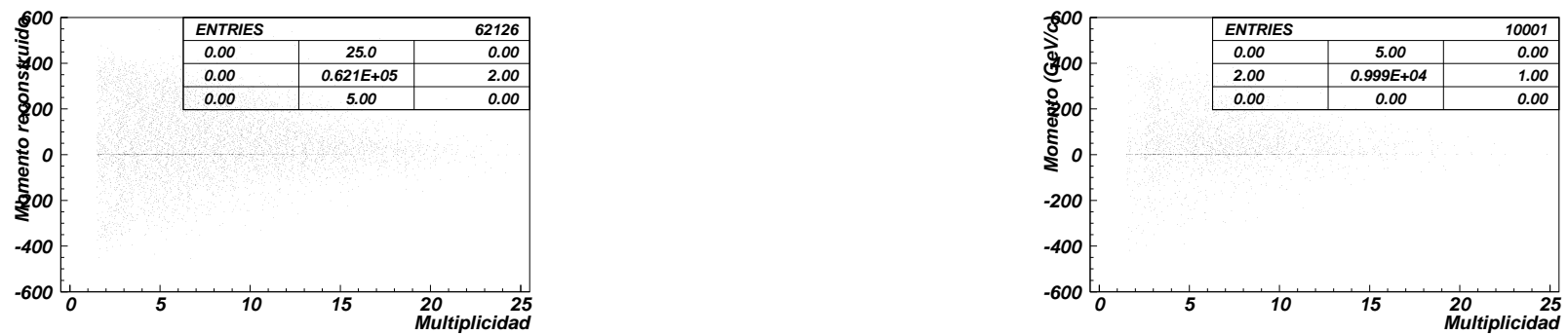

Figura 5.257: Multiplicidad contra momento.Izquierda: haz de bariones. Derecha: haz de mesones(pos $375 \mathrm{C})$. 
Distribuciones de momento total para eventos producidos por un haz de bariones
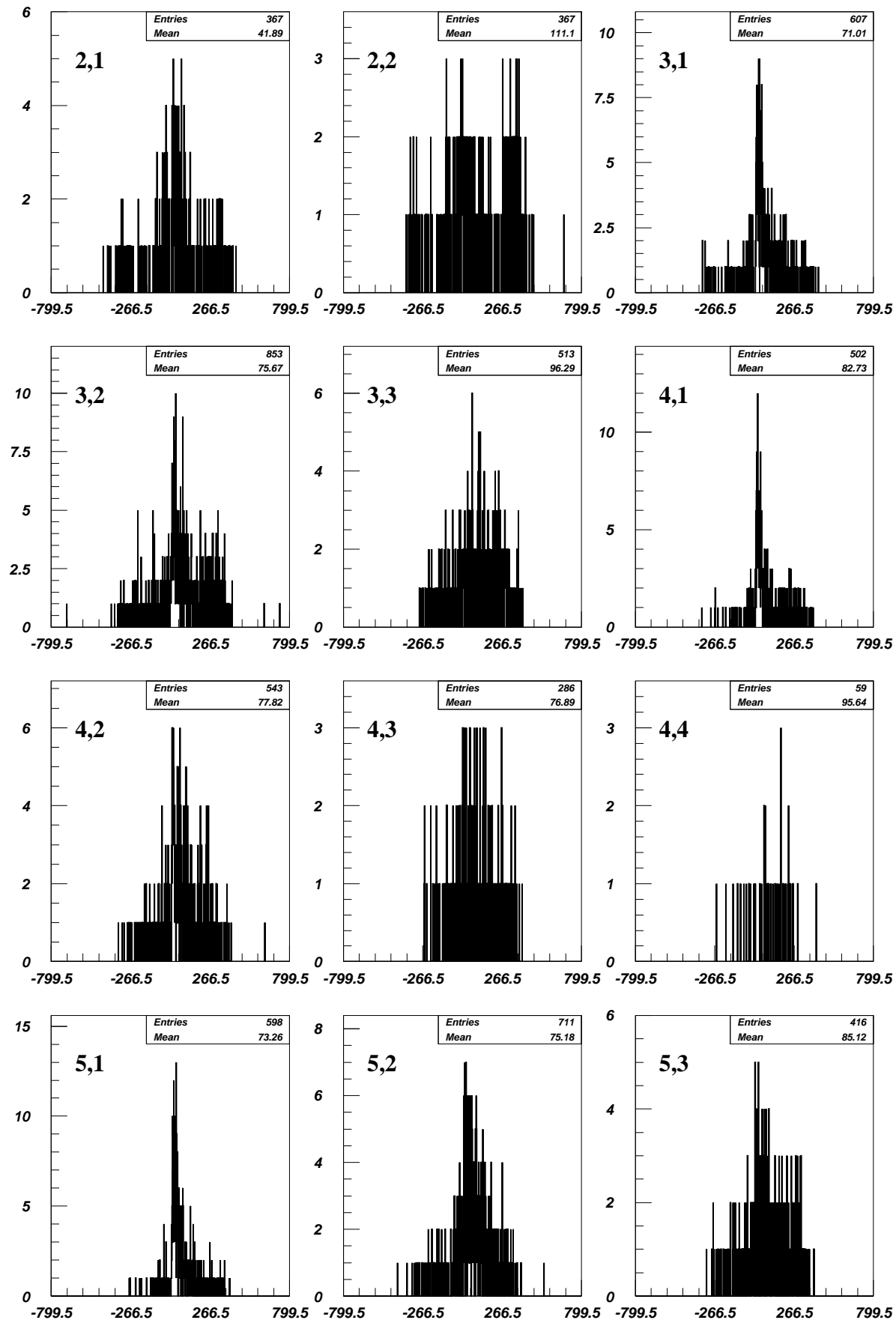

Figura 5.258: Distribuciones de momento. El primer indice: multiplicidad total, el segundo: multiplicidad con momento (pos $375 \mathrm{C}$ ) 

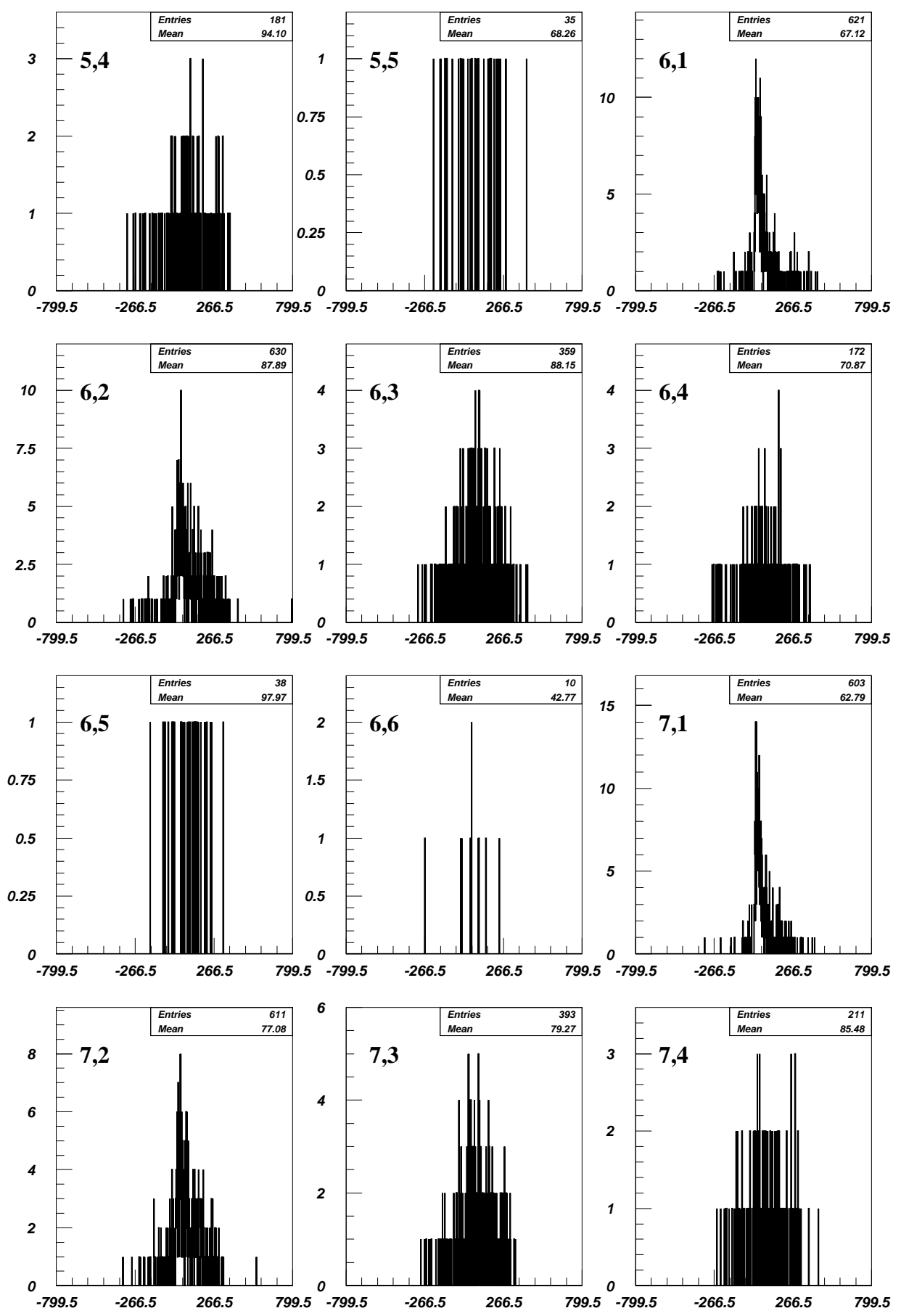

Figura 5.259: Distribuciones de momento. El primer índice: multiplicidad total, el segundo: multiplicidad con momento (pos $375 \mathrm{C}$ ). 

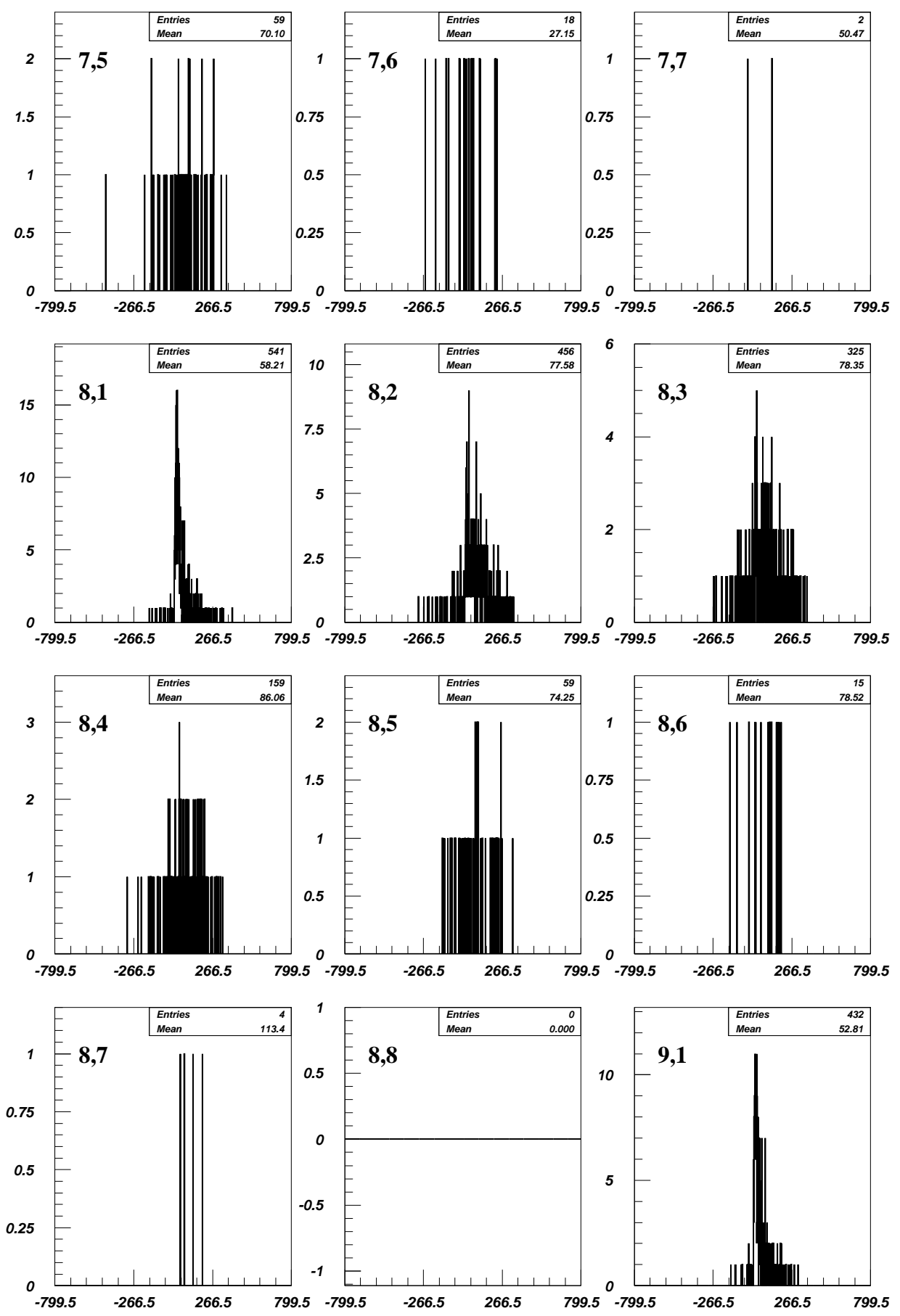

Figura 5.260: Distribuciones de momento. El primer índice: multiplicidad total, el segundo: multiplicidad con momento (pos $375 \mathrm{C}$ ). 

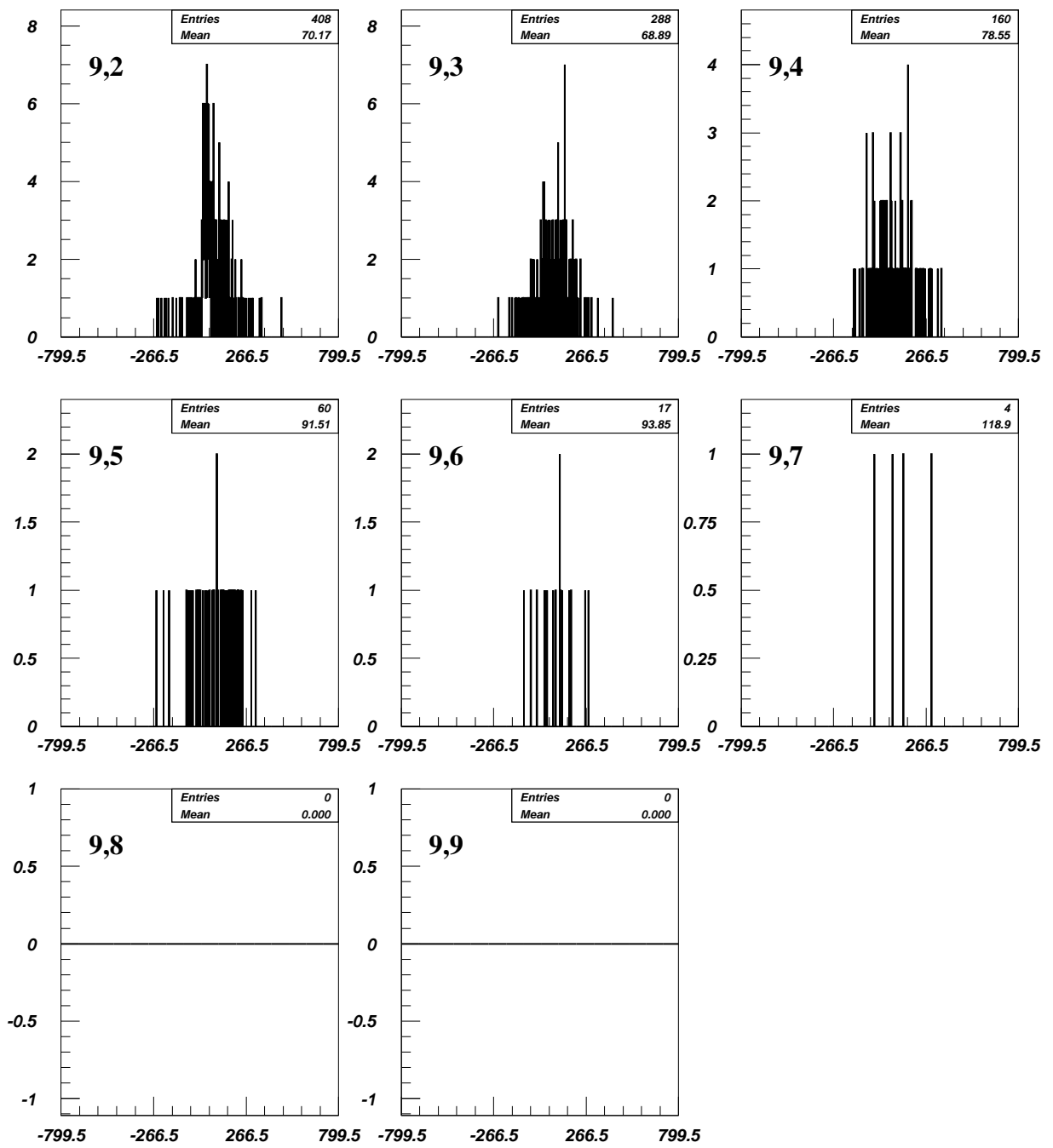

Figura 5.261: Distribuciones de momento. El primer índice: multiplicidad total, el segundo: multiplicidad con momento (pos $375 \mathrm{C}$ ). 
Distribuciones de momento total para eventos producidos por un haz de mesones
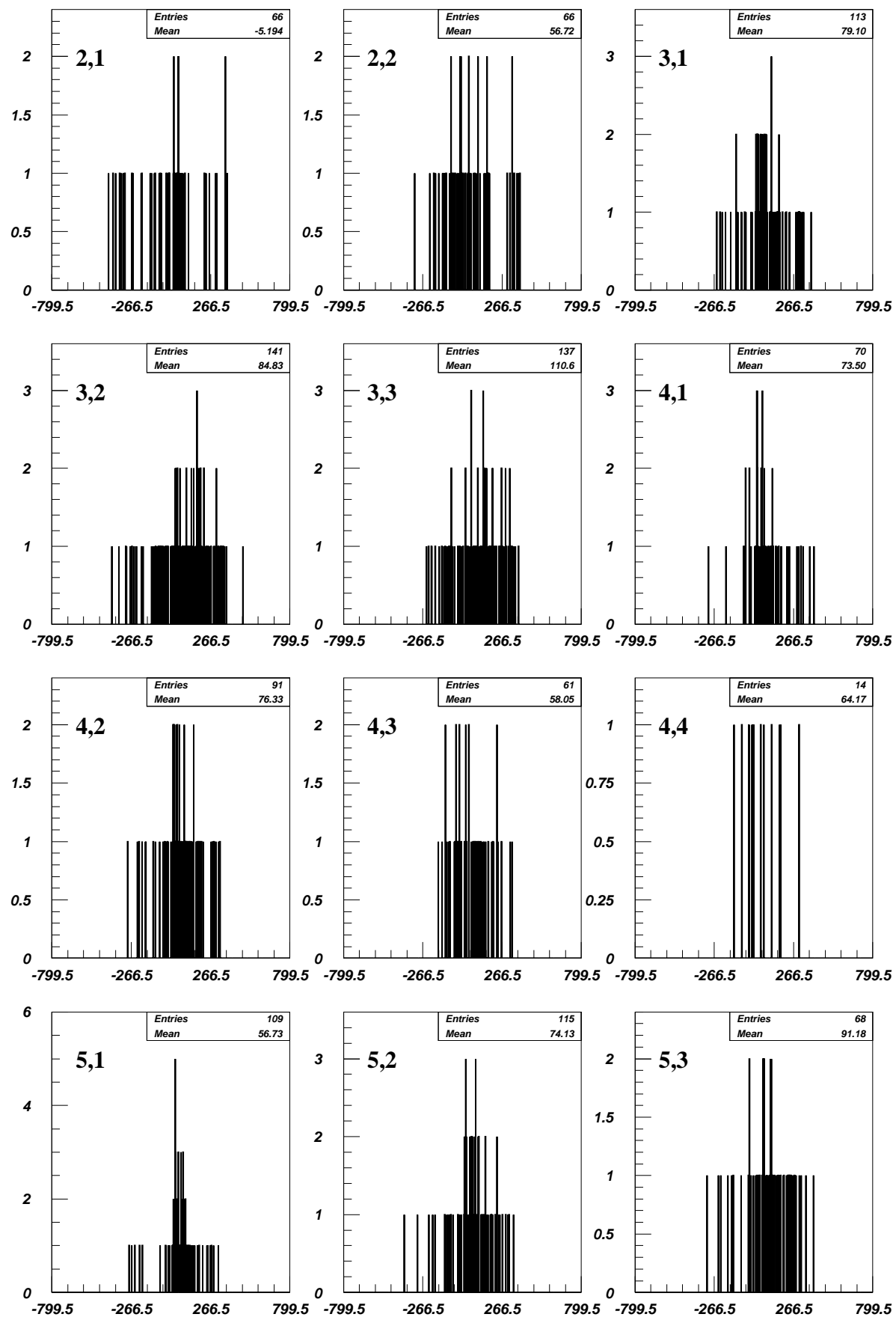

Figura 5.262: Distribuciones de momento. El primer indice: multiplicidad total, el segundo: multiplicidad con momento (pos $375 \mathrm{C}$ ) 

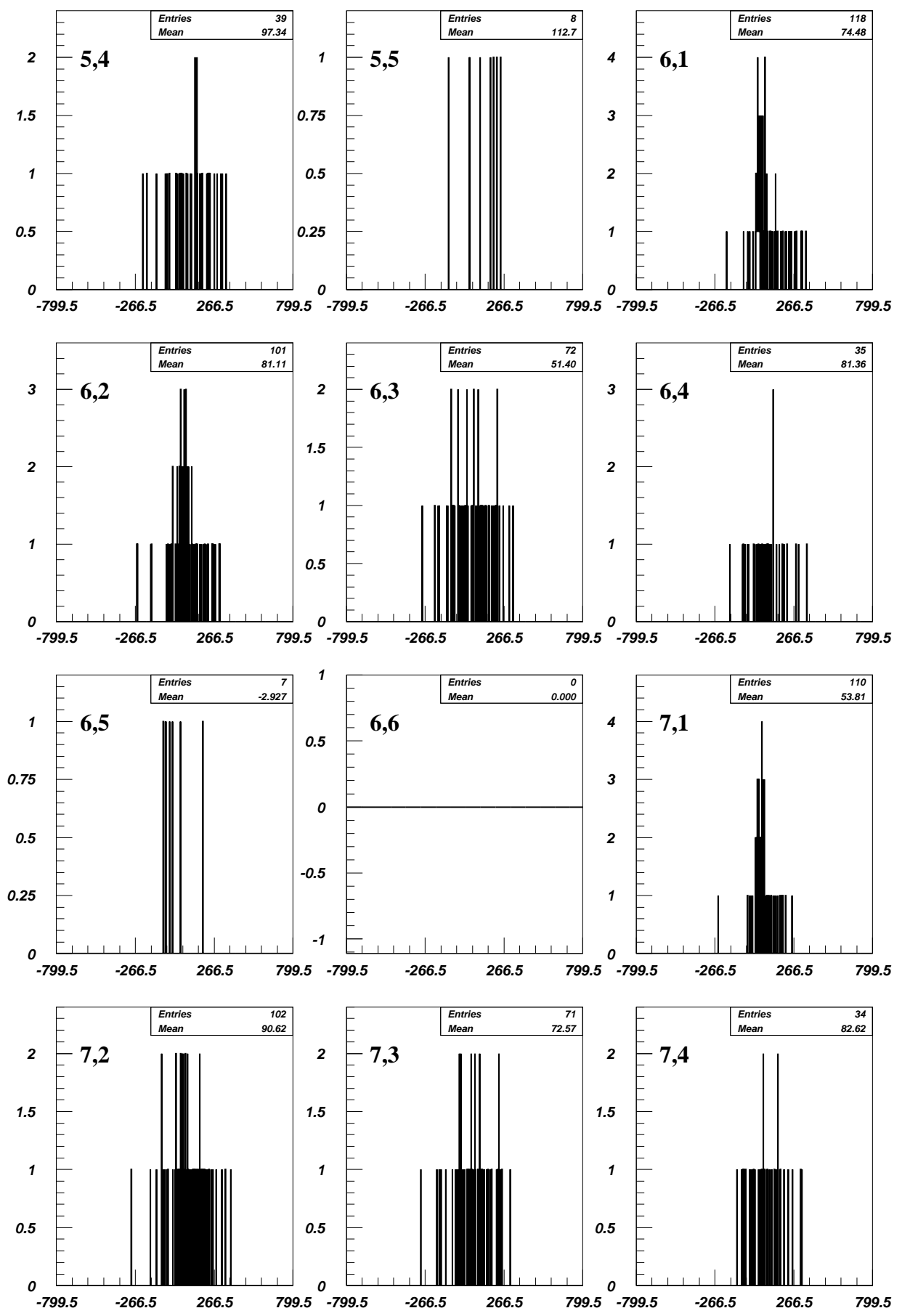

Figura 5.263: Distribuciones de momento. El primer índice: multiplicidad total, el segundo: multiplicidad con momento(pos $375 \mathrm{C})$. 

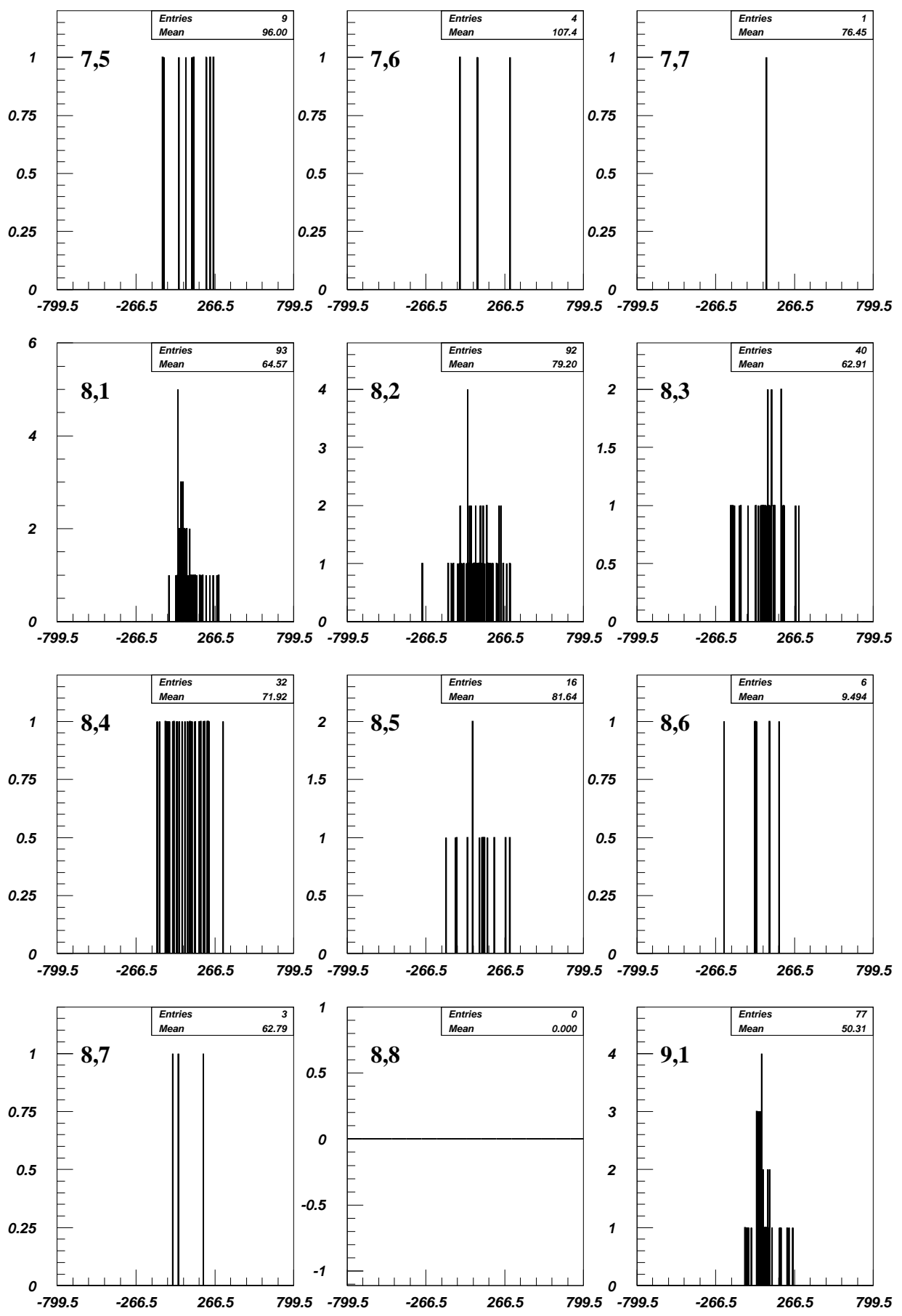

Figura 5.264: Distribuciones de momento. El primer índice: multiplicidad total, el segundo: multiplicidad con momento(pos $375 \mathrm{C})$. 

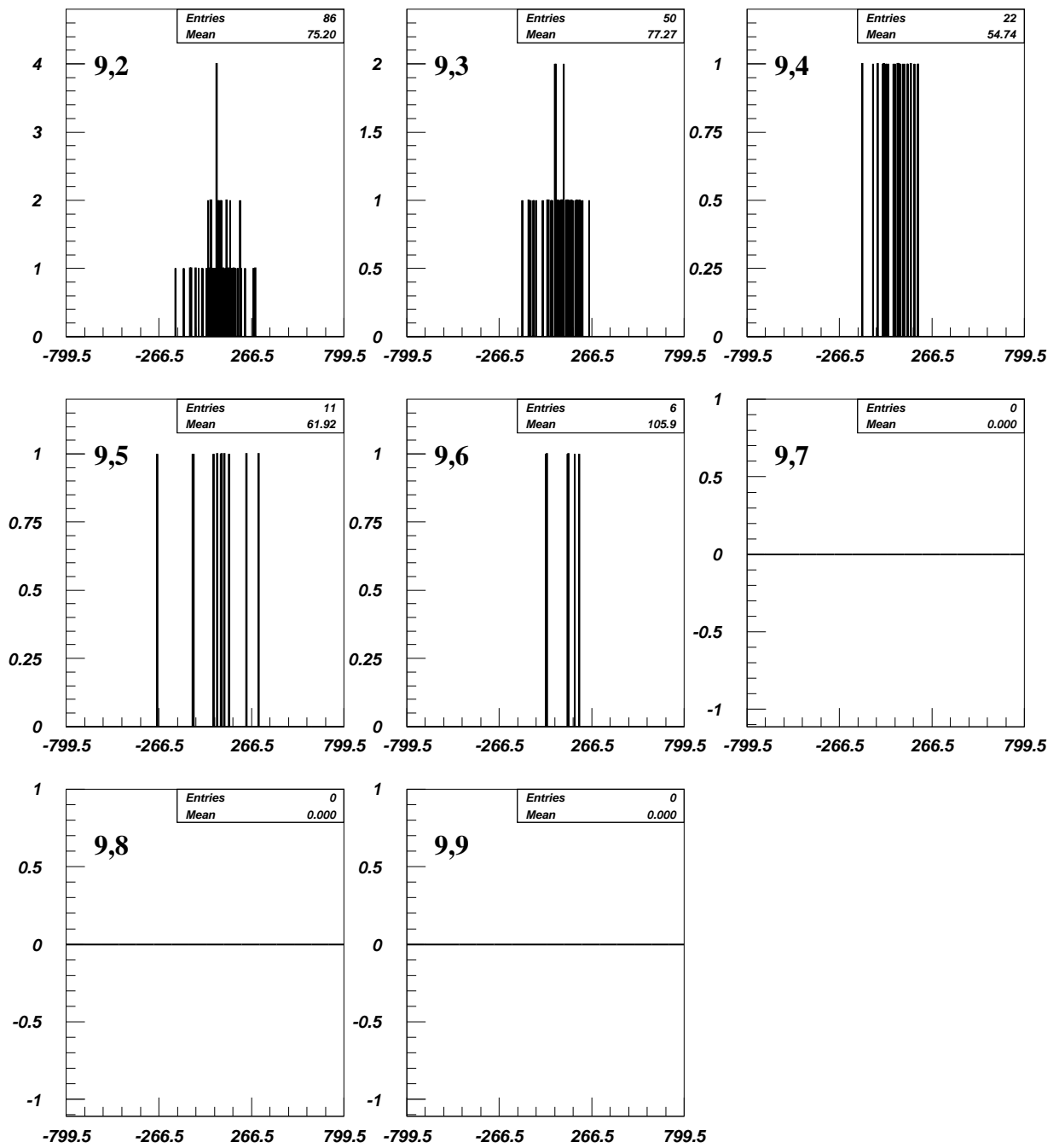

Figura 5.265: Distribuciones de momento. El primer índice: multiplicidad total, el segundo: multiplicidad con momento(pos $375 \mathrm{C})$. 
Distribuciones del valor absoluto del momento total para eventos producidos por un haz de bariones
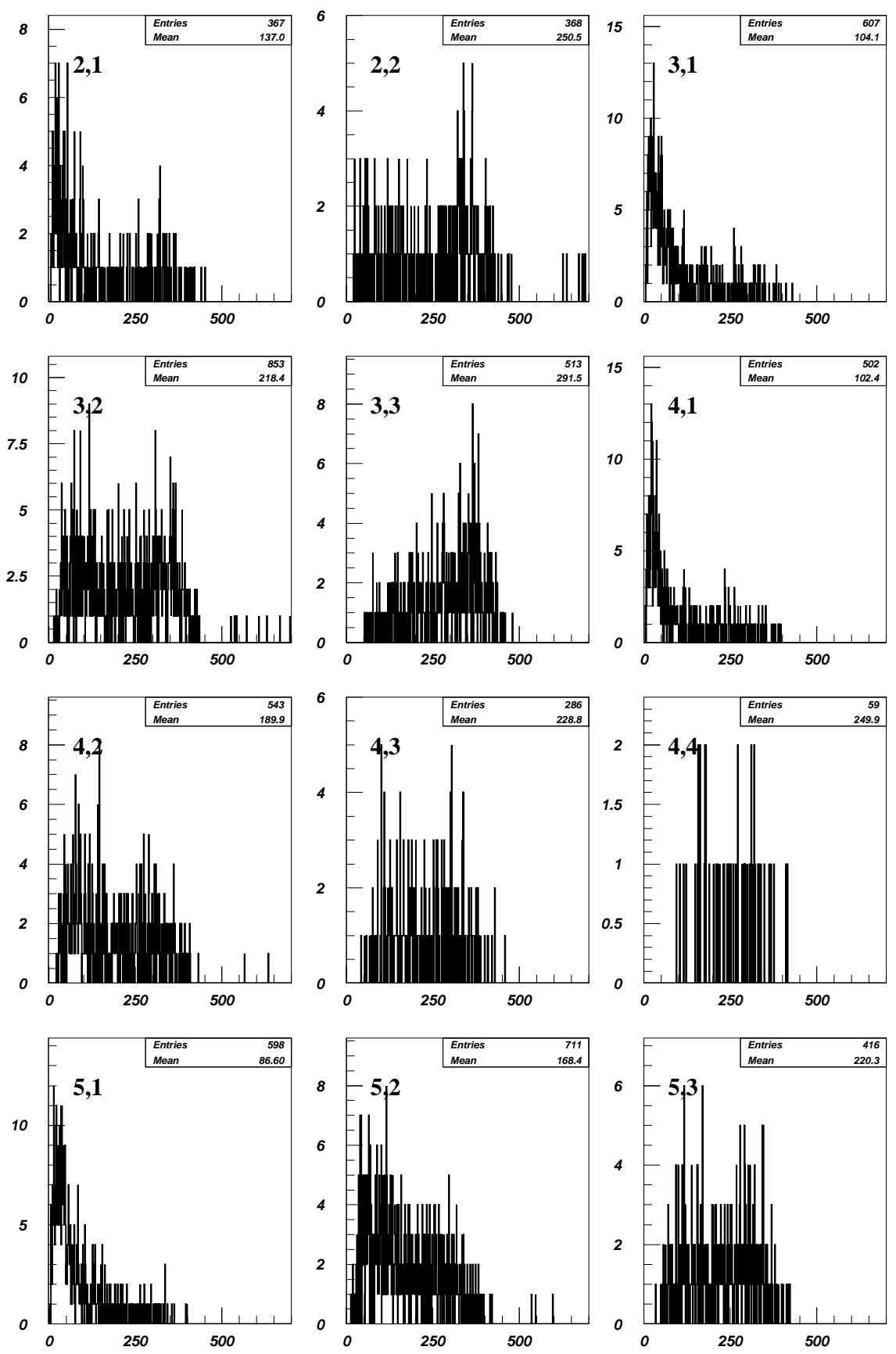

Figura 5.266: Distribuciones de momento. El primer indice: multiplicidad total, el segundo: multiplicidad con momento(pos $375 \mathrm{C})$. 

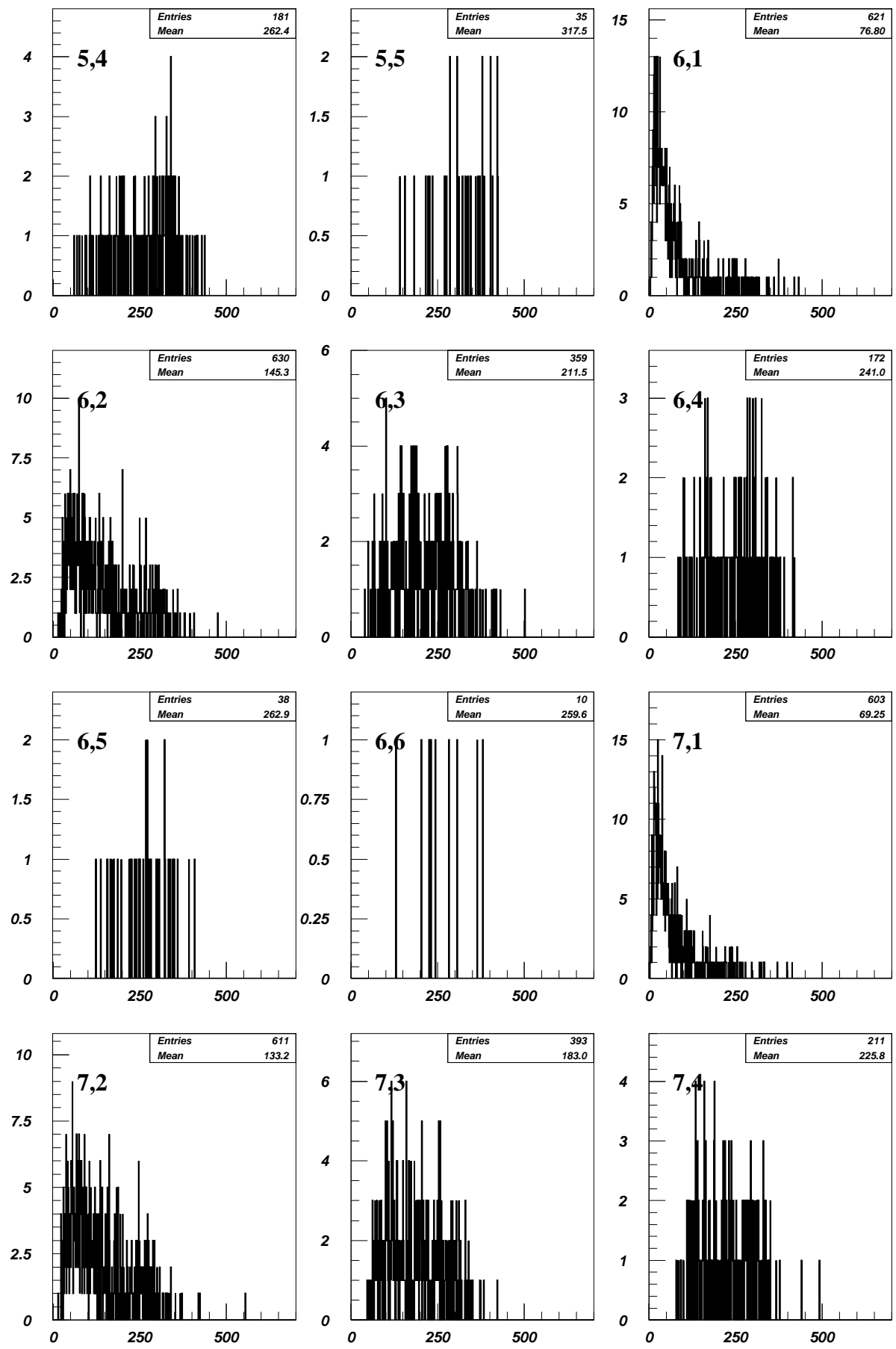

Figura 5.267: Distribuciones de momento. El primer índice: multiplicidad total, el segundo: multiplicidad con momento(pos $375 \mathrm{C})$. 

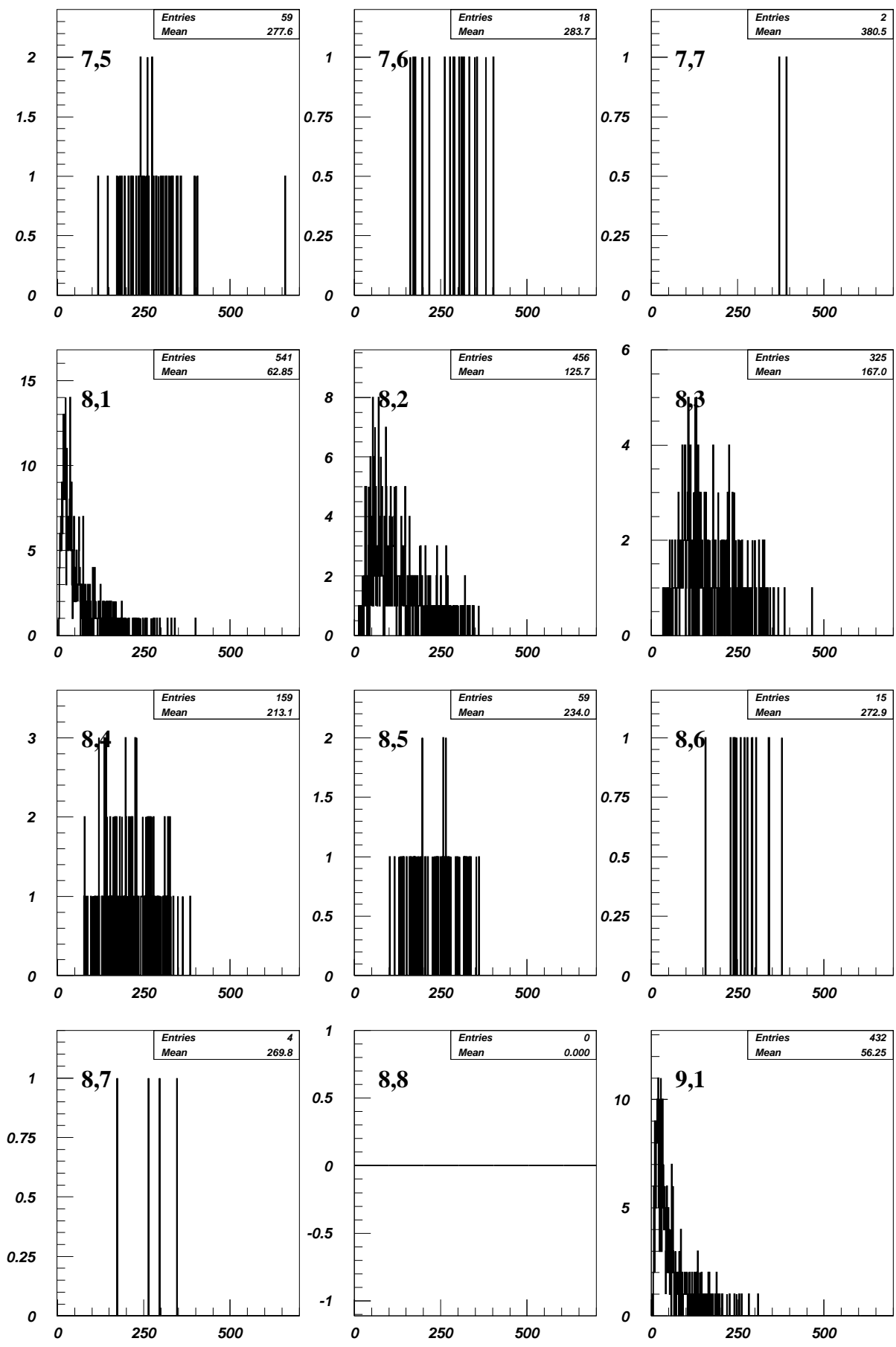

Figura 5.268: Distribuciones de momento. El primer índice: multiplicidad total, el segundo: multiplicidad con momento(pos $375 \mathrm{C})$. 

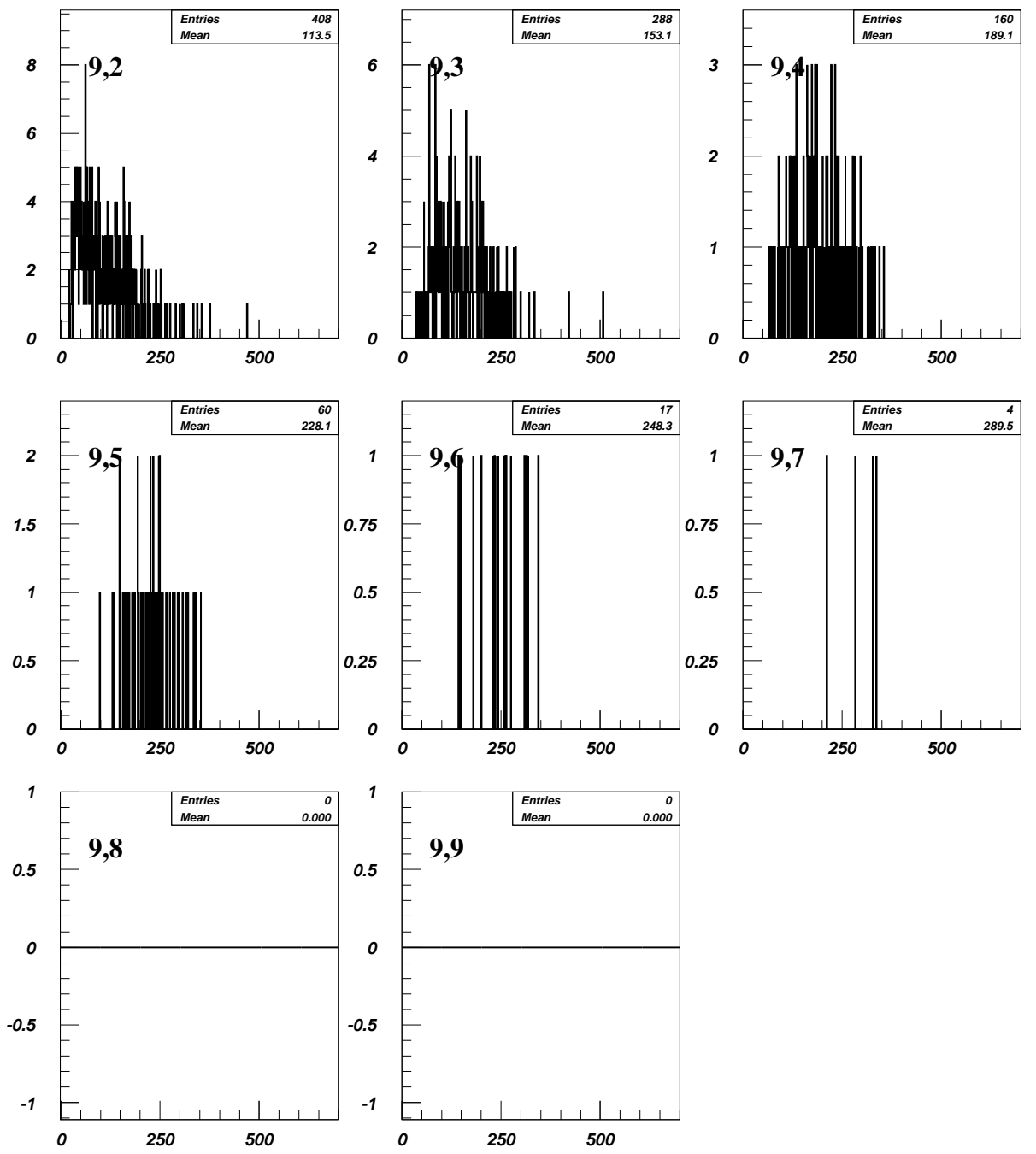

Figura 5.269: Distribuciones de momento. El primer índice: multiplicidad total, el segundo: multiplicidad con momento(pos $375 \mathrm{C})$. 
Distribuciones del valor absoluto del momento total para eventos producidos por un haz de mesones
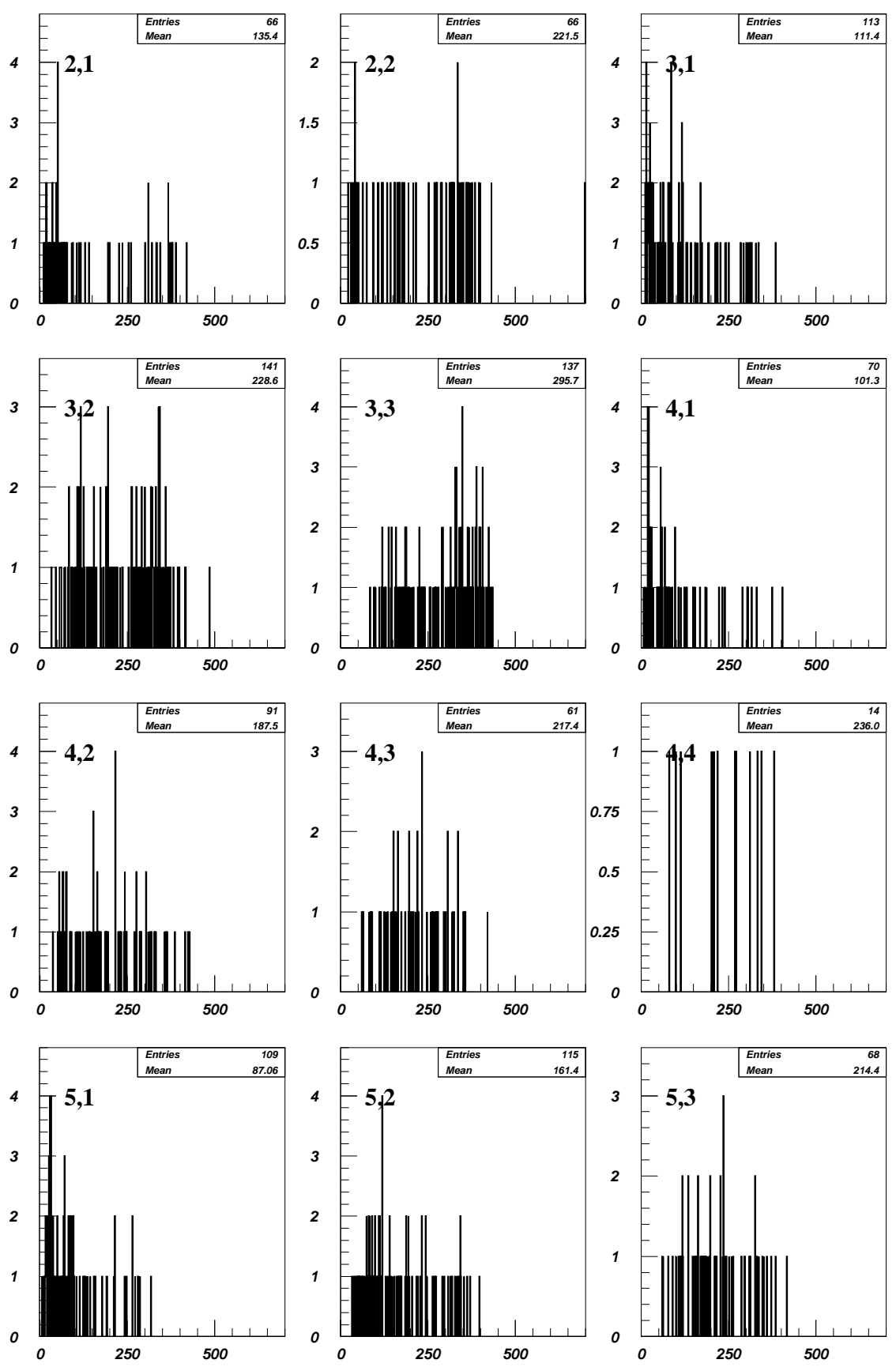

Figura 5.270: Distribuciones de momento. El primer indice: multiplicidad total, el segundo: multiplicidad con momento (pos $375 \mathrm{C}$ ) 

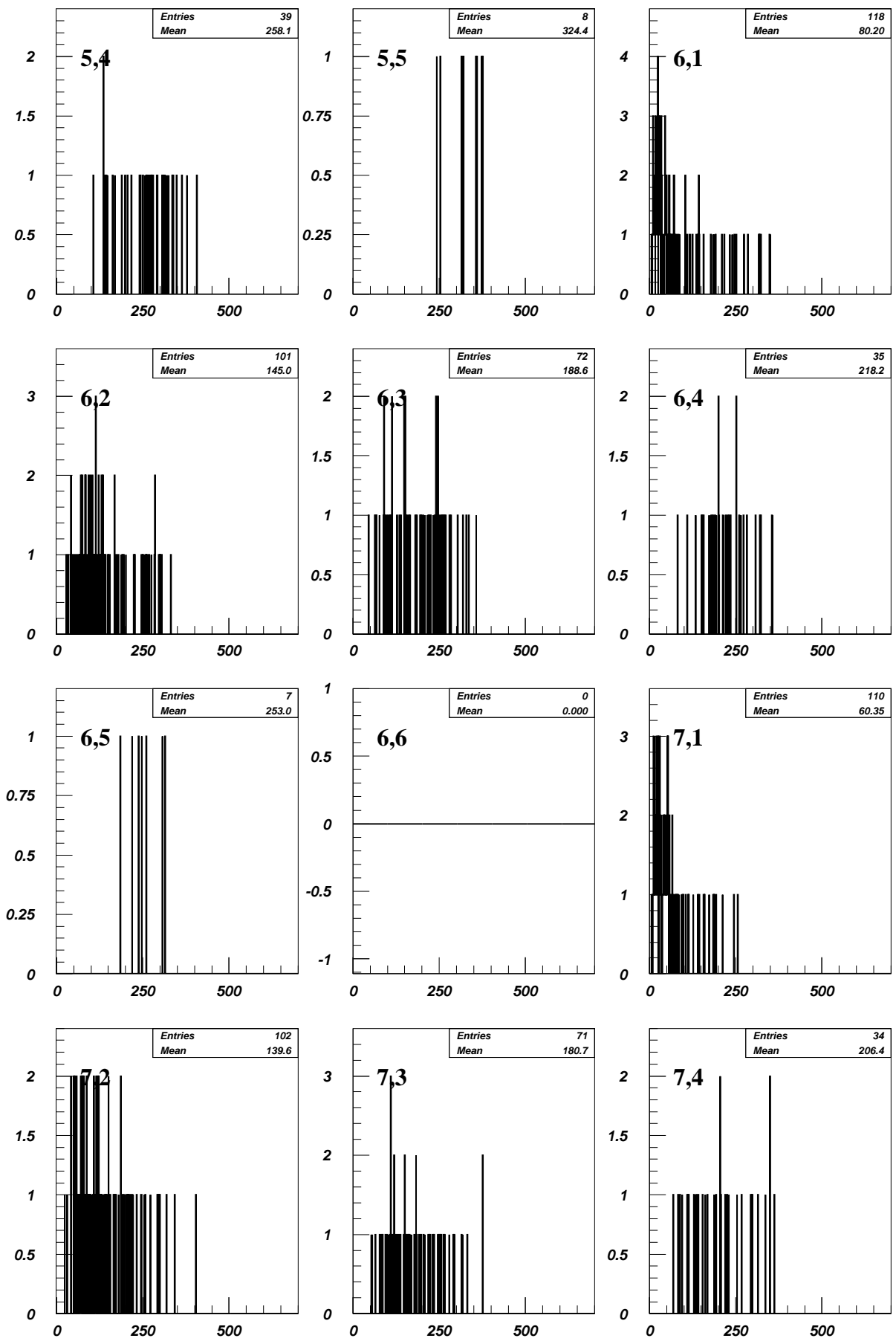

Figura 5.271: Distribuciones de momento. El primer índice: multiplicidad total, el segundo: multiplicidad con momento (pos $375 \mathrm{C}$ ). 

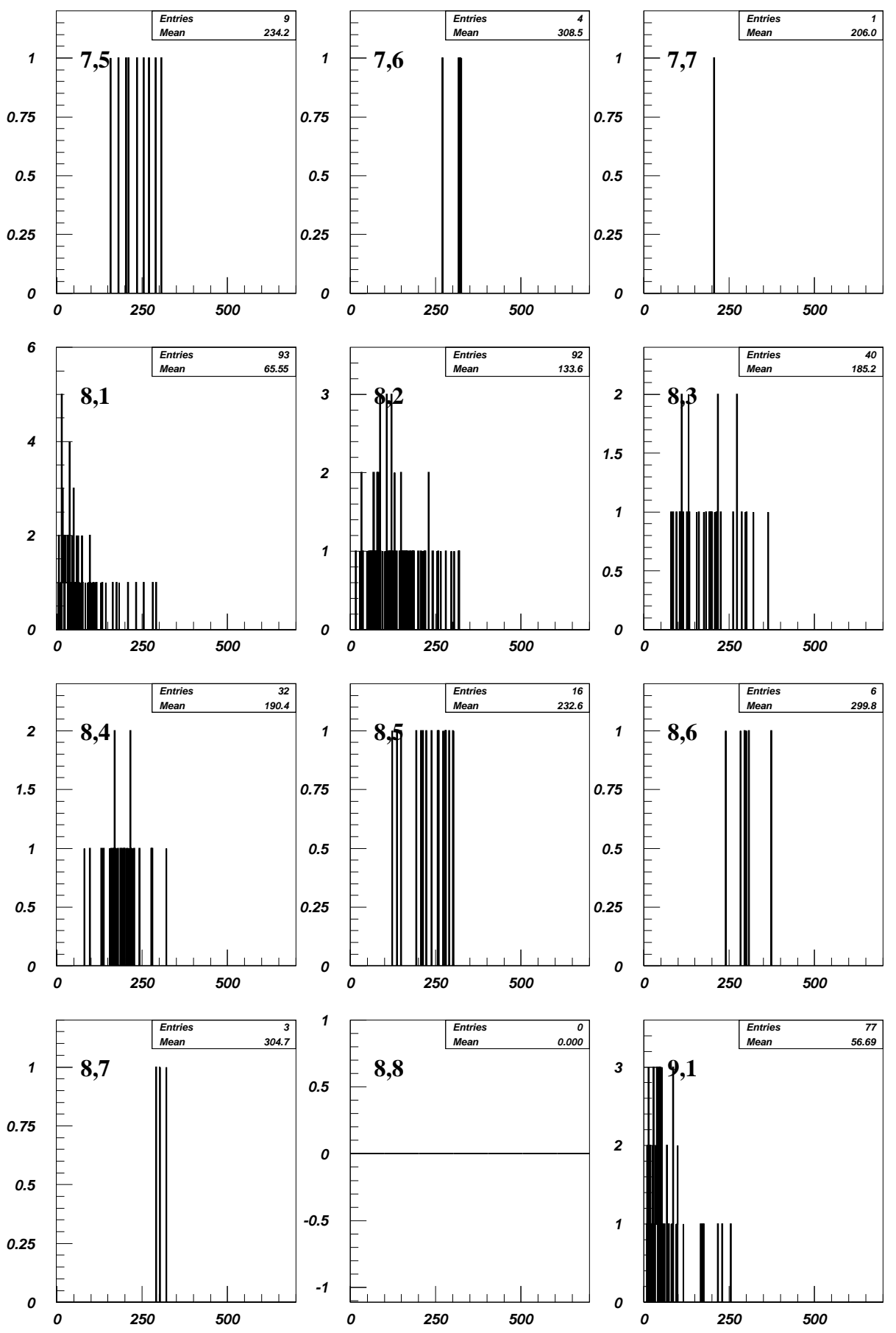

Figura 5.272: Distribuciones de momento. El primer índice: multiplicidad total, el segundo: multiplicidad con momento (pos $375 \mathrm{C}$ ). 

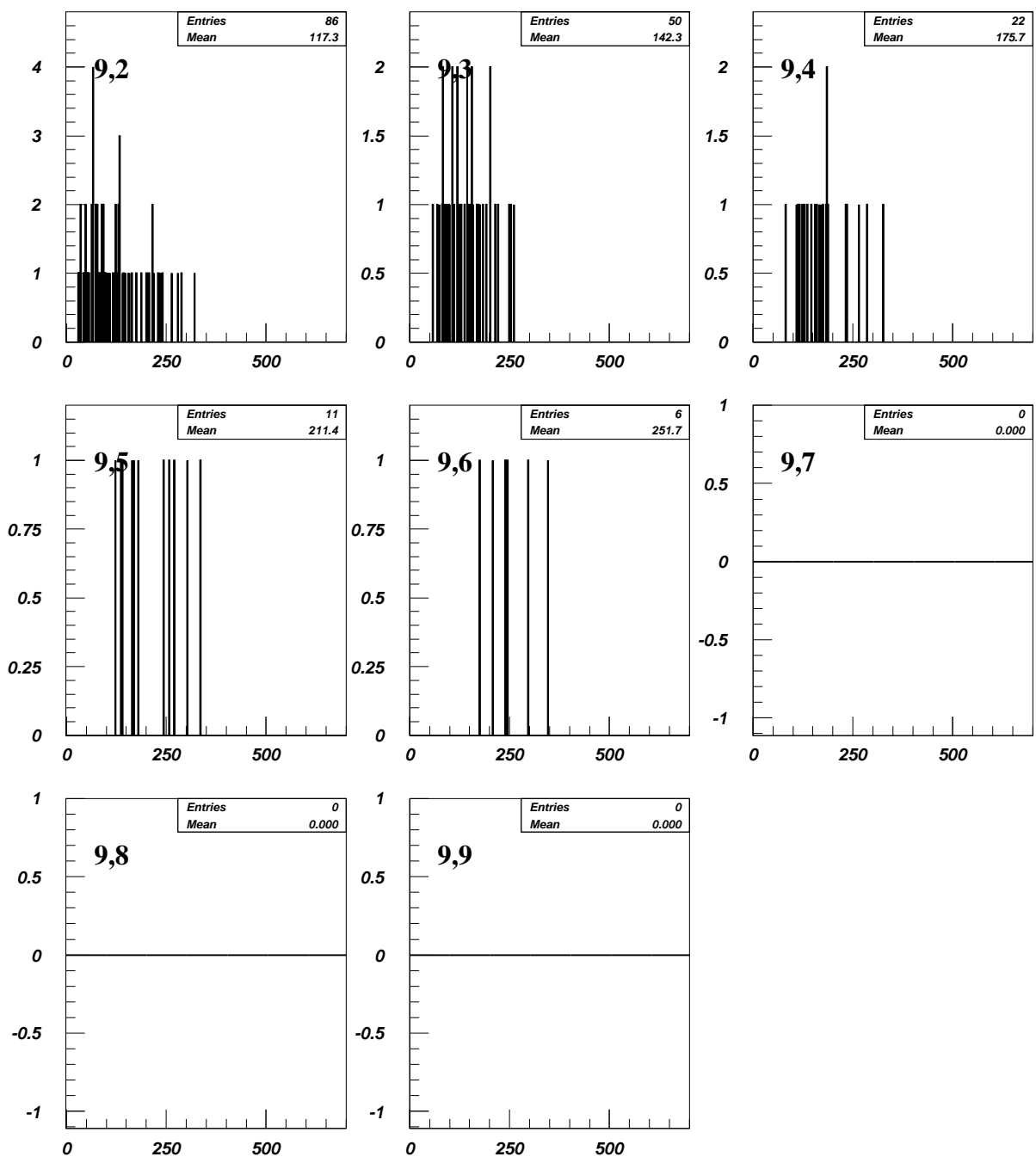

Figura 5.273: Distribuciones de momento. El primer índice: multiplicidad total, el segundo: multiplicidad con momento (pos $375 \mathrm{C}$ ). 
Distribuciones del momento de las trayectorias para eventos producidos por un haz de bariones
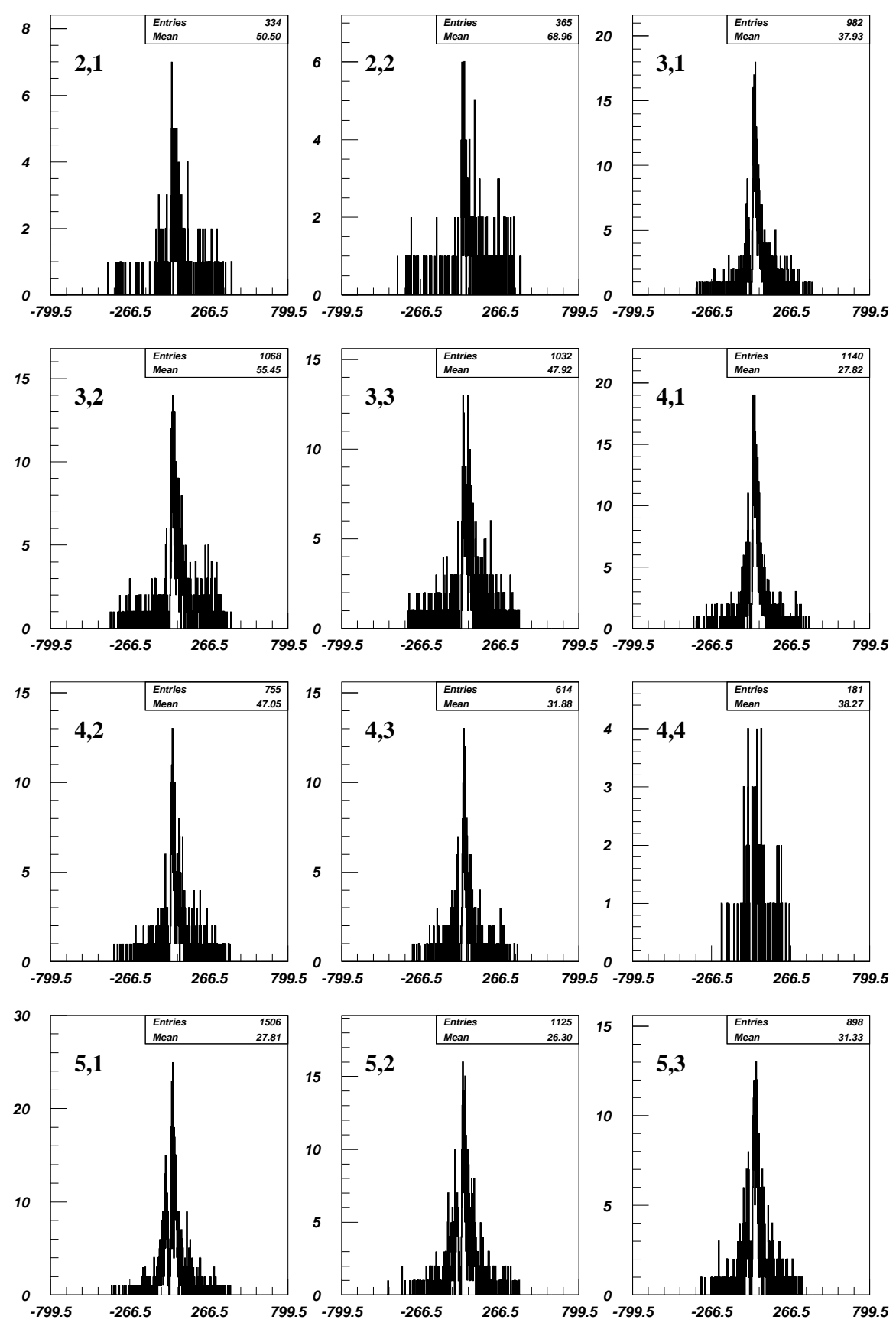

Figura 5.274: Distribuciones de momento. El primer indice: multiplicidad total, el segundo: multiplicidad con momento (pos $375 \mathrm{C}$ ) 

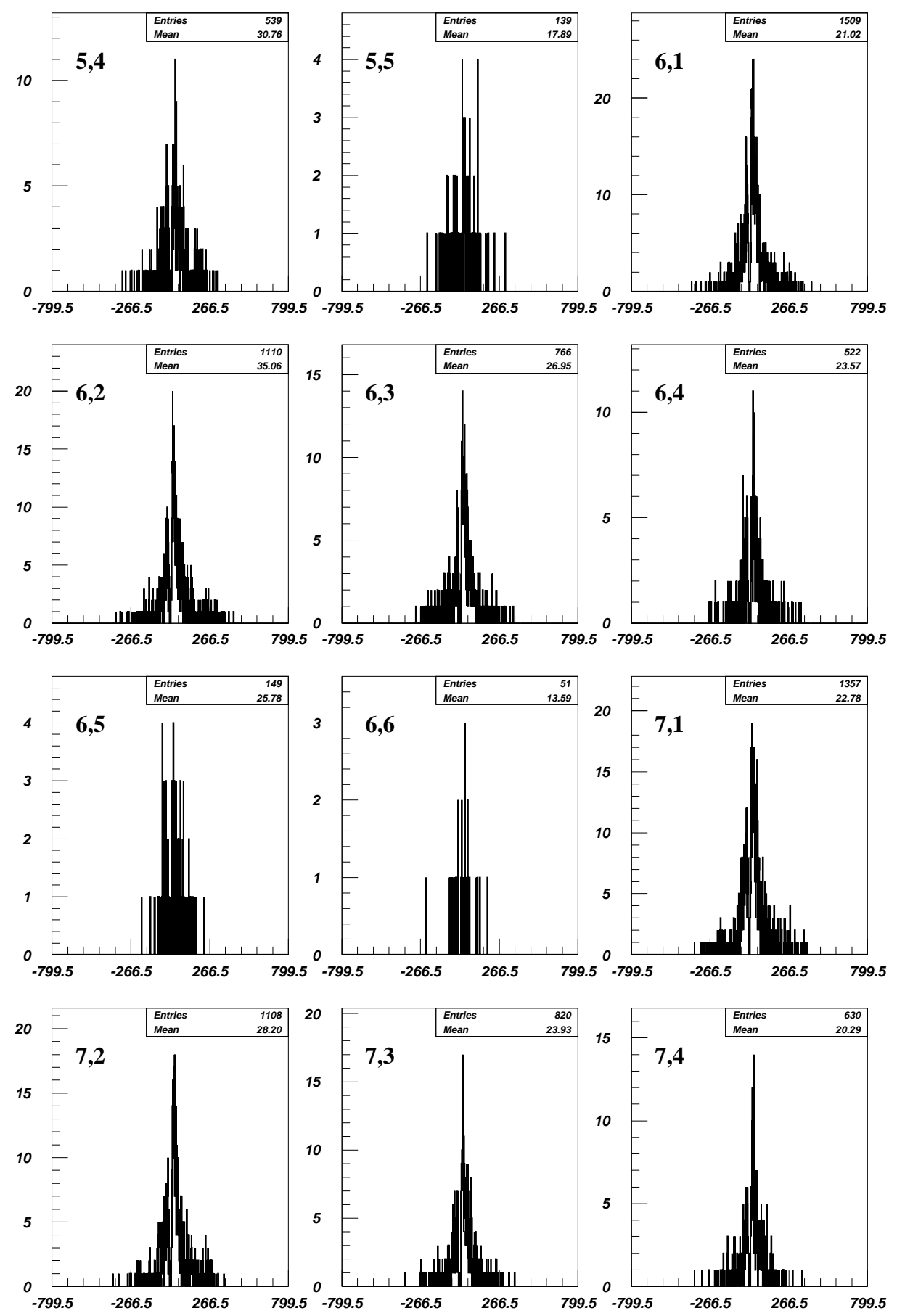

Figura 5.275: Distribuciones de momento. El primer índice: multiplicidad total, el segundo: multiplicidad con momento (pos $375 \mathrm{C}$ ). 

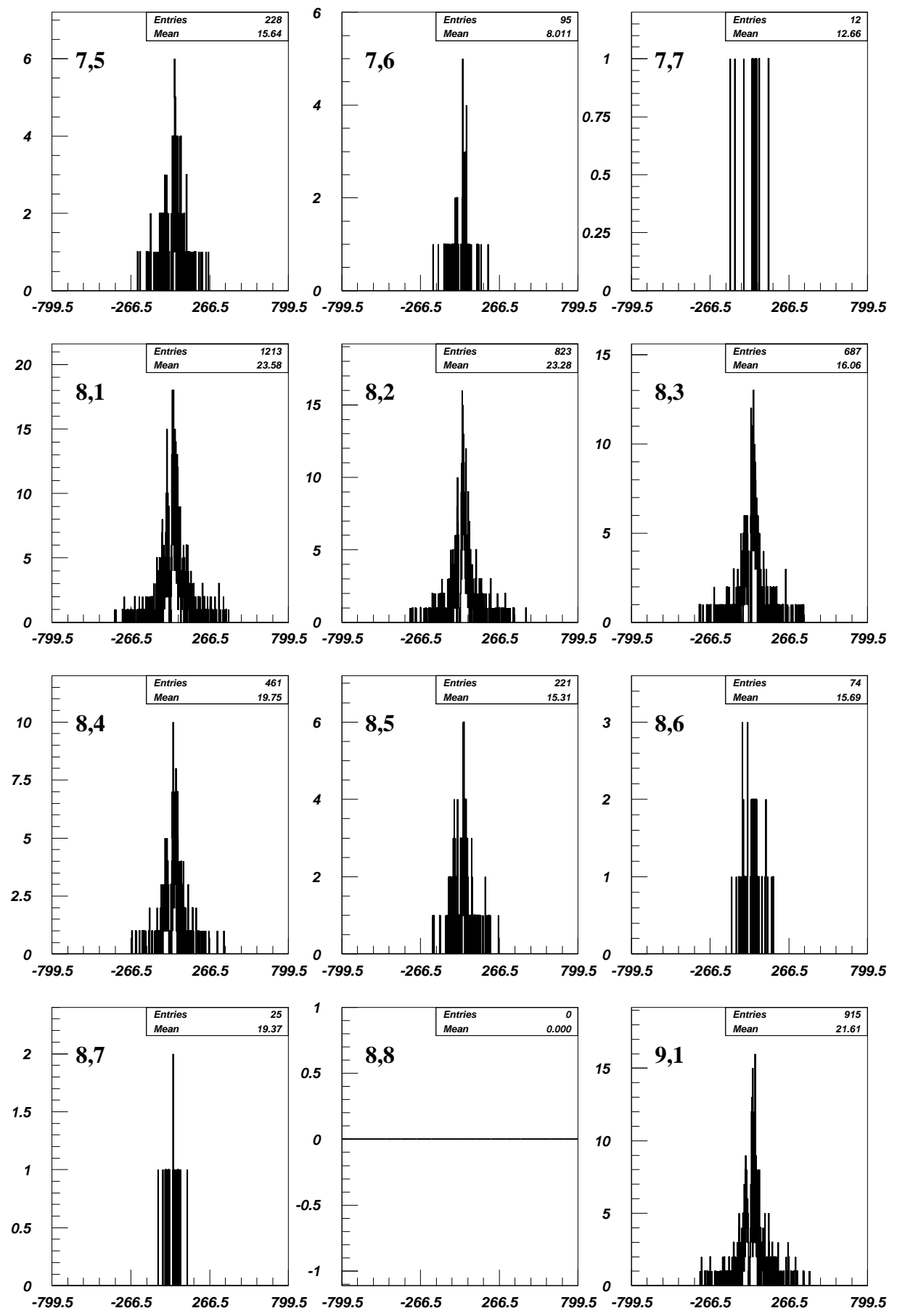

Figura 5.276: Distribuciones de momento. El primer índice: multiplicidad total, el segundo: multiplicidad con momento (pos $375 \mathrm{C}$ ). 

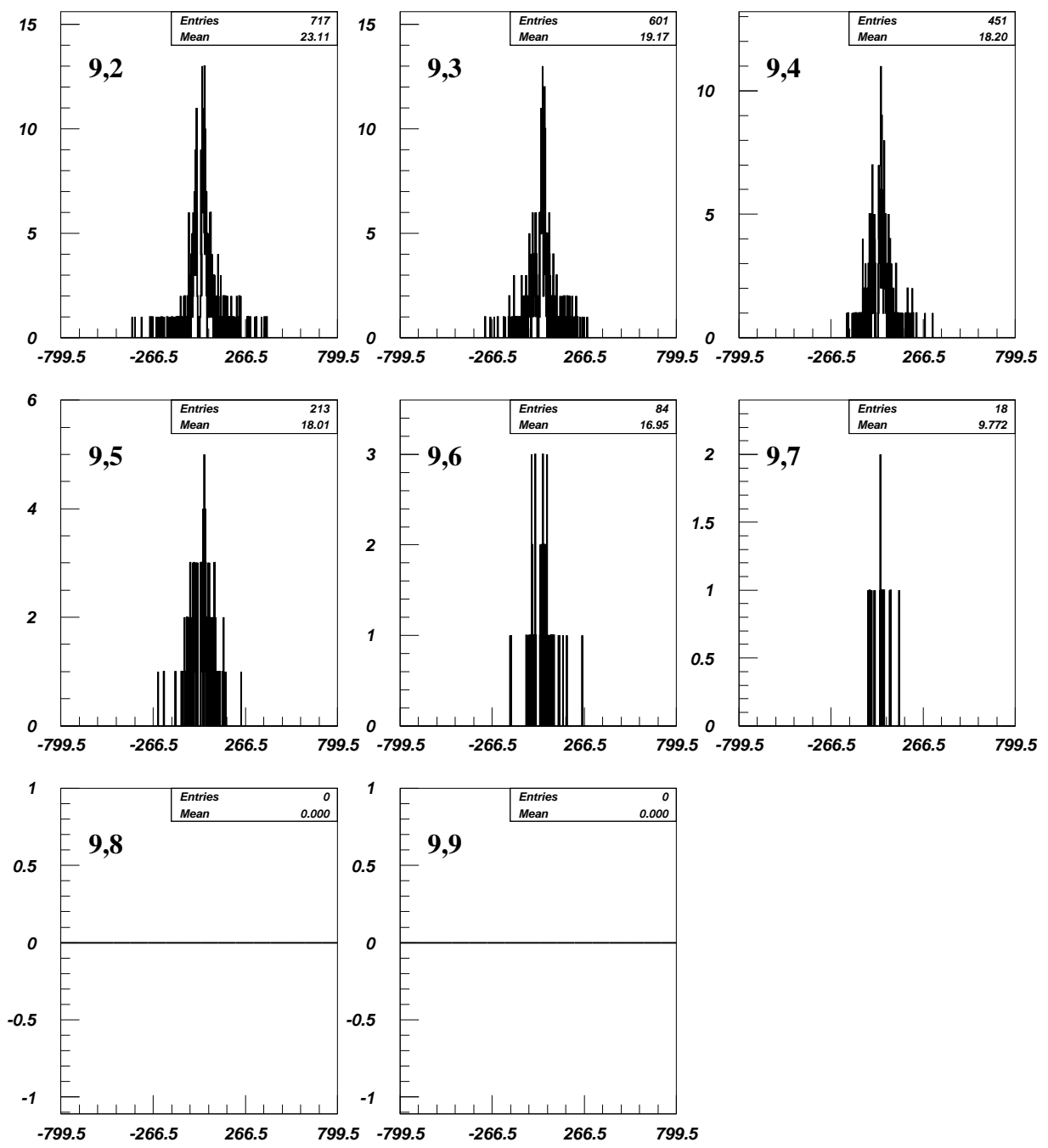

Figura 5.277: Distribuciones de momento. El primer índice: multiplicidad total, el segundo: multiplicidad con momento (pos $375 \mathrm{C}$ ). 
Distribuciones del momento de las trayectorias para eventos producidos por un haz de mesones
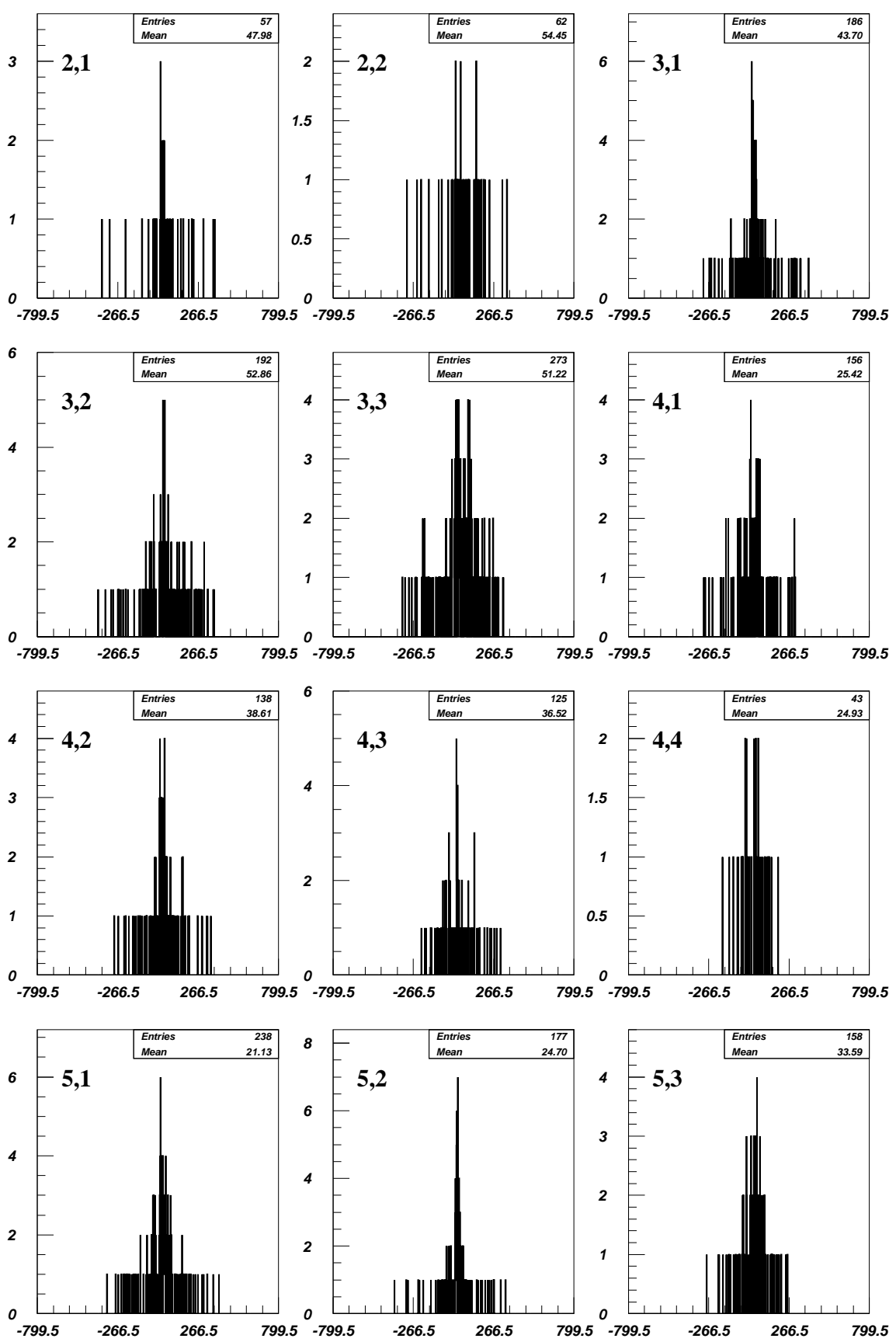

Figura 5.278: Distribuciones de momento. El primer indice: multiplicidad total, el segundo: multiplicidad con momento (pos $375 \mathrm{C}$ ) 

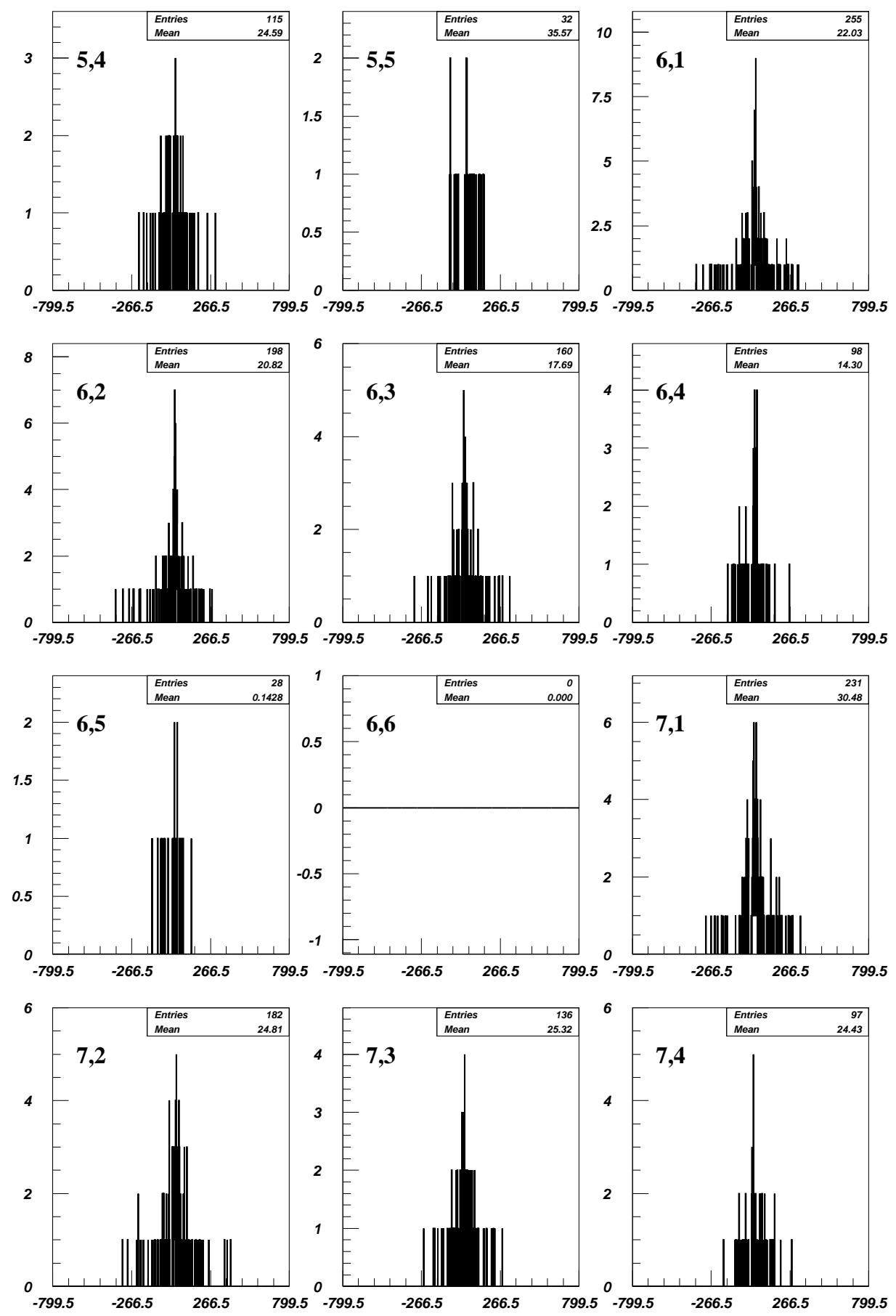

Figura 5.279: Distribuciones de momento. El primer índice: multiplicidad total, el segundo: multiplicidad con momento (pos $375 \mathrm{C}$ ). 

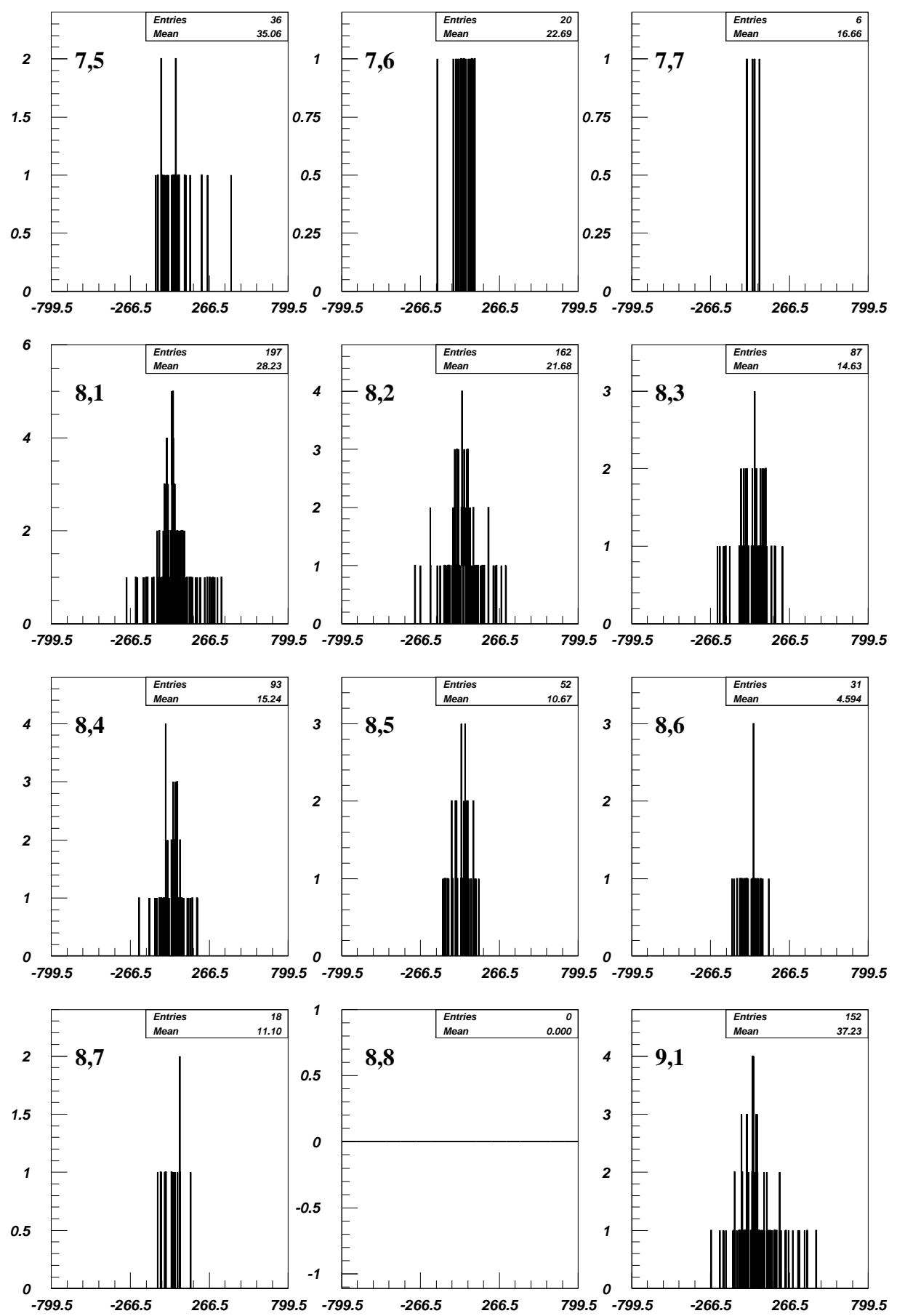

Figura 5.280: Distribuciones de momento. El primer índice: multiplicidad total, el segundo: multiplicidad con momento (pos $375 \mathrm{C}$ ). 

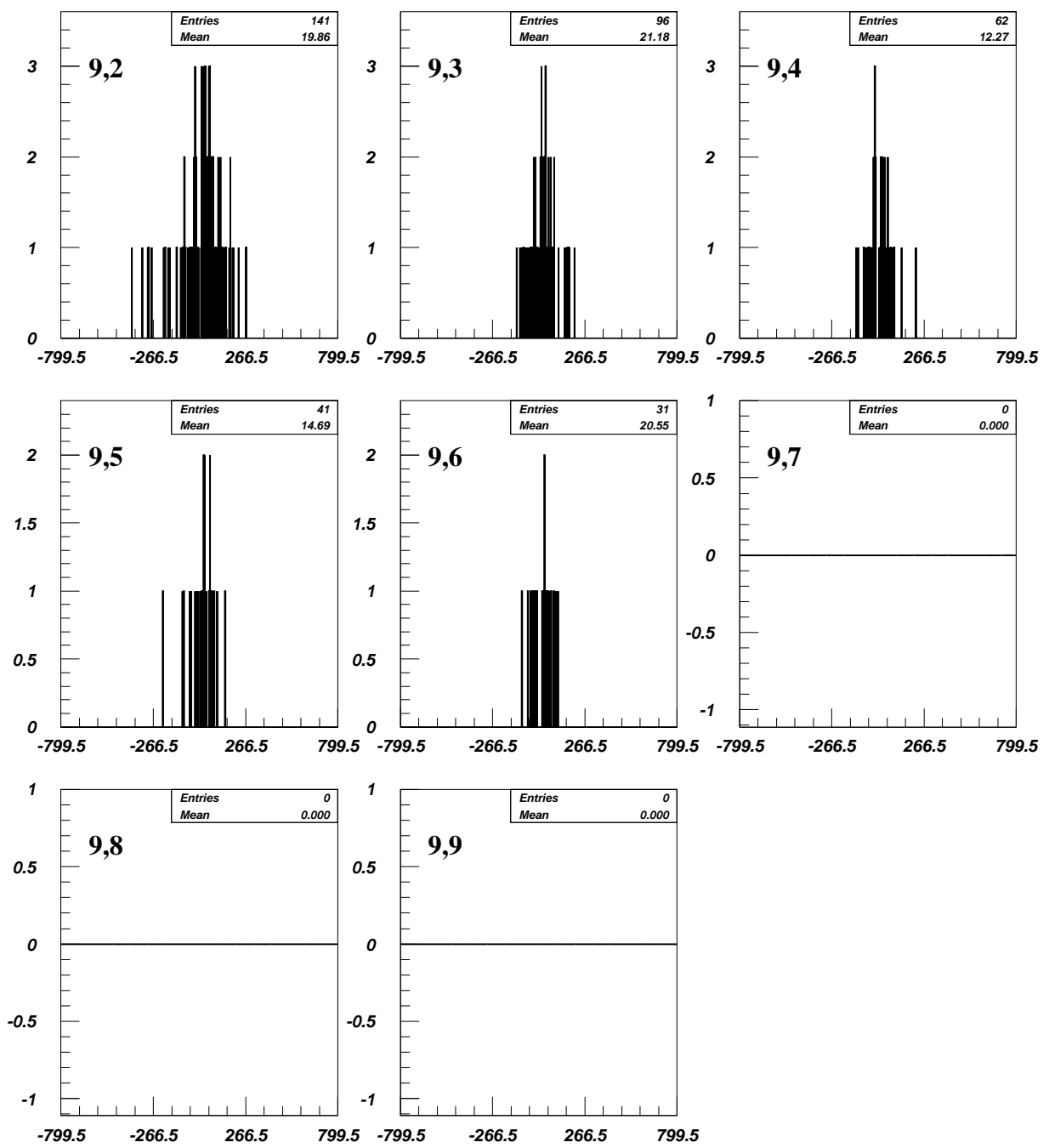

Figura 5.281: Distribuciones de momento. El primer índice: multiplicidad total, el segundo: multiplicidad con momento (pos $375 \mathrm{C}$ ). 


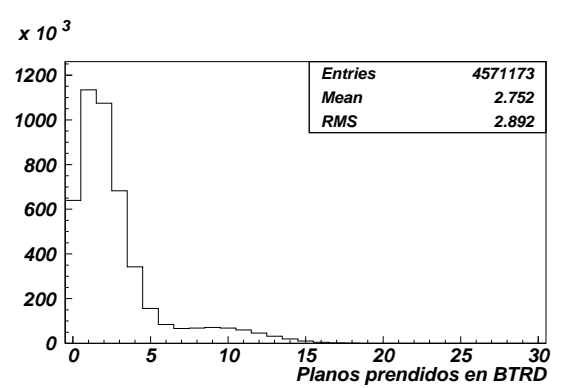

Figura 5.283: Planos prendidos en BTRD. Proporción bariónica y mesónica del haz primario(pos $500 \mathrm{C})$.
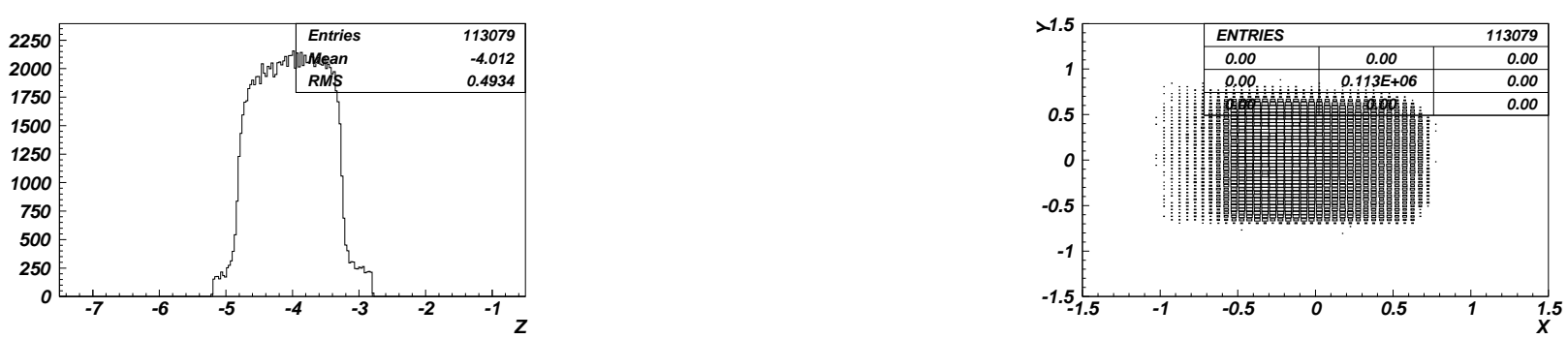

Figura 5.284: Vértice primario. Izquierda: coordenada z. Derecha: proyección x,y (pos 500 C). 
5.11. Haz de polaridad positiva, con momento $500 \mathrm{GeV}$, con blanco de producción para el haz secundario de carbón

5.11.1. Histogramas de control
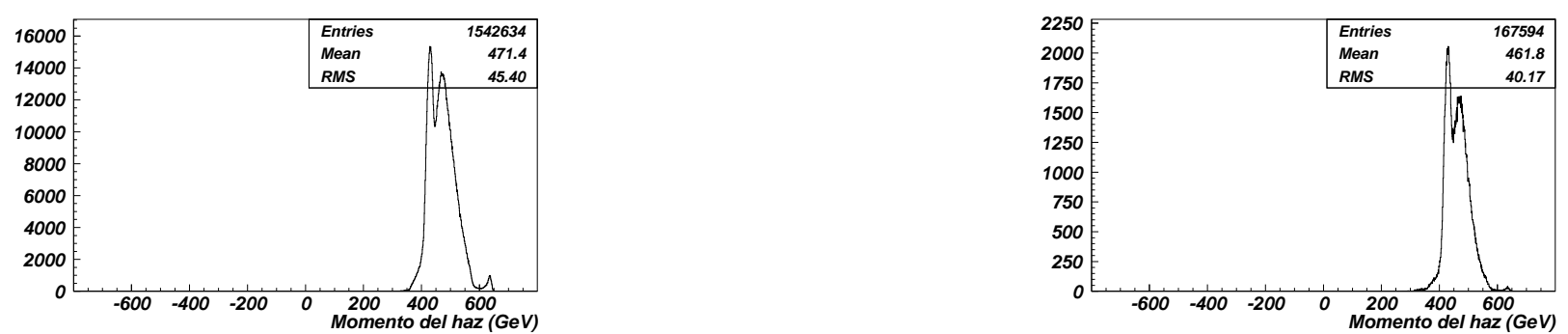

Figura 5.282: Distribución de momento del haz primario. Izquierda: bariones. Derecha: mesones (pos $500 \mathrm{C})$. 


\subsubsection{Multiplicidad en la región del vértice}
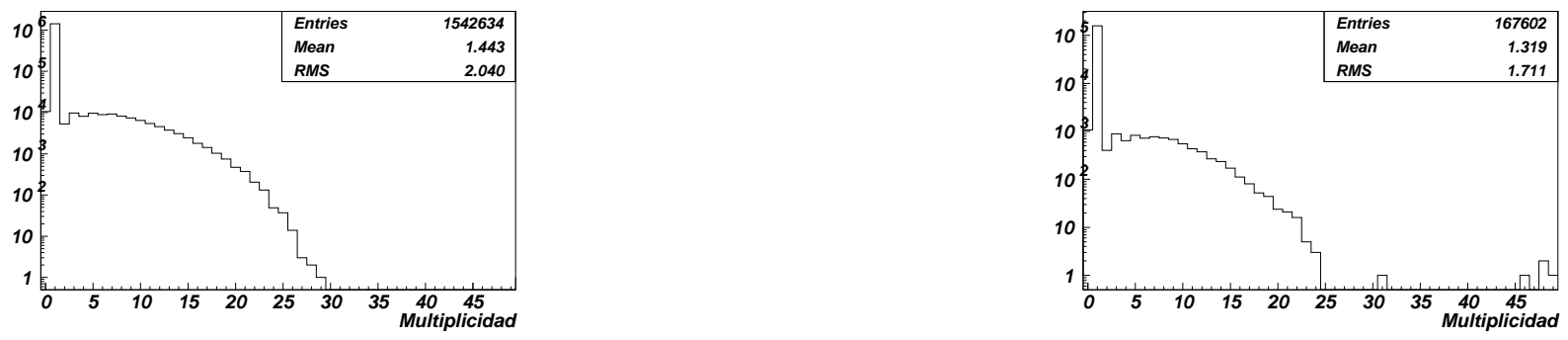

Figura 5.285: Multiplicidad total. Izquierda: haz de bariones. Derecha: haz de mesones(pos $500 \mathrm{C})$.
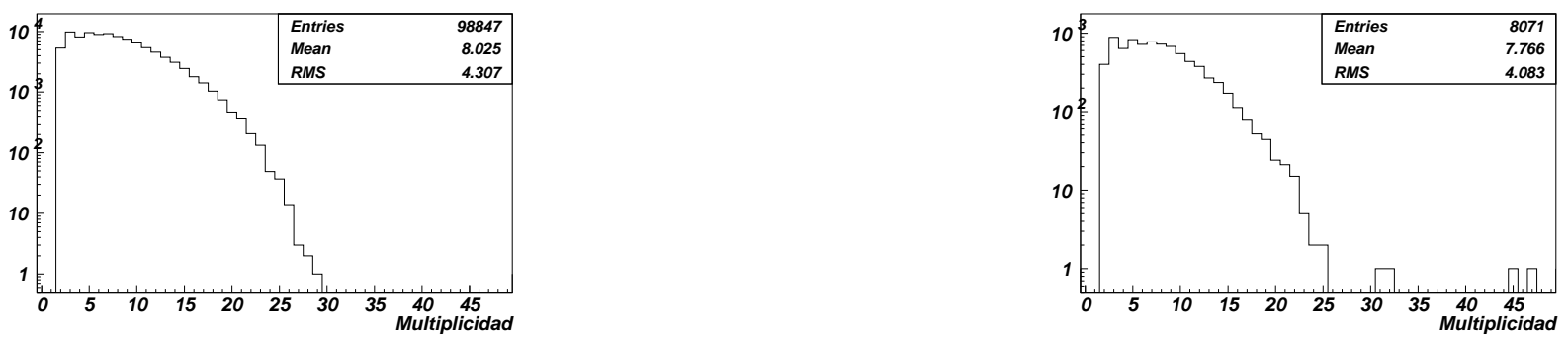

Figura 5.286: Multiplicidad en eventos con más de una trayectoria en la región del vértice. Izquierda: haz de bariones. Derecha: haz de mesones(pos $500 \mathrm{C}$ ). 


\subsubsection{Distribuciones de multiplicidad y momento}
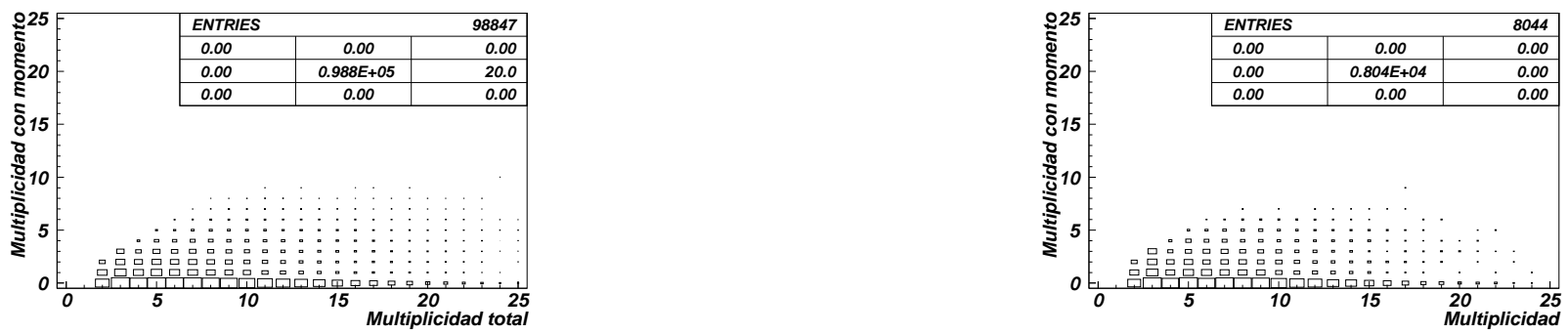

Figura 5.287: Multiplicidad total contra multiplicidad con momento medido. Izquierda: haz de bariones. Derecha: haz de mesones(pos $500 \mathrm{C}$ ).
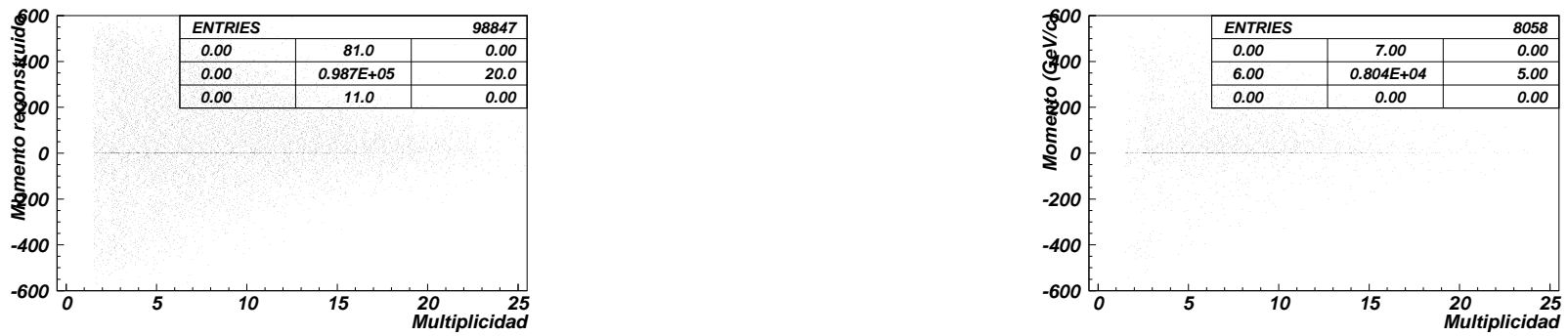

Figura 5.288: Multiplicidad contra momento.Izquierda: haz de bariones. Derecha: haz de mesones(pos $500 \mathrm{C})$. 
Distribuciones de momento total para eventos producidos por un haz de bariones
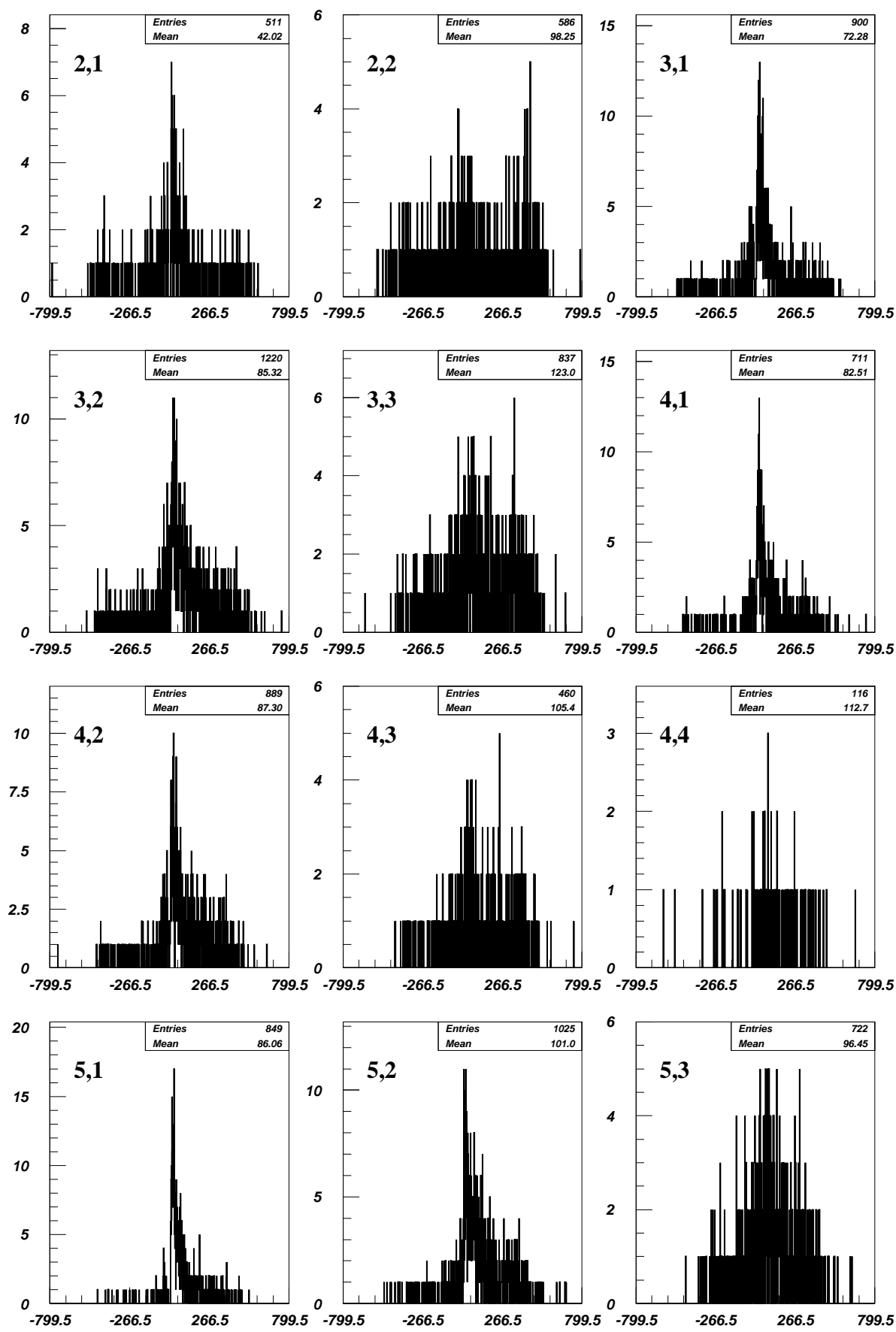

Figura 5.289: Distribuciones de momento. El primer indice: multiplicidad total, el segundo: multiplicidad con momento (pos $500 \mathrm{C}$ ) 

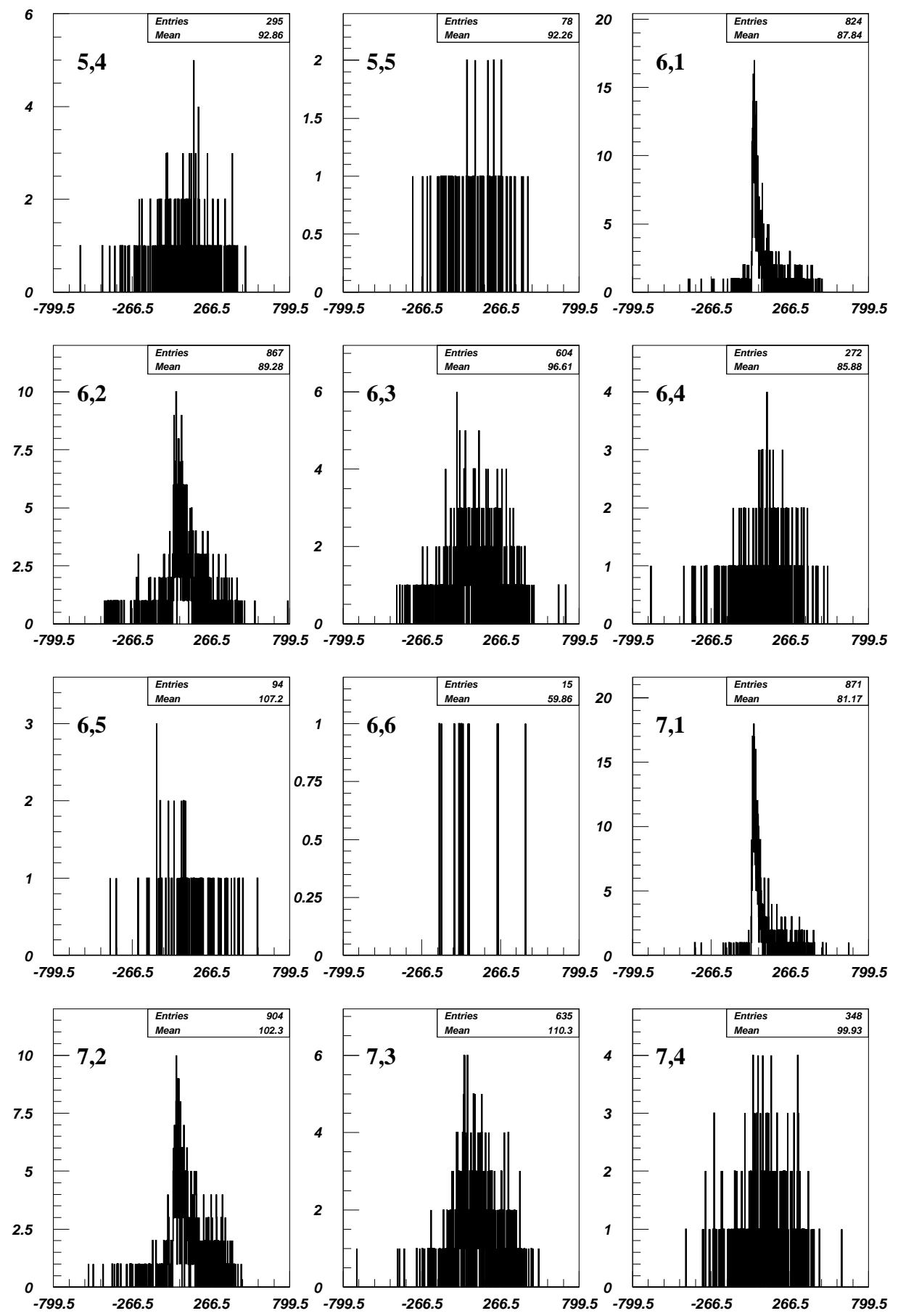

Figura 5.290: Distribuciones de momento. El primer índice: multiplicidad total, el segundo: multiplicidad con momento (pos $500 \mathrm{C}$ ). 

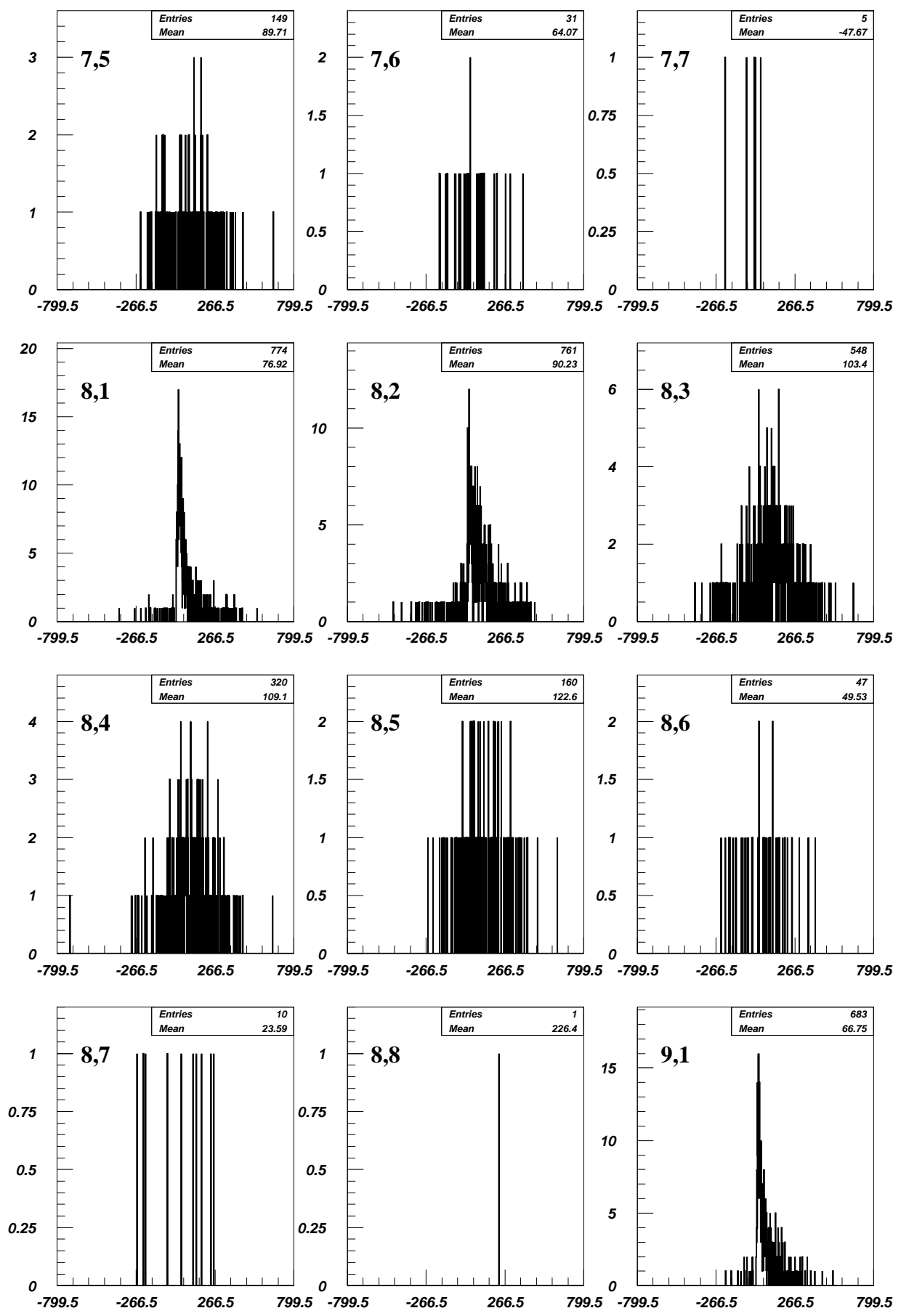

Figura 5.291: Distribuciones de momento. El primer índice: multiplicidad total, el segundo: multiplicidad con momento (pos $500 \mathrm{C}$ ). 

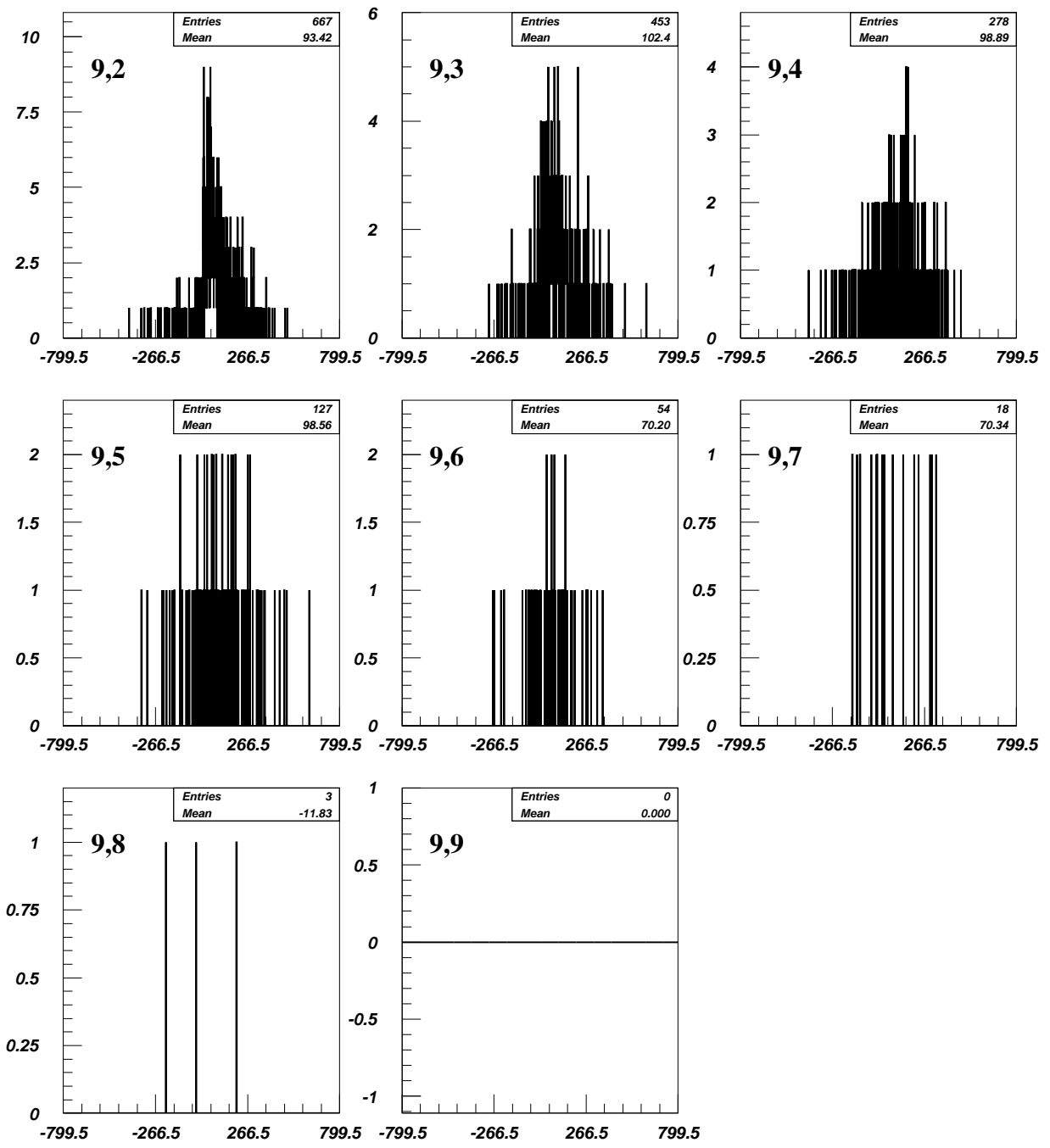

Figura 5.292: Distribuciones de momento. El primer índice: multiplicidad total, el segundo: multiplicidad con momento (pos $500 \mathrm{C}$ ). 
Distribuciones de momento total para eventos producidos por un haz de mesones
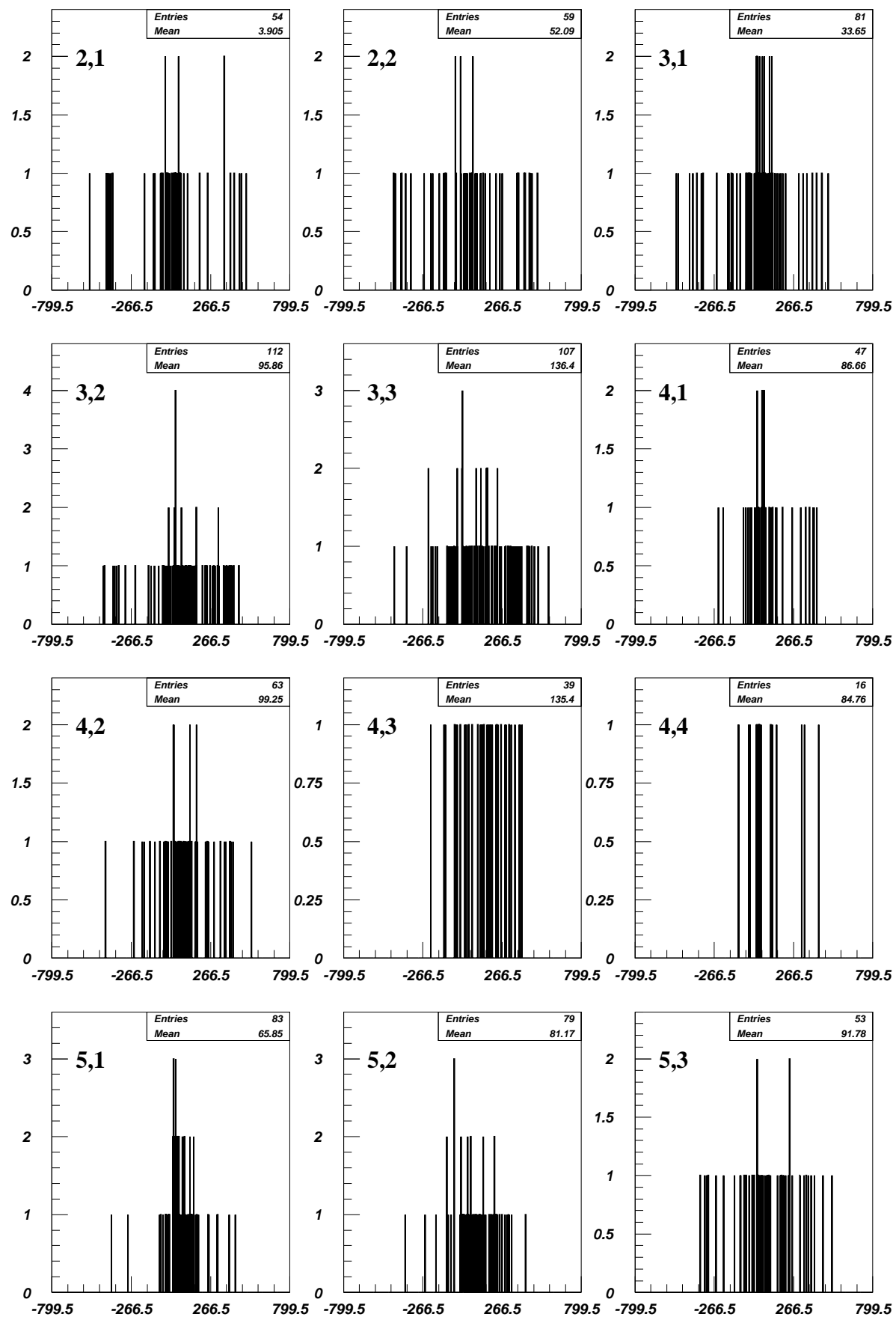

Figura 5.293: Distribuciones de momento. El primer indice: multiplicidad total, el segundo: multiplicidad con momento (pos $500 \mathrm{C}$ ) 

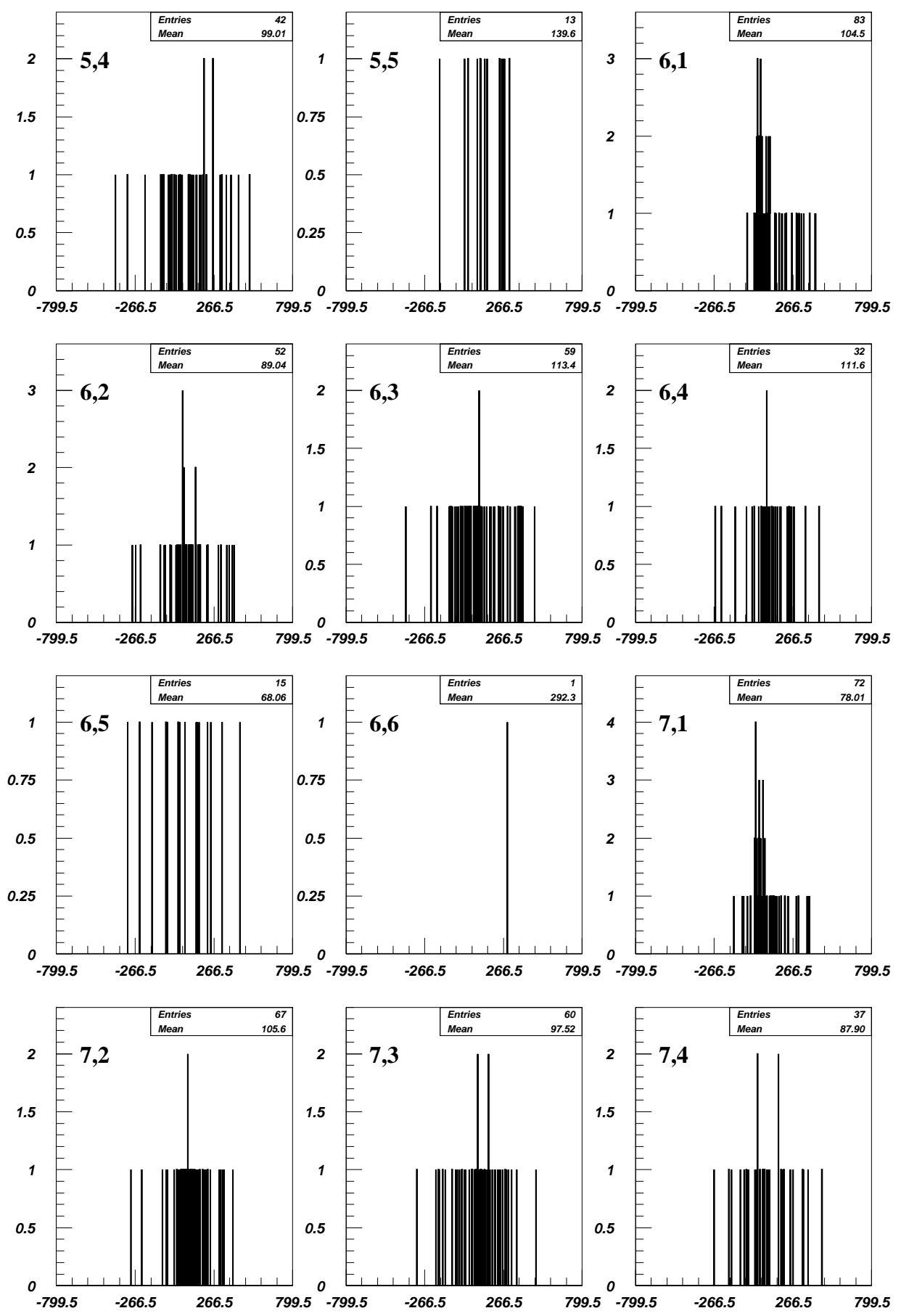

Figura 5.294: Distribuciones de momento. El primer índice: multiplicidad total, el segundo: multiplicidad con momento (pos $500 \mathrm{C}$ ). 

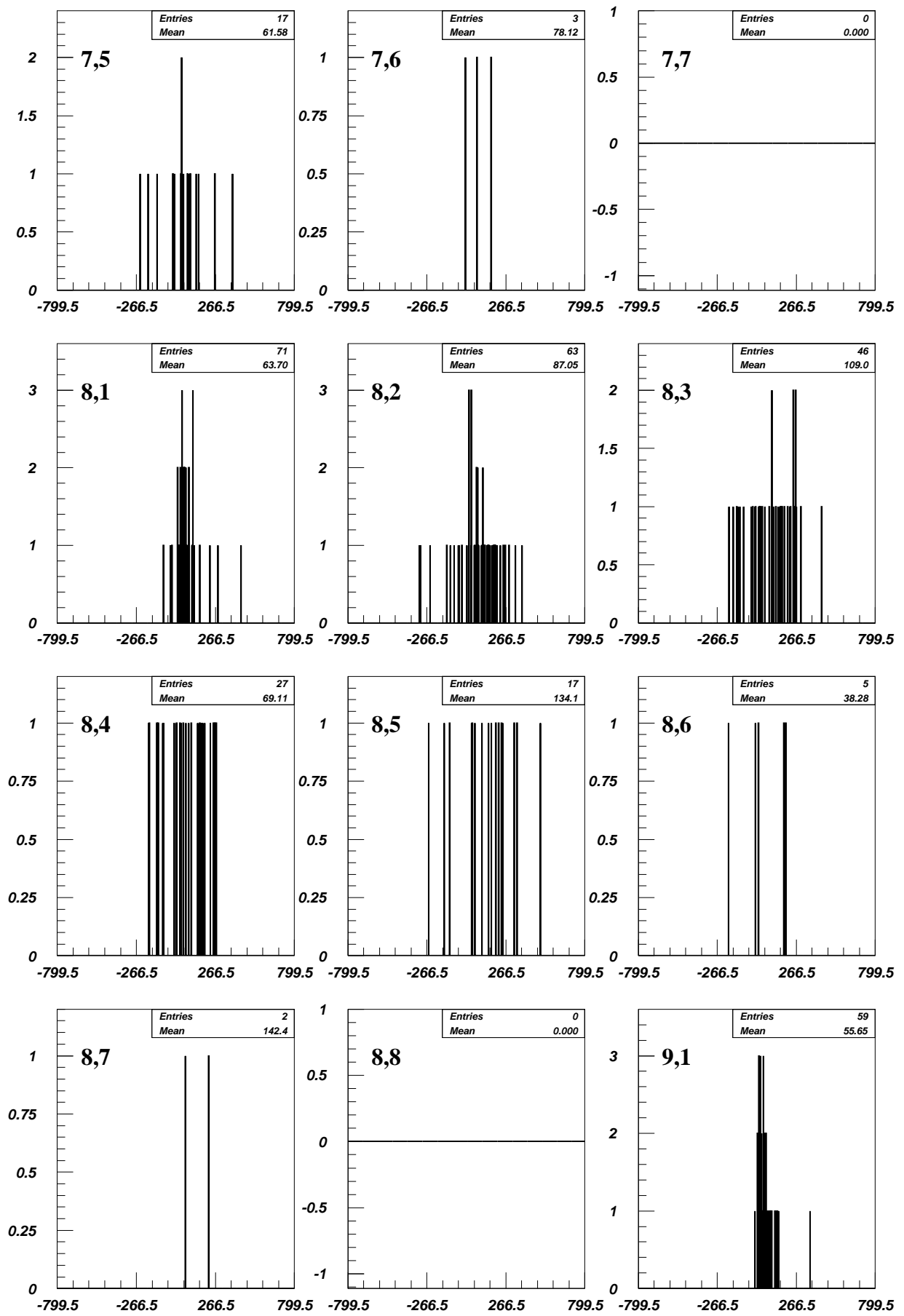

Figura 5.295: Distribuciones de momento. El primer índice: multiplicidad total, el segundo: multiplicidad con momento (pos $500 \mathrm{C}$ ). 

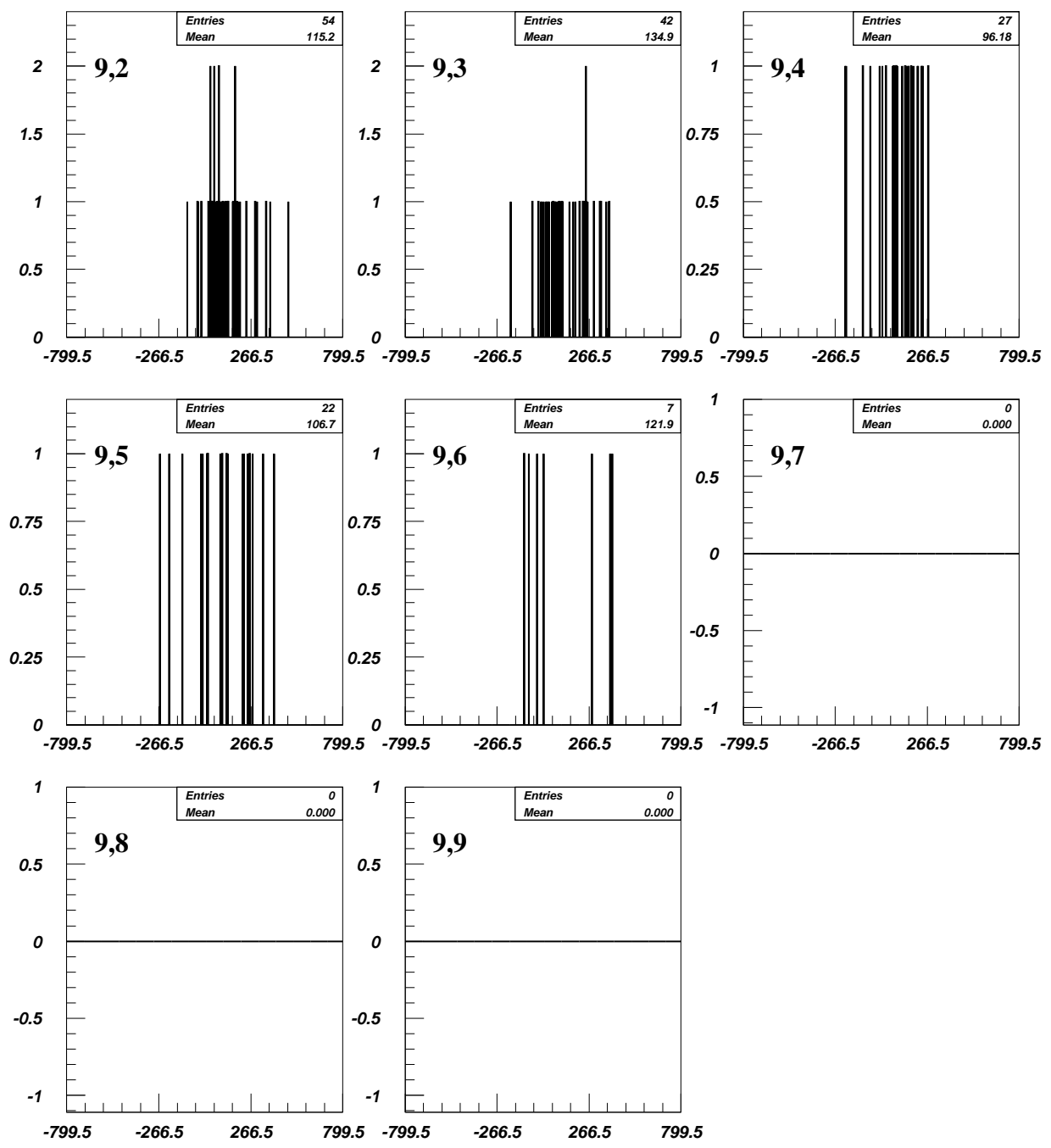

Figura 5.296: Distribuciones de momento. El primer índice: multiplicidad total, el segundo: multiplicidad con momento (pos $500 \mathrm{C}$ ). 
Distribuciones del valor absoluto del momento total para eventos producidos por un haz de bariones
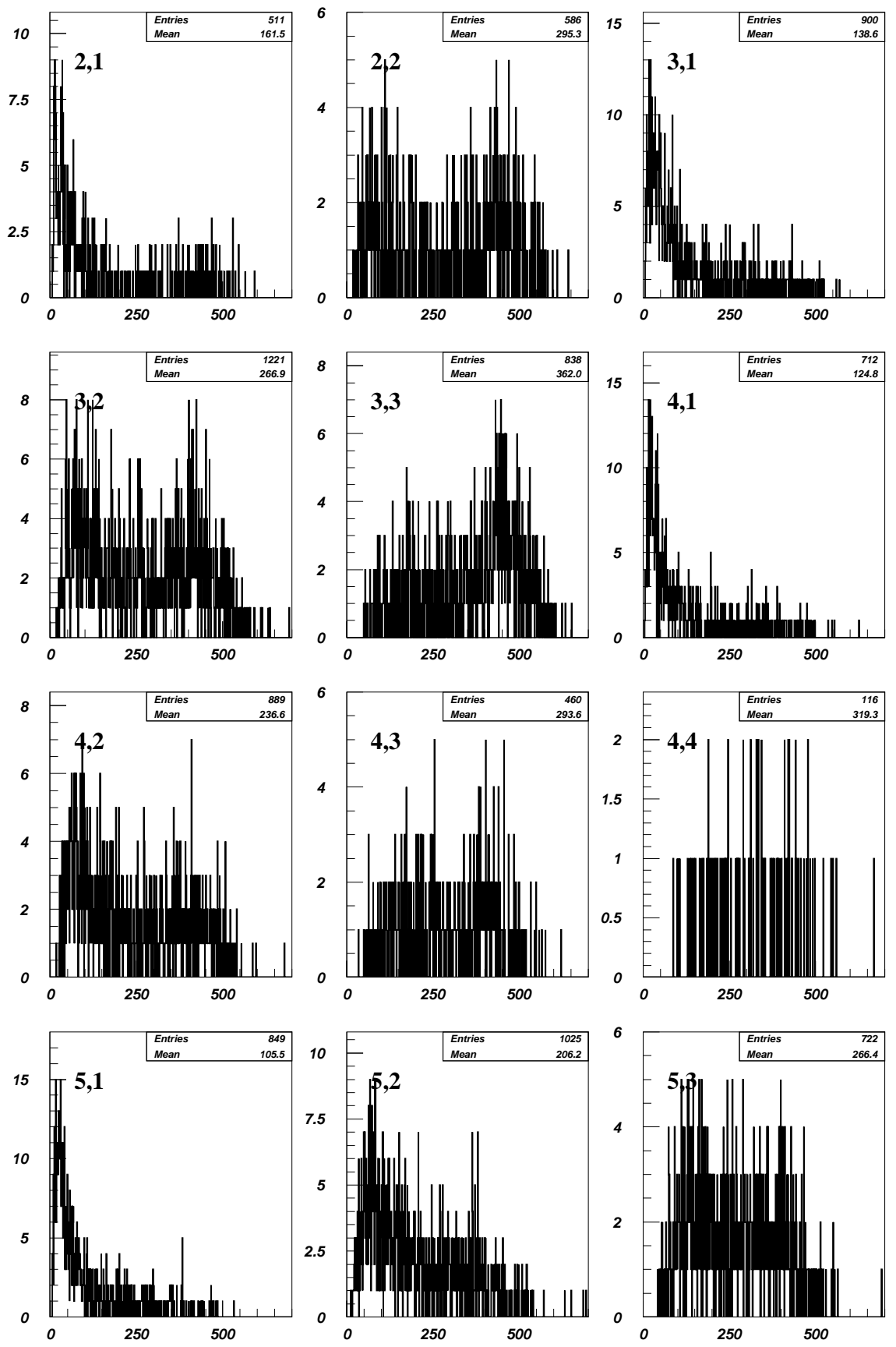

Figura 5.297: Distribuciones de momento. El primer indice: multiplicidad total, el segundo: multiplicidad con momento (pos $500 \mathrm{C}$ ). 

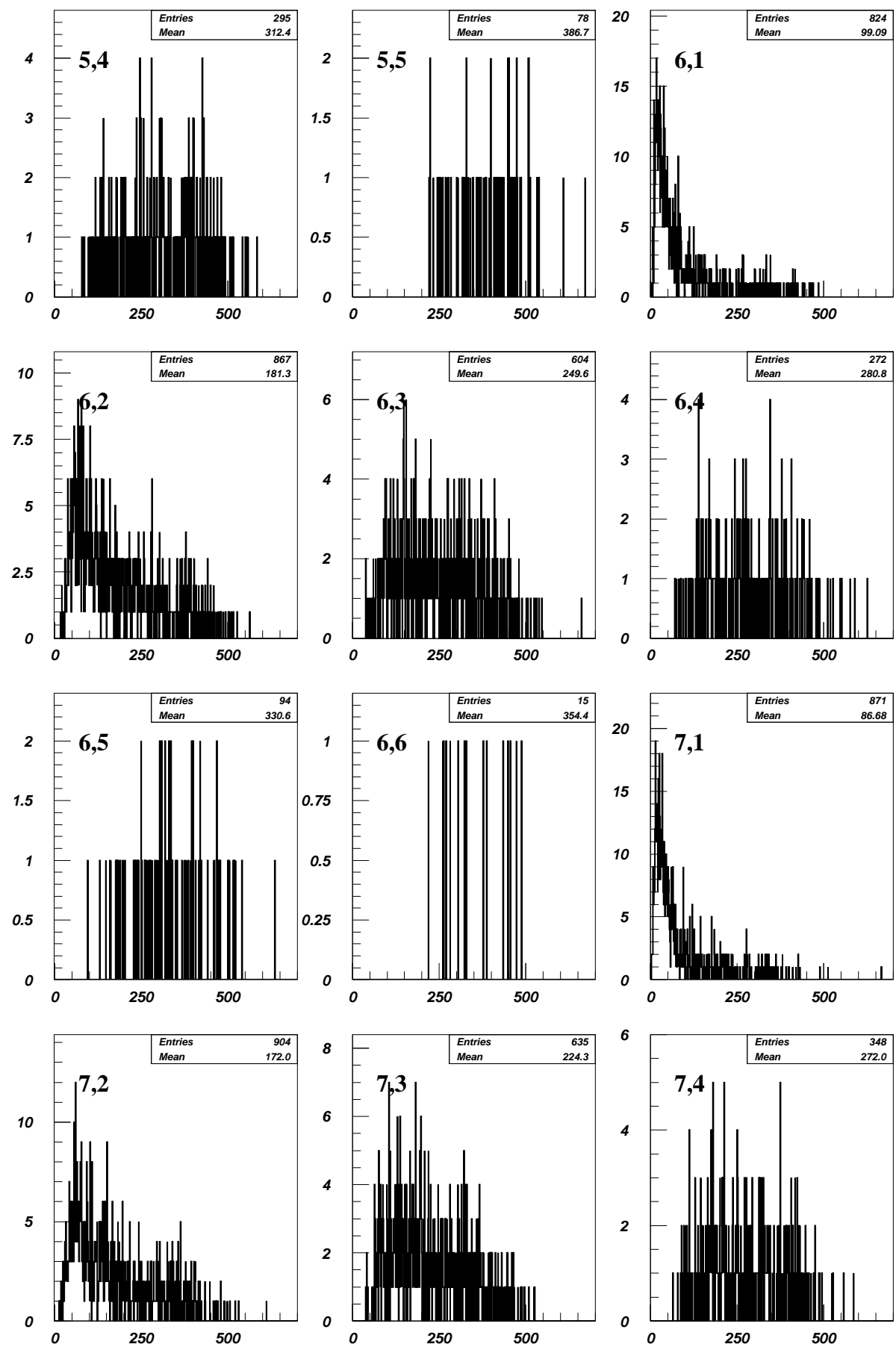

Figura 5.298: Distribuciones de momento. El primer índice: multiplicidad total, el segundo: multiplicidad con momento (pos $500 \mathrm{C}$ ). 

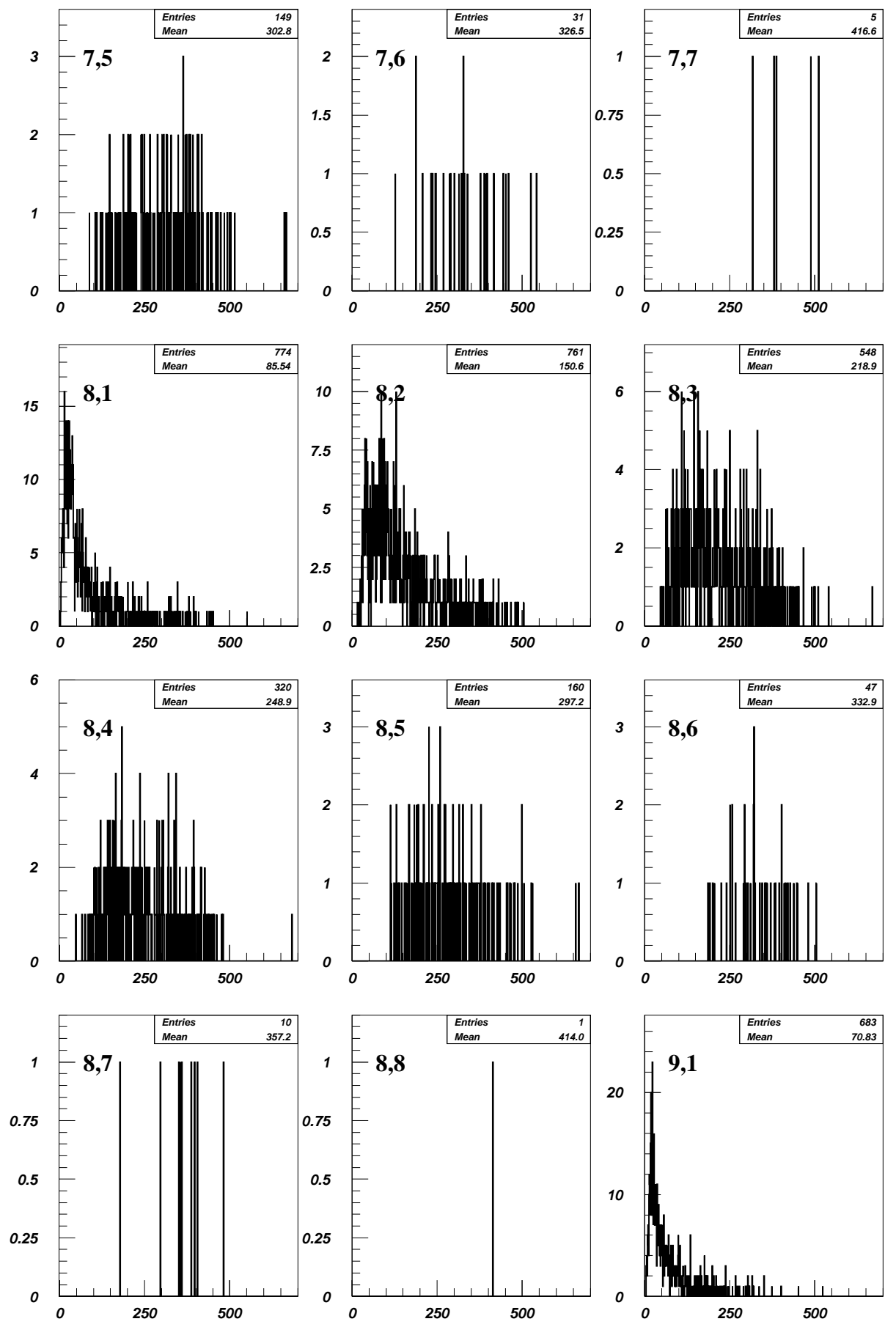

Figura 5.299: Distribuciones de momento. El primer índice: multiplicidad total, el segundo: multiplicidad con momento (pos $500 \mathrm{C}$ ). 

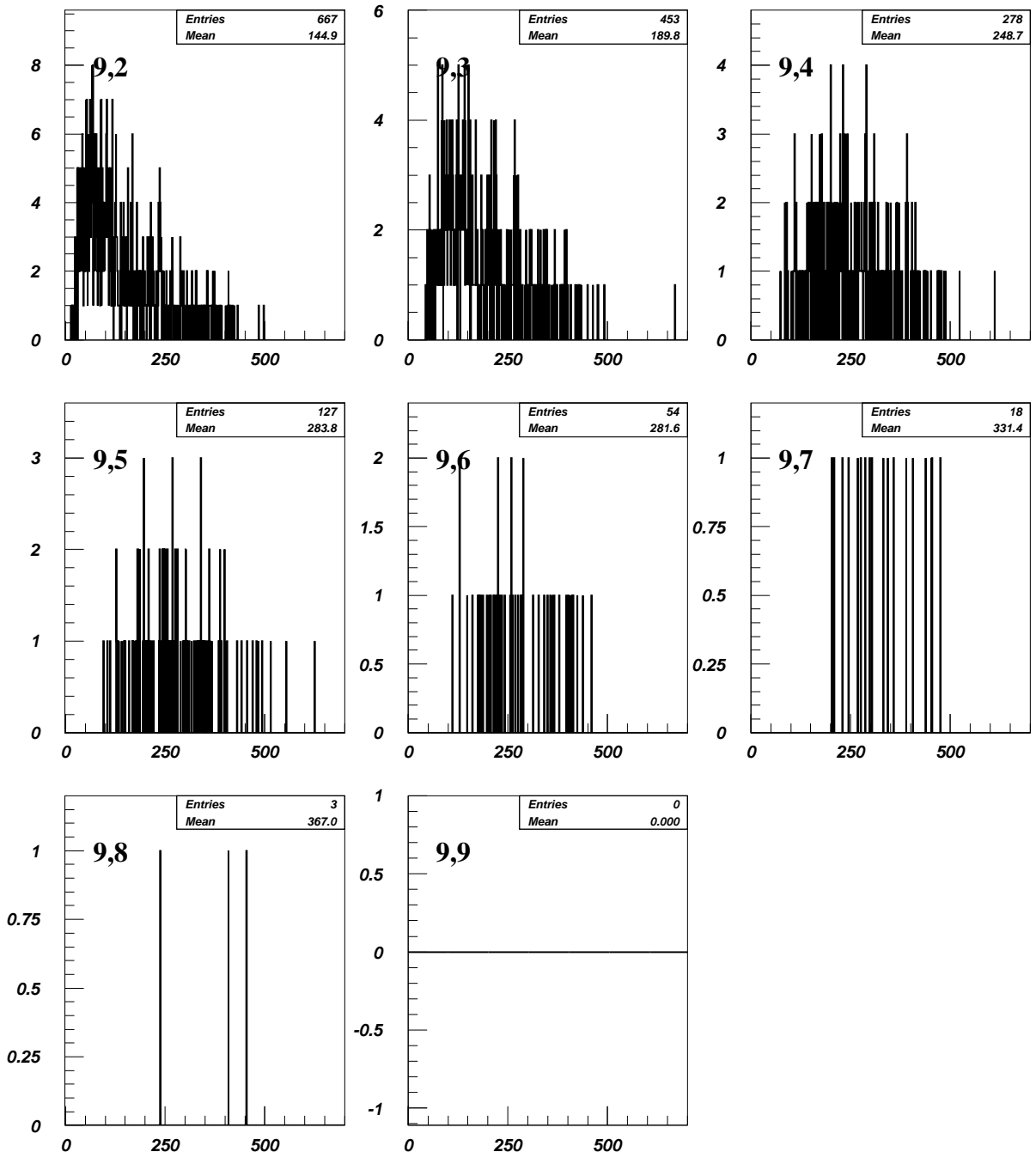

Figura 5.300: Distribuciones de momento. El primer índice: multiplicidad total, el segundo: multiplicidad con momento (pos $500 \mathrm{C}$ ). 
Distribuciones del valor absoluto del momento total para eventos producidos por un haz de mesones
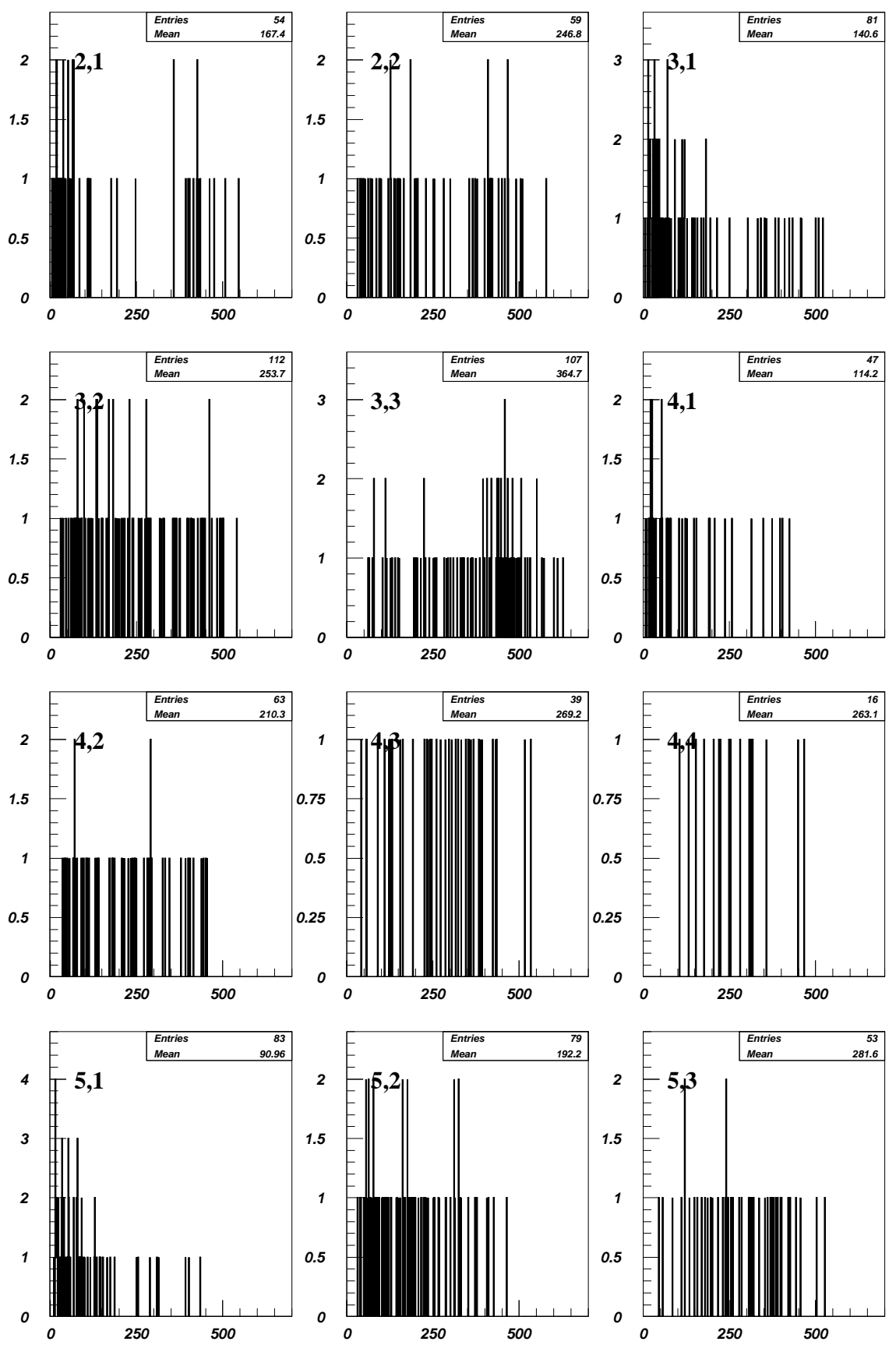

Figura 5.301: Distribuciones de momento. El primer indice: multiplicidad total, el segundo: multiplicidad con momento (pos $500 \mathrm{C}$ ) 

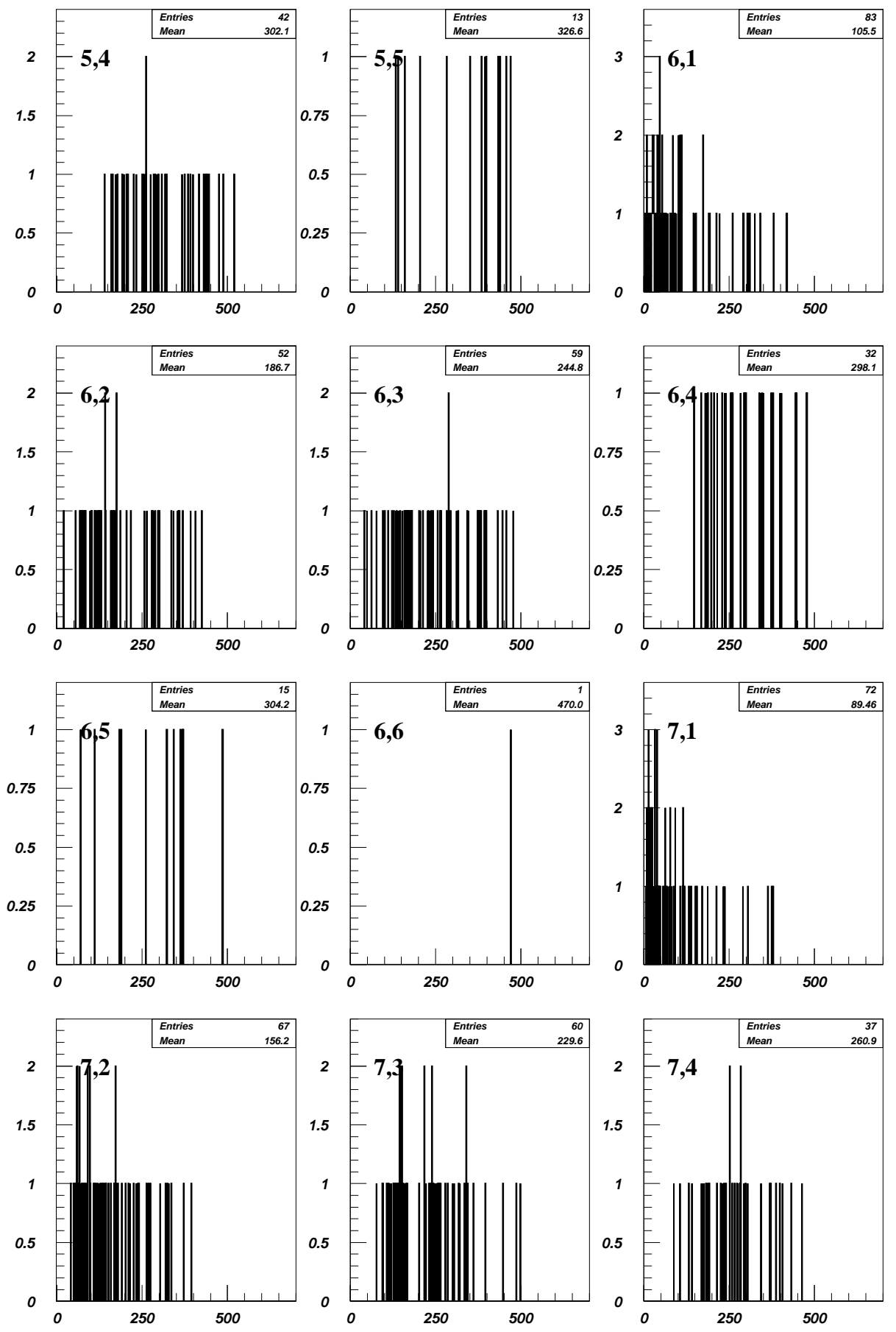

Figura 5.302: Distribuciones de momento. El primer índice: multiplicidad total, el segundo: multiplicidad con momento (pos $500 \mathrm{C}$ ). 

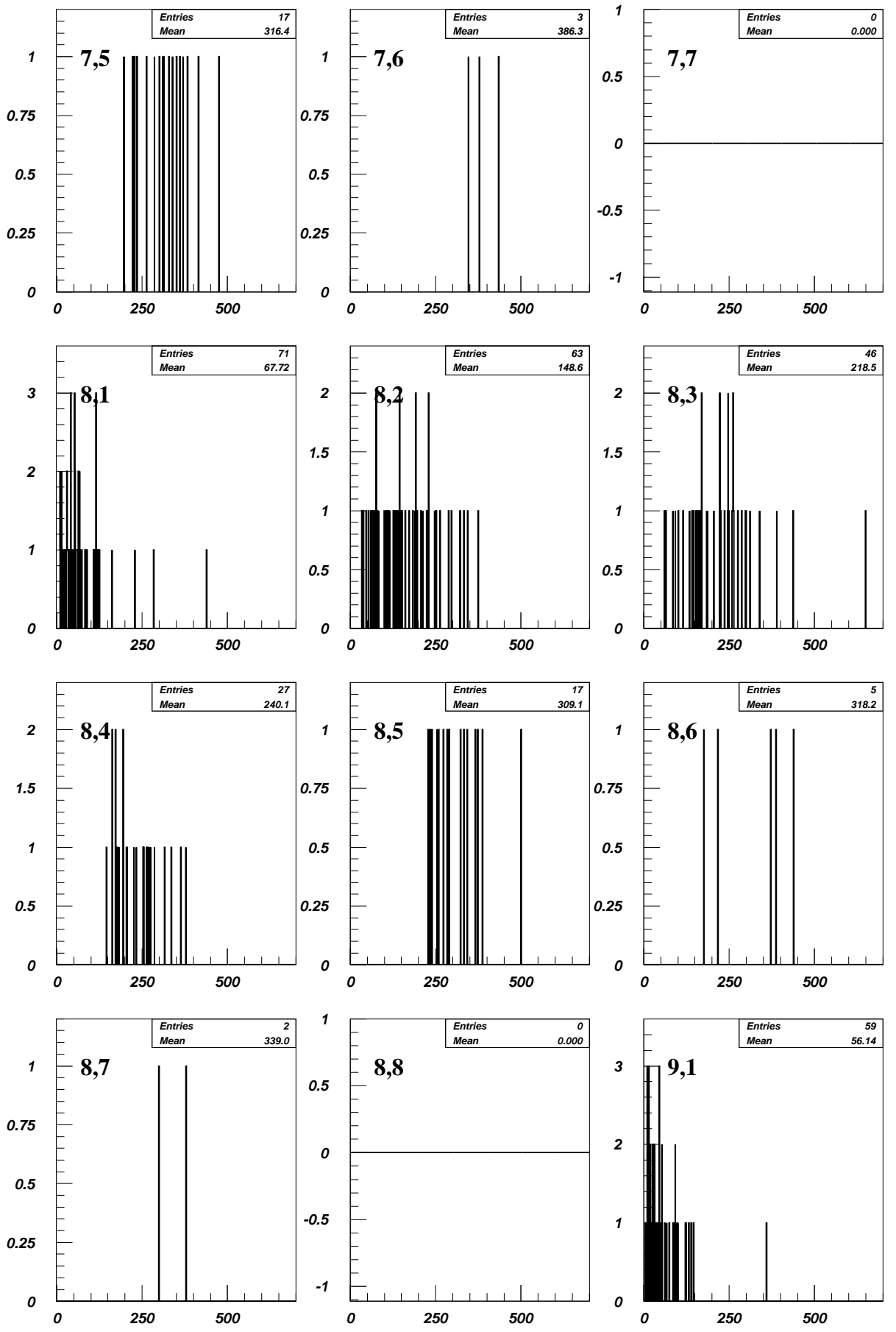

Figura 5.303: Distribuciones de momento. El primer índice: multiplicidad total, el segundo: multiplicidad con momento (pos $500 \mathrm{C}$ ). 

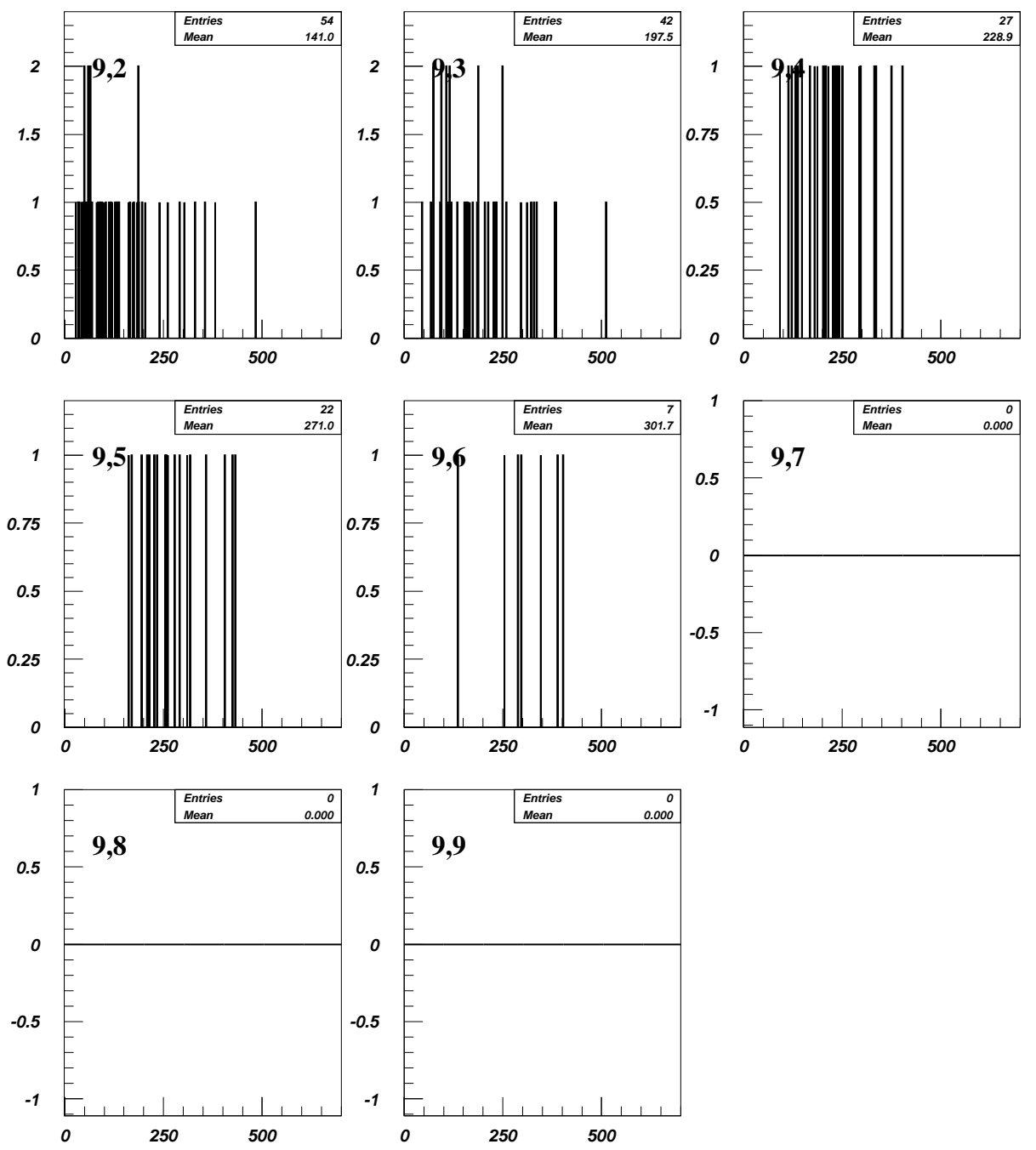

Figura 5.304: Distribuciones de momento. El primer índice: multiplicidad total, el segundo: multiplicidad con momento (pos $500 \mathrm{C}$ ). 
Distribuciones del momento de las trayectorias para eventos producidos por un haz de bariones
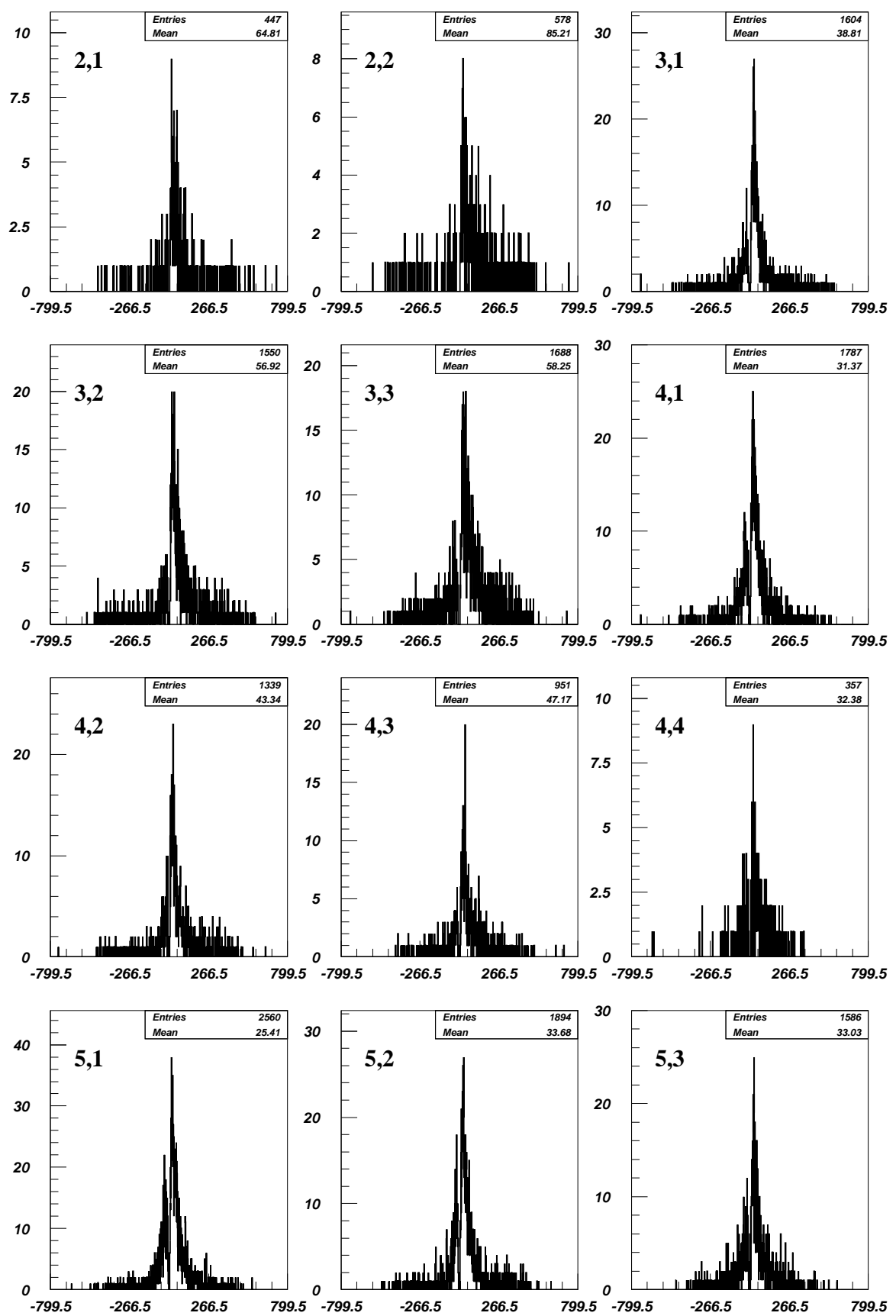

Figura 5.305: Distribuciones de momento. El primer indice: multiplicidad total, el segundo: multiplicidad con momento (pos $500 \mathrm{C}$ ) 

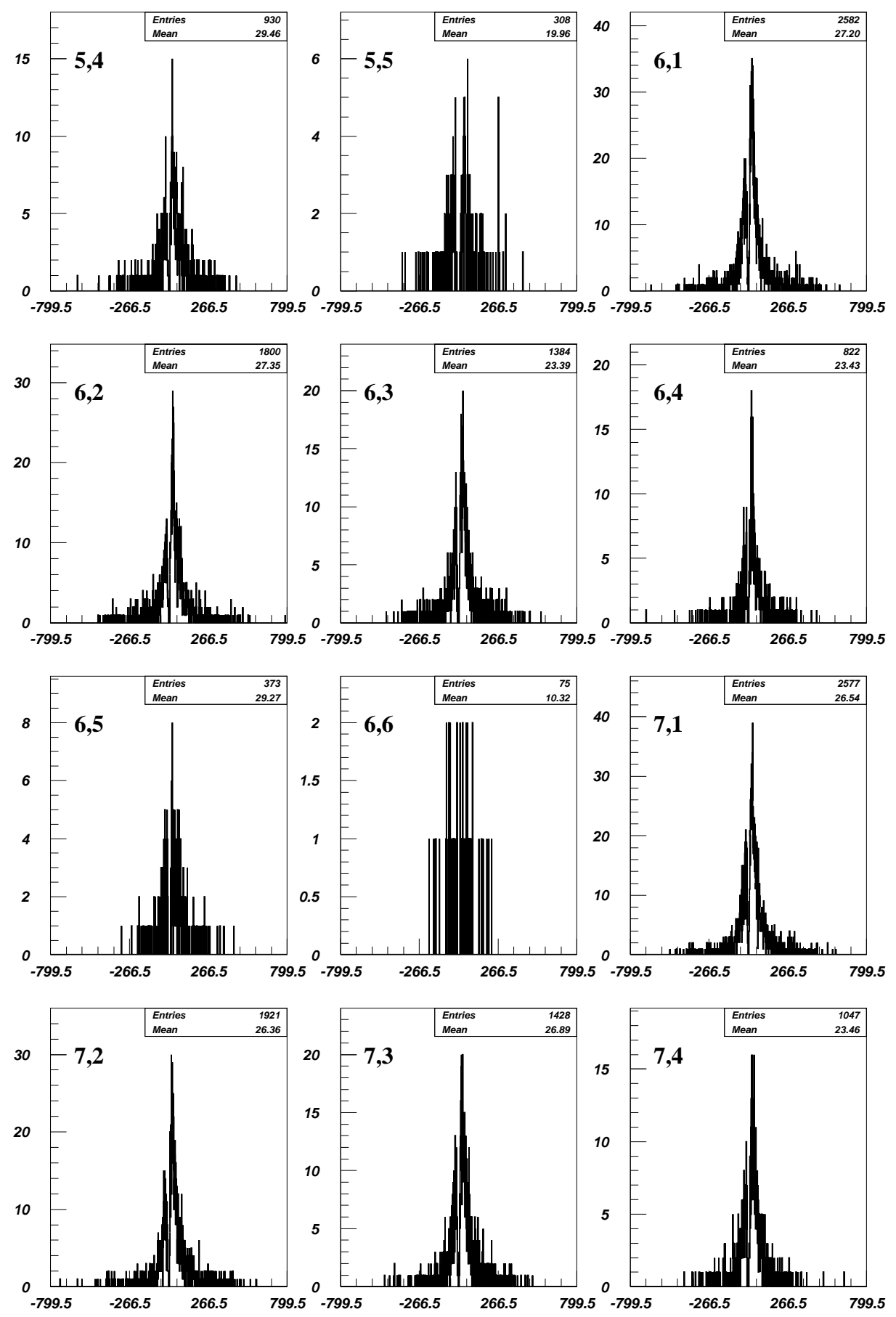

Figura 5.306: Distribuciones de momento. El primer índice: multiplicidad total, el segundo: multiplicidad con momento (pos $500 \mathrm{C}$ ). 

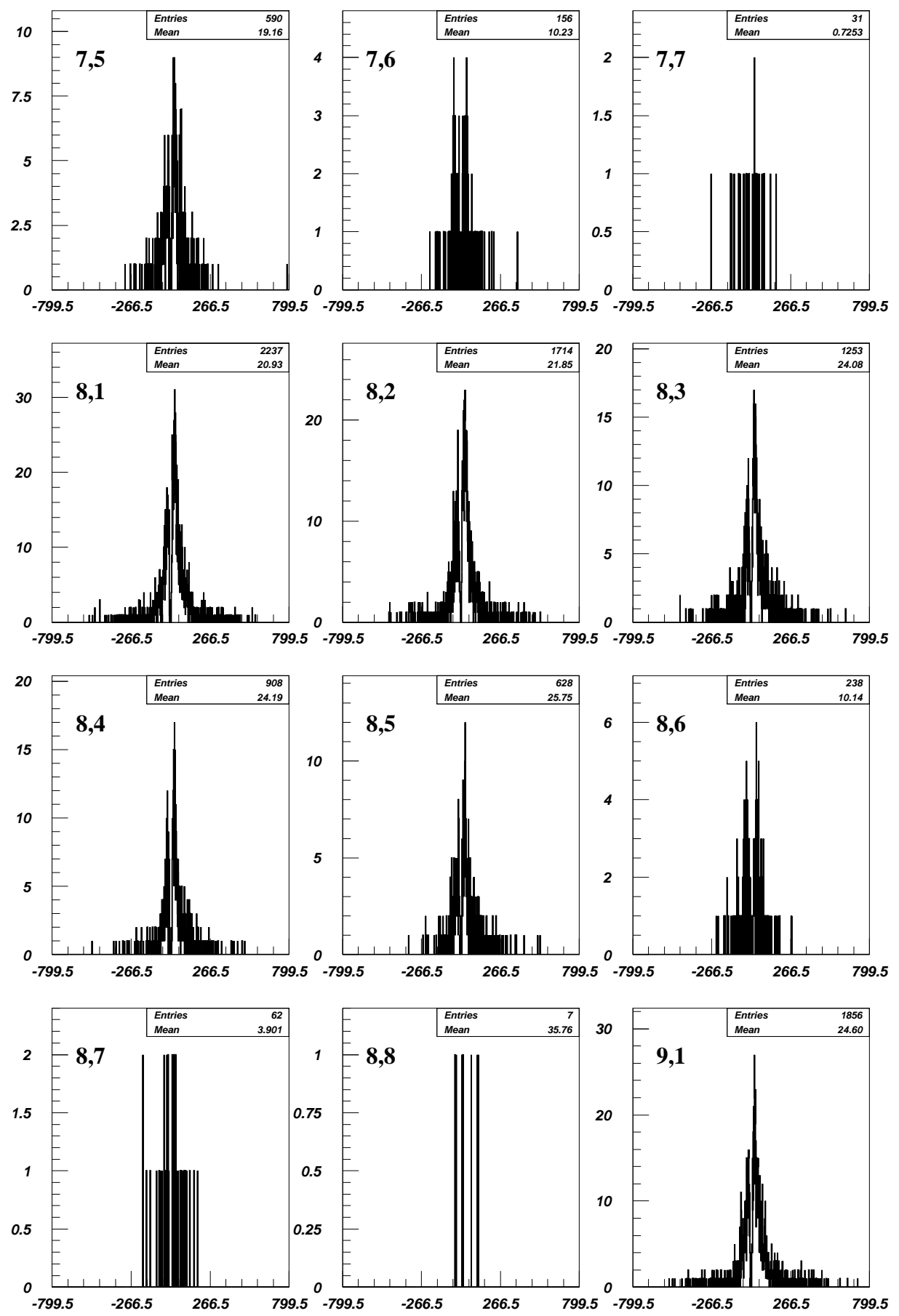

Figura 5.307: Distribuciones de momento. El primer índice: multiplicidad total, el segundo: multiplicidad con momento (pos $500 \mathrm{C}$ ). 

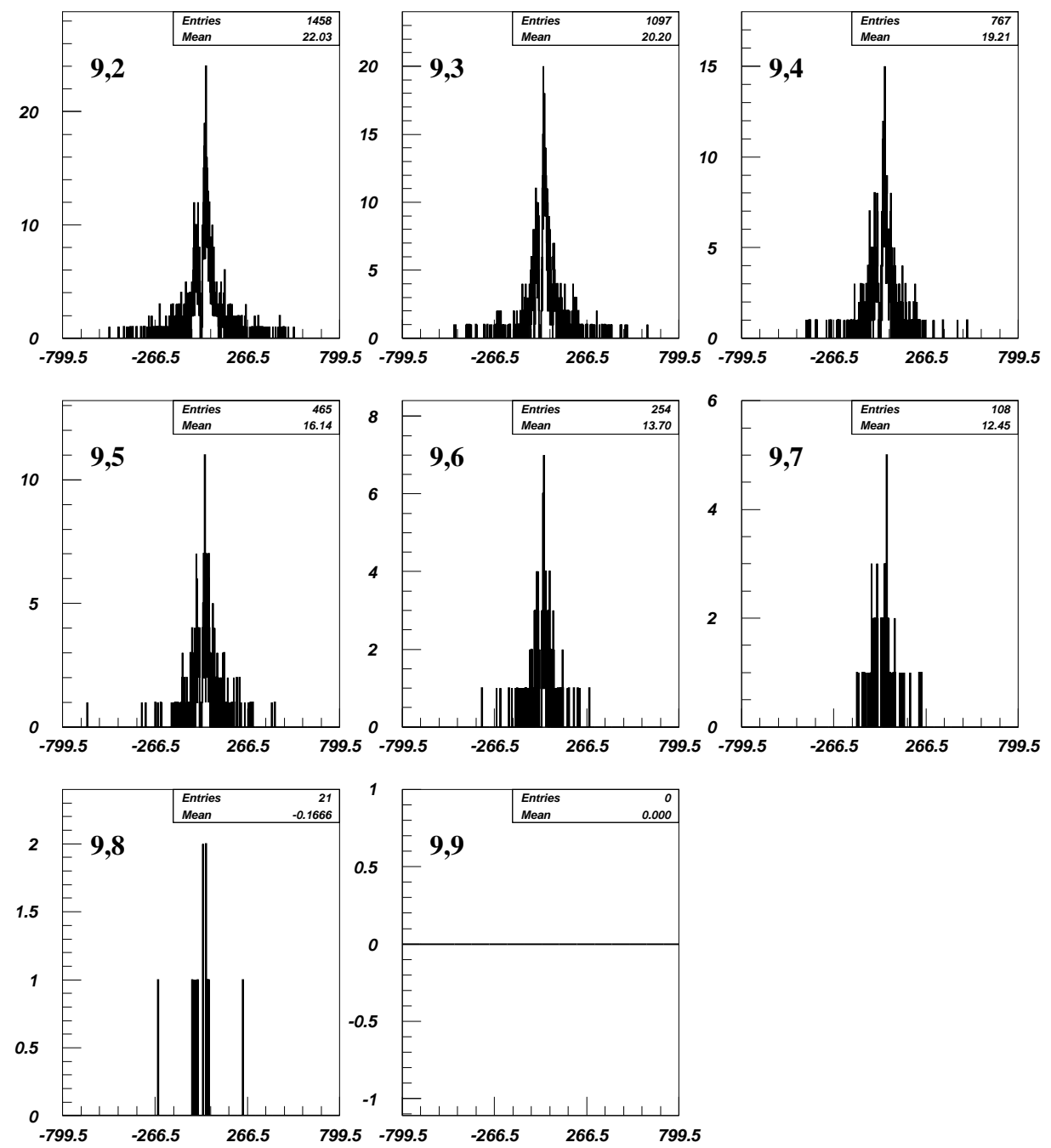

Figura 5.308: Distribuciones de momento. El primer índice: multiplicidad total, el segundo: multiplicidad con momento (pos $500 \mathrm{C}$ ). 
Distribuciones del momento de las trayectorias para eventos producidos por un haz de mesones
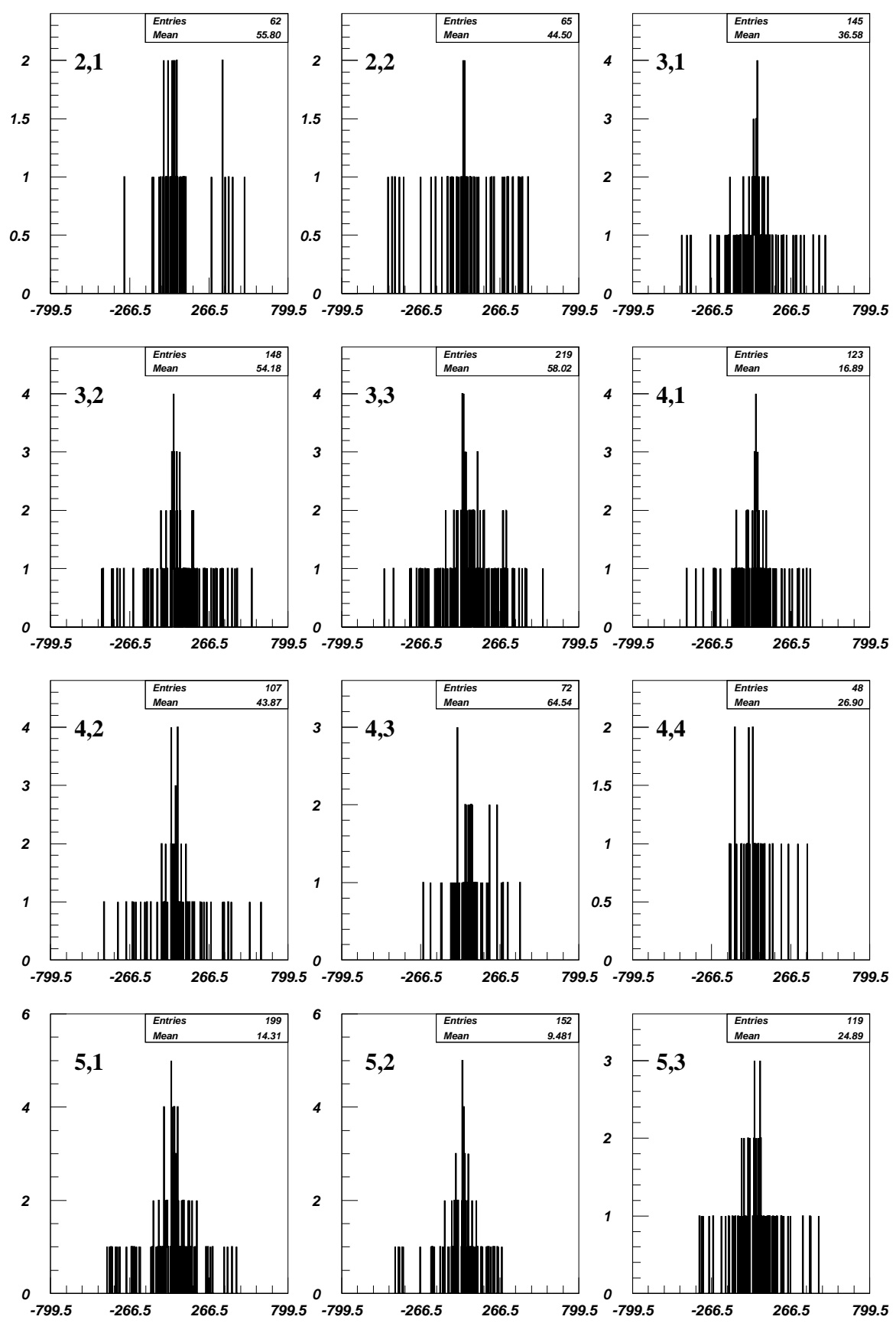

Figura 5.309: Distribuciones de momento. El primer indice: multiplicidad total, el segundo: multiplicidad con momento (pos $500 \mathrm{C}$ ). 

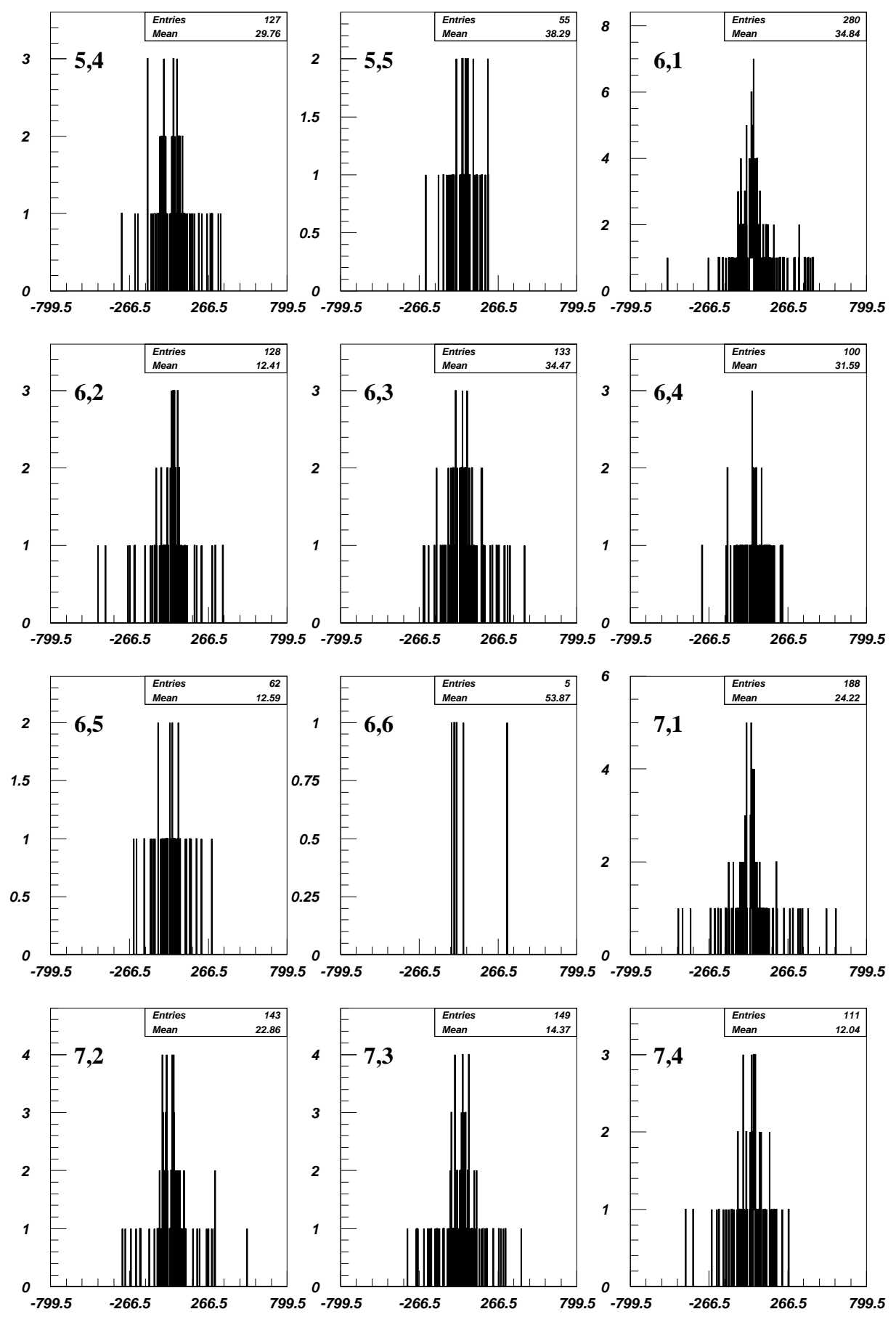

Figura 5.310: Distribuciones de momento. El primer índice: multiplicidad total, el segundo: multiplicidad con momento (pos $500 \mathrm{C}$ ). 

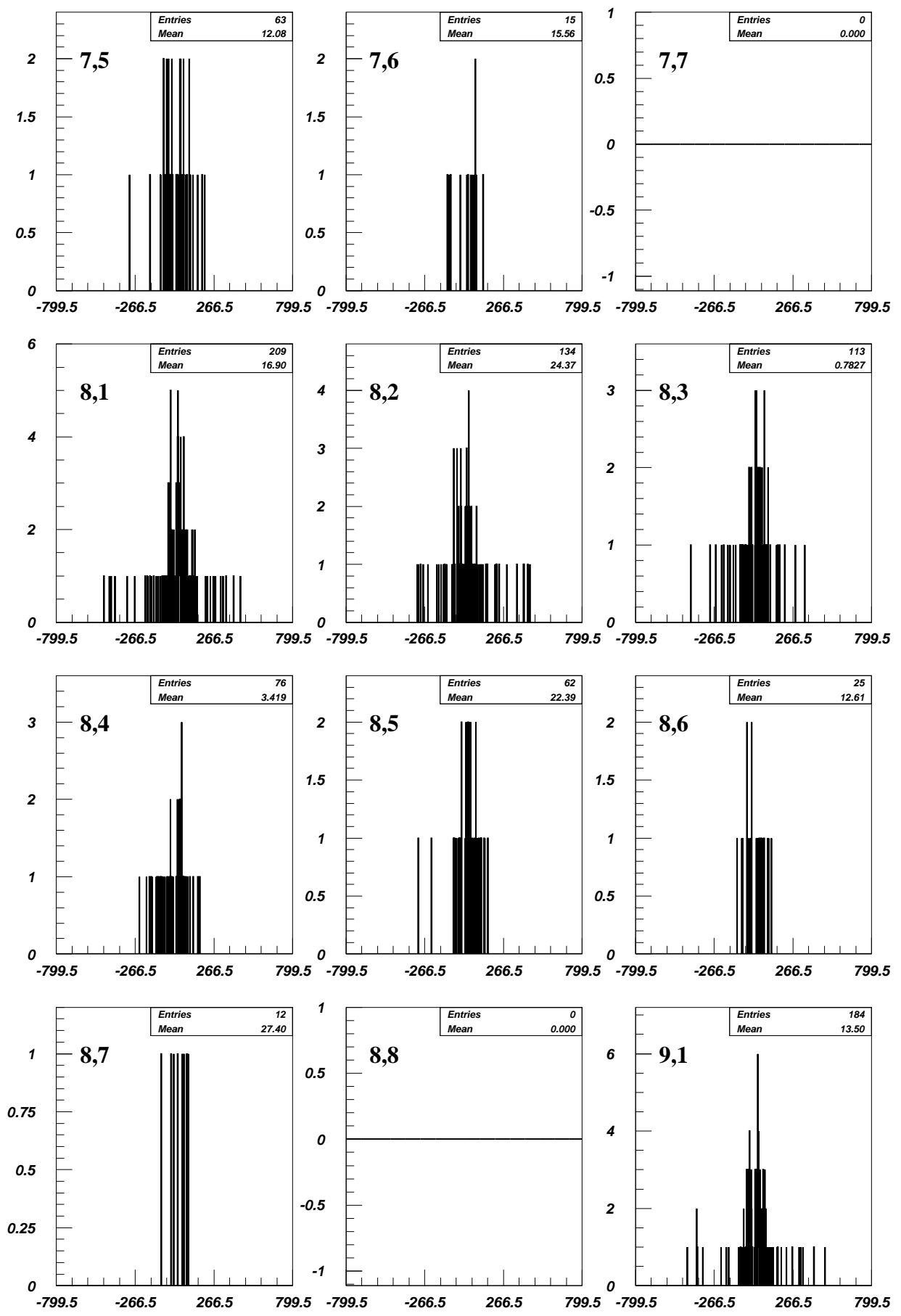

Figura 5.311: Distribuciones de momento. El primer índice: multiplicidad total, el segundo: multiplicidad con momento (pos $500 \mathrm{C}$ ). 

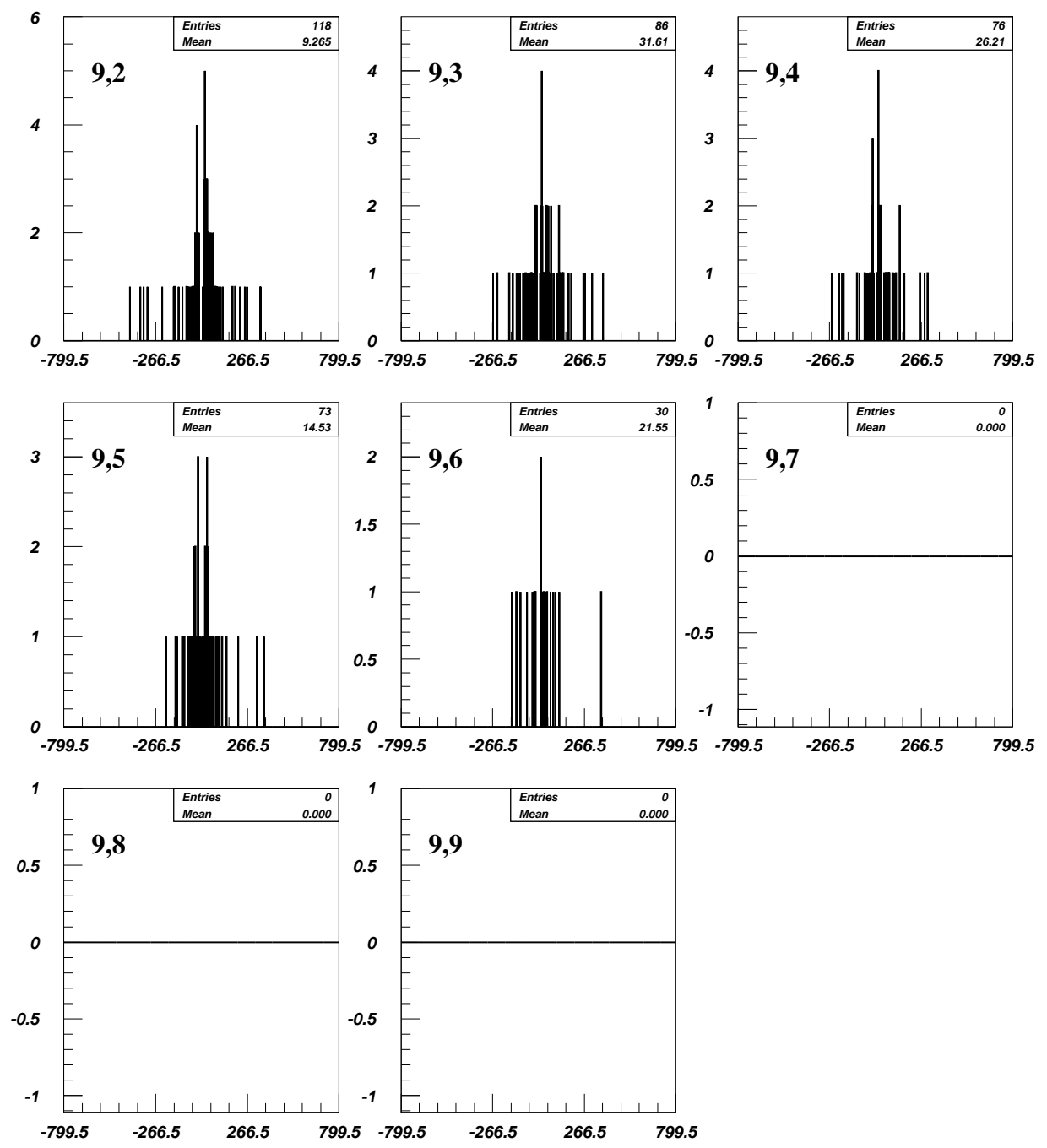

Figura 5.312: Distribuciones de momento. El primer índice: multiplicidad total, el segundo: multiplicidad con momento (pos $500 \mathrm{C}$ ). 


\subsection{Estudio de aceptancia en ángulo}
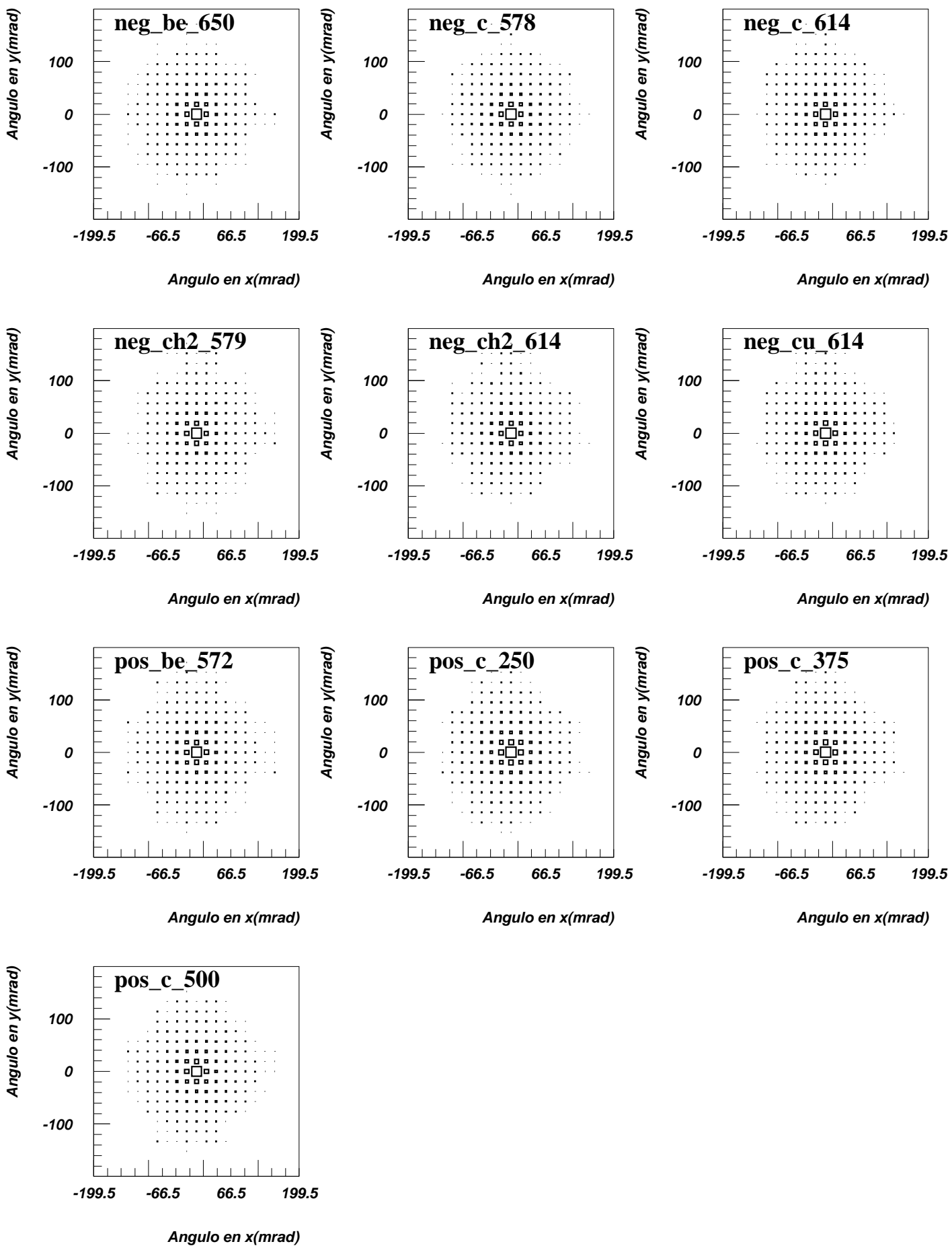

Figura 5.313: Histogramas de distribucion angular para datos producidos por haz de bariones 

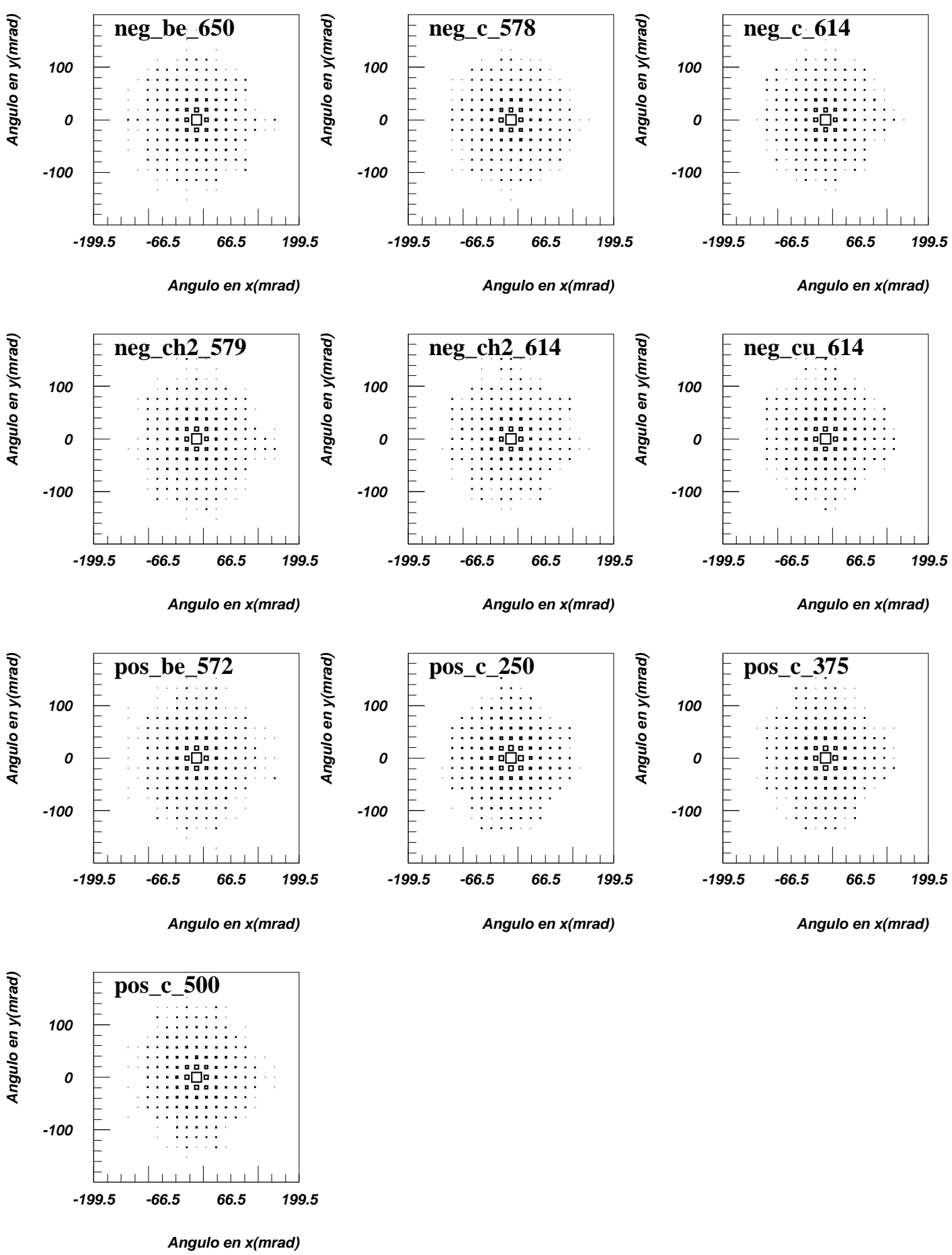

Figura 5.314: Histogramas de distribucion angular para datos producidos por haz de mesones 


\section{Capítulo 6}

\section{Conclusiones}

Como resultado de este trabajo se obtuvieron, distribuciones de multiplicidad y momento de las multiplicidades, que ya en si constituyen la principal contribución de esta tesis, pues toda la información presentada en el capítulo anterior es aplicable a la simulación montecarlo utilizada en la investigación de física de rayos cósmicos y de pruducción de neutrinos.

Es claro que con tan amplia gama de resultados es posible hacer multiples comparaciones entre los datos que se presentan, a fin de obtener información más específica. A continuación se presentan solo algunas comparaciones útiles de distribuciones de multiplicidades con diferentes condiciones fijas y solo una condición variable, a partir de las cuales se pueden observar a simple vista algunas de las propiedades del comportamiento de la multiplicidad en las interacciónes hadrónicas.

\subsection{Comparación de multiplicidad con haces de en- ergías diferentes}

En esta sección se presentan comparaciones hechas fijando las condiciones de material del blanco y polaridad y composición del haz y variando la energía. 

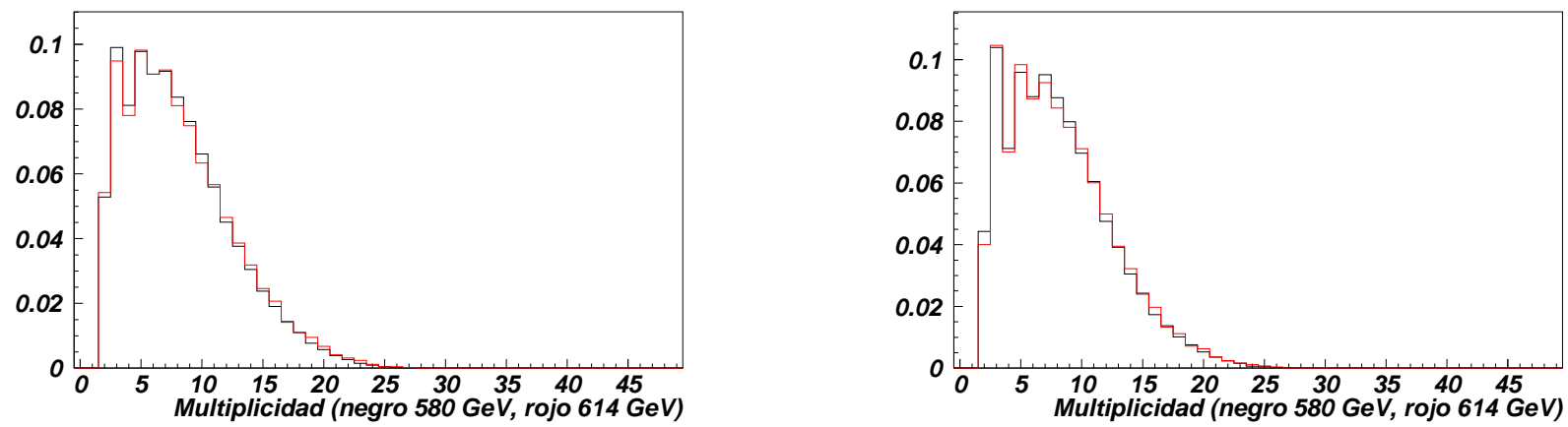

Figura 6.1: Comparación de multiplicidad, utilizando un haz negativo sobre un blanco de polietileno. Izquierda: haz de bariones. Derecha: haz de mesones.
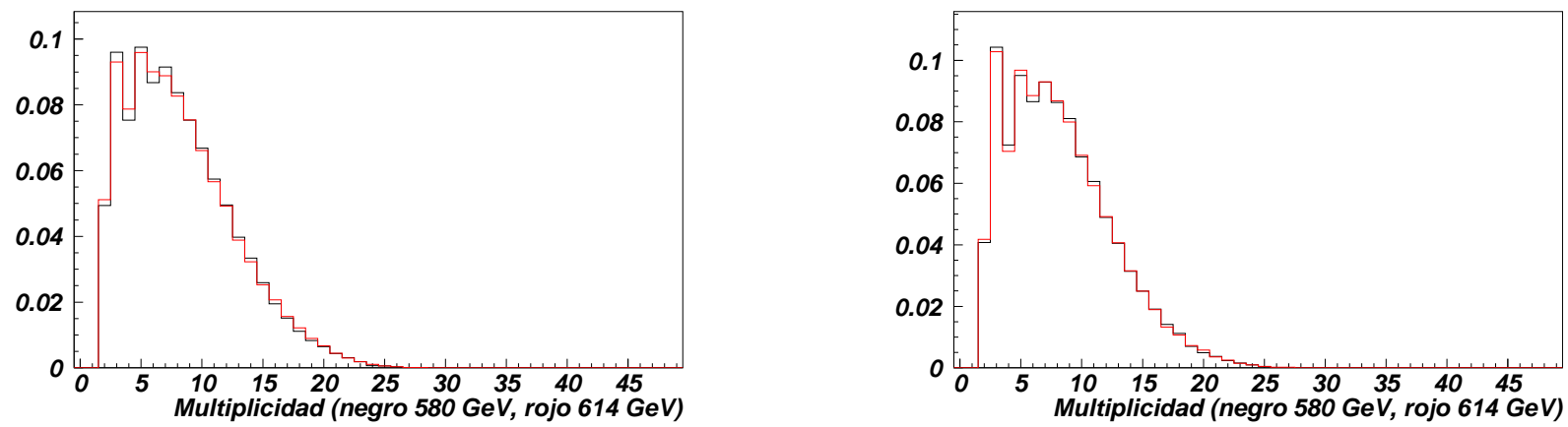

Figura 6.2: Comparación de multiplicidad, utilizando un haz negativo sobre un blanco de carbón. Izquierda: haz de bariones. Derecha: haz de mesones.
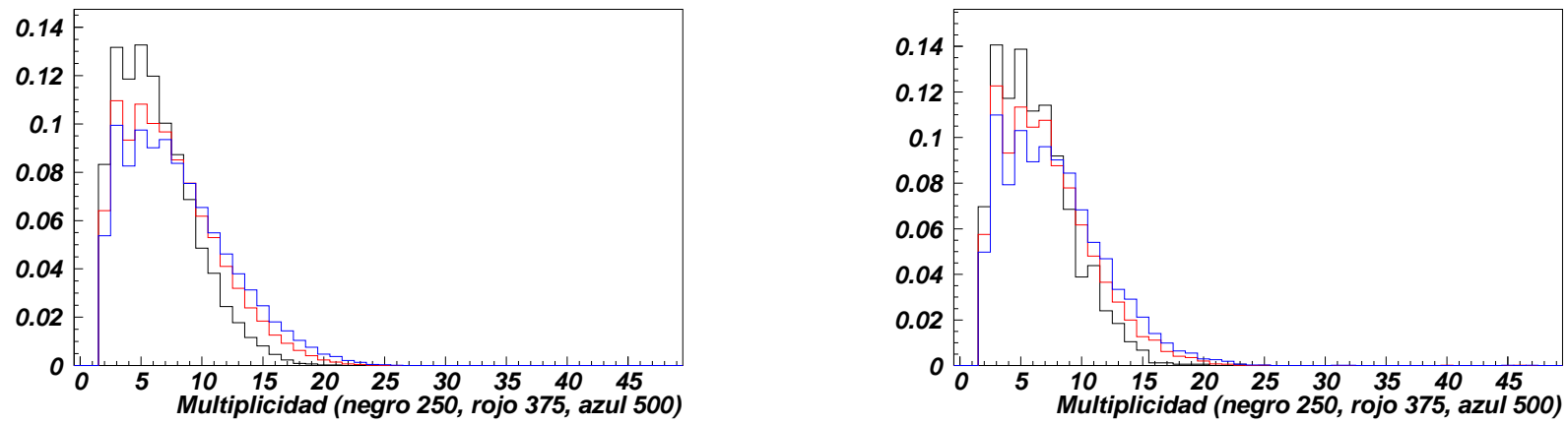

Figura 6.3: Comparación de multiplicidad, utilizando un haz positivo sobre un blanco de carbón.Izquierda: haz de bariones. Derecha: haz de mesones. 
En estos histogramas de comparación se puede observar que en efecto existe una dependencia de la multiplicidad con la energía del haz que la produce. En los histogramas donde la diferencia de energía no es mucha, ésta dependencia no es claramente apreciable, sin embargo, para el caso donde existe un factor 2 de diferencia entre la energía más baja y la más alta, esta diferencia es clara (fig 6.3).

A continuación se presenta una gráfica que muestra como varía la media de la multiplicidad como función de la energía del haz que la produce.

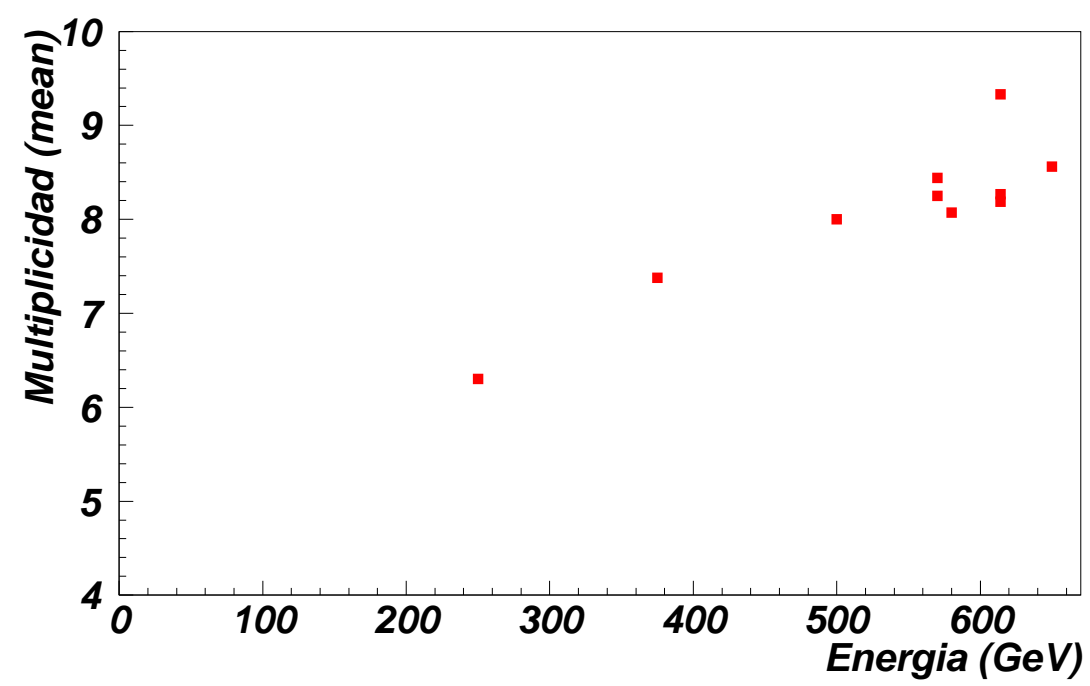

Figura 6.4: Comportamiento de la multiplicidad en función de la energía del haz.

Esta información se puede comparar con la que predicen los modelos ya existentes para la dependencia de la multiplicidad con el momento de las partículas que la producen, sin embargo ese trabajo ya va más allá del alcance de esta tesis. 


\subsection{Comparación de multiplicidad con composiciones del haz diferentes}

Las distribuciones, al igual que en el capítulo anterior se dividen en aquellas obtenidas por un haz de bariones o de mesones. A continuación se muestran comparaciones en donde se fijan todas las demás condiciones excepto la composición de haz (bariones, mesones).

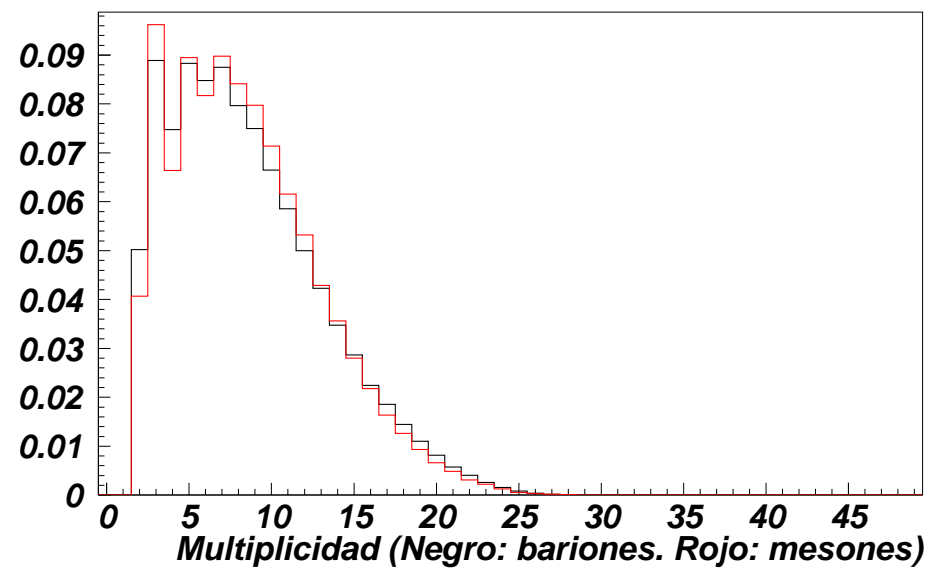

Figura 6.5: Comparación de multiplicidad entre un haz de mesones y un haz de bariones, para un haz de polaridad negativa de $650 \mathrm{GeV}$ sobre un blanco de berilio.

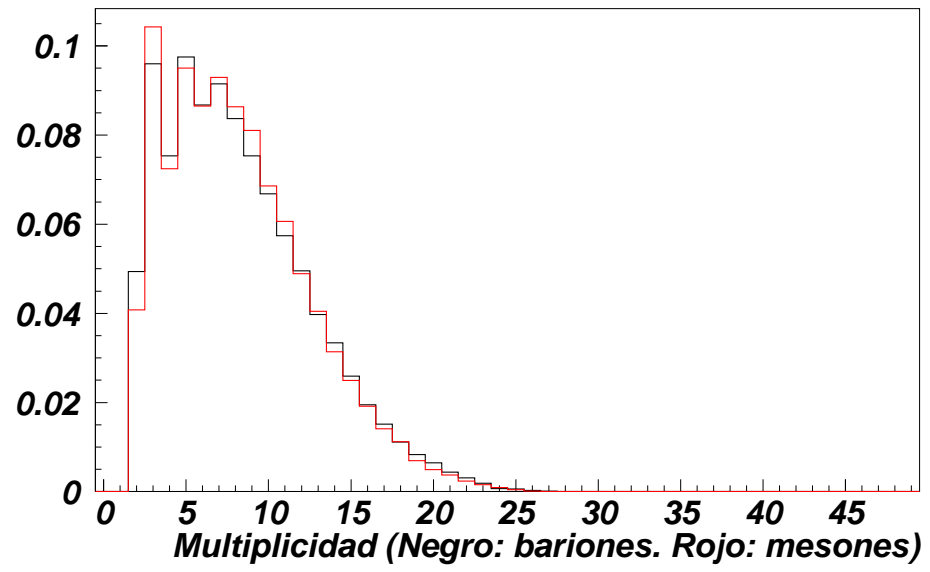

Figura 6.6: Comparación de multiplicidad entre un haz de mesones y un haz de bariones, para un haz de polaridad negativa de $580 \mathrm{GeV}$ sobre un blanco de carbón. 


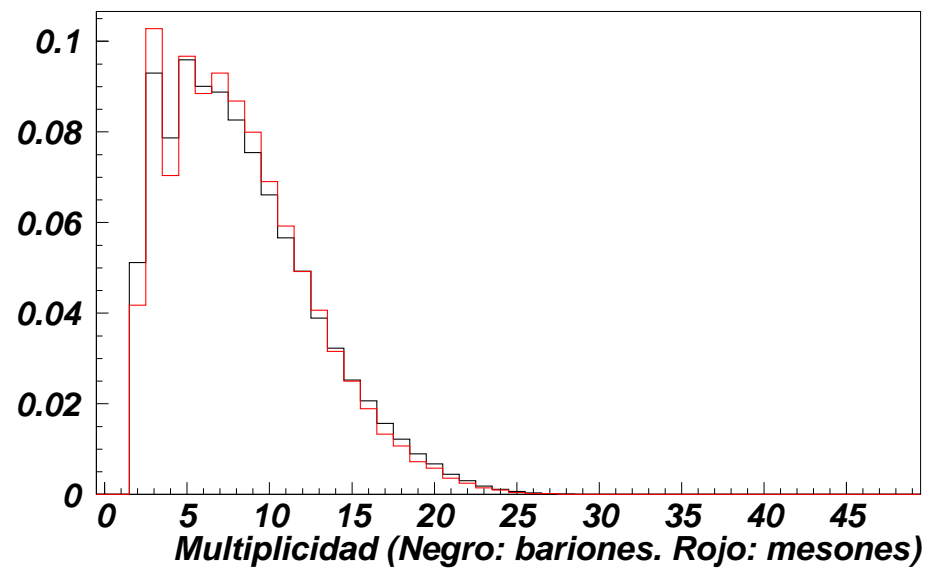

Figura 6.7: Comparación de multiplicidad entre un haz de mesones y un haz de bariones, para un haz de polaridad negativa de $614 \mathrm{GeV}$ sobre un blanco de carbón.

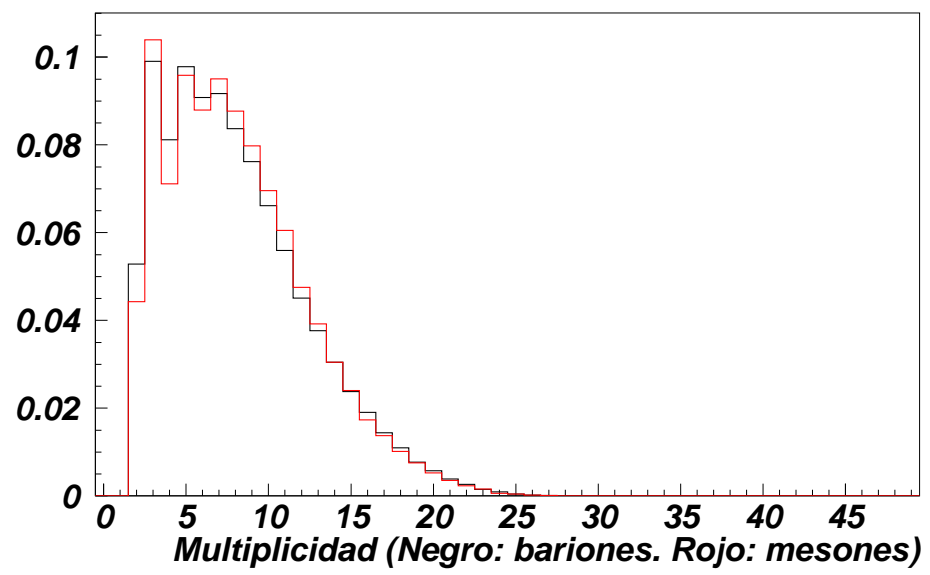

Figura 6.8: Comparación de multiplicidad entre un haz de mesones y un haz de bariones, para un haz de polaridad negativa de $580 \mathrm{GeV}$ sobre un blanco de polietileno. 


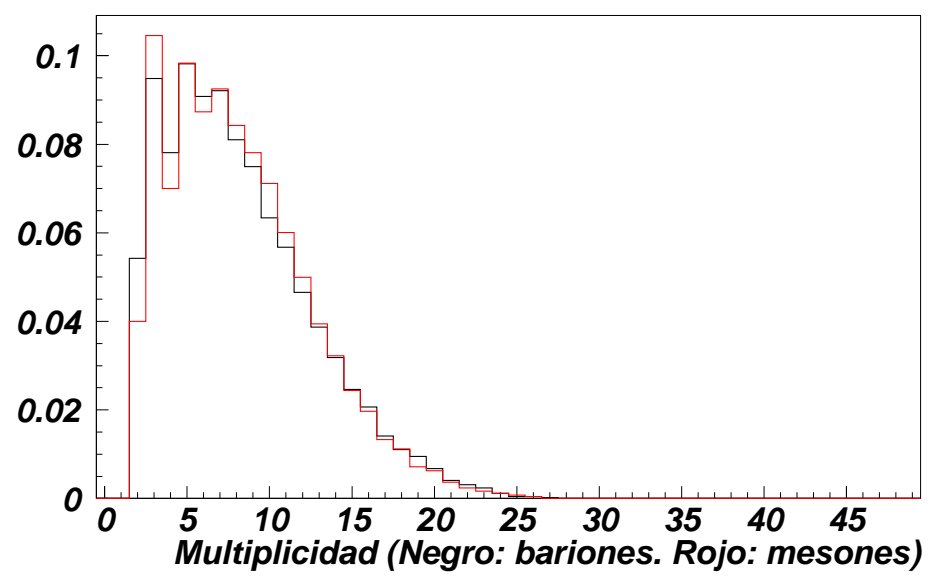

Figura 6.9: Comparación de multiplicidad entre un haz de mesones y un haz de bariones, para un haz de polaridad negativa de $614 \mathrm{GeV}$ sobre un blanco de polietileno.

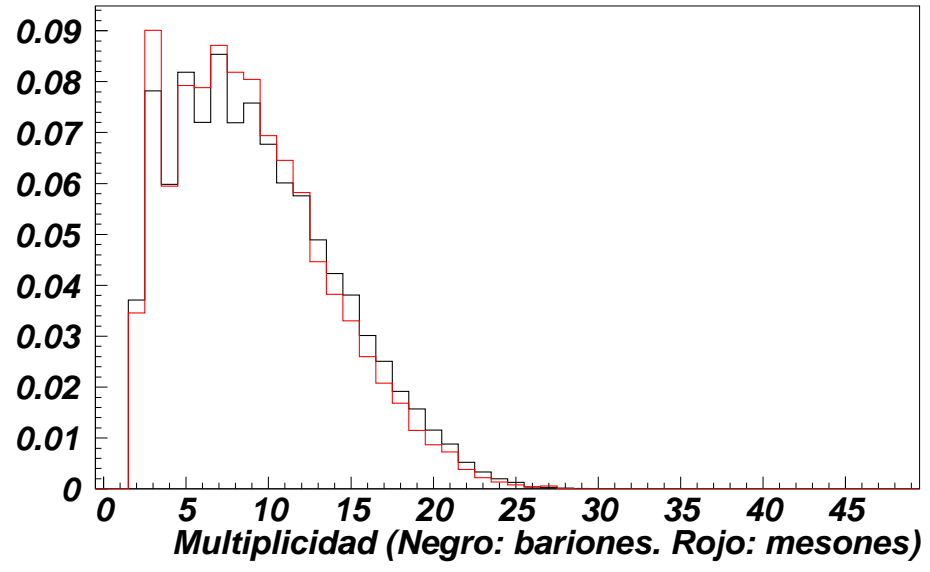

Figura 6.10: Comparación de multiplicidad entre un haz de mesones y un haz de bariones, para un haz de polaridad negativa de $614 \mathrm{GeV}$ sobre un blanco de cobre. 


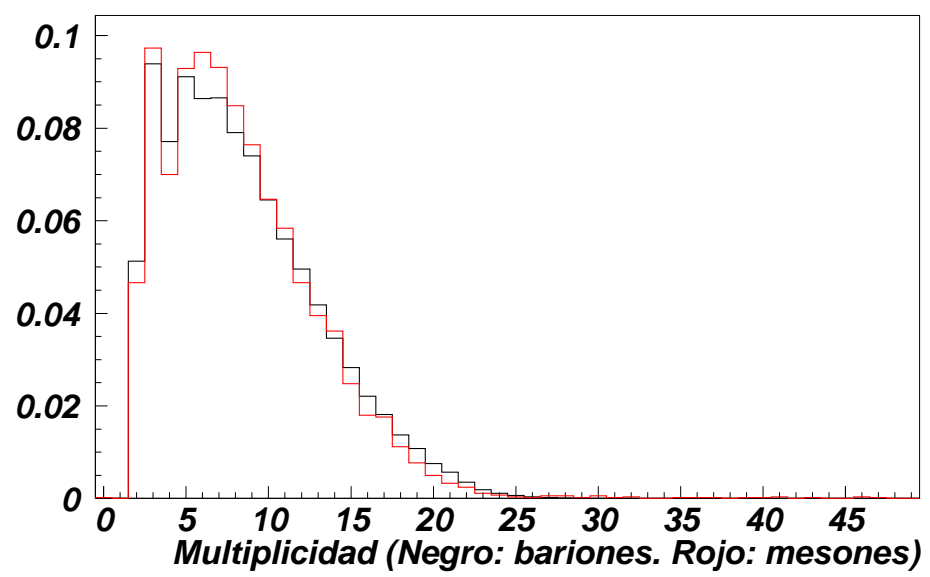

Figura 6.11: Comparación de multiplicidad entre un haz de mesones y un haz de bariones, para un haz de polaridad positiva de $572 \mathrm{GeV}$ sobre un blanco de berilio.

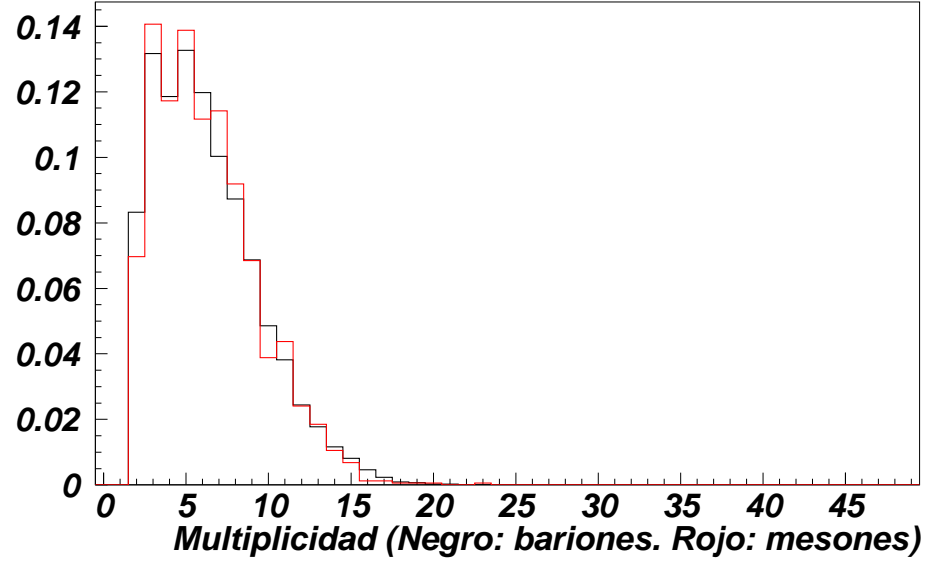

Figura 6.12: Comparación de multiplicidad entre un haz de mesones y un haz de bariones, para un haz de polaridad positiva de $250 \mathrm{GeV}$ sobre un blanco de carbón. 


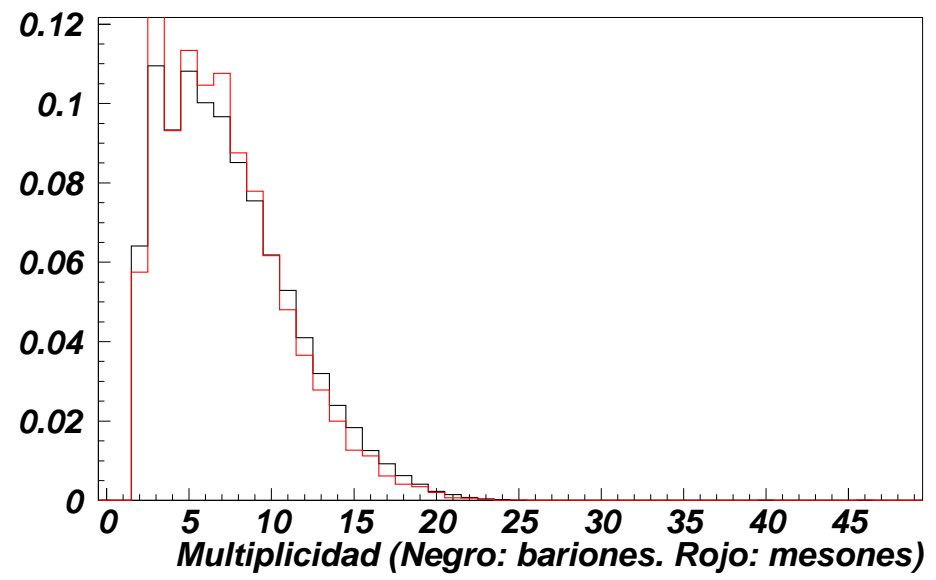

Figura 6.13: Comparación de multiplicidad entre un haz de mesones y un haz de bariones, para un haz de polaridad positiva de $375 \mathrm{GeV}$ sobre un blanco de carbón.

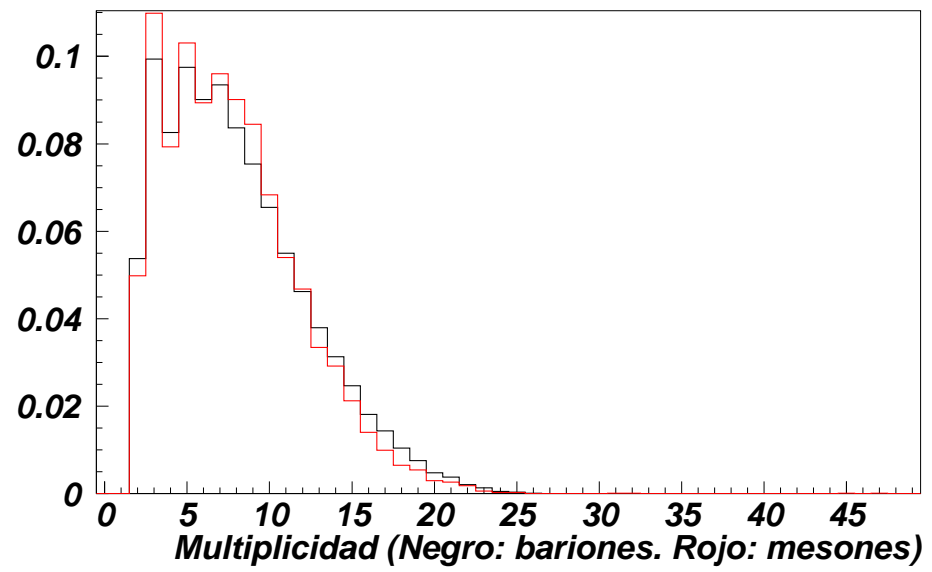

Figura 6.14: Comparación de multiplicidad entre un haz de mesones y un haz de bariones, para un haz de polaridad positiva de $500 \mathrm{GeV}$ sobre un blanco de carbón.

A partir de estas comparaciones se puede observar que no existe o es despreciable la dependencia de la multiplicidad con la partícula que la produce (barion o meson). 


\subsection{Comparación de multiplicidad con blancos dife- rentes}

A continuación se presenta la comparacion de las multiplicidades para la misma energía variando el material del blanco.

En este experimento se usaron 4 blancos de distintas masas atómicas (A), a saber:

- Berilio 9.1

- Carbón 12.0

- Polietileno 14.02

- cobre 63.6

Encontrandose el siguiente comportamiento de la multiplicidad como función de este parámetro:

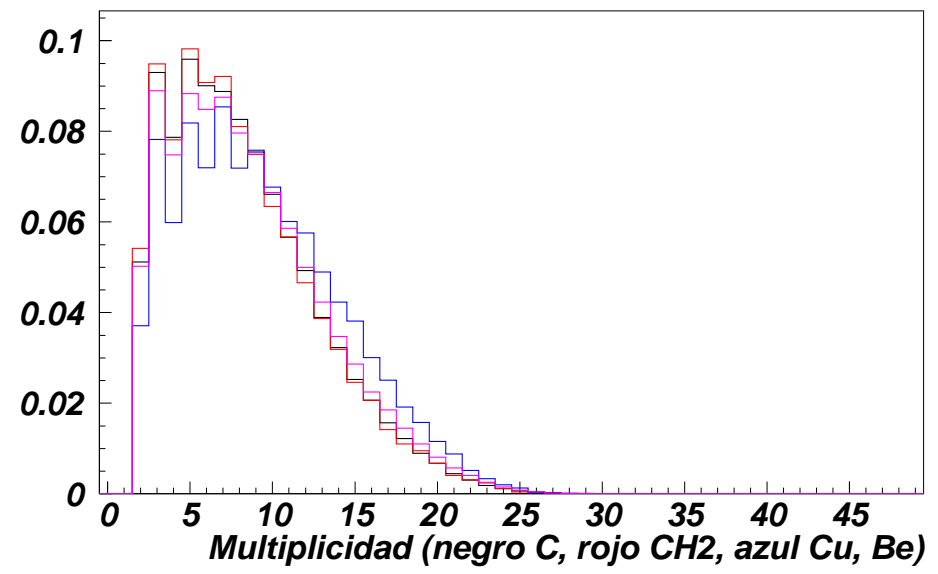

Figura 6.15: Comparación de multiplicidades producidas con la misma energía con diferente blanco, para blancos de carbón, polietileno, cobre y berilio con haz de $614 \mathrm{GeV}$. 


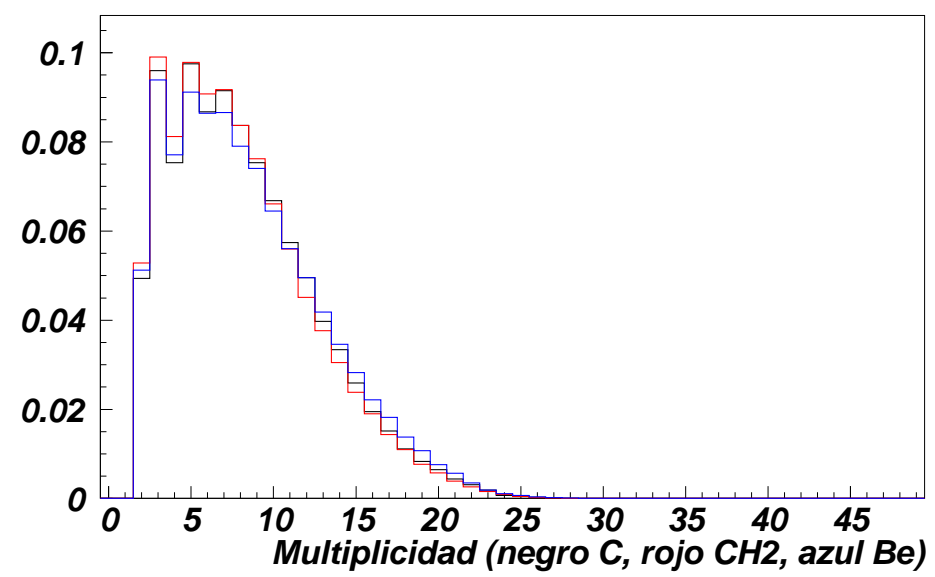

Figura 6.16: Comparación de multiplicidades producidas con la misma energía con diferente blanco, para blancos de carbón, polietileno y berilio con haz de $580 \mathrm{GeV}$.

La siguiente gráfica muestra la media de la multiplicidad como función de la masa atómica del blanco para una energía de haz de $614 \mathrm{GeV}$.

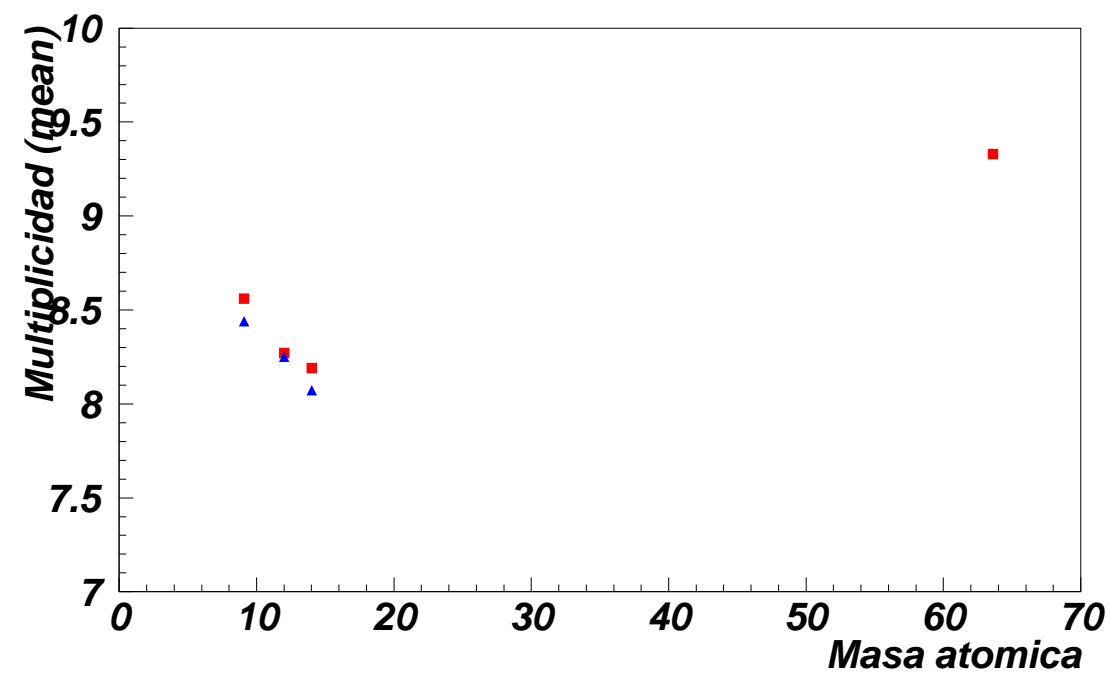

Figura 6.17: Comportamiento de las multiplicidades como funcion de la masa atómica del blanco. Cuadros: haz de $614 \mathrm{GeV}$, triangulos: haz de $580 \mathrm{GeV}$.

Donde se observa un comportamiento casi constante. 


\subsection{Resultados del estudio de aceptancia en ángulo}

Se estudió la aceptancia del experimento como función del ángulo de cada una de las trayectorias de la multiplicidad, encontrándose que la pérdida de trayectorias por éste factor es nula y por lo tanto no afecta los resultados aquí presentados.

Para este estudio se realizó simulación de Montecarlo, introduciendo al programa de análisis (SOAP) un archivo de datos ficticios producidos por un programa que los generaba con ángulos controlados en todo el rango posible. encontrandose que el experimento tiene una aceptancia angular de $150 \mathrm{mrad}$

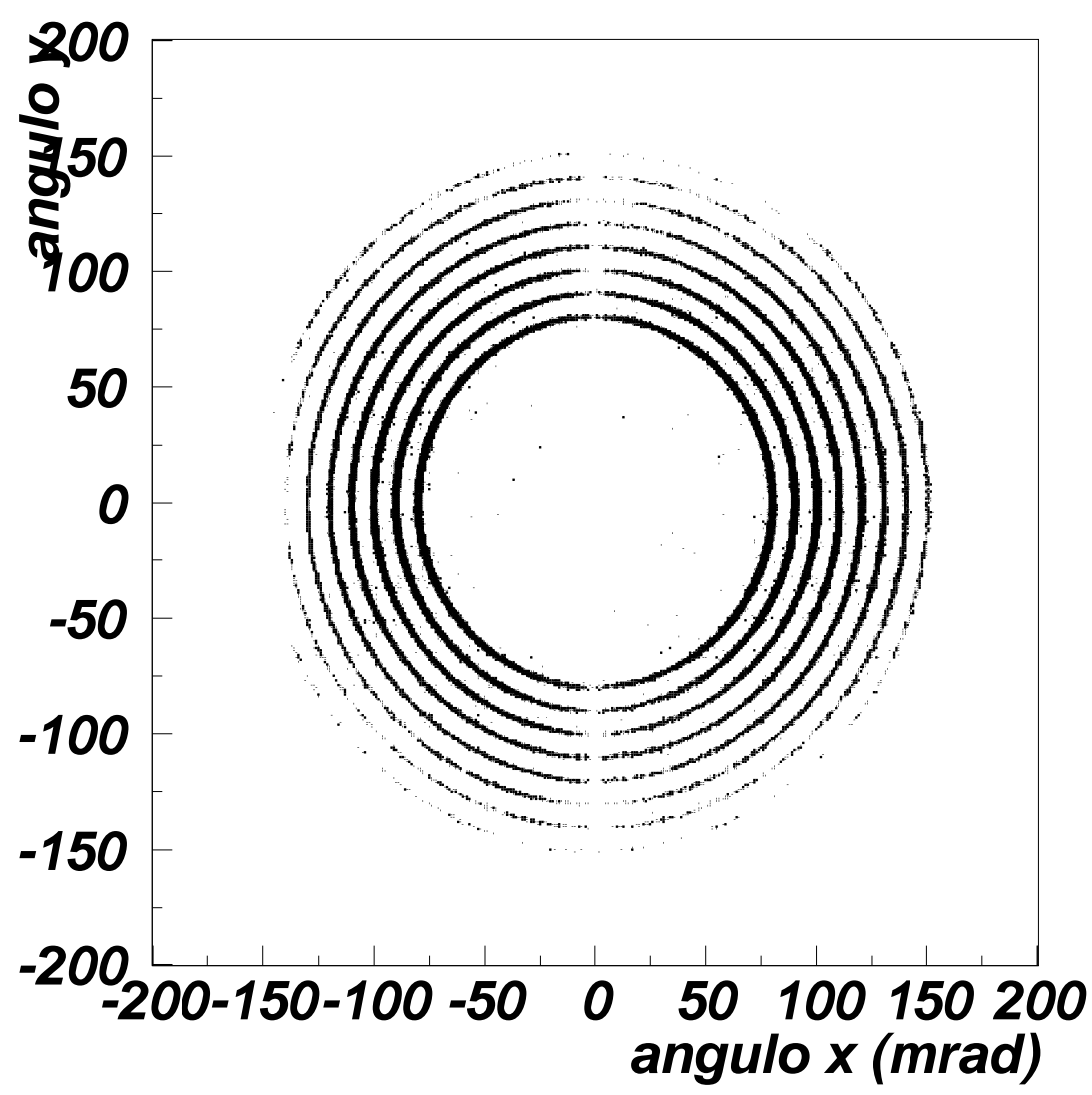

Figura 6.18: Análisis de la distribución angular con Montecarlo.

Por otro lado se analizó la distribución angular de los eventos utilizados para este análisis encontrándose los siguientes resultados: 
A partir de los histogramas mostrados en el capítulo anterior se puede observar que la distribución angular en los eventos analizados queda muy por debajo del limite de aceptancia del experimento.

Incluso si comparamos las distribuciones para mesones y para bariones observamos que no hay diferencia. A continuación se muestran dos ejemplos de estas comparaciones, tomando de los histogramas anteriores, las proyecciones en $\mathrm{x}$ para dos paquetes de datos con diferentes blancos, energías y polaridades.
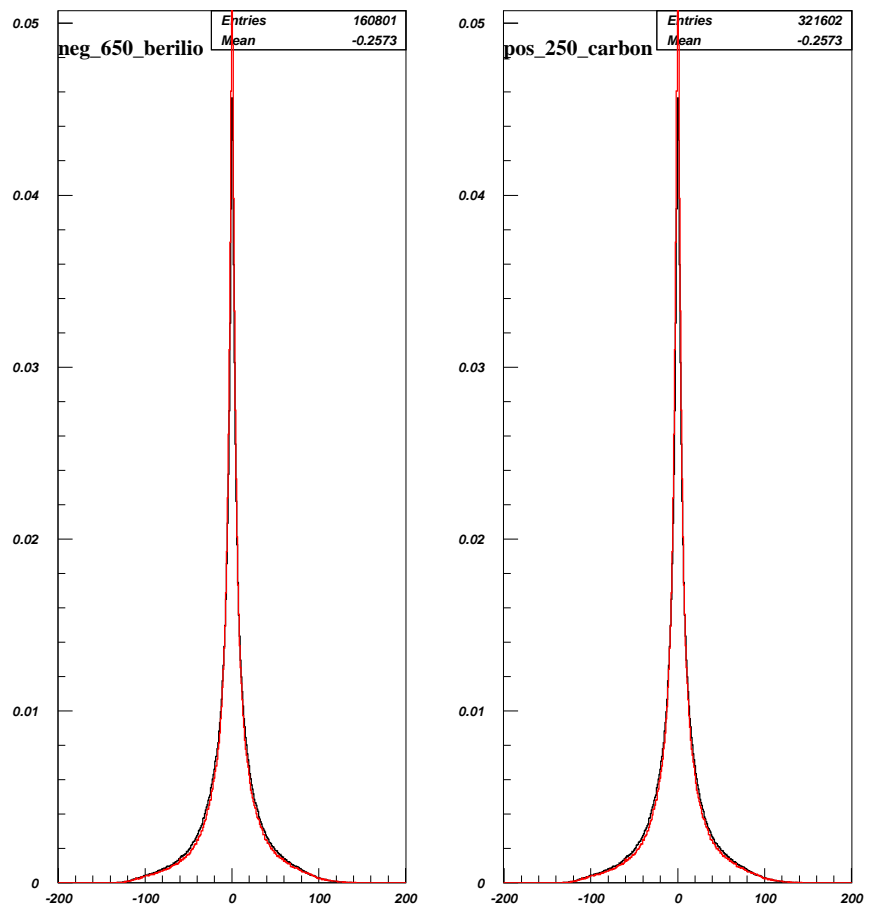

Figura 6.19: Comparación de la distribución angular para mesones y bariones. 


\title{
Apéndice A
}

\section{Apéndice}

\section{La Colaboracion de SELEX}

\author{
G.P. Thomas
}

Ball State University, Muncie, IN 47306, U.S.A.

E. Gülmez

Bogazici University, Bebek 80815 Istanbul, Turkey

R. Edelstein, S.Y. Jun, A.I. Kulyavtsev ${ }^{1}$, A. Kushnirenko ${ }^{2}$, D. $\mathrm{Mao}^{3}$, P. Mathew ${ }^{4}$, M. Mattson, M. Procario ${ }^{5}$, J. Russ, J. You ${ }^{1}$ Carnegie-Mellon University, Pittsburgh, PA 15213, U.S.A.

\section{A.M.F. Endler}

Centro Brasileiro de Pesquisas Físicas, Rio de Janeiro, Brazil

P.S. Cooper, J. Kilmer, S. Kwan, J. Lach, E. Ramberg, D. Skow, L. Stutte

Fermi National Accelerator Laboratory, Batavia, IL 60510, U.S.A.

V.P. Kubarovsky, V.F. Kurshetsov, A.P. Kozhevnikov, L.G. Landsberg ${ }^{6}$, V.V. Molchanov, S.B.Ñurushev, S.V. Petrenko, A.N. Vasiliev, D.V. Vavilov, V.A. Victorov Institute for High Energy Physics, Protvino, Russia 
Li Yunshan, Mao Chensheng, Zhao Wenheng, He Kangling, Zheng Shuchen, Mao Zhenlin Institute of High Energy Physics, Beijing, P.R. China

M.Y. Balatz ${ }^{6}$, G.V. Davidenko, A.G. Dolgolenko, G.B. Dzyubenko, A.V. Evdokimov, M.A. Kubantsev, I. Larin, V. Matveev, A.P.Ñilov, V.A. Prutskoi, A.I. Sitnikov, V.S. Verebryusov, V.E. Vishnyakov Institute of Theoretical and Experimental Physics, Moscow, Russia

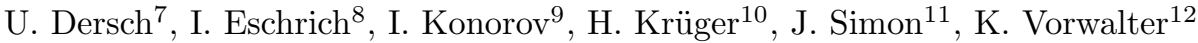
Max-Planck-Institut für Kernphysik, 69117 Heidelberg, Germany

I.S. Filimonov ${ }^{6}$, E.M. Leikin, A.V.Ñemitkin, V.I. Rud Moscow State University, Moscow, Russia

A.G. Atamantchouk ${ }^{6}$, G. Alkhazov, N.F. Bondar, V.L. Golovtsov, V.T. Kim, L.M. Kochenda, A.G. Krivshich, N.P. Kuropatkin ${ }^{1}$, V.P. Maleev, P.V.Ñeoustroev, B.V. Razmyslovich ${ }^{13}$, V. Stepanov ${ }^{13}$, M. Svoiski ${ }^{13}$, N.K. Terentyev ${ }^{14}$, L.N. Uvarov, A.A. Vorobyov Petersburg Nuclear Physics Institute, St. Petersburg, Russia

I. Giller, M.A. Moinester, A. Ocherashvilii ${ }^{15}$, V. Steiner Tel Aviv University, 69978 Ramat Aviv, Israel

J. Amaro-Reyes, A. Blanco C., J. Engelfried, A. Morelos, I. Torres, E. Vázquez-Jáuregui Universidad Autónoma de San Luis Potosí, San Luis Potosí, Mexico

M. Luksys

Universidade Federal da Paraíba, Paraíba, Brazil

V.J. Smith

University of Bristol, Bristol BS8 1TL, United Kingdom

U. Akgun, A.S. Ayan, M. Kaya ${ }^{16}$, E. McCliment, K.D.Ñelson ${ }^{17}$, C.Ñewsom, Y. Onel, E. Ozel, S. Ozkorucuklu ${ }^{18}$, P. Pogodin ${ }^{19}$

University of Iowa, Iowa City, IA 52242, U.S.A.

\section{L.J. Dauwe}


University of Michigan-Flint, Flint, MI 48502, U.S.A.

M. Gaspero, M. Iori

University of Rome "La Sapienza" and INFN, Rome, Italy

L. Emediato, C.O. Escobar ${ }^{20}$, F.G. Garcia ${ }^{1}$, P. Gouffon, T. Lungov, M. Srivastava, R. Zukanovich-Funchal University of São Paulo, São Paulo, Brazil

A. Lamberto, A. Penzo, G.F. Rappazzo, P. Schiavon University of Trieste and INFN, Trieste, Italy 


\footnotetext{
${ }^{1}$ Now at Fermi National Accelerator Laboratory, Batavia, IL 60510, U.S.A.

${ }^{2}$ Now at Institute for High Energy Physics, Protvino, Russia

${ }^{3}$ Present address: Lucent Technologies, Naperville, IL

${ }^{4}$ Present address: Baxter Healthcare, Round Lake IL

${ }^{5}$ Present address: DOE, Germantown, MD

${ }^{6}$ deceased

${ }^{7}$ Present address: Advanced Mask Technology Center, Dresden, Germany

${ }^{8}$ Present address: University of California at Irvine, Irvine, CA 92697, USA

${ }^{9}$ Present address: Physik-Department, Technische Universität München, 85748 Garching, Germany

${ }^{10}$ Present address: The Boston Consulting Group, München, Germany

${ }^{11}$ Present address: Siemens Medizintechnik, Erlangen, Germany

${ }^{12}$ Present address: Allianz Insurance Group IT, München, Germany

${ }^{13}$ Present address: Solidum, Ottawa, Ontario, Canada

${ }^{14}$ Now at Carnegie-Mellon University, Pittsburgh, PA 15213, U.S.A.

${ }^{15}$ Present address: Sheba Medical Center, Tel-Hashomer, Israel

${ }^{16}$ Present address: Kafkas University, Kars, Turkey

${ }^{17}$ Present address: University of Alabama at Birmingham, Birmingham, AL 35294

${ }^{18}$ Present address: Süleyman Demirel Universitesi, Isparta, Turkey

${ }^{19}$ Present address: Legal Department, Oracle Corporation, Redwood Shores, California

${ }^{20}$ Present address: Instituto de Física da Universidade Estadual de Campinas, UNICAMP, SP, Brazil
} 


\section{Bibliografía}

[1] U. Dersch et al., Total cross section measurements with $\pi^{-}, \Sigma^{-}$and protons on nuclei and nucleons around 600GeV/c, Nucl. Phys. B 579 (2000), 277-312, hep-ex/9910052.

[2] U. Dersch, Messung totaler Wirkungsquerschnitte mit $\pi^{-}, \Sigma^{-}$und $p$ bei $600 \mathrm{GeV} / \mathrm{c} \mathrm{La-}$ borimpuls, PhD Thesis (1998).

[3] C. Alt et al (the NA49 Collaboration), Inclusive production of charged pions in $p^{+} p$ collisions at $158 \mathrm{GeV} / \mathrm{c}$ beam momentum, arxiv hep-ex/0510009.

[4] J.J.Aubert et al., Experimental observation of a heavy particle J, Phys. Rev. Lett 33(1974)1404.

[5] J.E.Augustin et al., Discovery of a narrow resonance in $e^{+} e^{-}$annihilation Phys. Rev. Lett 33(1974)1407.

[6] A.Y. Kushnirenko, Precision measurements of $\Lambda_{c}^{+}$and $D^{0}$ lifetimes, PhD. thesis, Carnegie Mellon University, 2000.

[7] K. Nelson and C. Newsom, E781 beam silicon detector alignment procedure and database, Research Note H-771, SELEX Collaboration, 1996.

[8] P. Pogodin et al., Drift chamber of the M1 spectrometer: The detector, electronics and software, Research Note H-788, SELEX Collaboration 1997.

[9] K. Königsmann, S. Masciocchi, and K. Vorwalter, The large angle silicon detectors (LASD) for E781, Research Note H-661, SELEX Collaboration, 1994. 
[10] U. Dersch et al., Mechanical design of the large angle silicon detectors, Research Note H-804, SELEX Collaboration, 1998.

[11] G. Dirkes et al., E781 hodoscope 1 position and efficiency measurement, Research Note H-818, SELEX Collaboration, 1999.

[12] J. Engelfried et al., The SELEX phototube RICH detector, Nucl. Instrum. and Meth. A 431 (1999), 53-59, hep-ex/9811001.

[13] T. Lungov and L.G. Emediato, Vector drift chambers database, Research Note H-779, SELEX Collaboration, 1997.

[14] A. Kulyatsev et al. E781 hardware trigger preliminary design, Research Note H-676, SELEX Collaboration, 1994.

[15] J. Engelfried, P.S. Cooper, and D. Mao, E781 trigger and data acquisition system Research Note H-643, SELEX Collaboration, 1995.

[16] G. Oleynik et al.:DART - Data Acqusition for the Next Generation of Fermilab Fixed Target Experiments. IEEE Trans. Nucl. Sci 41 (1994) 45.

[17] M.E. Mattson, Search for baryons with two charm quarks, PhD. thesis, Carnegie Mellon University, 2002.

[18] P.S. Cooper et al., SELEX charged particles tracking, Research Note, SELEX Collaboration, 1996.

[19] J. Russ, VERTEX code package, Research Note, SELEX Collaboration, 1997.

[20] P. Matthew and J. Russ, E781 reconstruction for $\Lambda_{c} \rightarrow p K^{-} \pi^{+}$at $x_{F} \geq 0,20$, Research Note H-678, SELEX Collaboration, 1994.

[21] J. Engelfried, Recon, Research Note, SELEX Collaboration, 1998.

[22] The Particle Data Group Review of particle properties, Phys. Rev. D (1996) 
[23] SELEX Collaboration, P. Pogodin et al.:Polarization of $\Sigma^{+}$Hyperons produced by 800GeV/c Protons on $\mathrm{Cu}$ and Be., Physical Review D 70, 112005 (2004). Preprint FERMILAB-PUB-03-279-E. 